\title{
Rural Homegardens in Central Sulawesi, Indonesia: An Example for a Sustainable Agro-Ecosystem?
}

\author{
Dissertation \\ zur Erlangung des Doktorgrades \\ der Fakultät für Agrarwissenschaften \\ der Georg-August-Universität Göttingen
}

\author{
Vorgelegt von \\ Katja Kehlenbeck \\ geboren in Hamburg
}

Göttingen, April 2007 
D 7

1. Referent: Prof. Dr. Holm Tiessen

2. Referent: Prof. Dr. Michael Kessler

Tag der mündlichen Prüfung: 15. Mai 2007 


\section{TABLE OF CONTENTS}

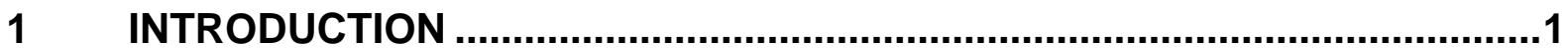

1.1 Homegardens: Definition and functions ............................................................1

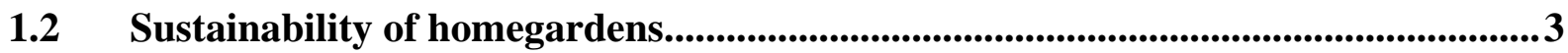

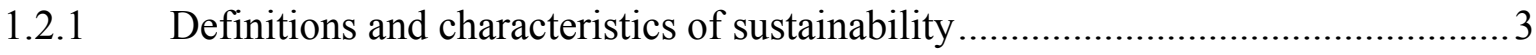

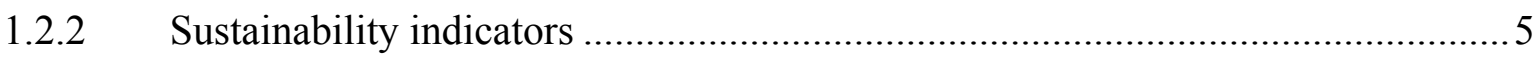

1.3 Functions of biodiversity towards sustainability ..................................................

1.4 Influence of different factors on crop diversity in homegardens ..............................8

1.5 Homegardens as places for in situ conservation of plant genetic resources...........14

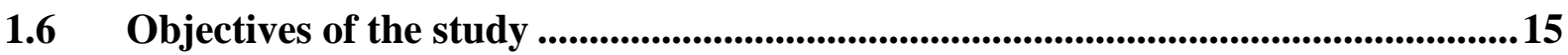

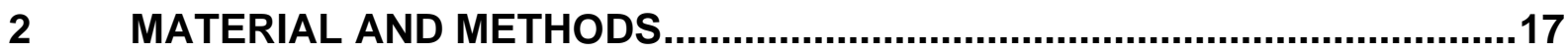

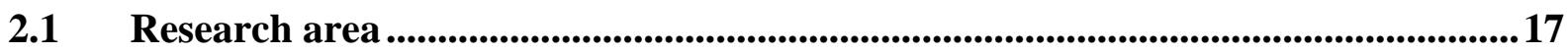

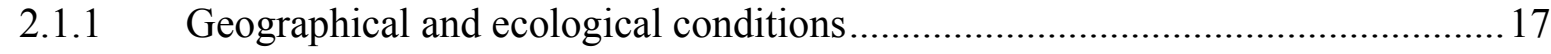

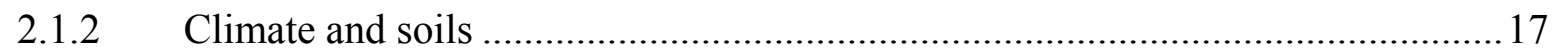

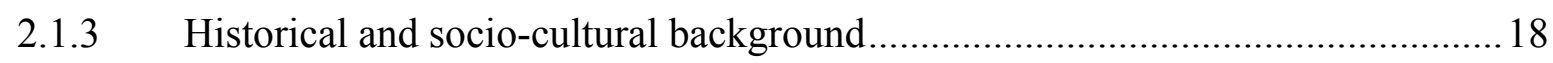

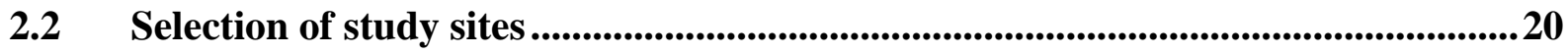

2.3 Socio-economic characteristics of sample households and farms ..........................222

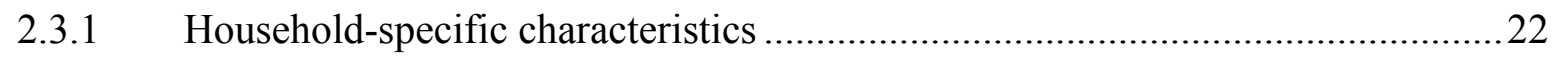

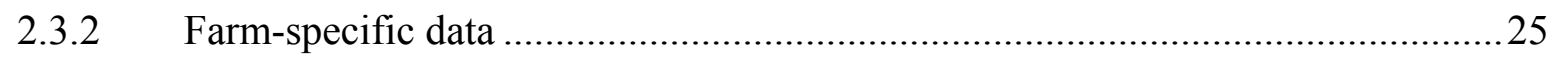

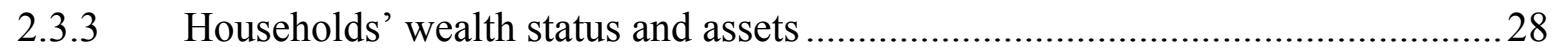

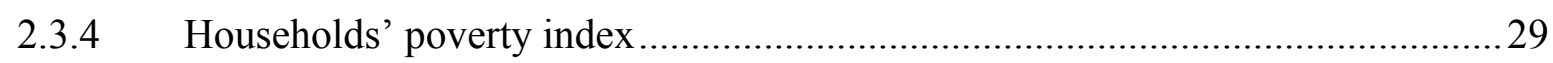

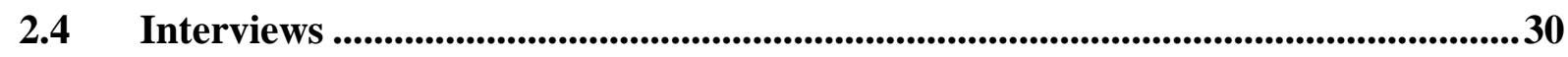

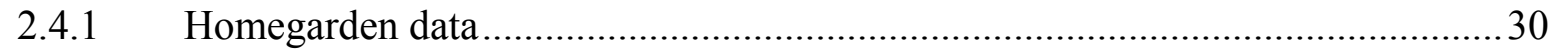

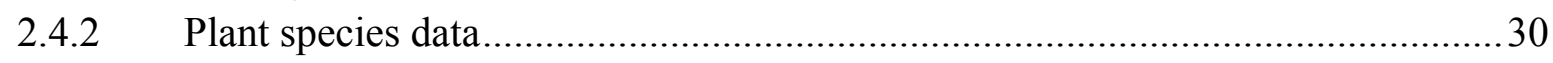

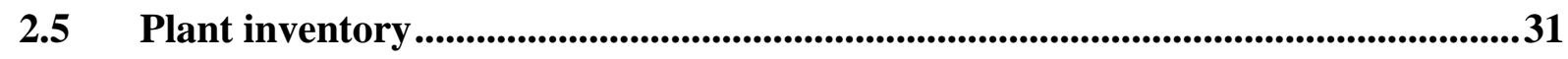

2.6 Soil investigation .......................................................................................................... 32

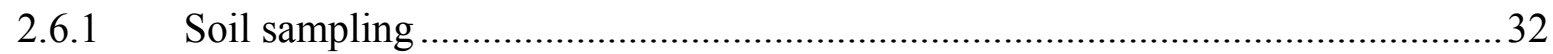

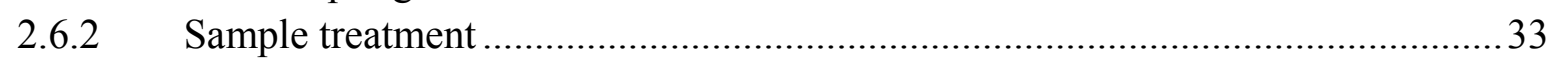

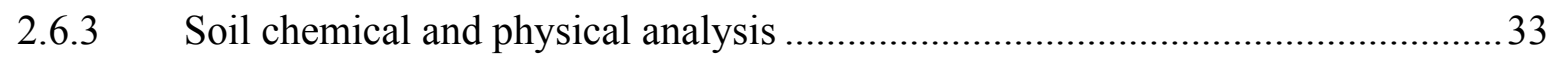

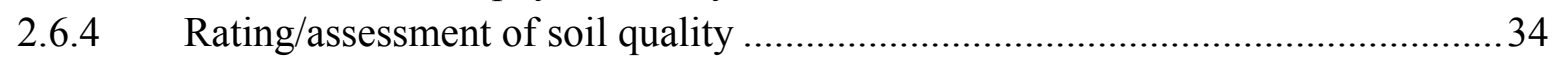

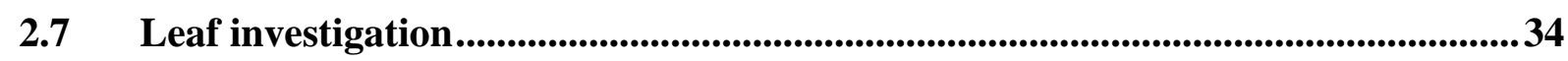

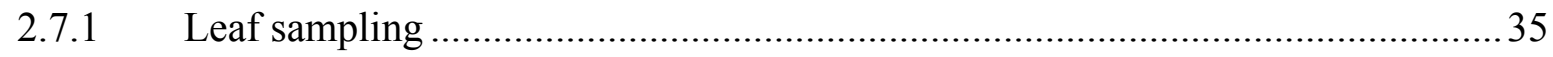

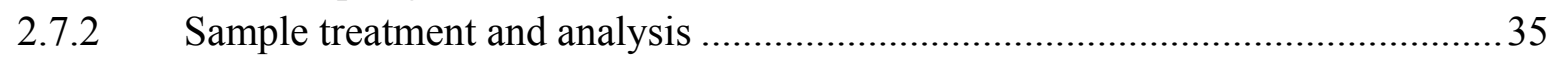




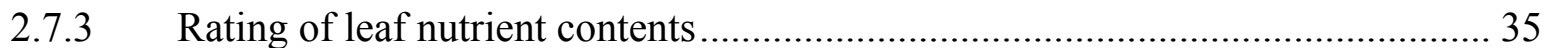

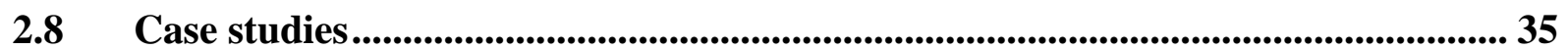

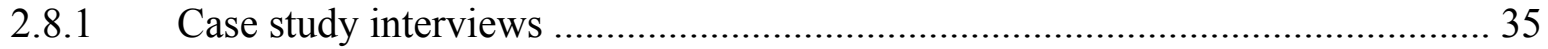

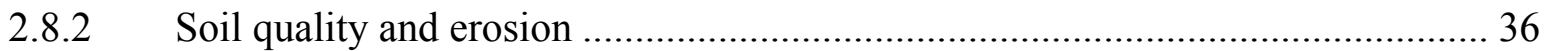

2.8.3 Microclimate and PAR (photosynthetic active radiation).................................. 36

$2.9 \quad$ Data processing and statistical analysis ................................................................ 37

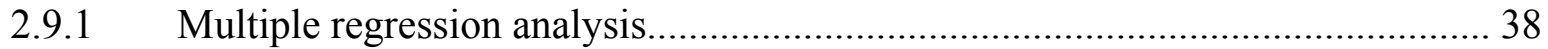

2.9.2 Specific analyses of vegetation and diversity data............................................ 38

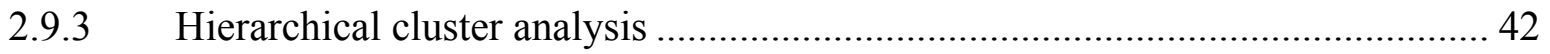

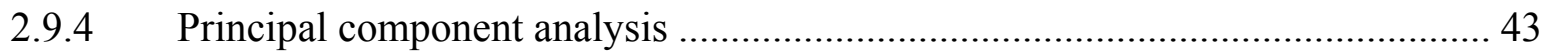

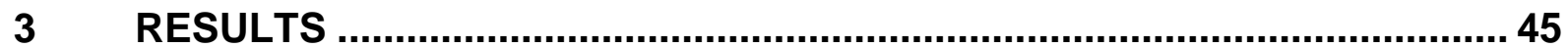

Age of homegardens and their former land use ............................................... 45

$3.2 \quad$ Function and role of homegardens ........................................................................... 45

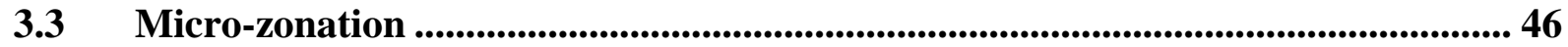

3.4 Homegarden management and inputs/outputs .................................................49

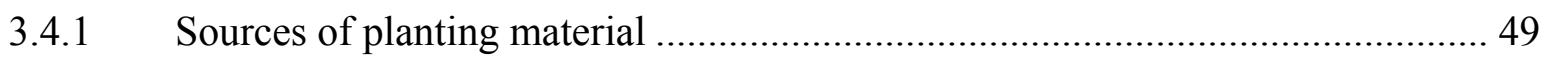

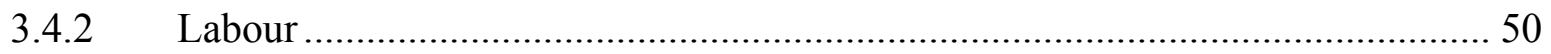

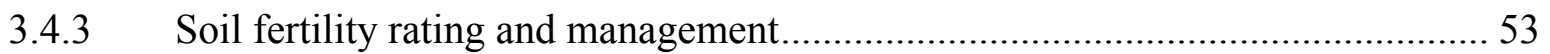

3.4.4 Control of weeds, crop pests, and diseases ........................................................ 56

3.4.5 Other limitations of homegarden management ..................................................... 58

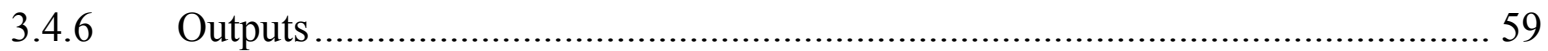

3.5 Floristic composition and vegetation structure in the year 2004 ..........................60

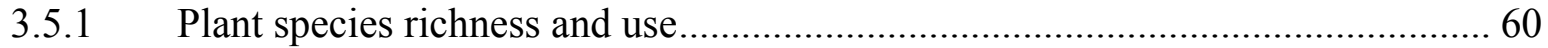

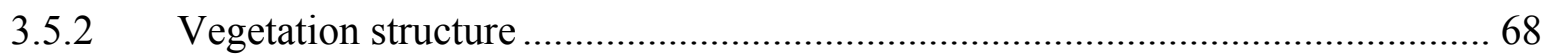

3.5.3 Crop diversity indices based on heterogeneity and equitability ........................ 70

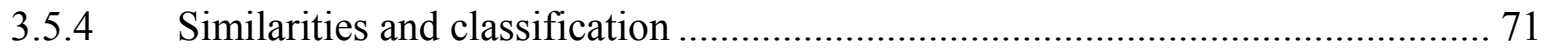

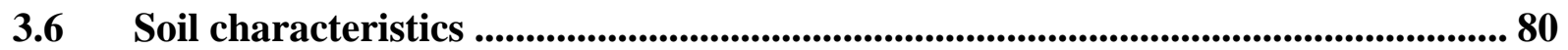

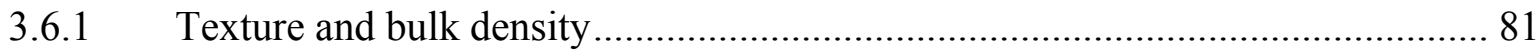

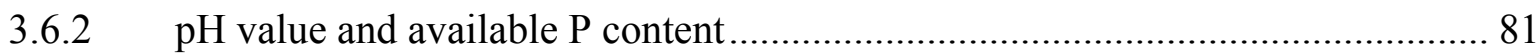

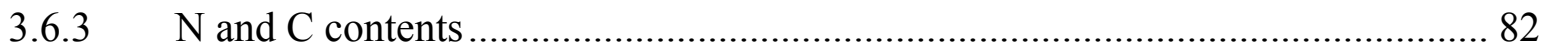

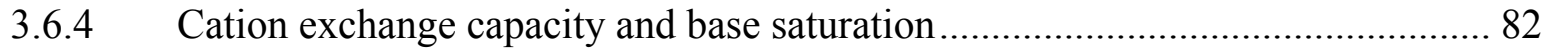

3.6.5 Differences of physico-chemical soil characteristics among production zones .. 83

3.6.6 Suitability of the soil in cacao/coffee zones for production of cacao .................. 85

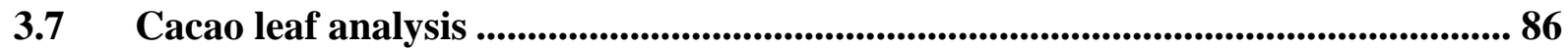

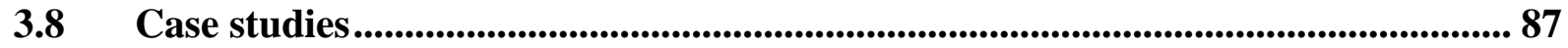

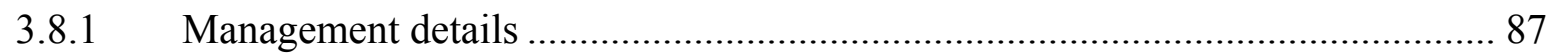




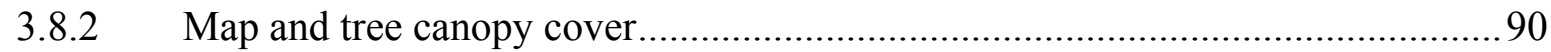

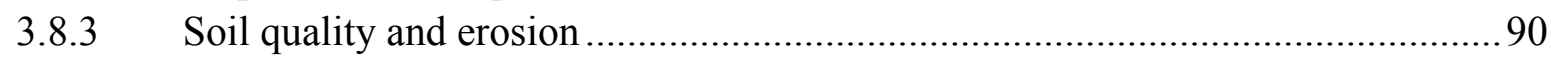

3.8.4 Microclimate and Photosynthetic Active Radiation (PAR) ............................... 93

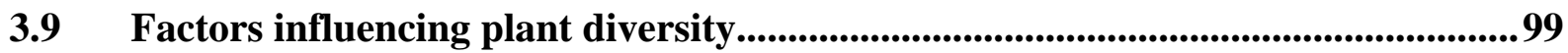

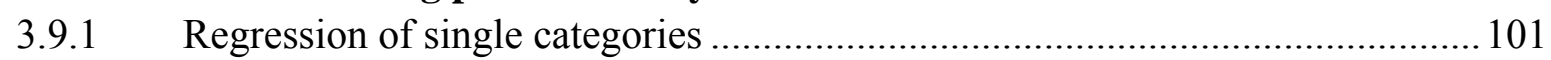

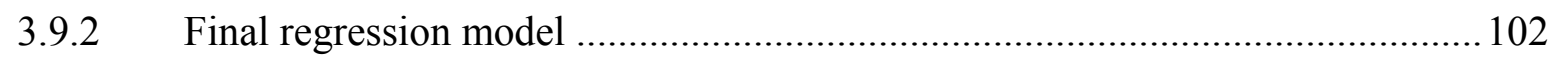

3.10 Changes of different homegarden features over time .......................................103

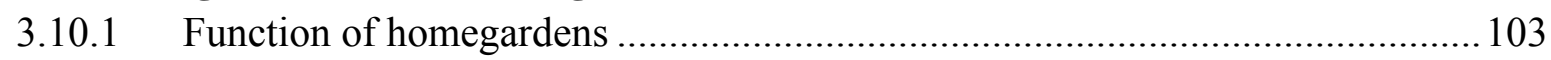

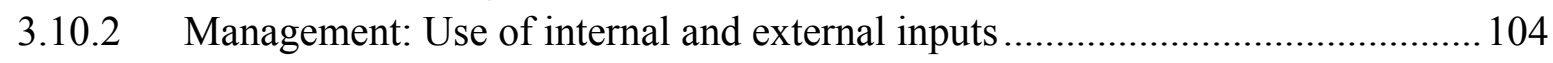

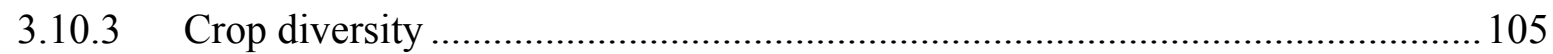

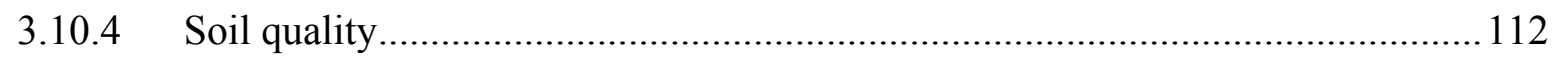

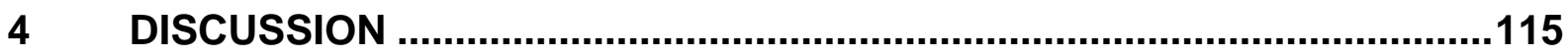

4.1 Are the homegardens socio-economically sustainable?......................................115

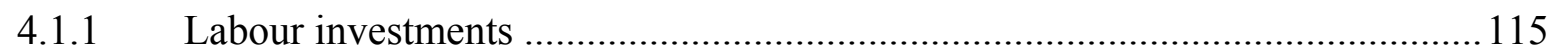

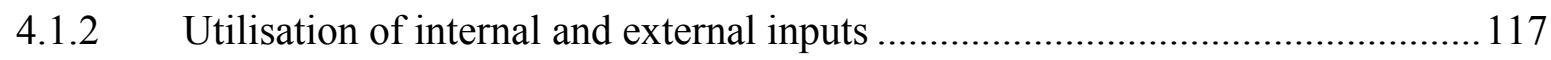

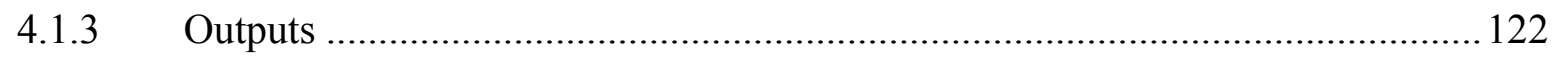

4.2 Is soil quality in homegardens managed in a sustainable manner?......................124

4.3 Is the resource 'light' used efficiently in homegardens? ....................................128

4.4 How valuable and how variable is crop diversity in the homegardens? ..............131

4.5 Can crop diversity be maintained in homegardens? Which factors are

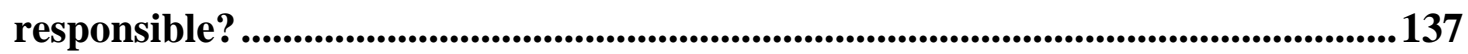

4.6 Are homegardens suitable for in situ conservation of PGR?............................... 140

4.7 Can productivity of homegardens be improved? ....................................................143

4.8 Did the methods applied in this study serve the research questions? ..................146

4.9 Do homegardens have a future? What kind of research is necessary for better understanding this agro-ecosystem? ......................................................................... 151

5 CONCLUSIONS AND RECOMMENDATIONS .....................................153

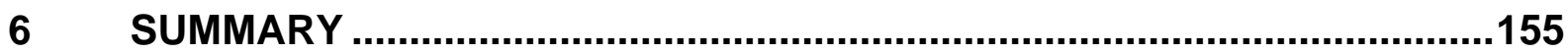

$7 \quad$ ZUSAMMENFASSUNG...................................................................159

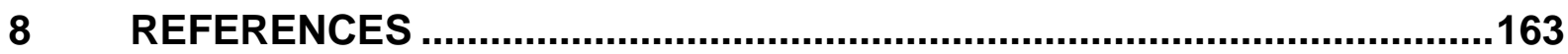




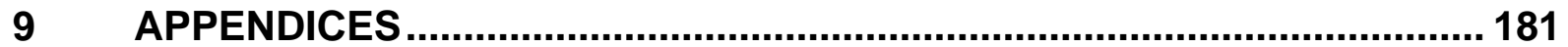

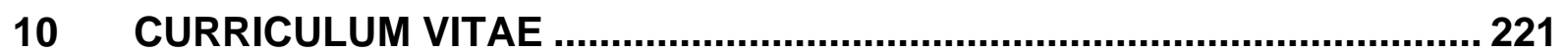

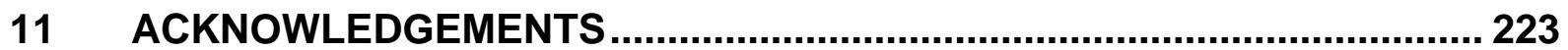




\section{LIST OF TABLES}

Table 2.1. Characteristics of five villages studied in the Napu valley, Central Sulawesi (2003/2004). 21

Table 2.2. Composition and characteristics of 50 households $(\mathrm{HH})$ in five villages of the Napu valley, Central Sulawesi, 2004 (medians, ranges in brackets). $\mathrm{N}=10$ per village, apart from age of household head in Rompo and Wanga $(\mathrm{N}=9)$.......

Table 2.3. Formal education and attendance at agricultural training in percentages of household heads (of wives in brackets) in five villages of the Napu valley, Central Sulawesi, 2004. $\mathrm{N}=10$ per village, apart from HH-heads in Rompo and Wanga, where $\mathrm{N}=9$.

Table 2.4. Main occupation in percentages of household heads (of wives in brackets) in five villages of the Napu valley, Central Sulawesi, 2004. N = 10 per village, apart from household heads in Rompo and Wanga, where $\mathrm{N}=9$.

Table 2.5. Median characteristics in sizes (ranges in brackets) of 50 farms with homegardens investigated in five villages of the Napu valley, Central Sulawesi, 2004. N = 10 per village, apart from Rompo, where $\mathrm{N}=9$ for total and cropped farm size as well as for proportion $\mathrm{HG} /$ farm.

Table 2.6. Proportion of households per village owning cattle, pig, dog, duck, and chicken (heads per households in brackets) as well as median TLU per household (range in brackets) in five villages of the Napu valley, Central Sulawesi, 2004. $\mathrm{N}=10$ per village.

Table 2.7. Proportion of households (in \%) belonging to different wealth status groups in five villages of the Napu valley, Central Sulawesi. $\mathrm{N}=10$ per village.

Table 2.8. Questionnaire for plant species data (checked for each species). 30

Table 2.9. Physical and chemical analyses of the soil samples from homegardens in the Napu valley, carried out in 2001 and 2004 in different laboratories. 33

Table 2.10. Rating of several soil characteristics according to different authors. 34

Table 3.1. Median monthly homegardening working hours (ranges in brackets) of the household head (HHH.), his wife, his children, or his friends and relatives as well as median working hours in total per month, and per $100 \mathrm{~m}^{2}$ garden area as given by respondents interviewed in 39 households in four villages of the Napu valley, Central Sulawesi, 2004. $\mathrm{N}=10$ per village, apart from Rompo, where $\mathrm{N}$ $=9$.

Table 3.2. Median monthly homegardening working hours (ranges in brackets) allocated to different kinds of work, as given by respondents interviewed in 39 households in four villages of the Napu valley, Central Sulawesi, 2004. $\mathrm{N}=10$ per village, apart from Rompo, where $\mathrm{N}=9$. 52

Table 3.3. Proportion of female workers (\%) performing the different kinds of homegarden work as given by respondents interviewed in five villages of the Napu valley, Central Sulawesi, 2004. N $=10$ per village, apart from Rompo, where $\mathrm{N}=9$.

Table 3.4. Proportion of female household members (\%) responsible for different homegarden plant types as given by respondents interviewed in five villages of the Napu valley, Central Sulawesi, 2004. N = 10 per village, apart from Rompo, where $\mathrm{N}=9$. 
Table 3.5. Rating (in \%) of soil fertility, its changes over time, and its role in hindering successful homegarden management by 49 gardeners in five villages of the Napu valley, Central Sulawesi, 2004. $\mathrm{N}=10$ per village, apart from Rompo, where $\mathrm{N}=9$.

Table 3.6. Crop species numbers in total, per village, and per functional group of 48 homegardens in five villages of the Napu valley, Central Sulawesi, 2004. $\mathrm{N}=10$ per village, apart from Rompo, where $\mathrm{N}$ $=8$.

Table 3.7. Total homegarden area sampled per village, total species and individual number, as well as selected community structure parameter of crop species cultivated in homegardens of five villages in the Napu valley, Central Sulawesi, 2004. $\mathrm{N}=10$ per village, apart from Rompo, where $\mathrm{N}=8$.

Table 3.8. Mean crop species numbers per homegarden, mean Margalef index, and mean crop species density per $1000 \mathrm{~m}^{2}$ calculated by regression residuals method (R) ${ }^{\dagger}$ and by the Arrhenius formula (A) (ranges in brackets) of 48 homegardens in five villages of the Napu valley, Central Sulawesi, 2004. N $=10$ per village, apart from Rompo, where $\mathrm{N}=8$.

Table 3.9. Diversity of ornamentals (total number per village, median number per garden, range per village, and number of frequently grown ornamentals per village) of 48 homegardens in five villages of the Napu valley, Central Sulawesi, 2004. $\mathrm{N}=10$ per village, apart from Rompo, where $\mathrm{N}=8$.

Table 3.10. Knowledge of weed species and their use (median numbers of named and used weed species, given by the gardeners, ranges in brackets) of 49 gardeners interviewed in five villages of the Napu valley, Central Sulawesi, 2004. N = 10 per village, apart from Rompo, where $\mathrm{N}=9$.

Table 3.11. Median diversity and evenness indices (ranges in brackets) of 48 homegardens in five villages of the Napu valley, Central Sulawesi, 2004. $\mathrm{N}=10$ per village, apart from Rompo, where $\mathrm{N}=8 \ldots . .70$

Table 3.12. Sørensen's coefficient and Renkonen index of crop species composition and abundance of 48 homegardens at village-level in five villages of the Napu valley, Central Sulawesi, 2004. N=10 per village, apart from Rompo, where $\mathrm{N}=8$. Comparisons among local villages are bolded. 71

Table 3.13. Mean similarity indices (based on data of single homegardens and calculated both within and among villages) of crop species composition and abundance of 48 homegardens in five villages of the Napu valley, Central Sulawesi, 2004. $\mathrm{N}=10$ per village, apart from Rompo, where $\mathrm{N}=8$. Comparisons among local villages are bolded.

Table 3.14. Median number of individuals (ranges in brackets) of selected crop species per homegarden causing separation of clusters among 44 homegardens in five villages of the Napu valley, Central Sulawesi, 2004, selected by discriminant analysis (method: stepwise inclusion of variables).

Table 3.15. Median number of crop species per use category (ranges in brackets) of clusters among 44 homegardens in five villages of the Napu valley, Central Sulawesi, 2004.

Table 3.16. Mean crop species richness, density (dens.) per $1000 \mathrm{~m}^{2}$, and diversity (ranges in brackets) per cluster based on crop species abundance data of 44 homegardens in five villages of the Napu valley, Central Sulawesi, 2004.

Table 3.17. Median garden size and its proportion of the whole cultivated farm area, share of cash crop individuals, share of female gardeners, and median poverty index per cluster performed on crop species abundance data of 44 homegardens in five villages of the Napu valley, Central Sulawesi, 2004 (ranges in brackets). 
Table 3.18. Medians of selected physical and chemical soil parameters (ranges in brackets) per cluster performed on crop species abundance data of 44 homegardens in five villages of the Napu valley, Central Sulawesi, 2004. .78

Table 3.19. Summary table and variable loadings for the first two axes of the 11 most important crops (variable loadings $>0.2$ for at least one of the axes) as a result of Principal Component Analysis, based on abundance data of 206 crop species cultivated in 48 homegardens in five villages of the Napu valley, Central Sulawesi, 2004. N $=10$ per village, apart from Rompo, where N = 8. Species abundance data $\mathrm{ln}$ - transformed and centred before analysis. 79

Table 3.20. Medians of physical top soil properties (ranges in brackets) in 50 homegardens in five villages of the Napu valley, Central Sulawesi, 2004. N=10 per village.

Table 3.21. Medians of $\mathrm{pH}$ values and available $\mathrm{P}$ contents of top soil (ranges in brackets) in 50 homegardens in five villages of the Napu valley, Central Sulawesi, 2004. $\mathrm{N}=10$ per village.

Table 3.22. Medians of $\mathrm{N}$ and $\mathrm{C}$ contents as well as $\mathrm{C} / \mathrm{N}$ ratios of top soil (ranges in brackets) in 50 homegardens in five villages of the Napu valley, Central Sulawesi, 2004. $\mathrm{N}=10$ per village. 82

Table 3.23. Medians of effective cation exchange capacity (CEC), exchangeable $\mathrm{K}$ and $\mathrm{Al}$, as well as base saturation of top soil (ranges in brackets) in 50 homegardens in five villages of the Napu valley, Central Sulawesi, 2004. $\mathrm{N}=10$ per village. 83

Table 3.24. Median water content, bulk density, and $\mathrm{N}$ and $\mathrm{C}$ contents of top soil in vegetable and cacao/coffee zones (ranges in brackets) of 17 homegardens in four villages of the Napu valley, Central Sulawesi, 2004. 83

Table 3.25. Medians (ranges in brackets) of $\mathrm{pH}$ value, available $\mathrm{P}$ content, effective cation exchange capacity (CEC), exchangeable (exch.) $\mathrm{Ca}$ and $\mathrm{K}$, and base saturation of top soil in fertilised $(\mathrm{N}=9$ ) and unfertilised $(\mathrm{N}=8)$ vegetable zones as compared to adjacent cacao/coffee zones of the same 17 homegardens in four villages of the Napu valley, Central Sulawesi, 2004.

Table 3.26. Portion of soils (\%) fulfilling the minimum requirements for successful cacao production concerning different soil parameters in cacao production zones of 38 homegardens in five villages of the Napu valley, Central Sulawesi, 2004. $\mathrm{N}=8$ in Wuasa; $\mathrm{N}=7$ each in Rompo, Wanga, and Siliwanga; $\mathrm{N}=9$ in Tamadue.

Table 3.27. Median dry weight, water content, as well as $\mathrm{N}$ and $\mathrm{C}$ contents of cacao leaves sampled in 40 homegardens of five villages of the Napu valley, Central Sulawesi, 2004. N = 9 each in Wuasa and Tamadue; $\mathrm{N}=8$ each in Rompo and Siliwanga; $\mathrm{N}=6$ in Wanga.

Table 3.28. Median P, K, Ca, and Mg contents of cacao leaves sampled in 40 homegardens of five villages of the Napu valley, Central Sulawesi, 2004. $\mathrm{N}=9$ each in Wuasa and Tamadue; $\mathrm{N}=8$ each in Rompo and Siliwanga; $\mathrm{N}=6$ in Wanga.

Table 3.29. Median chemical and physical soil quality parameters (ranges in brackets) in the vegetable and cacao production zones of homegarden no. 8, belonging to the type 'small spice garden' and located in Wuasa, Napu valley, Central Sulawesi. Significantly higher values are given in bold.

Table 3.30. Median chemical and physical soil quality parameters (ranges in brackets) in the vegetable and cacao production zones of homegarden no. 10, belonging to the type 'large fruit tree garden' and located in Wuasa, Napu valley, Central Sulawesi. Significantly higher values are given in bold....... 91 
Table 3.31. Median chemical and physical soil quality parameters (ranges in brackets) in the vegetable and cacao production zones of homegarden no. 29, belonging to the type 'very large migrant garden' and located in the migrant village Siliwanga, Napu valley, Central Sulawesi. Significantly higher values are given in bold.

Table 3.32. Mean activity of Caesium-137 (range in brackets) in top soil of vegetable and cacao zones of the spice and fruit gardens, and of cassava and cacao zones in the migrant garden as well as in soil of two undisturbed reference zones (forest and grassland), Napu valley, Central Sulawesi, in 2004.......92

Table 3.33. Mean overall soil temperatures (ranges in brackets), mean minimum, maximum, and amplitudes (all values in ${ }^{\circ} \mathrm{C}$ ) in different production zones of three different homegarden types in the Napu valley, Central Sulawesi, in 2004. For the different time periods of measurement, see Figure 3.30 .

Table 3.34. Mean overall air temperatures (ranges in brackets), mean minimum, maximum, and amplitudes (all values in ${ }^{\circ} \mathrm{C}$ ) in different production zones of three different homegarden types in the Napu valley, Central Sulawesi, in 2004. For the different time periods of measurement, see Figure 3.30 ..94

Table 3.35. Mean relative light intensity in $\%$ of bare space light intensity (ranges in brackets) in different strata and production zones of three homegardens in the Napu valley, Central Sulawesi, referring to diurnal sums (05:45-18:14 h). Duration of measurement was five days each (for exact time period see Figure 3.32).

Table 3.36. Categories, names, units, and ranges of variables used for multiple regression analysis on crop diversity of 48 homegardens of five villages of the Napu valley, Central Sulawesi, 2004. N $=10$ per village, apart from Rompo, where $\mathrm{N}=8$. 100

Table 3.37. Simplified results of stepwise multiple regression analysis on crop diversity for single categories of variables for 48 homegardens of five villages of the Napu valley, Central Sulawesi, 2004. $\mathrm{N}=10$ per village, apart from Rompo, where $\mathrm{N}=8$.

Table 3.38. Results of stepwise multiple regression analyses on different crop diversity parameters for 48 homegardens of five villages of the Napu valley, Central Sulawesi, 2004. N $=10$ per village, apart from Rompo, where $\mathrm{N}=8$. For each independent variable the standardised regression coefficient (beta coefficient) and the significance level is presented. Non-standardised regression coefficients are given in brackets

Table 3.39. Summary table as a result of Principal Component Analysis, based on mean abundance data per village of 196 crop species cultivated in 30 homegardens surveyed over time in the Napu valley, Central Sulawesi; species abundance data ln-transformed and centred before analysis. 106

Table 3.40. Changes of median sand, $\mathrm{N}$, and $\mathrm{C}$ contents (ranges in brackets) of topsoil $(0-15 \mathrm{~cm})$ of 26 homegardens in three villages of the Napu valley, Central Sulawesi, from 2001 to 2004. $\mathrm{N}=10$ in Wuasa, $\mathrm{N}=8$ each in Rompo and Siliwanga.

Table 3.41. Changes of median $\mathrm{pH}$ values and available $\mathrm{P}$ content (ranges in brackets) of topsoil $(0-15 \mathrm{~cm})$ of 26 homegardens in three villages of the Napu valley, Central Sulawesi, from 2001 to 2004. N=10 in Wuasa, $\mathrm{N}=8$ each in Rompo and Siliwanga.

Table 4.1. Plant species richness in homegardens (including ornamentals, but excluding weeds, if not differently indicated) as total number per study area and/or mean per garden in different regions of the world. Garden sizes are given in means (ranges in brackets). 


\section{LIST OF FIGURES}

Figure 1.1. Main functions of homegardens and selected products/outputs (modified after KEHLENBECK et al., 2007). .. 3

Figure 1.2. Schematic illustration of the relative importance of different factors on crop diversity in homegardens and their temporal changes (modified after KEHLENBECK et al., 2007). Here, the importance of socio-economic factors (e.g. commercialisation) increases over time, while that of agro-ecological characteristics (e.g. infertile soil) decreases, for example due to the use of industrial fertiliser.

Figure 1.3. Schematic development of crop diversity (except ornamentals) in homegardens over time under the influence of changing socio-economic conditions (modified after KEHLENBECK et al., 2007). Agro-ecological factors (e.g. elevation) may limit plant diversity, while short-term/small-scale climatic events may cause a certain fluctuation around a mean level. 10

Figure 2.1. Location of the research area in Central Sulawesi and the five study villages in the Napu valley. 18

Figure 2.2. Origin of household heads (HH-H.) and their wives in five villages of the Napu valley, Central Sulawesi, 2004. $\mathrm{N}=10$ per village, apart from $\mathrm{HH}$-heads in Rompo and Wanga, where $\mathrm{N}=9$........ 23

Figure 2.3. Median farm area allocated to different crop types in five villages of the Napu valley, Central Sulawesi, 2004. $\mathrm{N}=10$ per village, apart from Rompo, where $\mathrm{N}=9$...... 27

Figure 3.1. Occurrence (in \%) of different cultivated micro-zones in homegardens of five villages in the Napu valley, Central Sulawesi, 2004. $\mathrm{N}=10$ per village. 46

Figure 3.2. Different vegetation zones in homegardens of the Napu valley, Central Sulawesi. (a) Vegetable zone in a garden in Rompo; (b) Fallow zone in a garden in Tamadue; (c) Cacao/coffee zone in a garden in Tamadue; (d) Fruit tree zone in a garden in Wuasa; (e) Nursery for vanilla in a garden in Tamadue.

Figure 3.3. Median sizes of cultivated zones and fallows in homegardens of five villages in the Napu valley, Central Sulwesi, 2004. $\mathrm{N}=10$ per village.

Figure 3.4. Sources of planting material as mentioned by the owners of 50 homegardens in five villages of the Napu valley, Central Sulawesi, 2003. $\mathrm{N}=10$ per village.

Figure 3.5. Use of different fertilisers in 49 homegardens according to gardeners' responses in five villages of the Napu valley, Central Sulawesi, 2004. $\mathrm{N}=10$ per village, apart from Rompo, where $\mathrm{N}=9 \ldots . .55$

Figure 3.6. Use of industrial fertiliser in homegardens and in plots planted to paddy rice, perennials, or annuals, as given by 49 respondent households in five villages of the Napu valley, Central Sulawesi, 2004. $\mathrm{N}=10$ per village, apart from Rompo, where $\mathrm{N}=9$.

Figure 3.7. Use of herbicides in homegardens and in plots planted to paddy rice, perennials, or annuals, as given by 49 respondent households in five villages of the Napu valley, Central Sulawesi, 2004. N = 10 per village, apart from Rompo, where $\mathrm{N}=9$.

Figure 3.8. Use of insecticides in homegardens and in plots planted to paddy rice, perennials, or annuals, as given by 49 respondent households in five villages of the Napu valley, Central Sulawesi, 2004. N = 10 per village, apart from Rompo, where $\mathrm{N}=9$. 
Figure 3.9. Species-area curve for 206 crop species cultivated in 48 homegardens of five villages in the Napu valley, Central Sulawesi, 2004. Total garden area sampled was $51,972 \mathrm{~m}^{2}$, homegardens were ordered randomly. $\mathrm{N}=10$ per village, apart from Rompo, where $\mathrm{N}=8$.

Figure 3.10. Abundance of 206 crop species cultivated in 48 homegardens of five villages in the Napu valley, Central Sulawesi, 2004. $\mathrm{N}=10$ per village, apart from Rompo, where $\mathrm{N}=8$.

Figure 3.11. Some of the banana varieties cultivated in homegardens of the Napu valley, Central Sulawesi. The scale of the photos is similar.

Figure 3.12. Number of varieties/landraces per crop species in different use categories. Results of inventories of 50 homegardens and of interviews of 50 gardeners in five villages of the Napu valley, Central Sulawesi, 2003.

Figure 3.13. Mean number of crop species in different use categories of 48 homegardens in five villages of the Napu valley, Central Sulawesi, 2004. $\mathrm{N}=10$ per village, apart from Rompo, where $\mathrm{N}=8 \ldots \ldots \ldots \ldots 65$

Figure 3.14. Summed dominance ratio (SDR) of crop species in different use categories of 48 homegardens in five villages of the Napu valley, Central Sulawesi, 2004. N = 10 per village, apart from Rompo, where $\mathrm{N}=8$.

Figure 3.15. Relations between garden size and crop species number in homegardens managed by local $(\mathrm{N}=29)$ and migrant $(\mathrm{N}=19)$ gardeners studied in five villages of the Napu valley, Central Sulawesi, 2004. $\mathrm{N}=10$ per village, apart from Rompo, where $\mathrm{N}=8$. Broken lines indicate trend lines, however, only the regression of the variable 'Locals' is significant. Between the dotted lines, homegardens used for comparison of mean species number in gardens of local and migrant gardeners were grouped together.

Figure 3.16. Example for a typical multi-layered vegetation structure in homegarden no. 10 in Wuasa, Napu valley, Central Sulawesi, 2004.

Figure 3.17. Mean proportion of crop species occurring in different strata of 48 homegardens in five villages of the Napu valley, Central Sulawesi, 2004. $\mathrm{N}=10$ per village, apart from Rompo, where $\mathrm{N}$ $=8$.

Figure 3.18. Dendrogram as result of hierarchical cluster analysis on the basis of $\ln$-transformed crop species abundance data of 44 homegardens in five villages of the Napu valley, Central Sulawesi, 2004, using Ward's method and squared Euclidian distances. Homegardens no. 1, 2, 9, and 14 were identified as outliers before and were, therefore, excluded from this cluster analysis.

Figure 3.19. Median number of crop individuals in different use categories per cluster based on crop species abundance data of 44 homegardens in five villages of the Napu valley, Central Sulawesi, 2004. Cluster 1, $\mathrm{N}=9$; Cluster 2, $\mathrm{N}=9$; Cluster 3, $\mathrm{N}=16$; Cluster 4, $\mathrm{N}=10$...

Figure 3.20. Mean proportion of crop species occurring in different strata per cluster based on crop species abundance data of 44 homegardens in five villages of the Napu valley, Central Sulawesi, 2004. Cluster 1, $\mathrm{N}=9$; Cluster 2, $\mathrm{N}=9$; Cluster 3, $\mathrm{N}=16$; Cluster 4, $\mathrm{N}=10$.

Figure 3.21. Examples of homegardens in the Napu valley, Central Sulawesi, grouped in different clusters.

(a) A large cash crop homegarden of cluster 1 in the migrant village Tamadue; (b) A homegarden of cluster 2 in the migrant village Siliwanga with a poorly developed vegetation structure; (c) A speciesrich homegarden of cluster 3, located in Rompo; (d) A small, species-poor homegarden of cluster 4 in Wanga. . .78 
Figure 3.22. Result of Principal Component Analysis (cases scores of axis 1 and 2), based on lntransformed and centred abundance data of 206 crop species cultivated in 48 homegardens of five villages in the Napu valley, Central Sulawesi, 2004.

Figure 3.23. Soil sample with orange-coloured iron-oxide concretions, taken from about $20 \mathrm{~cm}$ depth in a homegarden of the migrant village Siliwanga, Napu valley, Central Sulawesi. 86

Figure 3.24. Mean daily time and work allocation among family members in homegarden management studied during 15 days in three different homegarden types in the Napu valley, Central Sulawesi, in $2004(\mathrm{HH}-\mathrm{H}=$ Household head $)$. Homegarden sizes: Spice garden $=580 \mathrm{~m}^{2}$; Fruit garden $=1050 \mathrm{~m}^{2}$; migrant garden $=2420 \mathrm{~m}^{2}$.

Figure 3.25. Mean daily time allocation to different farm operations among family members studied during 15 days in three different homegarden types in the Napu valley, Central Sulawesi, in 2004 (HH-H = Household head). 88

Figure 3.26. Monetary value of homegarden products harvested for sale and for home consumption during 15 days in three different homegarden types in the Napu valley, Central Sulawesi, in 2004. 10,000 IR $\approx 1$ Euro (March 2004). 89

Figure 3.27. An example of soil erosion in the front yard of a homegarden in Rompo, Napu valley, Central Sulawesi, 2004. The broken line indicates soil surface during planting of the ornamentals along the fence; the dotted line shows the present surface. Difference was about $30 \mathrm{~cm}$. 92

Figure 3.28. PAR measurement units in the small spice garden in Wuasa, Napu valley, Central Sulawesi.

(a) The reference zone; (b) The cacao zone; (c) The tree zone. 95

Figure 3.29. Temperature and PAR measurement units in the large fruit garden in Wuasa, Napu valley, Central Sulawesi. (a) The reference zone; (b) The vegetable zone; (c) The cacao zone. 95

Figure 3.30. Mean daily courses of soil and air temperatures in different production zones of three different homegarden types in the Napu valley, Central Sulawesi, in 2004. Measurement periods: Spice garden $=27.03 .-13.04 .2004 ;$ Fruit garden $=02.05 .-14.05 .2004$; Migrant garden $=21.05 .-02.06 .2004$. 96

Figure 3.31. Temperature and PAR measurement units in the migrant garden in Siliwanga, Napu valley, Central Sulawesi. (a) The reference zone; (b) The cassava zone; (c) The cacao zone. 97

Figure 3.32. Mean daily courses of PAR (Photosynthetic Active Radiation) in different production zones and strata (heights in $\mathrm{m}$ ) of three different homegarden types in the Napu valley, Central Sulawesi, in May 2004. Time periods of measurement: spice garden 6-10 May, fruit garden 11-15 May, migrant garden 22-26 May. (Veg. zone = Vegetable zone; Cass. zone = Cassava zone).

Figure 3.33. Mean duration (in minutes per day) of direct radiation ( $\geq 250 \mu \mathrm{E} / \mathrm{m}^{2} \mathrm{~s}$ ) in different vegetation strata and zones of three different homegarden types in the Napu valley, Central Sulawesi, in 2004. Veg. $=$ Vegetable; Cass. $=$ Cassava

Figure 3.34. Relation between mean daily duration of direct radiation near the soil surface and mean soil temperature in different production zones of three different homegarden types in the Napu valley, Central Sulawesi, in 2004. Note: Time periods of measurement were different for radiation and temperature in the three homegardens. 
Figure 3.35. Main and secondary functions of homegardens in three villages of the Napu valley, Central Sulawesi, in 2001 and 2004, as given by the gardeners (pale-coloured bars: secondary function). N per village $=10$, apart from Rompo 2004 and Siliwanga 2004, where $\mathrm{N}=9$ and $\mathrm{N}=8$, respectively.

Figure 3.36. Use of natural fertilisers in homegardens in three villages of the Napu valley, Central Sulawesi, in 2001 and 2004, as given by the gardeners. N per village = 10, apart from Rompo 2004 and Siliwanga 2004, where $\mathrm{N}=9$ and $\mathrm{N}=8$, respectively.

Figure 3.37. Use of external inputs in homegardens in three villages of the Napu valley, Central Sulawesi, in 2001 and 2004, as given by the gardeners. $\mathrm{N}=10$ in Wuasa; $\mathrm{N}=9$ in Rompo; $\mathrm{N}=9$ and $\mathrm{N}=8$ in Siliwanga in 2001 and 2004, respectively.

Figure 3.38. Changes of crop species composition from 2001 to 2004 in 30 homegardens of three villages (Market village $=$ Wuasa; Forest village $=$ Rompo; Migrant village $=$ Siliwanga) in the Napu valley, Central Sulawesi. Biplot of cases (linked by bold arrows) and selected crop species as a result of Principal Component Analysis, based on mean abundance data per village of 196 crop species cultivated in the homegardens surveyed over time; species abundance data ln-transformed and centred before analysis.

Figure 3.39. Temporal changes (means per village) in the portions of the overall number of crop individuals per use category in 30 homegardens in three villages of the Napu valley, Central Sulawesi, from 2001 to 2004. Due to very low portions, the use categories 'wood' and 'others' are not shown. Indiv. = Individuals. 108

Figure 3.40. Mean temporal changes (means per village) of crop species numbers in different use categories from 2001 to 2004 in 30 homegardens in three villages of the Napu valley, Central Sulawesi. Veget. = Vegetables; Stimul. $=$ Stimulants; Medic. $=$ Medicinal.

Figure 3.41. Crop diversity parameters of 30 homegardens in three villages of the Napu valley, Central Sulawesi, from 2001 to 2004. (a) Total species richness; (b) Mean species richness per garden; (c) Mean species density (according to the Arrhenius formula); (d) Mean individual density; (e) Median Shannon index; (f) Mean Shannon evenness index. (In villages followed by an asterisk, changes of the respective variable over time were significant at $\mathrm{P} \leq 0.05$ by Friedman test).

Figure 3.42. Reasons given by gardeners for the decrease of crop species number in different use categories in 30 homegardens in three villages of the Napu valley, Central Sulawesi, from 2001 to 2004.

Figure 4.1. An example for waste disposal in homegardens. Here, garbage was thrown into a pond in a garden in Tamadue, Napu valley, Central Sulawesi, 2004.

Figure 4.2. Highly commercialised homegardens lacking a multi-layered vegetation structure, managed by migrant families in the Napu valley, Central Sulawesi, 2004. (a) Cabbage garden in Tamadue. (b) Cacao garden with scattered shade trees, south of Wuasa. Note: These homegardens were not included in the sample gardens of this study.

Figure 4.3. Fallowed vegetable zone in a homegarden of Wanga, Napu valley, Central Sulawesi, 2004...144 




\section{Introduction}

\subsection{Homegardens: Definition and functions}

Homegardens are one of the most complex and diverse agro-ecosystems worldwide. Homegarden systems have existed for millennia (KUMAR \& NAIR, 2004; SOEMARWOTO \& CONWAY, 1992) in many tropical regions, where they played an important role towards the development of early agriculture and domestication of crops and fruit trees, a still ongoing process (KimBer, 1978; Miller \& NAIR, 2006; NiÑEZ, 1987; SMiTH, 1996). The high and maintained diversity of both cultivated and wild plant species makes homegardens suitable for in situ conservation of plant genetic resources (ALVAREZ-BUYLLA ROCHES et al., 1989; DAMANIA, 1996; MAXTED et al., 1997; WATSON \& EYZAGUIRRE, 2002). Individual homegardens have been continuously cultivated for many decades and even centuries, for example, in Sri Lanka (HocheGger, 1998). For this reason, homegardens are generally regarded as a sustainable agro-ecosystem (CHRISTANTY, 1990; KUMAR \& NAIR, 2004; SOEMARWOTO \& CONWAY, 1992; TORQUEBIAU, 1992). However, quantitative support for this statement is rare, as most of the published homegarden studies are rather descriptive. This might be due to the difficulty or even impossibility to measure sustainability per se, resulting in an indirect assessment by using more or less widely accepted sustainability indicators (HuXley, 1999; Gliessman, 1990a; Kumar \& NAir, 2004; PiePho, 1996; TorQuebiau, 1992), as presented in detail under 1.2.2.

As the appearance of homegardens is highly variable, there are several definitions of this system. Homegardens are commonly defined as:

A piece of land with a definite boundary surrounding a homestead, being cultivated with a diverse mixture of perennial and annual plant species, arranged in a multilayered vertical structure, often in combination with raising livestock, and managed mainly by household members for subsistence production (CHRISTANTY, 1990; Fernandes \& NAIR, 1986; HoOgerbrugGe \& FresCO, 1993; Kumar \& NAIR, 2004; RugalEMA et al., 1994; SOEMARWOTO, 1987).

NAIR \& KUMAR (2006) emphasised that the multi-layered vegetation structure as well as the intimate combination of trees, shrubs, and annual crops are essential for the concept of homegardens, whereas physical proximity to the homestead is, in some situations, not crucial.

Besides definition, also classification of homegardens is difficult due to their variable appearance. They have been commonly classified on the basis of garden characteristics that are easy to investigate, such as age or succession stage (herbaceous, shrub, fruit tree, and timber tree stages), dominating species, structure (e.g. vertical stratification, integration of livestock), or socio-economics (e.g. level of inputs, budget/subsistence/commercial production, or level of urbanisation/ornamentalisation) (CHRISTANTY, 1990; DE CLERCK \& Negreros-Castillo, 2000; Del Angel-Pérez \& Mendoza B., 2004; Michon \& Mary, 1994; NiÑEZ, 1987). However, a classification based on certain socio-economic characteristics such as traditional versus modern gardens, as suggested by MICHON \& MARY 
(1994), could be biased by individual ways of assessing these criteria by the researcher. Multivariate analyses (e.g. cluster analysis) used for classification may avoid such bias and has recently been performed in some studies (e.g. BLANCKAERT et al., 2004; KEHLENBECK \& MAass, 2004; MÉndeZ et al., 2001; PeYre et al., 2006; TeSfAYe AbebE et al., 2006). Despite the number of classification schemes proposed for tropical homegardens, none has been universally accepted.

\section{The multiple roles of tropical homegardens}

The basic function of homegardens is subsistence production, particularly in rural areas (Figure 1.1) (KUMAR \& NAIR, 2004; SOEMARWOTO \& CONWAY, 1992). Because of the high plant species diversity existing in homegardens, a wide spectrum of multiple-use products can be generated with relatively low labour, cash, or other external inputs (CHRISTANTY, 1990; HochegGer, 1998; SoEMARWOTO \& CONWAY, 1992). Homegardens generally serve as a complement to staple crop fields by producing mainly fruits, vegetables, spices, and many non-food products (ALBUQUERQUE et al., 2005; KARYONO, 1990; KEHLENBECK \& MAASS, 2004; Kumar \& NAIR, 2004; Michon \& MARY, 1994; Peyre et al., 2006). However, homegardens may also provide large portions of staple food, for example for poor families and in densely populated or heavily degraded areas without sufficient staple crop fields (Soemarwoto \& Conway, 1992; TeSfaye AbeBe et al., 2006). Homegarden products, including those from animals reared in the gardens, have a relatively high nutritional value in terms of protein, minerals, and vitamins (SOEMARWOTO \& CONWAY, 1992), thus, being important for the nutritional security of the gardeners' families (NAIR, 2006). As these diverse products are available year-round, homegardens also contribute to food security in times or seasons of scarcity (ChristANTY, 1990; FERnANDES \& NAIR, 1986; KARYONO, 1990). Therefore, the importance of homegardens for combatting malnutrition and food insecurity has attracted increasing attention (KUMAR \& NAIR, 2004). This, for example, has resulted in several manuals for the promotion of growing vegetables in tropical homegardens, as compiled by FAO (2001) and HELEN KELLER INTERNATIONAL (2004).

The second important function of homegardens is the generation of cash income, particularly in regions with good market access (Figure 1.1) (CHRISTANTY et al., 1986; MICHON \& MARY, 1994; TESFAYE ABEBE, 2006; TRINH et al., 2003). Most of the income is said to be derived from perennials such as fruit and spice trees, cacao, and coffee, but in peri-urban areas or tourist centres as well as in tropical highlands, also vegetables and/or ornamentals are frequently grown as cash crops (ABDOELlAH et al., 2002; SOEMARWOTO \& CONWAY, 1992). However, gardeners often do not cultivate certain crops exclusively for sale, but rather sell any marketable surplus of their subsistence crops (FERNANDES \& NAIR, 1986). Thus, the portion of income from a homegarden may vary from 0\% (GEBAUER, 2005; MÉNDEZ et al., 2001 ) to more than $50 \%$ of the household's total cash income (TRINH et al., 2003), depending on market access, among other factors.

In addition to the productive functions, homegardens have important social and cultural functions (Figure 1.1) (ABdoellah et al., 2002; Christanty, 1990; KARYONO, 2000; SOEMARWOTO \& CONWAY, 1992). They are mostly 'open' for everyone, thus, providing a place for children to play and for the neighbourhood to meet and chat. The exchange of homegarden products and planting material is common in many traditional societies. Homegardens also serve as status symbol and the aesthetic purpose partly might outweigh the 
productive function, especially in urban areas and better-off households (ARIFIN et al., 1998; KARYONO, 1990). Some plant species in homegardens are believed to have a magical value (ABDOELLAH et al., 2002), others are necessary for religious ceremonies, e.g., Hindu Balinese families need their homegardens as source and place for making sacrifices (pers. obs.).

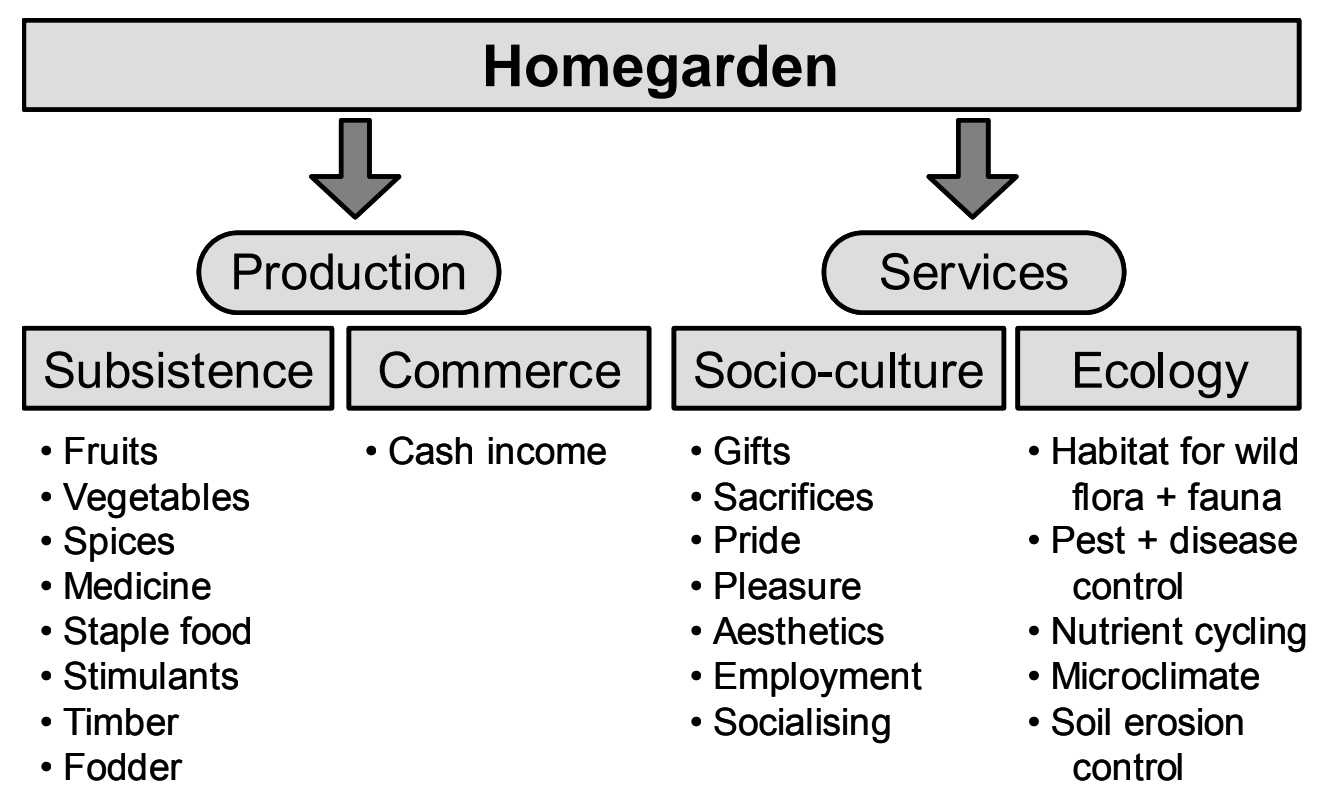

Figure 1.1. Main functions of homegardens and selected products/outputs (modified after KEHLENBECK et al., 2007).

Homegardens also fulfil ecological functions (Figure 1.1), particularly in those landscapes where large, monotonous, and monofunctional agricultural fields dominate (CHRISTANTY, 1990). The multi-layered vegetation structure of homegardens is said to resemble natural forests and offers a habitat for a diverse community of wild plants and animals (Albuquerque et al., 2005; Hemp, 2006; Karyono, 1990; Michon \& MAry, 1994). This structure appears to contribute substantially to the sustainability of homegarden systems, presented in detail in the following.

\subsection{Sustainability of homegardens}

\subsubsection{Definitions and characteristics of sustainability}

Traditional agricultural systems, including homegardens and other multi-species agroforestry systems, are frequently mentioned as a time-tested example for sustainable production systems. Many definitions of sustainable agriculture have been developed; HuXLEY'S (1999) may serve as a baseline:

'Sustainable landuse is that, which achieves production sufficient to meet the needs of present and future populations, while conserving or enhancing the land resources on which that production depends' (HUXLEY, 1999). 
Similar, rather general definitions were also given by GLIESSMAN (1990b) and TORQUEBIAU (1992), whereas others include more details such as efficient use of resources, integration of natural biological cycles, restoration after disturbances, reduced risk of environment pollution, maintenance of economic viability of farm operations, enhancement of life quality for farmers and the whole society, and/or social acceptability (HARTEMINK, 2003; HUXLEY, 1999; USDA, 2006). The concept of sustainability has, therefore, not only ecological, but also social dimensions (PEYRE et al., 2006). According to WIERSUM (2004), the term sustainability is often used only referring to present and stable conditions, but the changing needs of future generations and social dynamics should also be considered. Consequently, a sustainable agroecosystem should, in addition, be able to respond/adjust to changes in environmental and socio-economic conditions (GLIESSMAN, 1990b).

Typical characteristics/attributes of traditional multi-species agro-ecosystems, contributing to their ecological, economic, and social sustainability are, for example (ALTIERI, 2002; Gliessman, 1990a; ToRQuebiau \& PenOt, 2006):

- Utilisation of locally available, renewable resources instead of external, purchased inputs.

- Long-term maintenance of productive capacity, for example related to soil fertility, together with positive on- and off-farm environmental impact.

- Adaptation to local conditions rather than dependence on the control of the environment.

- $\quad$ Maintenance of a high level of biodiversity, including intra- and inter-specific diversity of wild and domesticated plants and animals.

- $\quad$ Efficient resource use by horizontal and vertical stratification.

- $\quad$ Stable production of adequate domestic and exportable crops.

- Utilisation and maintenance of local knowledge and culture.

Homegardens are frequently regarded as sustainable, sometimes simply because they have been successfully practised for many centuries (CHRISTANTY, 1990; FERNANDES et al., 1984 ), or because they are associated with the same ecological functions and processes as natural forests (Hochegger, 1998; Jose \& Shanmugaratnam, 1993; Wickramasinghe, 1995). The forest-like character of homegardens is related to certain sustainability attributes such as close nutrient cycling as well as efficient use of resources such as water, nutrients, space, and light by a dynamic, multi-layered vegetation structure, which not only harbours a high species diversity, but also favors biological interactions and reduces soil erosion (ALVAREZ-BUYLLA Roches et al., 1989; Hochegger, 1998; Soemarwoto \& Conway, 1992). Another characteristic for sustainability of homegardens, recognised only recently, might be their promising capacity for carbon sequestration (KUMAR \& NAIR, 2004), however, there is not yet much data available on the exact determination of this potential (KUMAR, 2006; ROSHETKO et al., 2002).

Besides such ecological attributes of sustainability, homegardens are said to fulfil also many economic and social requirements of sustainable agro-ecosystems. For example, homegardens provide the gardeners' families with year-round available, diverse products for subsistence, 
sale, and exchange (MÉNDEZ, 2001). For homegardening, only simple tools and low labour, cash, and external inputs are needed (ALVAREZ-BuYLLA ROCHES et al., 1989; BLANCKAERT et al., 2004). However, due to low inputs, productivity may be relatively low and, thus, could be subject of improvement in part of the homegardens (KARYONO, 1990; RUGALEMA et al., 1994; SOEMARWOTO, 1987). Homegardens are also able to easily react to changing socio-economic conditions and increasing inputs (SOEMARWOTO \& CONWAY, 1992), e.g. by integrating cash crops. Commercialisation and modernisation can, on the other hand, substantially reduce the ecological and socio-economic sustainability of homegardens (ABDOELLAH et al., 2006; JOSE \& Shanmugaratnam, 1993) as described under 1.4.

Most of the statements concerning the sustainability of homegardens are only based on qualitative and descriptive data (BLANCKAERT et al., 2004; MÉNDEZ, 2001), whereas quantitative studies are rare (e.g. see GAJASENI \& GAJASENI, 1999). In addition, no long-term quantitative study of the same homegardens has been reported. Assessing sustainable land management is as difficult as defining it (HARTEMINK, 2003; IZAC \& SWIFT, 1994), and the question arises if it is possible to assess sustainability per se by one single parameter (PIEPHO, 1996). This may be solved by selecting suitable descriptors and indicators of sustainability that cover its different dimensions (Torquebiau, 1992; HuXley, 1999). Some of such indicators, partly applied in this study, are presented in the following.

\subsubsection{Sustainability indicators}

To assess sustainability of agro-ecosystems, suitable descriptors (i.e. attributes of sustainability) and indicators (i.e. precise, measurable variables of the descriptor) must be identified (HuXLeY, 1999; TORQUeBIAU, 1992). Sustainability indicators should be simply to define, easy to measure, and reproducible in time and space. They can be related to different spatial levels such as plot, farm, or village/regional level, thus, requiring clearly defined spatial boundaries (IZAC \& SWIFT, 1994). In this study, assessing sustainability was restricted only to the plot level of the agro-ecosystem 'homegarden'.

A suitable set of indicators should cover the ecological, economic, and socio-cultural dimensions of sustainability. For each agro-ecosystem, not only the set of suitable indicators, but also their desired specific rates, levels, or values may differ (GLIESSMAN, 2001). As a consequence, variable sets of indicators are provided in the literature (see e.g. IZAC \& SWIFT, 1994; Kumar \& Nair, 2004; Torquebiau \& Penot, 2006). Gliessman (2001), for example, suggested to assess parameters related to the soil resource, hydrogeological factors, biotic factors, ecosystem characteristics, ecological economics, and the socio-cultural environment. For agroforestry systems, HUXLEY (1999) considered descriptors based on biology (e.g. yields, biomass, soil biota), physical resources (e.g. soil fertility, water availability), economics (e.g. inputs, labour, outputs), and social aspects (e.g. food security, welfare). TORQUEBIAU (1992) suggested several indicators for assessing sustainability of homegardens that are related to the resource base (e.g. soil, light, water, biodiversity), the system's socioeconomic performance (e.g. labour, inputs, outputs), and its impact on other systems (e.g. forests, wildlife). In this study, a subset of the indicators recommended by TORQUEBIAU (1992) that were also used in other homegarden studies (e.g. GAJASENI \& GAJASENI, 1999) were applied. The selected indicators, described below, focus on socio-economic and resource-based aspects, particularly on plant species diversity that is said to be a key factor 
towards sustainability (ALTIERI, 2002; BENJAMIN et al., 2001; HodEL et al., 1999; IZAC \& SWIFT, 1994; NAIR, 2006).

\section{Indicators related to socio-economic sustainability}

To assess the management and performance of homegardens, TORQUEBIAU (1992) recommended to measure the amounts of endogenous and external inputs, labour requirements, and outputs. In a sustainable systems, mostly endogenous, locally available inputs such as manure, compost, or alternative pest and weed control measures are applied instead of exogenous, cash-demanding ones, e.g. industrial fertilisers, pesticides, or purchased planting material. In addition, labour requirements are relatively low and allocated in a flexible manner throughout the whole year. No hired, but family labour of both males and females is used, often those of weaker household members such as children, elderly, or women caring for small children. Produce meets the diverse needs of the household, including food, medicine, wood, fodder, cash, or exchange. It is of high nutritional value and available year-round (TORQUEBIAU, 1992).

\section{Indicators related to ecological sustainability: Resources soil and light}

To evaluate sustainability concerning the resource base of homegardens, TORQUEBIAU (1992) suggested to assess parameters of soil quality and its maintenance such as rates of soil erosion, soil organic matter content and bulk density, as well as soil moisture status and temperature. The immense importance of the soil component towards sustainability of agroecosystems has frequently been mentioned in the literature (e.g. HARTEMINK, 2003; HuXLEY, 1999; KUMAR \& NAIR, 2004). In general, homegarden soil keeps its moisture and has low temperatures due to the dense layers of litter and undergrowth that contributes also to low rates of soil erosion, close nutrient cycling, and high soil organic matter contents. However, studies on soil quality usually refer to a single 'snapshot' of the status quo without any further consideration for variation over space and time.

Concerning the resource light, TORQueBIAU (1992) stated that it is used efficiently by the multi-layered vegetation structure of homegardens. For its assessment, understorey temperature and photosynthetic active radiation (PAR) should be measured, among others.

\section{Indicators related to ecological sustainability: Biodiversity}

Biodiversity, particularly plant species diversity, is the aspect/criterion probably most frequently assessed in homegarden research (e.g. AlBUQUERQUE et al., 2005; HEMP, 2006; PEYRE et al., 2006; WEZEL \& BENDER, 2003). The wide spectrum of plant species creates the multi-layered vegetation structure in homegardens, which is responsible for many benefits and advantages of the system and, thus, for its sustainability (see 1.3). Animals also contribute to different aspects of sustainability, e.g. for food, sale, traction, or manure (KUMAR \& NAIR, 2004; TESFAYE ABEBE et al., 2006). Consequently, plant and animal diversity is considered as a sustainability indicator (TORQUEBIAU, 1992). An extensive assessment of plant diversity should include not only species numbers and frequencies, but also variety numbers as well as species abundances, expressed by different diversity indices (Huston, 1994; LUDWIG \& REYNOLDS, 1988; NAIR, 2006; PEET, 1974; PIEPHO, 1996). In addition to species diversity as such, also particular species compositions and/or the diversity of functional groups (e.g. staples, vegetables, fruits) may be important for the sustainability of homegardens (ALTIERI \& Nicholls, 1999; Tesfaye ABEBE et al., 2006). 


\subsection{Functions of biodiversity towards sustainability}

The multi-layered vegetation structure in homegardens, created by a wide spectrum of cultivated and wild plants, appears to be responsible for many benefits/advantages of this system. Both the complex structure and the high plant diversity usually found in homegardens contribute substantially to their sustainability concerning ecological aspects (BENJAMIN et al., 2001; NAIR, 2006; SoEmarwoto \& CONWAy, 1992; Torquebiau, 1992), e.g. by creating a favourable microclimate or by enabling efficient use of nutrients and other resources. FERNANDES et al. (1984) and GAJASENI \& GAJASENI (1999) particularly emphasised the positive aspects of the relatively lower air and soil temperatures as well as the higher humidity in homegardens with a complex vegetation structure. However, the latter may also favour fungal diseases; the diverse structure may harbour injurious birds and insects (NAIR \& SREEDHARAN, 1986 in MATHIAS-MuNDY et al., 1992), but severe attacks have rarely been reported from homegardens (see below).

The positive influence of (agro-)biodiversity on (agro-)ecosystem functioning and sustainable production is more and more recognised both for man-made and natural systems (ALTIERI, 2002; Atta-Krah et al., 2004; CARdinale et al., 2006; Clergue et al., 2005; Main, 1999; SCHWARTZ et al., 2000). Theoretically, different species successfully coexist in the same system due to niche differentiation. Consequently, a diverse polyculture produces more biomass by exploiting more of the limited resources as compared to a monoculture (CARDINALE et al., 2006). Additionally, even without ecological complementarity, polycultures are more likely to include highly productive species under a given environmental situation, a mechanism known as the sampling or selection effect (LOREAU \& HECTOR, 2001). Most of the experimental studies available, including two meta-analyses (BALVANERA et al., 2006; CARDINALE et al., 2006), supported the theory of a positive response of ecosystem properties to increasing biodiversity, although some did not reveal such influence, possibly due to the relatively small spatial and temporal scale of the experiments (BALVANERA et al., 2006; CARdinale et al., 2006; LOREAU et al., 2001; MAIN, 1999). However, many studies concluded that not so much biodiversity or species numbers per se contribute to ecosystem functioning and stability, but rather the occurrence of certain functional groups or keystone species such as leguminous plants with nitrogen-fixing symbionts (CARDINALE et al., 2006; HoOPER \& VitOUSEK, 1997; MCCANN, 2000), as postulated also for agro-ecosystems (Altieri \& Nicholls, 1999; Clergue et al., 2005; IZAC \& SwifT, 1994; NAiR, 2006).

Both genetic and species diversity play important roles towards (agro-)ecosystem processes and services. On the one hand, intra-specific diversity is not only a key source for breeding, but also essential for sustainability because it enables individual species to adapt to a changing environment and, therefore, ensures their long-term survival (ATTA-KRAH et al., 2004; MAIN, 1999). Inter-specific diversity, on the other hand, leads to important synergistic ecological processes and enables ecosystem functioning. This refers to efficient, complementary resource utilisation, efficient nutrient recycling, reduced invader abundance, and a low risk of soil erosion, but also to performance of ecosystem services such as regulation of local hydrological processes or detoxification of harmful chemicals (BAlvanera et al., 2006; Clergue et al., 2005; Gliessman, 2000; Main, 1999; Kumar \& Nair, 2004; Power \& Kenmore, 2002; Soemarwoto \& Conway, 1992; Torquebiau, 1992; WIERSUM, 2004). 
In agro-ecosystems, biodiversity not only contributes to ecological, but also to socioeconomic aspects of sustainability. Productivity of a species-rich agro-ecosystem is generally higher and more stable as compared to a monocropping system because the multi-species system exploits available resources efficiently and forms a buffer against biotic (pests and diseases) as well as abiotic (storms and droughts) stresses (ATTA-KRAH et al., 2004; CLERGUE et al., 2005; Power \& KenMORE, 2002; SWIFT et al., 1996; WiERSuM, 2004). In more detail, a diverse system provides a favourable microclimate and several micro-environments suitable for different crop species (GLIESSMAN, 2000). Resources such as water, nutrients, and light are utilised complementarily and more efficiently by a combination of annual and perennial species, where, for example, tree roots may capture nutrients not reached or not exploited by the roots of annual plants (SCHROTH et al., 2001). Pests may be better controlled in multispecies systems by providing habitat, alternative food sources, and nesting sites to predators and other beneficial organisms, not only on a spatial, but also on a temporal scale (ALTIERI \& Nicholls, 1999; Gliessman, 2000; POWER \& KenMORE, 2002; SwIFT el al., 1996). Besides, pest attacks have been said to be constrained in multi-species systems by effects of protection, camouflage, trapping, deterrence, or disrupting the searching behaviour of the pest (ALTIERI \& NiCHOLLS, 1999). In relatively diverse homegardens, for example, DRESCHER (1996) reported a higher abundance of aphid predators; whereas NAIR (2006) supposed increasing frequencies of invader species in simplified gardens. For agroforestry systems, recent studies demonstrate the importance and monetary value of plant diversity for pollination services and pest control, e.g. by offering a habitat to bees or insectivorous birds (KLEIN et al., 2006; SCHULZE et al., 2004). A diverse, multi-species production system reduces the risk of total crop failure and provides year-round available products of high nutritional value (GLIESSMAN, 2000; MAIn, 1999). For homegardens, MARTEN \& ABDOELlah (1988) postulated a positive influence of crop species number on nutrient production per $\mathrm{m}^{2}$ garden size. Thus, plant diversity contributes to sustainability in the aspect of household food and nutritional security (Atta-Krah et al., 2004; HuXley, 1999; Kumar \& NAIR, 2004; Main, 1999).

WIERSUM (2004) stressed a further potential of multi-species agroforestry systems towards sustainability: a diverse range of useful plant species in a system enables its effective adjustment to changing socio-economic conditions and demands of future generations. In addition, biodiversity has 'heritage' functions, e.g. due to its aesthetic value on the landscape scale, or its heritage value on the habitat, species, or even genetic scale (CLERGUE et al., 2005). Highly diverse agro-ecosystems such as homegardens are, therefore, also regarded as an ideal production system for in situ conservation of plant genetic resources (WATSON \& EYZAGUIRRE, 2002), crucial for long-term sustainability (see 1.5). Nevertheless, the suitability of biodiversity as an indicator to assess sustainability might be critically examined because there is no threshold value for an ideal number of species in a sustainable system (MAIN, 1999). Biodiversity also seems to be highly variable over time, while homegarden research has, so far, neglected to quantify such changes. Chapter 1.4 deals with major known factors influencing crop diversity in homegardens and, thus, possibly causing some changes.

\subsection{Influence of different factors on crop diversity in homegardens}

Crop diversity of homegardens in space and time varies depending on a combination of external and intrinsic factors that are mainly related to the categories agro-ecology (including 
garden features) and socio-economics (CHRISTANTY et al., 1986; HodEL et al., 1999; HoOgerbrugge \& Fresco, 1993; SOEMARWOTO, 1987). However, intrinsic characteristics of the gardener, like individual preferences, practices, and culture, may play an overriding role for determining crop species composition and diversity (ABDOELLAH et al., 2002; CASTIÑEIRAS et al., 2002, HodEL et al. 1999). The manifold, complex interactions existing among these factors are not yet fully understood and make the analysis of their influences on crop diversity more difficult. In addition, these factors may vary in their relative importance over time (Figure 1.2). A better understanding of the interrelationships and the processes leading to them would help to assess the sustainability of the system as well as its suitability for in situ conservation of plant genetic resources. In the following, the influence of selected factors on crop diversity in homegardens is described in more detail.

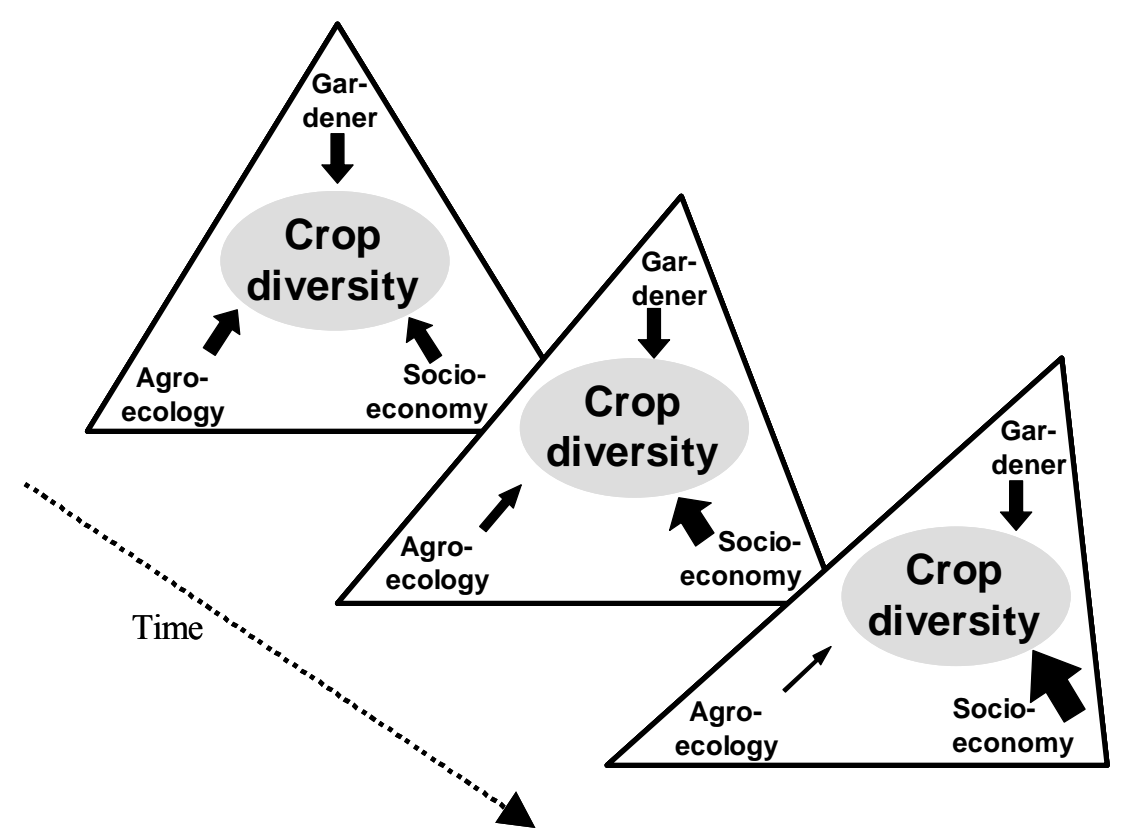

Figure 1.2. Schematic illustration of the relative importance of different factors on crop diversity in homegardens and their temporal changes (modified after KEHLENBECK et al., 2007). Here, the importance of socio-economic factors (e.g. commercialisation) increases over time, while that of agro-ecological characteristics (e.g. infertile soil) decreases, for example due to the use of industrial fertiliser.

\section{Agro-ecological factors}

Agro-ecological factors such as elevation, climate, or soil quality may limit crop diversity in homegardens (Figure 1.3). Many studies have highlighted the effect of elevation on crop diversity. Species richness is generally said to decrease with increasing elevation $(0-1500 \mathrm{~m})$ due to decreasing mean temperature (HODEL et al., 1999; KARYONO, 1990). However, decreasing species richness in homegardens along the elevation gradient often overlap with also decreasing garden sizes (HoDEL et al., 1999; KEHLENBECK et al., 2007; KHOSHBAKHT, 2005), thus, making a clear differentiation of the driving factors impossible. Other studies reported highest species richness at intermediate elevation of 600-1700 m asl., where gardeners have the opportunity to cultivate both tropical and subtropical crops (JOHN \& NAIR, 1999; QUIROZ et al., 2004; SUNWAR et al., 2006). On the other hand, no influence of elevation 
on species number was recorded for homegardens in Cuba (CASTIÑEIRAS et al., 2002) and in Ethiopia at 1500-2000 m asl. (TESFAYE ABEBE et al., 2006). Along the elevation gradient, however, structural complexity of homegardens decreases due to changes of crop species composition. Less fruit tree species, but more vegetables and medicinal plants were cultivated in homegardens of higher elevations (CASTIÑEIRAS et al., 2002; SHRESTHA et al., 2002; SoEmarwoto \& CONWAY, 1992). For the natural flora, highest diversity is also noted at intermediate elevation between $1000 \mathrm{~m}$ and $1300 \mathrm{~m}$ asl. (HEMP, 2006) or at about 1500-1700 $\mathrm{m}$ for certain plant groups (KESSLER, 2002; KLUGE et al., 2006) due to overlapping of different vegetation communities and advantageous climatic conditions at this elevation in the tropics (e.g. high humidity, intermediate temperatures).

Not only temperature, but also precipitation influences crop diversity. Homegardens in West Java harbour higher crop diversity in the wet than in the dry season (SOEMARWOTO \& CONWAY, 1992). Crop diversity of Ghanaian homegardens is higher in the humid forest ecozone than in the hot and dry savannah zone (BENNETT-LARTEY et al., 2004). Similar results have been described for the comparison between rather dry and humid environments in Guatemala (Azurdia \& LeIVA, 2004; Gillespie et al., 1993), Bangladesh (Millat-EMustafa et al., 1996), and Martinique (KIMBER, 1966). An absent or only short dry period can promote high species richness (HOOGERBRUGGE \& FRESCO, 1993; ZALDIVAR et al., 2002), not only in homegardens, but also in natural environments (CLINEBELL II et al., 1995; HAWKINS et al., 2003; KESSLER, 2002). A generally rather low diversity is reported in homegardens of semiarid environments, e.g. in Sudan (GEBAUER, 2005). In contrast, Cuban homegardens harbour higher crop diversity under semiarid as compared to humid conditions due to irrigation (WEZEL \& BENDER, 2003). However, variation in crop diversity may occur also due to small-scale climatic variation, like flooding or droughts caused, for example, by El Niño events (Figure 1.3).

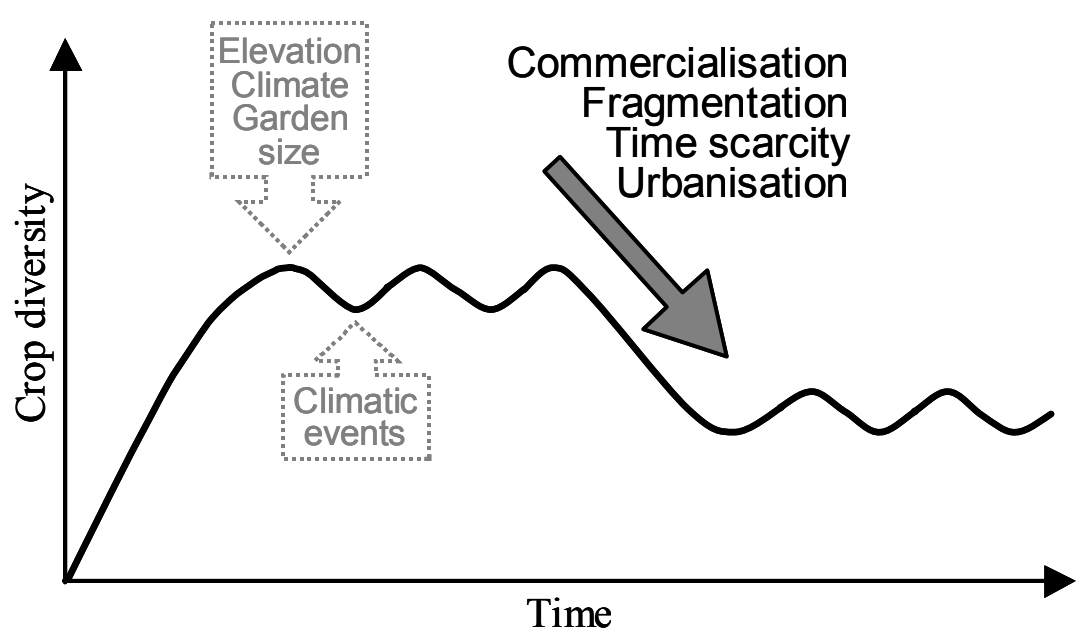

Figure 1.3. Schematic development of crop diversity (except ornamentals) in homegardens over time under the influence of changing socio-economic conditions (modified after KEHLENBECK et al., 2007). Agroecological factors (e.g. elevation) may limit plant diversity, while short-term/small-scale climatic events may cause a certain fluctuation around a mean level. 
Soil quality is another agro-ecological factor that generates variation of crop diversity in homegardens, but its influence has not yet been studied in detail. HoDEL et al. (1999) simply assumed an influence of soil factors on diversity without quantifying this. A general low crop diversity is said to occur on rather marginal, harsh environments having only poor soil quality, e.g. sandy or shallow soils (CECCOLINI, 2002; KiMBER, 1966; Millat-E-MustafA et al., 1996; OKUBO et al., 2003; WIERSUM, 2006). In forest gardens, KAYA et al. (2002) reported lower species diversity on marginal soils as compared to more fertile soils. Many cultivated plant species, particularly vegetables and spices, do not give adequate yields under unfavourable soil conditions characterised by, for example, low $\mathrm{pH}$ value or plant available $\mathrm{P}$ content. Due to high competition on poor homegardens soils, tree density is said to be rather low, too (WIERSUM, 2006). Therefore, gardeners may stop cultivating unsuitable species while switching to a reduced set of crops that can cope with poor soil quality (HVOSLEF, 1994).

\section{Garden features}

Within the major factors influencing crop diversity, garden size is one of those frequently analysed. A positive relationship between garden size and species richness has been documented in many countries, e.g. Indonesia (ABDOELLAH et al., 2002; ARIFIN et al., 1997 and 1998), India (DAS \& DAS, 2005), Nepal (Sunwar et al., 2006), Bangladesh (Millat-EMustafa et al., 1996), and Venezuela (QuIROZ et al., 2004). However, its influence on species richness was found to be rather weak in other studies (HODEL et al., 1999; RICO-GRAY et al., 1990) or not even existing (ABDOELlah et al., 2006; AlbuQUERQue et al., 2005; BlANCKAERT et al., 2004; HoCHEGGER, 1998; KUMAR et al., 1994). In small homegardens, particularly tree species richness decreases, resulting in a poor vertical vegetation structure. However, an increasing number of annual crops like vegetables and spices partly may compensate the decrease of perennial crops in small gardens. Consequently, crop species density may decrease with increasing garden size (HOCHEGGER, 1998). In addition, diversity expressed by indices (e.g. Shannon index) is said to decrease with increasing garden size, probably due to more uniform planting patterns and the dominance of a few species in larger gardens (KumAr et al., 1994; PEYrE et al., 2006).

Homegarden age is thought to influence crop species richness positively (BAN \& COOMES, 2004; Quiroz et al., 2004; WeZEL \& OHL, 2005; Wiersum, 2006). When setting up a new homegarden, gardeners start planting with a rather small set of crops, particularly staples as an initial source for subsistence (COOMES \& BAN, 2004). Over time, more and more species may be introduced by gardeners or resprout from the former vegetation, while established, reliable species remain (Figure 1.3). Particularly tree species richness and abundance in homegardens may increase over time (BACKES, 2001; WeZEL \& OHL, 2005). However, BlANCKAERT et al. (2004) and HoDEL et al. (1999) did not find any relationship between crop diversity and age when surveying homegardens of Mexico and Vietnam, respectively.

\section{Socio-economic factors}

Among socio-economic factors, the negative influence of market proximity and intensive market-oriented production on crop diversity in homegardens has frequently been recorded (Figure 1.3) (ABDOEllaH et al., 2002; Ali, 2005; CASTIÑEIRAS et al., 2002; CECCOLINI, 2002; Christanty, 1990; Hoogerbrugge \& Fresco, 1993; Michon \& Mary, 1994; Shrestha et 
al. 2004; Soemarwoto \& Conway, 1992; Tesfaye Abebe et al., 2006). In remote areas, traditional subsistence homegardens provide the owner families with a wide spectrum of products to meet their daily needs, resulting in high crop diversity (ABDOELLAH \& MARTEN, 1986; Millat-E-Mustafa et al., 1996). Good market access, on the other hand, may drive gardeners from subsistence to semi-commercial or commercial production. The cultivation of cash crops, particularly of annual vegetables or ornamentals, leads to both genetic erosion of traditional vegetables and decreasing numbers of perennials such as fruit and timber trees (PEYRE et al., 2006; SHRESTHA et al., 2004). As a consequence, commercial homegardens often lack a complex vegetation structure. The focus of development agencies on improving cash income generation and nutrition through the promotion of mostly exotic, annual vegetables can lead to such negative effects, associated with the loss of indigenous knowledge and cultural erosion (KARYONO, 2000; SHRESTHA et al., 2004). In addition, the nutritional value of exotic vegetables often is markedly lower as compared to traditional ones, thereby, affecting the important role of homegardens for family nutrition (ABDOELLAH et al., 2006). Commercialisation with perennial cash crops, partly also supported by development projects, often was accompanied by a marked decrease in forest trees, vegetables, medicinal plants, and traditional fruit tree species and varieties (BELACHEW WASSIHUN et al., 2003; DAS \& DAS, 2005; Michon \& MARY, 1994; SOEMARWOTO, 1987; VogL et al., 2002).

Market proximity and commercialisation, on the other hand, could also have no (LAMONT et al., 1999; TRINH et al., 2003) or even a positive influence on crop diversity in homegardens (Hodel et al., 1999; KIMBER, 1966). The slightly positive effect could be explained by a higher amount of cash income generated in semi-commercialised homegardens accompanied by higher labour investment, from which also subsistence crops could profit. GONZALES (1985, cited in GLIESSMAN, 1990b) as well as QUIROZ et al. (2004) argued that a wellbalanced mix of subsistence and cash crop production can lead to higher plant diversity in homegardens with an intermediate market access, particularly if there is a demand for traditional crops in urban centres (SUNWAR et al., 2006). In contrast, WEZEL \& OHL (2005) reported a rather low diversity in very remote and isolated homegardens, where gardeners had only little contact to other ethnic groups and were still much engaged in gathering food from the forests instead of cultivating it.

Besides commercialisation, the scarcity of land and high population density generally also reduce homegarden biodiversity. Families with insufficient crop fields are forced to grow high proportions of staples in their homegardens (SoEmarwoto \& CONWAY, 1992). As many staple food crops are light-demanding, perennials like fruit or timber trees disappear from such homegardens (KARYONO, 1990). High population density is often accompanied by fragmentation of homegardens, thus, causing a decrease of crop diversity due to decreased garden sizes (ARIFIN et al., 1997; HoOgerbrugGe \& FresCO, 1993; TeSFAYE ABEBE et al., 2006). Urbanisation is also said to reduce crop species diversity (Figure 1.3) (MICHON \& MARY, 1994). Along the urbanisation gradient, more and more crop species are replaced by ornamentals (KARYONO, 1990; KEHLENBECK et al., 2007; RICO-GRAY et al., 1990). In periurban regions with good access to large markets in the city, traditional homegardens may be completely converted into commercial fruit tree or vegetable gardens, thereby, losing not only their potential for subsistence production, but also much of their ecological and social functions (SoEmARwoto \& SOEMARWoto, 1982). At the highest urbanisation level, homegardens are generally rather small and dominated by ornamentals, giving priority to the 
aesthetic function instead of subsistence production (ARIFIN et al., 1998). These effects of modernisation and urbanisation may even reach rural areas (SOEMARWOTO \& SOEMARwOTO, 1982).

\section{Gardeners' characteristics}

Certain characteristics of the gardener and his/her household are known to influence crop diversity in homegardens. A gardener's age can influence crop diversity positively (QUIROZ et al., 2004), possibly because, over the years, gardeners try to cultivate new crops while they continue to plant well-tried species. In addition, older gardeners often have more time for homegardening and are supported by their grown-up children. Consequently, higher time allocation to homegardening leads to higher crop diversity (HoDEL et al., 1999). Large, rather 'old' households with large labour force generally maintain a higher species richness in their homegardens as compared to small and rather 'young', labour force-constrained households (see Figure 1.3) (COOMES \& BAN, 2004; HoOgerbrugge \& Fresco, 1993; Quiroz et al., 2004; Stoler, 1981 (cited in Christanty et al., 1986); Tesfaye AbeBe et al., 2006). Farmers as compared to gardeners with off-farm employment may cultivate more crop species in their homegardens due to higher time allocation and experience of the farmers (ARIFIN et al., 1997; CARON, 1995; LAMONT et al., 1999; QUIROZ et al., 2004).

How formal education or sex of the gardener influence crop diversity in homegardens is still uncertain. CASTIÑEIRAS et al. (2002) reported a slightly positive correlation between gardener's formal education and species richness that was, however, not confirmed by QUIROZ et al. (2004). In homegardens of higher educated gardeners, KARYONO (1990) noted a higher importance of ornamentals. Some studies indicated a higher species richness and diversity in homegardens managed mainly by females as compared to males (BAN \& COOMES, 2004; DRESCHER, 1996 for rural gardens; WILSON, 2003), whereas other did not find any influence (HODEL et al., 1999). Similarly, the influence of a household's wealth status on crop diversity is debated controversially. In general, homegardens of well-off households are said to harbour fewer food-producing plant species because such households purchase food and prefer ornamentals (HODEL et al., 1999; KARYONO, 1990). In other cases, higher crop diversity found in homegardens of wealthy families was related to larger garden sizes, larger landholdings suitable for staple crop production, or to their more pronounced mobility and social contacts used for gathering planting material (ABDOELLAH \& MARTEN, 1986; COOMES \& BAN, 2004; DAS \& DAS, 2005; SHRESTHA et al., 2004). A positive influence of household's wealth status concerning crop diversity at farm level was also postulated by PERZ (2005) due primarily to larger labour forces.

Ethnicity of the gardener may also be a factor explaining variation in crop diversity of homegardens (HODEL et al., 1999). Ethnic and cultural influences are particularly important for species composition (WIERSUM, 2006). Different ethnic groups prefer different plant products and, therefore, cultivate for example more vegetables or more medicinal plants in their homegardens (ABdoellah, 1980 in SoEmarwoto \& CONWAY, 1992; Azurdia \& LeIVA, 2004; Shrestha et al., 2004; Trinh et al., 2003). Migration and mobility can, thus, have a positive effect on crop diversity in homegardens (SHRESTHA et al., 2004; SOEMARWOTO, 1987). The positive influence will occur as long as plant species brought from the migrants' home regions establish successfully in the new environment and, on the other hand, migrants also adopt useful plants from indigenous gardeners. However, plant diversity 
in migrant homegardens and those of minorities could also be rather low due to poverty and discrimination (HODEL et al., 1999), e.g., by assigning land of poor soil quality for settlement to such groups (HoldEN \& HvOSLEF, 1995). Besides, shortage of labour for homegarden management and poor access to suitable agricultural land for staple food crops may further decrease crop diversity in migrant homegardens. Rather low crop diversity was reported not only from homegardens of migrant families, but in the initial years also overall for their farms (PERZ, 2005) or for their mixed plantations (KUSUMANINGTYAS et al., 2006).

In conclusion, no individual factor alone determines the crop diversity found in homegardens, but rather a complex combination of agro-ecological, socio-economic, cultural, and political factors causes spatial and temporal variation of crop species.

\subsection{Homegardens as places for in situ conservation of plant genetic resources}

The maintenance of both species and genetic diversity is commonly accepted as an important feature towards long-term sustainability of agro-ecosystems (ALTIERI, 2002; GLIESSMAN, 2001; Hodel et al., 1999; PIEPHO, 1996; TORQUEBIAU, 1992). High inter- and intra-specific diversity enables the adaptation of agro-ecosystems to changing environmental and socioeconomic conditions (ATTA-KRAH et al., 2004; MAIN, 1999). Agro-biodiversity (here, in the sense of plant genetic resources), including traditional crop varieties and landraces as well as wild ancestors of crop species, is a valuable asset for breeding activities and the development of 'new' crops, among others (BROOKFIELD, 2001; POWER \& KENMORE, 2002; TORQUEBIAU, 1992).

Scientific activities for a systematic conservation of plant genetic resources (PGR) initially amost exclusively focussed on ex situ techniques (i.e. conservation of species and varieties outside their natural habitats), whereas the importance of in situ techniques has been emphasised only since the 1980s (MAXTED et al., 1997). In situ conservation refers in general to the conservation of whole (agro-)ecosystems that provide the habitats of target species and varieties (MAXTED et al., 1997). Concerning in situ conservation of agro-biodiversity, it is commonly performed on traditional farms or parts of farms such as homegardens, leading to the term 'on-farm conservation'. Such a conservation technique allows for further crop evolution and adaptation to changing environments, while genetic diversity is regarded 'frozen' in ex situ approaches (BROOKFIELD, 2001; MAXTED et al., 1997). On the other hand, on-farm conserved materials are highly vulnerable to loss caused by changes in farming practices, e.g. commercialisation or modernisation, particularly if farmers do not earn any compensation or economic benefit by maintaining PGR (MAXTED et al., 1997; RHOADES \& NAZAREA, 1999). Thus, complementary strategies including both ex situ and in situ approaches are regarded most appropriate to insure against the erosion of agro-biodiversity (DAMANiA, 1996; MAXTED et al., 1997).

Homegardens are said to harbour a very high agro-biodiversity, possibly the highest of all agro-ecosystems (SWIFT \& ANDERSON, 1993 in NAIR, 2006; SWIFT et al., 1996). Therefore, homegardens are regarded as an ideal production system for in situ conservation of PGR, particularly of crop species and their varieties (BENNETT-LARTEY et al., 2004; ESQUIVEL \& HAMMER, 1992; MAXTED et al., 1997; WATSON \& EYZAGUIRRE, 2002). However, the overall 
impact of homegardens towards PGR conservation may be rather low because homegardens generally only occupy a small portion of the total agricultural area (ALVAREZ-BUYLLA Roches et al., 1989). Besides, the mostly low genetic diversity (i.e. small populations, few varieties) of species in individual homegardens can further reduce this impact (DAMANIA, 1996). Consequently, not single, but all homegardens of the same or even several regions should be combined to one conservation unit and, in addition, exchange of planting material between these gardens should be promoted (DAMANIA, 1996; GUARINO \& HOOGENDIJK, 2004; OAKLEY, 2004). To address the increasing problem of crop species and variety loss caused by changes of environmental, cultural, and socio-economic conditions, further approaches should be considered such as developing market opportunities for traditional crop products, improving seed supply, or even paying subsidies for PGR conservation (BRUSH, 1995; Damania, 1996; RhoAdes \& NAZAREA, 1999; Smale et al., 2004; Smith et al., 1992).

Homegardens do not only play an important role for in situ conservation of domesticated plants, but they can also contribute substantially to the conservation of wild plants, particularly where natural ecosystems like forests have largely been replaced by agricultural fields (AlbuQuerque et al., 2005; HeMP, 2006; Schroth et al., 2004). In Indonesia, the conversion of primary forest to frequently unsustainable agricultural lands has increased dramatically, contributing to a tremendous PGR loss. Forest margins are particularly concerned due to easy access, even in protected areas, e.g. national parks. Sustainable and productive agricultural systems urgently need to be promoted in such agricultural frontier areas to reduce the pressure on further forest conversion. Traditional agro-ecosystems such as homegardens and forest gardens could help to protect valuable forest resources, and they could serve as a model for the design of sustainable agroforestry systems (DE CLERCK \& Negreros-Castillo, 2000; Schroth et al., 2004). However, despite an increasing body of literature, even partly summarised in two recent reviews (KUMAR \& NAIR, 2006; EYZAGUIRRE \& LINARES, 2004), neither the functioning nor the potential of homegardens have been

satisfactorily studied. Research is needed, particularly, concerning nutrient and water balances, the value of non-conventional products and services, system productivity, and sustainability, including temporal changes and factors driving them (KUMAR \& NAIR, 2004).

\subsection{Objectives of the study}

The principal objective of this study was to assess the sustainability of homegardens with the help of selected sustainability indicators. Rural homegardens in Central Sulawesi, Indonesia, were targeted for the investigation because a data set from 2001 was available (KEHLENBECK, 2002; KEHLENBECK \& MAASS, 2004). The study aimed at determining spatial differences and temporal changes of resource quality in homegardens and the underlying driving forces, focussing especially on crop diversity, but also on soil quality, microclimate, and management of homegardens.

Specifically, the following research questions were addressed:

- Are the homegardens socio-economically sustainable?

- Is the resource 'soil' managed in a sustainable manner in homegardens?

- Is the resource 'light' used efficiently in homegardens? 
- Are there systematic spatial differences of the resource 'crop diversity' in homegardens?

- Can crop diversity in homegardens be maintained over time?

- Which factors are responsible for spatial and temporal differences of crop diversity in homegardens?

Finally, potentials for improving homegarden productivity and their suitability for in situ conservation of plant genetic resources were assessed. This study was associated to the interdisciplinary German-Indonesian collaborative research program STORMA (Stability of Rainforest Margins in Indonesia, SFB 552; STORMA, 2007). 


\section{Material and Methods}

Homegardens in the highlands of Central Sulawesi were studied from March to November 2001 and re-visited in 2003/2004 to evaluate changes in homegarden management, soil quality, and crop diversity over time. For the in-depth study from June 2003 to June 2004, the sample size was expanded to reveal more details about the influence of agro-ecological and socio-economic factors on crop diversity. Methods in this study mainly focussed on determining certain indicators for the assessment of sustainability with regard to socioeconomic and biophysical aspects, as suggested by GLIESSMAN (1990a), HUXLEY (1999), and TORQUEBIAU (1992) (see 1.2.2).

\subsection{Research area}

\subsubsection{Geographical and ecological conditions}

The research was carried out in the Napu valley, subdistricts Lore Utara and Lore Tengah, district Poso, province Central Sulawesi (Figure 2.1). The valley is located at the eastern margins of the Lore Lindu National Park (latitude $1^{\circ} 23^{\prime}-37^{\prime}$ South, longitude $120^{\circ} 18^{\prime}-20^{\prime}$ East) at an altitude of about $1,100 \mathrm{~m}$ asl. Small asphalt roads lead to the province capital, Palu, situated northwest of the valley (approx. $100 \mathrm{~km}$ away) and to the district capital, Poso, east of the valley (approx. $50 \mathrm{~km}$ away).

The Lore Lindu National Park was founded in 1993 and covers an area of about 220,000 ha. The park provides a habitat for highly diverse flora and fauna, including many endemic and endangered species. Therefore, it has been assigned as a Man and Biosphere Reserve by UNESCO already in 1977 (UNESCO, 2006). Concerning the Napu valley, the natural vegetation is classified as lower montane rain forest (WHITTEN et al., 1987).

\subsubsection{Climate and soils}

In the research area, temperature is rather constant throughout the year. Mean temperature is $21{ }^{\circ} \mathrm{C}$ with a range of about $13-32{ }^{\circ} \mathrm{C}$ (STORMA climatic measurements from December 2001 to September 2004, subproject Z2). Annual mean precipitation is about $1800 \mathrm{~mm}$ with a slightly dryer season from June to August. Mean annual relative atmospheric humidity is about $83 \%$, being slightly lower in the dryer season, when temperature is mostly lower as well.

In the valleys of the research area, mainly colluvial, alluvial, and lacustrine sediments are covering crystalline and metamorphic parent material (DECHERT et al., 2004). Soils of the Napu valley are mainly Fluvic Cambisols, Fluvisols, and Gleysols (FAO classification, revision of 1988), many of which have been transformed into Anthrosols (paddy soils) by wet rice cultivation; whereas those of the adjacent slopes are Eutric or Dystric Cambisols and Leptosoles, depending on parent material and topographic position (MACKENSEN et al., 1999; unpublished report). 

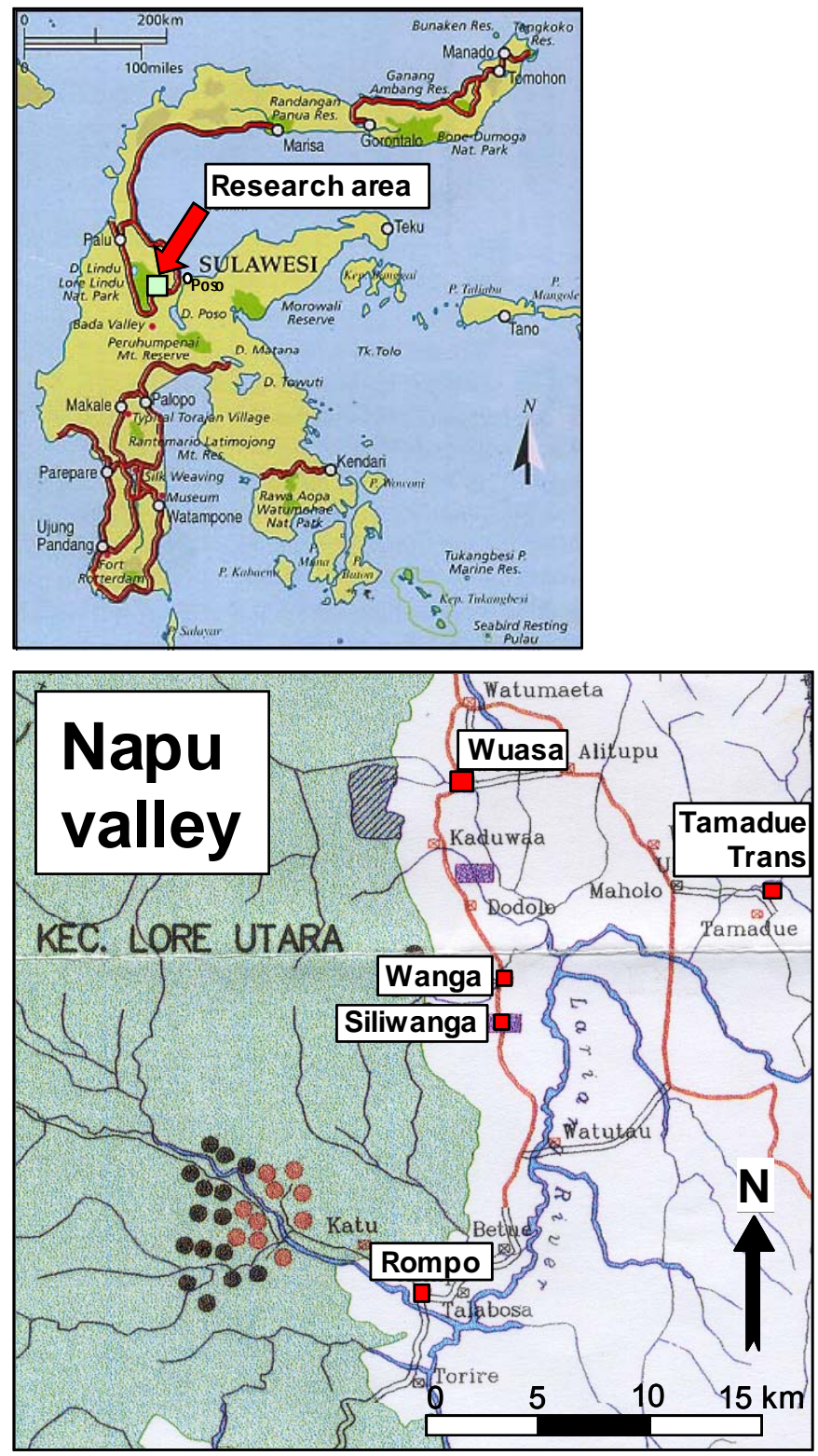

\section{Sulawesi and the Napu valley}

\begin{tabular}{|c|c|}
\hline $\begin{array}{l}\text { Sources: } \\
\text { - http://asiatre } \\
\text { - TNC survey } \\
\text { interviews, }\end{array}$ & $\begin{array}{l}\text { avel.com/ujungmap.html } \\
\text { s and other field } \\
1996\end{array}$ \\
\hline LEGEND & \\
\hline & Asphalt Road \\
\hline & Gravel Road \\
\hline & Track \\
\hline$\sim$ & River \\
\hline$-\cdot-1$ & Provincial Boundary \\
\hline$-\cdots-\cdots$ & Kabupaten Boundary \\
\hline$-\cdots-$ & Kecamatan Boundary \\
\hline 0 & Lake Lindu \\
\hline . & Village \\
\hline . & Less Developed Villoge \\
\hline$\otimes$ & Kecamatan Centre \\
\hline - & Provincial Capital \\
\hline $\mathrm{OS}$ & National Park Boundary \\
\hline matumanem & Project Area Boundary \\
\hline$\infty$ & Coffee/Cacao Plantation \\
\hline (x) & Logging \\
\hline$\because \bullet$ & Rattan Collection \\
\hline$\because$ & Shifting Agriculture \\
\hline$\therefore$ & Hunting \\
\hline$=$ & Collection of Maleo Eggs \\
\hline$\Delta$ & PLTA Development Plan \\
\hline$=$ & $\begin{array}{l}\text { Transmigration/Resettlement } \\
\text { Program/Plan }\end{array}$ \\
\hline & Proposed Road within LLNP \\
\hline
\end{tabular}

Figure 2.1. Location of the research area in Central Sulawesi and the five study villages in the Napu valley.

\subsubsection{Historical and socio-cultural background}

The Napu valley came under European influence in 1907, after the Dutch colonialists had defeated the local inhabitants in the 'Peore war' (WEBER, 2005). The local ethnic group called itself 'Pekurehua', derived from the similar sounding call of a common bird in this valley (WEBER, 2005). The inhabitants were feared head hunters, frequently attacking villages in neighbouring valleys and in the Poso plain, where they were named 'Napu', i.e. manslaughterer in the Poso language. The pre-colonial subsistence agriculture in the Napu valley was based mainly on shifting cultivation with the main crops being upland rice, maize, tuber crops, and some vegetables (SUNITO, 2004). The extended grasslands in the South of the valley were used for raising water buffaloes and horses. Paddy rice cultivation was limited to some small suitable plots only. One of the first scientists visiting the Napu valley in 1911, 
GRUBAUER (1923), reported well-tended and fenced homegardens for growing vegetables and ornamentals around the houses.

The Dutch promoted cultivation of paddy rice in the Napu valley, and they introduced improved agricultural techniques as well as new crops such as robusta coffee ${ }^{1}$ that was planted in cleared forest plots (SUNITO, 2004). The colonial administration forced the locals to move from their scattered semi-permanent huts in the mountains to newly founded villages in the valley, where they could be controlled/monitored and converted by missionary work. However, many villagers preferred to live in huts on their upland fields, guarding crops against wild pigs, monkeys, and birds. According to WEBER et al. (2003), people in the village of Wanga returned to their village houses for school and church service only on weekends until the 1980s.

The next major changes in the study region occurred when the asphalt roads to Palu and Poso were completed in the early 1990s. The earlier small influx of migrants into the Napu valley increased drastically, resulting in a population growth of $166 \%$ from 1980 to 2001 (MAERTENS et al., 2002). However, population density is still low with 8 inhabitants $/ \mathrm{km}^{2}$. In 2001, about $30 \%$ of all inhabitants in the Napu village were migrants (MAERTENS et al., 2002), but their share differed markedly among the villages (see below). On the one hand, migration took place spontaneously, particularly from other parts of Sulawesi, driven by the availability of large flat and fertile land areas (BURKARD, 2002a). On the other hand, the Indonesian government founded three transmigration resettlement projects in the Napu valley, mainly for Javanese and Balinese migrants (HOPPE \& FAUST, 2004). The migrants introduced cacao and arabica coffee cultivation as well as large-scale vegetable growing. Many migrants were rather successful both in agriculture and trading or other entrepreneurships, thus, arousing envy by the locals. Social integration of the migrants is still very limited and many prejudices against the other groups exist (e.g. migrants think that locals are lazy, locals feel that migrants want to 'master'/dominate them) (ABDULKADIR-SUNITO, 2004; HOPPE \& FAUST, 2004).

Since 2000, a recent increase of the population in the Napu valley occurs because of the influx of refugees from the district capital Poso (FAUST et al., 2003). Due to the inter-religious struggles that already claimed more than 1000 lives, Christian families fled the city and took refuge in the Napu valley, among other regions. The refugees were distributed over the villages; houses and fields were given to them. Although the situation in Poso gradually got safer in 2004, many refugees decided to stay in the Napu valley, as they already got settled there and lost their economic basis in Poso (ABDULKADIR-Sunito, 2004).

The present agriculture in the Napu valley is based on paddy rice production (about $20 \%$ of the agricultural area) in the bottom of the valley and agroforestry systems (about $30 \%$ of the agricultural area) with mixed or sole cash crops cacao, coffee, and/or fruit trees on the slopes (RHEENEN et al., 2004). Besides, rainfed crops such as maize and french beans or groundnuts are cultivated, both for self consumption and sale. Some migrant farmers specialised on vegetable production (mainly spring onions, carrots, cabbages, tomatoes, and potatoes) to service the market in Palu. Large parts of the valley are covered by unutilised grasslands

\footnotetext{
${ }^{1}$ For scientific plant species names see Appendix 12.
} 
(partly infested by Imperata cylindrica), smaller parts by fallow or secondary forests. Most of the inhabitants in the research area are self-employed small-scale farmers, off-farm employment opportunities, mainly as government officials, being scarce (MAERTENS et al., 2002).

\subsection{Selection of study sites}

To assess differences in the homegardens' resource quality and factors causing these differences, five villages out of 15 within the Napu valley were chosen for this study. The selected villages differ in their market access, origin of inhabitants, and soil quality, among others (Table 2.1). The selection procedure of the five villages was partly carried out by STORMA, subproject A4 (Socio-economic analysis of farm households and their enterprises). STORMA randomly selected four villages in the Napu valley (Wuasa, Watumaeta, Wanga, and Rompo) with mainly indigenous inhabitants (ZELLER et al., 2001). For the basic homegarden study in 2001, two of these STORMA-selected villages (Wuasa and Rompo) and the village Siliwanga, inhabited by migrants, were chosen to allow comparisons between local and migrant homegardens (KEHLENBECK \& MAASS, 2004). To further clarify the specific influence of soil quality and ethnic group of the gardener towards crop diversity, the sample size was extended in 2003 by two suitable villages. Out of the STORMA-selected villages, Wanga was chosen because of its indigenous inhabitants, whereas Tamadue-Trans was selected as a further migrant village. In the following, the five research villages are described in more detail.

Wuasa is the administrative centre of the sub-district 'Lore Utara' (Napu valley) since the 1960s. Many government offices are located in this village. There is also a small hospital, a police station, a small military base, and junior and senior high schools. Many shops and small restaurants as well as garages and petrol stations can be found. Therefore, many of the inhabitants are employed in the service sector.

Rompo is a small, remote village about $35 \mathrm{~km}$ south of Wuasa. The village is surrounded by forest, most of the inhabitants are locals and still rooted in their traditions. There are only two small shops and a primary school. Market access is rather poor, but has been recently improved due to road construction. In 2001, about $10 \mathrm{~km}$ of the road to Rompo were a small dirt road. Many of the wooden bridges between Wuasa and Rompo were broken, therefore, rivers had to be crossed via fords that where hardly passable after heavy rains. This situation changed in 2004, when all bridges were rebuilt and the road was asphalted, except the last 5 $\mathrm{km}$.

The third village chosen was Wanga, a small village around $12 \mathrm{~km}$ south of Wuasa, located directly at the paved road to Rompo. Until the 1960s, Wanga was the administrative centre of the sub-district because it was the residence of the last king of Napu (WEBER et al., 2003). The inhabitants are mostly locals, engaged in agriculture and fishing in the nearby Wanga lake. Some migrants from South Sulawesi and the western margins of the Lore Lindu National Park arrived in the 1990s. Soil quality was said to be poor in Wanga (DECHERT, 2003).

Siliwanga was founded only recently for settling transmigrant families mostly from Bali $(60 \%)$ and East Java (20\%) (Table 2.1). As usual for transmigrant programmes, each 
household was provided with 1 ha land for paddy rice cultivation, 0.75 ha dry-land, and 0.25 ha homegarden, including a small, wooden house. Allotted by lottery, some households received one head of Bali cattle in addition. The village Siliwanga is located about $20 \mathrm{~km}$ south of Wuasa along the road Wuasa-Rompo, surrounded by rather infertile grasslands that were formerly used for buffalo grazing only. Due to the low soil quality of the assigned land and the lack of a irrigation system for paddy rice cultivation, about $70 \%$ of the 300 transmigrant families have already left Siliwanga (HOPPE \& FAUST, 2004). The remaining families try to cope with the poor conditions by raising cattle and clearing forest plots for maize and cacao cultivation. However, the depopulated village with its empty houses and its overgrown gardens and paths is a pathetic sight. Most of the remaining households would leave Siliwanga as soon as possible, if they had the means.

Another transmigrant village selected for this study was Tamadue-Trans, called also Merkasari, which is part of the old village Tamadue-Kampung. This village is located in the eastern part of the Napu valley, about $30 \mathrm{~km}$ south-east of Wuasa, near the road Wuasa-Poso. The last $5 \mathrm{~km}$ leading from this road to the village are not yet asphalted. Due to poor road and bridge conditions, access to Tamadue is difficult after heavy rains. Before the foundation of Tamadue-Trans in 1991, the area was covered with forest, growing on rather fertile soil. This migrant village was initially settled exclusively by about 200 Moslem transmigrant families from Java and Lombok (HOPPE \& FAUST, 2004). However, 75\% of the transmigrant families left Tamadue-Trans soon after arrival because the agricultural land allotted to them was mostly still covered by forest. These out-migrated households were replaced by about 170 'spontaneous' migrant families of Javanese or Balinese origin that bought the deserted houses and fields. Most of the Balinese migrants were descendants of transmigrants already settled in other parts of Central Sulawesi in the 1960s (HopPE \& FAUST, 2004). Today, about 50\% of the 250 households are of Javanese and $30 \%$ of Balinese origin. Despite the poor access to their village, the migrants of Tamadue-Trans are successful in paddy rice, cacao and vegetable production.

Table 2.1. Characteristics of five villages studied in the Napu valley, Central Sulawesi (2003/2004).

\begin{tabular}{|c|c|c|c|c|c|}
\hline & Wuasa & Rompo & Wanga & Siliwanga & Tamadue-Trans \\
\hline $\begin{array}{l}\text { Year of } \\
\text { foundation }\end{array}$ & 1892 & 1915 & 1923 & 1992 & 1991 \\
\hline Inhabitants (no.) & 2,600 & 400 & 350 & 600 & 700 \\
\hline Ethnicity & $90 \%$ locals & $90 \%$ locals & $75 \%$ locals & $95 \%$ migrants & $99 \%$ migrants \\
\hline
\end{tabular}

Sources: ZELLER et al. (2001) and own data.

In each of the five research villages, 10 households with homegardens were randomly selected. In Wuasa, Rompo, and Wanga, these households were selected out of the sample chosen by subproject A4 (ZELLER et al., 2001), and in Siliwanga and Tamadue-Trans from the village household lists. For comparability among the migrant villages, in Tamadue-Trans only households of Balinese origin were included into the sample. In 2003, two homegardens selected for the 2001-survey in Siliwanga had been abandoned. To replace these gardens, two 'new' households were randomly selected in 2004 in the same village. Two other selected 
homegardens in the village Rompo that had been abandoned in 2004, however, were not replaced.

\subsection{Socio-economic characteristics of sample households and farms}

For gathering basic socio-economic data of the households surveyed, a standardised, formal questionnaire was used, designed by subproject A4 of STORMA, but shortened for the purpose of this study. Included questions concerned household composition and characteristics (number, age, origin, ethnic group, religion, formal education, and occupation of the household members), possession of land and livestock, plot-specific use and amounts of inputs and outputs, and wealth status (food, $d$ welling, other assets) of the household (see

Appendix 1). The complete STORMA-questionnaire is available from the internet: <www.gwdg.de./ uare/research/projects/storma_a4/activities.php>. In 2001, relevant data of the selected households in the villages Wuasa and Rompo were made available through subproject A4 (S. SCHWARZE, personal communication, 2002). Because the village Siliwanga was not covered by the STORMA-survey, a translator assisted the author to conduct the interviews without asking questions concerning the wealth status. In 2004, the author herself completely carried out all interviews in the five villages.

\subsubsection{Household-specific characteristics}

Household sizes ranged from 1 to 14 persons, being rather small in the migrant villages Siliwanga and Tamadue (Table 2.2, for complete data see Appendix 3). Whereas median number of children per household was more or less similar among the villages, the number of adults was rather high in Wuasa and low in the migrant villages. This is reflected in differences of the median number of men able to work between 15 and 67 years per household that was $2-3$ in the local villages, but only 1 in the migrant villages. Families in the migrant villages were rather young, particularly in Siliwanga (Table 2.2). In Wuasa, the percentage of households with small children and old people (mostly parents or parents-in-law of the household head) as well as median ages of household heads and their wives were rather high. However, medians of the mean age of adults per household did not differ significantly.

Table 2.2. Composition and characteristics of 50 households (HH) in five villages of the Napu valley, Central Sulawesi, 2004 (medians, ranges in brackets). $N=10$ per village, apart from age of household head in Rompo and Wanga $(N=9)$.

\begin{tabular}{|c|c|c|c|c|c|c|c|c|c|c|}
\hline & \multicolumn{2}{|c|}{ Wuasa } & \multicolumn{2}{|c|}{ Rompo } & \multicolumn{2}{|c|}{ Wanga } & \multicolumn{2}{|c|}{ Siliwanga } & \multicolumn{2}{|c|}{ Tamadue } \\
\hline HH members total & $8.0 \mathrm{a}$ & $(3-14)$ & $5.0 \mathrm{ab}$ & $(1-11)$ & $5.5 \mathrm{ab}$ & $(3-8)$ & $4.0 \mathrm{ab}$ & $(3-6)$ & $3.5 \mathrm{~b}$ & $(2-6)$ \\
\hline Children (0-14) & $2.0 \mathrm{a}$ & $(0-5)$ & $1.5 \mathrm{a}$ & $(0-5)$ & $1.0 \mathrm{a}$ & $(0-3)$ & $2.0 \mathrm{a}$ & $(1-3)$ & $1.0 \mathrm{a}$ & $(0-2)$ \\
\hline Adults $(>14)$ & $5.0 \mathrm{a}$ & $(3-10)$ & $3.0 \mathrm{ab}$ & $(1-6)$ & $4.0 \mathrm{ab}$ & $(2-7)$ & $2.0 \mathrm{~b}$ & $(2-3)$ & $2.0 \mathrm{ab}$ & $(2-7)$ \\
\hline Men (15-67) & $2.0 \mathrm{a}$ & $(1-6)$ & $2.0 \mathrm{ab}$ & $(0-4)$ & $3.0 \mathrm{ab}$ & $(1-4)$ & $1.0 \mathrm{~b}$ & $(1-2)$ & $1.0 \mathrm{ab}$ & $(1-2)$ \\
\hline $\begin{array}{l}\text { HH with small children } \\
\qquad(<5)\end{array}$ & $80 \%$ & & $60 \%$ & & $20 \%$ & & $50 \%$ & & $20 \%$ & \\
\hline $\begin{array}{l}\text { HH with old people } \\
\qquad(>67)\end{array}$ & $40 \%$ & & $10 \%$ & & $20 \%$ & & $10 \%$ & & $0 \%$ & \\
\hline Age of household h & $55 \mathrm{a}$ & $(34-)-1)-1$ & $50 \mathrm{ab}$ & $(25-$ & $47 \mathrm{a}$ & $(43$ & $36 b$ & $(30$ & $42 \mathrm{ab}$ & $(32-$ \\
\hline Age of HH head's $v$ & $53 a$ & $(32-71)$ & $40 \mathrm{ab}$ & $(20-1)-1)$ & $47 a b$ & $(33-$ & $33 b$ & $(28$ & $36 a b$ & $(31-55)$ \\
\hline e of adults/HH & $37 a$ & $(30-54)$ & $31 \mathrm{a}$ & $(22-45)$ & $36 \mathrm{a}$ & $(26-54)$ & $35 \mathrm{a}$ & $(29-49)$ & $39 a$ & $(26-58)$ \\
\hline Christian HH & $100 \%$ & & $100 \%$ & & $100 \%$ & & $20 \%$ & & $10 \%$ & \\
\hline
\end{tabular}

Medians are given because variables were not normally distributed.

Medians in a row followed by different letters are significantly different at $\mathrm{P} \leq 0.05$. 
In the three local villages Wuasa, Rompo, and Wanga, all households belonged to the Christian religion (Table 2.2), mainly to the Protestant church, except some families that were members of the Catholic, Pentecost, or Salvation Army church. Most of the heads of Christian households and their wives were of Napu origin, some had migrated from some other provinces of Sulawesi (Figure 2.2). In the migrant villages Siliwanga and Tamadue, most of the households surveyed were of Hindu religion and Balinese origin. However, in Tamadue, one Balinese family had recently converted to Protestant religion (Table 2.2). In Siliwanga, two Christian households came from North or Central Sulawesi, one Muslim household was of mixed Javanese origin.

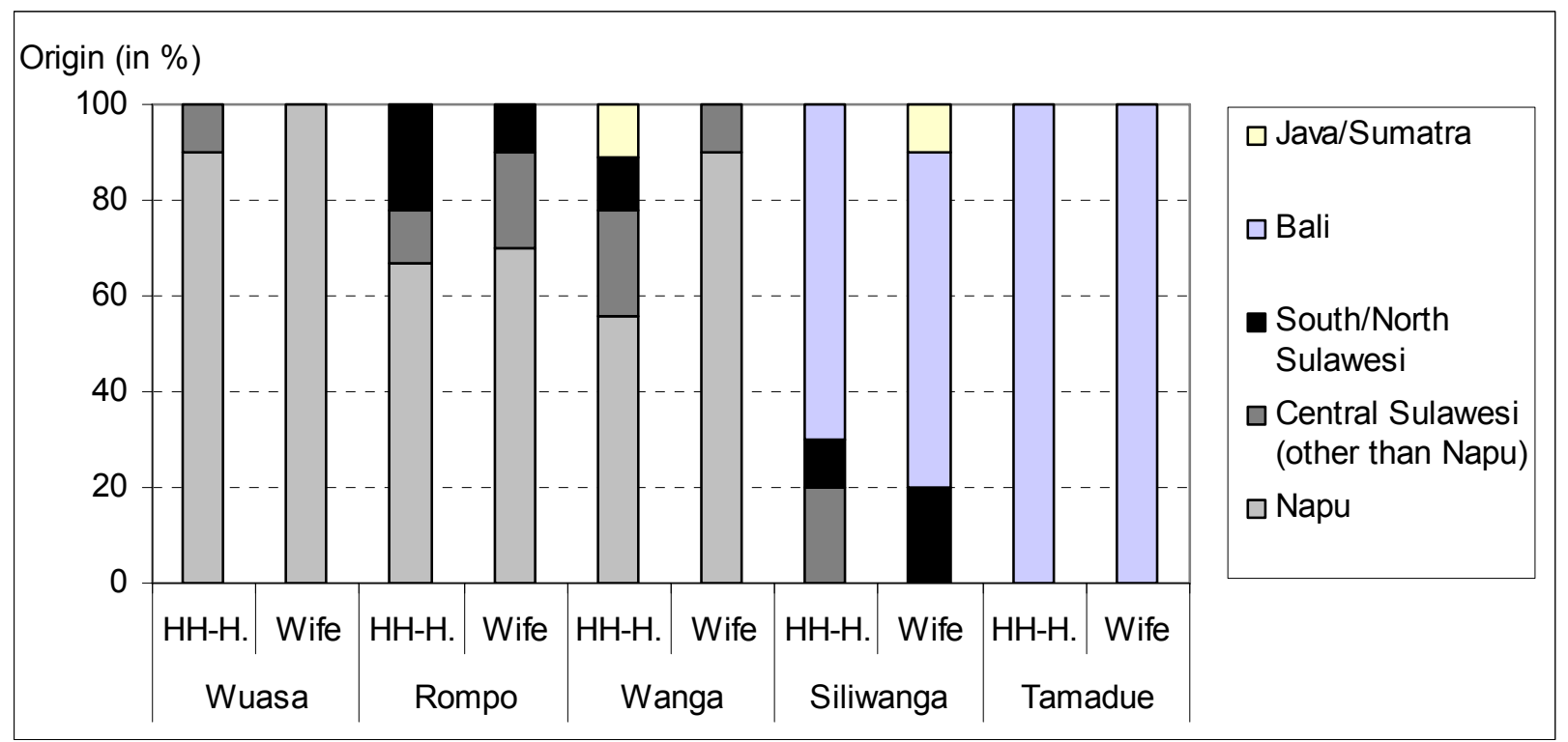

Figure 2.2. Origin of household heads (HH-H.) and their wives in five villages of the Napu valley, Central Sulawesi, 2004. $N=10$ per village, apart from HH-heads in Rompo and Wanga, where $N=9$.

Formal education differed not only among the five villages, but also among males and females. In all five villages, household heads generally had a higher education grade than their wives (Table 2.3). The percentage of respondents, who did not complete primary school or never attended school was high in the migrant villages, particularly in Tamadue. However, some male and/or female respondents with an academic degree or diploma (e.g. teacher, pastor) were contained in the sample in all villages, except for Wanga. In the local villages Wuasa, Rompo, and Wanga, about half of the household heads already attended some agricultural training courses, whereas in the migrant village Siliwanga, even $80 \%$ of household heads attended such training, mostly in the frame of the transmigrant programme. In contrast, only few household heads in Tamadue ever attended some training, although all households were engaged in agriculture. Women's attendance in agricultural training courses was conspicuously low. 
Table 2.3. Formal education and attendance at agricultural training in percentages of household heads (of wives in brackets) in five villages of the Napu valley, Central Sulawesi, 2004. $N=10$ per village, apart from HH-heads in Rompo and Wanga, where $N=9$.

\begin{tabular}{lrrrll}
\hline & Wuasa & Rompo & Wanga & Siliwanga & Tamadue \\
\hline Not completed primary school & $0(20)$ & $0(0)$ & $0(20)$ & $20(50)$ & $50(60)$ \\
Only completed primary school & $30(30)$ & $33(50)$ & $44(50)$ & $20(30)$ & $20(20)$ \\
Only completed secondary school & $60(40)$ & $56(40)$ & $56(30)$ & $40(10)$ & $20(20)$ \\
Completed Academy/University & $10(10)$ & $11(10)$ & $0(0)$ & $20(10)$ & $10(0)$ \\
& & & & & \\
Attended agricultural training & $50(20)$ & $56(20)$ & $56(0)$ & $80(20)$ & $30(0)$ \\
\hline
\end{tabular}

Most household heads worked mainly as farmers, ranging from $60 \%$ in Wuasa to $100 \%$ in the remote village Rompo (Table 2.4). The second important field of occupation was the civil service sector, particularly in the village Wuasa with its offices, schools and the small hospital. However, in the villages Rompo and Tamadue, no respondent worked mainly as a civil servant. Instead, in Tamadue some household heads employed themselves as tradesmen in own kiosks. This was a sideline also in the other villages, apart from Rompo. Popular second occupations of household heads were farming for all those not being a farmer as main occupation, or handicrafts (particularly carpenter) for those being mainly farmers. As wage labour opportunities were rare, only few household heads in the migrant village Siliwanga occasionally searched for such work besides farming their own land.

Table 2.4. Main occupation in percentages of household heads (of wives in brackets) in five villages of the Napu valley, Central Sulawesi, 2004. $N=10$ per village, apart from household heads in Rompo and Wanga, where $N=9$.

\begin{tabular}{lrrrrr}
\hline & Wuasa & Rompo & Wanga & Siliwanga & Tamadue \\
\hline Farmer & $60(30)$ & $100(70)$ & $67(40)$ & $80(70)$ & $80(40)$ \\
Civil servant/pensioner & $40(0)$ & $0(10)$ & $33(0)$ & $10(0)$ & $0(10)$ \\
Self-employed (trade/transport) & $0(10)$ & $0(0)$ & $0(0)$ & $0(0)$ & $20(10)$ \\
Housewife & $-(60)$ & $-(20)$ & $-(60)$ & $-(30)$ & $-(40)$ \\
\hline
\end{tabular}

Wives of the household heads selected for this study were mainly engaged either in agriculture or housework, only very few female respondents were civil servants (e.g. teacher, nurse) or tradeswomen (Table 2.4). However, marked differences existed between villages. In Wuasa and Wanga, the majority of wives were occupied mainly with housework, with farming only as a sideline, whereas in Rompo and Siliwanga $70 \%$ worked mainly as farmers, although $50-60 \%$ of these women had to care for small children (Table 2.2).

To reveal, if the 50 sample households surveyed in this study were representativ for the whole study region, selected basic socio-economic data (i.e. household size, formal education, and occupation of household members) were compared with results of the STORMA household survey concerning the subdistrict Lore Utara or the whole STORMA research area, as given in SCHWARZE (2004). The average overall household size of 5.2 in this study (see Table 2.2) corresponded quite well with the respective STORMA data of 5.8 for Lore Utara. Even the median numbers of adults and children per household in this study (2-5 and 1-2, respectively) were rather similar to the respective means as given by SCHWARZE (2004) (4.1 and 1.7, respectively). However, marked differences in household size and composition existed among the local and migrant villages in this study. Households in the two migrant villages Siliwanga 
and Tamadue were clearly smaller than those in the local villages (median total sizes: 4.0 vs. 5.5, adults: 2.0 vs. 4.0 ). Thus, the households in the local villages were more representative for the overall subdistrict than those in the migrant villages.

A similar trend is obvious concerning levels of education. For Lore Utara, ScHWARZE (2004) reported $91 \%$ of the adults having at least completed primary school, which is much more than in total Indonesia (about 76\%, survey data from 2004, BPS, 2004). In the present homegarden study, $100 \%$ of the household heads in the three local villages and $80-100 \%$ of their wives did at least complete primary school (Table 2.3). However, in the migrant villages only $50-80 \%$ of household heads and $40-50 \%$ of their wives did so. The slightly lower education level of women, particularly for higher education, was already stated by SCHWARZE (2004) for the whole STORMA research area. As reported by SCHWARZE (2004), 96\% of the households in the whole STORMA research area were engaged in agriculture. This statement corresponded well with the results of the present research, where $100 \%$ of the households were fully or partly engaged in agricultural tasks (Table 2.4).

\subsubsection{Farm-specific data}

Farm sizes were highly variable and did not differ significantly among the villages (Table 2.5, for complete data see Appendix 4). Because fallow areas contributed markedly to large farm sizes, particularly in Rompo, Wanga, and Siliwanga (Figure 2.3), the size of the cropped farm area was calculated additionally. Median cropped area was highest in Tamadue and lowest in Rompo and Wanga, but differences were not significant (Table 2.5). However, the cropped farm area per household member differed significantly between villages, being rather large in Tamadue and small in Wuasa. Homegardens as part of the whole farming system were owned by nearly all households. Only in Rompo, two homegardens were rented together with the houses. Total homegarden sizes, as given by the respondents, varied from 350-2500 $\mathrm{m}^{2}$ (Table 2.5). Median homegarden sizes were significantly larger in the migrant than in the local villages. Sizes of cultivated/cropped areas in homegardens (i.e. total size minus fallow areas and such occupied by houses and yards) were mostly slightly smaller than total homegarden sizes, apart from Siliwanga, where gardeners mentioned the poor soil quality as a reason for large uncultivated areas inside their homegardens. Proportions of the total homegarden size to the total farm area were higher in the migrant villages, particularly in Siliwanga, as compared to the local villages. This indicated that the living of many migrant families depended considerably on their homegardens.

Most households divided their farm area into several plots planted either to paddy rice, upland annual crops, or perennials, according to the suitability of the land, needs of the household, and its capability to work the land. However, proportion and sizes of these plots were highly variable among farms and villages (Figure 2.3). Perennials, mostly coffee and cacao, usually occupied the largest part of the cropped farm area and were mainly sold as cash crops. The majority of households owned such plots, varying from 100\% in Rompo and Tamadue, 90\% in Wuasa and Rompo, to $80 \%$ in Siliwanga, where farmers assessed the surrounding grasslands as unsuitable for growing perennials. The median size of plots planted to perennials was particularly high in Tamadue and rather low in Wanga and Siliwanga (Figure 2.3), but differences were not significant. Paddy rice was grown mainly for subsistence, although not all households owned such plots. In the local villages, Wuasa, Rompo and 
Wanga, $70-80 \%$ of the sampled households possessed paddy rice plots with median plot sizes between 3000 and $5400 \mathrm{~m}^{2}$ (Figure 2.3). Fewer households in the migrant villages, Siliwanga and Tamadue, owned paddy rice plots (50-60\%), however, median sizes were markedly, but not significantly different between these villages. In Siliwanga, lacking an irrigation system, paddy rice plots were rather small, whereas in Tamadue, they were extremely large (up to 4 ha per household).

Table 2.5. Median characteristics in sizes (ranges in brackets) of 50 farms with homegardens investigated in five villages of the Napu valley, Central Sulawesi, 2004. $N=10$ per village, apart from Rompo, where $N=9$ for total and cropped farm size as well as for proportion HG/farm.

\begin{tabular}{|c|c|c|c|c|c|}
\hline & Wuasa & Rompo & Wanga & Siliwanga & Tamadue \\
\hline $\begin{array}{l}\text { Total farm size } \\
\text { (ha) }\end{array}$ & $2.6 \mathrm{a} \quad(0.9-8.8)$ & 5.9a (1.7-11.5) & $3.9 \mathrm{a} \quad(2.1-19.5)$ & $3.1 \mathrm{a} \quad(1.9-8.8)$ & $4.0 \mathrm{a} \quad(1.8-29.3)$ \\
\hline $\begin{array}{l}\text { Cropped area } \\
\text { (ha) }\end{array}$ & $2.3 \mathrm{a} \quad(0.6-3.3)$ & $1.8 \mathrm{a}(0.5-4.2)$ & $1.6 \mathrm{a} \quad(0.3-10.5)$ & $2.0 \mathrm{a} \quad(0.3-3.6)$ & $3.1 \mathrm{a} \quad(1.1-6.2)$ \\
\hline $\begin{array}{l}\text { Cropped area/ } \\
\text { HH member } \\
\text { (ha) }\end{array}$ & $0.2 b \quad(0.2-0.5)$ & $0.4 \mathrm{~b}(0.1-0.7)$ & $0.4 \mathrm{ab}(0.1-1.7)$ & $0.4 \mathrm{ab}(0.1-0.9)$ & $0.9 \mathrm{a} \quad(0.3-1.6)$ \\
\hline $\begin{array}{r}\text { Total HG size } \\
\text { (in } 1000 \mathrm{~m}^{2} \text { ) }\end{array}$ & $1.0 \mathrm{~b} \quad(0.4-1.8)$ & $0.8 b(0.4-2.0)$ & $0.7 \mathrm{~b} \quad(0.4-2.0)$ & $2.5 \mathrm{a} \quad(2.5)$ & $2.5 \mathrm{a} \quad(2.0-2.5)$ \\
\hline $\begin{array}{l}\text { Cropped HG } \\
\text { area } \\
\left(\text { in } 1000 \mathrm{~m}^{2} \text { ) }\right.\end{array}$ & $0.7 \mathrm{~b} \quad(0.3-1.1)$ & $0.6 \mathrm{~b}(0.3-1.4)$ & $0.6 \mathrm{~b} \quad(0.3-1.4)$ & $0.9 \mathrm{ab}(0.5-2.4)$ & $2.3 \mathrm{a} \quad(0.7-2.4)$ \\
\hline $\begin{array}{c}\text { Proportion } \\
\text { total HG/ } \\
\text { farm }(\%)\end{array}$ & $2.4 \mathrm{ab}(0.7-16.7)$ & $1.7 b(0.6-4.3)$ & $1.7 \mathrm{~b} \quad(0.2-6.5)$ & $8.3 \mathrm{a} \quad(2.9-13.2)$ & $6.3 \mathrm{ab}(0.9-14.3)$ \\
\hline
\end{tabular}

Note: $\mathrm{HH}=$ Household, $\mathrm{HG}=$ Homegarden.

Medians are given because variables were not normally distributed.

Medians in a row followed by different letters are significantly different at $\mathrm{P} \leq 0.05$.

Annual crops, such as maize, french beans, or groundnuts, were usually grown on upland plots and used both for sale and self-consumption. Such plots were common in the local villages, where frequency of ownership as well as median plot sizes were similar to the data of paddy rice plots. In the migrant villages, fewer households owned upland plots $(60 \%$ in Siliwanga, 20\% in Tamadue) and median sizes were rather small (Figure 2.3). Fallows (i.e. abandoned fields owned by the household, but currently not being worked; covered mostly by herbs, shrubs, and small trees) occurred commonly in most of the villages, apart from Tamadue (only $60 \%$ instead of $80-100 \%$ households owning fallow plots). Fallow plot sizes were highly variable, resulting in no significant differences of medians among villages. However, in the remote village Rompo with its surrounding forests, fallow sizes were extremely large (up to 7.2 ha per household), whereas in the more densely populated village Wuasa, households owned rather small fallow plots.

As for basic socio-economic data, also selected farm-specific data of the sample households were compared with the results of the STORMA household survey (SCHWARZE, 2004). In the subdistrict Lore Utara, mean farm size was 2.7 ha (SCHWARZE, 2004). As mean household size was stated as 5.8, mean farm area per capita was 0.47 ha. Following SCHWARZE (2004), mean size of homesteads (i.e. homegardens) in Lore Utara was $780 \mathrm{~m}^{2}$ per household, that of irrigated paddy rice fields 0.5 ha, and that of all upland, rainfed fields (including annual and perennial crops) 1.8 ha. Similar to the basic socio-economic household characteristics (see 
2.3.1), some of these results corresponded much better with the three local villages of the present study than with the migrant villages. In the migrant villages, median total homegarden size was as much as $2500 \mathrm{~m}^{2}$, whereas in the local villages, it varied from $700-1000 \mathrm{~m}^{2}$ (Table 2.5). However, median sizes of paddy rice as well as of upland fields (annual crops plus perennials) were mostly lower in all villages (except Tamadue) of the present study (Figure 2.3) as compared to the subdistrict Lore Utara. Due to rather large fallow plots, median total farm sizes were mostly larger in the present study, but farm area per capita smaller than in the whole subdistrict (Table 2.5). In summary, sample households of the present study could be considered as representative for the subdistrict Lore Utara, both for household as well as farm characteristics.

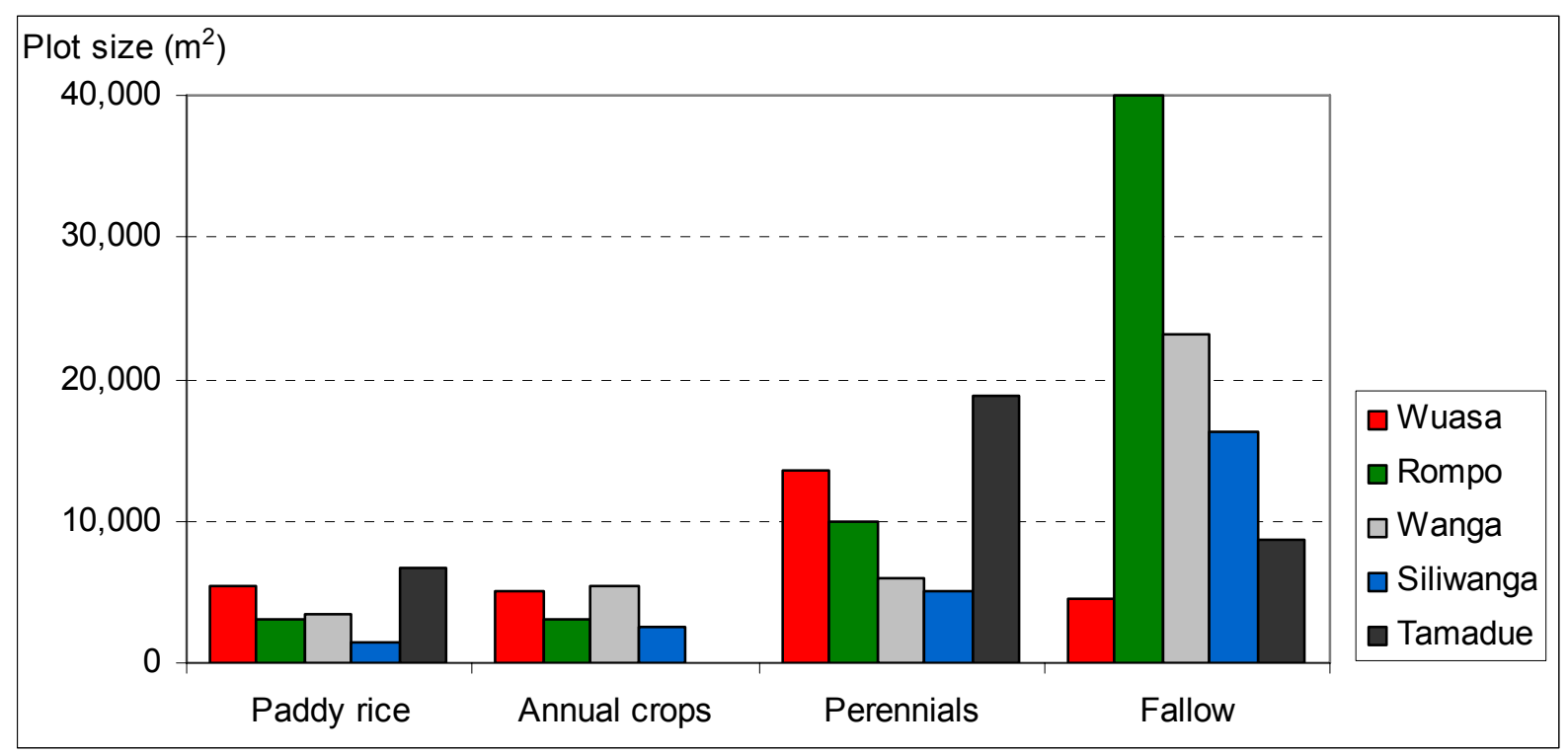

Figure 2.3. Median farm area allocated to different crop types in five villages of the Napu valley, Central Sulawesi, 2004. $N=10$ per village, apart from Rompo, where $N=9$.

All sample households in the Napu valley owned some livestock with summed values from 45,000 IR (Indonesian Rupiah) to 26,600,000 IR per household (exchange rate in 2004: $10,000 \mathrm{IR} \approx 1$ Euro). In the local villages Wuasa, Rompo, and Wanga, households owned in median 1.1-1.3 $\mathrm{TLU}^{2}$ (Tropical Livestock Units) (Table 2.6), having a median value of 1,300,000-1,500,000 IR. In the migrant village Siliwanga, both median TLU per household and value of livestock was rather high (median value $=7,200,000$ IR), but in Tamadue only low (median value $=700,000 \mathrm{IR}$ ). However, differences among villages were not significant. Overall, horses and buffaloes were rarely reared and mostly for prestige. Only three households in Wuasa and Rompo reared buffaloes and one household each in Wuasa and Tamadue owned horses. Cattle were also seldomly reared (Table 2.6), apart from Wanga, where communal grazing areas were available in the uplands, and from the migrant village Siliwanga, where cattle was distributed initially by the transmigrant programme and extensive grasslands surrounded the village. In Wanga, cattle were mostly kept for prestige outside of

\footnotetext{
${ }^{2}$ TLU were calculated based on SCHWARZE (2004).
} 
the homegarden. In Siliwanga, cattle were indispensable for the rather poor families, who could not afford to rent a tractor for ploughing their small paddy rice plots. Additionally, cattle offspring was the sole important source of cash income for many households in Siliwanga. Most of them kept their cattle in small stables in their back yard gardens over night. Raising pigs in the homegardens was very common, particularly in the local villages and in Tamadue, where most households owned 1-3 heads. Pigs were used for sale (e.g. for yearly payment of school fees), for exchange (e.g. for land or for other kinds of livestock), for gift (e.g. for bride price), and/or for self-consumption, served only on important private or religious celebrations such as Christmas, baptism, weddings, or funerals.

Table 2.6. Proportion of households per village owning cattle, pig, dog, duck, and chicken (heads per households in brackets) as well as median TLU per household (range in brackets) in five villages of the Napu valley, Central Sulawesi, 2004. $N=10$ per village.

\begin{tabular}{|c|c|c|c|c|c|}
\hline Possession of & Wuasa & Rompo & Wanga & Siliwanga & Tamadue \\
\hline Cattle & $10 \%(0-5)$ & $0 \% \quad(0)$ & $40 \% \quad(0-4)$ & $70 \% \quad(0-7)$ & $10 \%(0-2)$ \\
\hline Pig & $100 \%(1-6)$ & $70 \%(0-4)$ & $100 \%(1-8)$ & $40 \% \quad(0-1)$ & $90 \%(0-13)$ \\
\hline Dog & $60 \% \quad(0-4)$ & $50 \%(0-8)$ & $80 \% \quad(0-8)$ & $70 \% \quad(0-4)$ & $40 \%(0-10)$ \\
\hline Duck & $80 \%(0-20)$ & $20 \% \quad(0-7)$ & $10 \%(0-2)$ & $10 \%(0-2)$ & $50 \%(0-13)$ \\
\hline Chicken & $70 \%(0-23)$ & $90 \%(0-27)$ & $80 \%(0-11)$ & $100 \%(1-19)$ & $70 \% \quad(0-50)$ \\
\hline TLU & $1.3 \quad(0.4-8.7)$ & $1.3(0.1-2.7)$ & $1.1 \quad(0.4-4.7)$ & $2.3 \quad(0.1-5.3)$ & $0.9 \quad(0.2-6.4)$ \\
\hline
\end{tabular}

Note: TLU = Tropical Livestock Units.

Medians are given because variables were not normally distributed.

Dogs were raised by the majority of respondent households, except for Tamadue (Table 2.6). Besides guarding the houses, dogs were used for assisting in hunting and, frequently, also for self-consumption, being served at minor festivities or at the weekly private Bible and praying meetings of neighbourhoods. Occasionally, dogs were sold for this purpose as well. Raising poultry in homegardens was very popular among the respondent households. However, ducks were common only in Wuasa and Tamadue, whereas chicken were raised by $70-100 \%$ of the households in all villages (Table 2.6). Households without chicken lost their flock only recently by the 2004 raged Asian bird flu that caused many losses. Both ducks and chicken were raised for their eggs and meat, for sale and, by the Hindu respondents, also for making sacrifices. Rabbits occurred only recently in the Napu valley, being distributed by an NGO to only two respondent households in Wuasa. Fish were raised in large ponds only by one gardener each in Wuasa, Siliwanga, and Tamadue.

\subsubsection{Households' wealth status and assets}

Size, condition, and equipment of houses differed among the villages (see Appendix 5 for complete data). Houses were largest in Wuasa (median: $135 \mathrm{~m}^{2}$ ), medium-sized in Rompo, Wanga, and Tamadue (about $100 \mathrm{~m}^{2}$ ), and smallest in Siliwanga (only $69 \mathrm{~m}^{2}$ ). Most of the houses were roofed with corrugated iron, apart from Rompo, where bamboo roofs still existed. Cement floors were common in nearly all houses, only in Siliwanga some houses had only earth flooring. Wooden planks were the usual wall material, however, in Wuasa wood was already replaced by bricks and cement in many cases. Most households were connected to electricity, apart from the remote village Rompo, where electricity was available, but households could not afford the connection costs. In Wuasa, Wanga, and Siliwanga, 70\% of 
respondents' houses were equipped with private water pipes, although water supply often broke down and water quality was far away from drinking quality. In Rompo, water was available only from public wells or taps, whereas in Tamadue public water supply did not exist anymore. Households drew their muddy water from self-dug holes behind their houses, often located very close to latrines and stables. Improved latrines were common only in the local villages, whereas more than $50 \%$ of the migrant families used their homegardens as a toilet.

Private-owned motorised vehicles were rare in the research area, particularly cars and tractors, possessed by only one household in Tamadue. Motorcycles were slightly more common in the villages Wuasa and Tamadue, where $30-40 \%$ of respondents owned one. All migrant households in Siliwanga and Tamadue owned at least one bicycle, used mainly for transport of the harvest. In the local villages, this was done by rented carts or, in some cases, by own handcarts. Frequency of pesticide sprayer possession was highest in Tamadue and Wuasa (100 and 80\%, respectively), medium in Rompo and Siliwanga (50-60\%), and low in Wanga $(40 \%)$. Chain saws were owned by only few respondents in Wuasa, Wanga, and Tamadue.

Common electronic assets were radio-tapes, particularly in Wuasa and the migrant villages. Televisions with satellites (and sometimes also video players) were owned by some respondents in Wuasa and Tamadue, whereas in Rompo, Wanga, and Siliwanga such appliances were still very rare. Concerning household appliances, kerosene cookers were the most frequent one, owned by $70-80 \%$ of the respondents in Wuasa, Wanga, and Tamadue, but only $20-30 \%$ in Rompo and Siliwanga. Some wives had mechanical sewing machines, but not in Siliwanga. In Tamadue, few households owned a small rice mill or water pump.

\subsubsection{Households' poverty index}

Households were each assigned to one of three wealth status levels (i.e. poor, medium, welloff) by characterising their welfare situation with a poverty index. To generate this index, Principal Component Analysis (PCA) of all assessed wealth indicators was carried out to select in an iterative process the most important ones. The methodology of this complex procedure is described in detail by HENRY et al. (2003). For the 50 households studied, the final PCA was only performed on the basis of 10 selected wealth indicators (see Appendix 6). The scores of the resulting first factor (accounting for nearly $34 \%$ of the variability) were taken as poverty index. Households were then divided into terciles according to the index. As a result, 16-17 households each were assigned to the groups of poor, medium, or well-off households (see Appendix 5). In Siliwanga, most of the households were characterised as poor, in Rompo as medium, whereas in Wanga as well-off (Table 2.7). In Wuasa and Tamadue, wealth status of households was mixed.

Table 2.7. Proportion of households (in \%) belonging to different wealth status groups in five villages of the Napu valley, Central Sulawesi. $N=10$ per village.

\begin{tabular}{lccccc}
\hline & Wuasa & Rompo & Wanga & Siliwanga & Tamadue \\
\hline Poor & 30 & 10 & 20 & 80 & 20 \\
Intermediate & 20 & 60 & 20 & 20 & 50 \\
Well-off & 50 & 30 & 60 & 0 & 30 \\
\hline
\end{tabular}




\section{$2.4 \quad$ Interviews}

Each household was visited three times for individual interviews. First, the interview on basic socio-economic data (see 2.3) was carried out with the head of the household and/or his wife. At a second visit, homegarden-specific data were gathered. Questions on plant species use and yield were asked at a third visit. Questions on homegarden and plant species were asked to the person mainly responsible for the homegarden, if possible. Otherwise, the head of the household and/or his wife were interviewed. Every interview lasted between one and two hours and was conducted in the homestead. However, gardeners that were exceptionally busy on their paddy rice fields or plantations were visited on their plots as well.

\subsubsection{Homegarden data}

For gathering homegarden-specific data, a semi-structured questionnaire was developed (see Appendix 2). This questionnaire included questions on age, history and function of the homegardens, soil quality and its changes, inputs and outputs, management patterns, and problems with homegarden management such as crop pests and diseases, weed infestation, shortage of time, among others. A translator assisted in all interviews and translated the answers in 2001, whereas in 2004, the interviews were conducted by the author herself. In 2004, some questions were added or asked in more detail as compared to 2001 (see Appendix 2).

\subsubsection{Plant species data}

Cultivated plant species were completely listed for each homegarden (see 2.5). Gardeners' appreciation of each single species grown in their homegardens was assessed using the plant lists as a kind of questionnaire (Table 2.8). In 2004, question no. 4 was added and question no. 7 emphasised more details than in 2001. To monitor changes in crop diversity, gardeners already interviewed in 2001 were asked additionally, why they had stopped to grow any plant species that previously occurred in their homegarden but was not located in the 2003-survey. The interviews were carried out by the author herself in both survey rounds.

Table 2.8. Questionnaire for plant species data (checked for each species).

1. How do you use this plant species (e.g. staple food, fruit, vegetable, spice, medicine, fodder, ornamental, construction, fuel wood, fence, shade, green manure, cash-crop, ...)? If used as medicine, what part is used, for what kind of illness?

2. Are there different varieties of this plant? Please list the local names and describe the varieties!

3. From where did you get the seeds/seedlings of this plant species (e.g. own reproduced seeds, neighbour, market/shop, gathered, occurred spontaneously, project, ...)?

4. What is the yield of this plant species per week/month/year?

5. When did you harvest this plant species the last time?

6. How do you use the products of this plant species (self consumption, sale, gift, ...)?

7. If you already sold products of this plant species, how much per week/year, and what was the price? 


\section{$2.5 \quad$ Plant inventory}

Before starting the plant inventory, the borders of each homegarden were identified together with the gardener. In most homegardens, borders were clearly defined by fences, hedges, ditches, or marking trees. In few cases, borders were rather indistinct because the homegarden gradually turned into a plantation of the same owner. Areas only dominated by a sole crop like coffee were then excluded from the homegarden area. In the same way, larger areas within the homegarden not cultivated at all or used as paddy rice fields were excluded. The size of each homegarden was measured with a tape, excluding the area occupied by the house. Rough sketches of the homegardens were drawn, including arrangements of houses, sheds, stables, paths, yards, wells, toilets, and the different production zones. In 2003/2004, the sizes of both cultivated and uncultivated zones (e.g. yards, stables, ponds) were roughly estimated. Production zones were classified visually according to the plants dominantly cultivated in a particular zone, i.e. vegetable zone, ornamental zone, coffee/cacao zone, fruit tree zone, and mixed zone. Mixed zones were characterised by a close mixture of different crop types. Parts of the homegardens not planted for a while and covered only by grasses and small herbs were classified as fallow zone. The occurrence of tree nurseries was recorded. Seedlings were included in the plant species inventory if they were planted in the soil, but not if they were planted into small plastic bags. The latter were mostly not intended to be planted in the homegarden where they were raised, but to be transplanted to plantations of the household.

Complete plant species inventories, initially together with the gardener, were carried out to assess number of species and abundance of crops and ornamentals. For assessing the dynamics of crop diversity, homegardens visited in 2001 (July-October) were re-inventoried in 2003 (July-August) as well as in 2004 (June), whereas the 'new' homegardens (in the villages Wanga and Tamadue) were inventoried only once in 2004 (January and February). In this study, the term 'crop' is applied to all useful plant species except ornamentals. Therefore, a 'crop' includes both planted species as well as those spontaneously occurring and additionally promoted. For trees, the height was estimated. For vertical structure analysis, all individual plants were assigned to one of five strata $(0-1 \mathrm{~m}, 1-2 \mathrm{~m}, 2-5 \mathrm{~m}, 5-10 \mathrm{~m},>10 \mathrm{~m})$, as suggested by KARYONO (1990) and ABDOELlaH et al. (2002). The occurrence of weeds, defined as undesired plants from the gardener's view, was documented, but not quantified. Plants were recorded with local, Indonesian and/or scientific names. For identification of crop and weed species, the following literature was used:

PROSEA-series (Plant Resources of South-East Asia):

FARIDAH Hanum et al., 1997; Flach \& RUMAWAS (1996); GUZMAN \& SiEMONSMA (1999); Lemmens (2003); Maesen \& SomaAtmadja (1992); Padua et al. (1999); Siemonsma \& Kasem PilueK (1994); VAlKenburg \& Bunyapraphatsara (2001); VERHEIJ \& CORONEL (1992); VOSSEN \& WESSEL (2000).

Further literature:

BÄrtels (1993); Burkill (1966); Franke (1992); Hendrian \& TRi Hadiah (1999); Heyne (1927); LeVAng \& Foresta (1991); OOMEn \& Grubben (1977); Perry (1980); REHM \& ESPIG (1991). 
As some of the ornamental species have medicinal properties, a few ornamentals were identified by the literature mentioned above. The more frequently planted ornamentals were mostly well known and/or mentioned by BÄRTELS (1993). However, as the focus of this study was on crop diversity, many of the ornamentals were not identified.

Nomenclature was basically taken from the Mansfeld database of agricultural and horticultural crops (online: $<$ http://mansfeld.ipk-gatersleben.de/mansfeld/>), if a species name was available, or otherwise after ZANDER \& ERHARD (2002). Of unidentifiable plant species, specimens were taken and sent for identification to Herbarium Celebense (Index Herbariorum CEB) in the 2001-survey or to Herbarium Bogoriense (BO) in the 2003/2004-survey. Crop species were classified into the following 9 use categories, according to the literature mentioned above or the gardener's statement about the main utilisation: Fruits, vegetables, sweets and stimulants, spices, medicines, staple food, construction and fuel wood, multi purpose use, and others (e.g. wrapping, fodder, toys).

Besides crop species number, also crop species density per $1000 \mathrm{~m}^{2}$ homegarden area and several similarity coefficients as well as diversity indices were calculated (see 2.9.2). To assess, if the sampled area was large enough for collecting a representative proportion of all species present, a species-area curve was drawn by plotting the cumulative species number against the cumulative garden area sampled. In general, this curve has a relatively steep slope at first, but it flattens out when the accumulated area of the sample plots is sufficient to represent the total species number in a homogeneous (agro-)ecosystem (EVANS et al., 1955). DIERßEN (1990) suggested an area as sufficient, if 95\% of the total species number were included in the sample. To investigate community structure pattern of the homegardens studied, the species abundance model was graphically assessed by plotting the number of individuals per species (in log scale) against the species in rank order, beginning with the most abundant species (KREBS, 1999). For a logarithmic series, the species-abundance curve should follow a nearly straight line, whereas for a lognormal distribution, it follows a reverse S-shaped curve. According to PIEPHO (1996), the lognormal distribution characterises very diverse and complex ecosystems. The logarithmic distribution is typical for more simple ecosystems that are dominated by relatively few factors.

\subsection{Soil investigation}

\subsubsection{Soil sampling}

Samples of the litter-free top soil (0-15 cm depth) were taken from 30 homegardens in 2001 and from 50 homegardens in 2003 . The sampling methods were slightly different in the two years. In 2001, a short, T-handled soil auger with an inner diameter of about $1.5 \mathrm{~cm}$ was used. From each homegarden 20 soil samples were randomly taken and bulked, avoiding disturbed areas, such as yards, paths, stable areas, or rubbish pits. In four rather large homegardens with two clearly distinct production zones, 20 soil samples were taken separately in each zone.

In 2003, a soil corer with an inner diameter of $3.9 \mathrm{~cm}$ was used for sampling. If the garden was small $\left(<350 \mathrm{~m}^{2}\right)$ or planted rather uniformly, five soil samples per garden were randomly collected and bulked. In large gardens with distinct zones for vegetables, coffee/cacao or fruit production and/or with fallow areas, five samples per zone were randomly collected and 
bulked separately. To determine overall means for soil quality parameters in these large gardens, weighted means were calculated according to the proportions in sizes of particular production zones to the total homegarden sizes. Despite the general use of the term 'soil fertility' in the literature and when interviewing gardeners about their rating/management of garden soils, in this study 'soil quality' is mainly applied because the former term strongly refers to crop yields.

\subsubsection{Sample treatment}

After sorting out stones and roots, the field-moist samples were weighed and crushed. Samples were air-dried and stored in cardboard boxes. In STORMA's laboratory at University of Palu, the soil samples were dried at $80{ }^{\circ} \mathrm{C}$ for about 8 hours, weighed again and passed through a $2 \mathrm{~mm}$ sieve.

\subsubsection{Soil chemical and physical analysis}

Soil analyses were conducted in different laboratories of the universities of Palu (STORMA laboratory), Bogor (IPB, Dept. of Soil Sciences) and Göttingen (Table 2.9). Bulk density was determined in 2004 only by assessing the dry weight of soil samples with known field volume (determined by the soil corer). Sand, silt, and clay contents were measured using the pipette method in both years. According to the texture, soil was classified following the German System DIN 4220 (SCHEFFER, 1998). For assessing pH values, soil was mixed with distilled water or $0.01 \mathrm{M} \mathrm{CaCl}_{2}$, respectively, at a ratio of $1: 2.5$. Sub samples were powdered with a ballmill for determination of total $\mathrm{C}$ - and $\mathrm{N}$-contents, using a $\mathrm{C} / \mathrm{N}$-Analyser (in Göttingen: Carlo Erba, ANA 1400; in Palu: Vario EL, Elementar).

Table 2.9. Physical and chemical analyses of the soil samples from homegardens in the Napu valley, carried out in 2001 and 2004 in different laboratories.

\begin{tabular}{|c|c|c|c|c|c|}
\hline Parameter & Method (Reference) & $\begin{array}{c}\text { Analysed } \\
\text { in } 2001\end{array}$ & $\begin{array}{c}\text { Analysed } \\
\text { in } 2004\end{array}$ & $\begin{array}{l}\text { Laboratory } \\
2001\end{array}$ & $\begin{array}{l}\text { Laboratory } \\
2004\end{array}$ \\
\hline Bulk density & & No & Yes & - & STORMA Palu \\
\hline Texture & Pipette & Yes & Yes & Göttingen ${ }^{\mathrm{a}}$ & IPB Bogor \\
\hline $\mathrm{pH} \mathrm{H} \mathrm{H}_{2} \mathrm{O}$ & $1: 2.5$ & Yes & Yes & Göttingen ${ }^{\mathrm{b}}$ & STORMA Palu \\
\hline $\mathrm{pH} \mathrm{CaCl}{ }_{2}$ & $1: 2.5$ & Yes & Yes & Göttingen ${ }^{\mathrm{b}}$ & STORMA Palu \\
\hline $\mathrm{C}$ and $\mathrm{N}_{\text {total }}$ & $\mathrm{C} / \mathrm{N}$-Analyser & Yes & Yes & Göttingen ${ }^{\mathrm{a}}$ & STORMA Palu \\
\hline Available P & Olsen (OLSEN \& SOMMERS, 1982) & Yes & Yes & Göttingen ${ }^{\mathrm{b}}$ & STORMA Palu \\
\hline - "- & Bray I (ANONYMOUS, 1979) & No & Yes & - & Göttingen ${ }^{c}$ \\
\hline Exchange. K & CAL (SCHÜLLER, 1969) & Yes & No & Göttingen ${ }^{b}$ & - \\
\hline $\mathrm{CEC}_{\text {effective }}$ & Extraction (LÜER \& BÖHMER, 2000) & No & Yes & - & Göttingen $^{\mathrm{d}}$ \\
\hline $\mathrm{BS}$ & - “- & No & Yes & - & Göttingen $^{\mathrm{d}}$ \\
\hline
\end{tabular}

Göttingen $^{\mathrm{a}}=$ Institute of Agricultural Soil Sciences.

Göttingen ${ }^{b}=$ Institute of Agricultural Chemistry.

Göttingen $^{c}=$ Institute for Crop and Animal Production in the Tropics.

Göttingen $^{\mathrm{d}}=$ Geographical Institute, Dept. of Landscape Ecology.

Note: Exchange. $=$ Exchangeable; $\mathrm{CEC}=$ Cation exchange capacity; $\mathrm{BS}=$ Base saturation.

Plant available phosphorus was determined using the methods of Olsen and/or Bray I (Table 2.9) by spectrometer (Göttingen) or Continous Flow Analyser AA3/Bran \& Luebbe (Palu). The P-Bray method was applied in 2004 because the P-Olsen method, used in 2001, is not recommended for acid soils (LANDON, 1991). However, the latter was additionally applied in 
2004 to enable the determination of changes in available P contents over time. In 2001, exchangeable $\mathrm{K}$ was assessed following the CAL method and determined from the extract by flame photometer. In 2004, exchangeable cations ( $\mathrm{Al}, \mathrm{Ca}, \mathrm{Mg}, \mathrm{K}, \mathrm{Na}, \mathrm{Mn}, \mathrm{Fe}$ ) were determined after extraction with $1 \mathrm{M} \mathrm{NH}_{4} \mathrm{Cl}$ using ICP-OES (Inductive Coupled Plasma Optical Emission Spectrometry) (Optima 4300 DV, Perkin Elmer). Effective cation exchange capacity $\left(\mathrm{CEC}_{\text {eff. }}\right)$ and base saturation (BS) were calculated from the amount of exchangeable cations and $\mathrm{pH}$ value before and after extraction (LÜER \& BÖHMER, 2000).

\subsubsection{Rating/assessment of soil quality}

LANDON (1991) suggested that soil bulk density should not exceed $1.7 \mathrm{~g} / \mathrm{cm}^{3}$. Soils with a $\mathrm{pH}$ value under 5.5 (measured in $\mathrm{H}_{2} \mathrm{O}$ ) were rated as 'acid' (LANDON, 1991), while WHITTEN et al. (1987) assessed a value under 4.5 as 'very acid'. Table 2.10 shows the rating of other soil nutrients and characteristics according to different authors.

Table 2.10. Rating of several soil characteristics according to different authors.

\begin{tabular}{lllllll}
\hline & $\begin{array}{l}\text { N content } \\
(\%)^{\dagger}\end{array}$ & $\begin{array}{l}\text { C content } \\
(\%)^{\dagger}\end{array}$ & $\begin{array}{l}\text { P content } \\
\text { Olsen }(\mathrm{ppm})^{\dagger}\end{array}$ & $\begin{array}{l}\text { P content } \\
\text { Bray I }(\mathrm{ppm})^{\ddagger}\end{array}$ & $\begin{array}{l}\mathrm{CEC}_{\text {eff. }} \\
(\mathrm{cmol} / \mathrm{kg})^{\dagger}\end{array}$ & $\begin{array}{l}\mathrm{BS} \\
(\%)^{\S}\end{array}$ \\
\hline Very Low & $<0.1$ & $<2$ & & $<3$ & $<5$ & $<20$ \\
Low & $0.1-0.2$ & $2-4$ & $<5$ & $3-7$ & $5-15$ & $20-40$ \\
Medium & $0.2-0.5$ & $4-10$ & $5-15$ & $7-20$ & $15-25$ & $40-60$ \\
High & $0.5-1.0$ & $10-20$ & $>15$ & $>20$ & $25-40$ & $60-80$ \\
Very High & $>1.0$ & $>20$ & & & $>40$ & $>80$ \\
\hline † LANDON (1991). & & & & \\
† OLSEN \& SOMMERS (1982). & & & & \\
§ WHITTEN et al. (1987). & & & & &
\end{tabular}

For successful production of cacao, top soil $(0-15 \mathrm{~cm})$ should meet the following requirements (HARDY, 1958):

$$
\begin{array}{ll}
\mathrm{N}>0.22 \% & \mathrm{C}>2 \%(\text { or organic matter }>3,5 \%) \\
\mathrm{C} / \mathrm{N} \text { ratio }>9 & \mathrm{pH}>6.0 \\
\mathrm{~K}>0.24 \mathrm{cmol} / \mathrm{kg} & \mathrm{Ca}>8.0 \mathrm{cmol} / \mathrm{kg} \\
\mathrm{Mg}>2.0 \mathrm{cmol} / \mathrm{kg} & \\
\mathrm{P}(\text { Truog) }>18 \mathrm{ppm} \text { (corresponding to 'low level' according to LANDON (1991)) }
\end{array}
$$

In addition, WOOD \& LASS (1985) recommended a cation exchange capacity of more than $12 \mathrm{cmol} / \mathrm{kg}$ and a base saturation of more than $35 \%$ for suitable cacao soils. They also emphasised that cacao roots are very sensitive to waterlogging and suggested a sand content of at least $50 \%$ for good drainage and aeration. Concerning contents of Al, HALLIDAY \& TRENKEL (1992) mentioned a level of more than 3\% of total CEC as harmful for cacao.

\subsection{Leaf investigation}

To relate soil nutrient content with the nutrient supply to selected crops, cacao leaves were sampled for analysis of relevant plant nutrients. Cacao was chosen as a perennial crop because of its high frequency in homegardens and its importance for income generation of gardeners. 


\subsubsection{Leaf sampling}

Within each homegarden with cacao trees $(\mathrm{N}=40), 10$ leaves of randomly selected trees were taken. As recommended by ACQUAYE (1964), the most recently matured leaf of a twig (usually the third leaf from the tip) was picked with its petiole, excluding damaged leaves or those with abnormal sizes.

\subsubsection{Sample treatment and analysis}

The samples were packed in plastic bags, weighed, air-dried, and transported to the STORMA laboratory in Palu. After final oven-drying (about 4 hours at $80^{\circ} \mathrm{C}$ ), samples were ground to powder and stored in plastic bags. All analyses were carried out in the STORMA laboratory. $\mathrm{N}$ content of the leaf material was analysed by a $\mathrm{C} / \mathrm{N}$-Analyser (Vario EL, Elementar). For analysis of $\mathrm{P}, \mathrm{K}, \mathrm{Mg}, \mathrm{Fe}$, and $\mathrm{Ca}$, plant material was completely digested by $\mathrm{HNO}_{3}$ under pressure. Nutrient contents were detected by ICP-OES (Optima 2000 DV, Perkin Elmer).

\subsubsection{Rating of leaf nutrient contents}

Following the suggestions of HALLIDAY \& TRENKEL (1992) for cacao production in Trinidad, near-mature cacao leaves with nutrient contents less than $1.8 \% \mathrm{~N}, 0.13 \% \mathrm{P}, 1.2 \% \mathrm{~K}, 0.3 \% \mathrm{Ca}$, $0.2 \% \mathrm{Mg}$, and $50 \mathrm{ppm}$ Fe should be rated as severely deficient. Normal nutrient contents should be higher than $2.0 \% \mathrm{~N}, 0.2 \% \mathrm{P}, 2.0 \% \mathrm{~K}, 0.4 \% \mathrm{Ca}, 0.45 \% \mathrm{Mg}$, and $65 \mathrm{ppm} \mathrm{Fe}$.

\subsection{Case studies}

To shed more light on sustainability issues, three homegardens in Wuasa and Siliwanga were chosen for a detailed case study of soil quality and erosion, microclimate and management patterns in March, April and June 2004. The homegardens selected represented the three main garden types found in the research area (KEHLENBECK \& MAASS, 2004). In Wuasa, one homegarden of 'type 1' (small spice garden) and one of 'type 2' (large, species-rich fruit tree garden) were selected. In Siliwanga, one garden of 'type 3' (very large, species-poor migrant garden) was chosen. The selected households had similar sizes (2-4 adults and 1-2 children per household) and were exclusively engaged in agriculture.

\subsubsection{Case study interviews}

For a period of two weeks, households chosen were visited every evening when at least the household head and his wife were available for daily interview, lasting about $30 \mathrm{~min}$. The purpose of these interviews was to study in detail time and work allocation of the household concerning homegarden management, including other homegarden-related inputs and outputs. In a 24-hour recall, the following questions were asked:

1. What kind of work did each household member perform today in the homegarden or somewhere else (except housework such as cooking, washing, cleaning)? How long did it take?

2. What was harvested today from the homegarden? What was the amount per item? For what purpose each item was harvested? What and how much was harvested from other farm plots? 


\subsubsection{Soil quality and erosion}

In the selected homegardens, topsoil samples $(0-15 \mathrm{~cm})$ were taken again from the different production zones (2-3 zones per garden) to estimate small-scale variation of soil quality and soil erosion. Therefore, samples were not bulked, but analysed separately. Soil treatment after sampling was the same as described under 2.6.2. Texture analysis was carried out in Bogor, $\mathrm{pH}$-value (in $\mathrm{H}_{2} \mathrm{O}$ ) as well as $\mathrm{C}$ and $\mathrm{N}$ contents were analysed in Palu. In Göttingen, plant available P (Bray I), CEC effective and base saturation were determined (for methodology see 2.6.3).

For assessment of soil erosion, the content of Caesium-137 was analysed according to WU \& TIESSEN (2002) in the same topsoil samples as described above. To serve as reference samples, three undisturbed topsoil samples $(0-15 \mathrm{~cm})$ were taken each from forest near Wuasa and grassland in Siliwanga. To obtain the required amount for Caesium-137 analysis (minimum $250 \mathrm{ml}$ dry soil), each sample was combined from three cores, taken in immediate vicinity. Dried and sieved subsamples were transported to Göttingen. Analysis of Caesium137 was carried out by gamma spectroscopy in the LARI-laboratory of the Institute for Forest Botany, University of Göttingen. Caesium-137 activity was measured 24 to 70 hours per 250 ml soil sample.

\subsubsection{Microclimate and PAR (photosynthetic active radiation)}

Microclimate and PAR (photosynthetic active radiation) measurements were conducted in different production zones of the three selected homegardens. Microclimate (i.e. soil temperature and air temperature) was measured by $\mathrm{HOBO}^{\mathrm{TM}}$ Pro $\mathrm{RH} / \mathrm{Temp}$-data loggers over a period of two weeks. Three data loggers were each fitted on a wooden pole of $1.3 \mathrm{~m}$ length, provided with a wooden board on its top for data logger's protection from direct sunlight and rain (see Figure 3.29 as an example). These poles were hammered into the soil to such depth that the data loggers sensors were exactly $1 \mathrm{~m}$ above soil surface. Per garden, one data logger each was installed between cacao trees in the cacao production zone, and either in the vegetable, fruit tree or (in Siliwanga) cassava production zone, while a third data logger served as a reference at a bare place. Three further data loggers, protected in plastic bags, were buried at the base of each pole in $5 \mathrm{~cm}$ depth for recording soil temperature. Data loggers were adjusted to measure and store temperature every hour. After finishing two weeks' measurements, stored data were transferred to a notebook computer for further processing. For every daily course, the minimum, the maximum, and the mean temperatures of air and soil, as well as the amplitudes were used to calculate overall means of the whole measurement period per zone and garden. Besides, mean daily courses of air and soil temperatures were calculated per zone and garden.

PAR (photosynthetic active radiation, wavelength $380-710 \mathrm{~nm}$ ) was measured to describe light regimes in different production zones of homegardens, using three data loggers 'Ecotec DL-424'. To allow comparison with data already generated in the area, measurement was conducted following BRODBECK (2004) with slight adaptations. Four sensors were fitted on each of two bamboo poles, at heights of $0.3,1.3,3.0$, and $4.5 \mathrm{~m}$. The sensors of each pole were connected to a data logger. For reference measurement, only one sensor, connected to a third data logger, was fitted on a third pole at $3.0 \mathrm{~m}$ height. The three poles were planted in the different production zones of each homegarden, just beside the position of the 
microclimate measurement units (see above). Measurement was carried out in May 2004 for a period of five days per homegarden and was adjusted to one measurement every ten seconds and saved as an integrated value every minute. Stored data were transferred to a notebook computer after finishing each measurement of five days. Mean daily courses of PAR were calculated for each zone and stratum as well as for the bare space per garden. In addition, the mean duration of direct solar radiation (defined as periods of time with PAR $\geq 250 \mu \mathrm{E} / \mathrm{m}^{2} \mathrm{~s}$ ) per day as well as mean relative light intensity (i.e. PAR measured in the stand in relation to PAR at bare space of the same garden) were calculated per zone and stratum for each of the three gardens (BRODBECK, 2004).

The layout of one selected case study homegarden was measured in detail. Position and size of the house, toilette, stable, and pathways were determined using a measuring tape and drawn on a map of the particular garden. In addition, the position of all trees, shrubs, and single herbs were included into this map. Herbs occurring in clumps were not marked individually in the maps. Instead, their production area was drawn. Both crops and ornamentals were considered for mapping. Heights and crown diameters of all trees and banana plants taller than $2 \mathrm{~m}$ were determined using a measuring stick. Each crown diameter was measured twice, forming a right angle, for calculating the mean diameter and canopy area of the respective tree. For trees and bananas planted exactly at the border of the garden, only half of the canopy area was considered for calculating the total canopy cover; for those individuals planted in less than $1 \mathrm{~m}$ distance to the garden border, only $67 \%$ of the canopy area was considered.

\subsection{Data processing and statistical analysis}

Raw data were arranged in MS Excel 2000 spreadsheets and statistically analysed using SPSS software (version 11.0). For each metric variable, normal distribution and homogeneity of variances were tested by Shapiro-Wilk and Levene test, respectively (JANSSEN \& LAATZ, 2003). If test conditions were fulfilled, differences between group means were determined by t-test (for comparing two groups) or one-way ANOVA (for comparing more than two groups), followed by post-hoc Tukey's HSD test. Concerning not normally distributed variables, medians were presented in the tables and differences between groups were identified by non-parametric Mann-Whitney's U-test (for comparing two groups) or KruskallWallis' H-test (for comparing more than two groups), followed by Nemenyi test for revealing the significantly different groups (TIMISCHL, 2000). Spatial differences of soil quality parameters between production zones within homegardens were analysed as 'paired samples' using the Wilcoxon signed-rank test. To analyse changes in related variables over time (e.g. crop species richness per garden in the years 2001, 2003, and 2004), Friedman test was used. Linear bivariate relations between variables were analysed using Pearson's correlation coefficients for metric variables and Spearman's correlation coefficients for ordinal variables (JANSSEN \& LAATZ, 2003). 


\subsubsection{Multiple regression analysis}

To identify factors that influence crop diversity, multiple linear regression analysis was performed. The dependent variables were crop species richness, Margalef index, crop species density, crop individual density, diversity expressed by the Shannon index, and Shannon evenness index. The explanatory, independent variables belonged to four different categories: garden features (i.e. age and size), characteristics of the gardener and his/her household (e.g. gardeners age, origin, and sex, profession of household head, household size), socio-economic features including farm characteristics and wealth status of the household (e.g. market access, farm area per household member, poverty index, cash oriented production), and soil characteristics (e.g. C, N, and available $\mathrm{P}$ content, $\mathrm{pH}$ value). These independent variables were selected mainly according to the available literature, presented in detail in 1.4. After checking the influence of all variables per single category each, a final multiple regression analysis was carried out using only the most important explanatory variables out of the four categories. Some highly correlated pairs of independent variables such as soil N and C contents or $\mathrm{pH}$ value and available $\mathrm{P}$ content were converted to dummy variables to avoid multicollinearity. Nominal variables, e.g. origin of the gardener or market access, were included into the model as dummy variables. After running the analysis with non-transformed independent variables only, non-linear variables were transformed to their natural logarithm to check a possible improvement of the model.

Regression analysis was performed using the stepwise method, including only variables with an F-probability of their partial correlation coefficient $\mathrm{P} \leq 0.05$ and excluding such with $\mathrm{P} \geq$ 0.1 (BACKHAUS et al., 2006). Auto-correlation among independent variables was examined by the Durbin-Watson test, provided by SPSS. The result of this test should be in certain limits around the value 2.0, depending on the number of cases and number of explanatory variables in the model (e.g. limits for 50 cases and three explanatory variables: 1.59-2.41; for five explanatory variables: 1.69-2.31) (BACKHAUS et al., 2006). To detect multicollinearity, the 'condition index' was calculated by SPSS. Following BELSLEY et al. (1980), an index higher than 15-30 indicates multicollinearity. In this study, regression models with an index of more than 16 were rejected. To test for heteroscedasticity, an analysis of the residuals was performed visually by plotting standardised predicted values against standardised residuals (BACKHAUs et al., 2006). No relation between these two variables indicates the required nonheteroscedasticity.

\subsubsection{Specific analyses of vegetation and diversity data}

Species density

To calculate species density per $1000 \mathrm{~m}^{2}$ garden area, two methods were used. One measure was based on regression analysis of all cases and calculation of residuals for each single case, followed by estimation of species number in a standard plot according to the percentage difference between counted and predicted species number for the measured plot size, but extrapolated to a standard $1000 \mathrm{~m}^{2}$ plot. Before regression analysis, garden size was $\mathrm{ln}$ transformed to ensure linearity of its influence on species number.

The second measure for species density was calculated for a standard plot size of $1000 \mathrm{~m}^{2}$ according to the modified Arrhenius equation, as suggested by EVANS et al. (1955): 


$$
\mathrm{S}=\frac{\mathrm{S}}{\log (\mathrm{x}+1)} \times \log (\mathrm{X}+1)
$$

where

$$
\begin{aligned}
& \mathrm{S}=\text { Estimated number of species in a standard plot } \\
& \mathrm{S}=\text { Number of species counted in the plot } \\
& \mathrm{X}=\text { Measured size of the plot } \\
& \mathrm{X}=\text { Standard plot size }
\end{aligned}
$$

\section{Diversity indices}

Alpha diversity is commonly measured as species richness of an individual sample unit. However, sample sizes might not be equal in a study and, thus, influencing species richness per sample. Besides, equitability or evenness of abundance is not included in the measure of species richness, although it is an essential component of diversity. In addition to species richness, this study presents different diversity indices as suggested by KREBS (1999), MAGURRAN (1988), and MCCUNE et al. (2002), among others.

1. The Margalef index counts for the positive relationship between number of individuals (i.e. size) of a sample and its number of species. It is calculated as follows (LUDWIG \& REYNOLDS, 1988):

$$
\mathrm{M}=\frac{\mathrm{S}-1}{\ln \mathrm{N}}
$$

where

$$
\begin{aligned}
& M=\text { Margalef' } s \text { index } \\
& S=\text { Number of species } \\
& N=\text { Total number of individuals }
\end{aligned}
$$

As suggested by PIEPHO (1996), an index such as the Margalef index should be provided beside the pure species richness for comparing diversity among samples of different sizes.

2. The Shannon index is probably the most common diversity index based on heterogeneity, calculated as follows (MAGURRAN,1988):

$$
\mathrm{H}^{\prime}=-\sum_{\mathrm{i}=1}^{\mathrm{s}} \mathrm{p}_{\mathrm{i}} \times \ln \mathrm{p}_{\mathrm{i}}
$$

where

$$
\begin{aligned}
& H^{\prime}=\text { Shannon index of diversity } \\
& \mathrm{S}=\text { Number of species } \\
& \mathrm{p}_{\mathrm{i}}=\text { Abundance of the } i \text { th species }
\end{aligned}
$$

The measure H' increases with the number of species and evenness of their abundance. It is sensitive to changes rather in the rare species than in the dominant species of a community (PEet, 1974). 
3. The first nonparametric heterogeneity measure of diversity used in ecology was Simpson's index (KREBS, 1999), given by:

$$
\lambda=\sum_{\mathrm{i}=1}^{\mathrm{s}} \mathrm{p}_{\mathrm{i}}^{2}
$$

where $\quad \lambda=$ Simpson's index of diversity

$\mathrm{S}=$ Number of species

$\mathrm{p}_{\mathrm{i}}=$ Abundance of the $i$ th species

Simpson's index ranges from 0 to 1 and describes the probability that two individuals randomly picked from one plot belong to the same species. The higher the index the lower the diversity. According to PEET (1974), Simpson's index is more sensitive to changes in the dominant than in the rare species.

4. The reciprocal of Simpson's index, called also Hill's $\mathbf{N}_{2}$, is calculated as follows (LUDWIG \& REYNOLDS, 1988):

$$
\begin{array}{ll} 
& \mathrm{D}=\frac{1}{\lambda} \\
\text { where } \quad \mathrm{D}=\text { Hill's } \mathrm{N}_{2} \\
\lambda=\text { Simpson's index }
\end{array}
$$

Hill's $\mathrm{N}_{2}$ ranges between 0 and $\mathrm{S}$ (number of species), pointing towards the number of very abundant species. Therefore, a high value indicates a high diversity.

5. One of the measures of evenness is the Shannon evenness index or Pielou's J (PEET, 1974) that is:

$$
\mathrm{E}=\frac{\mathrm{H}^{\prime}}{\mathrm{H}_{\text {max }}^{\prime}}=\frac{\mathrm{H}^{\prime}}{\ln \mathrm{S}}
$$

where

$$
\begin{aligned}
& E=\text { Shannon evenness index } \\
& H^{\prime}=\text { Shannon index of diversity } \\
& H^{\prime}{ }_{\text {max }}=\text { Maximum possible value for Shannon index, given S species }
\end{aligned}
$$

Shannon evenness index ranges from 0 to 1 , giving the percentage of $\mathrm{H}^{\prime}$ obtained when all species are evenly distributed. Increasing values indicate more equally abundant species (LUDWIG \& REYNOLDS, 1988). 


\section{Similarity measures}

Floristic similarity between crop plant communities among samples (i.e. beta diversity) was estimated by calculating Sørensen's coefficient as follows (modified after MAGURRAN, 1988):

$$
\mathrm{S}_{\mathrm{S}}=\frac{2 \mathrm{c}}{\mathrm{a}+\mathrm{b}}
$$

where $\quad \mathrm{S}_{\mathrm{S}}=$ Sørensen's similarity coefficient

$\mathrm{a}=$ Number of species present in sample A

$b=$ Number of species present in sample $B$

$\mathrm{c}=$ Number of species present in both samples

The higher $\mathrm{S}_{\mathrm{S}}$, ranging from 0 to 1 , the more similar are the plant communities among the two samples. Species common in both samples are weighed double. However, only presenceabsence data are included in this measure, information on species abundance is ignored.

As an index that includes species abundance data, the Renkonen index or "percentage similarity' was calculated as follows (KREBS, 1999):

$$
\mathrm{P}_{\mathrm{S}}=\sum_{\mathrm{i}=1}^{\mathrm{S}} \min \left(\mathrm{p}_{1 \mathrm{i}}, \mathrm{p}_{2 \mathrm{i}}\right)
$$

where

$\mathrm{P}_{\mathrm{S}}=$ Renkonen index

$\mathrm{S}=$ Number of species

$\min =$ Minimum when comparing two samples, 1 and 2

$\mathrm{p}_{1 \mathrm{i}}=$ Abundance of the $i$ th species in sample 1

$\mathrm{p}_{2 \mathrm{i}}=$ Abundance of the $i$ th species in sample 2

As the abundance of a few species was extremely high in some cases, all individual counts were transformed in the same way as for the principal component analysis (see 2.9.4) before the Renkonen index was calculated, following the suggestions of KREBS (1999).

\section{Importance value}

Importance values are averages of at least two of the parameters relative dominance, relative density/abundance, and relative frequency (MCCunE et al., 2002). These measures have the advantage to level out the bias of single variables such as high absolute abundance. In this study, the importance value Summed Dominance Ratio (SDR) was analysed on village level to compare the importance or dominance of different crop use categories among the villages. First, the relative densities and relative frequencies per village were calculated for each species as follows (MCCUNE et al., 2002): 


$$
\mathrm{RD}_{\mathrm{j}}(\%)=\frac{\text { Indiv }_{\cdot_{\mathrm{j}}}}{\text { Sum of all individuals }} \times 100
$$

and $\quad \mathrm{RF}_{\mathrm{j}}(\%)=\frac{\text { No. of plots }_{\mathrm{j}}}{\text { Sum of all plots }} \times 100$

where $\quad R D_{j}=$ Relative density of the species $\mathrm{j}$ in a village

$R F_{j}=$ Relative frequency of the species $j$ in a village

Indiv. $\mathrm{j}_{\mathrm{j}}=$ Number of individuals of the species $\mathrm{j}$ in a village

No. of plots ${ }_{j}=$ Number of plots in a village, where species $\mathrm{j}$ occurred

Second, the SDR per species and village was calculated by:

$$
\mathrm{SDR}=\frac{\mathrm{RD}+\mathrm{RF}}{2}
$$

Third, the single SDR values of all species per use category (e.g. of all fruit species) and per village were summed up.

\subsubsection{Hierarchical cluster analysis}

Cluster analysis was performed to detect patterns of similarity and, hence, separate different homegarden types based on their plant composition. In 2001, presence-absence data of plant species were used for analysis, applying squared Euclidean distances as a measure of dissimilarity and the average linkage method (KEHLENBECK \& MAASS, 2004). Disadvantages of this method were its tendency for chaining and the loss of all information on species abundance data. Consequently, data of the 2003/2004-survey were analysed as abundance data using squared Euclidean distances and the 'Ward' or 'minimum variance' method that is space-conserving and tends to generate homogenous clusters (BACKHAUS et al., 2006; MCCunE et al., 2002). Species abundance data were transformed before analysis as recommended by MCCUNE et al. (2002) because of the high degree of variation within variables (i.e. abundance data). Transformation of the original data was calculated as follows:

$$
\mathrm{x}=\ln (\mathrm{y}+1)
$$

where $\quad x=$ transformed value $\mathrm{y}=$ original value

To detect outliers that influence the final cluster analysis, BACKHAUs et al. (2006) suggested to perform first a cluster analysis using the 'nearest neighbour' (single linkage) method. The final analysis was then performed without the outliers. Cluster analysis was carried out using MVSP (Multi-Variate Statistical Package), version 3.13m, Kovach Computing Services (2006). For the decision, where to 'cut' the resulting dendrogram and, thus, defining the correct number of different clusters in the final solution, the 'elbow' criterion was used 
(BACKHAUS et al., 2006). 'Sum of squares' were plotted against the respective number of clusters. The resulting curve shows an 'elbow' point at the optimal number of clusters, indicating that heterogeneity among clusters increases is markedly 'before', but only little 'behind' this point. Stepwise discriminant analysis was carried out using SPSS to prove if cluster groups differed significantly from each other and to determine variables/species that contributed most to the separation of groups (MCCUNE et al., 2002).

\subsubsection{Principal component analysis}

Principal component analysis (PCA) was performed using MVSP to detect and visualize changes of plant composition over time. Species abundance data were transformed (see 2.9.3) and centred to assess normality of the variables and to reduce the bias from very dominant species in the analysis (MCCUNE et al., 2002; LePŠ \& ŠMILAUER, 2003). PCA axes to be extracted were determined following Kaiser's rule (MCCUNE et al., 2002). For analysing changes over time, the mean abundance per village was calculated for each species and each year. PCA was then performed with the transformed and centred mean abundance data. As suggested by MCCUNE et al. (2002), rare species (i.e. species that occurred in less than $5 \%$ of the sample plots) were not deleted before analysis because the focus of this study was on species diversity, thus, all species were regarded as important for characterisation of the homegardens. 



\section{Results}

\subsection{Age of homegardens and their former land use}

The homegardens surveyed were cultivated for periods between 2 and 40 years (see Appendix 8). However, some gardeners were uncertain, in which year they initially planted their homegardens. On avarage, the oldest homegardens were found in Wuasa with a median of 26 years, while in Rompo and Wanga they were of intermediate age (13.5 and 14 years, respectively), and in the migrant villages Siliwanga and Tamadue they were youngest ( 9.5 and 10 years, respectively). However, differences among medians were significant between Wuasa and the migrant villages only. The areas of most of the homegardens in the migrant villages had never been planted before, thus, were forest (in Tamadue) or grassland (in Siliwanga) until first cultivation. Only one garden in Siliwanga and three in Tamadue were already used as homegardens by previous owners, however, had been planted only sparsely. In the local villages, the present area of most of the homegardens had already been cultivated before, mostly planted with upland crops $(20-50 \%)$ or robusta coffee $(10-20 \%)$. Some gardens had already been used as homegardens by previous owners (0-30\%). Only $20-40 \%$ of the homegardens in the local villages had not been cultivated for an unknown long time, covered mostly by herbs, shrubs, and small trees.

\subsection{Function and role of homegardens}

The primary function of homegardens was subsistence-oriented crop production for supplying the gardeners' families with non-staple food, such as fruits, vegetables, and spices (see Appendix 8). However, some gardens served mainly as sources of cash income or for ornamental purposes. The proportions of these functions differed among the villages surveyed. In the remote village Rompo, all gardeners used their homegarden products mainly for self-consumption, in Wanga 80\%, and in the migrant villages 60-70\%. In Wuasa, only $50 \%$ of the gardeners mentioned subsistence production, but $40 \%$ decoration as a main function. In the migrant villages, $20-30 \%$ of the gardeners rated their gardens mainly as source for additional cash income that was important for only $10 \%$ of the gardeners in Wuasa or Wanga. Secondary functions of homegardens were mainly decoration (particularly in Rompo and Wanga) or generation of cash income (particularly in Tamadue). Although the general importance of homegardens for daily life was rated as high to very high by $67 \%$ of the gardeners $(\mathrm{N}=49)$, their contributions to cash income and subsistence were assessed to be low. No gardener mentioned the homegarden as main source for daily food supply $(\mathrm{N}=47)$, apart from one gardener in Tamadue, who harvested many fruits from his homegarden. For all gardeners, paddy rice fields or plantations served as main cash sources, homegardens were said to contribute nothing or only little. On average, homegardens were said to contribute only about $6 \%$ of the total household's cash income (range $0-33 \%$, given by 30 respondents, see Appendix 8). However, portions differed according to the function of homegardens. Gardeners, who mentioned that a main or second function of their homegarden was generation of additional cash income $(\mathrm{N}=12)$ obtained a mean income portion of $10 \%$ from 
them. In contrast, gardeners managing a rather subsistence-oriented homegarden $(\mathrm{N}=18)$ stated to gain on average only less than $3 \%$ of their total cash income from homegarden products. However, instead of the productive function many gardeners stressed particularly the important social functions of their gardens as meeting point, place for relaxing and children's playground.

\subsection{Micro-zonation}

In the homegardens studied, 11 different management zones were identified, six cultivated and five non-cultivated zones. Cultivated zones were dominated either by ornamentals, tree seedlings, vegetables and spices, cacao and coffee trees, or by fruit trees. In mixed vegetation zones, no functional plant species group dominated. Non-cultivated zones were fallows, residential areas (including house, yard, toilets, and wells), stables, ponds and ditches, or other zones (e.g. kiosks, sheds, sites for constructions, or, in the case of Balinese households, the shrine area). In most homegardens, seven different micro-zones were found, ranging from 2 10 zones per garden (for details and sizes of zones see Appendix 7). Besides the residential zone that was found in all homegardens, ornamental and cacao/coffee zones were found most frequently both in local (i.e. Wuasa, Rompo, and Wanga) and migrant villages (Figure 3.1). Vegetable zones and tree nurseries were more common in local than in migrant villages. The occurrence of fruit tree and mixed zones varied markedly among villages. Fallow zones were found in all homegardens of Siliwanga, but in only $30-50 \%$ of those in the other four villages. In the migrant villages, zones for stables and other such as kiosks or shrine areas were generally found more often (60-100\%) than in local villages (30-60\%). Fish ponds occurred only in the villages Wuasa, Siliwanga, and Tamadue (30-40\% of the homegardens).

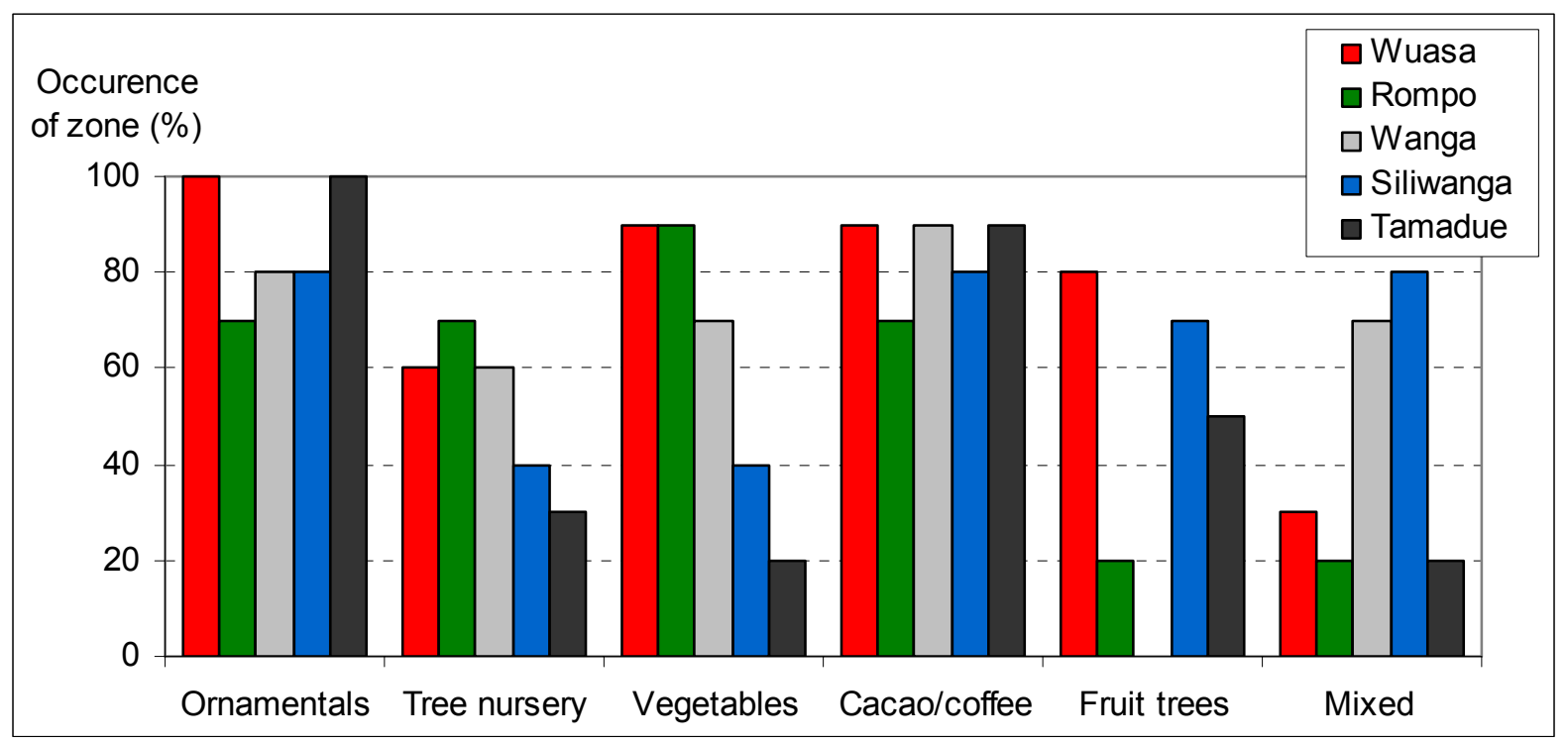

Figure 3.1. Occurrence (in \%) of different cultivated micro-zones in homegardens of five villages in the Napu valley, Central Sulawesi, 2004. $N=10$ per village.

The location of the different zones within homegardens was clearly fixed, based on practical considerations as well as traditions. Ornamentals were planted exclusively in front and/or at 
the sides of houses as well as along the front fence. Balinese gardeners cultivated ornamentals additionally around the shrine area in their front garden. Nurseries for trees and/or vanilla (Figure 3.2) were found mostly at a shady place in the back yard very close to the house, where they could be watered regularly and protected from thieves. Zones for vegetables were laid out mostly close to the house in the front or side garden, often fenced to protect them from livestock and children. In many vegetable zones, also spicy, medicinal, and ornamental plants were cultivated, whereas trees occurred very rarely.
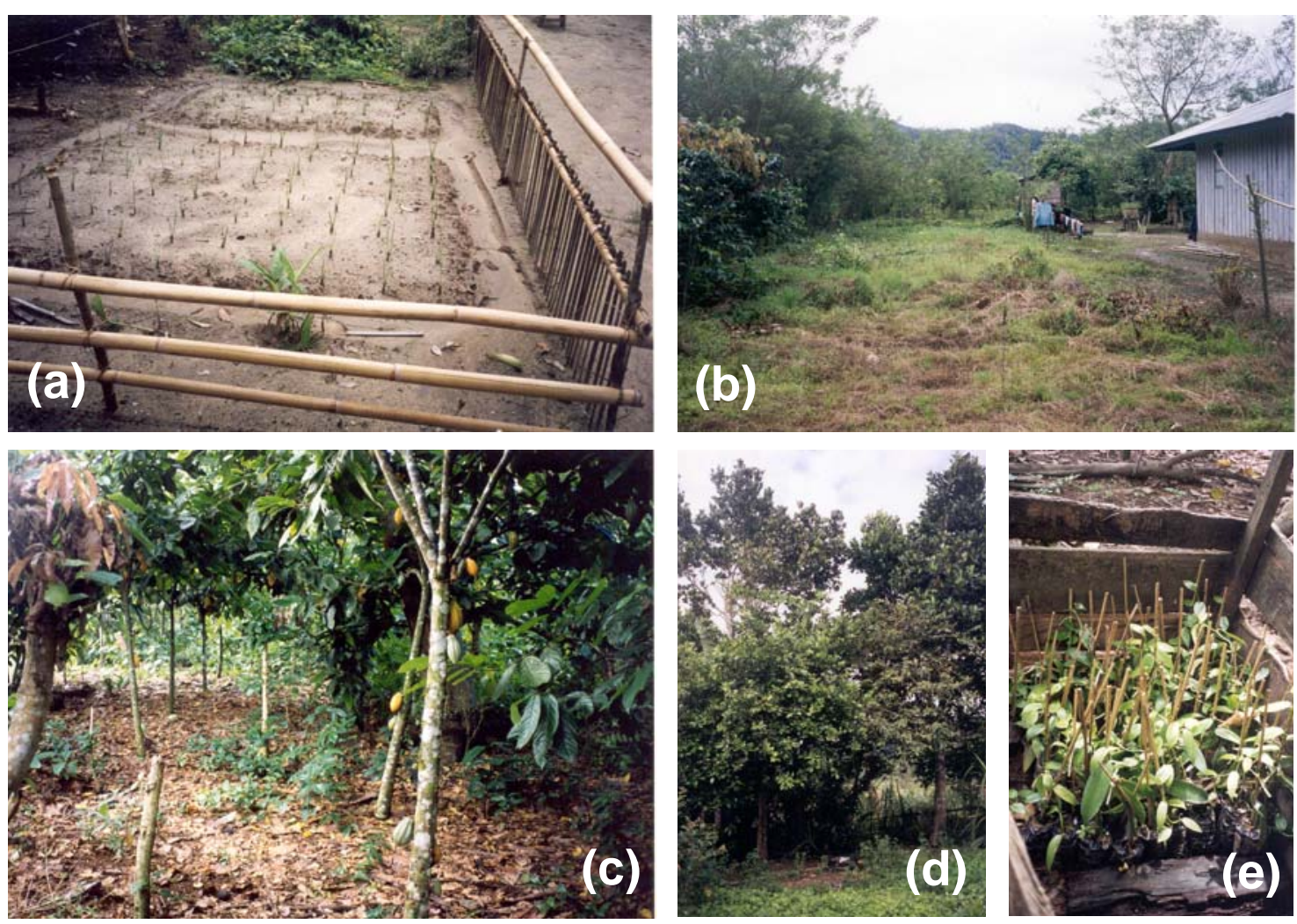

Figure 3.2. Different vegetation zones in homegardens of the Napu valley, Central Sulawesi. (a) Vegetable zone in a garden in Rompo; (b) Fallow zone in a garden in Tamadue; (c) Cacao/coffee zone in a garden in Tamadue; (d) Fruit tree zone in a garden in Wuasa; (e) Nursery for vanilla in a garden in Tamadue.

The cacao and coffee zone was mostly located beside or in the back of houses (Figure 3.2). Most cacao/coffee zones were shaded by fruit or multipurpose trees. If planted not too densely, staple food crops such as cassava, taro, or sweet potato were commonly grown under cacao and coffee trees. Fruit trees were often planted along homegarden borders, sometimes also in groups beside or behind the houses. They occurred only rarely in the front garden because this place was occasionally used as a temporary roofed party place in cases of weddings or funerals when existing trees would have to be felled. Fallow zones were found mostly in the back part of gardens, where unfavourable conditions hindered cultivation, e.g. due to water logging (Figure 3.2). Temporary fallows, caused by lack of time for hoeing and planting after harvesting the last crop, were sometimes found beside or in front of houses. Stables and ponds were laid out mainly in the back edges of homegardens to avoid unpleasant smell. However, in very large gardens, stables were found not too far away from houses in the back garden. 
The sizes of micro-zones and their proportions of total homegarden areas differed among villages. Ornamental zones occupied, on average, only about $1-5 \%$ of the total homegarden area. They were important in proportion in the local villages Wuasa and Wanga, but their sizes were largest in Wuasa and the migrant village Tamadue (Figure 3.3). Median sizes of ornamental zones differed significantly only between Wuasa and Rompo. Vegetable zones were largest in the local villages Wuasa and Rompo, where they occupied about 4\% and 10\% (median) of the total homegarden area, respectively. In Tamadue, both median size and median proportion of vegetable zones were significantly lower than in Wuasa or Rompo. Cacao and coffee zones occupied 20-30\% (medians) of the homegarden area in the local villages. In Siliwanga, cacao and coffee zones were very small (5\%), whereas in Tamadue, they were the most important zones, occupying nearly $70 \%$ of the total homegarden area. However, apparent differences among villages were not significant due to the large variability. Fruit tree zones were rather small, occupying only up to $4 \%$ of the total garden area. However, single fruit trees were often integrated in the mixed vegetation zone that was small in Wuasa, Rompo, and Tamadue, but rather large in Wanga and Siliwanga (about 16\% of total garden area). Fallow zones within homegardens were of importance in size and proportion mainly in Siliwanga (median: $33 \%$ of the total garden area), caused by unfavourable soil conditions.

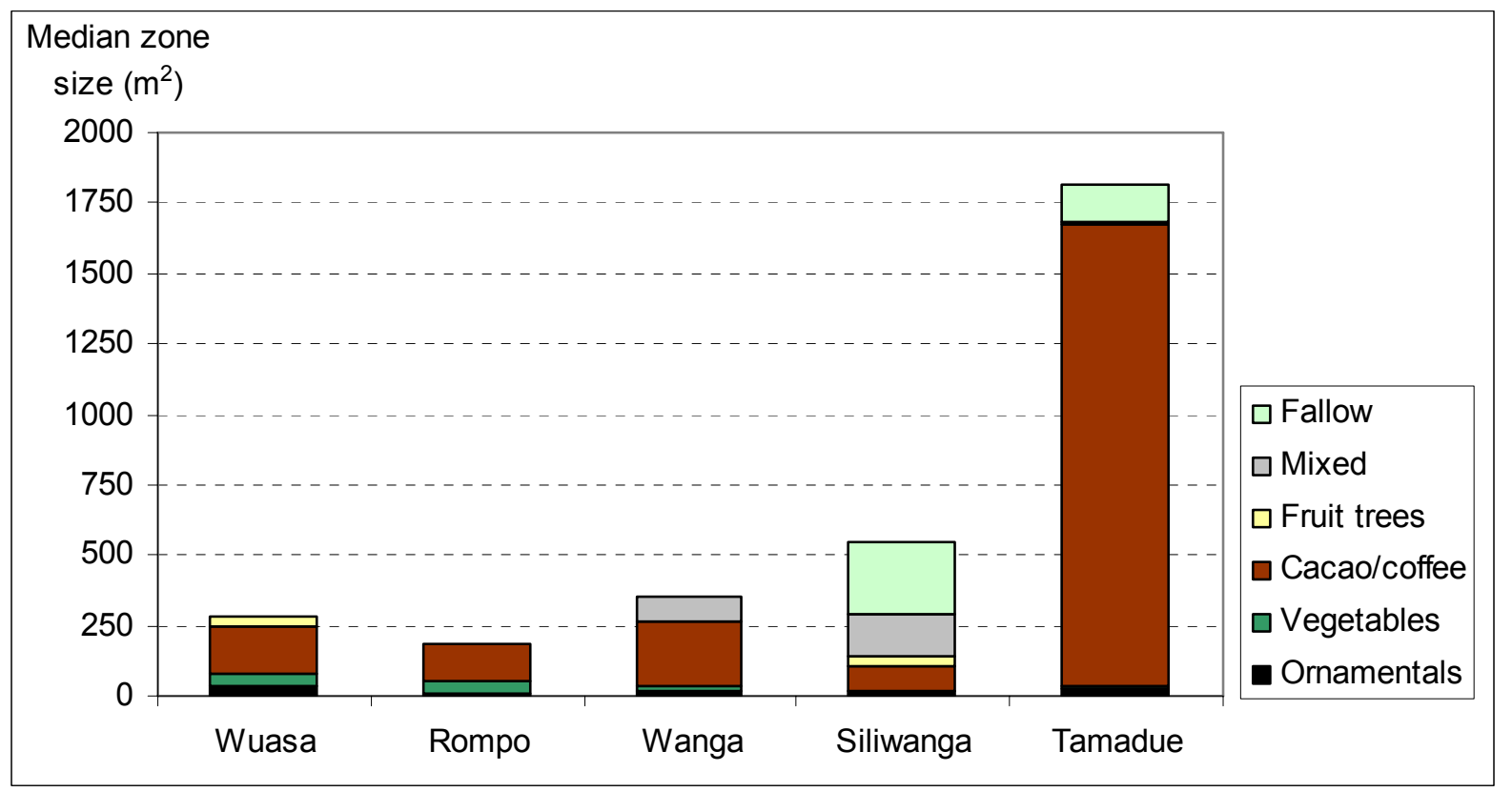

Figure 3.3. Median sizes of cultivated zones and fallows in homegardens of five villages in the Napu valley, Central Sulwesi, 2004. $N=10$ per village.

Residential areas occupied about 26-36\% (medians) of the homegarden area in the local villages, but in Siliwanga and Tamadue only $19 \%$ and $15 \%$, respectively. Differences of median proportion were significant between Wanga and Tamadue only, whereas median sizes of residential areas did not differ markedly, being rather small in Rompo and Siliwanga (medians 210-220 $\mathrm{m}^{2}$ ), medium in Wuasa and Wanga (about $240 \mathrm{~m}^{2}$ ), and large in Tamadue (about $300 \mathrm{~m}^{2}$ ). Ponds, stables, and other buildings such as shelters occupied only $2-6 \%$ of total garden area, being rather large in the migrant villages, where many pigs and cattle were 
raised in the homegardens. In the local villages, ponds were not common (apart from Wuasa) and pigs were often not stabled, but tethered. Ponds and ditches were dug for better drainage exclusively in Wuasa, Siliwanga, and Tamadue. Only larger ponds (50-400 $\mathrm{m}^{2}$ ) were used for raising fish, whereas smaller ones were used in some cases for cultivation of semi-aquatic plants such as water spinach. However, many gardeners used their ponds mainly as a place for their household rubbish.

\subsection{Homegarden management and inputs/outputs}

\subsubsection{Sources of planting material}

Gardeners mentioned several different sources of planting material. About one third of the planting material was supplied by family members, friends, or neighbours, another third had already been planted by previous garden owners or was self-established from seeds of wild or previously cultivated plants. About $10 \%$ of the planting material each was harvested from own plots, supplied by alien people, purchased, or received by development projects. However, differences in the sources of planting material existed among the villages. Own plots as a source of planting material were more important in the local villages (particularly in Wanga) than in the migrant villages Siliwanga and Tamadue, where gardeners often asked friends and neighbours for new planting materials (Figure 3.4). In the recently founded migrant village Siliwanga, rather large portions of the planting material were requested from alien people (i.e. mostly inhabitants of the nearby local village Wanga), received by projects (i.e. mostly from the governmental transmigrant programme) or brought from the home region Bali. Self-establishment of plants seemed to play a larger role in the local than in the migrant villages. Purchasing of planting material was more important in Wuasa and Tamadue than in the other three villages.

Sources of planting material did not only differ among villages, but also among crop use categories. Both fruit and vegetable species were most often self-established or requested from friends and neighbours. In the migrant villages, gardeners received about $20 \%$ of their fruit species from projects. For both local and migrant gardeners, such projects were also the main sources for planting material (about 22\% and 27\%, respectively) of stimulant species (e.g. cacao, tea, and arabica coffee). Planting material of spices, medicinal plants, and multi purpose trees (MPT) was mostly requested from friends and neighbours (about 35-40\% each). However, in the local villages own plots were an important source for MPT species, too. Large parts of staple crop species were already planted by former garden owners. For local gardeners, own fields were another important source for staple crops, whereas migrants mostly requested planting material of such crops from their friends and neighbours.

For wood and timber species, the most important source of planting material was simply selfestablishment from the natural vegetation nearby (about 70\%), but some species were also transplanted by the gardeners from the wild (about 7\%). Gathering from the wild was a rather important source also for some medicinal species, particularly in the local villages (nearly $10 \%$ ). Migrant gardeners brought nearly $20 \%$ of their medicinal plants from their home region Bali. Purchasing of planting material was important only for the use categories 'fruits' and 'spices' (local gardeners about 14\% and 8\%, migrant gardeners about 13\% and 14\%, respectively). However, gardeners mostly did not purchase seeds or plantlets in shops or 
markets. Instead, they bought fruits and spices for consumption and planted some of the seeds or remnants of rhizomes in their homegarden. Planting material could sometimes be transported even over rather large distances. Most of the mentioned fruits were bought by the gardeners in the markets of urban centres such as Poso or Palu up to $100 \mathrm{~km}$ away from the Napu valley. Also visits of relatives living farther away were often used as an opportunity to request new planting material, even from alien people living in the village visited.

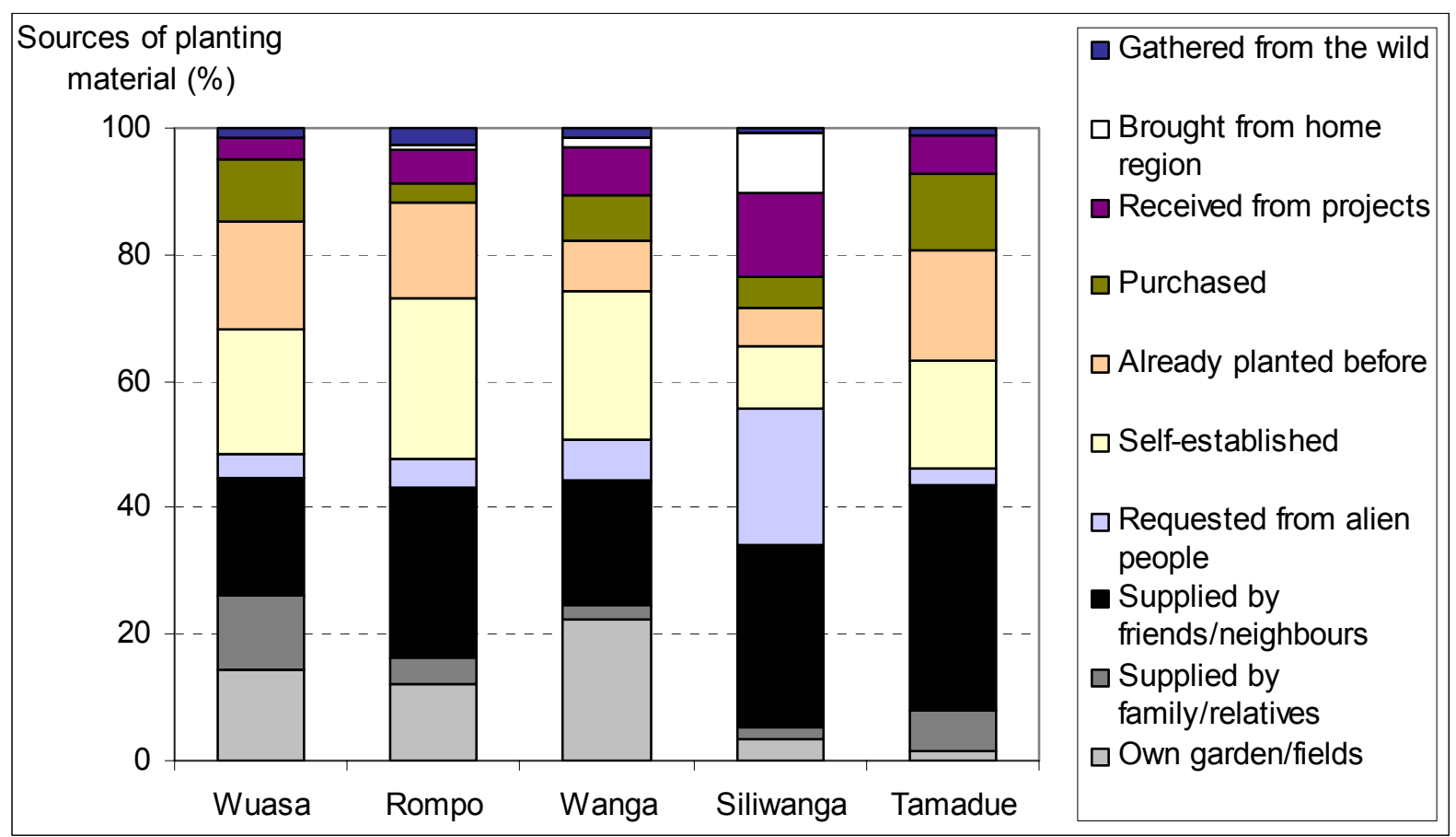

Figure 3.4. Sources of planting material as mentioned by the owners of 50 homegardens in five villages of the Napu valley, Central Sulawesi, 2003. $N=10$ per village.

Many gardeners also have given away planting material. However, no quantitative data about recipients or the frequency and amount of material flow were recorded. A few gardeners even mentioned that sometimes too many people asked for planting material. One female gardener in Wuasa complained that some of her homegarden crops already were reduced to very small numbers due to repeated requests by neighbours and relatives. She explained that rejecting the requests only would led to the stealing of desired plants. Stealing of planting material occurred rarely in homegardens, but it was mentioned by the gardeners as a severe problem in the more remote upland fields and plantations, particularly in cacao and vanilla plantations.

\subsubsection{Labour}

Main homegarden work was carried out mostly by household heads or their wives, but marked differences existed among villages. In the interviews, respondents in the more traditional local villages Rompo and Wanga stated that in about $90 \%$ of the homegardens main gardeners were females (see Appendix 8). In Wuasa and Siliwanga, however, $60 \%$ of the gardens were said to be managed mainly by males, in Tamadue with its coffee- and cacaodominated homegardens even about $90 \%$. According to calculations of the detailed working time schedules for males and females, however, the portion of mainly female-managed 
homegardens shifted slightly (Rompo and Wanga about 80\%, Wuasa and Siliwanga 60\%). Median monthly working hours of household heads and their wives, given in Table 3.1, partly reflect these results (for details see Appendix 9). In Rompo and Wanga, wives worked 5-10 times more than their husbands, but in Siliwanga, household heads worked slightly more than their wives. However, differences between males and females were not significant because of extremely high variation. The village Tamadue was excluded from the detailed analysis as data were incomplete. Children and children-in-law mostly only assisted in homegarden work, although in some households, children contributed markedly to homegarden management, particularly in Wuasa and Siliwanga (see range in Table 3.1). In few cases, also friends, neighbours, or relatives were involved in homegarden management. In the local villages, female household members carried out most of the total homegarden work (median Wuasa $57 \%$, Rompo 90\%, Wanga 93\%), whereas in the migrant village Siliwanga, females carried out less than half of the work (median 47\%).

Summed monthly working time varied from about 3-52 hours per household, village medians were fairly similar with a range of about 9-12 hours per month (Table 3.1). As homegarden size varied markedly, monthly working hours per $100 \mathrm{~m}^{2}$ cultivated garden area were also calculated. In Wuasa, Rompo, and Wanga, median working time $/ 100 \mathrm{~m}^{2}$ was about 2 hours per month, in Siliwanga, it was only 0.9 hours. Calculated on a daily basis, median daily working time was about $4 \mathrm{~min} . / 100 \mathrm{~m}^{2}$ garden area in the three local villages, but less than 2 $\mathrm{min} . / 100 \mathrm{~m}^{2}$ in the migrant village (range $0.4-20 \mathrm{~min} . / 100 \mathrm{~m}^{2}$ ). However, differences among villages were not significant.

Table 3.1. Median monthly homegardening working hours (ranges in brackets) of the household head (HH-H.), his wife, his children, or his friends and relatives as well as median working hours in total per month, and per $100 \mathrm{~m}^{2}$ garden area as given by respondents interviewed in 39 households in four villages of the Napu valley, Central Sulawesi, 2004. $N=10$ per village, apart from Rompo, where $N=9$.

\begin{tabular}{|c|c|c|c|c|}
\hline & Wuasa & Rompo & Wanga & Siliwanga \\
\hline Working hours HH-H. & $1.8 \mathrm{a}(0.0-23.1)$ & $1.0 \mathrm{a} \quad(0.0-22.0)$ & $0.7 \mathrm{a}(0.0-19.0)$ & $3.9 \mathrm{a}(0.0-20.0)$ \\
\hline Working hours wife & $2.5 \mathrm{a}(0.0-32.0)$ & $5.7 \mathrm{a}(0.2-19.3)$ & $7.1 \mathrm{a}(0.0-20.9)$ & $3.4 \mathrm{a} \quad(0.2-22.9)$ \\
\hline Working hours children & $1.1 \mathrm{a}(0.0-20.3)$ & $0.0 \mathrm{a} \quad(0.0-12.0)$ & $0.1 \mathrm{a}(0.0-8.0)$ & $0.0 \mathrm{a} \quad(0.0-28.0)$ \\
\hline $\begin{array}{l}\text { Working hours friends } \\
\text { and relatives }\end{array}$ & $0.0 \mathrm{a}(0.0-2.1)$ & $0.0 \mathrm{a}(0.0-6.0)$ & $0.0 \mathrm{a} \quad(0.0-0.1)$ & $0.0 \mathrm{a} \quad(0.0-0.04)$ \\
\hline Working hours total & $12.3 \mathrm{a} \quad(3.4-47.4)$ & $10.1 \mathrm{a}(4.6-36.6)$ & $9.3 \mathrm{a} \quad(2.8-27.6)$ & $8.6 \mathrm{a} \quad(4.8-51.9)$ \\
\hline Working hours $/ 100 \mathrm{~m}^{2}$ & $2.0 \mathrm{a} \quad(0.3-10.1)$ & $2.0 \mathrm{a}(0.3-5.7)$ & $2.2 \mathrm{a}(0.2-5.9)$ & $0.9 \mathrm{a}(0.4-2.8)$ \\
\hline
\end{tabular}

Note: As medians are given, total working hours are not equal to the overall sum of the three worker categories. Medians are given because variables were not normally distributed.

Medians in a row followed by different letters are significantly different at $\mathrm{P} \leq 0.05$.

Hoeing and pulling up/mowing weeds were carried out regularly by more than $80 \%$ of the gardeners. These kinds of work consumed most of gardener's working time, particularly in the local villages Wuasa, Rompo, and Wanga (Table 3.2, for details see Appendix 9). Harvesting was carried out regularly by $96 \%$ of the gardeners, who spent 2.4 hours per month (median) with harvesting in all villages. In the villages Wanga, Siliwanga and Tamadue, all gardeners sprayed their gardens regularly, whereas in Wuasa and Rompo only $70 \%$ and $56 \%$ did so, respectively. Time spent on spraying was significantly higher in Siliwanga than in Rompo, but it was generally rather low (Table 3.2). Fertilising of homegardens was more common in the migrant villages Siliwanga and Tamadue ( $>90 \%$ of the gardeners) than in the 
local villages (60-80\%). Accordingly, time used for fertilising was markedly higher in Siliwanga than in the local villages. Planting and pruning trees consumed only $0.1-0.3$ hours per month (median) in all villages (Table 3.2). Planting was carried out regularly by more than $90 \%$ of the gardeners in all villages, apart from Tamadue, where only $30 \%$ did so. Pruning trees was performed only if trees, particularly cacao trees, were cultivated in the homegarden. In Tamadue, $90 \%$ of the gardeners pruned their trees regularly, in Wuasa and Rompo 70-80\%, and in Wanga and Siliwanga only 50-60\%.

Table 3.2. Median monthly homegardening working hours (ranges in brackets) allocated to different kinds of work, as given by respondents interviewed in 39 households in four villages of the Napu valley, Central Sulawesi, 2004. $N=10$ per village, apart from Rompo, where $N=9$.

\begin{tabular}{|c|c|c|c|c|}
\hline & Wuasa & Rompo & Wanga & Siliwanga \\
\hline Hoeing & $6.0 \mathrm{a} \quad(0.0-36.0)$ & $4.0 \mathrm{a} \quad(1.0-24.0)$ & $5.0 \mathrm{a} \quad(0.0-12.0)$ & $0.7 \mathrm{a}(0.0-9.0)$ \\
\hline $\begin{array}{l}\text { Weeding/mowing } \\
\text { weeds }\end{array}$ & $1.3 \mathrm{a} \quad(0.0-30.0)$ & $1.2 \mathrm{a} \quad(0.3-24.0)$ & $1.0 \mathrm{a} \quad(0.1-15.0)$ & $2.5 \mathrm{a} \quad(0.1-45.0)$ \\
\hline Harvesting & $2.4 \mathrm{a} \quad(0.3-3.0)$ & $2.4 \mathrm{a} \quad(2.4-4.0)$ & $2.4 \mathrm{a} \quad(0.5-4.0)$ & $2.4 \mathrm{a} \quad(0.0-3.0)$ \\
\hline Spraying & $0.1 \mathrm{ab}(0.0-1.8)$ & $0.0 \mathrm{~b} \quad(0.0-0.2)$ & $0.3 \mathrm{ab}(0.1-0.5)$ & $0.5 \mathrm{a} \quad(0.0-1.0)$ \\
\hline Fertilising & $0.1 \mathrm{ab}(0.0-2.0)$ & $0.2 \mathrm{ab}(0.0-0.7)$ & $0.0 \mathrm{~b} \quad(0.0-2.4)$ & $0.7 \mathrm{a} \quad(0.2-3.0)$ \\
\hline Planting & $0.3 \mathrm{a} \quad(0.0-6.1)$ & $0.2 \mathrm{a} \quad(0.0-1.0)$ & $0.1 \mathrm{a} \quad(0.0-1.0)$ & $0.2 \mathrm{a} \quad(0.0-0.9)$ \\
\hline Pruning trees & $0.2 \mathrm{a} \quad(0.0-0.5)$ & $0.1 \mathrm{a} \quad(0.0-4.0)$ & $0.3 \mathrm{a} \quad(0.0-1.4)$ & $0.1 \mathrm{a}(0.0-1.0)$ \\
\hline
\end{tabular}

Medians are given because variables were not normally distributed.

Medians in a row followed by different letters are significantly different at $\mathrm{P} \leq 0.05$.

Most of the different kinds of work were clearly assigned either to male or female workers. However, Table 3.3 shows some differences among migrant and local households. Hoeing was carried out mainly by women (i.e. wives and daughters/daughters-in-law of the household head) in the local villages Wuasa, Rompo, and Wanga, but by men (i.e. household heads and their sons/sons-in-law) in the migrant villages. Weeding was performed by both males and females in the villages Rompo and Siliwanga, whereas in Wuasa and Wanga more females and in Tamadue more males were involved in it. A clear female task was harvesting; only in Tamadue, where mainly cacao and coffee was harvested, $40 \%$ male household members took part in this kind of work. Spraying was almost always done by males, not exclusively by household members, but also by friends or neighbours. Only in the villages Wuasa and Tamadue, a few women joined the spraying activities. Fertilising was mostly a female task in the local villages and Siliwanga, but a male one in Tamadue. Planting was carried out mainly by women in the local villages, but by men in the migrant villages. In all villages, males mainly performed pruning of trees.

In the interviews, 27 gardeners mentioned also sweeping the yard and some of the bordering zones as a typical homegarden work. This activity was said to take mostly between 5 and 15 min., carried out daily (by $78 \%$ of the 27 gardeners) or every second day. In most of the cases (63\%), only females swept, in only $15 \%$ exclusively male household members did so. However, as not all gardeners mentioned this activity that could also be classified as part of the housework, it was excluded from the analysis. 
Table 3.3. Proportion of female workers (\%) performing the different kinds of homegarden work as given by respondents interviewed in five villages of the Napu valley, Central Sulawesi, 2004. N=10 per village, apart from Rompo, where $N=9$.

\begin{tabular}{lccccc}
\hline & Wuasa & Rompo & Wanga & Siliwanga & Tamadue \\
\hline Hoeing & 63 & 62 & 91 & 36 & 20 \\
Weeding & 60 & 46 & 83 & 50 & 33 \\
Harvesting & 78 & 75 & 80 & 92 & 60 \\
Spraying & 13 & 0 & 0 & 0 & 18 \\
Fertilising & 56 & 100 & 100 & 75 & 29 \\
Planting & 67 & 89 & 89 & 44 & 0 \\
Pruning trees & 12 & 12 & 7 & 7 & 19 \\
\hline
\end{tabular}

The specific work allocation between men and women was reflected by different responsibilities for the various homegarden plant types as shown in Table 3.4 (for details see Appendix 8). In the local villages Wuasa, Rompo, and Wanga, in most cases women were responsible for ornamentals, medicinal plants, spices, and vegetables. In these production zones, the typical female tasks of hoeing, planting, fertilising, and harvesting were performed frequently. In the migrant villages, more women than men were responsible for ornamentals and medicinal plants, whereas men mainly took care of spices in Siliwanga and of vegetables in Tamadue. In all villages, mostly men were responsible for fruit and cacao/coffee trees, corresponding to their main tasks pruning and spraying that both was carried out mainly in the fruit and cacao/coffee production zone of homegardens. In Tamadue, exclusively fruit trees and the cacao/coffee zones were fertilised, thus, men were mainly involved in fertilising activities only in this particular village (Table 3.3).

Table 3.4. Proportion of female household members (\%) responsible for different homegarden plant types as given by respondents interviewed in five villages of the Napu valley, Central Sulawesi, 2004. $N=$ 10 per village, apart from Rompo, where $N=9$.

\begin{tabular}{lccccc}
\hline & Wuasa & Rompo & Wanga & Siliwanga & Tamadue \\
\hline Ornamentals & 92 & 100 & 100 & 76 & 75 \\
Medicinal plants & 100 & 100 & 91 & 91 & 64 \\
Spices & 100 & 67 & 100 & 0 & 70 \\
Vegetables & 90 & 100 & 90 & 67 & 0 \\
Fruit trees & 9 & 10 & 23 & 11 & 17 \\
Cacao/coffee trees & 20 & 17 & 14 & 0 & 17 \\
\hline
\end{tabular}

In summary, the quantity of time allocated for homegarden management was rather small. When compared with the time needed for cultivation of paddy rice fields and plantations, homegarden management was rated as less time-consuming by $90 \%$ of the gardeners. Concerning the quality of work, $96 \%$ of the gardeners stated that working their paddy rice fields and plantations was very heavy, but homegarden work was an easy task.

\subsubsection{Soil fertility rating and management}

Most of the gardeners assessed soil fertility of their homegardens as medium to high, apart from Siliwanga, where $70 \%$ of the gardeners rated the soil as poor and complained about it as a main constraint for successful homegarden production (Table 3.5, for details see Appendix 10). Low soil fertility was rated as a serious problem not only in Siliwanga, but also in Rompo and Wanga. Concerning changes of soil fertility over time, many gardeners perceived 
deterioration, particularly in Wuasa. However, in Siliwanga, most gardeners mentioned some improvement of soil fertility over time. Nearly all gardeners stated that fertilising (besides hoeing) was the best method for improving soil fertility. Nevertheless, $20-40 \%$ of gardeners in the local villages Wuasa, Rompo, and Wanga did not fertilise their homegardens (Figure 3.5). Reasons for not fertilising at all given by the gardeners were mostly lack of means (for industrial fertiliser) or knowledge (for manure and ash), sometimes also lack of time, laziness, and revulsion (for manure).

Table 3.5. Rating (in \%) of soil fertility, its changes over time, and its role in hindering successful homegarden management by 49 gardeners in five villages of the Napu valley, Central Sulawesi, 2004. N=10 per village, apart from Rompo, where $N=9$.

\begin{tabular}{lccccc}
\hline & Wuasa & Rompo & Wanga & Siliwanga & Tamadue \\
\hline Soil fertility low & 30 & 10 & 30 & 70 & 20 \\
Low soil fertility is a & 30 & 78 & 80 & 70 & 0 \\
$\quad$ serious problem & & & & & \\
& & 56 & 40 & 0 & 50 \\
Fertility deteriorated & 0 & 44 & 30 & 10 & 10 \\
Fertility unchanged & 20 & 0 & 30 & 90 & 40 \\
Fertility improved & & & & & \\
\hline
\end{tabular}

The most frequently used fertiliser in homegardens was kitchen ash that was available daily to virtually all gardeners (for details see Appendix 10). Figure 3.5, however, shows obvious differences among villages. Whereas only $20 \%$ of the gardeners in Tamadue used ash as a fertiliser, in Siliwanga 90\% did so. In the local villages Wuasa, Rompo, and Wanga, 50-60\% of gardeners fertilised with ash. Applying ash was mostly carried out weekly or monthly, however, also daily application existed. In the local villages, about $90 \%$ of gardeners applied ash exclusively to vegetables and spices, whereas in the migrant villages, it was used mainly for fruit trees and cash crops such as cacao and coffee. Applied amounts were only 0.25-4 small buckets (i.e. about 51 volume) per month, however, mainly spread on a rather small area such as the vegetable zone.

Industrial fertiliser such as urea, triple-super-phosphate, potassium chloride or NPK-fertiliser was less commonly used, apart from the migrant villages (Figure 3.5). In Tamadue and Siliwanga, $60 \%$ and $40 \%$ of gardeners, respectively, applied industrial fertiliser, whereas in the local villages, no one or only few gardeners in Wuasa did so. If industrial fertiliser was used, it was applied 1-4 times a year nearly exclusively to fruit trees and cash crops such as cacao and coffee. In most cases, extremely small amounts were applied such as 1-6 kg per year and garden, however, in Tamadue the migrant gardeners used 30-100 kg/year, particularly in the commercialised homegardens. Concerning the villages surveyed over time, use of industrial fertiliser increased markedly only in Siliwanga (see 3.10.2). 


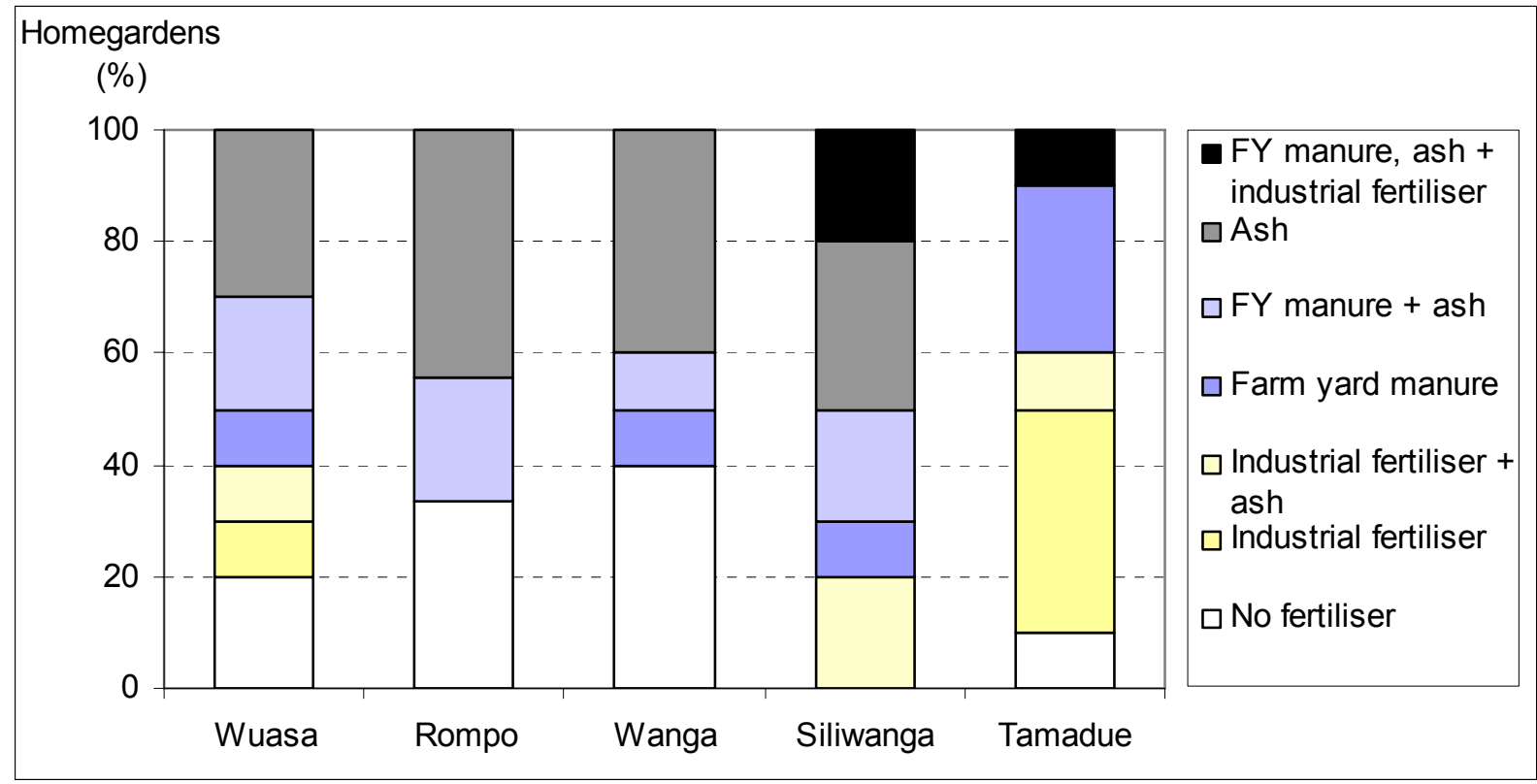

Figure 3.5. Use of different fertilisers in 49 homegardens according to gardeners' responses in five villages of the Napu valley, Central Sulawesi, 2004. $N=10$ per village, apart from Rompo, where $N=9$.

Farm yard manure was available to $80 \%$ of gardeners that reared pigs and/or cattle in their homegardens. However, it was used as a fertiliser only by $20-50 \%$ of the gardeners in each village, due to unawareness, revulsion, or time scarcity of gardeners. In the migrant villages Siliwanga and Tamadue, the proportions of manure utilization were slightly higher than in the local villages (Figure 3.5). Cash crops and fruit trees were almost exclusively fertilised with manure in the migrant villages, whereas gardeners in the local villages mostly fertilised vegetables and spices with manure. The applied amount ranged mainly around 2-10 large buckets (i.e. about 101 volume) per year and garden, distributed in some cases to up to 80 cacao, coffee, and fruit trees. Only three gardeners in Siliwanga and Tamadue applied more manure (40-180 large buckets per year) to their trees. For all kinds of fertilisers, the applied amount per year was rather small in relation to the sizes of homegardens.

Figure 3.6 shows the use of industrial fertiliser in farm plots according to different crops. Farmers stated to use industrial fertiliser mainly for their paddy rice fields, particularly in the migrant villages. In Tamadue, more than $50 \%$ of the farmers fertilised also perennial and annual crops as well as their homegardens with industrial fertiliser, whereas in the other villages, comparably few or even no farmers mentioned to do so. Besides ethnicity of the gardeners, also wealth status of households influenced fertiliser use. Only 13\% of the poor households reported to use industrial fertiliser or farm yard manure as a main fertiliser in their homegardens, whereas $41 \%$ of the intermediate and $53 \%$ of the well-off households did so. On the other hand, $69 \%$ of poor gardeners, but only $35 \%$ of the rich used ash as a main fertiliser in their homegardens. 


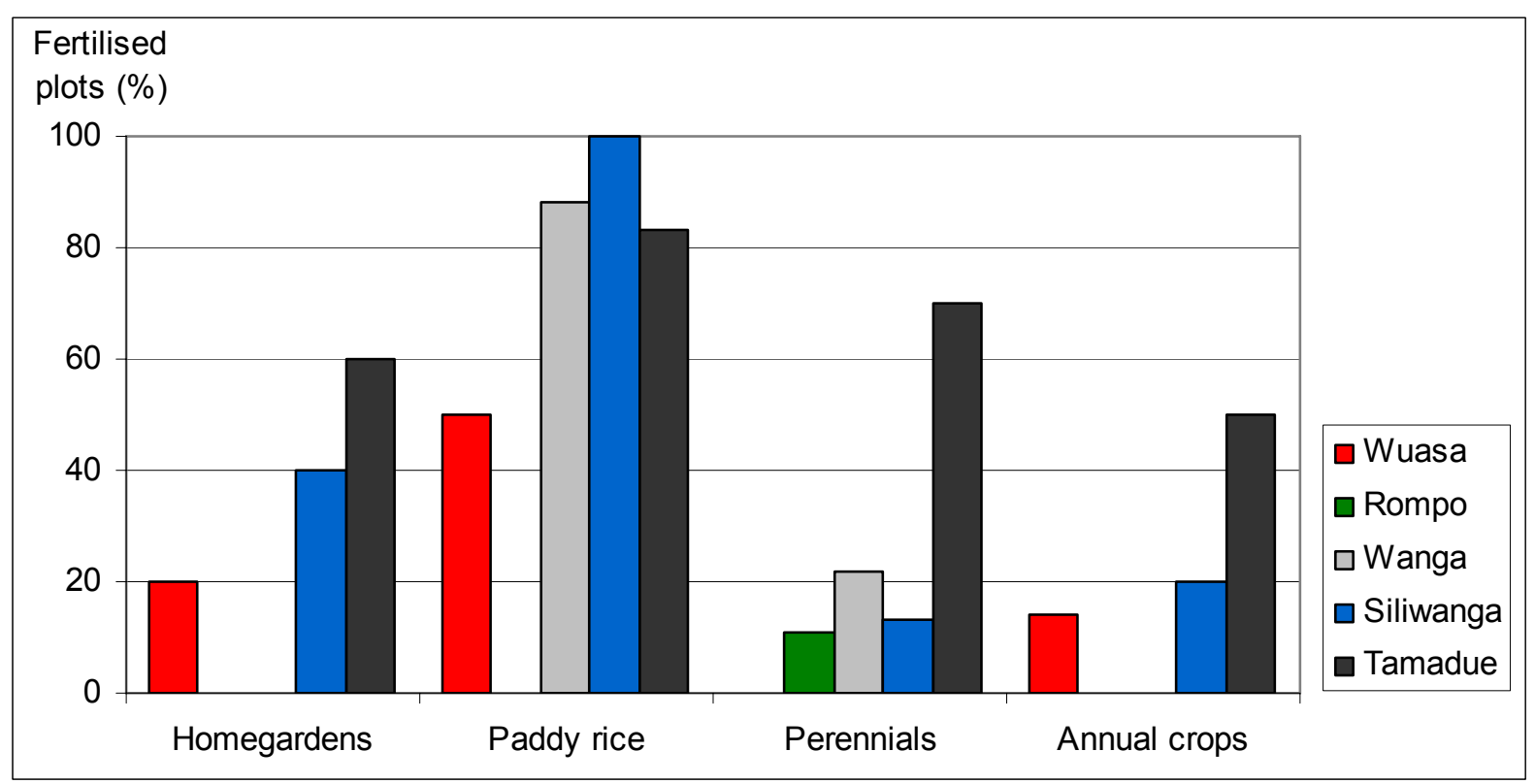

Figure 3.6. Use of industrial fertiliser in homegardens and in plots planted to paddy rice, perennials, or annuals, as given by 49 respondent households in five villages of the Napu valley, Central Sulawesi, 2004. $N=10$ per village, apart from Rompo, where $N=9$.

\subsubsection{Control of weeds, crop pests, and diseases}

Weeds were rated as a very serious or at least as a 'normal' problem in homegardens by $96 \%$ of the gardeners interviewed. This was reflected by the high share of working time needed for weed control (see 3.4.1), carried out mainly by spraying herbicides about $1-4$ times per year (see Appendix 11). However, in the remote village Rompo, only $50 \%$ of the gardeners applied herbicides, whereas in the other villages, $70-100 \%$ did so (Figure 3.7). Alternative methods for weed control were said to be carried out by $96 \%$ of the gardeners, mostly by hoeing $(80 \%)$, by weeding/pulling out the weeds $(61 \%)$, and by mowing $(57 \%)$. In all villages surveyed over time, the use of herbicides increased markedly (see 3.10.2).

Most important crop pests according to gardeners were leaf-feeding caterpillars (86\%), black and red ants (59\%), and aphids (39\%) (see Appendix 11). These pests were said to damage mainly cash crops such as cacao and spring onion, besides other leafy vegetables and spices. Spraying insecticides in homegardens was common only in the migrant village Tamadue (Figure 3.8), where exclusively cacao trees that dominated many homegardens were regularly treated 4-12 times per year. In the other villages, in most cases insecticides were applied only occasionally in the past, but not regularly. Instead, in the local villages Wuasa, Rompo, and Wanga, $70-90 \%$ of the gardeners stated to carry out alternative methods for crop pest control, such as cutting off infested plant parts, collecting and killing of the insects, dusting with ash, and spraying soap-suds. However, in the migrant villages, only $20-30 \%$ of gardeners mentioned to apply such alternative methods. 


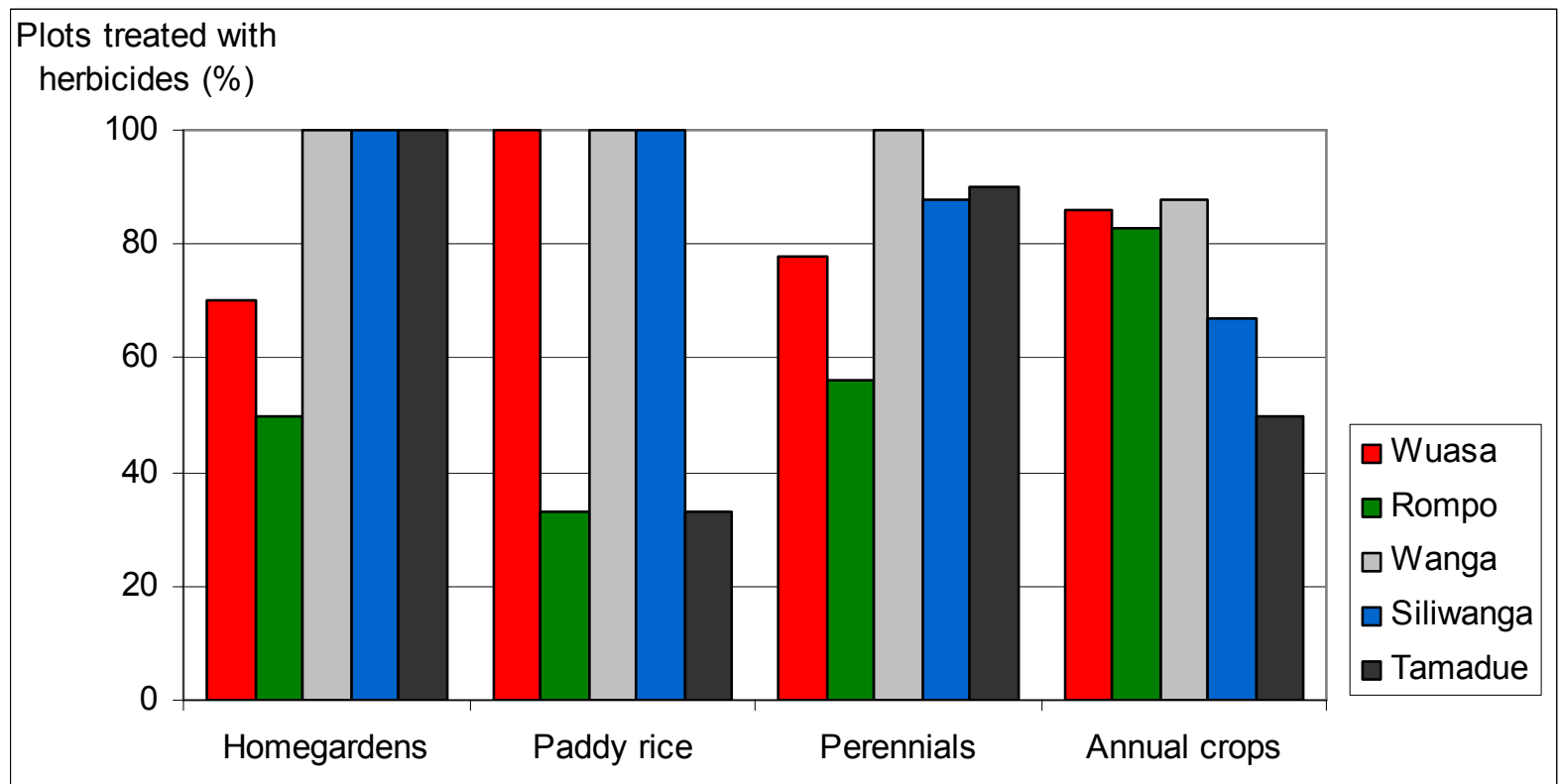

Figure 3.7. Use of herbicides in homegardens and in plots planted to paddy rice, perennials, or annuals, as given by 49 respondent households in five villages of the Napu valley, Central Sulawesi, 2004. $N=$ 10 per village, apart from Rompo, where $N=9$.

Crop diseases were recognised by the gardeners only rarely and almost exclusively on cacao trees. Gardeners described these diseases mostly as 'die-back', first of the branches and later of the whole cacao tree, often accompanied by a white coating on the infested bark surface. Besides, gardeners mentioned another important and problematic disease of cacao fruits, which they named 'cancer'. Only few gardeners distinguished three different kinds of 'cancer' on cacao fruits, i.e. 'stone cancer', 'black cancer', and 'spotted cancer'. Of these, only 'black cancer' is a fungal disease, namely the black pod rot, caused by Phytophthora spp. The other two 'cancers' were caused by insects that were not recognised by the gardeners. 'Stone cancer' is caused by the cacao pod borer Conopomorpha cramerella, a common cacao pest in Southeast Asia. Caterpillars of the pod borer feed inside the unripe fruits only, thus, not being visible any more at harvest time. 'Spotted cancer' is caused by the bites of nocturnal Helopeltis bugs. Spraying fungicides against the mentioned diseases (or even pests) in homegardens was mentioned exclusively by one gardener in Siliwanga and six gardeners in Tamadue, where many households depended on additional cash income from sales of cocoa. In the three local villages, most of the gardeners did nothing against crop diseases or they applied some alternative control methods, e.g. removing infested cacao fruits/branches or general pruning of cacao trees. About $30 \%$ of the gardeners rated problems with pests and diseases as 'very severe' and $60 \%$ as 'normal'.

Spraying herbicides was common not only in homegardens, but also in other plots planted to paddy rice, perennials, and annual crops (Figure 3.7). In the local villages, the portion of herbicide use was mostly lower in homegardens than in other plots, whereas in the migrant villages, it was higher in homegardens. Insecticides were used mainly in the migrant villages, particularly for paddy rice fields (Figure 3.8). In homegardens, insecticides were mostly used less often than in the rice fields, but more often than in perennial or annual crops. As 
compared to the migrant villages, farmers in the local villages used insecticides in a markedly lower proportion, but also mainly for spraying rice fields and homegardens.

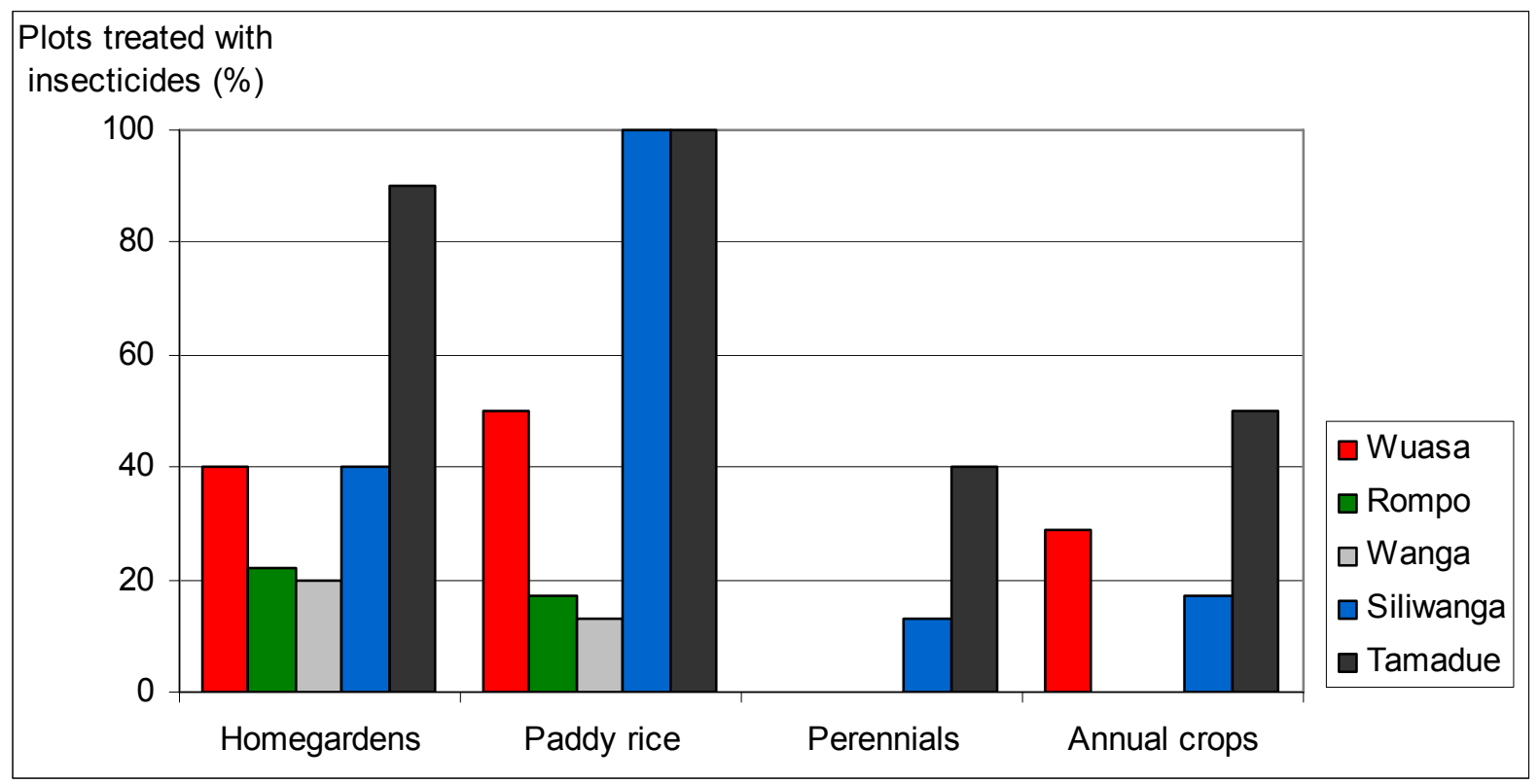

Figure 3.8. Use of insecticides in homegardens and in plots planted to paddy rice, perennials, or annuals, as given by 49 respondent households in five villages of the Napu valley, Central Sulawesi, 2004. $N=$ 10 per village, apart from Rompo, where $N=9$.

\subsubsection{Other limitations of homegarden management}

Besides problems with soil fertility, weeds, and pests and diseases, crop production in homegardens was further constrained. Gardeners mentioned particularly their lack of time, which was stressed as a very serious problem in the local villages Rompo and Wanga, whereas in Wuasa and Tamadue it was mostly no or only a 'normal' problem (see Appendix 11). Instead, $60 \%$ of the gardeners in Tamadue complained very much about bad crop varieties that did not give adequate yields. Although this problem did not seem as severe in the other villages, most gardeners appeared to be unsatisfied with their traditional varieties. If available, $88 \%$ of all gardeners would like to cultivate high-yielding varieties, particularly cacao and fruit trees. Nearly $50 \%$ of them would even cut down their mature cacao and fruit trees to replace them with improved varieties.

Many gardeners complained about limitations of successful homegarden production due to damage by small children and free-roaming livestock. Homegardens in the Napu valley were generally not completely closed by fences or hedges. For socio-cultural reasons, at least the main entrance must not have a gate. As a result, children used homegardens as playing and football ground, thus damaging many crops and ornamentals. Besides, small children liked very much to climb even young trees for harvesting mostly unripe fruits, breaking branches and trampling down the herbal undergrowth. Poultry was said to be another severe problem in homegardens, particularly in the rather traditional villages Rompo and Wanga. Scraping chicken in seed beds, and ducks feeding on small leafy crops were an everyday sight in the villages and caused heavy damages, particularly on vegetables and spices, but also on 
ornamentals and recently planted trees. Sometimes also escaped pigs, cattle, buffaloes, or horses entered homegardens at night and destroyed the crops. Many gardeners already stopped growing vegetables and spices, due to constant damages by livestock; but only $16 \%$ of the gardeners mentioned better fencing as a method for improving homegarden production.

About $25 \%$ of such gardeners that sold some homegarden produce $(\mathrm{N}=38)$ complained about very serious problems with sale. Nearly all of them mentioned the low prices they got for coffee and cacao. Some gardeners complained also about low number of and bad access to trustworthy middleman, particularly in Wanga.

\subsubsection{Outputs}

The homegardens surveyed served mostly for subsistence production, some also for income generation. Only two of 206 species found in homegardens (see 3.5.1) were cultivated exclusively for sale (cacao and vanilla). On average, gardeners used only less than one species grown in their homegarden for sale in the villages Wanga and Siliwanga, but 2.5-3 species in the villages Wuasa, Rompo, and Tamadue. Of the 49 gardeners asked for species uses, only about $18 \%$ did not sell any produce of their homegarden, $33 \%$ sold produce of one species, $20 \%$ that of two species, and nearly $30 \%$ that of three or more species. The most common produce was cacao, traded by about $75 \%$ of the gardeners, followed by coffee (mostly arabica, but also some robusta coffee), sold by about $30 \%$, and by the spicy fruits of the candlenut tree, sold by nearly $20 \%$ of the gardeners. A few gardeners also traded surplus of fruits, such as avocados, mandarins, pineapples, or water apples. Vegetables such as tomatoes or pumpkins were sold only by single gardeners. However, the contribution of sold produce from homegardens to the total household income was mostly less than $10 \%$ (see 3.2). No detailed information on amounts of cash income generated in the homegardens surveyed was available.

Concerning the produce for family consumption, yield estimates of gardeners seemed to be very difficult and not reliable. Most often, gardeners estimated amounts of harvest only as 'much', 'enough', or 'little'. When gardeners mentioned quantities, they often used 'a handful', 'a small bowl', or 'one meal'. Some were even not able to state anything about the yield, particularly for continuously harvested fruit trees. Consequently, only the occurrence of a harvest within the preceding year, but not its frequency or amount was analysed for each crop species. On average, only $54 \%$ of the species cultivated in the homegardens surveyed were used by the gardeners in the preceding year. However, large differences of the used portions existed according to different crop use categories. The most exploited use categories were spices (on average, $75 \%$ of the species were harvested by the gardeners), and stimulants as well as staple crops (73\% harvested each), followed by vegetables $(60 \%)$ and fruits $(54 \%)$. A typical reason for not harvesting any produce from a species cultivated in the homegarden was simply that the plant had not yet reached its productive stage. Besides, certain crops were neglected by the gardener, other species did not fruit because of insufficient management or unsuitable climate. Concerning medicinal plant species, only a small portion (25\%) was harvested and used by the gardeners to cure illness. Respondents mentioned that they rather preferred the modern medicaments available in the shops instead of time-consuming preparation of traditional medicine. Some young gardeners stated that they still recognised the function of a medicinal plant, but they lacked the knowledge on how to prepare a medicine 
from it. However, single gardeners also highly regarded the value of traditional medicine and used up to $100 \%$ of the medicinal plant species in their homegardens. Many gardeners also mentioned that they sometimes gave away medicinal plant parts to their friends and neighbours. Out of the species used mainly for fuel wood and timber as well as such for multipurpose use, only $5 \%$ and $2 \%$ were said to be harvested, respectively.

In summary, the production potential of homegardens was not fully exploited, both for subsistence and cash income generation.

\subsection{Floristic composition and vegetation structure in the year 2004}

\subsubsection{Plant species richness and use}

In the 2004-survey, a combined total of 206 crop species belonging to 71 plant families were cultivated in the 48 homegardens studied. Complete lists of these crop species, their occurrence in the homegardens, and information on their utilisations are given in Appendix 12 and Appendix 13. Fifty of the 206 crop species were considered to be wild species, mostly from the surrounding natural vegetation. They were used particularly as fuel wood and timber (28 species), but several species were also utilised as a medicine or vegetable (10 or 8 , respectively). The species-area curve shown in Figure 3.9 indicates that the overall sampled garden area of about 5.2 ha can be regarded as representative for the set of crop species occurring in homegardens of the research region. A further increase in sample area would not add a considerable number of new crop species. About $90 \%$ (i.e. 187 spp.) of the total crop species number were already reached with 30 gardens covering an area of 3.45 ha.

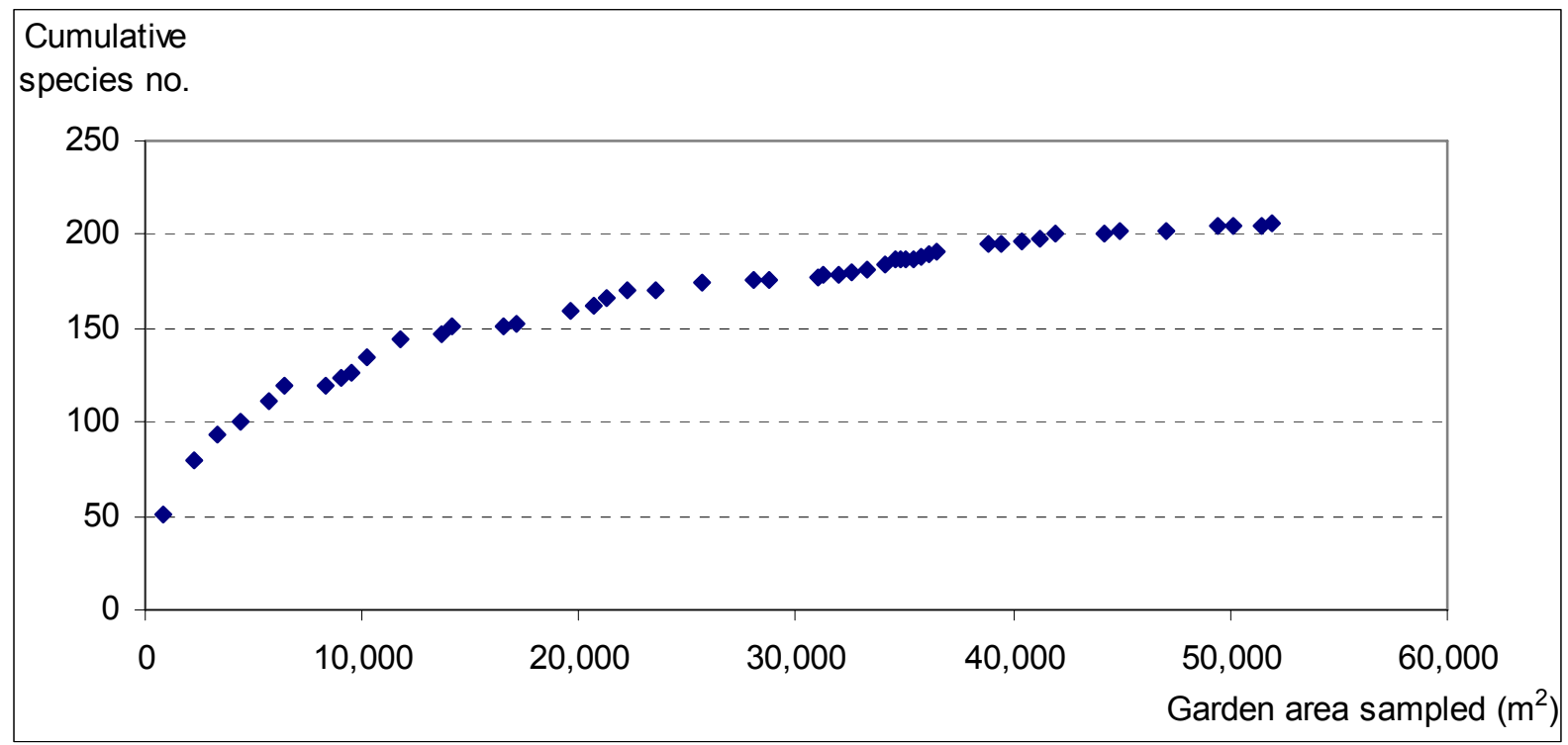

Figure 3.9. Species-area curve for 206 crop species cultivated in 48 homegardens of five villages in the Napu valley, Central Sulawesi, 2004. Total garden area sampled was 51,972 $\mathrm{m}^{2}$, homegardens were ordered randomly. $N=10$ per village, apart from Rompo, where $N=8$.

According to their predominant use, about $20 \%$ of the 206 crop species were classified each as vegetables or medicinal plants, and about $15 \%$ each as fuel wood/timber plants, fruits, or 
spices (Table 3.6). Less than 5\% were grown each for their sweet and stimulant properties, as staple food, as multiple-purpose-trees (MPT) or for other utilization such as wrapping, fodder, handicraft, or toys. However, for most of the crop species not only one single utilization was given by the gardener, but two, three or even more (see Appendix 12). All fruit trees, for example, were said to yield good fuel wood beside fruits; some were used additionally as medicinal plants. Also for many spices, gardeners mentioned an additional medicinal value. Most of the staple food crops were predominantly used for feeding pigs, although gardeners still mentioned their value for human nutrition and as famine food. Among villages, the highest number of crop species was cultivated in Rompo, followed by Wuasa and Wanga (Table 3.6). Homegardens in the migrant villages harboured less crop species, mainly due to smaller numbers of medicinal and fuel wood/timber plants.

Table 3.6. Crop species numbers in total, per village, and per functional group of 48 homegardens in five villages of the Napu valley, Central Sulawesi, 2004. $N=10$ per village, apart from Rompo, where $N=8$.

\begin{tabular}{lcccccc}
\hline & All villages & Wuasa & Rompo & Wanga & Siliwanga & Tamadue \\
\hline Species total & 206 & 117 & 124 & 105 & 98 & 99 \\
Fruits & 30 & 24 & 21 & 22 & 19 & 19 \\
Vegetables & 40 & 17 & 24 & 18 & 20 & 19 \\
Stimulants/sweets & 10 & 7 & 9 & 5 & 6 & 7 \\
Spices & 28 & 20 & 16 & 18 & 15 & 19 \\
Medicinals & 39 & 24 & 21 & 17 & 12 & 10 \\
Staple foods & 10 & 6 & 6 & 7 & 7 & 7 \\
Fuel wood/timber & 34 & 14 & 20 & 14 & 6 & 9 \\
MPT & 8 & 2 & 4 & 2 & 8 & 4 \\
Other & 7 & 3 & 3 & 2 & 5 & 5 \\
\hline
\end{tabular}

Five crop species were grown in more than $90 \%$ of the homegardens studied, i.e. cacao, arabica coffee, the shade tree Gliricidia sepium, the fruit tree guava, and the spice chilli (for scientific names see Appendix 12). Additionally, the staple food crops tannia and cassava as well as the fruits banana and mango were cultivated in more than $80 \%$ of the homegardens. In summary, only 29 crop species were grown rather frequently, occurring in at least $50 \%$ of the gardens. On the other hand, 86 crop species were found only very rarely, being cultivated in less than $5 \%$ of the homegardens.

Concerning their abundance, many of the crop species found in homegardens were represented only by very few individuals, whereas the majority of the individuals belonged to only few crop species. In more detail, 30 species were represented by only one single individual each, nearly half of the species were represented by less than ten individuals each (Figure 3.10). On the other hand, only seven very abundant species (i.e. 3.4\% of total species) contained more than $50 \%$ of all individuals, as these species were represented by more than 1,000 individuals each. Therefore, the community structure pattern followed a logarithmic distribution model. 


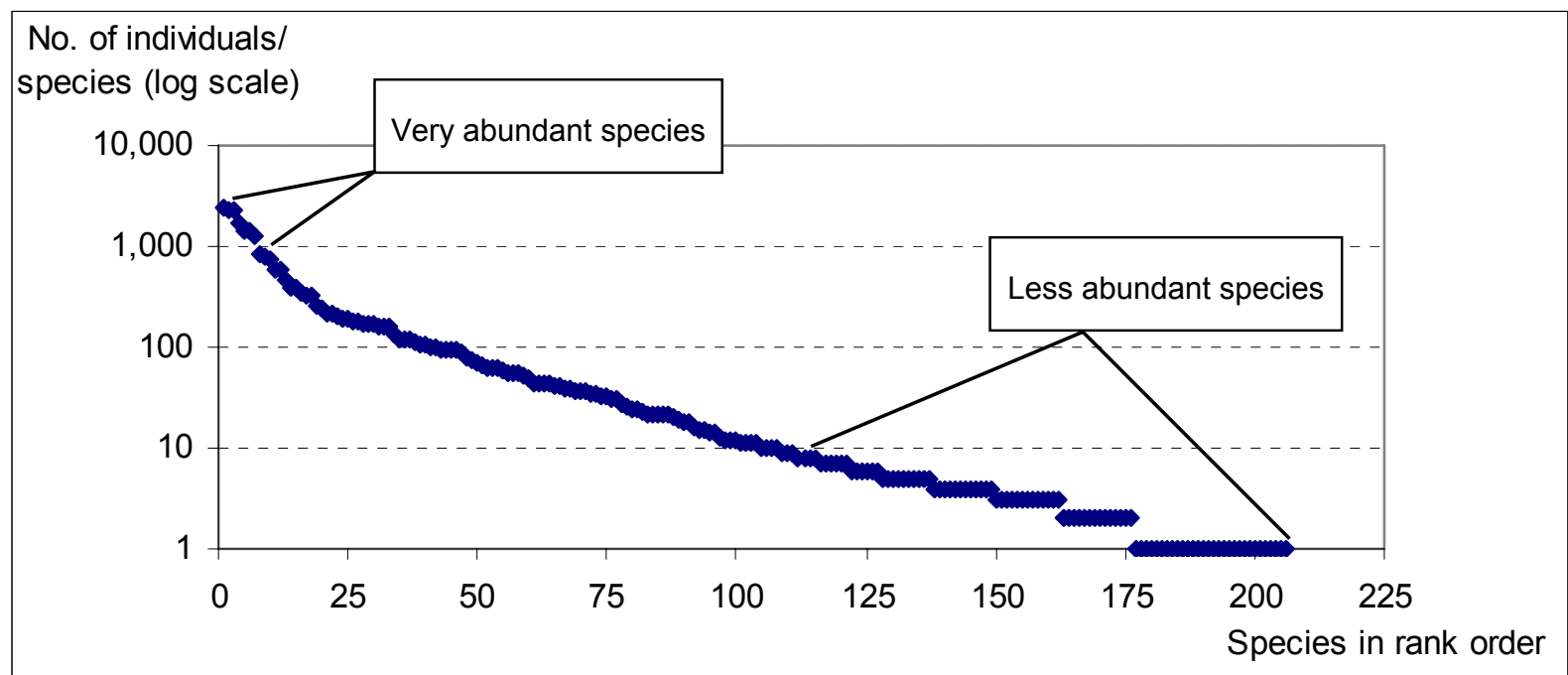

Figure 3.10. Abundance of 206 crop species cultivated in 48 homegardens of five villages in the Napu valley, Central Sulawesi, 2004. $N=10$ per village, apart from Rompo, where $N=8$.

The analysis of the species distribution pattern per village revealed clear differences between portions of less abundant and very abundant species (Table 3.7). The portion of less abundant species (i.e. species represented each by less than $0.1 \%$ of the total individuals) was rather low in Wanga as compared to the other four villages. On the other hand, the portion of very abundant species (i.e. species represented each by more than $5 \%$ of the total individuals) was relatively low in Wuasa. In addition, the portion of individuals included in the two most abundant species differed among villages. In Tamadue and Wuasa, homegardens were characterised by a high share of individuals belonging to only two most dominant species (cash crops cacao and arabica coffee or groundnut and spring onion, respectively).

Table 3.7. Total homegarden area sampled per village, total species and individual number, as well as selected community structure parameter of crop species cultivated in homegardens of five villages in the Napu valley, Central Sulawesi, 2004. $N=10$ per village, apart from Rompo, where $N=8$.

\begin{tabular}{lrrrrr}
\hline & Wuasa & Rompo & Wanga & Siliwanga & Tamadue \\
\hline Total garden area sampled $\left(\mathrm{m}^{2}\right)$ & 7,009 & 6,186 & 7,395 & 12,138 & 19,244 \\
Total species (no.) & 117 & 124 & 105 & 98 & 99 \\
Total individuals (no.) & 8,196 & 4,171 & 3,086 & 5,328 & 4,612 \\
Less abundant species $^{\dagger}(\%)$ & 43.6 & 46.8 & 27.6 & 38.8 & 46.5 \\
$\begin{array}{l}\text { Very abundant species } \\
\text { Individuals represented by the two }\end{array}$ & 2.6 & 4.0 & 4.8 & 5.1 & 5.1 \\
$\quad$ most abundant species (\%) & 38.0 & 24.2 & 19.1 & 28.1 & 41.6 \\
\hline
\end{tabular}

${ }^{\dagger}$ Species represented each by less than $0.1 \%$ of total individuals.

$\star$ Species represented each by more than $5 \%$ of total individuals.

${ }^{\S}$ Different according to village.

When varieties or landraces were included into the analysis as additional units, crop diversity in the 50 homegardens surveyed in 2003 was as high as 329 species and/or varieties/landraces. The highest varietal diversity was found in the use category 'fruit species', where more than $50 \%$ of the species were represented by more than only one variety/landrace (Figure 3.12, for detailed data see Appendix 12). Following the gardeners, 
banana and mango had the highest varietal diversity with 28 and 11 varieties/landraces, respectively (for bananas see Figure 3.11). However, sometimes the same variety/landrace might have been named differently by the gardeners due to their different ethnic background and native languages, thus, causing a certain double counting.

A high varietal diversity was also found in the use categories 'stimulant species' and 'staple crops', where 40 and $50 \%$ of the species were represented by more than one variety/landrace, respectively (Figure 3.12). Cacao with seven and cassava with four different varieties/landraces showed the highest varietal diversity in these two use categories. In the categories 'vegetables' and 'spices', about $25 \%$ and $15 \%$ of the species had more than one variety/landrace, respectively, with common eggplant (8) and chilli (10) having the highest numbers of varieties/landraces. In the categories 'medicine', 'wood', 'MPT', and 'other', no or only few species (two medicinal plants) were said to be represented by more than one variety/landrace (Figure 3.12).
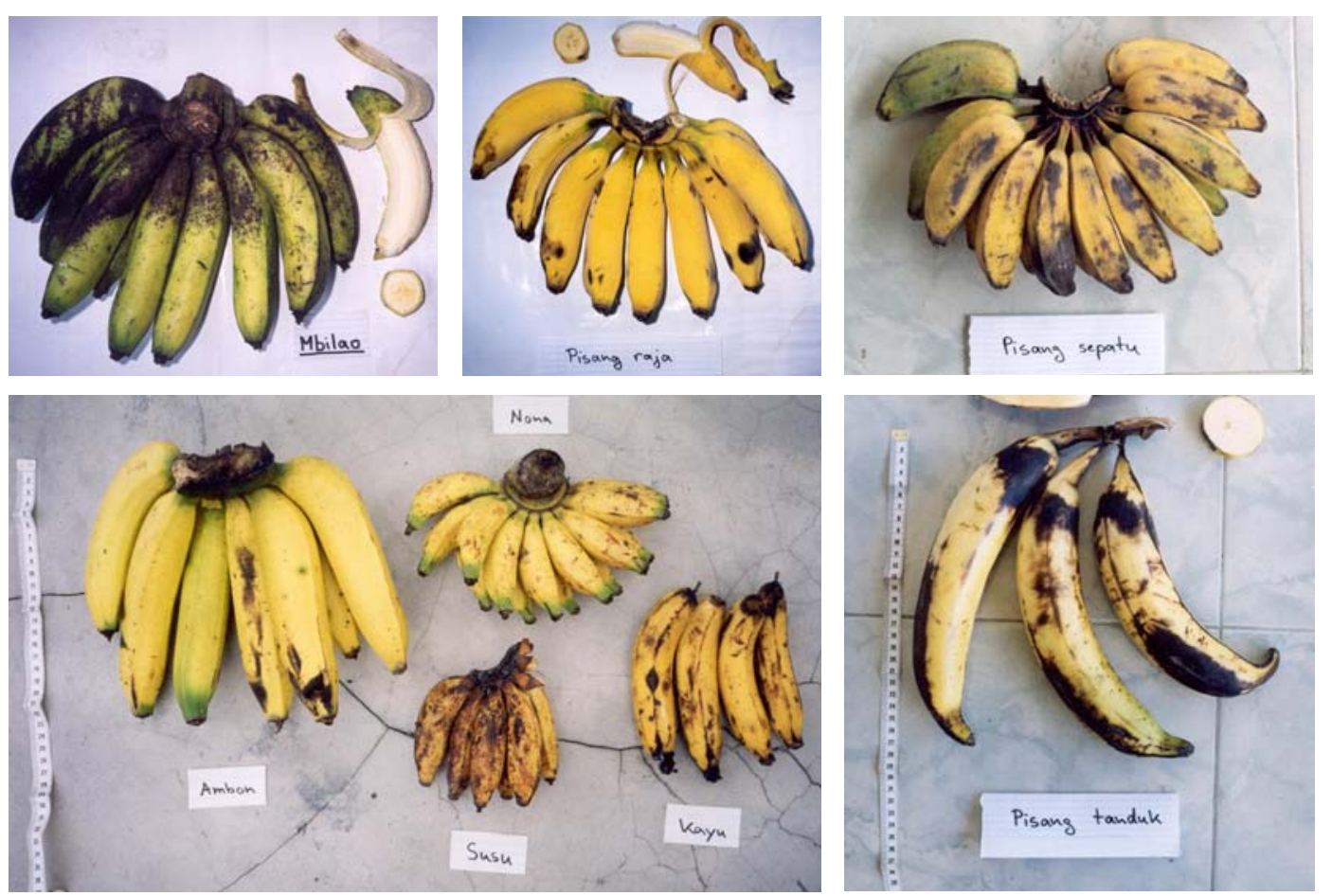

Figure 3.11. Some of the banana varieties cultivated in homegardens of the Napu valley, Central Sulawesi. The scale of the photos is similar.

For some of the crop species, the spectrum of cultivated varieties differed substantially among villages. For example, only one of the 28 banana varieties/landraces was cultivated in all five villages. On the other hand, 2-4 different banana varieties/landraces were planted exclusively in every village, except Tamadue. Similarly, only two out of 11 mango and two out of seven cacao varieties/landraces were grown in all five villages. In the local villages (particularly in Wuasa), a higher varietal diversity of some crop species was found as compared to the migrant villages Siliwanga and Tamadue. In Wuasa and Rompo, 6-7 different varieties/ landraces of common eggplant were grown, whereas in the migrant villages only 1-2. For avocado, pummelo, and squash, three varieties/landraces were cultivated in the local, but only 
one in the migrant villages each. On the other hand, varietal diversity of durian, malay apple, and rambutan was higher in the migrant (particularly Tamadue) than in the local villages.

Names of the varieties/landraces as given by the gardeners mostly reflected the morphological appearance of a particular variety/landrace. Very often, the colours of seeds, fruits, or stems and leaves were used for naming, e.g. varieties/landraces 'white', 'red' and 'green' for yard long beans (following their seed colours). Shape or size of the fruits were commonly used also for naming, e.g. for banana varieties/landraces 'horn', 'sickle', 'candle', and 'shoe'. Fruit taste was sometimes used as a variety name also, e.g. 'sweet' and 'sour', or variety/landrace 'milk' for both avocado and banana. Gardeners mentioned only 18 crop species with modern varieties, mostly fruit and cash crop species, e.g. durian, mandarin, coconut, pineapple, rambutan, jackfruit, cacao, spring onion, and tomato. Modern varieties were often named 'hybrid', 'agriculture', or after the region, where the variety was said to have originated, e.g. 'Ambon', 'Bogor', 'Jember', 'the South'.

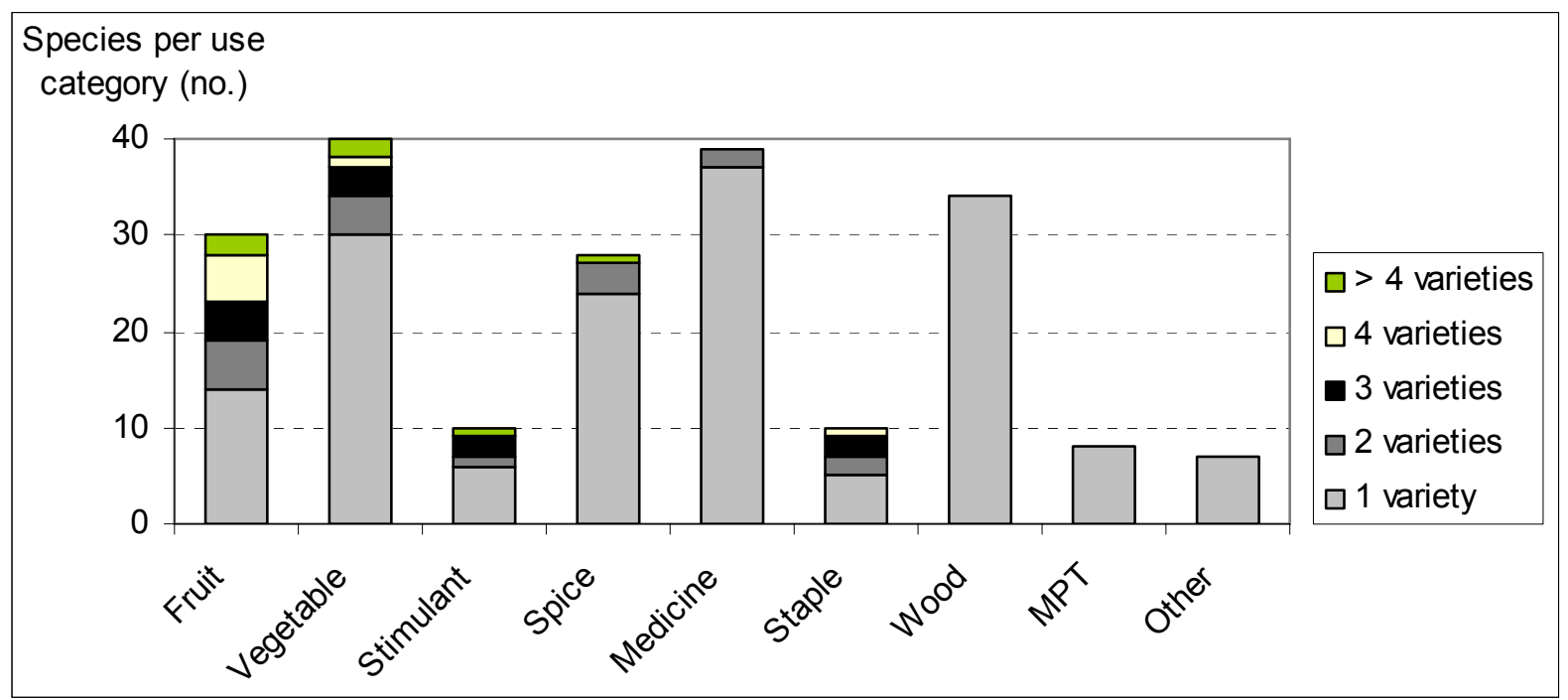

Figure 3.12. Number of varieties/landraces per crop species in different use categories. Results of inventories of 50 homegardens and of interviews of 50 gardeners in five villages of the Napu valley, Central Sulawesi, 2003.

The mean number of crop species per garden differed markedly among villages, although values varied strongly (13-68 species per garden). Homegardens in Wuasa harboured significantly more crop species than in Tamadue (Table 3.8), mainly due to differences in the mean number of vegetables, spices, and medicinal plants (Figure 3.13). In contrast, the number of fruit species, stimulants, staple food crops, and species for other uses did not differ among the villages.

Not only the mean number of crops per use category may characterise homegardens and differentiate villages, but also the number of cultivated individuals per species and frequency of occurrence per village. Calculation of the summed dominance ratio (SDR) that included both number of individuals and frequency of cultivation resulted in marked differences for some of the use categories among villages (Figure 3.14). Similarly to the mean number of fruit species (Figure 3.13), also SDR of fruit species did not differ among villages. In Rompo, the rather high mean number of vegetable species was reflected by a just as high SDR. 
Although mean numbers of stimulant species were similar among villages, the SDR of stimulants was markedly higher in Tamadue than in the other villages. For Wuasa, the high importance of both spices and medicinal plants (Figure 3.13) was supported by the SDR. Staple crops were rather similar in mean species number among villages, but the SDR indicated their high dominance in Siliwanga. Higher mean numbers of wood species, but lower numbers of MPT species in the local villages Wuasa, Rompo, and Wanga as compared to Siliwanga and Tamadue were similarly reflected by the respective SDR values.

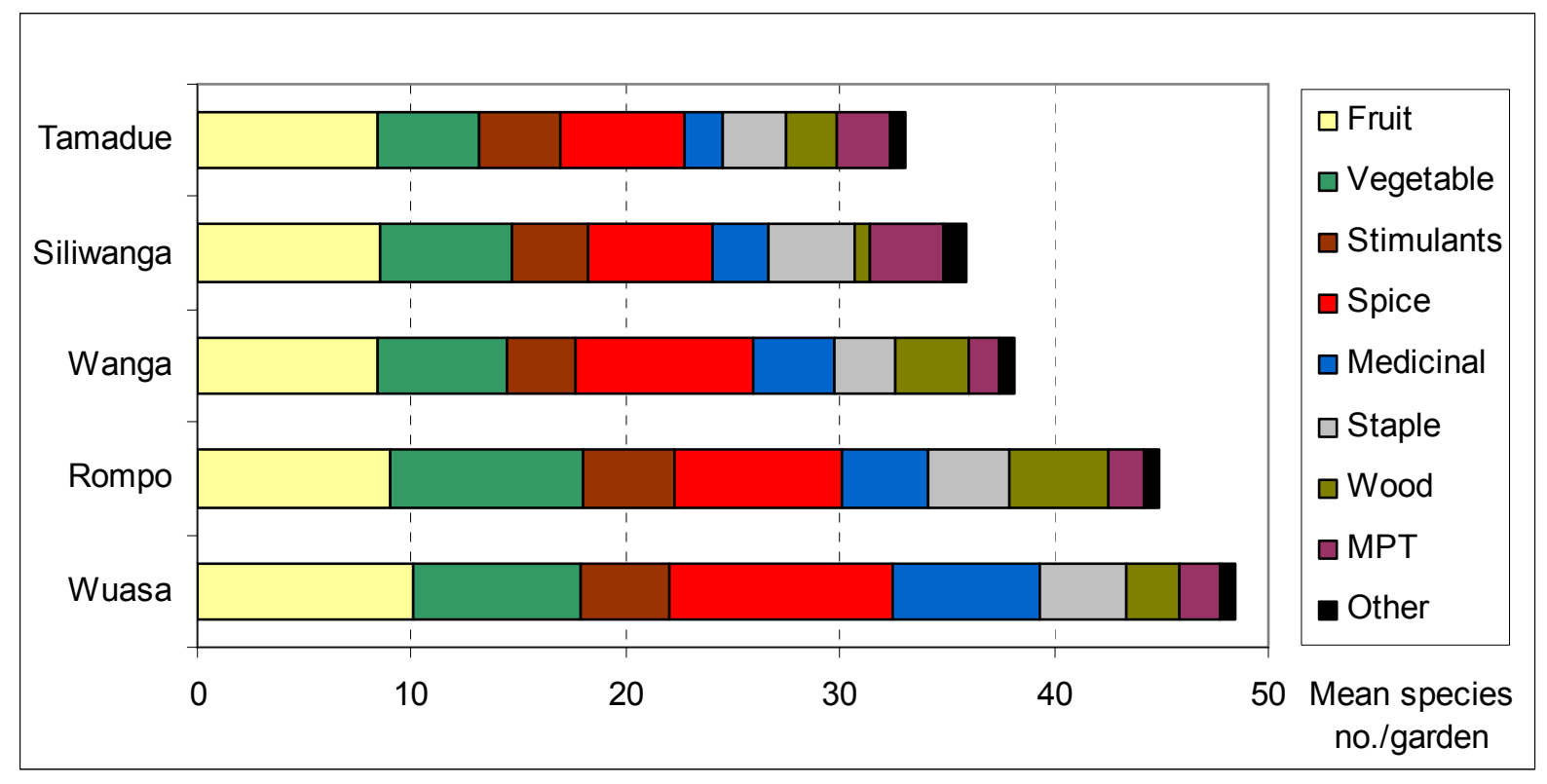

Figure 3.13. Mean number of crop species in different use categories of 48 homegardens in five villages of the Napu valley, Central Sulawesi, 2004. $N=10$ per village, apart from Rompo, where $N=8$.

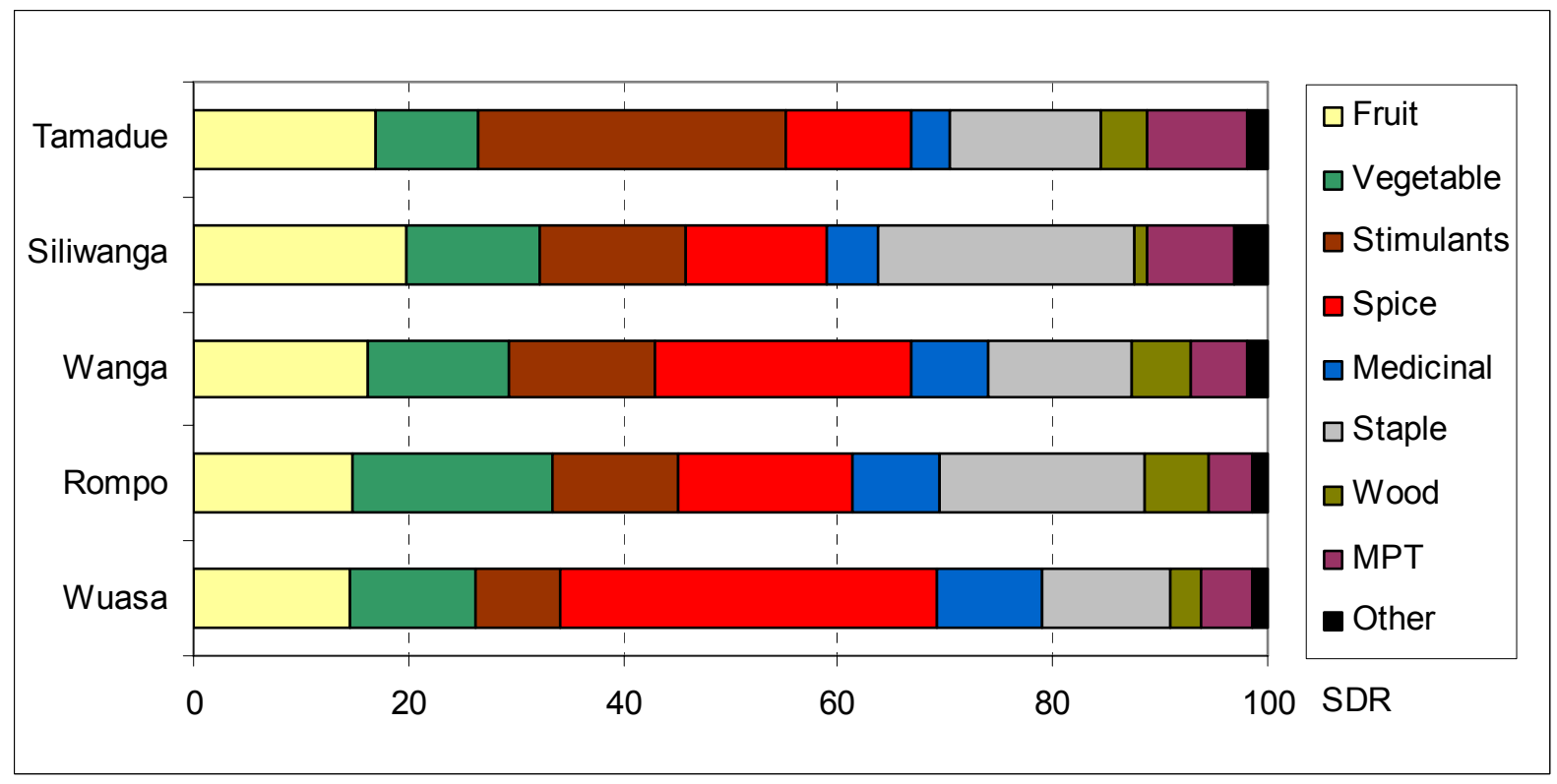

Figure 3.14. Summed dominance ratio (SDR) of crop species in different use categories of 48 homegardens in five villages of the Napu valley, Central Sulawesi, 2004. $N=10$ per village, apart from Rompo, where $N=8$. 
As homegarden size and density of crop individuals might influence the number of crop species per garden, Margalef index as well as crop species density per $1000 \mathrm{~m}^{2}$ garden area were calculated additionally to compare the homegardens. However, Margalef index values followed the same pattern as crop species number (Table 3.8), being highest in Wuasa and lowest in Tamadue. To calculate species density, garden sizes (ln-transformed) were plotted against crop species numbers and a regression was calculated (see 2.9.2). When all homegardens studied were included in the calculation, there was no significant influence of homegarden size on crop species number $\left(\mathrm{R}^{2}=0.028\right)$. However, Figure 3.15 highlights marked differences between gardens managed by local or migrant gardeners. The latter harboured less crop species than those of locals. Concerning the homegardens with comparable sizes ('overlapping area' in Figure 3.15), these differences were even significant (T-test, $\mathrm{P} \leq 0.001$ ). Crop species number was influenced by garden size only in homegardens managed by locals, but not in those managed by migrants. As a consequence, regression analysis was only carried out for homegardens managed by local gardeners, including almost all gardeners in the local villages Wuasa, Rompo, and Wanga (except garden no. 50) as well as two gardeners living in Siliwanga, but originating from Sulawesi (gardens no. 22 and 25). Thus, species density based on residuals of regression analysis could only be calculated for the villages Wuasa, Rompo, Wanga, and the two gardens of Siliwanga. However, means did not differ among the villages (Table 3.8).

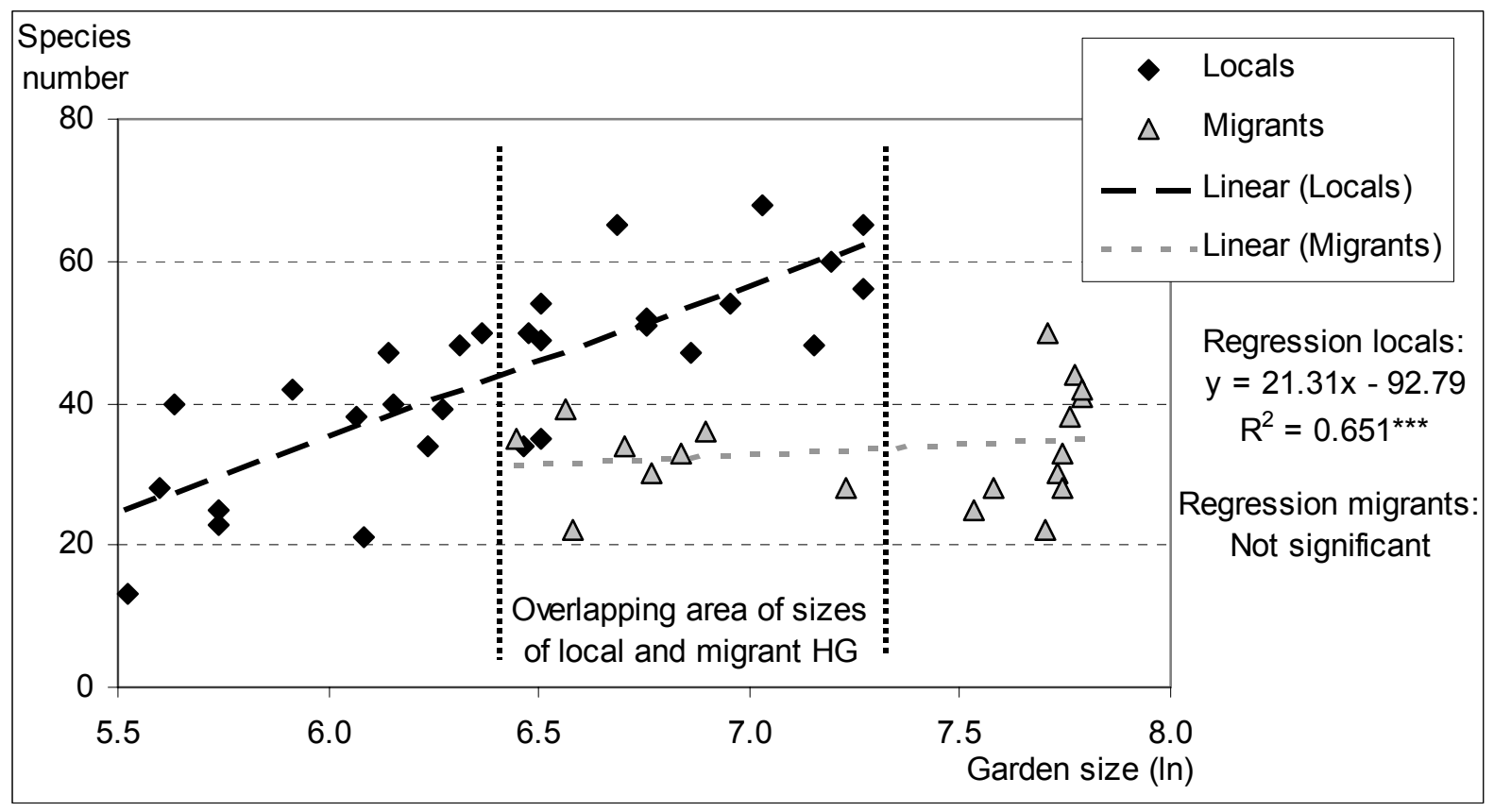

Figure 3.15. Relations between garden size and crop species number in homegardens managed by local $(N=29)$ and migrant $(N=19)$ gardeners studied in five villages of the Napu valley, Central Sulawesi, 2004. $N=10$ per village, apart from Rompo, where $N=8$. Broken lines indicate trend lines, however, only the regression of the variable 'Locals' is significant. Between the dotted lines, homegardens used for comparison of mean species number in gardens of local and migrant gardeners were grouped together.

To evaluate all villages with homegardens managed by both local and migrant gardeners, species density was additionally calculated following the Arrhenius formula (see 2.9.2), 
results of which are presented in the following chapters, when species density is concerned. Again, no differences were found among the local villages. However, existing differences were confirmed regarding local and migrant villages, as already revealed concerning species number and Margalef index (Table 3.8).

Table 3.8. Mean crop species numbers per homegarden, mean Margalef index, and mean crop species density per $1000 \mathrm{~m}^{2}$ calculated by regression residuals method $(R)^{\dagger}$ and by the Arrhenius formula (A) (ranges in brackets) of 48 homegardens in five villages of the Napu valley, Central Sulawesi, 2004. $N=10$ per village, apart from Rompo, where $N=8$.

\begin{tabular}{|c|c|c|c|c|}
\hline & $\begin{array}{c}\text { Mean crop species } \\
\text { number }\end{array}$ & $\begin{array}{l}\text { Mean Margalef } \\
\text { index }\end{array}$ & $\begin{array}{c}\text { Mean crop species } \\
\text { density } / 1000 \mathrm{~m}^{2}(\mathrm{R})^{\dagger}\end{array}$ & $\begin{array}{l}\text { Mean crop species } \\
\text { density } / 1000 \mathrm{~m}^{2}(\mathrm{~A})\end{array}$ \\
\hline Wuasa & $(23-68)$ & $7.5 \mathrm{a} \quad(4.9-10.2)$ & $59.3 \mathrm{a}(41.5-79.8)$ & $(27.7-67.1)$ \\
\hline Rompo & $44.9 \mathrm{ab}(28-65)$ & 7.1ab (4.9-9.8) & $53.8 \mathrm{a}(41.2-68.8)$ & $47.0 \mathrm{ab} \quad(34.5-61.7)$ \\
\hline Wanga & $38.1 \mathrm{ab}(13-56)$ & $6.5 \mathrm{ab}(2.8-9.0)$ & $49.1 \mathrm{a}(28.4-64.0)$ & $40.3 \mathrm{abc}(16.3-57.3)$ \\
\hline Siliwanga & $35.9 \mathrm{a} \quad(22-44)$ & $5.7 \mathrm{ab}(3.7-6.4)$ & $54.4 \mathrm{a}(52.0-56.8)$ & $36.2 \mathrm{bc} \quad(19.7-44.9)$ \\
\hline Tamadue & $33.0 \quad(22-50)$ & $5.4 \mathrm{~b} \quad(4.1-7.1)$ & n.a. & $30.4 \mathrm{c} \quad(22.9-44.8)$ \\
\hline
\end{tabular}

Means in a column followed by different letters are significantly different at $\mathrm{P} \leq 0.05$.

$\dagger$ Calculated only for homegardens managed by local gardeners, $\mathrm{N}=10$ in Wuasa, $\mathrm{N}=8$ in Rompo, $\mathrm{N}=9$ in Wanga, $\mathrm{N}=2$ in Siliwanga.

In summary, homegardens in Wuasa had very high crop species richness and density; they were dominated mainly by spice crops. In the remote village Rompo, homegardens harboured high species richness in a rather balanced mixture of different crop use categories. Mixed cultivation was found also in Wanga, where homegardens had intermediate species richness. Homegardeners in the migrant village Siliwanga focussed more on producing staple crops, their gardens harboured intermediate to low species richness. In Tamadue, where homegardens were dominated by stimulant crops, species richness and density were low.

\section{Ornamentals}

In addition to the 206 crop species, 162 ornamental species were cultivated in the homegardens studied in the 2004-survey. The most frequently grown ornamentals, cultivated in more than $50 \%$ of all homegardens, were african marigolds (Tagetes spp.), bougainvillea (Bougainvillea sp.), garden kroton (Codiaeum variegatum), caladium (Caladium bicolor), and chrysanthemum (Dendranthema x grandiflorum). In the local villages, gardeners frequently also cultivated zinnia (Zinnia elegans) and garden balsamine (Impatiens balsamina), whereas also allamanda (Allamanda cathartica), rose (Rosa sp.), and hibiscus (Hibiscus rosa-sinensis) were grown frequently in the migrant villages. Nearly $50 \%$ of the ornamental species were cultivated only very rarely, i.e. in less than $5 \%$ of the homegardens. Marked differences in diversity of ornamental plants existed among the villages. Both total and median numbers of ornamentals were quite high in Wuasa, but low in Rompo and Siliwanga (Table 3.9). Besides, also the number of common ornamental species (grown in at least $50 \%$ of the homegardens) was rather high in Wuasa as compared to the other villages. 
Table 3.9. Diversity of ornamentals (total number per village, median number per garden, range per village, and number of frequently grown ornamentals per village) of 48 homegardens in five villages of the Napu valley, Central Sulawesi, 2004. $N=10$ per village, apart from Rompo, where $N=8$.

\begin{tabular}{lcccc}
\hline & $\begin{array}{c}\text { Total number of } \\
\text { ornamental species }\end{array}$ & $\begin{array}{c}\text { Median species no. } \\
\text { per garden }\end{array}$ & Range & $\begin{array}{c}\text { No. of common } \\
\text { ornamental species }^{\dagger}\end{array}$ \\
\hline Wuasa & 115 & $25.5 \mathrm{a}$ & $11-60$ & 20 \\
Rompo & 48 & $11.5 \mathrm{~b}$ & $1-19$ & 6 \\
Wanga & 79 & $14.5 \mathrm{ab}$ & $2-33$ & 8 \\
Siliwanga & 61 & $12.0 \mathrm{~b}$ & $4-22$ & 7 \\
Tamadue & 68 & $18.5 \mathrm{ab}$ & $9-27$ & 11 \\
\hline
\end{tabular}

Medians are given because variables were not normally distributed.

Medians in a column followed by different letters are significantly different at $\mathrm{P} \leq 0.05$.

$\dagger$ Species cultivated in more than $50 \%$ of the homegardens in the particular village.

\section{Weeds}

Besides 206 crop and 162 ornamental species, 57 weed species were found in the homegardens. The weed species belonged to 22 plant families, however, 19 of the species were grasses (for the complete list with scientific names and potential uses see Appendix 14). Despite their denomination as weeds, gardeners mentioned several potential uses for most of these species, e.g. $60 \%$ of them were said to have some medicinal value, $40 \%$ were used as fodder, and about $20 \%$ for handicraft. For only $15 \%$ of the weed species, no gardener mentioned any utility. However, knowledge about weeds and their uses differed markedly among villages. Both the number of named and used weed species were significantly higher in the local villages Wuasa, Rompo, and Wanga than in the migrant villages (Table 3.10), where many gardeners did not know a single weed name or any utilisation. Knowledge about weed names and their uses was positively correlated with the age of the interviewed gardener $(\mathrm{r}=0.5$ for names $(\mathrm{P}<0.001) ; \mathrm{r}=0.4$ for uses $(\mathrm{P}=0.006))$. Most of the gardeners who were able to name at least 20 different weed species, were about 60 years old.

Table 3.10. Knowledge of weed species and their use (median numbers of named and used weed species, given by the gardeners, ranges in brackets) of 49 gardeners interviewed in five villages of the Napu valley, Central Sulawesi, 2004. $N=10$ per village, apart from Rompo, where $N=9$.

\begin{tabular}{lcccc}
\hline & \multicolumn{2}{c}{ No. of named weed species } & \multicolumn{2}{c}{ No. of used weed species } \\
\hline Wuasa & $15.0 \mathrm{a}$ & $(6-27)$ & $8.0 \mathrm{a}$ & $(2-15)$ \\
Rompo & $12.0 \mathrm{a}$ & $(3-29)$ & $6.0 \mathrm{a}$ & $(3-27)$ \\
Wanga & $9.0 \mathrm{ab}$ & $(4-19)$ & $5.5 \mathrm{a}$ & $(2-14)$ \\
Siliwanga & $2.5 \mathrm{bc}$ & $(0-4)$ & $2.0 \mathrm{ab}$ & $(2-4)$ \\
Tamadue & $2.0 \mathrm{c}$ & $(0-3)$ & $0.0 \mathrm{~b}$ & $(0-3)$ \\
\hline
\end{tabular}

Medians are given because variables were not normally distributed.

Medians in a column followed by different letters are significantly different at $\mathrm{P} \leq 0.05$.

\subsubsection{Vegetation structure}

For vertical structure analysis, vegetation of homegardens was assigned to five strata. In the first stratum $(<1 \mathrm{~m})$, mostly annual spices and vegetables or tuber crops such as spring onion, chilli, tomato, sweet potato, or taro were found. Species reaching the second layer $(1-2 \mathrm{~m})$ were both larger annual and perennial, bushy plants, e.g. tobacco, cotton, or cassava. In the third stratum (2-5 m), mostly woody perennials such as cacao, coffee, and mandarin, but also the non-woody banana and some climbers, e.g. chayote, passion fruit, and vanilla, occurred. 
The fourth stratum $(5-10 \mathrm{~m})$ was reached only by larger trees such as guava, pummelo, durian, or pine. Only few plants, e.g. bamboo or coconut, grew higher than $10 \mathrm{~m}$ and formed the fifth layer (see Figure 3.16).

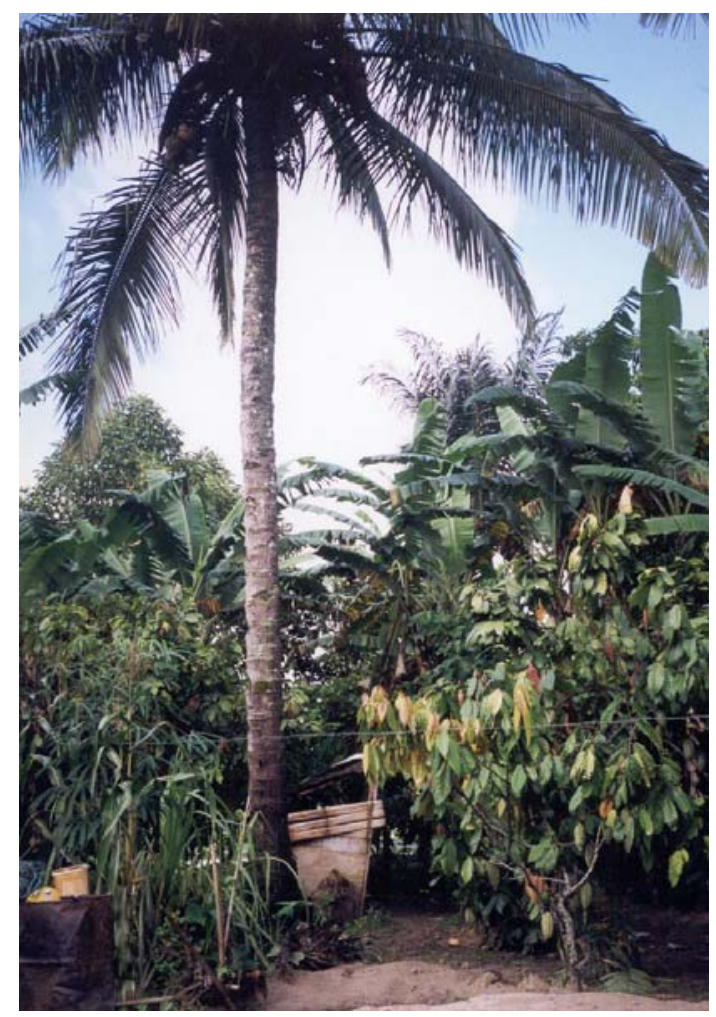

Figure 3.16. Example for a typical multi-layered vegetation structure in homegarden no. 10 in Wuasa, Napu valley, Central Sulawesi, 2004.

Figure 3.17 indicates marked differences of the vegetation structure among local and migrant homegardens. In homegardens of the local villages Wuasa, Rompo, and Wanga, crop species number decreased continuously from the lower to the higher strata. However, in the migrant villages (particularly in Tamadue), also most species occurred in the first stratum, but the second most important stratum was the third, dominated by the cash crops coffee and cacao and shade trees. Only small proportions of crop species were found in the fourth and fifth layers in all villages, particularly in Siliwanga.

Similar differences were revealed when analysing the proportions of crop individuals per stratum. In the local villages, the proportions of individuals decreased continuously from lower to higher strata (i.e. 55-70\% of individuals occurred in the first, $20-32 \%$ in the second, and $9-13 \%$ in the third layer). Concerning the migrant villages, homegardens in Siliwanga followed the same pattern as the local homegardens, whereas in Tamadue, the highest proportion of individuals was found in the second layer (36\%), followed by the third and the first layers (32 and 30\%, respectively). Proportions of individuals in the fourth and fifth layers were rather small (i.e. $0.5-2.0$ and $0-0.3 \%$, respectively) in all villages, particularly in Siliwanga. 


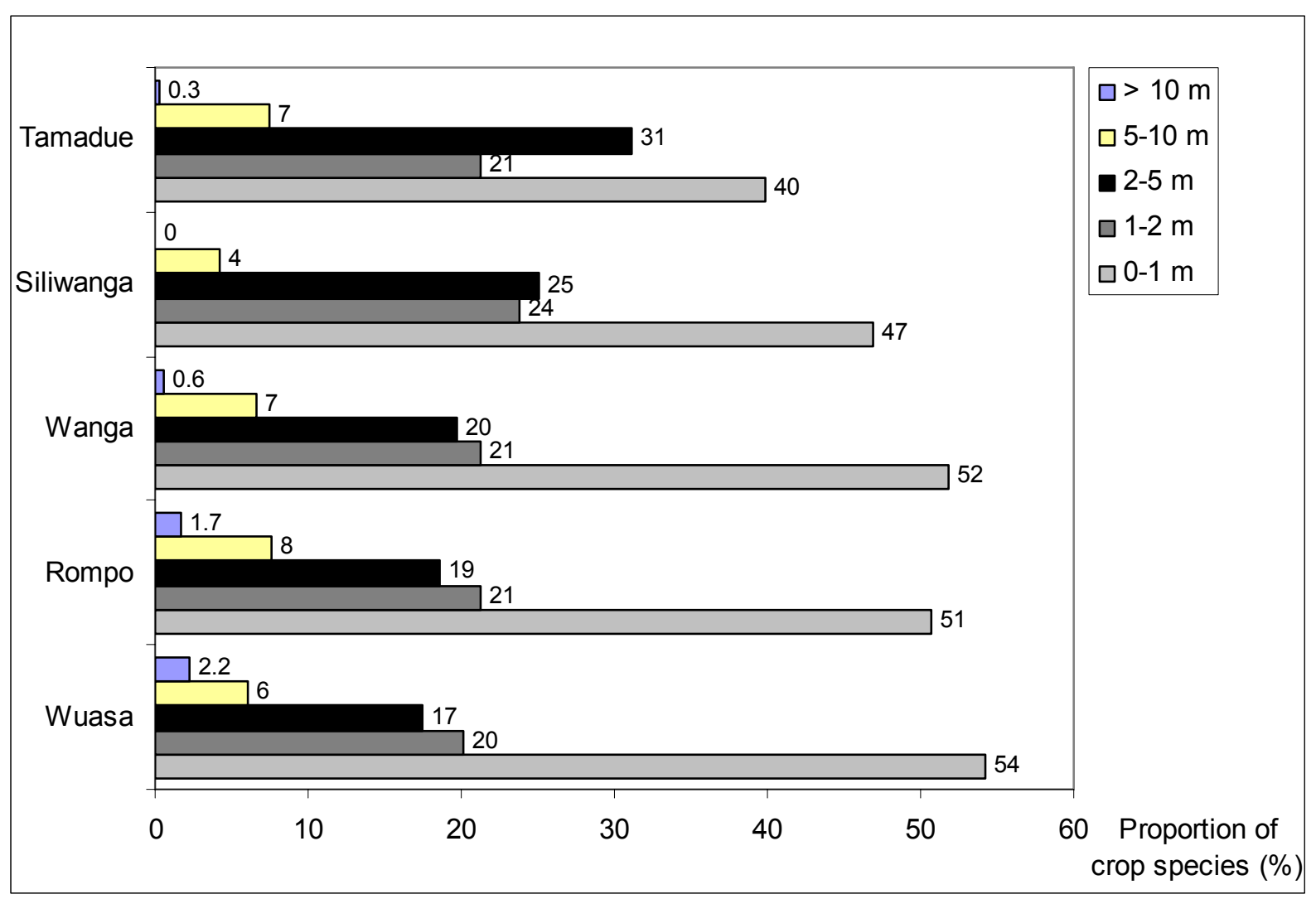

Figure 3.17. Mean proportion of crop species occurring in different strata of 48 homegardens in five villages of the Napu valley, Central Sulawesi, 2004. $N=10$ per village, apart from Rompo, where $N=8$.

\subsubsection{Crop diversity indices based on heterogeneity and equitability}

Median crop species diversity and evenness showed high variation (Table 3.11, for detailed data see Appendix 16). Shannon diversity and evenness indices were high in the local, but low in the migrant villages, particularly in Tamadue with its cacao- and coffee-dominated homegardens. Simpson's index was fairly low in the local and slightly higher in the migrant villages, also indicating a higher diversity in the local villages (note: Simpson's index describes the probability that two individual plants picked from one plot belonged to the same species. This probability was only $8-9 \%$ in the local, but $12-18 \%$ in the migrant villages). The same tendency was shown by Hill's $\mathrm{N}_{2}$. Diversity was high in the local villages with a number of about 12 very abundant species as compared to only about 6-8 in the migrant villages. Differences among all diversity indices (apart from Shannon evenness) were significant only between Rompo and the migrant village Tamadue.

Table 3.11. Median diversity and evenness indices (ranges in brackets) of 48 homegardens in five villages of the Napu valley, Central Sulawesi, 2004. $N=10$ per village, apart from Rompo, where $N=8$.

\begin{tabular}{|c|c|c|c|c|}
\hline & Shannon index H' & Shannon evenness & Simpson's index $\lambda$ & Hill's $\mathrm{N}_{2}$ \\
\hline Wuasa & 3.0ab (1.5-3.5) & $(0.37-0.88)$ & $0.09 \mathrm{ab}(0.04-0.50)$ & $11.0 \mathrm{ab}(2.0-23.8)$ \\
\hline Rompo & $(2.4-3.3)$ & $0.80 \mathrm{a} \quad(0.6$ & $0.09 \mathrm{~b} \quad(0.05-0.17)$ & $(6.0-18.9)$ \\
\hline $\mathrm{Wa}$ & $3.1 \mathrm{ab}(1.5-3.3)$ & $0.81 \mathrm{a} \quad(0$. & $0.08 \mathrm{ab}(0 . \mathrm{c}$ & $12.9 \mathrm{ab}(2.1-18.9)$ \\
\hline anga & $2.6 \mathrm{ab}(2.3-3.0)$ & $0.74 \mathrm{a}$ & $0.12 \mathrm{ab}(0 . \mathrm{c}$ & 8.2ab (5.7-15.4) \\
\hline Tamadue & $2.3 b \quad(2.1-2.9)$ & $0.66 \mathrm{a} \quad(0.58-0.83)$ & $0.18 \mathrm{a} \quad(0.08-0.23)$ & $5.6 \mathrm{~b} \quad(4.3-12.0)$ \\
\hline
\end{tabular}

Medians are given because variables were not normally distributed.

Medians in a column followed by different letters are significantly different at $\mathrm{P} \leq 0.05$. 


\subsubsection{Similarities and classification}

For comparison among villages, Sørensen's coefficient and Renkonen index were calculated based on crop species occurance at village-level. For both indices, Table 3.12 indicates markedly higher similarity among the three local villages Wuasa, Rompo, and Wanga, (numbers in bold) than among these and the migrant villages, or between these latter two.

Table 3.12. Sørensen's coefficient and Renkonen index of crop species composition and abundance of 48 homegardens at village-level in five villages of the Napu valley, Central Sulawesi, 2004. N=10 per village, apart from Rompo, where $N=8$. Comparisons among local villages are bolded.

\begin{tabular}{lllllllll}
\hline & \multicolumn{3}{l}{ Sørensen's coefficient $\mathrm{S}_{\mathrm{S}}$} & \multicolumn{6}{c}{ Renkonen index $\mathrm{P}_{\mathrm{S}}$} \\
& Wuasa & Rompo & Wanga & Siliwanga & Wuasa & Rompo & Wanga & Siliwanga \\
\hline Rompo & $\mathbf{0 . 7 3}$ & - & & & $\mathbf{7 0 . 9}$ & - & & \\
Wanga & $\mathbf{0 . 7 6}$ & $\mathbf{0 . 7 2}$ & - & & $\mathbf{7 0 . 4}$ & $\mathbf{6 7 . 8}$ & - & \\
Siliwanga & 0.61 & 0.58 & 0.62 & - & 59.4 & 58.8 & 61.6 & - \\
Tamadue & 0.61 & 0.60 & 0.63 & 0.64 & 59.0 & 60.3 & 58.8 & 61.5 \\
\hline
\end{tabular}

In general, the same tendency was found in similarities of the different functional crop species groups. Similarities among local villages were higher than when comparing these and the migrant villages or between the two migrant villages, apart from the group 'sweets and stimulants', where highest similarity existed among the migrant villages. However, the values of similarity indices differed markedly among functional groups. 'Sweets and stimulants' as well as 'staple food crops' showed the highest values for similarity among villages (range $\mathrm{S}_{\mathrm{S}}$ : $0.71-0.92$ and $0.57-1.00$; range $P_{S}: 74.7-90.2 \%$ and $65.2-88.9 \%$, respectively), due to small species numbers in these two functional groups and their high cultivation frequency. The use category 'fruits' also showed rather high similarity (range $\mathrm{S}_{\mathrm{S}}$ : 0.73-0.88; $\mathrm{P}_{\mathrm{S}}$ : 66.9-82.8\%), followed by 'spices' (range $\mathrm{S}_{\mathrm{S}}$ : $0.71-0.88$; $\mathrm{P}_{\mathrm{S}}$ : 58.4-81.4\%). Lowest similarities among villages were found in the two groups 'medicinal plants' and 'fuel wood and timber plants' (range $\mathrm{S}_{\mathrm{S}}: 0.33-0.64$ and $0.13-0.59 ; \mathrm{P}_{\mathrm{S}}: 27.8-51.0 \%$ and $7.3-44.8 \%$, respectively). In the groups of vegetables and plants for multi-purpose-use or other uses, similarities were intermediate.

Table 3.13 shows mean similarities of crop species composition and abundance, calculated on the basis of similarity indices of single homegardens. As compared to Table 3.12, mean similarities among the local villages were rather low. Among local and migrant villages, similarities were slightly lower than among local villages only. Within a village, mostly crop species composition of homegardens was more similar than among the villages. Particularly homegardens in the migrant villages Siliwanga and Tamadue shared many crop species. Homegardens in Tamadue, however, shared only few crops with homegardens of the other four villages. 
Table 3.13. Mean similarity indices (based on data of single homegardens and calculated both within and among villages) of crop species composition and abundance of 48 homegardens in five villages of the Napu valley, Central Sulawesi, 2004. $N=10$ per village, apart from Rompo, where $N=8$. Comparisons among local villages are bolded.

\begin{tabular}{lllllllllll}
\hline & \multicolumn{3}{c}{ Mean Sørensen's coefficient $\mathrm{S}_{\mathrm{S}}$} & \multicolumn{6}{c}{ Mean Renkonen index $\mathrm{P}_{\mathrm{S}}$} \\
& Wuasa & Rompo & Wanga & Siliw. & Tamad. & Wuasa & Rompo & Wanga & Siliw. & Tamad. \\
\hline Within & 0.54 & 0.47 & 0.49 & 0.56 & 0.53 & 30.0 & 29.0 & 29.2 & 37.4 & 34.2 \\
Rompo & $\mathbf{0 . 5 1}$ & - & & & & $\mathbf{2 9 . 1}$ & - & & & \\
Wanga & $\mathbf{0 . 4 8}$ & $\mathbf{0 . 4 5}$ & - & & & $\mathbf{2 6 . 5}$ & $\mathbf{2 5 . 0}$ & - & & \\
Siliwanga & 0.48 & 0.45 & 0.50 & - & & 24.5 & 28.3 & 28.5 & - & \\
Tamadue & 0.45 & 0.42 & 0.42 & 0.44 & - & 21.5 & 22.0 & 23.4 & 25.3 & - \\
\hline
\end{tabular}

Note: Siliw. $=$ Siliwanga; Tamad. $=$ Tamadue .

Classification was carried out by hierarchical cluster analysis on the basis of transformed crop species abundance data of each single homegarden. The homegardens no. 1, 2, and 9 in Wuasa as well as no. 14 in Rompo were identified as outliers (see Appendix 17) and were excluded from further analysis. Three of these outliers, namely gardens no. 1, 2, and 14, belonged to the most species-rich gardens of the survey (i.e. 60-68 species per garden) and were characterised by special combinations of rare crop species (e.g. up to four 'endemic' species per garden). Homegarden no. 9 was predominated by the cash crop groundnut $(70 \%$ of all individuals belonged to this species). Figure 3.18 presents the results of the cluster analysis of crop species abundance data in the remaining 44 homegardens. A final number of four clusters was chosen according to graphical detection by the 'elbow' criterion (see Appendix 18).

The first principal division into two large groups clearly separated homegardens into migrant and local gardens with only few exceptions (Figure 3.18). In the next major division, resulting in four clusters, the location in a village was partly reflected in cluster patterns. In cluster 1 , almost exclusively homegardens were found of the village Tamadue and in cluster 2 of Siliwanga. In contrast, homegardens of clusters 3 and 4 were mainly located in the local villages Wuasa, Rompo, and Wanga. Results of the cluster analysis, thus, partly reflected those of the similarity analysis (Table 3.12 and Table 3.13). Both analyses showed a high degree of homogeneity of crop species composition of homegardens within each migrant village, resulting in clearly separated clusters 1 and 2. Among migrant and local villages, homegardens were more heterogeneous, only few migrant homegardens were included into clusters 3 or 4 . On the other hand, the separation among the three local villages was rather poor. The relatively high similarity indices among these villages were reflected by the mixtures of homegardens from Wuasa, Rompo, and Wanga in clusters 3 and 4. 


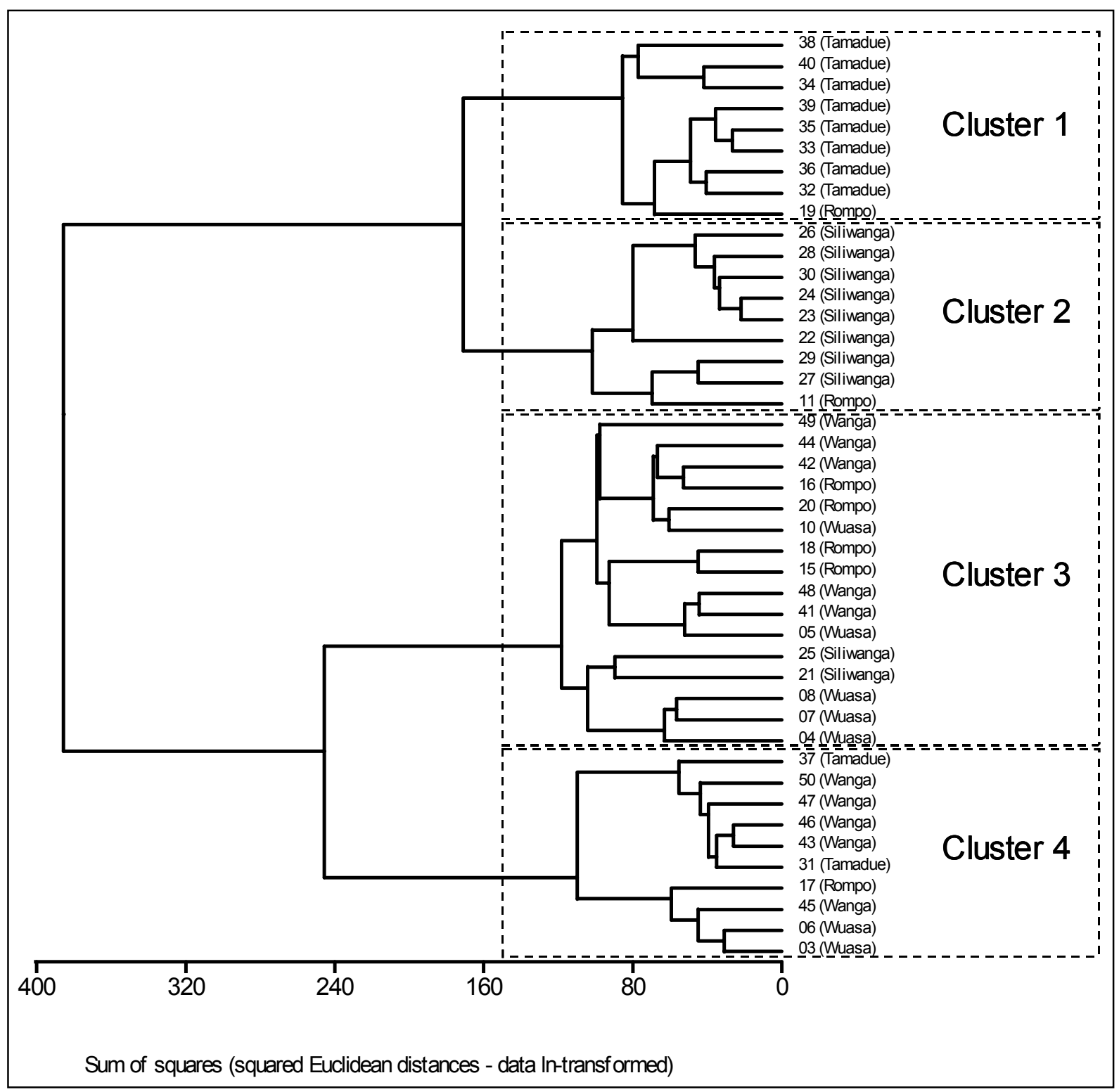

Figure 3.18. Dendrogram as result of hierarchical cluster analysis on the basis of ln-transformed crop species abundance data of 44 homegardens in five villages of the Napu valley, Central Sulawesi, 2004, using Ward's method and squared Euclidian distances. Homegardens no. 1, 2, 9, and 14 were identified as outliers before and were, therefore, excluded from this cluster analysis.

The four clusters identified were tested for significant differences by discriminant analysis that confirmed the correct classification of all 44 homegardens included in the final analysis (see Appendix 19 and Appendix 20). In addition, discriminant analysis revealed the 13 most important crop species responsible for the separation of clusters, i.e. spring onion, napier grass, coconut, tree cassava, cacao, soybean, pineapple, Sauropus androgynus, Glochidion sp., sweet potato, chilli, bitter gourd, and potato (given in order of inclusion by SPSS to stepwise analysis). Homegardens classified in cluster 1 were, thus, characterised by many individuals of coconut, cacao, and sweet potato, but few or no individuals of spring onion, chilli, and pineapple (Table 3.14). Consequently, also homegarden no. 19, located in Rompo, was grouped into this cluster. Differently from nearly all other local homegardens, no single spring onion, chilli, or pineapple plant was cultivated in garden no. 19. Cluster 2 grouped homegardens with many individuals of pineapple, sweet potato, and cacao, but very few 
spring onion plants. Besides, tree cassava was frequently grown in these gardens. Homegarden no. 11, located in Rompo, but grouped into cluster 2, was the only garden managed by locals having tree cassava plants. Homegardens in cluster 3 harboured many spring onions and chilli plants, but only few coconut palms. The two gardens located in Siliwanga, but included in cluster 3 (i.e. gardens no. 21 and 25), were the only ones in Siliwanga with spring onion. Besides, at least part of the household members managing these two gardens originated from Sulawesi. In cluster 4, homegardens with no or only few individuals of pineapple, coconut, cacao, and sweet potato were found. The homegardens no. 31 and 37 located in Tamadue, but included in cluster 4, were the only ones in the village Tamadue having no single coconut palm and only very few (1-4) cacao trees.

Table 3.14. Median number of individuals (ranges in brackets) of selected crop species per homegarden causing separation of clusters among 44 homegardens in five villages of the Napu valley, Central Sulawesi, 2004, selected by discriminant analysis (method: stepwise inclusion of variables).

\begin{tabular}{lcccll}
\hline & Cluster 1 & Cluster 2 & \multicolumn{2}{c}{ Cluster 3 } & \multicolumn{2}{c}{ Cluster 4 } \\
& $\mathrm{N}=9$ & $\mathrm{~N}=9$ & $\mathrm{~N}=16$ & $\mathrm{~N}=10$ \\
\hline Spring onion & $0 \mathrm{~b}(0-7)$ & $0 \mathrm{~b}(0-1)$ & $48 \mathrm{a}$ & $(0-195)$ & $6 \mathrm{ab}(0-50)$ \\
Coconut & $3 \mathrm{a}(1-16)$ & $1 \mathrm{~b}(0-4)$ & $1 \mathrm{ab}(0-6)$ & $0 \mathrm{~b}(0-1)$ \\
Cacao & $105 \mathrm{a}(11-227)$ & $29 \mathrm{a}(4-135)$ & $30 \mathrm{ab}(4-89)$ & $2 \mathrm{~b}(1-34)$ \\
Pineapple & $0 \mathrm{c}-$ & $14 \mathrm{a}(0-118)$ & $4 \mathrm{ab}(0-24)$ & $0 \mathrm{bc}(0-2)$ \\
Sweet potato & $10 \mathrm{a}(0-142)$ & $14 \mathrm{a}(6-90)$ & $2 \mathrm{ab}(0-38)$ & $0 \mathrm{~b}(0-10)$ \\
Chilli & $1 \mathrm{~b}(0-5)$ & $6 \mathrm{a}(2-39)$ & $10 \mathrm{a}$ & $(1-33)$ & $7 \mathrm{ab}(0-26)$ \\
\hline
\end{tabular}

Medians are given because variables were not normally distributed.

Medians in a row followed by different letters are significantly different at $\mathrm{P} \leq 0.05$.

Clusters differed significantly not only in number of individuals of the 6 crop species shown in Table 3.14, but also in median numbers of species and individuals in the different use categories. Cluster 1 tied homegardens with only few vegetable species, but rather high numbers of fruit, stimulant, and staple food species (Table 3.15). In these gardens, stimulants were found in very high individual numbers, particularly cacao and arabica coffee (Figure 3.19). Homegardens of cluster 2 were characterised by low species and individual numbers of spices, but high to very high numbers of fruit as well as staple food crop species and individuals. In cluster 3, homegardens with many species and individuals of vegetables, spices, and medicinal plants were found. Homegardens of cluster 4 harboured only small numbers of species and individuals of fruits, vegetables, medicinal plants, and staple food crops. Additionally, the total number of individuals in homegardens belonging to cluster 4 was significantly lower than in the other clusters. Further differences among clusters existed comparing woody and herbal crop plants. In homegardens of cluster 3, significantly more herbal species and individuals were cultivated than in cluster 4 (median species number 24.0 and 10.5, median individual number 258 and 76, respectively). Woody crop plant species and individuals were found in significantly higher numbers in homegardens of cluster 1 as compared to cluster 4 (median species number 20.0 and 12.5, median individual number 392 and 53, respectively). 
Table 3.15. Median number of crop species per use category (ranges in brackets) of clusters among 44 homegardens in five villages of the Napu valley, Central Sulawesi, 2004.

\begin{tabular}{|c|c|c|c|c|c|}
\hline & $\begin{array}{c}\text { Cluster } 1 \\
\mathrm{~N}=9\end{array}$ & $\begin{array}{c}\text { Cluster } 2 \\
\mathrm{~N}=9\end{array}$ & $\begin{array}{c}\text { Cluster } 3 \\
\mathrm{~N}=16\end{array}$ & & $\begin{array}{l}\text { ster } 4 \\
=10\end{array}$ \\
\hline Fruit & $8 \mathrm{ab} \quad(4-12)$ & $9 \mathrm{a} \quad(4-13)$ & $10 \mathrm{a}(4-16)$ & $5 b$ & $(1-9)$ \\
\hline Vegetable & $5 b \quad(3-6)$ & $6 \mathrm{ab} \quad(3-10)$ & $8 \mathrm{a}(5-10)$ & $5 b$ & $(1-9)$ \\
\hline Stimulant & $4 a \quad(2-5)$ & $(2-5)$ & $4 a(2-6)$ & $3 a$ & $(1-5)$ \\
\hline Spice & $6 a b \quad(3-9)$ & $5 b \quad(2-9)$ & $10 \mathrm{a}(3-15)$ & $6 a b$ & $(1-10)$ \\
\hline Medicinal & $3 a b \quad(0-4)$ & $3 \mathrm{ab} \quad(1-5)$ & $5 \mathrm{a}(0-13)$ & $2 b$ & $(0-6)$ \\
\hline Staple food & $(2-5)$ & $(3-5)$ & $4 a \quad(2-5)$ & $2 b$ & $(0-4)$ \\
\hline Wood & $(0-14)$ & $(0-15)$ & $2 \mathrm{a}(0-7)$ & $1 \mathrm{a}$ & $(0-5)$ \\
\hline MPT & $3 a b \quad(2-4)$ & $(2-5)$ & $2 b \quad(1-2)$ & $2 b$ & $(1-3)$ \\
\hline Other & $1 \mathrm{a} \quad(0-2)$ & $(0-2)$ & $1 \mathrm{a}(0-2)$ & $1 \mathrm{a}$ & $(0-1)$ \\
\hline
\end{tabular}

Medians are given because variables were not normally distributed.

Medians in a row followed by different letters are significantly different at $\mathrm{P} \leq 0.05$.

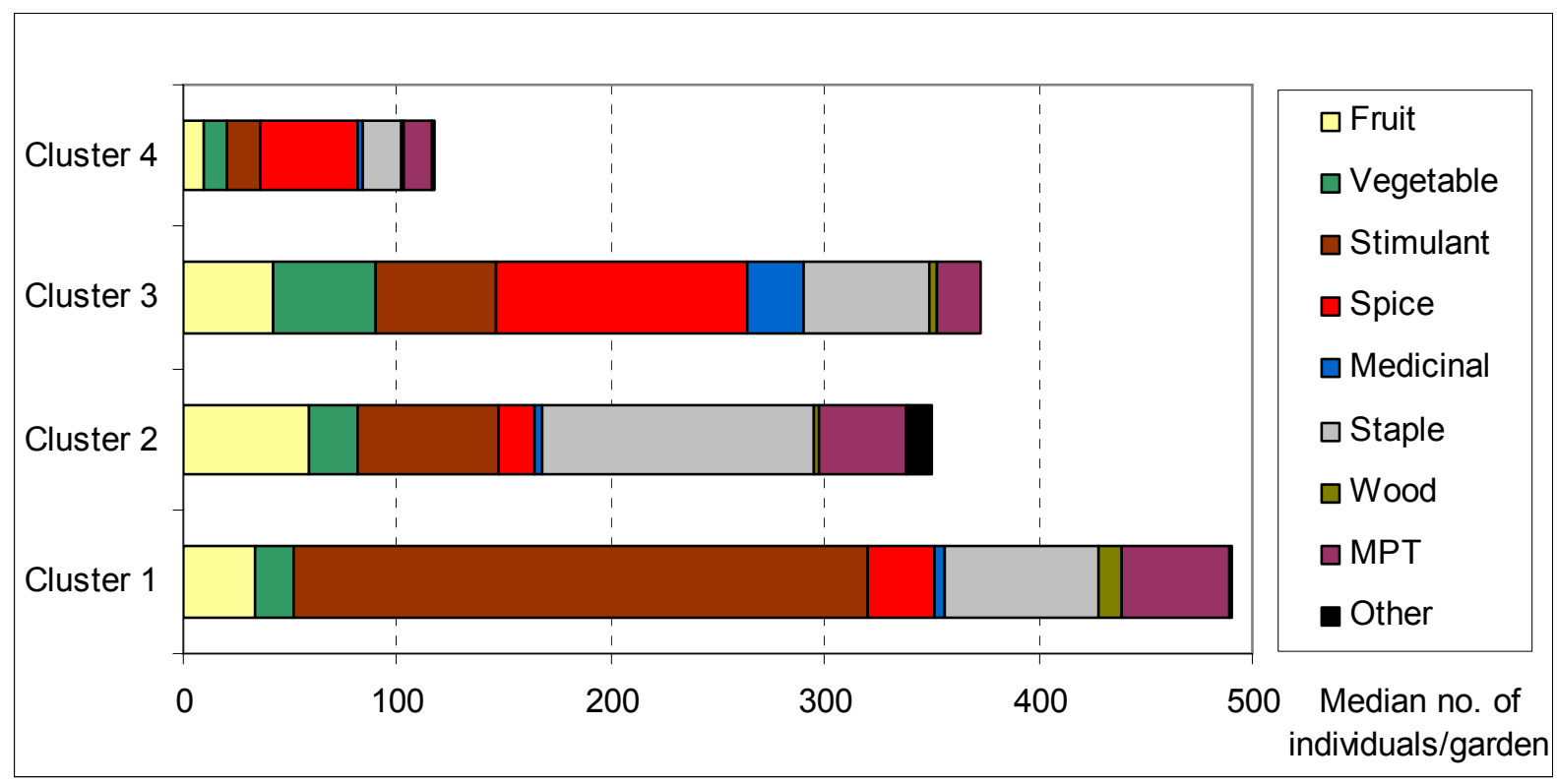

Figure 3.19. Median number of crop individuals in different use categories per cluster based on crop species abundance data of 44 homegardens in five villages of the Napu valley, Central Sulawesi, 2004. Cluster 1, $N=9$; Cluster 2, $N=9$; Cluster 3, $N=16$; Cluster 4, $N=10$.

Not only crop species composition, but also vegetation structure showed marked differences among clusters (Figure 3.20). The highest proportions of crop species were found in the first stratum (i.e. $0-1 \mathrm{~m}$ height) in homegardens of all four clusters. In homegardens of clusters 1 and 2, the second largest proportion of species occurred in the third stratum (i.e. $2-5 \mathrm{~m}$ height), followed by the second stratum (i.e. 1-2 m height). In contrast, proportions of crop species decreased continuously from the first to the fifth strata in homegardens of clusters 3 and 4. The upper stratum of trees taller than $10 \mathrm{~m}$ was absent in homegardens of cluster 4 .

Proportions of crop individuals per stratum also differed among clusters. Homegardens of cluster 1 with their clear dominance of coffee and cacao trees harboured nearly $33 \%$ of all crop individuals in each of the first, second, and third strata. In contrast to cluster 1 , proportions of crop species in homegardens of clusters 2, 3, and 4 decreased continuously 
from the first to the fifth strata. Homegardens grouped in clusters 3 and 4 were additionally characterised by a very high share of individuals in the first stratum (i.e. $62 \%$ and $63 \%$, respectively), confirming the importance of mostly annual vegetables and spices in these gardens (Figure 3.19). However, in homegardens of cluster 4 no individual plant reached the fifth stratum, in those of cluster 2 only very few did so.

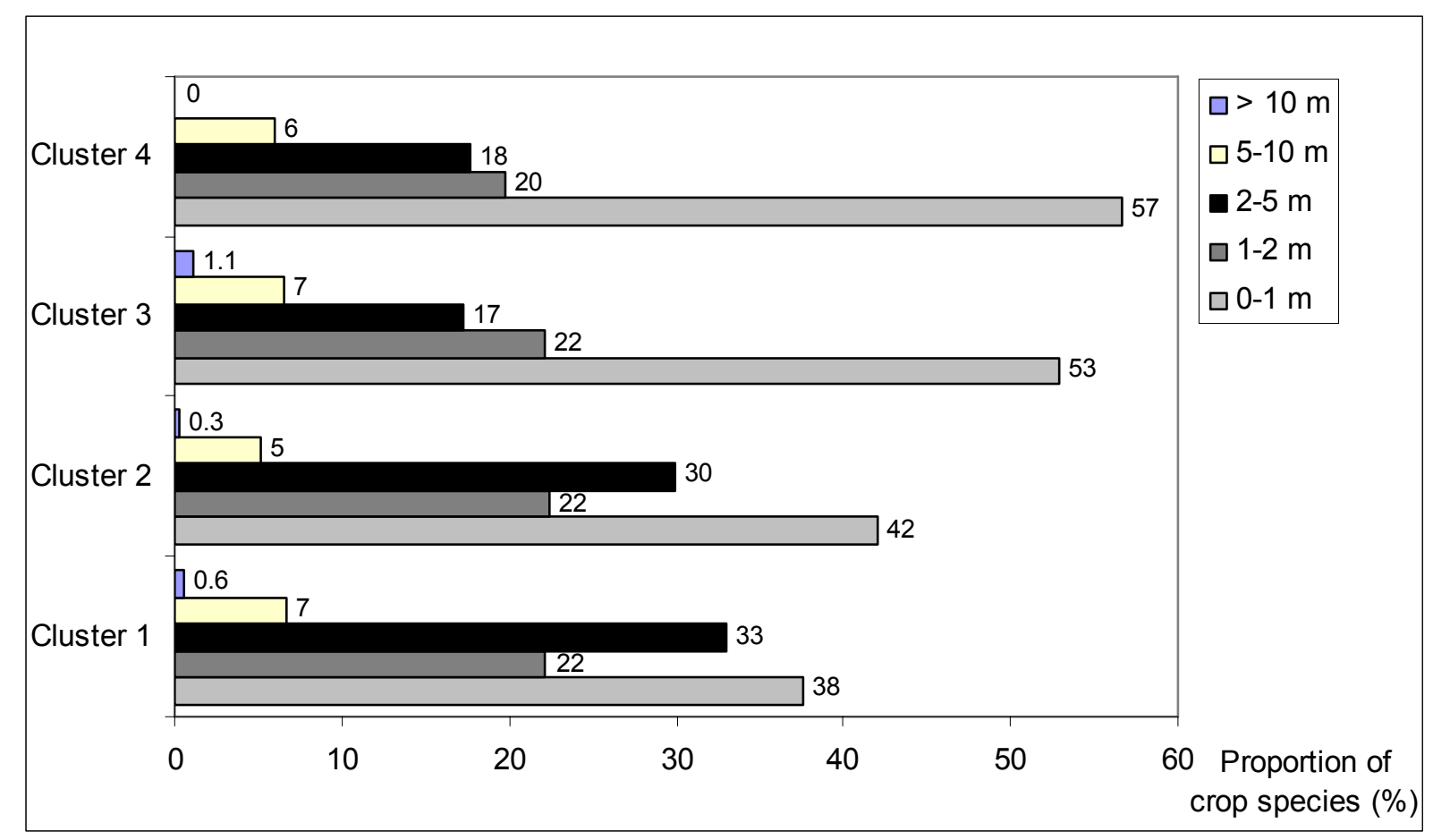

Figure 3.20. Mean proportion of crop species occurring in different strata per cluster based on crop species abundance data of 44 homegardens in five villages of the Napu valley, Central Sulawesi, 2004. Cluster 1, $N=9$; Cluster 2, $N=9$; Cluster 3, $N=16$; Cluster 4, $N=10$.

Besides numbers of species and individuals per use category as well as vegetation structure, also crop species richness, density, and diversity indices differed significantly among clusters (Table 3.16). For clusters 1 and 2, these characteristics mainly followed the same patterns as for the villages Tamadue and Siliwanga, respectively (i.e. being comparably low or intermediate), already described in 3.5.1 (Table 3.8), and 3.5.3 (Table 3.11). Homegardens of cluster 3 stand for significantly highest diversity parameter. Cluster 4 tied homegardens with very low species number, Margalef index, and species density as well as low to intermediate diversity indices. 
Table 3.16. Mean crop species richness, density (dens.) per $1000 \mathrm{~m}^{2}$, and diversity (ranges in brackets) per cluster based on crop species abundance data of 44 homegardens in five villages of the Napu valley, Central Sulawesi, 2004.

\begin{tabular}{|c|c|c|c|c|c|c|c|}
\hline & $\begin{array}{c}\text { Cluster } 1 \\
\mathrm{~N}=9\end{array}$ & & $\begin{array}{l}\text { luster } 2 \\
\mathrm{~N}=9\end{array}$ & & $\begin{array}{l}\text { luster } 3 \\
N=16\end{array}$ & & $\begin{array}{l}\text { luster } 4 \\
N=10\end{array}$ \\
\hline Richness & $36.3 \mathrm{ab}(25-50)$ & $38.4 \mathrm{ab}$ & $(22-65)$ & $45.7 \mathrm{a}$ & $(34-56)$ & $26.6 \mathrm{~b}$ & $(13-40)$ \\
\hline Margalef index & $5.8 \mathrm{ab}(4.1-7.8)$ & $6.1 \mathrm{ab}$ & $(3.7-9.8)$ & $7.7 \mathrm{a}$ & $(5.3-9.0)$ & $5.0 \mathrm{~b}$ & $(2.8-7.4)$ \\
\hline Dens. $/ 1000 \mathrm{~m}^{2}$ & $33.6 \mathrm{~b} \quad(22.9-47.3)$ & $37.7 \mathrm{~b}$ & $(19.7-61.7)$ & $48.3 \mathrm{a}$ & $(36.3-57.3)$ & $30.0 \mathrm{~b}$ & $(16.3-49.0)$ \\
\hline Shannon H' & $2.4 \mathrm{~b} \quad(2.1-3.0)$ & $2.7 \mathrm{ab}$ & $(2.3-3.0)$ & $3.0 \mathrm{a}$ & $(2.4-3.5)$ & $2.4 \mathrm{~b}$ & $(1.5-3.2)$ \\
\hline $\mathrm{H}^{\prime}$ evenness & $0.68 \mathrm{~b}(0.58-0.83)$ & $0.75 \mathrm{ab}$ & $(0.68-0.86)$ & $0.79 a$ & $(0.66-0.88)$ & $0.75 \mathrm{ab}$ & $(0.46-0.88)$ \\
\hline $\operatorname{Simpson} \lambda$ & $0.17 \mathrm{a}(0.07-0.23)$ & $0.12 \mathrm{ab}$ & $(0.06-0.17)$ & $0.09 \mathrm{t}$ & $(0.04-0.17)$ & $0.17 \mathrm{ab}$ & $(0.06-0.48)$ \\
\hline
\end{tabular}

Means in a row followed by different letters are significantly different at $\mathrm{P} \leq 0.05$.

Although the cluster analysis was performed only on the basis of crop species abundance, marked differences of some other garden characteristics among clusters were also found (Table 3.17). Median sizes of homegardens in cluster 1 were rather large as opposed to clusters 3 and 4 . Cluster 2 grouped homegardens with a high proportion of the garden to the whole farm area cultivated. At the same time, homegardens of cluster 2 harboured a high number of staple food crops (Figure 3.19). Families not owning large fields apart from the homegarden seemed to rely a lot on obtaining their daily food from their homegardens. Additionally, owners of the homegardens in cluster 2 were rated rather poor (lowest poverty index) as compared to the other families of the sample (Table 3.17). Cultivation of homegardens grouped in cluster 1 was largely cash-oriented (being correct also for garden no. 19), indicated by the high share of cash crop individuals (i.e. cacao, arabica coffee, vanilla, and mandarin). Homegardens of cluster 1 were mostly managed by male gardeners, whereas those of the other three cluster by female gardeners.

Table 3.17. Median garden size and its proportion of the whole cultivated farm area, share of cash crop individuals, share of female gardeners, and median poverty index per cluster performed on crop species abundance data of 44 homegardens in five villages of the Napu valley, Central Sulawesi, 2004 (ranges in brackets).

\begin{tabular}{|c|c|c|c|c|}
\hline & $\begin{array}{c}\text { Cluster } 1 \\
\mathrm{~N}=9\end{array}$ & $\begin{array}{c}\text { Cluster } 2 \\
\mathrm{~N}=9\end{array}$ & $\begin{array}{r}\text { Cluster } 3 \\
\mathrm{~N}=16 \\
\end{array}$ & $\begin{array}{r}\text { Cluster } 4 \\
\mathrm{~N}=10 \\
\end{array}$ \\
\hline Garden size $\left(\mathrm{m}^{2}\right)$ & $2280 \mathrm{a} \quad(930-2450)$ & $1000 \mathrm{ab}(470-2420)$ & $645 b \quad(370-1400)$ & $370 b c \quad(250-1900)$ \\
\hline $\begin{array}{l}\text { Prop. garden/farm } \\
\text { cultivated }(\%)\end{array}$ & $6 a b(2-13)$ & $12 \mathrm{a} \quad(2-30)$ & $4 a b \quad(2-11)$ & $(0.2-12)$ \\
\hline $\begin{array}{l}\text { Share of cash crop } \\
\text { individuals }(\%)\end{array}$ & $49 a \quad(10-69)$ & $22 \mathrm{ab}(10-33)$ & $15 \mathrm{ab} \quad(5-41)$ & $(1-63)$ \\
\hline $\begin{array}{l}\text { Share of female } \\
\text { gardeners }(\%)\end{array}$ & 13 & 67 & 69 & 60 \\
\hline Poverty index & $-0.11 \mathrm{a} \quad(-1.0-2.9)$ & $-1.0 b(-1.4--0.5)$ & $-0.5 \mathrm{ab} \quad(-1.4-2.3)$ & $0.4 a(-1.1-1.4)$ \\
\hline
\end{tabular}

When analysing chemical and physical soil parameters, additional differences among clusters were revealed. For clusters 1 and 2, soil characteristics mainly followed the same patterns as for the villages Tamadue and Siliwanga, respectively (i.e. low available P contents; in Tamadue high, but in Siliwanga low $\mathrm{CEC}_{\text {eff. }}$ and base saturation), as described in more detail in 3.6 (Table 3.21 and Table 3.23). Soil of the homegarden no. 11, which was located in Rompo, but grouped in cluster 2 , had very similar characteristics like many gardens of the 
village Siliwanga (i.e. low $\mathrm{pH}$ value, available $\mathrm{P}$ content, and base saturation, see Appendix 21). In cluster 3 , homegardens with slightly acid soils of rather low $C$ and available $P$ contents as well as low $\mathrm{CEC}_{\text {eff., }}$ were tied together. However, the base saturation of these homegardens was rather high. Soils of homegardens in cluster 4 resemble those of cluster 3, but in cluster 4 , soils were less acid than in cluster 3 . Besides $\mathrm{pH}$ value, also the other soil parameters were rather high in homegardens of cluster 4 .

Table 3.18. Medians of selected physical and chemical soil parameters (ranges in brackets) per cluster performed on crop species abundance data of 44 homegardens in five villages of the Napu valley, Central Sulawesi, 2004.

\begin{tabular}{|c|c|c|c|c|c|c|c|}
\hline & $\begin{array}{c}\text { Clus } \\
\mathrm{N}\end{array}$ & $\begin{array}{l}\text { ster } 1 \\
=9\end{array}$ & $\begin{array}{c}\text { Clus } \\
\mathrm{N}=\end{array}$ & $\begin{array}{l}\text { er } 2 \\
=9\end{array}$ & $\begin{array}{l}\text { Clus } \\
\mathrm{N}=\end{array}$ & $\begin{array}{l}\text { ter } 3 \\
=16\end{array}$ & $\begin{array}{c}\text { Cluster } 4 \\
\mathrm{~N}=10\end{array}$ \\
\hline Clay & $32.0 \mathrm{a}$ & $(27-45)$ & $20.0 \mathrm{~b}$ & $(15-47)$ & $18.5 \mathrm{~b}$ & $(5-26)$ & $22.5 \mathrm{ab}(14-38)$ \\
\hline $\mathrm{pH}(\mathrm{C}(\mathrm{c}) \mathrm{e}$ & $5.4 \mathrm{ab}$ & $(4.9-$ & $4.6 \mathrm{c}$ & $(4.6)$ & $5.0 \mathrm{bc}$ & (4. & $5.6 \mathrm{a} \quad(5.0-6.2)$ \\
\hline $\mathrm{C}$ content $(\%)$ & $3.9 \mathrm{a}$ & $(3.2-5.1)$ & $2.8 \mathrm{~b}$ & $(1.6-4.7)$ & $2.1 \mathrm{~b}$ & $(1.1-4.8)$ & $2.8 \mathrm{~b} \quad(1.6-4.5)$ \\
\hline P-Bray (ppm) & $44.0 \mathrm{c}$ & $(26-75)$ & $52.0 \mathrm{bc}$ & $(29-188)$ & $194.0 \mathrm{ab}$ & $(45-338)$ & $278.0 \mathrm{a} \quad(52-440)$ \\
\hline $\mathrm{CEC}_{\text {efff }}(\mathrm{me} / 100 \mathrm{~g})$ & $29.9 \mathrm{a}$ & $(18.0-37.9)$ & $5.0 \mathrm{c}$ & $(4.0-9.5)$ & $9.8 \mathrm{bc}$ & $(4.7-17.7)$ & 16.1ab (9.9-25.4) \\
\hline Base saturation (\%) & $98.3 \mathrm{a}$ & $(95.6-99.3)$ & $85.9 \mathrm{~b}$ & $(39.8-96.4)$ & $97.9 \mathrm{ab}$ & $(58.4-99.5)$ & $99.8 \mathrm{a} \quad(97.5-100)$ \\
\hline
\end{tabular}

Medians are given because variables were not normally distributed.

Medians in a row followed by different letters are significantly different at $\mathrm{P} \leq 0.05$.
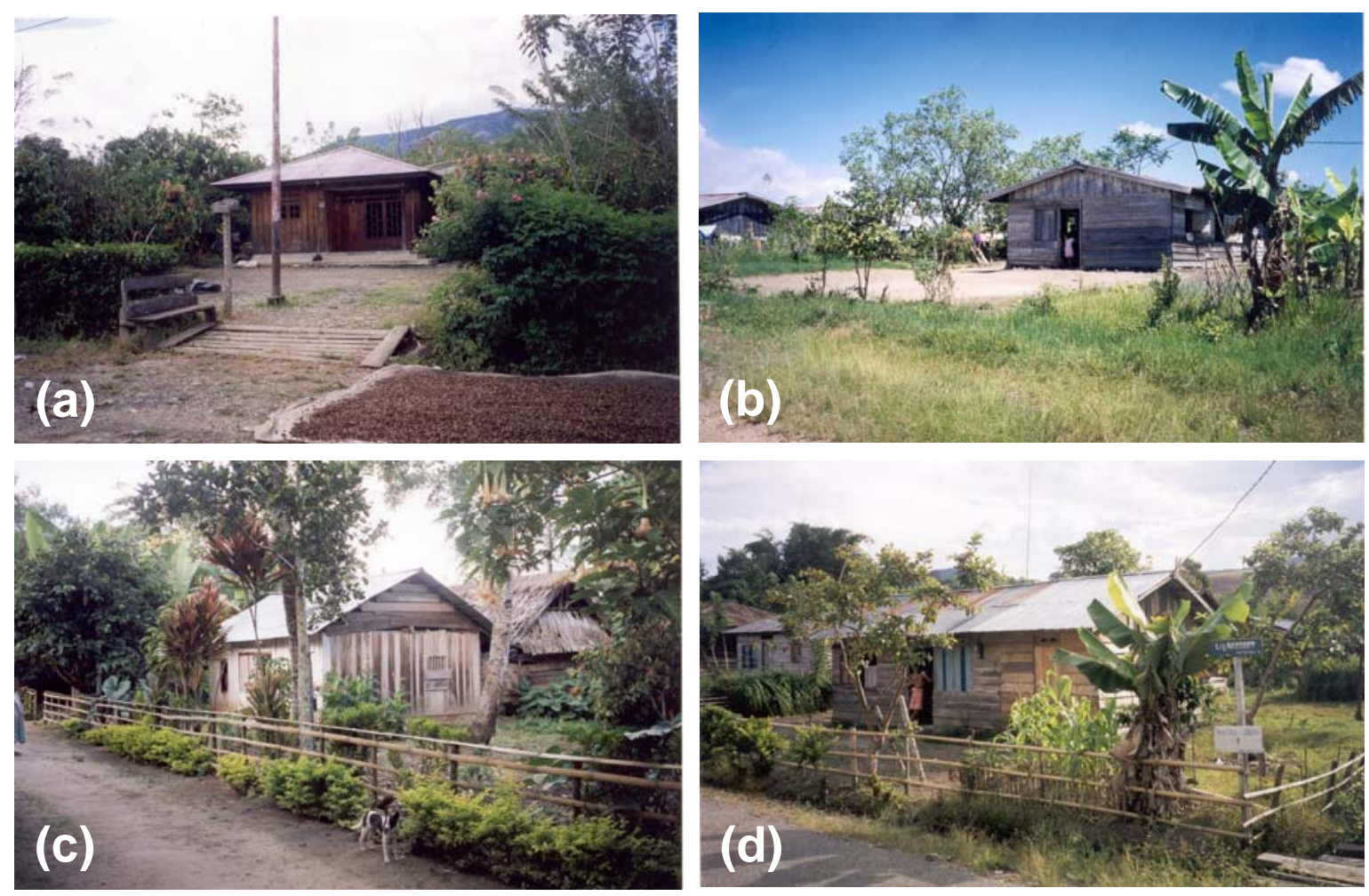

Figure 3.21. Examples of homegardens in the Napu valley, Central Sulawesi, grouped in different clusters. (a) A large cash crop homegarden of cluster 1 in the migrant village Tamadue; (b) A homegarden of cluster 2 in the migrant village Siliwanga with a poorly developed vegetation structure; (c) A species-rich homegarden of cluster 3, located in Rompo; (d) A small, species-poor homegarden of cluster 4 in Wanga. 
In summary, in cluster 1 very large cash crop gardens with a rather low diversity and owned mostly by migrants were found (Figure 3.21). Soils of these homegardens were fertile, but of low available $\mathrm{P}$ content. Homegardens of cluster 2 were of intermediate size and diversity. They were mostly managed by poor migrant families that cultivated many staple food crops, but nearly no tall trees. Soil quality in homegardens of cluster 2 was very poor. In cluster 3, homegardens of medium size that harbour a very high diversity, particularly of spices, vegetables, and medicinal plants were grouped together. Soils of these homegardens were rather fertile, but of low $\mathrm{pH}$ and $\mathrm{CEC}_{\text {eff. }}$. Cluster 4 tied small homegardens with rather low diversity, few woody plants and no trees taller than $10 \mathrm{~m}$, but with the most fertile soils.

In addition to the cluster analysis, Principal Component Analysis (PCA) of species abundance data was carried out to further differentiate homegardens based on their crop species composition. Axis 1 explains about $15 \%$ of the total variability (Table 3.19) and is positively correlated with spring onion, yard-long bean, and Heliconia indica. Axis 2, explaining about $13 \%$ of the total variability, is positively correlated with spring onion, but negatively with cacao, arabica and robusta coffee, banana, pineapple, cassava, cocoyam, and sweet potato. Four of these species (spring onion, cacao, pineapple, and sweet potato) were also detected as being important for the cluster analysis (see Table 3.14).

Table 3.19. Summary table and variable loadings for the first two axes of the 11 most important crops (variable loadings $>0.2$ for at least one of the axes) as a result of Principal Component Analysis, based on abundance data of 206 crop species cultivated in 48 homegardens in five villages of the Napu valley, Central Sulawesi, 2004. $N=10$ per village, apart from Rompo, where $N=8$. Species abundance data ln-transformed and centred before analysis.

\begin{tabular}{lllcc}
\hline & Axis 1 & Axis 2 & Axis 3 & Axis 4 \\
\hline Eigenvalues & 12.49 & 10.62 & 5.85 & 4.28 \\
Percentage & 14.97 & 12.73 & 7.01 & 5.13 \\
Cumulative Percentage & 14.97 & 27.70 & 34.71 & 39.83
\end{tabular}

Variable loadings:

\begin{tabular}{lrr} 
Spring onion & 0.432 & 0.266 \\
Yard-long bean & 0.244 & 0.042 \\
Heliconia indica & 0.215 & -0.031 \\
Cassava & 0.134 & -0.388 \\
Cacao & -0.002 & -0.301 \\
Banana & 0.117 & -0.263 \\
Cocoyam & 0.097 & -0.261 \\
Sweet potato & 0.065 & -0.254 \\
Pineapple & 0.167 & -0.232 \\
Arabica coffee & -0.176 & -0.219 \\
Robusta coffee & 0.076 & -0.217 \\
\hline
\end{tabular}

PCA confirmed parts of the cluster analysis, although the four homegarden types were not clearly separated. Homegardens of cluster 4 appear in the upper left part of Figure 3.22. In the upper right part of the figure, mostly homegardens tied in cluster 3 were found that were characterised (as in the cluster analysis) by large numbers of spring onions. In the lower left part of Figure 3.22, a mixture of homegardens belonging to the clusters 1 and 2 appear. These gardens were characterised by many individuals of arabica coffee (negative loadings of axis 1, Table 3.19). The four homegardens excluded as outliers from cluster analysis (i.e. gardens no. $1,2,9$, and 14) were also clearly separated by PCA. 
When applying PCA, migrant homegardens (marked by the dotted line) were not as distinct from local gardens as revealed by cluster analysis (Figure 3.22). Interestingly, species composition of the three local gardens (no. 5, 19, and 22), which interfere with the migrant garden group, was similar to the migrant gardens (dominance of cash crops like cacao and coffee). In contrast to cluster analysis, PCA revealed that garden no. 5 (cluster 3) also resembled gardens of clusters 1 or 2 . On the other hand, the local garden no. 22 , but also no. 11 (both cluster 2), showed a certain proximity to gardens of cluster 3.

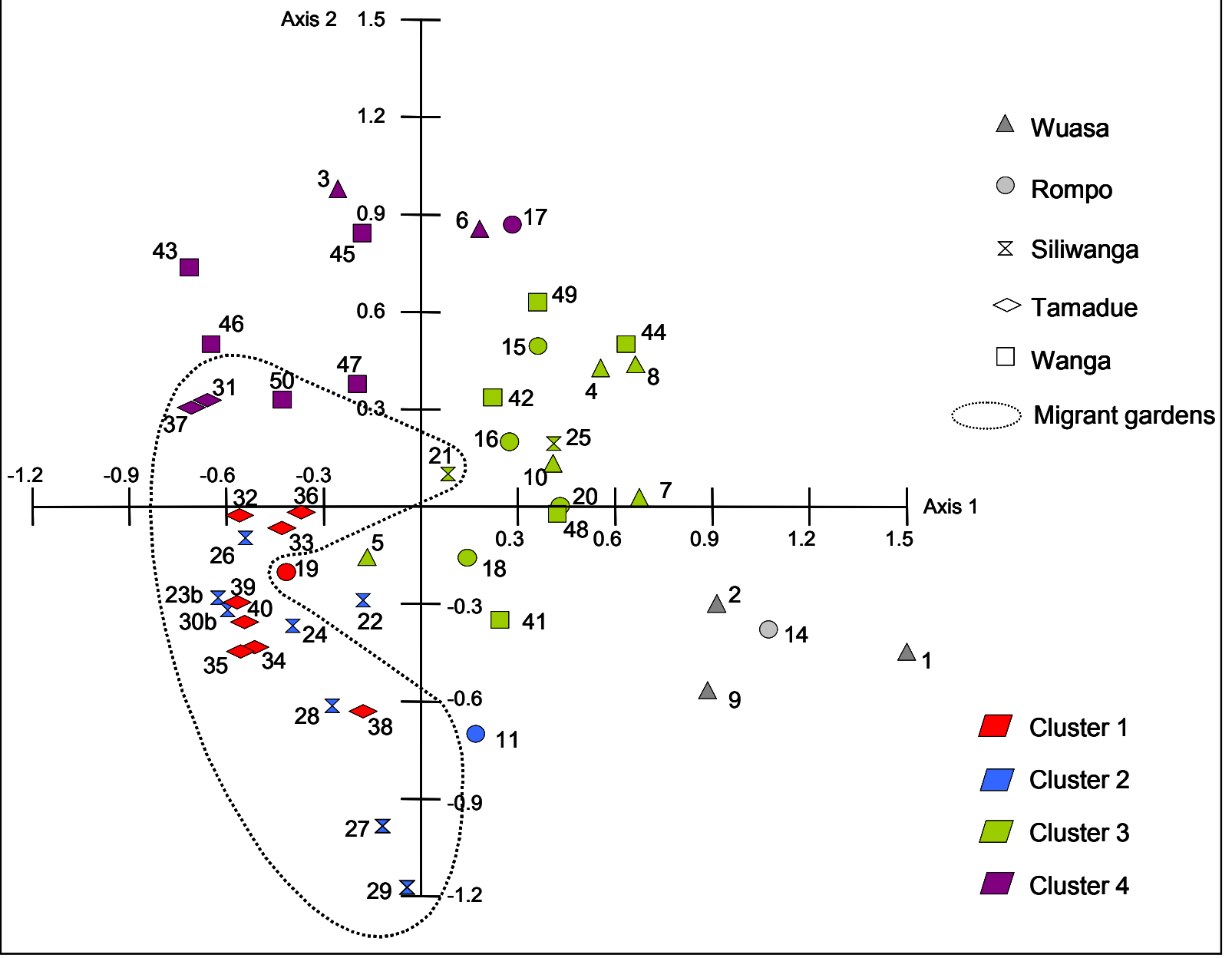

Figure 3.22. Result of Principal Component Analysis (cases scores of axis 1 and 2), based on ln-transformed and centred abundance data of 206 crop species cultivated in 48 homegardens of five villages in the Napu valley, Central Sulawesi, 2004.

\subsection{Soil characteristics}

Soil physical and chemical characteristics were highly variable, both among homegardens in the same villages and among different production zones of single homegardens (see Appendix 21 and Appendix 22). However, soil quality parameters showed different patterns in the five villages studied, suggesting different soil types. At first, these differences among villages are 
presented in detail below. Secondly, differences among production zones and possible reasons causing them are emphasised.

\subsubsection{Texture and bulk density}

Median sand content was highest in Wuasa and lowest in Tamadue, whereas medians of silt and clay contents were lowest in Wuasa and highest in Tamadue (Table 3.20). Consequently, most of the homegarden soils in Wuasa were classified as loamy or clay sand, only $20 \%$ as sandy loam. In Rompo, $70 \%$ of the soils were loam, in Wanga $100 \%$. Soil was rather heterogeneous in Siliwanga, were $50 \%$ of the samples were grouped as loamy or clay sand, $40 \%$ as sandy loam, and $10 \%$ as loamy clay. In Tamadue, $80 \%$ of the soils were classified as loam (mostly silt loam or silty clay loam) and $20 \%$ as silty clay. Bulk density was rather low and did not differ among the villages, apart from Tamadue, where it was significantly lower than in Wuasa, Rompo, and Siliwanga (Table 3.20).

Table 3.20. Medians of physical top soil properties (ranges in brackets) in 50 homegardens in five villages of the Napu valley, Central Sulawesi, 2004. $N=10$ per village.

\begin{tabular}{lllllllll}
\hline & \multicolumn{2}{c}{ Sand content $(\%)$} & \multicolumn{2}{c}{ Silt content $(\%)$} & \multicolumn{3}{c}{ Clay content $(\%)$} & \multicolumn{2}{c}{ Bulk density $\left(\mathrm{g} / \mathrm{cm}^{3}\right)$} \\
\hline Wuasa & $67 \mathrm{a}$ & $(48-86)$ & $14 \mathrm{~b}$ & $(8-35)$ & $16 \mathrm{~b}$ & $(5-24)$ & $1.0 \mathrm{a}$ & $(0.8-1.2)$ \\
Rompo & $47 \mathrm{ab}$ & $(31-71)$ & $28 \mathrm{ab}$ & $(14-47)$ & $23 \mathrm{ab}$ & $(10-32)$ & $0.9 \mathrm{a}$ & $(0.7-1.3)$ \\
Wanga & $44 \mathrm{~b}$ & $(33-55)$ & $33 \mathrm{ab}$ & $(26-41)$ & $23 \mathrm{ab}$ & $(19-30)$ & $0.9 \mathrm{ab}$ & $(0.7-1.1)$ \\
Siliwanga & $51 \mathrm{ab}$ & $(22-67)$ & $32 \mathrm{ab}$ & $(10-41)$ & $19 \mathrm{~b}$ & $(12-47)$ & $1.0 \mathrm{a}$ & $(0.6-1.1)$ \\
Tamadue & $11 \mathrm{~b}$ & $(9-51)$ & $46 \mathrm{a}$ & $(24-58)$ & $34 \mathrm{a}$ & $(22-45)$ & $0.6 \mathrm{~b}$ & $(0.5-1.0)$ \\
\hline
\end{tabular}

Medians are given because variables were not normally distributed.

Medians in a column followed by different letters are significantly different at $\mathrm{P} \leq 0.05$.

Note: As medians are given, sums of sand, silt, and clay contents are not equal to 100 .

\subsection{2 $\quad \mathrm{pH}$ value and available $P$ content}

Medians of $\mathrm{pH}$ values measured in water were similar in all five villages (Table 3.21). However, in all villages single gardens suffered from soil with a $\mathrm{pH}$ value under 5.5 that was rated as 'acid' (see 2.6.4). Such low $\mathrm{pH}$ values occurred in $40 \%$ of the homegardens in Siliwanga, 30\% in Wuasa and Rompo, but only 20\% in Wanga and Tamadue. When production zones were analysed separately, even 50\% of the homegardens in Wuasa, Rompo, and Siliwanga suffered at least in one zone from acid soil, in Wanga $40 \%$, and in Tamadue only $20 \%$. Median $\mathrm{pH}$ values measured in $\mathrm{CaCl}_{2}$ differed among villages, being high in Tamadue, but low in Siliwanga.

Table 3.21. Medians of $\mathrm{pH}$ values and available P contents of top soil (ranges in brackets) in 50 homegardens in five villages of the Napu valley, Central Sulawesi, 2004. $N=10$ per village.

\begin{tabular}{llllllll}
\hline & \multicolumn{1}{c}{$\mathrm{pH}\left(\mathrm{H}_{2} \mathrm{O}\right)$} & \multicolumn{2}{c}{$\mathrm{pH}\left(\mathrm{CaCl}_{2}\right)$} & \multicolumn{2}{c}{ P-Olsen $(\mathrm{ppm})$} & \multicolumn{2}{c}{ P-Bray $(\mathrm{ppm})$} \\
\hline Wuasa & $5.7 \mathrm{a}(5.3-6.8)$ & $5.2 \mathrm{ab}$ & $(4.8-6.2)$ & $56 \mathrm{a}$ & $(24-118)$ & $262 \mathrm{a}$ & $(73-440)$ \\
Rompo & $5.7 \mathrm{a}(5.0-6.3)$ & $5.1 \mathrm{ab}$ & $(4.5-6.1)$ & $39 \mathrm{ab}$ & $(11-106)$ & $117 \mathrm{ab}$ & $(30-247)$ \\
Wanga & $5.6 \mathrm{a}(5.4-6.2)$ & $5.1 \mathrm{ab}$ & $(4.9-5.8)$ & $11 \mathrm{bc}$ & $(1-19)$ & $237 \mathrm{a}$ & $(45-393)$ \\
Siliwanga & $5.6 \mathrm{a}(4.6-5.8)$ & $4.7 \mathrm{~b}$ & $(4.0-5.2)$ & $11 \mathrm{abc}$ & $(5-34)$ & $65 \mathrm{ab}$ & $(29-188)$ \\
Tamadue & $5.8 \mathrm{a}(5.2-6.1)$ & $5.3 \mathrm{a}$ & $(4.9-5.8)$ & $2 \mathrm{c}$ & $(1-3)$ & $47 \mathrm{~b}$ & $(26-65)$ \\
\hline
\end{tabular}

Medians are given because variables were not normally distributed.

Medians in a column followed by different letters are significantly different at $\mathrm{P} \leq 0.05$. 
Median P-Olsen contents were high in Wuasa, but very low in Tamadue (Table 3.21). In the latter village, all soils were rated as very low (see 2.6.4). Even in the villages Wanga and Siliwanga, some homegarden soils had only low to very low P-Olsen contents, whereas in Wuasa and Rompo, all soils were rated as medium or high. Concerning P-Bray contents, medians were highest in Wuasa and Wanga, intermediate in Rompo and Siliwanga, and lowest in Tamadue (Table 3.21). Similarly to $\mathrm{pH}$ values, single gardens in all five villages had rather low P-Bray contents. However, P-Bray contents were rated as 'high' in all homegardens and even in all production zones apart from one fallow zone in Rompo, where available $\mathrm{P}$ content was rated as 'medium' only (see 2.6.4). P-Bray content was correlated slightly positively to $\mathrm{pH}\left(\mathrm{H}_{2} \mathrm{O}\right)$ value $(\mathrm{r}=0.382 ; \mathrm{P}=0.006)$.

\subsection{3 $\quad \mathrm{N}$ and $\mathrm{C}$ contents}

As $\mathrm{N}$ and $\mathrm{C}$ contents were highly correlated $(\mathrm{r}=0.976, \mathrm{P}<0.001)$, both values showed the same patterns among villages. Soil in Tamadue had the highest median $\mathrm{N}$ and $\mathrm{C}$ contents, that in Wuasa and Rompo the lowest (Table 3.22). In Wuasa, $\mathrm{N}$ content of soil was rated as 'low' in all homegardens, $\mathrm{C}$ content as 'very low' in $80 \%$ of them. In homegardens of Rompo, both $\mathrm{N}$ and $\mathrm{C}$ contents were mostly rated as 'low', although soil of single gardens had 'very low' $\mathrm{N}$ (30\% of the gardens) and C (50\%) contents. In Wanga and Siliwanga, homegarden soil was mostly rated as 'medium' concerning $\mathrm{N}$ content and as 'low' concerning $\mathrm{C}$ content. Soil of homegardens in Tamadue had 'medium' $\mathrm{N}$ and $\mathrm{C}$ contents. $\mathrm{C} / \mathrm{N}$ ratios were highest in Siliwanga and lowest in Tamadue.

Table 3.22. Medians of $N$ and $C$ contents as well as $C / N$ ratios of top soil (ranges in brackets) in 50 homegardens in five villages of the Napu valley, Central Sulawesi, 2004. $N=10$ per village.

\begin{tabular}{llllllll}
\hline & \multicolumn{2}{c}{$\mathrm{N}$ content (\%) } & \multicolumn{2}{c}{ C content (\%) } & \multicolumn{2}{c}{ C/N ratio } \\
\hline Wuasa & $0.13 \mathrm{~b}$ & $(0.11-0.19)$ & $1.7 \mathrm{~b}$ & $(1.3-2.7)$ & & $12.3 \mathrm{ab}$ & $(10.7-15.0)$ \\
Rompo & $0.17 \mathrm{~b}$ & $(0.07-0.26)$ & $2.2 \mathrm{~b}$ & $(0.9-3.2)$ & & $12.8 \mathrm{ab}$ & $(11.1-13.6)$ \\
Wanga & $0.22 \mathrm{ab}$ & $(0.14-0.38)$ & $2.8 \mathrm{ab}$ & $(1.8-4.8)$ & & $12.2 \mathrm{ab}$ & $(11.7-14.0)$ \\
Siliwanga & $0.21 \mathrm{ab}$ & $(0.13-0.34)$ & $2.9 \mathrm{ab}$ & $(2.0-4.7)$ & & $14.2 \mathrm{a}$ & $(11.6-15.6)$ \\
Tamadue & $0.34 \mathrm{a}$ & $(0.20-0.46)$ & $4.0 \mathrm{a}$ & $(2.8-5.1)$ & & $11.9 \mathrm{~b}$ & $(11.0-13.6)$ \\
\hline
\end{tabular}

Medians are given because variables were not normally distributed.

Medians in a column followed by different letters are significantly different at $\mathrm{P} \leq 0.05$.

\subsubsection{Cation exchange capacity and base saturation}

Median effective cation exchange capacity (CEC eff.) of homegarden soils was highest in Tamadue and lowest in Siliwanga (Table 3.23). It could be rated as 'very low' in Siliwanga, 'low' in Wuasa and Rompo, 'medium' in Wanga, and 'high' in Tamadue. These differences in $\mathrm{CEC}$ eff. were mainly caused by differences in amounts of exchangeable $\mathrm{Ca}$ and $\mathrm{Mg}$ (not shown in Table 3.23). In Tamadue, amounts of both $\mathrm{Ca}$ and $\mathrm{Mg}$ were high (median for $\mathrm{Ca}=$ $19.0 \mathrm{cmol} / \mathrm{kg}$, for $\mathrm{Mg}=7.4 \mathrm{cmol} / \mathrm{kg}$ ), whereas in Siliwanga they were low (median for $\mathrm{Ca}=$ $2.6 \mathrm{cmol} / \mathrm{kg}$, for $\mathrm{Mg}=1.3 \mathrm{cmol} / \mathrm{kg}$ ). However, amounts of exchangeable $\mathrm{K}$ showed a quite different pattern: They were lowest in Tamadue and highest in Wuasa (Table 3.23). Consequently, soils in Tamadue, Siliwanga, and Rompo were rated as 'low' concerning the amount of exchangeable $\mathrm{K}$, that in Wanga and Wuasa as 'medium'. 
Table 3.23. Medians of effective cation exchange capacity (CEC), exchangeable $K$ and $A l$, as well as base saturation of top soil (ranges in brackets) in 50 homegardens in five villages of the Napu valley, Central Sulawesi, 2004. $N=10$ per village.

\begin{tabular}{lrlllllll}
\hline & \multicolumn{2}{c}{$\begin{array}{c}\text { CEC } \text { eff. } \\
(\mathrm{cmol} / \mathrm{kg})\end{array}$} & \multicolumn{2}{c}{$\begin{array}{c}\text { Exchangeable K } \\
(\mathrm{cmol} / \mathrm{kg})\end{array}$} & \multicolumn{2}{c}{$\begin{array}{c}\text { Exchangeable Al } \\
(\mathrm{cmol} / \mathrm{kg})\end{array}$} & \multicolumn{2}{c}{$\begin{array}{c}\text { Base saturation } \\
(\%)\end{array}$} \\
\hline Wuasa & $9.8 \mathrm{bc}$ & $(5.7-15.8)$ & $0.54 \mathrm{a}$ & $(0.43-0.95)$ & $0.02 \mathrm{~b}$ & $(0.00-0.26)$ & $97.2 \mathrm{a}$ & $(92.4-99.8)$ \\
Rompo & $11.2 \mathrm{bc}$ & $(5.5-19.5)$ & $0.38 \mathrm{abc}$ & $(0.16-0.84)$ & $0.01 \mathrm{ab}$ & $(0.00-0.82)$ & $97.8 \mathrm{ab}$ & $(85.9-99.8)$ \\
Wanga & $15.9 \mathrm{ab}$ & $(12.6-17.7)$ & $0.51 \mathrm{ab}$ & $(0.20-0.78)$ & $0.02 \mathrm{~b}$ & $(0.00-0.06)$ & $99.2 \mathrm{a}$ & $(96.1-100)$ \\
Siliwanga & $4.9 \mathrm{c}$ & $(4.0-8.2)$ & $0.24 \mathrm{bc}$ & $(0.11-0.45)$ & $0.39 \mathrm{a}$ & $(0.15-1.88)$ & $85.6 \mathrm{~b}$ & $(39.8-96.4)$ \\
Tamadue & $28.3 \mathrm{a}$ & $(17.8-37.9)$ & $0.17 \mathrm{c}$ & $(0.09-0.34)$ & $0.00 \mathrm{~b}$ & $(0.00-0.06)$ & $98.2 \mathrm{a}$ & $(95.6-99.3)$ \\
\hline
\end{tabular}

Medians are given because variables were not normally distributed.

Medians in a column followed by different letters are significantly different at $\mathrm{P} \leq 0.05$.

Median amounts of exchangeable Al were low in all villages apart from Siliwanga (Table 3.23). However, total amounts did not exceed the critical absolute value of about 2-3 $\mathrm{cmol} / \mathrm{kg}$. However, in two homegardens in Siliwanga the portion of Al from CEC eff. went above the critical portion of $30 \%$ (see 2.6.4). Base saturation of soils was more than $97 \%$ in Wuasa, Rompo, Wanga, and Tamadue, where it was rated as 'very high'. Only in Siliwanga, base saturation was slightly lower, but still rated as 'very high' in $80 \%$ of the homegardens surveyed.

\subsubsection{Differences of physico-chemical soil characteristics among production zones}

All soil characteristics studied showed high variability among the different production zones within a single homegarden. As vegetable and cacao/coffee production zones were the most frequent, only these zones were compared here. Out of the 50 homegardens studied, 17 had both vegetable and cacao/coffee production zones. Seven of them were located in Wuasa, four in Rompo, four in Wanga, and two in Siliwanga. Patterns of differences in several soil quality parameters among zones were identified according to the fertilising habits of the gardeners. Only few cacao/coffee zones were fertilised occasionally (29\%), but more than $50 \%$ of the vegetable zones were fertilised regularly, mostly with ash. Therefore, homegardens formed two groups: in one group, vegetable zones were regularly fertilised $(\mathrm{N}=9)$, in the other group, no fertiliser was used for vegetables $(\mathrm{N}=8)$. For the parameters $\mathrm{pH}$ value, available $\mathrm{P}$ content, $\mathrm{CEC}$, exchangeable $\mathrm{Ca}$ and $\mathrm{K}$ contents, and base saturation, differences among production zones were analysed separately in these two subgroups. For water content, bulk density and $\mathrm{N}$ and $\mathrm{C}$ contents, no differences between subgroups were found, hence, only differences between production zones were compared.

Table 3.24. Median water content, bulk density, and $N$ and $C$ contents of top soil in vegetable and cacao/coffee zones (ranges in brackets) of 17 homegardens in four villages of the Napu valley, Central Sulawesi, 2004.

\begin{tabular}{lrr}
\hline Soil parameter & \multicolumn{1}{c}{ Vegetable zone } & Cacao/coffee zone \\
\hline Water content $\mathrm{w} / \mathrm{w}(\%)$ & $25.00 \mathrm{~b}(16-43)$ & $33.00 \mathrm{a}(24-66)$ \\
Bulk density $\left(\mathrm{g} / \mathrm{cm}^{3}\right)$ & $0.99 \mathrm{a}(0.79-1.37)$ & $0.97 \mathrm{~b}(0.71-1.08)$ \\
$\mathrm{N}$ content $(\%)$ & $0.18 \mathrm{~b}(0.06-0.30)$ & $0.20 \mathrm{a}(0.10-0.27)$ \\
$\mathrm{C}$ content $(\%)$ & $2.00 \mathrm{~b}(0.90-4.30)$ & $2.60 \mathrm{a}(1.40-3.40)$ \\
\hline
\end{tabular}

Medians are given because variables were not normally distributed.

Medians in a row followed by different letters are significantly different at $\mathrm{P} \leq 0.05$ (Wilcoxon test). 
In all 17 homegardens studied, soil water content (w/w) was significantly higher in the cacao/coffee zones than in the vegetable zones (Table 3.24). Bulk density was lower in most of the cacao/coffee zones as compared to vegetable zones. In most of the homegardens, $\mathrm{N}$ and $\mathrm{C}$ contents were higher in cacao/coffee than in vegetable zones.

If vegetable zones were not fertilised with ash, $\mathrm{pH}$ values in vegetable and cacao/coffee zones were similar (Table 3.25). In fertilised vegetable zones, $\mathrm{pH}$ values were significantly higher than in the adjacent cacao/coffee zones. Available P contents were much lower in vegetable zones than in cacao/coffee zones, if vegetables zones were not fertilised, but higher, if they were fertilised. The same pattern was found by analysing relative available P content in soil of vegetable zones by defining available $\mathrm{P}$ content in the adjacent cacao/coffee zone as $100 \%$. In a median, soil of unfertilised vegetable zones contained only $38 \%$ of the available $\mathrm{P}$ in cacao/coffee zones, whereas that of fertilised vegetable zones as much as $139 \%$.

Table 3.25. Medians (ranges in brackets) of $\mathrm{pH}$ value, available P content, effective cation exchange capacity $(C E C)$, exchangeable (exch.) Ca and $K$, and base saturation of top soil in fertilised $(N=9)$ and unfertilised $(N=8)$ vegetable zones as compared to adjacent cacao/coffee zones of the same 17 homegardens in four villages of the Napu valley, Central Sulawesi, 2004.

\begin{tabular}{lccc}
\hline & $\begin{array}{c}\text { Vegetable zone } \\
\text { fertilised }\end{array}$ & Vegetable zone & Cacao/coffee zone \\
\hline $\mathrm{pH}\left(\mathrm{H}_{2} \mathrm{O}\right)$ & No & $5.5 \mathrm{a}(4.7-6.3)$ & $5.7 \mathrm{a}(5.2-5.8)$ \\
& Yes & $6.2 \mathrm{a}(5.3-6.9)$ & $5.7 \mathrm{~b}(5.2-5.8)$ \\
$\mathrm{P}-\mathrm{Bray}(\mathrm{ppm})$ & No & $97 \mathrm{~b}(24-343)$ & $253 \mathrm{a}(109-512)$ \\
& Yes & $240 \mathrm{a}(66-463)$ & $164 \mathrm{~b}(57-395)$ \\
$\mathrm{CEC}_{\text {eff. }}(\mathrm{cmol} / \mathrm{kg})$ & No & $8.0 \mathrm{~b}(3.9-14.2)$ & $11.7 \mathrm{a}(9.0-16.5)$ \\
& Yes & $12.1 \mathrm{a}(7.5-25.1)$ & $12.4 \mathrm{a}(4.5-19.4)$ \\
Exch. $\mathrm{Ca}(\mathrm{cmol} / \mathrm{kg})$ & No & $6.4 \mathrm{~b}(1.3-11.0)$ & $8.6 \mathrm{a}(5.8-12.2)$ \\
& Yes & $8.8 \mathrm{a}(5.8-19.9)$ & $8.9 \mathrm{a}(2.4-14.1)$ \\
Exch. $\mathrm{K}(\mathrm{cmol} / \mathrm{kg})$ & No & $0.3 \mathrm{~b}(0.1-0.6)$ & $0.6 \mathrm{a}(0.4-1.0)$ \\
& Yes & $0.4 \mathrm{a}(0.3-0.9)$ & $0.5 \mathrm{a}(0.2-0.8)$ \\
Base saturation $(\%)$ & No & $97.0 \mathrm{a}(49.9-100.0)$ & $98.7 \mathrm{a}(96.8-99.6)$ \\
& Yes & $99.7 \mathrm{a}(96.8-100.0)$ & $97.7 \mathrm{a}(81.7-99.9)$ \\
\hline
\end{tabular}

Medians are given because variables were not normally distributed.

Medians in a row followed by different letters are significantly different at $\mathrm{P} \leq 0.05$ (Wilcoxon test).

Effective cation exchange capacity (CEC) as well as exchangeable $\mathrm{Ca}$ and $\mathrm{K}$ were significantly lower in unfertilised vegetable zones than in the adjacent cacao/coffee zones (Table 3.25). However, fertilised vegetable zones had similar values as cacao/coffee zones. Fertilising vegetable zones with ash did not cause significant differences between zones in absolute values of base saturation, but in relative values. Unfertilised vegetable zones had only $98.5 \%$ of the base saturation of the adjacent cacao/coffee zone, whereas fertilised vegetable zones had $102 \%$. In summary, fertilising had raised $\mathrm{pH}$ value and available $\mathrm{P}$ content in soil of vegetable zones as compared to adjacent, mostly unfertilised cacao/coffee zones. Reduction of effective cation exchange capacity as well as exchangeable $\mathrm{Ca}$ and $\mathrm{K}$ in vegetable zones was prevented by fertilising. As the most used fertiliser in vegetable zones was ash, no positive effects on $\mathrm{N}$ and $\mathrm{C}$ contents of the soil were detected. 


\subsubsection{Suitability of the soil in cacao/coffee zones for production of cacao}

Cacao and/or coffee were produced in particular planting zones or in the main part of the garden in 38 from 50 homegardens studied. Due to the growing importance of cacao production for cash income generation, soil quality of these zones is rated in more detail in the following, according to the minimum requirements given in 2.6.4. As patterns of soil quality in cacao/coffee zones mostly were quite similar to the differences in overall soil quality among villages already presented in 3.6.2, 3.6.3, and 3.6.4, detailed data concerning the medians of cacao/coffee zones per village were given only in Appendix 23.

In all villages, $\mathrm{pH}$ value of most soils from cacao production zones were slightly too low for high production levels of cacao (Table 3.26). Available P contents were rated as 'sufficient' in all cacao zones concerning P-Bray. However, P-Olsen soil contents were considered as 'too low' in Tamadue and in one garden in Wanga. Concerning N contents, soils of cacao zones in homegardens of Wuasa, Rompo, and Siliwanga were mostly rated as 'too low'. In Wanga and Tamadue, most or all soils had sufficient $\mathrm{N}$ levels, respectively. About $50 \%$ of garden soils used for cacao production in Wuasa and Rompo did not contain sufficient $\mathrm{C}$, whereas in the other three villages no soil was rated as 'too low' in $\mathrm{C}$. $\mathrm{C} / \mathrm{N}$ ratios did all meet the minimum requirements for cacao production. Concerning exchangeable $\mathrm{K}$ in cacao soils, a severe shortage was detected only in Tamadue, but also in Siliwanga, some soils did not contain sufficient K. Amounts of $\mathrm{Ca}$ as well as CEC eff. were rated as 'too low' in all cacao soils of Siliwanga and some to many of them, respectively, in Wuasa and Rompo. Base saturation was sufficient in all cacao zones of the homegardens studied.

Table 3.26. Portion of soils (\%) fulfilling the minimum requirements for successful cacao production concerning different soil parameters in cacao production zones of 38 homegardens in five villages of the Napu valley, Central Sulawesi, 2004. $N=8$ in Wuasa; $N=7$ each in Rompo, Wanga, and Siliwanga; $N$ $=9$ in Tamadue.

\begin{tabular}{lrrrrr}
\hline Soil parameter & Wuasa & Rompo & Wanga & Siliwanga & Tamadue \\
\hline Sand $\geq 50 \%$ & 75 & 43 & 14 & 57 & 0 \\
$\mathrm{pH}\left(\mathrm{H}_{2} \mathrm{O}\right) \geq 6.0$ & 0 & 0 & 14 & 0 & 33 \\
$\mathrm{P}-\mathrm{Olsen} \geq 5 \mathrm{ppm}$ & 100 & 100 & 86 & 100 & 0 \\
$\mathrm{P}-\mathrm{Bray} \geq 7 \mathrm{ppm}$ & 100 & 100 & 100 & 100 & 100 \\
$\mathrm{~N} \geq 0.22 \%$ & 0 & 29 & 71 & 29 & 100 \\
$\mathrm{C} \geq 0.20 \%$ & 50 & 57 & 100 & 100 & 100 \\
$\mathrm{C} / \mathrm{N} \mathrm{ratio} \geq 9$ & 100 & 100 & 100 & 100 & 100 \\
$\mathrm{~K} \geq 0.24 \mathrm{cmol} / \mathrm{kg}$ & 100 & 86 & 86 & 57 & 22 \\
$\mathrm{Ca} \geq 8 \mathrm{cmol} / \mathrm{kg}$ & 50 & 57 & 100 & 0 & 100 \\
$\mathrm{CEC}$ eff. $\geq 12 \mathrm{cmol} / \mathrm{kg}$ & 38 & 29 & 100 & 0 & 100 \\
Base saturation $\geq 35 \%$ & 100 & 100 & 100 & 100 & 100 \\
\hline
\end{tabular}

In summary, soil of homegardens in Wanga was more suitable for cacao production as compared to the other villages. Only few garden soils in Wanga had too low levels of N, POlsen, or K. In Tamadue, soils were generally suitable for cacao production, apart from too low P-Olsen and K levels. In addition, the quite low sand contents of soils (Table 3.26, mostly below 15\%) might have caused problems with aeration of the soil. In Wuasa and Rompo, cacao trees might suffer mainly from $\mathrm{N}$ deficiencies, but also levels of $\mathrm{Ca}, \mathrm{Mg}$, and $\mathrm{K}$ were partly too low. The worst situation for cacao production was detected in Siliwanga, where most of the soils did not have sufficient amounts of $\mathrm{N}, \mathrm{Ca}, \mathrm{Mg}$, and $\mathrm{K}$, but too high levels of 
$\mathrm{Al}$ (data not shown). Besides, cacao production in Siliwanga suffered from imperfect drainage caused by high and fluctuating water tables, as indicated by orange-coloured iron-oxide concretions in about $20 \mathrm{~cm}$ depth, giving the soil a mottled appearance (Figure 3.23).

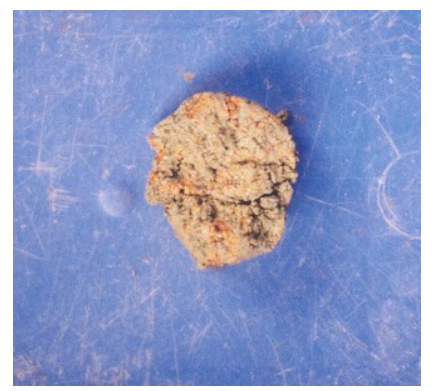

Figure 3.23. Soil sample with orange-coloured iron-oxide concretions, taken from about $20 \mathrm{~cm}$ depth in a homegarden of the migrant village Siliwanga, Napu valley, Central Sulawesi.

\subsection{Cacao leaf analysis}

Median dry matter contents varied between 36-41\%, being highest in Wuasa, Siliwanga, and Tamadue and lowest in Rompo (Table 3.27). $\mathrm{N}$ and $\mathrm{C}$ contents of cacao leaves did not differ among villages (Table 3.27). Concerning $\mathrm{N}$ contents, $80 \%$ of the analysed cacao leaf samples could be rated as severely deficient (see 2.7.3).

Table 3.27. Median dry weight, water content, as well as $N$ and $C$ contents of cacao leaves sampled in 40 homegardens of five villages of the Napu valley, Central Sulawesi, 2004. $N=9$ each in Wuasa and Tamadue; $N=8$ each in Rompo and Siliwanga; $N=6$ in Wanga.

\begin{tabular}{|c|c|c|c|}
\hline & $\begin{array}{l}\text { Dry matter content } \\
\text { (\% of fresh weight) }\end{array}$ & $\mathrm{N}$ content $(\%)$ & $\mathrm{C}$ content $(\%)$ \\
\hline Wuasa & $41.2 \mathrm{a} \quad(36.1-43.0)$ & $1.6 \mathrm{a}(1.4-1.9)$ & $45.5 \mathrm{a}(41.9-50.1)$ \\
\hline Rompo & $(34.2-39.2)$ & $1.7 \mathrm{a}(1.5-1.9)$ & $45.5 \mathrm{a} \quad(42.5-48.9)$ \\
\hline Wanga & $39.0 \mathrm{ab} \quad(37.4-42.3)$ & $1.6 \mathrm{a}(1.3-1.8)$ & $47.0 \mathrm{a} \quad(43.6-49.9)$ \\
\hline Siliwanga & $41.2 \mathrm{a} \quad(35.6-47.7)$ & $1.5 \mathrm{a}(1.4-2.0)$ & $47.1 \mathrm{a} \quad(42.2-51.0)$ \\
\hline Tamadue & $(39.0-44.4)$ & $1.6 \mathrm{a}(1.3-2.4)$ & $45.6 \mathrm{a} \quad(42.4-48.9)$ \\
\hline
\end{tabular}

Medians are given because variables were not normally distributed.

Medians in a column followed by different letters are significantly different at $\mathrm{P} \leq 0.05$.

Median $\mathrm{P}$ and $\mathrm{Mg}$ contents of cacao leaves did not differ among villages (Table 3.28). In Siliwanga, cacao leaves had markedly higher K contents than those in Tamadue, but lower $\mathrm{Ca}$ contents than those of Wuasa and Wanga. Median Fe contents did not differ among villages (data not shown, see Appendix 25). Although P contents of leaf samples were never rated as severely deficient, $50 \%$ of the samples did not reach the 'normal' $\mathrm{P}$ level (see 2.7.3). Concerning K contents, no sample reached the 'normal' $\mathrm{K}$ level, and nearly $70 \%$ were rated as severely deficient. $\mathrm{K}$ deficiency differed in the villages surveyed: in Wanga and Siliwanga, only less than $50 \%$ of the samples were rated as severely deficient, in Wuasa and Rompo about $60 \%$ and in Tamadue 100\%. However, $\mathrm{Ca}$ contents of all samples exceeded the 'normal' level. This applied also for $\mathrm{Mg}$ contents of most of the samples. Only about $13 \%$ of the leaf samples did not reach the 'normal' level of Mg. Concerning Fe contents, $55 \%$ of the samples were rated as deficient, nearly $40 \%$ as severely deficient. 
Table 3.28. Median P, $K, C a$, and $M g$ contents of cacao leaves sampled in 40 homegardens of five villages of the Napu valley, Central Sulawesi, 2004. $N=9$ each in Wuasa and Tamadue; $N=8$ each in Rompo and Siliwanga; $N=6$ in Wanga.

\begin{tabular}{lcclllll}
\hline & \multicolumn{2}{c}{ P content $(\%)$} & \multicolumn{2}{c}{ K content $(\%)$} & \multicolumn{2}{c}{ Ca content $(\%)$} & \multicolumn{2}{c}{ Mg content $(\%)$} \\
\hline Wuasa & $0.20 \mathrm{a}(0.15-0.25)$ & $1.04 \mathrm{ab}(0.69-1.42)$ & $1.66 \mathrm{a}$ & $(1.07-2.06)$ & $0.58 \mathrm{a}$ & $(0.46-0.76)$ \\
Rompo & $0.20 \mathrm{a}(0.17-0.24)$ & $1.08 \mathrm{ab}(0.67-1.34)$ & $1.48 \mathrm{ab}(0.92-1.89)$ & $0.54 \mathrm{a}$ & $(0.45-0.74)$ \\
Wanga & $0.18 \mathrm{a}$ & $(0.15-0.34)$ & $1.21 \mathrm{ab}(0.61-1.68)$ & $1.72 \mathrm{a}$ & $(1.20-2.34)$ & $0.59 \mathrm{a}$ & $(0.43-0.79)$ \\
Siliwanga & $0.22 \mathrm{a}$ & $(0.13-0.28)$ & $1.29 \mathrm{a}(0.77-1.83)$ & $1.08 \mathrm{~b}$ & $(0.78-1.71)$ & $0.59 \mathrm{a}$ & $(0.44-0.86)$ \\
Tamadue & $0.22 \mathrm{a}$ & $(0.17-0.27)$ & $0.75 \mathrm{~b}(0.42-1.18)$ & $1.42 \mathrm{ab}(1.04-1.80)$ & $0.63 \mathrm{a}$ & $(0.41-0.81)$ \\
\hline
\end{tabular}

Medians are given because variables were not normally distributed.

Medians in a column followed by different letters are significantly different at $\mathrm{P} \leq 0.05$.

Nutrient contents in cacao leaves and in the corresponding soils correlated only for some nutrients. $\mathrm{K}$ contents in the leaves were related strongly and positively to $\mathrm{K}$ contents $(\mathrm{r}=0.57$; $\mathrm{P}<0.001)$ and $\mathrm{P}-\mathrm{Bray}$ contents $(\mathrm{r}=0.57 ; \mathrm{P}<0.001)$ of the soil, but negatively to soil $\mathrm{Mg}$ contents $(\mathrm{r}=-0.34 ; \mathrm{P}=0.039)$. $\mathrm{Mg}$ contents of the leaves were not influenced by soil $\mathrm{Mg}$ contents, but were related negatively to soil $\mathrm{P}-\mathrm{Bray}(\mathrm{r}=-0.43 ; \mathrm{P}=0.008)$ and $\mathrm{K}$ contents $(\mathrm{r}=$ -0.48; $\mathrm{P}=0.003)$. N, P, Fe, and Ca contents of cacao leaves were not influenced by any soil parameter studied.

\subsection{Case studies}

\subsubsection{Management details}

In the three homegardens studied in detail for a time period of 15 days each, the most frequent management activities carried out were sweeping and harvesting. Both activities were done almost daily, mostly by the wives, and lasted about $25 \mathrm{~min}$. every day on average (Figure 3.24). However, the migrant garden was swept only once in this period. In this garden, nearly every day some fodder for cattle and pig was cut and chopped. For the migrant family, cutting fodder was the most time-consuming activity, lasting more than one hour per day. Hoeing was a rather frequent task in all homegardens, carried out 2-3 times per week. Wives spent about 10-20 min. per day on hoeing, sometimes supported by their husbands or sons (Figure 3.24). Pruning cacao and fencing the garden were rather seasonal activities, carried out mostly by the household heads.

Overall daily time investment in homegardening was $13 \mathrm{~min} . / 100 \mathrm{~m}^{2}$ on average in the small spice garden and about $5 \mathrm{~min} . / 100 \mathrm{~m}^{2}$ in the large fruit tree and the very large migrant garden each. Wives conducted $54-74 \%$ of the total homegarden work, household heads $12-46 \%$. Children helped only in the migrant garden, contributing $27 \%$ of the work. Instead, the already adult children of the two local families were engaged in cultivating paddy rice fields or doing cooperative and wage labour (Figure 3.25). Regarding the agricultural work activities of the whole family, homegardening accounted for only about $7 \%$ of the local families' time, but $15 \%$ of the migrant family's time. The family managing the spice garden was mostly engaged in paddy rice cultivation ( $62 \%$ of total time) and tending its plantation $(30 \%)$. For the family owning the fruit garden, paddy rice cultivation was only a minor task in the time period documented, accounting for only about $13 \%$ of the total active time. Instead, this family spent about $33 \%$ of its time in the plantation and for cooperative work, each. The migrant family was mainly engaged in paddy rice cultivation that consumed $68 \%$ of the 
working time. Besides, cattle husbandry and cooperative work accounted for $8-10 \%$ of the family's total working time.

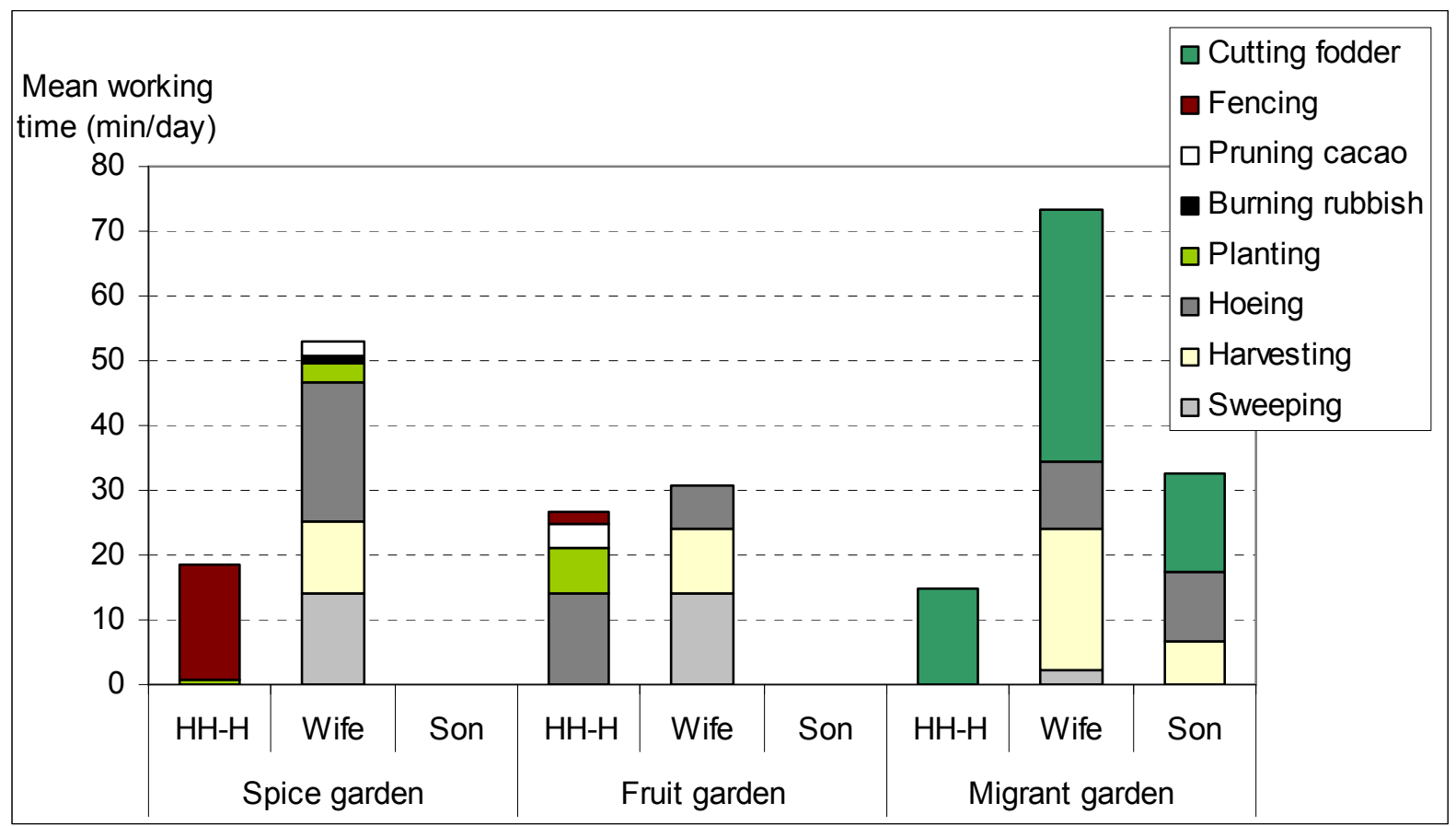

Figure 3.24. Mean daily time and work allocation among family members in homegarden management studied during 15 days in three different homegarden types in the Napu valley, Central Sulawesi, in 2004 $(H H-H=$ Household head $)$. Homegarden sizes: Spice garden $=580 \mathrm{~m}^{2} ;$ Fruit garden $=1050 \mathrm{~m}^{2}$; migrant garden $=2420 \mathrm{~m}^{2}$.

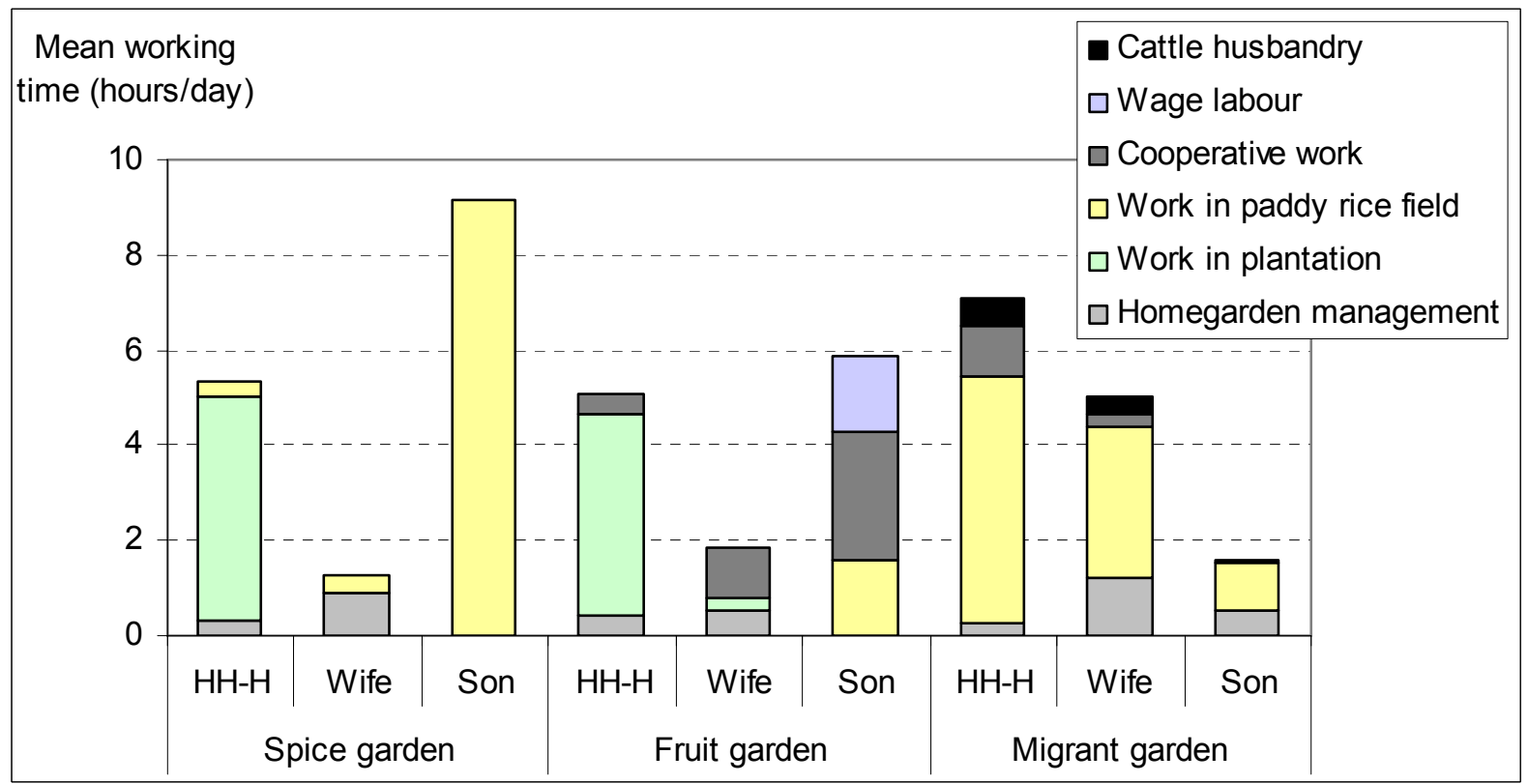

Figure 3.25. Mean daily time allocation to different farm operations among family members studied during 15 days in three different homegarden types in the Napu valley, Central Sulawesi, in 2004 (HH-H = Household head). 
In the spice and fruit gardens, the most frequently harvested crops were different spices such as spring onion or lemon grass. Spices were harvested by the local families every day in rather small amounts, i.e. one mixed portion per day with a monetary value of about 500 IR $(10,000$ $\mathrm{IR} \approx 1$ Euro in March 2004) (Figure 3.26). The migrant family only harvested 7 portions of spices in the same time period. Vegetables such as cassava or Vigna leaves were harvested 35 times during the 15 days studied only in the spice and migrant gardens. The value of the harvested vegetables also was about 500 IR per portion. In all three families interviewed, 50\% (fruit garden) to $76 \%$ (migrant garden) of the value of vegetables, spices, and fruits consumed in the 15 days surveyed was covered by products from their homegardens, the remainder was obtained from their plantations, by gifts, or, in the case of the migrants, from the shop. For the family managing the spice garden, cash income derived from sales of cacao cultivated in their homegardens was the only cash income source during the observed time period, whereas for the family managing the fruit garden, it accounted for only $28 \%$ of the total income. Cacao was harvested 6 times in the spice garden ( $4.5 \mathrm{~kg}$ dry seeds) and 2 times in the fruit garden (2 $\mathrm{kg}$ dry seeds) during the study period, fetching a price of $8,700 \mathrm{IR} / \mathrm{kg}$.

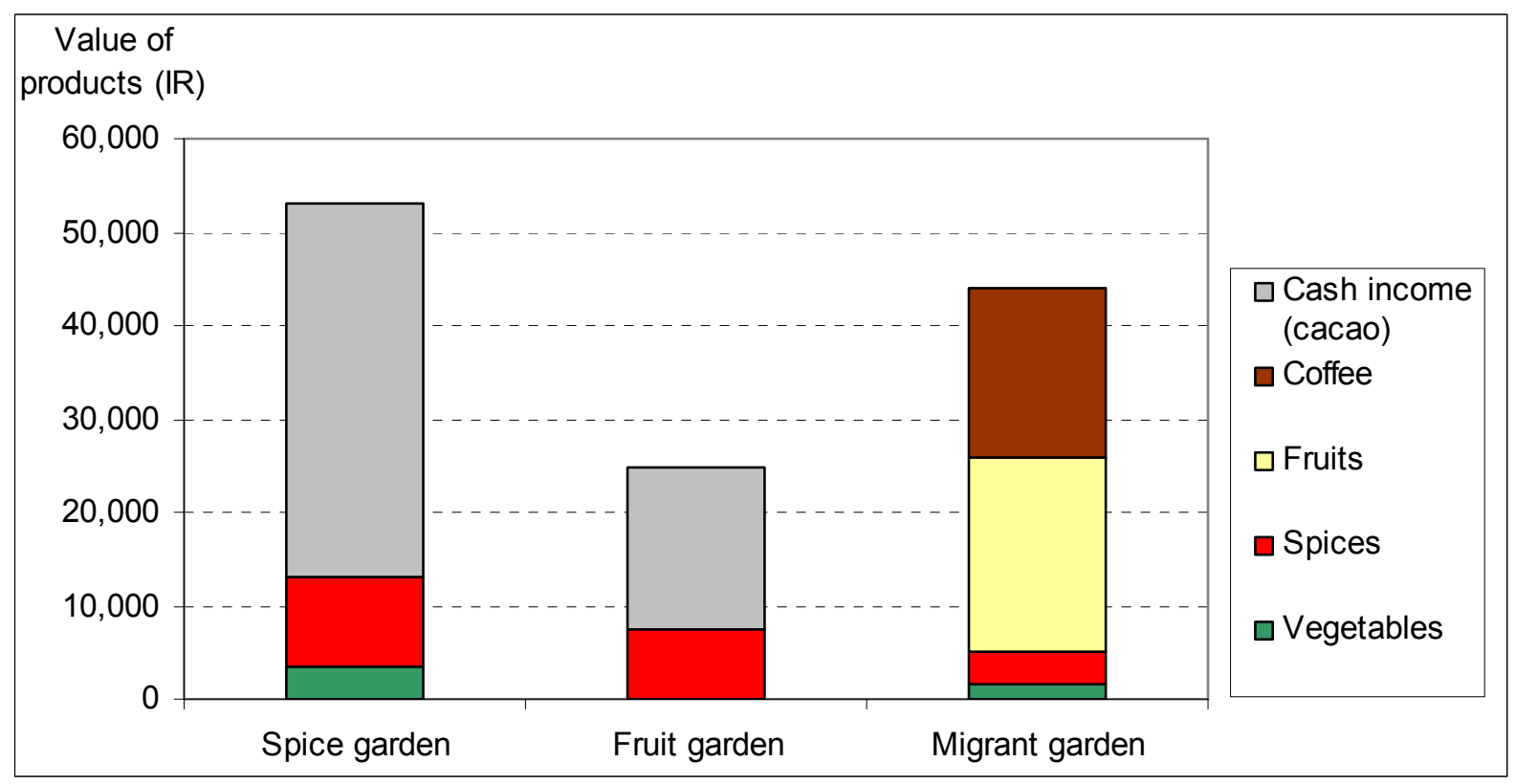

Figure 3.26. Monetary value of homegarden products harvested for sale and for home consumption during 15 days in three different homegarden types in the Napu valley, Central Sulawesi, in 2004. 10,000 IR $\approx 1$ Euro (March 2004).

The migrant family did not gain any cash income from their homegarden (Figure 3.26). They harvested $4.5 \mathrm{~kg}$ dry coffee seeds with a value of $4,000 \mathrm{IR} / \mathrm{kg}$, but only for their own consumption. The most important products from the migrant garden were fruits and fodder, harvested nearly every day. As fodder was not sold at markets in the region, no monetary value could be assessed. For all the fruits harvested, mainly mandarins and guavas, a total value of 21,000 IR was calculated. The two local families did not harvest any fruits during the 15 days studied because they mainly cultivated seasonal fruit species in their homegardens, e.g. mango and avocado. In the migrant garden, banana leaves for wrapping were harvested once, and flowers as well as fragrant screw pine leaves for sacrifices several times. The staple 
crop rice was obtained from own paddy rice fields in sufficient amount by all three families. Therefore, no staple crops were harvested in the homegardens during the observation period. Besides, neither medicinal plants nor fuel wood or timber were harvested in the same time.

In summary, homegarden management was a rather small part of the overall activities in the three families studied. Homegardens were worked in only 1-2 hours per day, mainly by women who spent much time on harvesting and hoeing. Men were rather engaged in cultivating plantations or paddy rice fields. The main function of homegardens was different among the families studied. The spice and fruit gardens, managed by local families, served both for subsistence and income generation, whereas all products of the migrant garden were consumed by the family.

\subsubsection{Map and tree canopy cover}

A detailed map of garden no. 8 (spice garden, Wuasa) is given in Appendix 26. Canopy cover of tree species and bananas higher than $2 \mathrm{~m}$ was calculated as $21.3 \%$ of the cultivated garden area for the stratum $2-5 \mathrm{~m}, 3.5 \%$ for the stratum $5-10 \mathrm{~m}$, and $4.1 \%$ for the stratum $>10 \mathrm{~m}$.

\subsubsection{Soil quality and erosion}

Soil quality varied largely among the three homegarden case studies as well as among different production zones of the same garden (Table 3.29, Table 3.30, and Table 3.31). In general, soil quality was higher in the spice and the fruit gardens than in the migrant garden. Particularly available P content was rather low in the migrant homegarden. The spice garden was never fertilised according to the gardener. Soil quality was markedly lower in the vegetable zone of this garden than in the cacao zone (Table 3.29). Large differences between production zones were present particularly in available $\mathrm{P}$ and exchangeable Al contents. Low nutrient contents in the vegetable zone might be related to the habit of daily sweeping there. On the other hand, litter was collected in garbage pits in the back yard, e.g. under the cacao trees, and occasionally burned, causing probably the higher soil nutrient contents in the cacao zone.

Table 3.29. Median chemical and physical soil quality parameters (ranges in brackets) in the vegetable and cacao production zones of homegarden no. 8, belonging to the type 'small spice garden' and located in Wuasa, Napu valley, Central Sulawesi. Significantly higher values are given in bold.

\begin{tabular}{lrr}
\hline Spice garden & \multicolumn{2}{c}{$\begin{array}{c}\text { Vegetable zone } \\
(\mathrm{N}=5)\end{array}$} \\
\hline $\mathrm{pH}\left(\mathrm{H}_{2} \mathrm{O}\right)$ & $\begin{array}{c}\text { Cacao zone } \\
(\mathrm{N}=5)\end{array}$ \\
$\mathrm{N}(\%)$ & $5.8 \mathrm{a}(5.2-6.0)$ & $6.1 \mathrm{a}(5.6-6.2)$ \\
$\mathrm{P}-\mathrm{Bray}(\mathrm{ppm})$ & $0.10 \mathrm{~b}(0.04-0.13)$ & $\mathbf{0 . 1 3 a}(0.11-0.17)$ \\
Exchangeable $\mathrm{Al}(\mathrm{cmol} / \mathrm{kg})$ & $18.8 \mathrm{~b}(17.9-36.3)$ & $\mathbf{1 7 1 . 5 a}(88.4-250.5)$ \\
Exchangeable $\mathrm{Ca}(\mathrm{cmol} / \mathrm{kg})$ & $\mathbf{0 . 3 5 a}(0.25-0.58)$ & $0.10 \mathrm{~b}(0.09-0.16)$ \\
Exchangeable $\mathrm{K}(\mathrm{cmol} / \mathrm{kg})$ & $5.83 \mathrm{~b}(3.52-6.57)$ & $\mathbf{8 . 1 8 a}(7.45-8.55)$ \\
$\mathrm{CEC}$ eff. $(\mathrm{cmol} / \mathrm{kg})$ & $0.18 \mathrm{~b}(0.16-0.20)$ & $\mathbf{0 . 4 4 a}(0.25-0.57)$ \\
Base saturation $(\%)$ & $7.95 \mathrm{~b}(4.76-8.32)$ & $\mathbf{1 1 . 8 8 a}(10.73-12.18)$ \\
Sand $(\%)$ & $91.9 \mathrm{~b}(88.6-94.5)$ & $\mathbf{9 7 . 4 a}(95.3-97.7)$ \\
Clay $(\%)$ & $61.2 \mathrm{a}(52.2-81.5)$ & $52.1 \mathrm{a}(46.6-54.1)$ \\
\hline
\end{tabular}

Medians are given because variables were not normally distributed.

Medians in a row followed by different letters are significantly different at $\mathrm{P} \leq 0.05$. 
The fruit tree garden was occasionally fertilised with ash in the vegetable zone and with farm yard manure in the cacao zone, according to the gardener. In this garden, soil quality did not differ very much among the production zones (Table 3.30). However, $\mathrm{pH}$ value and base saturation were significantly higher, but $\mathrm{N}$ and exchangeable $\mathrm{Al}$ contents lower in the vegetable than in the cacao zone. All other chemical soil properties showed slightly higher values in the vegetable than in the cacao zone. Occasional fertilising of the rather small vegetable zone with ash might have caused its higher soil quality.

Table 3.30. Median chemical and physical soil quality parameters (ranges in brackets) in the vegetable and cacao production zones of homegarden no. 10, belonging to the type 'large fruit tree garden' and located in Wuasa, Napu valley, Central Sulawesi. Significantly higher values are given in bold.

\begin{tabular}{lrr}
\hline Fruit garden & \multicolumn{2}{c}{$\begin{array}{c}\text { Vegetable zone } \\
(\mathrm{N}=4)\end{array}$} \\
\hline $\mathrm{pH}\left(\mathrm{H}_{2} \mathrm{O}\right)$ & \multicolumn{1}{c}{$\begin{array}{c}\text { Cacao zone } \\
(\mathrm{N}=5)\end{array}$} \\
$\mathrm{N}(\%)$ & $0.12 \mathrm{~b}(7.1-7.2)$ & $5.7 \mathrm{~b}(5.5-5.9)$ \\
$\mathrm{P}-\mathrm{Bray}(\mathrm{ppm})$ & $435.8 \mathrm{a}(419.9-733.8)$ & $\mathbf{0 . 1 4 a}(0.13-0.19)$ \\
Exchangeable $\mathrm{Al}(\mathrm{cmol} / \mathrm{kg})$ & $0.09 \mathrm{~b}(0.089-0.092)$ & $328.8 \mathrm{a}(174.0-470.8)$ \\
Exchangeable $\mathrm{Ca}(\mathrm{cmol} / \mathrm{kg})$ & $9.30 \mathrm{a}(5.18-14.82)$ & $\mathbf{0 . 1 4 a}(0.12-0.31)$ \\
Exchangeable $\mathrm{K}(\mathrm{cmol} / \mathrm{kg})$ & $0.85 \mathrm{a}(0.52-1.00)$ & $5.68 \mathrm{a}(5.31-7.72)$ \\
$\mathrm{CEC}$ eff. $(\mathrm{cmol} / \mathrm{kg})$ & $12.32 \mathrm{a}(7.09-17.22)$ & $0.57 \mathrm{a}(0.33-0.63)$ \\
Base saturation $(\%)$ & $\mathbf{9 9 . 1 a}(98.7-99.3)$ & $8.33 \mathrm{a}(7.78-11.25)$ \\
Sand $(\%)$ & $79.6 \mathrm{a}(76.4-88.9)$ & $96.7 \mathrm{~b}(93.1-97.1)$ \\
Clay $(\%)$ & $11.2 \mathrm{a}(6.8-12.0)$ & $66.2 \mathrm{a}(60.6-78.5)$ \\
\hline
\end{tabular}

Medians are given because variables were not normally distributed.

Medians in a row followed by different letters are significantly different at $\mathrm{P} \leq 0.05$.

In the large migrant garden, the gardeners regularly fertilised nearly exclusively the cacao production zone near the house with ash and farm yard manure. This has probably caused the markedly higher values of most of the soil quality parameters in the cacao than in the cassava zone (Table 3.31). High patchiness of soil quality in the cacao zone, e.g. in available $\mathrm{P}$ content, might be related to raising pigs in a small part of this zone in the past. The soil in the back yard garden, covered mainly by weeds and used only extensively for cassava and fodder production, was characterised by rather poor soil quality.

Table 3.31. Median chemical and physical soil quality parameters (ranges in brackets) in the vegetable and cacao production zones of homegarden no. 29, belonging to the type 'very large migrant garden' and located in the migrant village Siliwanga, Napu valley, Central Sulawesi. Significantly higher values are given in bold.

\begin{tabular}{lrr}
\hline Migrant garden & \multicolumn{2}{c}{$\begin{array}{c}\text { Cassava zone } \\
(\mathrm{N}=5)\end{array}$} \\
\hline $\mathrm{pH}\left(\mathrm{H}_{2} \mathrm{O}\right)$ & $5.9 \mathrm{~b}(5.3-6.0)$ & $\begin{array}{c}\text { Cacao zone } \\
(\mathrm{N}=5)\end{array}$ \\
$\mathrm{N}(\%)$ & $0.20 \mathrm{a}(0.15-0.23)$ & $\mathbf{6 . 2 a}(6.0-7.0)$ \\
$\mathrm{P}-\mathrm{Bray}(\mathrm{ppm})$ & $25.8 \mathrm{a}(11.3-30.2)$ & $0.20 \mathrm{a}(0.19-0.23)$ \\
Exchangeable $\mathrm{Al}(\mathrm{cmol} / \mathrm{kg})$ & $\mathbf{0 . 2 0 a}(0.14-1.50)$ & $38.6 \mathrm{a}(23.4-313.2)$ \\
Exchangeable $\mathrm{Ca}(\mathrm{cmol} / \mathrm{kg})$ & $3.72 \mathrm{~b}(1.66-4.86)$ & $0.12 \mathrm{~b}(0.10-0.14)$ \\
Exchangeable $\mathrm{K}(\mathrm{cmol} / \mathrm{kg})$ & $0.15 \mathrm{~b}(0.08-0.20)$ & $\mathbf{6 . 3 0 a}(4.92-9.44)$ \\
$\mathrm{CEC}$ eff. $(\mathrm{cmol} / \mathrm{kg})$ & $6.47 \mathrm{~b}(4.36-8.12)$ & $\mathbf{0 . 6 1 a}(0.28-1.07)$ \\
Base saturation $(\%)$ & $96.0 \mathrm{~b}(60.6-97.0)$ & $\mathbf{1 0 . 6 1 a}(9.72-15.37)$ \\
Sand $(\%)$ & $45.4 \mathrm{a}(36.7-47.6)$ & $\mathbf{9 8 . 3 a}(96.2-99.3)$ \\
Clay $(\%)$ & $11.9 \mathrm{a}(9.9-19.7)$ & $49.3 \mathrm{a}(29.6-55.1)$ \\
\hline
\end{tabular}

Medians are given because variables were not normally distributed.

Medians in a row followed by different letters are significantly different at $\mathrm{P} \leq 0.05$. 
The analysis of Caesium-137 for assessing soil erosion did not yield useful results because in all soil samples content of Caesium-137 was rather low (Table 3.32). In many samples, particularly of the fruit garden, Caesium-137 content even was below the limit of detection. Results given in Table 3.32 were, therefore, tainted with much uncertainty. However, soil erosion was an obvious and severe problem in some homegardens of the research area, as shown in Figure 3.27.

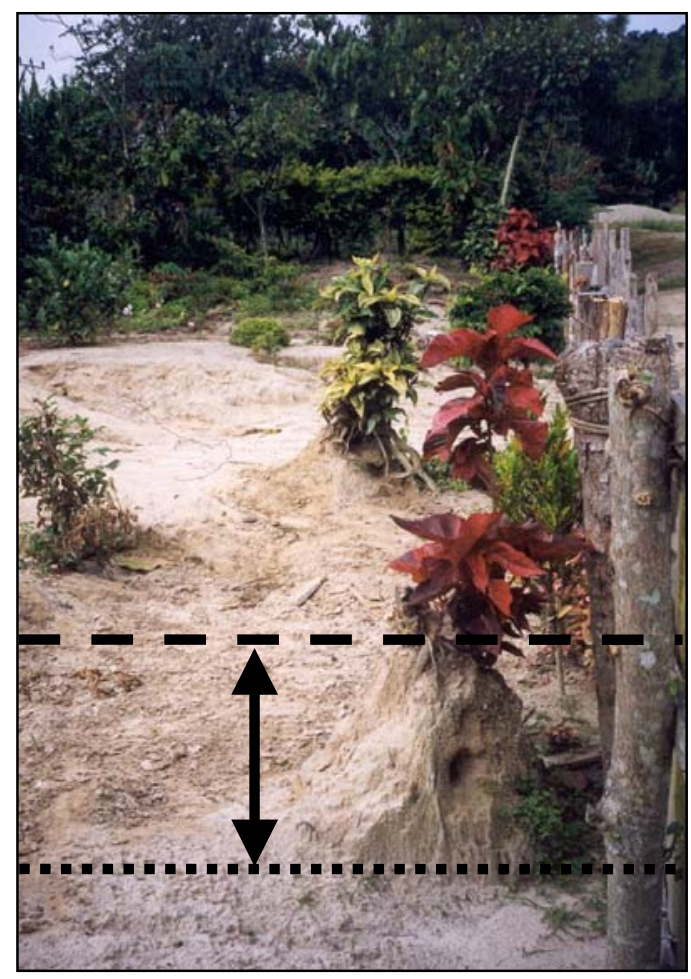

Figure 3.27. An example of soil erosion in the front yard of a homegarden in Rompo, Napu valley, Central Sulawesi, 2004. The broken line indicates soil surface during planting of the ornamentals along the fence; the dotted line shows the present surface. Difference was about $30 \mathrm{~cm}$.

Table 3.32. Mean activity of Caesium-137 (range in brackets) in top soil of vegetable and cacao zones of the spice and fruit gardens, and of cassava and cacao zones in the migrant garden as well as in soil of two undisturbed reference zones (forest and grassland), Napu valley, Central Sulawesi, in 2004.

\begin{tabular}{|c|c|c|c|c|c|c|c|c|}
\hline & \multicolumn{8}{|c|}{ Cs-137 activities $(\mathrm{Bq} / \mathrm{kg})$} \\
\hline & \multicolumn{2}{|c|}{ Vegetable/cassava zone } & \multicolumn{3}{|c|}{ Cacao zone } & \multicolumn{3}{|c|}{ Reference zone } \\
\hline Spice garden & $\mathrm{N}=2 \quad 0.7$ & $(0.59-0.74)$ & $\mathrm{N}=2$ & 1.7 & $(1.78-1.59)$ & & & \\
\hline Fruit garden & n.a. & & & n.a. & & & & \\
\hline Migrant garden & $\mathrm{N}=3 \quad 1.3$ & $(1.08-1.49)$ & $\mathrm{N}=4$ & 1.4 & $(1.31-1.46)$ & & & \\
\hline Forest Wuasa & & & & & & $\mathrm{N}=3$ & 1.4 & $(0.99-1.79)$ \\
\hline $\begin{array}{l}\text { Grassland } \\
\text { Siliwanga }\end{array}$ & & & & & & $\mathrm{N}=3$ & 0.8 & $(0.73-0.84)$ \\
\hline
\end{tabular}

Note: n.a. $=$ not available.

Comparing sand and clay contents of different production zones within single homegardens might serve as a substitute for a rough assessment of soil erosion. This seemed to be meaningful because mainly the frequently swept and hoed vegetable zones were affected by laminar soil erosion. Probably, clay particles might first be washed out from the soil, thus, leading to decreasing clay, but increasing sand contents. For the two homegardens with a vegetable zone (i.e. the spice and fruit gardens), texture analysis showed a slightly, but not 
significantly higher sand content in the vegetable than in the cacao zones (Table 3.29 and Table 3.30). However, clay contents did not differ among production zones.

To prove such differences for a larger sample size, all homegardens with a distinct vegetable and cacao zone were included into the analysis $(\mathrm{N}=17)$ (see 3.6.5). For homegardens cultivated for more than 20 years $(\mathrm{N}=9)$, texture analysis showed a markedly higher mean sand and lower mean clay content in vegetable (sand 63.1\%, clay $16.6 \%$ ) than in adjacent cacao zones (sand $55.9 \%$, clay 20.5\%). Differences were significant only for the clay contents. No differences in sand and clay contents between vegetable and cacao zones were detected in homegardens cultivated for less than 20 years $(\mathrm{N}=8)$.

\subsubsection{Microclimate and Photosynthetic Active Radiation (PAR)}

Besides soil quality, also microclimate and insolation might differ among production zones in the three case study homegardens (Figure 3.28, Figure 3.29, and Figure 3.31), thus, offering suitable micro-environments for several production tasks. Mean temperatures of air and soil decreased significantly from bare space to vegetable/cassava zones and from these to cacao/tree zones in all three homegardens, except for the migrant garden, where mean air temperatures of cassava and cacao zones were similar (Table 3.33, Table 3.34). Maximum soil and air temperatures were highest at bare space, intermediate in the vegetable or cassava production zones, and lowest in the cacao or tree zones of all three homegardens investigated (Table 3.33, Table 3.34). During the day time, temperature differences among production zones were markedly higher in the soil than in the air, especially around midday (Figure 3.30). Mean amplitudes of soil and air temperatures were highest at bare spaces and lowest in cacao/tree zones (Table 3.33, Table 3.34). Comparisons among the three homegardens were difficult, due to different weather conditions during the three time periods of measurement. Besides, partial shading slightly reduced maximum temperature at the bare place in the fruit garden, where no totally 'bare' place could be found for reference measurement.

Table 3.33. Mean overall soil temperatures (ranges in brackets), mean minimum, maximum, and amplitudes (all values in ${ }^{\circ} \mathrm{C}$ ) in different production zones of three different homegarden types in the Napu valley, Central Sulawesi, in 2004. For the different time periods of measurement, see Figure 3.30.

\begin{tabular}{llcccc}
\hline Garden type & Production zone & Overall mean & $\begin{array}{c}\text { Mean } \\
\text { minimum }\end{array}$ & $\begin{array}{c}\text { Mean } \\
\text { maximum }\end{array}$ & $\begin{array}{c}\text { Mean } \\
\text { amplitude }\end{array}$ \\
\hline Spice garden & Bare space & $25.3 \mathrm{a}(21.0-36.6)$ & $21.8 \mathrm{a}$ & $31.8 \mathrm{a}$ & $10.1 \mathrm{a}$ \\
& Cacao zone & $22.9 \mathrm{~b}(19.8-27.1)$ & $20.9 \mathrm{~b}$ & $25.6 \mathrm{~b}$ & $4.6 \mathrm{~b}$ \\
& Tree zone & $21.4 \mathrm{c}(19.8-22.9)$ & $20.6 \mathrm{c}$ & $22.4 \mathrm{c}$ & $1.8 \mathrm{c}$ \\
& & & & & \\
Fruit garden & Bare space & $24.1 \mathrm{a}(18.3-32.8)$ & $20.8 \mathrm{~b}$ & $29.7 \mathrm{a}$ & $8.9 \mathrm{a}$ \\
& Vegetable zone & $23.3 \mathrm{~b}(19.8-27.1)$ & $21.6 \mathrm{a}$ & $25.6 \mathrm{~b}$ & $3.9 \mathrm{~b}$ \\
& Cacao zone & $22.0 \mathrm{c}(20.2-23.6)$ & $21.1 \mathrm{~b}$ & $23.0 \mathrm{c}$ & $1.9 \mathrm{c}$ \\
\multirow{5}{*}{ Migrant garden } & Bare space & $25.2 \mathrm{a}(20.2-35.7)$ & $21.5 \mathrm{a}$ & $31.7 \mathrm{a}$ & $10.3 \mathrm{a}$ \\
& Cassava zone & $23.5 \mathrm{~b}(20.6-27.5)$ & $21.5 \mathrm{a}$ & $26.3 \mathrm{~b}$ & $4.8 \mathrm{~b}$ \\
& Cacao zone & $21.1 \mathrm{c}(19.8-22.5)$ & $20.5 \mathrm{~b}$ & $21.8 \mathrm{c}$ & $1.3 \mathrm{c}$ \\
\hline
\end{tabular}

Means in a column followed by different letters within one garden type are significantly different at $\mathrm{P} \leq 0.05$. 
Table 3.34. Mean overall air temperatures (ranges in brackets), mean minimum, maximum, and amplitudes (all values in ${ }^{\circ} \mathrm{C}$ ) in different production zones of three different homegarden types in the Napu valley, Central Sulawesi, in 2004. For the different time periods of measurement, see Figure 3.30.

\begin{tabular}{llcccc}
\hline Garden type & Production zone & Overall mean & $\begin{array}{c}\text { Mean } \\
\text { minimum }\end{array}$ & $\begin{array}{c}\text { Mean } \\
\text { maximum }\end{array}$ & $\begin{array}{c}\text { Mean } \\
\text { amplitude }\end{array}$ \\
\hline Spice garden & Bare space & $22.3 \mathrm{a}(15.2-35.7)$ & $18.1 \mathrm{a}$ & $31.9 \mathrm{a}$ & $13.8 \mathrm{a}$ \\
& Cacao zone & $21.8 \mathrm{~b}(15.6-32.8)$ & $18.0 \mathrm{a}$ & $29.8 \mathrm{~b}$ & $11.8 \mathrm{~b}$ \\
& Tree zone & $21.3 \mathrm{c}(15.2-30.7)$ & $18.0 \mathrm{a}$ & $28.2 \mathrm{c}$ & $10.2 \mathrm{c}$ \\
\multirow{5}{*}{ Fruit garden } & Bare space & $22.2 \mathrm{a}(14.5-32.8)$ & $18.0 \mathrm{~b}$ & $29.9 \mathrm{a}$ & $11.9 \mathrm{a}$ \\
& Vegetable zone & $21.7 \mathrm{~b}(14.9-30.7)$ & $18.2 \mathrm{a}$ & $28.2 \mathrm{~b}$ & $10.0 \mathrm{~b}$ \\
& Cacao zone & $21.3 \mathrm{c}(14.9-29.1)$ & $18.2 \mathrm{a}$ & $26.8 \mathrm{c}$ & $8.6 \mathrm{c}$ \\
\multirow{5}{*}{ Migrant garden } & Bare space & $20.8 \mathrm{a}(14.1-32.3)$ & $15.7 \mathrm{~b}$ & $29.6 \mathrm{a}$ & $14.0 \mathrm{a}$ \\
& Cassava zone & $20.5 \mathrm{~b}(14.1-31.1)$ & $15.7 \mathrm{~b}$ & $28.6 \mathrm{~b}$ & $12.9 \mathrm{~b}$ \\
& Cacao zone & $20.5 \mathrm{~b}(14.5-30.7)$ & $16.4 \mathrm{a}$ & $27.8 \mathrm{c}$ & $11.4 \mathrm{c}$ \\
\hline
\end{tabular}

Means in a column followed by different letters within one garden type are significantly different at $\mathrm{P} \leq 0.05$.

Soil temperature in the different production zones was directly related to the duration of direct radiation near the soil surface (Figure 3.34). The longer the soil was exposed to direct sunlight, the higher was the soil temperature $\left(\mathrm{R}^{2}=0.851\right)$. These differences in radiation were responsible for different soil and air temperatures in cacao zones among the homegardens. In the spice garden, where cacao was planted rather sparsely and direct radiation reached the stratum of $0.3 \mathrm{~m}$ height for more than three hours a day (Figure 3.33), the daily maximum for soil temperature in the cacao zone was about $25^{\circ} \mathrm{C}$ (Figure 3.30). In the fruit and migrant gardens, where cacao was planted either under shade trees or rather densely, maximum temperatures were only about 23 and $22{ }^{\circ} \mathrm{C}$, respectively. Air temperature followed similar patterns: In the spice garden, the maximum in the cacao zone was about $29{ }^{\circ} \mathrm{C}$, whereas in the fruit and migrant gardens only 26 and $27{ }^{\circ} \mathrm{C}$, respectively. However, as measurements were not carried out simultaneously, influences of different weather conditions could have influenced the results. During temperature measurement periods, project weather stations in about $5 \mathrm{~km}$ distance from the homegardens investigated determined a mean air temperature of $21.1{ }^{\circ} \mathrm{C}, 21.3{ }^{\circ} \mathrm{C}$, and $20.3{ }^{\circ} \mathrm{C}$ in the spice, fruit, and migrant gardens, respectively. 

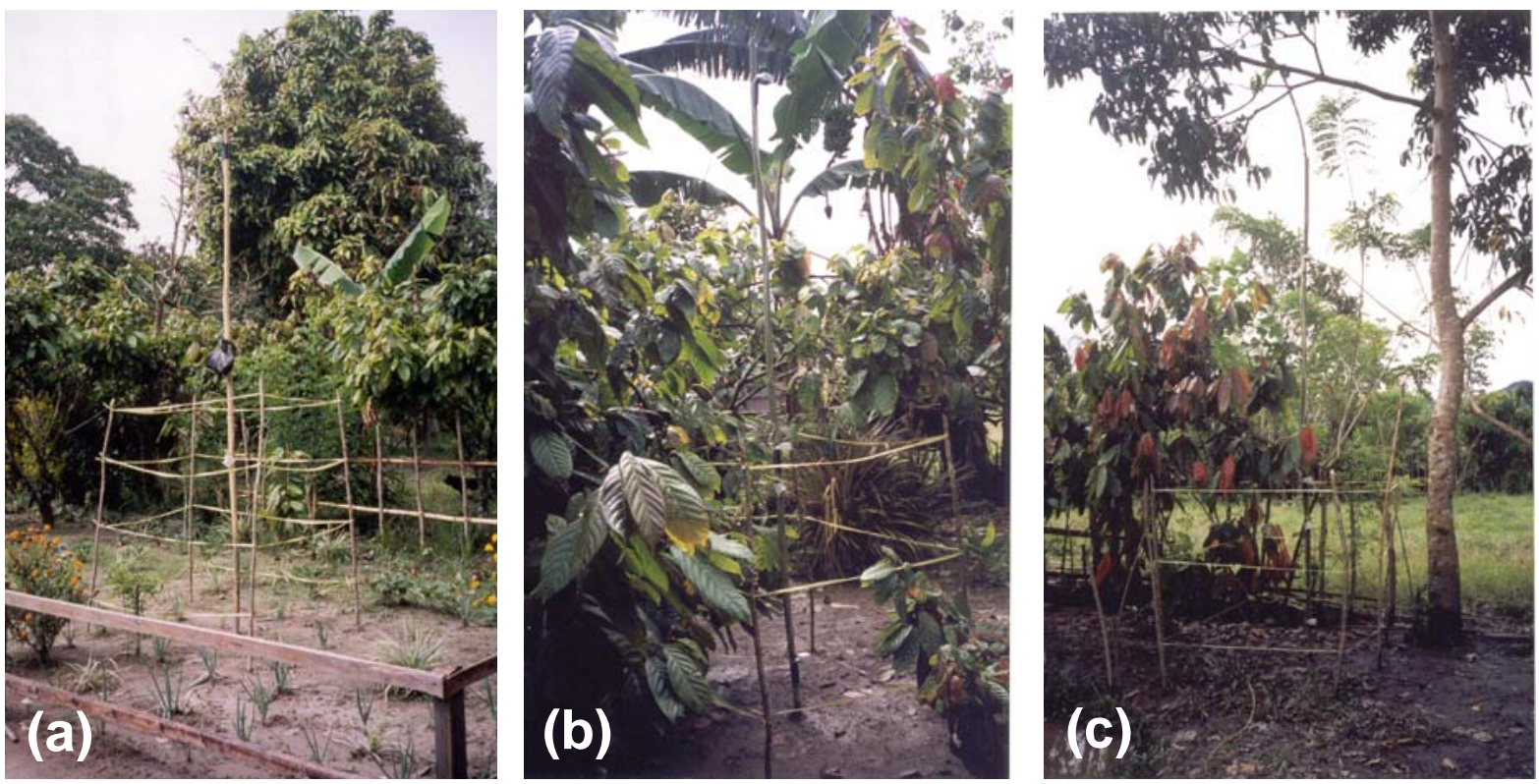

Figure 3.28. PAR measurement units in the small spice garden in Wuasa, Napu valley, Central Sulawesi. (a) The reference zone; (b) The cacao zone; (c) The tree zone.
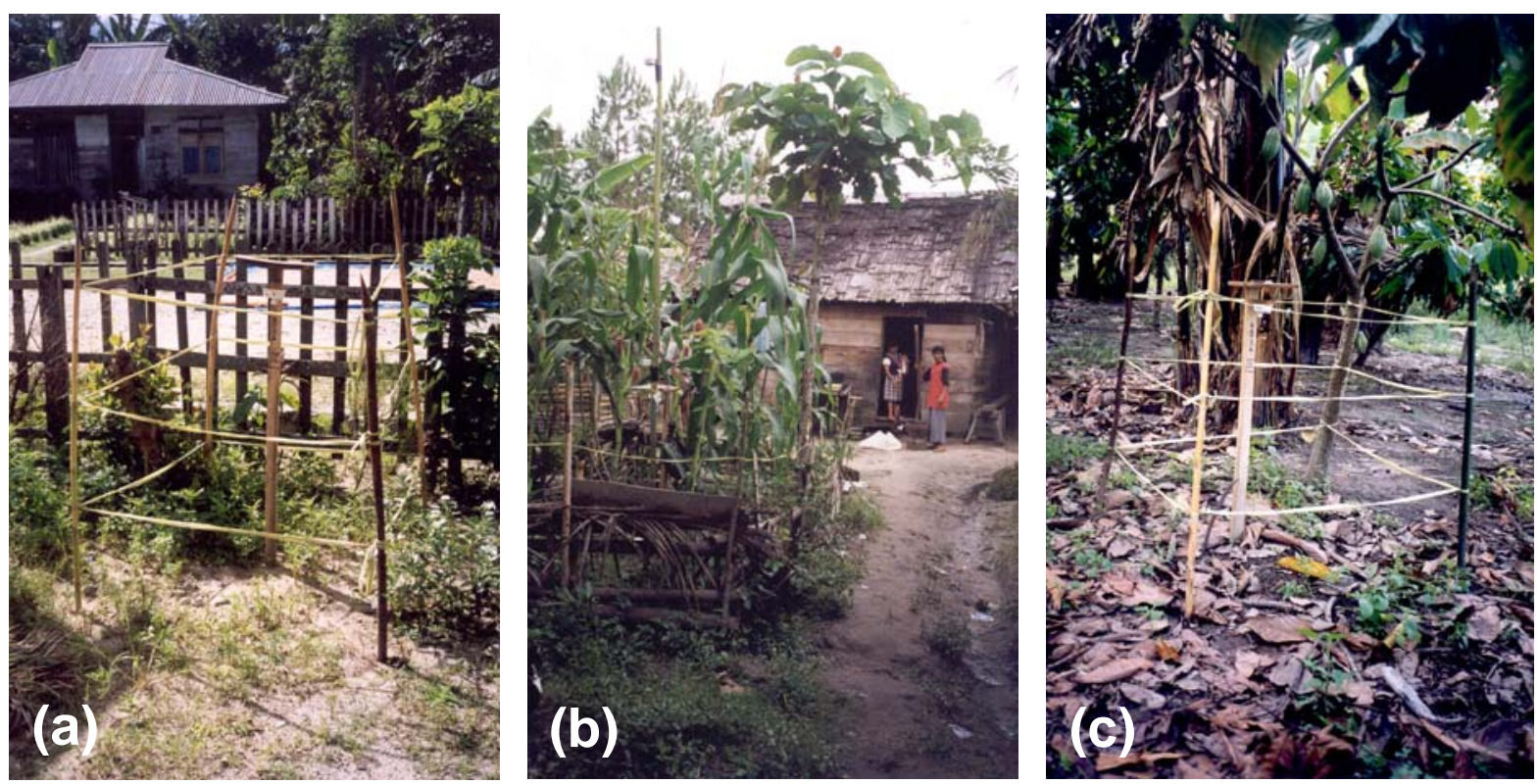

Figure 3.29. Temperature and PAR measurement units in the large fruit garden in Wuasa, Napu valley, Central Sulawesi. (a) The reference zone; (b) The vegetable zone; (c) The cacao zone. 
Soil temperature
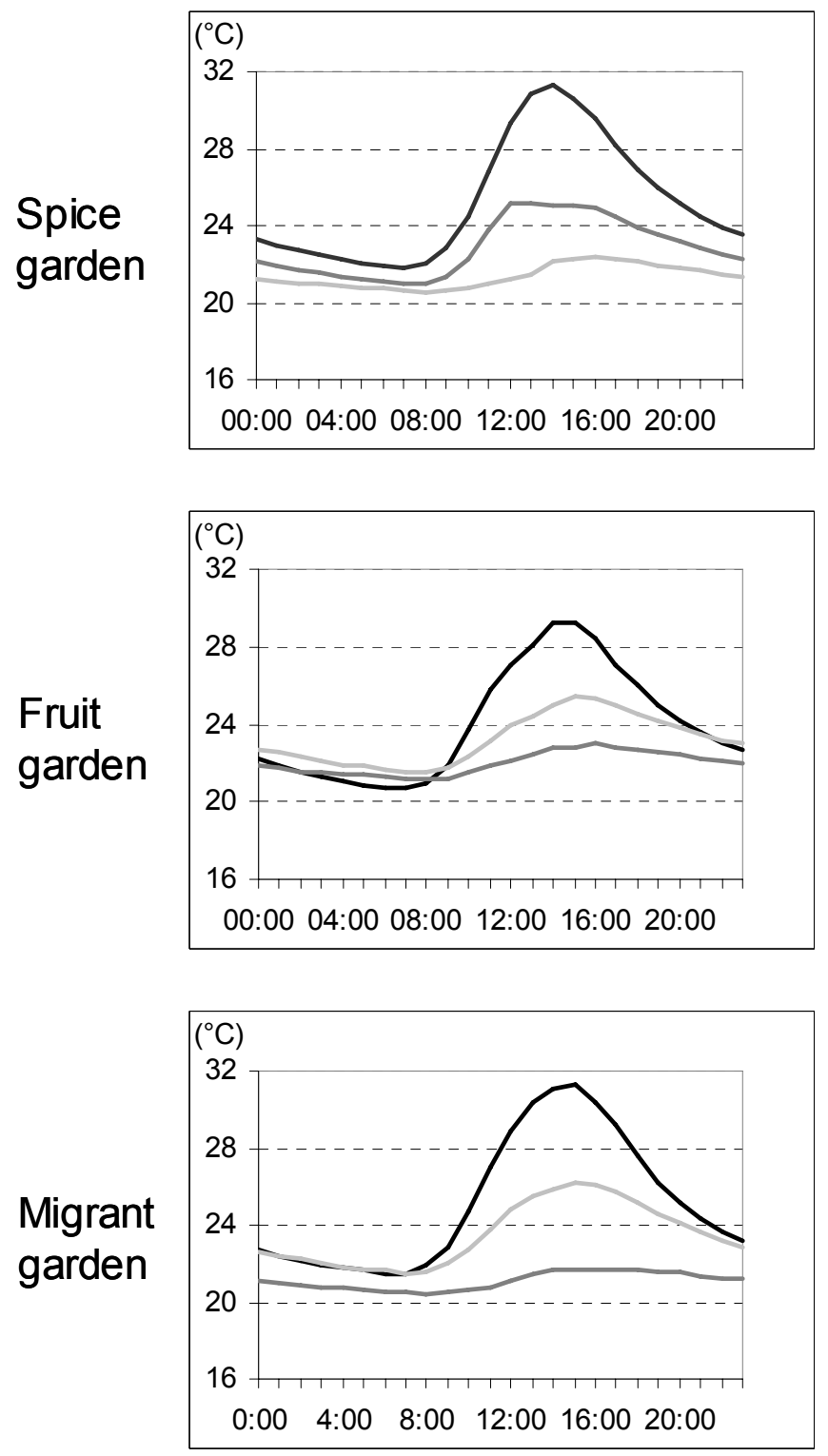

Air temperature
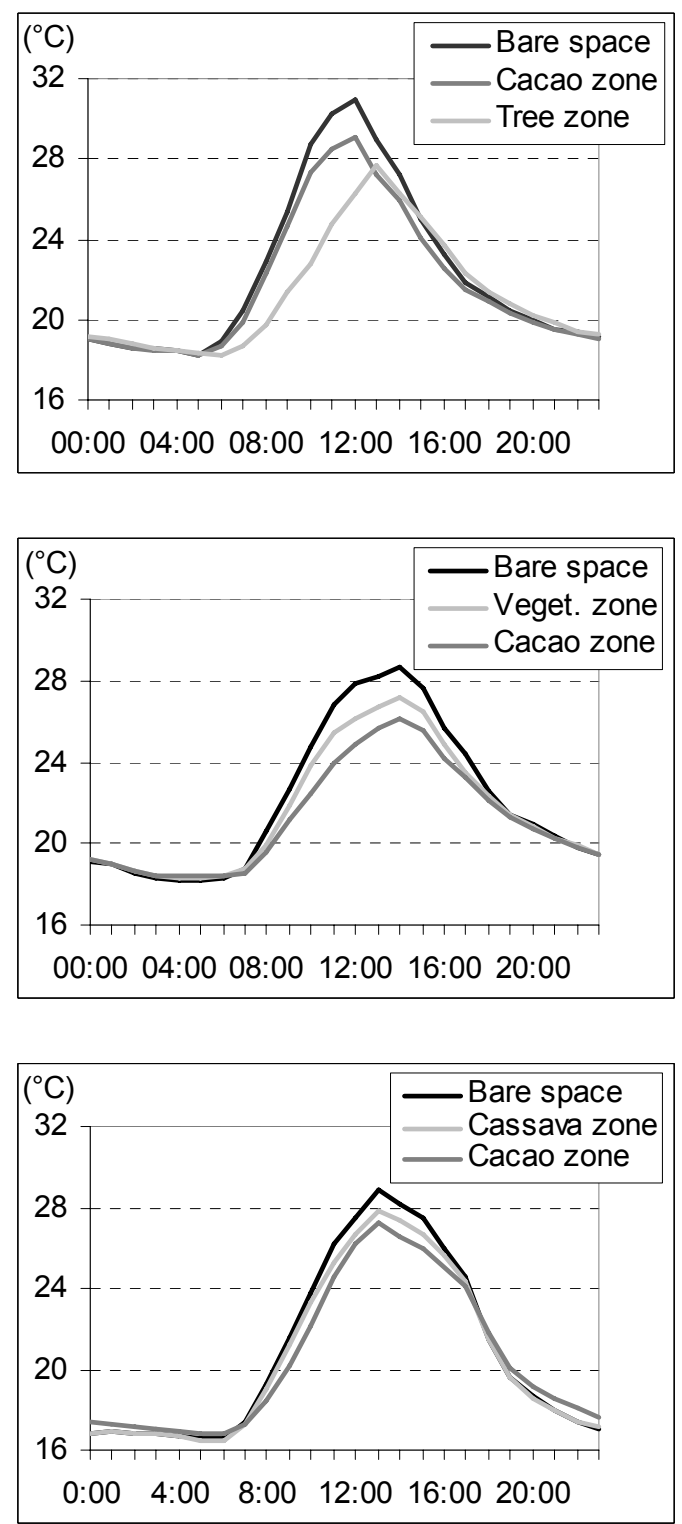

Figure 3.30. Mean daily courses of soil and air temperatures in different production zones of three different homegarden types in the Napu valley, Central Sulawesi, in 2004. Measurement periods: Spice garden $=27.03 .-13.04 .2004$; Fruit garden $=02.05 .-14.05 .2004$; Migrant garden $=21.05 .-$ 02.06.2004.

Photosynthetic Active Radiation (PAR) decreased markedly from higher to lower vegetation strata. Although variability was rather high, Figure 3.32 clearly shows different patterns among gardens. In the small spice garden (Figure 3.28), the cacao zone still received some direct radiation at $0.3 \mathrm{~m}$, namely $30 \%$ of the radiation at bare space (Table 3.35). Under the fruit trees, relative light intensity at $0.3 \mathrm{~m}$ and $1.3 \mathrm{~m}$ was less than $20 \%$ of the radiation in the open. At $3.0 \mathrm{~m}$, radiation under the fruit trees was also low, but in the cacao zone radiation was similar to that of the bare space, because cacao trees were rarely higher than $3.0 \mathrm{~m}$. 
Table 3.35. Mean relative light intensity in \% of bare space light intensity (ranges in brackets) in different strata and production zones of three homegardens in the Napu valley, Central Sulawesi, referring to diurnal sums (05:45-18:14 h). Duration of measurement was five days each (for exact time period see Figure 3.32).

\begin{tabular}{|c|c|c|c|c|c|c|c|}
\hline \multirow{2}{*}{$\begin{array}{c}\text { Garden } \\
\text { type }\end{array}$} & \multicolumn{4}{|c|}{ Strata in cacao zone } & \multicolumn{3}{|c|}{$\begin{array}{c}\text { Strata in: } \\
\text { Tree zone (spice garden)/ } \\
\text { Vegetable zone (fruit garden)/ } \\
\text { Cassava zone (migrant garden) }\end{array}$} \\
\hline & $0.3 \mathrm{~m}$ & $1.3 \mathrm{~m}$ & $3.0 \mathrm{~m}$ & $4.5 \mathrm{~m}$ & $0.3 \mathrm{~m}$ & $1.3 \mathrm{~m}$ & $3.0 \mathrm{~m}$ \\
\hline $\begin{array}{l}\text { Spice } \\
\text { garden }\end{array}$ & $30(26-32)$ & $49(43-54)$ & $96(94-98)$ & n.a. & $17(12-23)$ & $16(11-21)$ & $26(22-30)$ \\
\hline $\begin{array}{l}\text { Fruit } \\
\text { garden }\end{array}$ & $15(13-19)$ & $24(19-30)$ & $40(37-49)$ & $58(52-65)$ & $25(20-28)$ & $44(41-47)$ & $58(52-62)$ \\
\hline $\begin{array}{r}\text { Migrant } \\
\text { garden }\end{array}$ & $2 \quad(1-2)$ & $3 \quad(2-3)$ & $62(51-63)$ & $88(84-91)$ & $54(52-57)$ & $54(50-59)$ & $41(31-47)$ \\
\hline
\end{tabular}

Note: n.a. $=$ not available.

In the large fruit garden (Figure 3.29), radiation in the cacao zone was less than in the spice garden (Figure 3.32 and Table 3.35). Even in strata above $3.0 \mathrm{~m}$ height, relative light intensity in the cacao zone was less than $60 \%$ of the ambient radiation because cacao trees in this garden were shaded by bananas and large fruit and timber trees. The vegetable zone received only $25 \%$ of the ambient radiation at a height of $0.3 \mathrm{~m}$, where most of the leaves of small herbaceous spices occurred. However, higher strata in the vegetable zone received markedly more direct radiation than that the corresponding cacao zone in the same garden.

In the large migrant garden (Figure 3.31), only very small portions of the bare space radiation reached the two lowest strata in the cacao production zone (Figure 3.32 and Table 3.35). Almost no vegetation covered the soil under the densely planted cacao trees. In the cassava production zone, $41-54 \%$ of the ambient radiation reached all three strata measured. Cassava was planted only sparsely and the soil was densely covered with weeds.
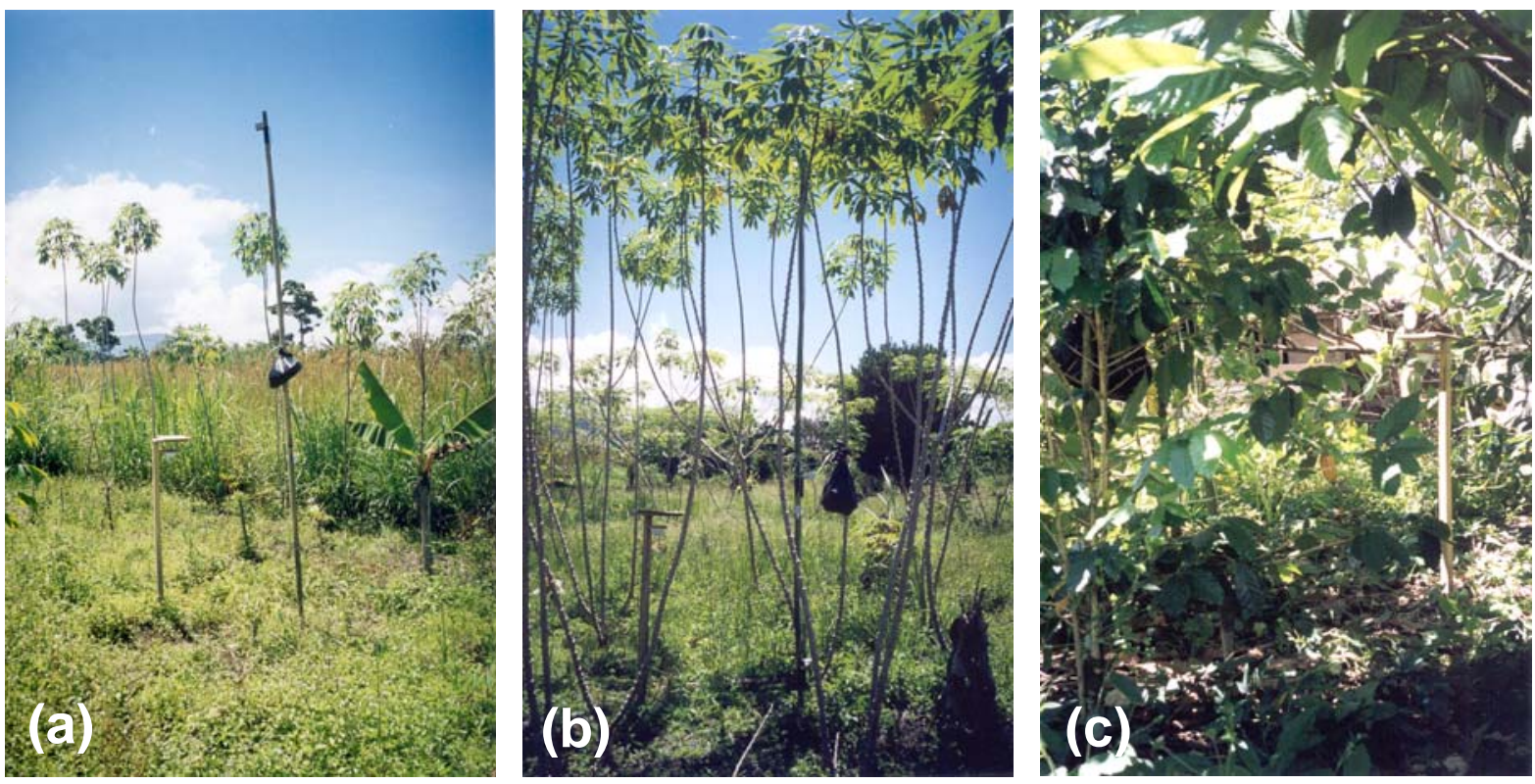

Figure 3.31. Temperature and PAR measurement units in the migrant garden in Siliwanga, Napu valley, Central Sulawesi. (a) The reference zone; (b) The cassava zone; (c) The cacao zone. 

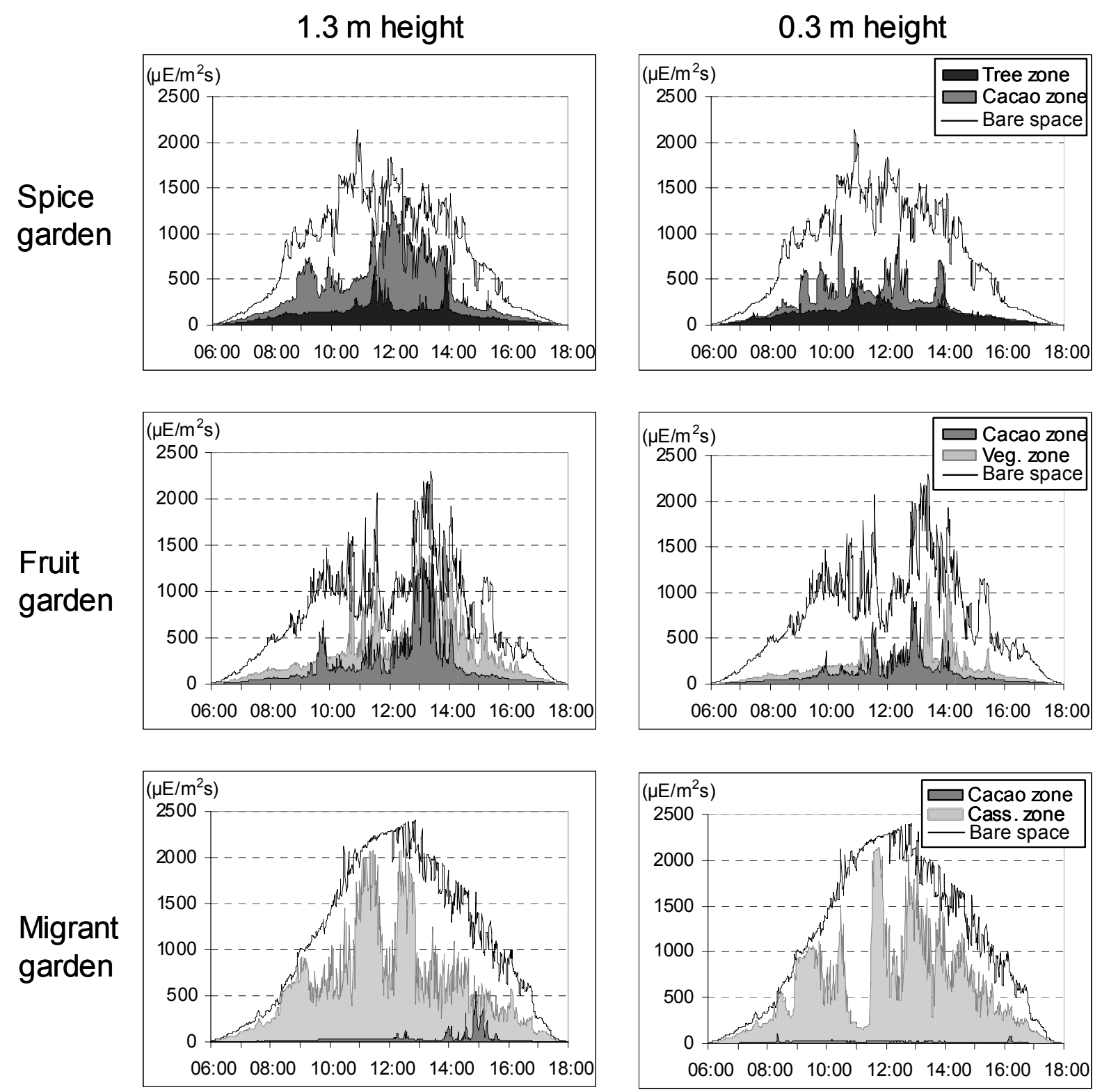

Figure 3.32. Mean daily courses of PAR (Photosynthetic Active Radiation) in different production zones and strata (heights in $\mathrm{m}$ ) of three different homegarden types in the Napu valley, Central Sulawesi, in May 2004. Time periods of measurement: spice garden 6-10 May, fruit garden 11-15 May, migrant garden 22-26 May. (Veg. zone = Vegetable zone; Cass. zone = Cassava zone).

The duration of direct radiation in the different homegardens followed similar patterns as the amount of radiation. Time periods of direct radiation decreased from higher to lower vegetation strata and from sparsely planted to densely planted zones (Figure 3.33). The duration of direct radiation was very low under the fruit trees of the spice garden. However, leaves of cacao trees received direct radiation for 3-8 hours a day. In the fruit garden, direct radiation reached the top leaves of cacao trees only for 4 hours a day, whereas leaves at $1.3 \mathrm{~m}$ height obtained only 2 hours of direct radiation. In the migrant garden, the lowest stratum in the cacao zone received direct radiation for only $1 \mathrm{~min}$. per day, that at $1.3 \mathrm{~m}$ height for only $17 \mathrm{~min}$. However, direct radiation reached the top cacao leaves for 7 hours a day. Also the 
cassava production zone obtained long periods of direct radiation, i.e. 5 to nearly 7 hours per day in all strata (Figure 3.33).

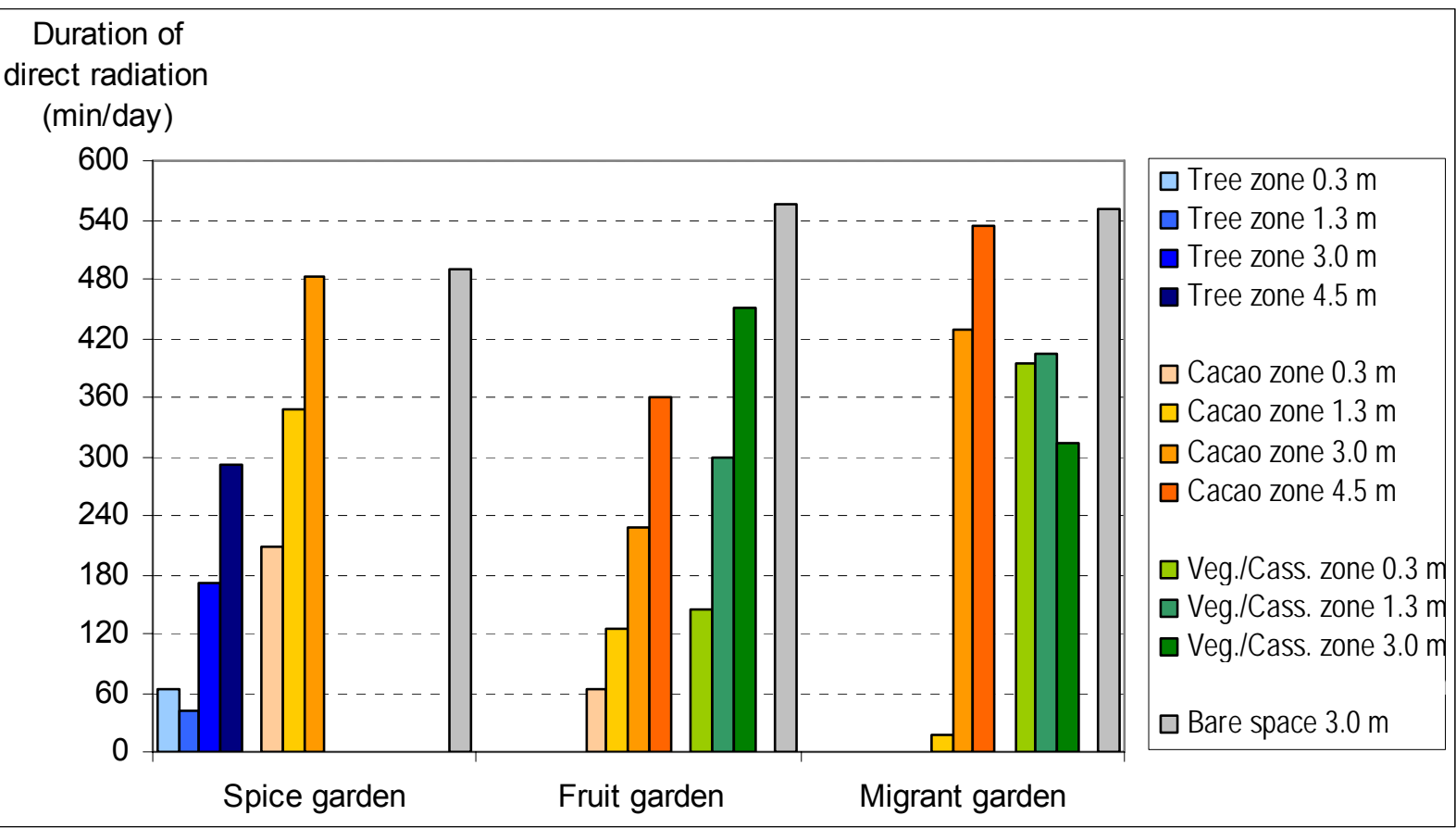

Figure 3.33. Mean duration (in minutes per day) of direct radiation $\left(\geq 250 \mu \mathrm{E} / \mathrm{m}^{2} \mathrm{~s}\right.$ ) in different vegetation strata and zones of three different homegarden types in the Napu valley, Central Sulawesi, in 2004. Veg. = Vegetable; Cass. $=$ Cassava .

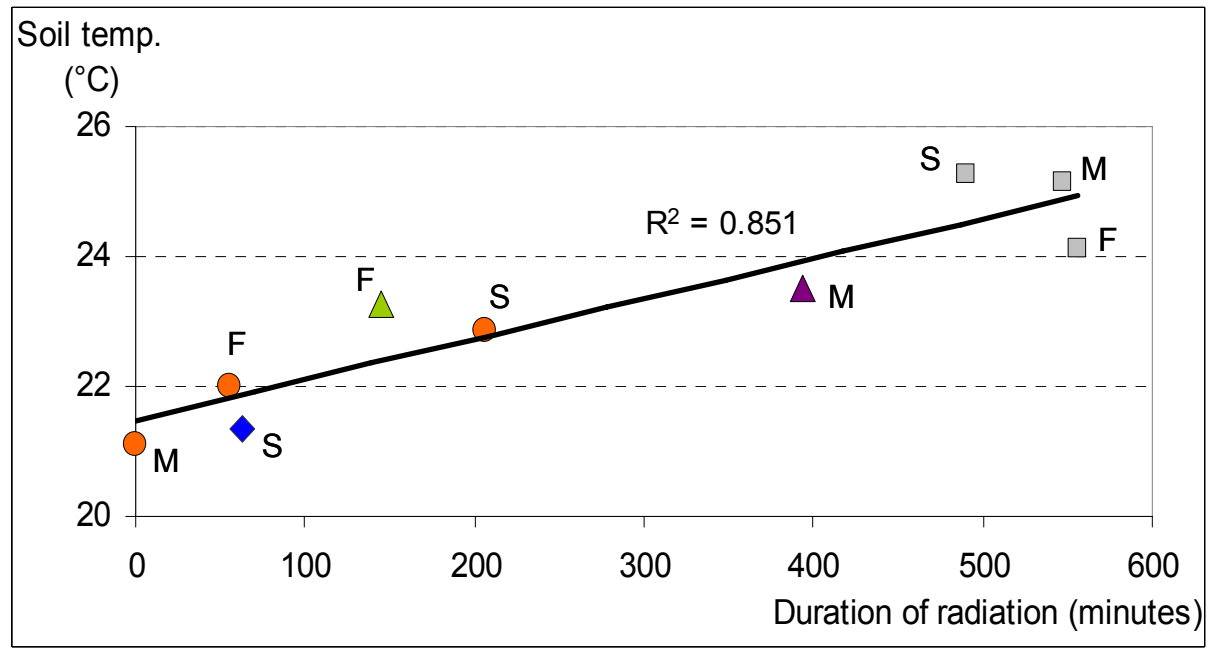

$$
\begin{aligned}
& S=\text { Spice garden } \\
& F=\text { Fruit garden } \\
& M=\text { Migrant garden }
\end{aligned}
$$

Figure 3.34. Relation between mean daily duration of direct radiation near the soil surface and mean soil temperature in different production zones of three different homegarden types in the Napu valley, Central Sulawesi, in 2004. Note: Time periods of measurement were different for radiation and temperature in the three homegardens.

\subsection{Factors influencing plant diversity}

To reveal the main factors that probably were responsible for the detected spatial differences in crop diversity parameters among homegardens (see 3.5), multiple regression analyses were 
performed. Firstly, only variables of the four categories garden characteristics, gardener/household features, socio-economics, and soil were included in the analyses. Table 3.36 lists the names, units, and ranges of six dependent and 26 independent variables belonging to four different categories. For the first regression model, only garden age and size were selected. The second analysis included nine characteristics of the gardener and his/her household (Table 3.36). For the third and fourth analyses, seven socio-economic characteristics and soil quality parameter each were selected. For the final regression model, only those variables were selected out of the four factor categories that were proved to influence crop diversity significantly or nearly significantly.

Table 3.36. Categories, names, units, and ranges of variables used for multiple regression analysis on crop diversity of 48 homegardens of five villages of the Napu valley, Central Sulawesi, 2004. $N=10$ per village, apart from Rompo, where $N=8$.

\begin{tabular}{|c|c|c|}
\hline Category & Variable name and unit & Minimum-Maximum \\
\hline \multicolumn{3}{|c|}{ Dependent variables: } \\
\hline \multirow[t]{6}{*}{ Crop diversity } & Species richness (spp. no.) & $13-68$ \\
\hline & Margalef diversity index & $2.8-10.2$ \\
\hline & Species density (spp. no. $/ 1000 \mathrm{~m}^{2}$ ) & $16-67$ \\
\hline & Individual density (individual no./100 $\mathrm{m}^{2}$ ) & $7-394$ \\
\hline & Shannon index & $1.46-3.49$ \\
\hline & Shannon evenness index & $0.37-0.88$ \\
\hline \multicolumn{3}{|c|}{ Independent variables: } \\
\hline \multirow[t]{2}{*}{ Garden } & Garden age (years) & $2-40$ \\
\hline & Garden size $\left(\mathrm{m}^{2}\right)$ & $250-2,420$ \\
\hline \multirow{9}{*}{$\begin{array}{l}\text { Gardener and } \\
\text { household }\end{array}$} & Age of the gardener (years) & $20-68$ \\
\hline & Origin of the gardener: Outside Sulawesi (no/yes) & $0-1$ \\
\hline & Sex of the gardener: Male (no/yes) & $0-1$ \\
\hline & Duration of gardener's formal education (years) & $0-17$ \\
\hline & Occupation of the HH head: Non-farmer (no/yes) & $0-1$ \\
\hline & HH size (no. of members) & $1-14$ \\
\hline & Mean age of adults in the $\mathrm{HH}$ (years) & $22-58$ \\
\hline & $\begin{array}{l}\text { Portion of adults without completed primary school } \\
(\%)\end{array}$ & $0-100$ \\
\hline & $\begin{array}{l}\text { Dependence ratio (ratio children }<15 \text { years/no. of } \\
\text { total HH member in \%) }\end{array}$ & $0-60$ \\
\hline \multirow[t]{7}{*}{ Socio-economics } & Market access: Good (no/yes) & $0-1$ \\
\hline & Cultivated farm area per HH member $\left(\mathrm{m}^{2}\right)$ & $694-17,542$ \\
\hline & Paddy rice field: Available (no/yes) & $0-1$ \\
\hline & Livestock units (TLU) & $0.06-8.72$ \\
\hline & Per capita expenditure on clothes per year (1000 IR) & $5-350$ \\
\hline & Poverty index: Very poor (no/yes) & $0-1$ \\
\hline & $\begin{array}{l}\text { Homegarden production cash-oriented (i.e. }>25 \% \text { of } \\
\text { crop individuals were cash crops) (no/yes) }\end{array}$ & $0-1$ \\
\hline \multirow[t]{7}{*}{ Soil } & Sand content $(\%)$ & $9-86$ \\
\hline & $\mathrm{N}$ content $<0.2 \%$ (no/yes) & $0-1$ \\
\hline & $\mathrm{C}$ content $(\%)$ & $0.9-5.1$ \\
\hline & P-Olsen content $<20$ ppm (no/yes) & $0-1$ \\
\hline & $\mathrm{pH}\left(\mathrm{H}_{2} \mathrm{O}\right)<5.5$ (no/yes) & $0-1$ \\
\hline & $\mathrm{K}$ content $(\mathrm{cmol} / 100 \mathrm{~g})$ & $0.09-0.95$ \\
\hline & Cation exchange capacity $\mathrm{CEC}_{\text {eff. }}(\mathrm{cmol} / 100 \mathrm{~g})$ & $4.0-37.9$ \\
\hline
\end{tabular}

Note: $\mathrm{HH}=$ Household, $\mathrm{IR}=$ Indonesian Rupiah (exchange rate in 2004: 10,000 IR $\approx 1$ Euro). 


\subsubsection{Regression of single categories}

\section{Garden features}

Garden age as one of the two garden-related features positively influenced only crop species density (Table 3.37). However, $\ln$ transformation of garden age resulted in a positive influence on crop species number and the value of the Margalef index. Garden size negatively influenced individual density and crop species evenness (i.e. Shannon evenness index), whereas diversity expressed by the Shannon index was not influenced by garden features.

\section{Characteristics of gardeners and households}

Out of the nine variables referring to gardeners' characteristics as well as structure and composition of his/her household, only four had a significant influence on all or some of the crop diversity parameters (Table 3.37). The most important variable was 'origin of the gardener from outside Sulawesi' that was the only one with a constantly strong negative influence on all crop diversity parameters. Age of the gardener had a varying influence on the diversity parameters (positive on species density, negative on evenness). Out of the household structure features, only mean age of adults and dependence ratio showed a varying influence on some diversity parameters, the latter, however, only if ln-transformed. Although the factor 'occupation of the household head' only nearly significantly influenced some diversity parameters $(\mathrm{P}=0.078$ and 0.093 for Shannon evenness index and the value of the Shannon index, respectively), it was considered for the final regression model.

Table 3.37. Simplified results of stepwise multiple regression analysis on crop diversity for single categories of variables for 48 homegardens of five villages of the Napu valley, Central Sulawesi, 2004. N=10 per village, apart from Rompo, where $N=8$.

\begin{tabular}{|c|c|c|c|c|c|c|}
\hline & $\begin{array}{l}\text { Species } \\
\text { richness }\end{array}$ & $\begin{array}{l}\text { Margalef } \\
\text { index }\end{array}$ & $\begin{array}{l}\text { Species } \\
\text { density }\end{array}$ & $\begin{array}{c}\text { Individual } \\
\text { density }\end{array}$ & $\begin{array}{c}\text { Shannon } \\
\text { index }\end{array}$ & $\begin{array}{c}\text { Shannon } \\
\text { evenness } \\
\text { index }\end{array}$ \\
\hline \multicolumn{7}{|l|}{ Garden: } \\
\hline Garden age & ns $(\ln +)$ & ns $(\ln +)$ & + & ns & ns & ns \\
\hline Garden size & ns & ns & ns & - & ns & - \\
\hline \multicolumn{7}{|l|}{ Gardener and household: } \\
\hline Age of the gardener & ns & ns & + & ns & ns & - \\
\hline Origin: Outside Sulawesi & - & - & - & - & - & - \\
\hline Mean age of adults in $\mathrm{HH}$ & + & + & ns & ns & ns & ns \\
\hline Dependence ratio & ns & ns & ns & ns $(\ln -)$ & ns $(\ln +)$ & ns $(\ln +)$ \\
\hline \multicolumn{7}{|l|}{ Socio-economics: } \\
\hline Market access: Good & + & + & + & + & ns & ns \\
\hline Cultiv. area/HH member & - & - & - & ns & ns $(\ln -)$ & ns \\
\hline Livestock units & ns & ns & ns & + & ns & ns \\
\hline Production: Cash-oriented & ns & ns & ns & - & - & ns \\
\hline \multicolumn{7}{|l|}{ Soil: } \\
\hline $\mathrm{N}$ content $<0.2 \%$ & + & + & + & ns & + & ns \\
\hline $\mathrm{P}$-Olsen content $<20 \mathrm{ppm}$ & ns & $\mathrm{ns}$ & ns & - & $\mathrm{ns}$ & ns \\
\hline
\end{tabular}

Note: $\mathrm{ns}=$ Not significant; $+=$ Positive influence $;-=$ Negative influence, $\mathrm{HH}=$ Household.

\section{Socio-economic factors}

In this category, not only variables describing market access, but also referring to farm characteristics and wealth status of the household were included. Among these factors, market 
access was the most important, having a positive influence on most of the diversity parameters (Table 3.37). In addition, size of cultivated farm area per capita negatively influenced most of the diversity parameters, partly, however, only in its ln-transformed form. A cash-oriented production had a negative influence on individual density and on crop diversity expressed by the Shannon index. The number of livestock units only positively influenced individual density of crops. Shannon evenness index was not influenced by any socio-economic factor. Variables concerning poverty index, clothing expenditures, and availability of paddy rice fields did not influence homegarden crop diversity.

\section{Soil quality parameter}

Among soil variables, $\mathrm{N}$ and available $\mathrm{P}$ contents (as dummy variables) were the only ones that tended to have a significant, but only small influence (adjusted $\mathrm{R}^{2}$ mostly around 0.10 ) on crop diversity parameters. Low $\mathrm{N}$ content of the soil positively influenced crop species richness and density as well as the Margalef index and crop diversity expressed by the Shannon index, whereas relatively low available $\mathrm{P}$ content negatively influenced individual density (Table 3.37). Ln transformations of the variables did not improve the regression models.

\subsubsection{Final regression model}

For the final regression analysis, 13 independent variables were selected out of 25 variables tested initially (see 3.9.1). Regression analysis performed best for the models explaining variability in species richness (56\%) and species density (60\%) (Table 3.38). Both were influenced by exactly the same factors with similar weights (i.e. positively by garden size and mean age of adults in a household, but negatively by the variables 'origin outside Sulawesi', 'production cash-oriented', and relatively low available P content of the soil). Apart from available $\mathrm{P}$ content, the same variables influenced the Margalef index, explaining $45 \%$ of its variation. Concerning crop individual density, only $33 \%$ of its variability was explained by the regression model (Table 3.38). Individual density was also negatively influenced by the variable 'production cash-oriented', but positively by a good market access and livestock units possessed by the household.

Crop diversity expressed by the Shannon index was influenced only by the single variable 'origin of gardener from outside Sulawesi' (beta coefficient $-0.38^{* *}$, adjusted $\mathrm{R}^{2}=0.13^{* *}$ ). Also crop species evenness was influenced only by the single variable 'garden size' (beta coefficient $-0.33 *$, adjusted $\mathrm{R}^{2}=0.09 *$ ). Ln transformation of independent variables did not improve the regression models.

In summary, large gardens managed by families with rather old members harboured a higher crop diversity (i.e. species richness, species density, and Margalef index) than small gardens of young families. Concerning species evenness, large gardens tended to be dominated by only few crop species. In homegardens of migrant families, significantly lower crop diversity parameters (i.e. species richness and density, values of Shannon and Margalef indices) could be expected than in that of locals. Good market access may enhance crop individual density. In homegardens dominated by cash crops, plant diversity parameters (apart from the values of Shannon diversity and evenness indices) was markedly lower than in subsistence 
homegardens. Homegardens with relatively low soil available P contents tended to have low crop species richness and density.

Table 3.38. Results of stepwise multiple regression analyses on different crop diversity parameters for 48 homegardens of five villages of the Napu valley, Central Sulawesi, 2004. N=10 per village, apart from Rompo, where $N=8$. For each independent variable the standardised regression coefficient (beta coefficient) and the significance level is presented. Non-standardised regression coefficients are given in brackets.

\begin{tabular}{|c|c|c|c|c|}
\hline & $\begin{array}{l}\text { Species } \\
\text { richness }\end{array}$ & $\begin{array}{l}\text { Margalef } \\
\text { index }\end{array}$ & $\begin{array}{l}\text { Species } \\
\text { density }\end{array}$ & $\begin{array}{l}\text { Individual } \\
\text { density }\end{array}$ \\
\hline Adjusted $\mathrm{R}^{2}$ & $0.56 * * *$ & $0.45 * * *$ & $0.60 * * *$ & $0.33 * * *$ \\
\hline Durbin-Watson statistic & 1.996 & 2.126 & 2.119 & 1.890 \\
\hline Maximum condition index & 15.38 & 14.07 & 15.38 & 3.33 \\
\hline \multicolumn{5}{|l|}{ Independent variables: } \\
\hline Constant & $(22.21 * *)$ & $(4.26 * * *)$ & $(30.30 * * *)$ & $(46.34 * *)$ \\
\hline Garden age & ns & ns & ns & ns \\
\hline Garden size & $0.79 * * *(0.01)$ & $0.59 * *(0.001)$ & $0.55 * *(0.01)$ & ns \\
\hline Age of gardener & ns & ns & ns & ns \\
\hline $\begin{array}{l}\text { Origin of gardener: Outside } \\
\text { Sulawesi }\end{array}$ & $\begin{array}{r}-0.67 * * * \\
(-17.39)\end{array}$ & $\begin{array}{r}-0.73 * * * \\
(-2.57)\end{array}$ & $\begin{array}{r}-0.67 * * * \\
(-17.40)\end{array}$ & ns \\
\hline $\begin{array}{l}\text { Occupation of } \mathrm{HH} \text { head: } \\
\text { Non-farmer }\end{array}$ & ns & ns & ns & ns \\
\hline Mean age of adults in the $\mathrm{HH}$ & $0.27 *(0.45)$ & $0.24 *(0.05)$ & $0.24 *(0.39)$ & ns \\
\hline Dependence ratio & ns & ns & ns & ns \\
\hline Market access: Good & ns & ns & ns & $0.35 * *(50.39)$ \\
\hline $\begin{array}{l}\text { Cultivated farm area/HH } \\
\text { member }\end{array}$ & ns & ns & ns & ns \\
\hline Livestock units & ns & ns & ns & $0.30 * \quad(9.50)$ \\
\hline $\begin{array}{l}\text { Homegarden production cash } \\
\text { oriented }\end{array}$ & $-0.40 * *(-10.66)$ & $-0.38 * *(-1.38)$ & $\begin{array}{l}-0.41 * * \\
(-11.00)\end{array}$ & $-0.33 *(-41.62)$ \\
\hline $\mathrm{N}$ content $<0.2 \%$ & ns & ns & ns & ns \\
\hline P-Olsen content $<20 \mathrm{ppm}$ & $-0.26 *(-6.80)$ & ns & $-0.27 *(-6.90)$ & ns \\
\hline
\end{tabular}

\subsection{Changes of different homegarden features over time}

In the 30 homegardens surveyed in 2001, 2003, and 2004, changes in their function, management, crop diversity, and soil quality were compared over time.

\subsubsection{Function of homegardens}

In all three villages, function of homegardens changed over time. Their importance for subsistence decreased markedly in Wuasa, but increased in Rompo (Figure 3.35). Simultaneously, their role for cash income generation increased in Wuasa, but decreased in Rompo. In the migrant village Siliwanga, homegardens became important for cash income generation only in 2004. The ornamental function of homegardens increased particularly in Wuasa, where $40 \%$ of the gardeners mentioned decoration as the main function of their gardens in the 2004 survey. The increasing importance of homegardens in Wuasa and 
Siliwanga for the generation of cash income was also reflected by the temporal changes in crop species composition in both villages (see 3.10.3).

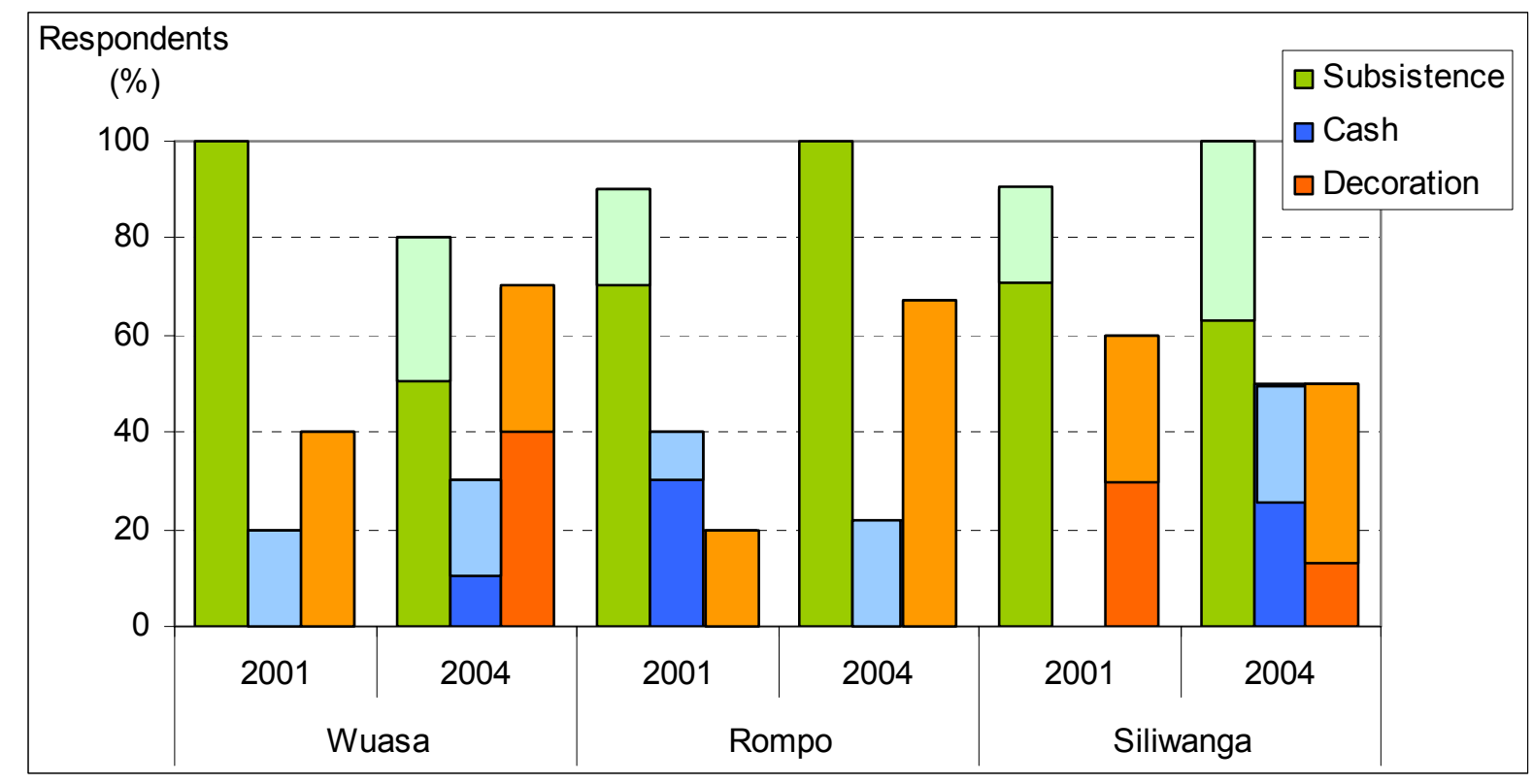

Figure 3.35. Main and secondary functions of homegardens in three villages of the Napu valley, Central Sulawesi, in 2001 and 2004, as given by the gardeners (pale-coloured bars: secondary function). $N$ per village $=10$, apart from Rompo 2004 and Siliwanga 2004, where $N=9$ and $N=8$, respectively.

\subsubsection{Management: Use of internal and external inputs}

Figure 3.36 shows different trends in the use of the internal input 'natural' fertiliser. In the local villages Wuasa and Rompo, the use of farm yard manure decreased markedly over time, whereas in the migrant village its use was mentioned by $50 \%$ of the gardeners in 2004 , but none in 2001. At the same time, the importance of ash increased in all three villages.

The use of external inputs in homegardens mostly increased over time (Figure 3.37). In 2001, only $7 \%$ of the 30 gardeners interviewed regularly used industrial fertiliser (one each in Wuasa and Siliwanga), three more gardeners in Wuasa used it only once due to supply by a village development programme (KEHLENBECK, 2002) that stopped free distribution in the year 2002. In 2004, already $21 \%$ of the gardeners used industrial fertiliser regularly (two in Wuasa and four in Siliwanga). In most of the homegardens studied, however, industrial fertiliser was still used only rarely. In the homegardens of the remote village Rompo, even in 2004 no industrial fertiliser was applied. Also the use of insecticides was mentioned by some gardeners only, but its use already increased over time. Herbicide use increased markedly over time in all three villages, particularly in Siliwanga. 


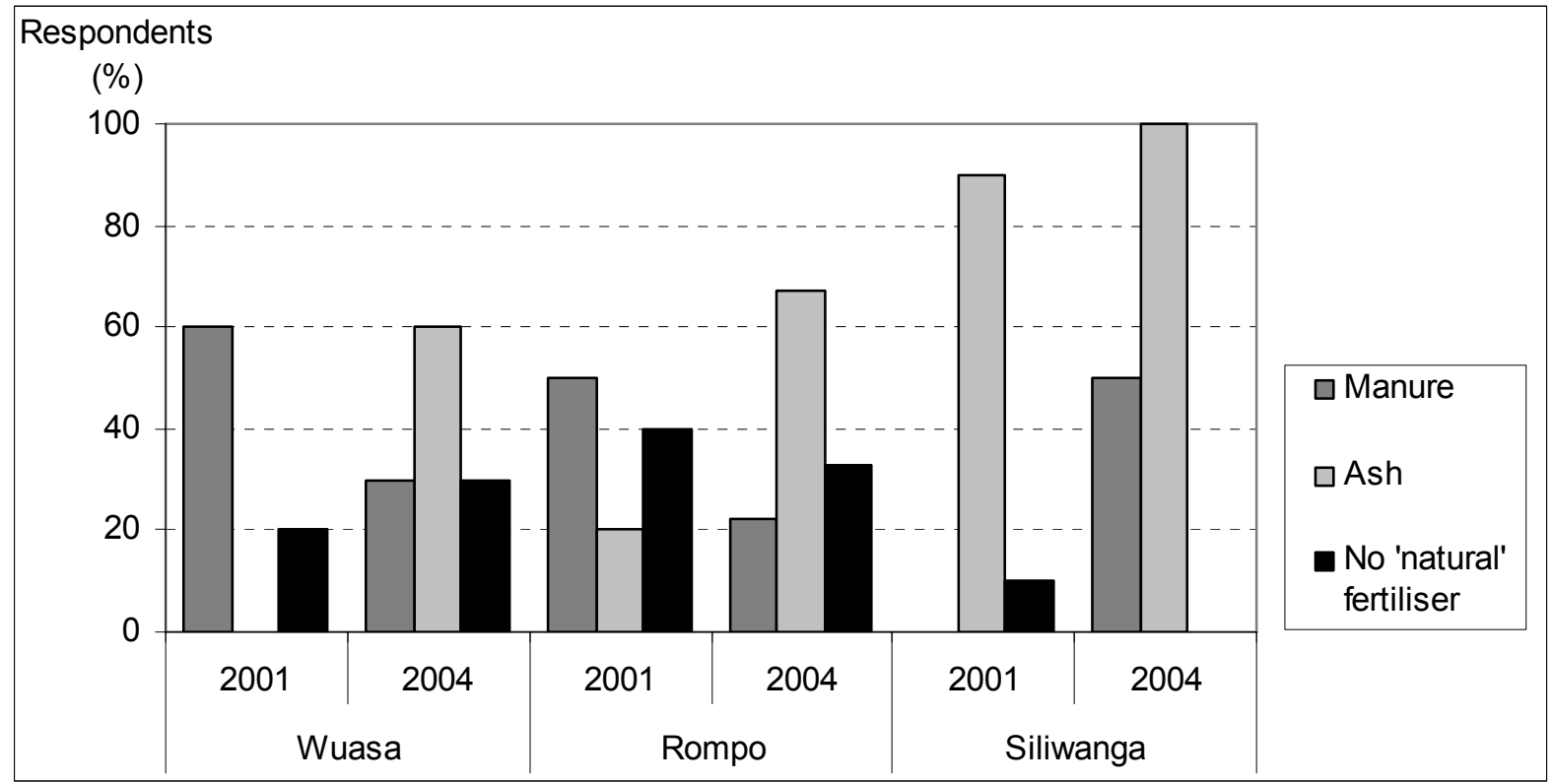

Figure 3.36. Use of natural fertilisers in homegardens in three villages of the Napu valley, Central Sulawesi, in 2001 and 2004, as given by the gardeners. $N$ per village =10, apart from Rompo 2004 and Siliwanga 2004, where $N=9$ and $N=8$, respectively.

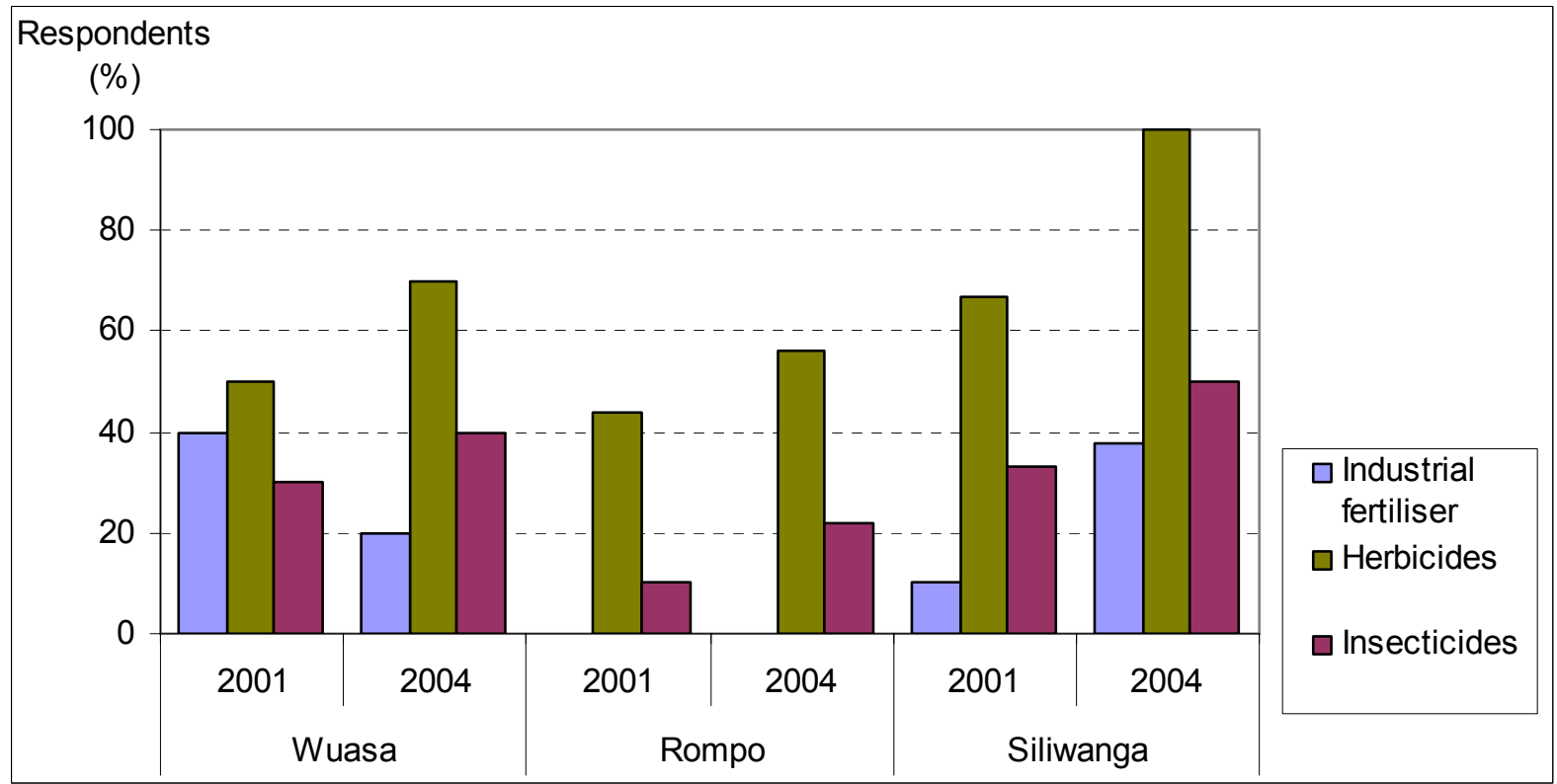

Figure 3.37. Use of external inputs in homegardens in three villages of the Napu valley, Central Sulawesi, in 2001 and 2004, as given by the gardeners. $N=10$ in Wuasa; $N=9$ in Rompo; $N=9$ and $N=8$ in Siliwanga in 2001 and 2004, respectively.

\subsubsection{Crop diversity}

\section{Crop species composition}

Principal Component Analysis (PCA) based on crop species composition and its changes over time (i.e. means of crop species abundance per village for the years 2001, 2003, and 2004, for 
detailed data on total individual numbers per village see Appendix 13) resulted in a clear distinction of the three villages along the first two ordination axes (Figure 3.38). Despite temporal changes, villages remain clearly separated in the ordination space. Axis 1 explains about $50 \%$ of the total variability (Table 3.39) and is positively correlated with tea and some staple crops, particularly paddy rice, cassava, and sweet potato. On the other hand, it is negatively correlated with some traditional fruit trees such as mango or pummelo and with certain rather modern crops, like spring onion, tomato, and vanilla, grown partly as cash crops. Therefore, axis 1 might reflect the continuum from subsistence staple crops to more diverse, mixed cultivation, used both for subsistence and income generation.

Axis 2, explaining about $20 \%$ of the total variability (Table 3.39), is negatively correlated with certain traditional crop species, such as the vegetables Clerodendron minahassae, and eggplants as well as the spicy fragrant screw pine (Figure 3.38). On the other hand, it is positively correlated with the cash crop species groundnut and cacao, accompanied by the shade tree Gliricidia sepium. Also vanilla and spring onion are slightly correlated positively with axis 2. Thus, axis 2 can be interpreted as reflecting the continuum from traditional subsistence crops towards modern cash crops. The distinct locations of the three villages in the ordination space confirm previous findings concerning importance of different crop use categories (Figure 3.14). Homegardens in Wuasa were characterised by many spices, partly used as cash crops, those in Siliwanga by staple crops, whereas those in Rompo by mixed cultivation, including many vegetables.

Table 3.39. Summary table as a result of Principal Component Analysis, based on mean abundance data per village of 196 crop species cultivated in 30 homegardens surveyed over time in the Napu valley, Central Sulawesi; species abundance data ln-transformed and centred before analysis.

\begin{tabular}{llccc}
\hline & Axis 1 & Axis 2 & Axis 3 & Axis 4 \\
\hline Eigenvalues & 21.39 & 8.98 & 4.53 & 3.14 \\
Percentage & 48.74 & 20.45 & 10.31 & 7.14 \\
Cumulative Percentage & 48.74 & 69.18 & 79.50 & 86.64 \\
\hline
\end{tabular}

Concerning temporal changes, homegardens in Wuasa were characterised by a rather small portion of staples, but a high portion of cash crops, even recently more emphasised (Figure 3.38). This pattern reflects the increasing importance of commercial crops in this particular village with its rather good market access. In the migrant village Siliwanga, a similar, but less pronounced trend was found. Its starting position was different from Wuasa, due to a markedly different crop species composition, characterised by the dominance of staple crops in Siliwanga. However, the abundance of these staples had already decreased over the short time span of this investigation. Partly, they were replaced, for example, by the cash crop cacao. In the remote village Rompo with rather poor market access, no change towards more cash crops has been detected. Homegardens in this village were still characterised, for example, by traditional vegetables, whereas abundance of cash crops was rather low. For cacao and vanilla, exclusively grown for income generation, mean portion of individuals per homegarden increased markedly over time both in Wuasa (from 7 to 11\%) and in Siliwanga (from 3 to $8 \%$ ), whereas in Rompo only from 7 to $8 \%$. 


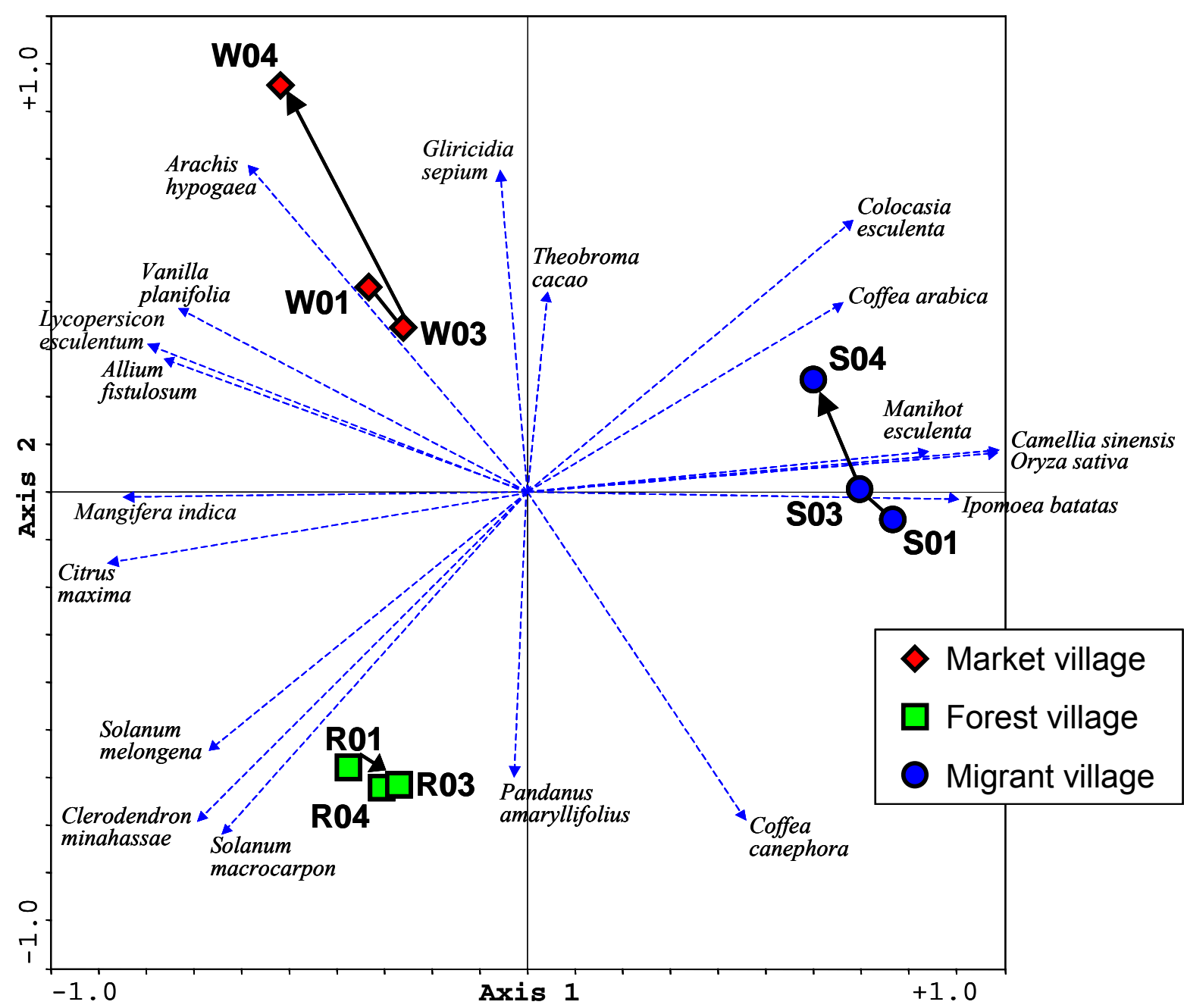

Figure 3.38. Changes of crop species composition from 2001 to 2004 in 30 homegardens of three villages (Market village $=$ Wuasa; Forest village $=$ Rompo; Migrant village $=$ Siliwanga) in the Napu valley, Central Sulawesi. Biplot of cases (linked by bold arrows) and selected crop species as a result of Principal Component Analysis, based on mean abundance data per village of $196 \mathrm{crop}$ species cultivated in the homegardens surveyed over time; species abundance data ln-transformed and centred before analysis.

Differences in temporal changes of overall number of individuals per use category among villages are also demonstrated by Figure 3.39. Homegardens in Wuasa were characterised by a rather constantly high portion of spices, including spring onion, groundnut, and vanilla for sale (note: Groundnut was used as spice by gardeners, not as oil crop). The other use categories were represented only by relatively small portions. Over time, portions of vegetables, medicinal plants, and multipurpose trees showed a slight increase, whereas those of fruit trees and stimulants tended to decrease. The decrease in stimulants, including the cash crop cacao, seems to be inconsistent with the results of the PCA (Figure 3.38). However, within the use category 'stimulants', also arabica coffee is included, whose portion decreased markedly over time in Wuasa (from $9 \%$ to $2 \%$ ), causing, therefore, the overall decrease of stimulants.

Homegardens in the remote village Rompo were not dominated by any particular crop. Apart from the portions of the recently increased staple crops and decreased spices, portions of the 
other use categories were rather evenly distributed and remained relatively stable over time (Figure 3.39). The mixture of different crops points towards the primary subsistence role of homegardens in Rompo. PCA results (Figure 3.38) were, therefore, confirmed. This applies also for the case of Siliwanga. Homegardens in the migrant village were clearly characterised by the high, but strongly declining portion of staple crops (Figure 3.39). On the other hand, portions of spices and stimulants slightly increased over time, showing the growing importance of these homegardens for income generation.
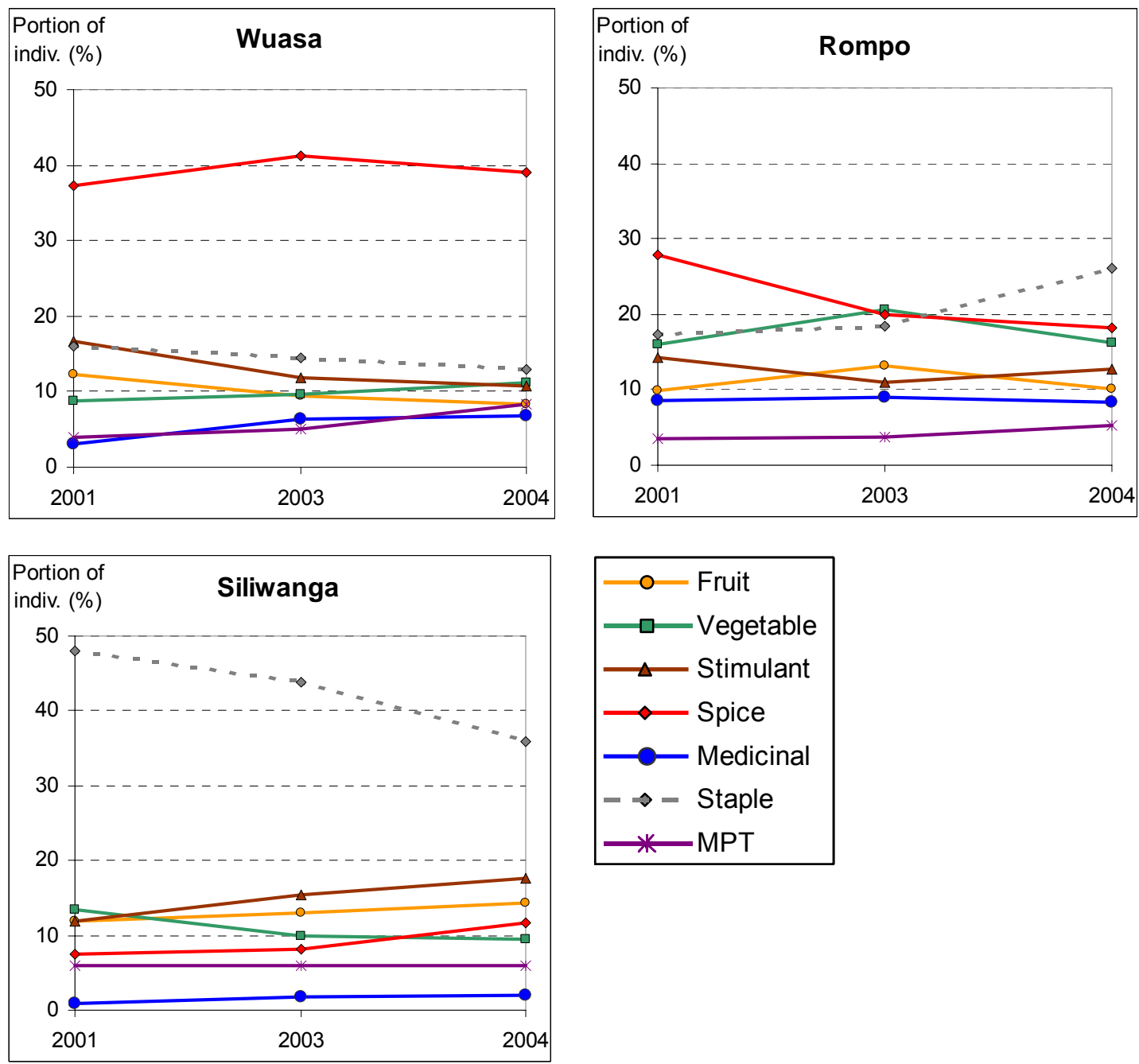

Figure 3.39. Temporal changes (means per village) in the portions of the overall number of crop individuals per use category in 30 homegardens in three villages of the Napu valley, Central Sulawesi, from 2001 to 2004. Due to very low portions, the use categories 'wood' and 'others' are not shown. Indiv. = Individuals.

Besides portions of the overall number of individuals per use category, also temporal changes in the number of species per use category differed markedly among villages (Figure 3.40). Although portions of crop individuals in some use categories markedly declined in single villages (e.g. spices in Rompo), species numbers increased over time in nearly all villages and use categories, particularly for vegetables. However, the species turnover for vegetables was found to be high, too. From 2001 to 2004, a mean of 3-5 vegetable species were introduced into the homegardens, but at the same time, the cultivation of 1-2 vegetable species was given 
up. Also the number of fruit crop species increased in the three villages, particularly in Wuasa. Mainly high-valuable species usable for sale such as durian, rambutan, and mandarin were introduced. In Wuasa, the number of medicinal plant species increased exceptionally by about 3.5 species per homegarden. Reasons for this are given below. In general, the increase in species number over time in the different use categories was rather high in Wuasa, intermediate in Siliwanga, and low in Rompo.

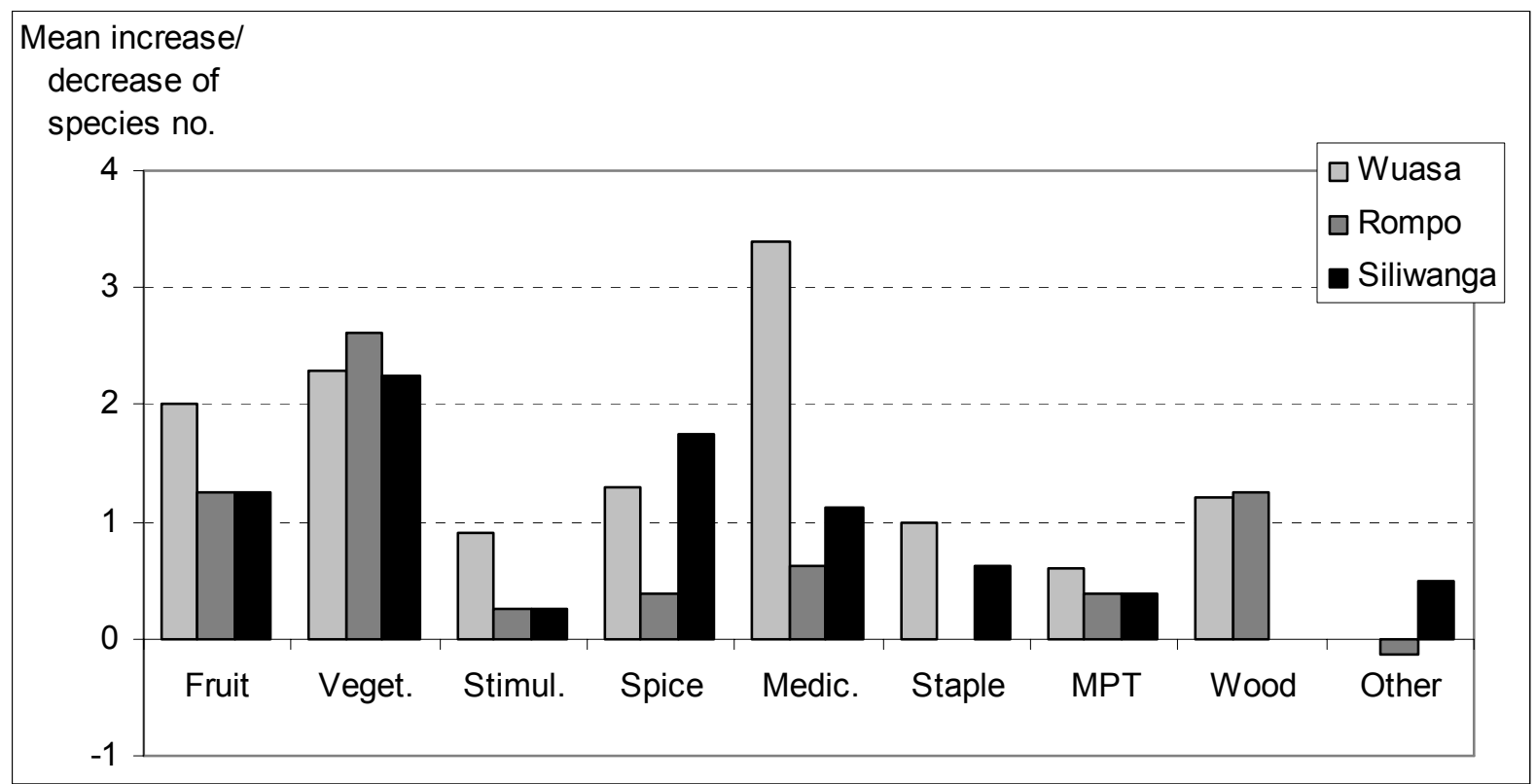

Figure 3.40. Mean temporal changes (means per village) of crop species numbers in different use categories from 2001 to 2004 in 30 homegardens in three villages of the Napu valley, Central Sulawesi. Veget. $=$ Vegetables; Stimul. $=$ Stimulants; Medic. $=$ Medicinal.

\section{Crop species richness and diversity}

Crop species richness in the homegardens revisited increased markedly over time both per village and per garden (Figure 3.41, for detailed data see Appendix 15 and Appendix 16). In the three villages, a combined total of 152,171 , and 178 useful plant species were identified in 2001, 2003, and 2004, respectively. Mean density of crop species increased significantly in Wuasa and Siliwanga, whereas changes of density of individuals did not show any trend. Changes in crop diversity expressed by the Shannon index were also not clear except in the migrant village Siliwanga, where the index increased significantly. This might be due to the decreasing dominance of staple crops in the migrant gardens (Figure 3.39). In Siliwanga, however, crop diversity mostly continued to be markedly lower than in the two local villages Wuasa and Rompo. 

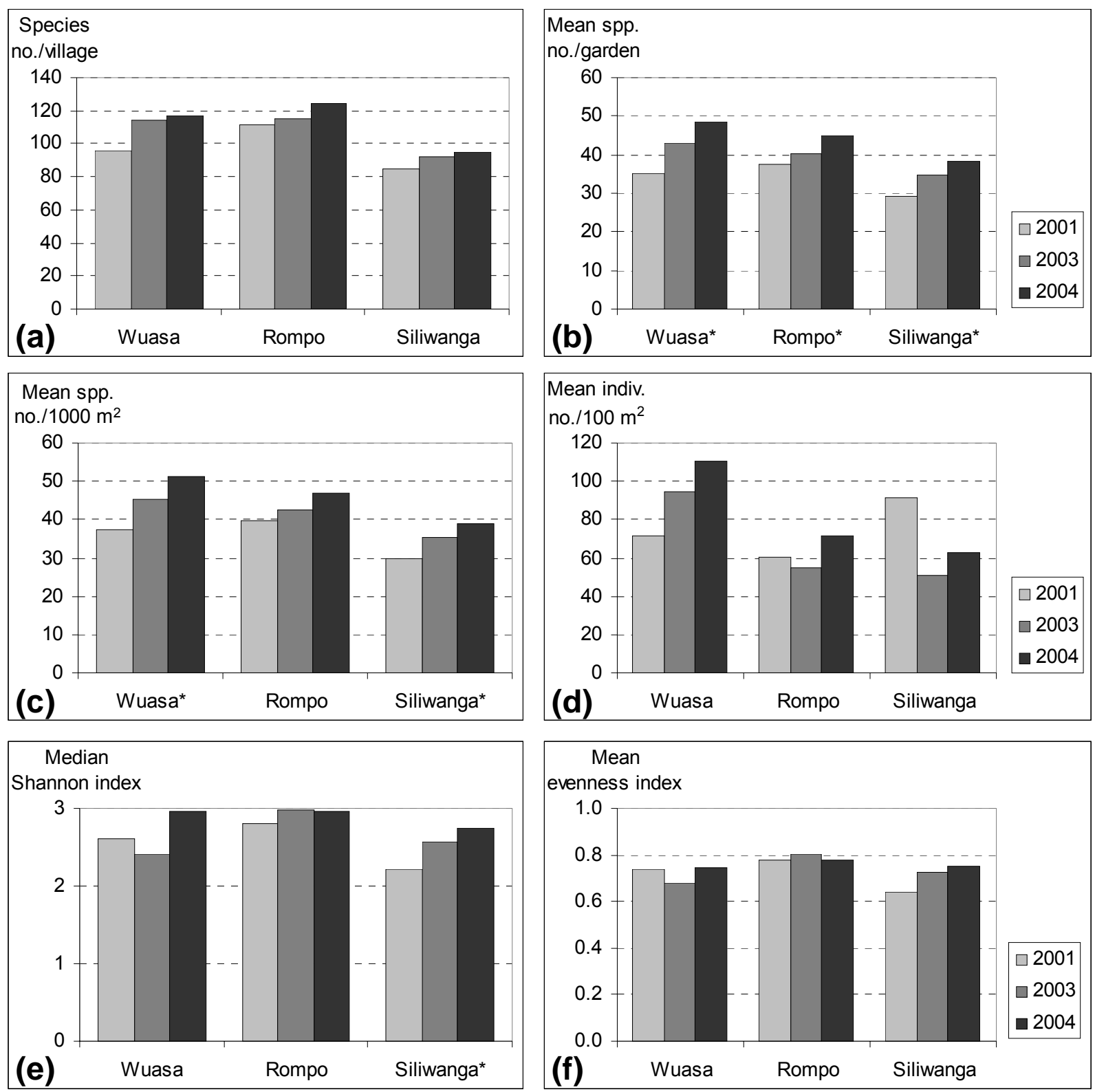

Figure 3.41. Crop diversity parameters of 30 homegardens in three villages of the Napu valley, Central Sulawesi, from 2001 to 2004. (a) Total species richness; (b) Mean species richness per garden; (c) Mean species density (according to the Arrhenius formula); (d) Mean individual density; (e) Median Shannon index; $(f)$ Mean Shannon evenness index. (In villages followed by an asterisk, changes of the respective variable over time were significant at $P \leq 0.05$ by Friedman test).

\section{Reasons for changes in crop diversity as given by the gardeners}

Gardeners gave different reasons for starting or giving up the cultivation of certain crop species. Increase in crop species number over time might be due to experimental cultivation of new crops in the homegardens, e.g. of new cash crop species for increasing income generation. Many gardeners mentioned that they try out, firstly in small plots of their homegardens, to grow new crops, which just came into 'fashion' such as soybean, vanilla, or teak. After successfully having tested the suitability and specific demands of the new crop, they start to plant it in larger numbers in their fields or plantations. Partly, crop species number also increased due to the activities of development projects that promoted the 
cultivation of particular crops. One project was focussing on the cultivation of medicinal plant species in homegardens. This campaign was initiated by the governmental organisation CSIADCP (Central Sulawesi Integrated Area Development and Conservation Project, funded by the Asian Development Bank). In general, it aimed at improving the protection of the Lore Lindu National Park by rising the socio-economic welfare of the people living in the adjacent villages. The homegarden part of this project was successful particularly in Wuasa, where the increase in medicinal plant species was profound (Figure 3.40), raising in total from 17 species in 2001 to 24 in 2004 and in a mean per garden from 3.4 to 6.8, respectively. However, this success was mainly caused by the Mayor of Wuasa, who pushed gardeners to grow these recommended plants. In the other two villages studied, the impact of this project on medicinal plants seemed to be rather low, as their number increased only slightly (Figure 3.40). The same development project distributed seedlings of a modern variety of mandarin trees in the research area during 2002/2003. Many gardeners planted the received trees in their homegardens, particularly in the villages Rompo and Siliwanga. Another development project, ECML (Environmental Conservation of Marginal Lands) initiated by CARE International Indonesia, distributed seeds of modern vegetable species, such as chinese cabbage and pak choi, grown in some homegardens in Rompo. However, in some cases also the personal interests of gardeners led to an increase in crop diversity. Gardeners particularly transplanted medicinal plants from the wild to their homegardens to have them available if required (see 3.4.1). In the homegardens surveyed, seasonal effects could not be made responsible for the significant increase in crop species number over time, because in all three years species inventories were carried out in the same season.

The reason most frequently mentioned for giving up cultivation of certain crops was the disappearance of the particular species, especially for fruits, vegetables, spices, stimulants, and medicinal plants (Figure 3.42). Species were said to disappear, for example, because of accidental hoeing of the young plants, dying off, pests and diseases, or by extraordinary climatic events such as heavy rains or drought. The latter was supposed to be responsible for the disappearance of many crop species during the El Niño event in the year 2002. The second important reason for decrease of crop species was simply their total harvest. As the availability of seeds is rather limited (e.g. low own production of seeds, see 3.4.1), cultivation of the crop concerned may not be continuous. Gardeners totally harvested particularly vegetables and spices, but also some staple crops.

Species numbers of trees such as fruit trees, stimulants, or fuel wood, partly decreased, because gardeners decided to cut trees down (Figure 3.42). Gardeners mentioned that they felled trees that disturbed cultivation (i.e. shade out more valuable crops), that might damage houses in case of storm, or that gave only small, low-quality, or low-price harvest. The latter reason was often given for felling traditional fruit tree species/varieties (e.g. pummelo, mandarin, water apple) and for removing arabica coffee that was suffering from decreasing prices and was recently replaced by cacao and vanilla. In some homegardens, the crop species number decreased because gardeners moved species to their other fields and plantations. Particularly valuable crop species such as vanilla, cacao, teak, or candle nut were sown at first in the homegardens for better control, and later moved on to their intended final location. 


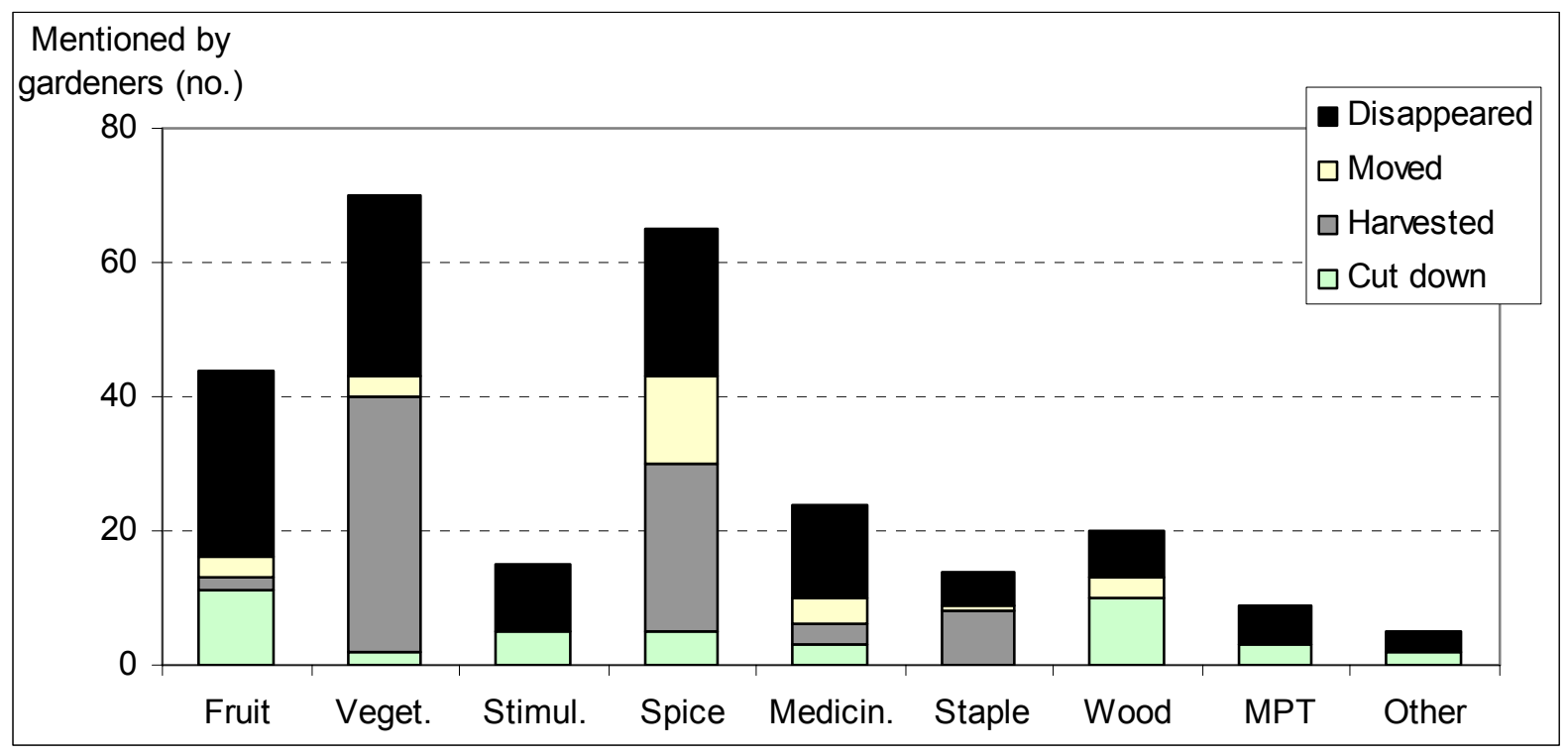

Figure 3.42. Reasons given by gardeners for the decrease of crop species number in different use categories in 30 homegardens in three villages of the Napu valley, Central Sulawesi, from 2001 to 2004.

\subsubsection{Soil quality}

As expected, sand contents of all homegardens did not change over time (Table 3.40), indicating that soil samples of 2001 and 2004 were comparable despite slightly different approaches for soil sampling in 2001 and 2004 (see 2.6.1). For all 26 homegarden soils analysed in 2001 and 2004, both $\mathrm{N}$ and $\mathrm{C}$ contents decreased markedly over time. When villages were analysed separately, only the $\mathrm{N}$ decrease in Siliwanga was significant, due to reduced sample sizes of only eight to ten homegardens per village.

Table 3.40. Changes of median sand, $N$, and $C$ contents (ranges in brackets) of topsoil (0-15 cm) of 26 homegardens in three villages of the Napu valley, Central Sulawesi, from 2001 to $2004 . \mathrm{N}=10 \mathrm{in}$ Wuasa, $N=8$ each in Rompo and Siliwanga.

\begin{tabular}{|c|c|c|c|c|}
\hline \multirow{2}{*}{ Wuasa } & & Sand content (\%) & $\mathrm{N}$ content $(\%)$ & $\mathrm{C}$ content $(\%)$ \\
\hline & 2001 & $68.5 \mathrm{a}(47.0-87.0)$ & $0.16 \mathrm{a} \quad(0.11-0.19)$ & $2.00 \mathrm{a}(1.27-2.23)$ \\
\hline & 2004 & $67.0 \mathrm{a} \quad(48.0-86.0)$ & $0.13 \mathrm{a} \quad(0.11-0.19)$ & $1.72 \mathrm{a} \quad(1.32-2.65)$ \\
\hline \multirow{2}{*}{ Rompo } & 2001 & $50.0 \mathrm{a} \quad(33.0-67.0)$ & $0.20 \mathrm{a} \quad(0.13-0.29)$ & $2.33 \mathrm{a}(1.63-3.35)$ \\
\hline & 2004 & $46.5 \mathrm{a} \quad(32.0-71.0)$ & $0.18 \mathrm{a} \quad(0.08-0.27)$ & $2.24 \mathrm{a} \quad(1.10-3.21)$ \\
\hline \multirow[t]{2}{*}{ Siliwanga } & 2001 & $49.5 \mathrm{a}(42.0-56.0)$ & $0.26 \mathrm{a} \quad(0.18-0.35)$ & $3.07 \mathrm{a} \quad(2.62-4.48)$ \\
\hline & 2004 & $50.5 \mathrm{a}(43.0-58.0)$ & $0.22 b \quad(0.16-0.34)$ & $3.00 \mathrm{a} \quad(2.49-4.67)$ \\
\hline
\end{tabular}

Medians are given because variables were not normally distributed.

Medians within a column and between years per village followed by different letters are significantly different at $\mathrm{P} \leq 0.05$.

Over time, $\mathrm{pH}\left(\mathrm{H}_{2} \mathrm{O}\right)$ did not change, whereas $\mathrm{pH}\left(\mathrm{CaCl}_{2}\right)$ decreased significantly for all homegardens (Table 3.41). When villages were analysed separately, only in Wuasa a significant decrease of $\mathrm{pH}\left(\mathrm{CaCl}_{2}\right)$ was detected. Although median available $\mathrm{P}$ contents 
decreased over time in all villages, changes were not significant, because in nearly $40 \%$ of the homegarden soils P-Olsen contents increased from 2001 to 2004 (possibly due to fertilising).

Table 3.41. Changes of median pH values and available P content (ranges in brackets) of topsoil (0-15 cm) of 26 homegardens in three villages of the Napu valley, Central Sulawesi, from 2001 to 2004. N=10 in Wuasa, $N=8$ each in Rompo and Siliwanga.

\begin{tabular}{lcccc}
\hline \multicolumn{2}{c}{$\mathrm{pH}\left(\mathrm{H}_{2} \mathrm{O}\right)$} & $\mathrm{pH}\left(\mathrm{CaCl}_{2}\right)$ & P-Olsen $(\mathrm{ppm})$ \\
\hline Wuasa & 2001 & $6.1 \mathrm{a}(5.3-6.5)$ & $5.7 \mathrm{a}(4.9-6.3)$ & $71 \mathrm{a}(34-96)$ \\
& 2004 & $5.7 \mathrm{a}(5.3-6.8)$ & $5.2 \mathrm{~b}(4.8-6.2)$ & $56 \mathrm{a}(24-118)$ \\
\multirow{2}{*}{ Rompo } & 2001 & $5.4 \mathrm{a}(4.7-5.8)$ & $5.0 \mathrm{a}(4.2-5.7)$ & $35 \mathrm{a}(8-77)$ \\
& 2004 & $5.6 \mathrm{a}(4.9-5.8)$ & $5.1 \mathrm{a}(4.3-5.4)$ & $32 \mathrm{a}(5-106)$ \\
\multirow{5}{*}{ Siliwanga } & & & & \\
& 2001 & $5.0 \mathrm{a}(4.5-6.5)$ & $4.8 \mathrm{a}(4.1-5.2)$ & $15 \mathrm{a}(11-21)$ \\
& 2004 & $5.6 \mathrm{a}(4.8-5.8)$ & $4.8 \mathrm{a}(4.3-5.2)$ & $10 \mathrm{a}(5-25)$
\end{tabular}

Medians are given because variables were not normally distributed.

Medians within a column and between years per village followed by different letters are significantly different at $\mathrm{P} \leq 0.05$. 



\section{Discussion}

\subsection{Are the homegardens socio-economically sustainable?}

Concerning socio-economic conditions, a sustainable agricultural system should be able to maintain its productive capacity by continuously yielding adequate amounts of diverse and valuable crops suitable for meeting both subsistence and cash needs of the farmer's household (Gliessman, 1990a; HuXley, 1999; Torquebiau, 1992). To maintain this productivity, endogenous, locally available and renewable inputs instead of exogenous, purchased inputs should be used. Besides, a sustainable system should enhance social and gender equity, traditional knowledge, and cultural integrity. Negative impacts on the environment as well as on the community should be small or even negligible. In the following, labour investments in the homegardens studied as well as inputs such as planting material, fertiliser, and pesticides, and outputs were valued according to the sustainability criteria mentioned above.

\subsubsection{Labour investments}

In a sustainable agricultural system, labour inputs should be rather small, well spread over the year and flexibly allocated (TORQUEBIAU, 1992). Besides, family labour instead of external, cash-demanding hired labour should be used. In the homegardens studied, median daily labour input was as small as 2-4 min. per $100 \mathrm{~m}^{2}$ garden area (range $0.4-20 \mathrm{~min} . / 100 \mathrm{~m}^{2}$ ), being rather low in the large migrant homegardens of Siliwanga (see 3.4.1, Table 3.1), many of which had a weedy appearance (see Figure 3.21b and Figure 3.31a, b). As a tendency, labour input seemed to increase with decreasing garden size (due to more intensive production) and with increasing proportion of the ornamental zone. Concerning the three case study homegardens, daily labour input was $13 \mathrm{~min} . / 100 \mathrm{~m}^{2}$ in the small spice garden, but only about $5 \mathrm{~min}$. in the large fruit tree and the very large migrant garden (see 3.8.1).

Labour input in the homegardens studied is comparable only to some of the very variable levels given in the literature. Mean daily labour inputs per $100 \mathrm{~m}^{2}$ vary from about $1 \mathrm{~min}$. (DASH \& MisRA, 2001), 2-4 min. (Ali, 2005), 9 min. (MÉNDEZ et al., 2001), and 5-10 min. (TrinH et al., 2003) to as much as 11-28 min. (HodEL et al., 1999), $25 \mathrm{~min}$. in very small urban gardens of Peru (NIÑEZ, 1985), or even 9-77 min. in intensively managed Javanese homegardens (STOLER, 1978). Higher labour input was said to occur in small as compared to large gardens (HodEL et al., 1999; STOLER, 1978) as well as in commercial as compared to subsistence gardens (ALI, 2005; TRINH et al., 2003). Based on their very low median labour input as compared to the literature, homegardens in the Napu valley could be rated as rather extensively managed.

Daily working time allocation of homegardeners in the Napu valley concerning agricultural tasks was recorded only for the three case study households. The two local families allocated $7 \%$ of their total daily working time to homegardening, the migrant family $15 \%$ (see 3.8 .1 , Figure 3.25). For two families, working in their paddy rice fields accounted for about $65 \%$ of their time, whereas for the third family, cooperative work as well as cultivation of the 
plantation were most time consuming (about 33\% each of the total time). A rather small proportion of total working time used for homegardening is mentioned also for other regions in Indonesia. In Java, ACHMAT et al. (1978) in SuRYANA \& SimATUPANG (1992) recorded $5.5 \%$ of the whole family labour used for gardening, STOLER (1978) reported a portion of $8 \%$ of men's working time.

\section{Gender division in homegardening}

In the Napu valley, main managers of homegardens with regard to labour input were mostly not the household heads, but their wives, apart from the migrant villages (see 3.4.1, Table 3.1 and Table 3.3). A more detailed analysis of the different responsibilities of male and female household members revealed different tasks according to sex. Females mostly managed vegetables, spices, medicinal plants, and ornamentals, whereas males were responsible for fruit trees and cash crops such as coffee and cacao (see 3.4.1, Table 3.4). Thus, in homegardens dominated by subsistence crops, females did most of the work, but in fruit tree and cash crop dominated homegardens, women contributed only little work. Such a clear gender division in homegarden responsibilities is frequently recorded in the literature, e.g. for Indonesia (ACHMAT et al., 1978, cited in ChristANTY, 1990), Vietnam (TrinH et al., 2003), Mexico (Alvarez-Buylla Roches et al., 1989; Del Angel-Pérez \& Mendoza B., 2004; different sources in HowARD, 2006), Peru (NIÑEZ, 1985), and Guatemala (AZURDIA \& LEIVA, 2004).

In addition to specific crop use categories, gender division was also recorded concerning specific working tasks. In the Napu valley, females did most of the hoeing, planting, weeding, fertilising, and harvesting, whereas males did the spraying and pruning (see 3.4.1, Table 3.3). However, in the cash crop dominated migrant homegardens of Tamadue, males also did much of the fertilising, planting, hoeing, and weeding. Dominance of females in hoeing, weeding, and harvesting, but of males in pruning and hard work such as preparing the land is stated also in the literature (e.g. TCHATAT et al. (1996) for Cameroon, Rugalema et al. (1994) for Tanzania, BENNETT-LARTEY et al. (2004) for Ghana). A rather equal division of labour between male and female household members without giving more detailed information is reported from Java, Indonesia (ANDAYANI, 1988, cited in SURYANA \& SimATUPANG, 1992), Vietnam (Hodel et al., 1999), Nicaragua (MÉNDEZ et al., 2001), and Martinique (KIMBER, 1966). However, in some regions, homegardens are said to be managed mainly or even exclusively by females, e.g. in Bangladesh (ALI, 2005; OAKLEY, 2004; OAKLEY \& MOMSEN, 2007), Thailand (Moreno-Black et al., 1996), Nepal (Shrestha et al., 2004), Yemen (CECCOLInI, 2002), or Tanzania (Rugalema et al., 1994). In contrast, dominance of males in homegardening is reported only from India (DASH \& MISRA, 2001).

Overall, homegardens of the Napu valley can be rated as socio-economically sustainable with regard to labour input. The homegardens studied were managed exclusively by family members, who were mostly following traditional roles in labour division between males and females. The work input in homegardens as compared to other agricultural tasks was regarded as rather small, not very heavy, and having no labour peaks. Instead, gardening was done continuously year-round and was allocated in a quite flexible manner, a feature also described frequently in the literature (AlvareZ-BuYlla Roches et al., 1989; CHRISTANTY et al., 1986; HVOSLEF, 1994; KiMBER, 1966). 


\subsubsection{Utilisation of internal and external inputs}

\section{Planting material}

Concerning the input 'planting material', the homegardens surveyed can be rated as sustainable. Homegardeners obtained about $85 \%$ of their planting material for free from locally available sources, mainly from gardens and fields of their own, from their friends and relatives, or from other people as well as from the natural vegetation or inherited from the previous garden owner (see 3.4.1, Figure 3.4). Using locally produced instead of purchased planting material ensures that these species and varieties are suitable for the local agroecological conditions and do not require much control of the environment by, for example, applying pesticides. Only about $8 \%$ of the planting material was of external, purchased origin. However, the main reason for buying the material mostly was consumption, and only seeds or remnants, otherwise thrown away, were used for planting. Planting material received from projects $(7 \%$ of the total material) mainly contributed to the diversity of few exportable and marketable crops, e.g. tea, cacao, improved varieties of mandarin or arabica coffee. However, the sustainability of such impacts could be discussed controversially. For example, the promoted cash crops tea and coffee declined tremendously in prices and were, thus, often abandoned or cut down, not only in homegardens but also in plantations. Vegetable crops distributed as seeds by CARE International Indonesia (see 3.10.3) for homegarden cultivation failed to produce seeds for the next growing season. Gardeners that received improved mandarin varieties were not informed that the grafted seedlings needed special pruning. As a consequence, water sprouts and branches of the root stock (Citrus medica, bearing only low valued, acid fruits) were not cut back and, thus, suppressed branching and fruiting of the scion.

Many scientists have stated that the main source of planting material in homegardening is obtained from previous crops or exchanged with relatives and friends. In Peru, about $40 \%$ of the planting material was received for free from other villagers, 15-23\% was obtained from swidden fields, and about 22\% was bought (large portions principally for consumption, e.g. fruits) (BAN \& COOMES, 2004). For Nepalese homegardens, SUNWAR et al. (2006) found that nearly $78 \%$ of the planting material was self-saved material, nearly $16 \%$ was purchased (particularly improved vegetable varieties), less than 5\% was requested from neighbours, and only $1.4 \%$ was gathered in the forest. Proportions of purchased planting material were $6-8 \%$ in Cameroon (TCHATAT et al., 1996), 7-9\% in Brazil (YAMADA \& OSAQUI, 2006), 6-17\% in Cuba (CASTIÑEIRAS et al., 2002), or 4-21\% and 13\% in Bangladesh (Millat-E-Mustafa et al., 2000 and OAKLEY \& MOMSEN, 2007, respectively). Other authors stressed that own or planting material exchanged for free were the main sources without giving exact proportions, e.g. WinkLERPRins (2002) for urban homegardens in Brazil, Shrestha et al. (2002) for Nepal, and FERNANDES et al. (1984) for Tanzania. However, in an urban setting, purchased planting material might be the most important source, as documented by GEBAUER (2005), who recorded $67 \%$ of the fruit tree species grown in urban homegardens of El Obeid (Sudan) as bought from local nurseries.

The importance of self-established and wild plant species in homegardens is frequently mentioned in the literature. In South Africa, for example, a mean of 3.4 'cultivated' crop species, but 4.5 wild (i.e. occurring spontaneously) vegetable species were grown in homegardens, the latter accounting for $31 \%$ of the total value of all homegarden products 
(High \& Shackleton, 2000). For Kenya, BACKes (2001) reported a mean of more than nine indigenous, but only about two 'exotic' tree species in old homegardens. As much as $28 \%$, $32 \%$, or $45 \%$ of all plants found in homegardens in Martinique, semi-arid Mexico, and Puerto Rico, respectively, were of spontaneous origin, but tolerated or even cared for (BLANCKAERT et al., 2004; KIMBER, 1973, 1966). These portions were much higher than the mean of 19\% species occuring spontaneously in homegardens of the Napu valley (see 3.4.1). Also other scientists reported rather low portions of plant species occuring spontaneously in homegardens, such as about $18 \%$ in humid Mexico (ALVAREZ-BuYLla Roches et al., 1989), 6-14\% in Peru (BAN \& COOMES, 2004; PADOCH \& DE JONG, 1991), or 7\% in Brazil (YAMADA \& OSAQUI, 2006). However, not all species occurring spontaneously are wild species, but also cultivated crops that germinated from seeds thrown away or spread by the mother plant. Protecting spontaneous species or even transplanting them from the wild is said to be a first step towards domestication of a wild species and can be observed as an ongoing process in many tropical homegardens (BAN \& COOMES, 2004; ESQUIVEL \& HAMMER, 1992; Fu et al., 2003; KimBer, 1978; Miller \& NAIR, 2006; MonTAGNini, 2006; MoreNO-BlacK et al., 1996; SMITH, 1996). This behaviour was also observed in the homegardens surveyed in the Napu valley, were some wild medicinal plants had been transplanted from the natural vegetation or protected after self-establishment in the garden (see 3.4.1 and 3.5.1). In addition to transplanting, several self-established wild tree species were tolerated as sources for fruits, vegetables, medicine, or fuel wood and timber. For Totonac homegardens in Mexico, DEL ANGEL-PÉREZ \& MENDOZA B. (2004) found that mostly women played an important role in the conservation of wild forest species for medicinal, food, or ritual uses, whereas men more often tried out the suitability of exotic, commercial field crops in homegardens. One reason for protecting and cultivating useful wild species in homegardens is to evaluate their potential as a future crop, as described, for example, by LEIVA et al. (2002) for the weedy vine Fernaldia pandurata that is now increasingly grown as a food and cash crop in homegardens of Guatemala. Another reason for protecting or transplanting of wild species, also given by Napu gardeners, is to have a rare wild species just available when needed, particularly for medicinal plants or in areas largely deforested (FU et al., 2003; MORENO-BLACK et al., 1996).

A sustainable system is characterised not only by low dependence on external inputs and high adaptation to local conditions, but also by long-term maintenance of productive capacity (Gliessman, 1990a; TorquebiaU, 1992). In homegardens, domestication of wild plant species as well as conservation and evolution of crop species might help to maintain the longterm productivity of the whole agricultural system. Domestication, as mentioned above, contributes by exploiting new food and income sources simultaneously with reducing the pressure on natural populations, including the conservation of rare wild species (MORENOBLACK et al., 1996). Conservation and evolution of crop species, on the other hand, is caught in part by extensive exchange of planting material by gardeners (see above). As stated by COOMES \& BAN (2004), such exchange also enhances the overall plant diversity in homegardens.

Germplasm exchange in homegarden systems takes place at different levels (BENNETTLARTEY et al., 2004; FUNDORA MAYOR et al., 2004). Exchange between homegarden and fields of the same owner is the lowest level because mostly the same species and varieties are exchanged. However, homegardens can play a major role in safeguarding and propagation of planting material used for transplanting to fields or plantations, particularly in regions with 
distinct seasons such as dry or flooding periods (COOMES \& BAN, 2004). The protected and easily controlled environment of homegardens offered also a place for detecting, selecting, and multiplying new varieties that might increase crop-genetic diversity (WILLIAMS, 2004). Exchange among gardeners of the same village, e.g. among friends and relatives might be of relative low importance, too, due to the similarity of exchanged varieties. However, FUNDORA MAYOR et al. (2004) stressed its role in restoring genetically eroded varieties.

A much higher level of germplasm exchange is the exchange between different villages that contributes substantially to crop genetic diversity, e.g. by introducing new species and varieties (FUNDORA MAYOR et al., 2004; KIMBER, 1978). Exchange of planting material with neighbouring villages is also said to be important for the maintenance of social networks (WINKLERPRINS, 2002). Although in general more material is exchanged within as compared to between communities (COOMES \& BAN, 2004), many gardeners, including those of the Napu valley (see 3.4.1), readily take the opportunity of gathering planting material while travelling or visiting relatives (FU et al., 2003; MORENO-BLACK et al., 1996; SHRESTHA et al., 2004; WILLIAMS, 2004). Many authors have stressed the importance of homegardens as a kind of 'experimental station', where gardeners evaluate the suitability and special needs of gathered new species and varieties or where they even breed new varieties (e.g. DEL ANGELPérez \& Mendoza B., 2004; Miller \& NAir, 2005; MontAgnini, 2006; NiÑEZ, 1987; SHRESTHA et al., 2004; SMith, 1996; WiLliams, 2004).

Other very high levels of germplasm exchange that increase genetic diversity are the flows from surrounding ecosystems (see above) and from the formal sector such as research institutions, development projects, or markets to the homegardens (BENNETT-LARTEY et al., 2004; FUNDORA MAYOR et al., 2004). The introduction of improved, mostly marketable species and varieties involves, however, also the danger of genetic erosion of local species and varieties (FUNDORA MAYOR et al., 2004; SUNWAR et al., 2006) as well as the overall shift in homegarden function towards commercialisation with its frequently negative consequences for plant species diversity (for more detailed discussion see 4.5). Additionally, many of these introduced species and varieties might reduce the overall sustainability of the homegarden system because they are less adapted to local environments, and their cultivation often requires the use of external, purchased inputs.

In summary, using mostly planting material of local origin and maintaining it in the homegardens surveyed contributed to the sustainability of the system. However, in the future this feature might be threatened by modernisation and commercialisation, as many gardeners rated their local varieties as inferior and wished to replace them with improved varieties (see 3.4.5). In the interviews, more than $20 \%$ of the gardeners rated the supply of improved planting material by development projects as most important for improving production in homegardens and other agricultural systems. The general suitability of homegardens for in situ conservation of plant genetic resources (of both wild and cultivated plants) is discussed in more detail in 4.6.

\section{Fertiliser}

In a sustainable agricultural system, inputs such as fertiliser should mostly be of endogenous origin and should help to ensure long-term maintenance of the soil quality. In the Napu valley, $0-20 \%$ of respondents in the local and $40-60 \%$ in the migrant villages stated to use industrial 
fertiliser (see 3.4.3, Figure 3.5), however, mostly in small amounts and only for fertilising cash crops. Nevertheless, some gardeners even reported to apply excessive amounts of industrial fertiliser (e.g. in garden no. 3: about $1600 \mathrm{~kg}$ NPK per ha and year, see Appendix 10) that in the future may cause environmental problems, such as water pollution. Much more often than for homegardens, industrial fertiliser was used for paddy rice fields (Figure 3.6). Migrants, as compared to locals, more often (and mostly in larger amounts, see 3.4.3) used industrial fertiliser on all field types, a finding also reported by BURKARD (2002a) for cacao plantations and by FAUST et al. (2003) for cacao (locals $8-10 \%$, migrants about $50 \%$ ) as well as paddy rice in the Napu valley.

No or nearly no use (less than $5 \%$ of the gardeners) of industrial fertiliser in homegardens is stated frequently in the literature (ALI, 2005; ALVAREZ-BuYLLA ROCHES et al., 1989; DASH \& Misra, 2001; Fernandes et al., 1984; GAJASEnI \& GAJASEnI, 1999; GeBAUER, 2005; Kimber, 1966; Millat-e-Mustafa et al., 2000; Rugalema et al., 1994; Shrestha et al., 2004; TCHATAT et al., 1996). On the other hand, some authors reported that $5-40 \%$ of homegardeners used industrial fertiliser (DRESCHER et al., 1999; HVOSLEF, 1994; MÉNDEZ et al., 2001; OAKLEY, 2004). However, within homegardens, most of the industrial fertiliser is said to be mainly applied to cash crops (Azurdia \& LeIVA, 2004; DHARMASENA \& Wijeratne, 1996; Hochegger, 1999; Méndez et al., 2001; Peyre et al., 2006), as also recorded in the Napu valley.

Instead of purchased industrial fertiliser, many homegardeners in the tropics use endogenous fertiliser sources such as farm yard manure, ash and refuse from the kitchen, mulch, litter, and compost in different proportions (ALI, 2005; Alvarez-BuYlla Roches et al., 1989; BenNEtT-LARTEY et al., 2004; Drescher et al., 1999; FernANDES et al., 1984; Hvoslef, 1994; Millat-e-Mustafa et al., 2000; OAKLey, 2004; Rugalema et al., 1994; Shrestha et al., 2004; TChAtAT et al., 1996; WinKLERPrins, 2002). In the Napu valley, using such endogenous fertiliser sources was also common (see 3.4.3, Figure 3.5). However, its application could be further increased in some villages, particularly that of the largely available farm yard manure, used by only $20-50 \%$ of the gardeners (Figure 3.5). Mulching and using compost were almost unknown in the research region. Thus, a rather high potential for improving soil fertility management by the use of fertiliser sources locally available was detected for the homegardens surveyed. A similar situation of neither sufficient nor effective use of available resources due to lack of information and technical support has also been reported from Sri Lanka (Dharmasena \& WiJERATNE, 1996), Zambia (Drescher, 1996), Yemen (CECCOLInI, 2002), and many regions of Mesoamerica (MontAGNini, 2006) as well as from migrant settlements in Sumatra (HvosLEF, 1994). BENJAMIN et al. (2001) further mentioned deterioration of soil fertility in Mexican homegardens due to the unfavourable habit of the owners to sweep and burn all litter, an activity also carried out daily in many of the homegardens surveyed in the Napu valley (3.4.1). This habit (together with insufficient fertilising) might be responsible also for the overall decrease of soil quality detected in the homegardens surveyed over time (see 3.10.4) that is discussed in more detail below (see 4.2). Over time, the use of industrial fertiliser increased only in the migrant village Siliwanga (see 3.10.2). Utilisation of ash increased over time in all villages, whereas that of farm yard manure increased only in Siliwanga, but decreased in the two local villages. 
In the future, increasing (and partly excessive) use of industrial fertiliser seems to be probable, thus, reducing the sustainability of the homegardens. Increasing wealth status (natural fertilisers were rated mostly as resource of the 'poor' people), higher portions of cash crops (the typical 'receivers' of industrial fertiliser), and improved market access (paved road to the remote village Rompo completed in 2004 makes supply of agro-chemicals easier) might contribute to enhance the importance of industrial fertiliser at the expense of readily available endogenous fertiliser sources.

\section{Pesticides}

Concerning control of crop pests and diseases as well as weeds, a sustainable agricultural system should rely on endogenous, alternative methods basing on traditional knowledge, instead of using purchased inputs, such as synthetic herbicides, insecticides, or fungicides. In homegardens of the Napu valley, however, herbicides were already used by $75 \%$ of the local and $100 \%$ of the migrant gardeners (see 3.4.4, Figure 3.7). Nevertheless, still $96 \%$ of all gardeners also applied traditional methods for weed control. Insecticides were regularly used by $90 \%$ of the migrant gardeners in Tamadue, but only occasionally by $20-40 \%$ of the gardeners in the other four villages. In the local villages, many more gardeners carried out alternative methods for pest and disease control than in the migrant villages. A higher utilisation of pesticides by migrants (49\%) as compared to locals (16-26\%) was also recorded by FAUST et al. (2003) for cacao plantations in the Napu valley.

In the literature, most authors stated that no or nearly no pesticides (including, e.g. herbicides, insecticides, and fungicides) are applied in homegardens (ALI, 2005; ARIFIN et al., 2005; Dharmasena \& Wijeratne, 1996; Gajaseni \& Gajaseni, 1999; Gebauer, 2005; OAKLey, 2004; RUGALEMA et al., 1994; SHRESTHA et al., 2004). Low pest and pathogen infestation is said to be attributed to high species and genetic diversity as well as to the complex vegetation structure of homegardens and other multi-species agro-ecosystems that offer a habitat or conservation areas for beneficial organisms (see 1.3 and, e.g., DRESCHER, 1996; HOCHEGGER, 1998). If homegardeners used pesticides, they were applied mostly to cash crops (ARIFIN et al., 2005; AzURDIA \& LEIVA, 2004; FERNANDES et al., 1984), a common habit also in the Napu valley (see 3.4.4). However, for homegardens of Zimbabwe, DRESCHER et al. (1999) documented already 100\% pesticide use, for those of Zambia (DRESCHER, 1996) about 50$80 \%$ insecticide use, particularly in the commercialised periurban gardens. According to ABDOELLAH et al. (2006), utilisation of external inputs such as industrial fertiliser and pesticides was significantly higher in commercialised than in subsistence homegardens in West Java (application by $94 \%$ vs. $27 \%$ of gardeners).

In the Napu valley, the more frequent application of herbicides in homegardens as compared to insecticides could be explained by the rather high share of labour invested in hoeing and weeding (see 3.4.1, Table 3.2). Particularly in the migrant village Siliwanga, gardeners complained about time and labour force scarcity (households with rather few and/or small children) as well as about high infestation of homegardens with the very problematic weed Imperata cylindrica that is hardly to control by occasional hoeing only. Besides, many gardeners rated weeds as a severe problem, whereas pests and diseases were recognised rarely or only on cacao. Herbicides were easily available in the villages and, in contrast to insecticides, their application did not require much special knowledge. On other fields and plantations, spraying herbicides mostly also was more common than applying insecticides 
(see 3.4.4, Figure 3.7 and Figure 3.8). Leftover herbicides from field spraying were sometimes used for spraying homegardens even by gardeners that did not spray their gardens regularly.

In the future, application of pesticides might further raise, as the importance of cash crop cultivation is still increasing in the research area, even in homegardens (see 3.10.3 and 4.5). From 2001 to 2004, the number of homegardeners using pesticides already increased markedly (see 3.10.2 and Figure 3.37). Besides, 44\% of the gardeners mentioned in the interviews that the supply of pesticides and sprayers by development projects would be one of the best approaches to improve production in both homegardens and other agricultural systems. However, about $20 \%$ of the respondents rated the supply of industrial fertilisers as most important, instead of pesticides. Due to the increasing use of pesticides, not only dependence on cash sources, but also the risk of endangering human as well as environmental health will further rise. No gardener used protective clothing while spraying, toxicity of pesticides was largely ignored, storing and disposal of pesticide remnants were mostly done in an irresponsible manner (pers. obs.).

In summary, sustainability of the homegardens studied regarding the use of purchased inputs industrial fertilisers and synthetic pesticides is already questionable and put at much more risk in the future, particularly in homegardens with emphasis on commercialisation. However, a detailed analysis of cash used to purchase such inputs (that is not yet carried out) would be necessary to further support this statement.

\subsubsection{Outputs}

In a sustainable agricultural system, outputs should be diversified and obtained in an efficient manner rather continuously throughout the year (GLIESSMAN, 1990a; HUXLEY, 1999; TORQUEBIAU, 1992). In addition, produce should be of high nutritional value and useful to meet both subsistence and cash needs of the farmer's family. Concerning socio-cultural functions, produce should give farmers the opportunity for exchange and interactions within their communities and for preserving their traditional habits and beliefs. A certain flexibility concerning kind and amount of homegarden produce might be postulated to react to changing needs of the gardener's household.

Homegardens in the Napu valley proved to fulfil many of these conditions. Gardeners obtained very diverse produce from their homegardens, ranging from fruits, vegetables, spices and some staples to medicines, stimulants, beverages, fodder, tools, toys, fuel wood, and timber (see 3.5.1). Some plants had cultural rather than productive functions, e.g. to prevent evil spirits from entering the garden and the house or for sacrifices in the Balinese households. In general, the nutritional value of the harvested products, particularly of fruits, vegetables, and spices, could be regarded as high concerning minerals, vitamins, and partly protein, but energy contents seemed to be quite low. Most of the produce was available year round and often harvested daily, apart from some seasonal fruit species (see 3.8.1). Exchange of produce and planting material played an important role for many gardeners (see 3.4.1 and 3.4.6). However, the amount of homegarden produce for both family consumption and sale seemed to be rather small, but this statement was mainly based on qualitative data. Concerning the three case studies, where quantitative data were assessed during a short time period of only 15 days each, the importance of the gardens was rather high. For example, the 
family managing the small spice garden obtained $100 \%$ of their cash income during the observation from their homegarden (see 3.8.1). The migrant family covered $76 \%$ of the value of their daily food needs (apart from the staple crop rice and beverages) by homegarden products. Unfortunately, the efficiency of the homegarden production could not be assessed because detailed quantitative data on both input and output were not available.

A rather low contribution of homegarden produce to the family's total income, comparable to the $3-10 \%$ obtained in the Napu valley (see 3.2), is also reported from some other regions in Indonesia. For example, ARIFIN et al. (2005) stated that only $1-7 \%$ of the household income was obtained from West Javanese homegardens. Migrants in Sumatra achieved 4-20\% of their total income from homegarden products (HOLDEN \& HVOSLEF, 1995). However, in other Indonesian regions, higher portions of income gained from homegardens were observed, e.g. 9-24\% (ACHMAT et al., 1980, cited in ChristANTY et al., 1986), 22-27\% (STOLER, 1978), or even 49\% (PENNy \& GinTING, 1984, cited in SoEMARWoto \& CONWAy, 1992).

For other tropical regions, a high variability of cash income received from homegarden produce has also been recorded, e.g. 0\% in Sudan (GEBAUER, 2005), 18\% in Guatemala (LEIVA et al., 2002), 35\% (range 0-100\%) in Nicaragua (MÉNDEZ et al., 2001), 52\% in Bangladesh (Ali, 2005), 4-54\% in Vietnam (HodEL et al., 1999; TRINH et al., 2003), and as much as $60 \%$ in Nigeria (LAGEMANN, 1977, cited by OKIGBO, 1990). The portion of income obtained from homegardens is said to be smaller in regions with rather poor market access, in rich households, or in commercialised homegardens (ACHMAT et al., 1980, cited in Christanty et al., 1986; ALI, 2005; ARIFIN et al., 2005). However, TrinH et al. (2003) reported a higher portion of cash income in market- than in subsistence-oriented homegardens. The latter statement agrees with findings from the Napu valley, where cashoriented homegardens contributed markedly more to the total income than subsistenceoriented ones (see 3.2).

Concerning the contribution of homegarden produce to the subsistence needs of the families managing it, quantitative data were said to be difficult to determine because gardeners normally do not register homegarden harvests in precise standard measures (NIÑEZ, 1987). In the Napu valley, most homegardeners also failed to estimate the amounts of homegarden produce used for family consumption (see 3.4.6). However, many quantitative output data are given in the literature. For example, SOEMARWOTO \& CONWAY (1992) mentioned that in rural Indonesia about $15 \%$ of total food requirement was obtained from homegardens. Portions of the families' daily energy requirements covered by homegarden products were said to range from only 3-18\% (ABDOELlah et al., 1981, and OCHSE \& TERRA, 1937, both cited in Christanty et al., 1986) to 9-38\% (Holden \& HVOSLEF, 1995). Regarding protein requirements, homegarden products might contribute only 6-8\% (DHARMASENA \& WiJeratne, 1996), 3-14\% (ABDOELlah et al., 1981, and OCHSE \& TERRA, 1937, both cited in Christanty et al., 1986), or as much as $20-47 \%$ of the households' needs (HOLDEN \& Hvoslef, 1995). Contrary to the mostly rather low contribution to energy and protein supply, homegarden produce covers much of the recommended daily allowance for minerals and vitamins, e.g. $126 \%$ of vitamin $\mathrm{A}$ and $23 \%$ of vitamin C (HARYADI, 1977, cited in Christanty, 1990) or 6-77\% of iron (different sources, cited in SURYANA \& SimATUPANG, 1992). In Bangladesh, families participating in a homegarden project increased both production of vegetables in their gardens and consumption of vegetables (TALUKDER et al., 
2000), resulting in lower prevalence of children suffering from night blindness (due to vitamin A deficiency) or underweight as compared to a control group (MARSH, 1996). In Bangladeshi households without a garden, the risk of having a young child suffering from xerophthalmia was 2.1-3.4 times higher than in households with garden (COHAN et al., 1985). BLOEM et al. (1996) found that the vitamin A intake of Bangladeshi women was positively influenced by the number of cultivated crops in their gardens (resulting in dietary diversity), but only little by the amount of harvested products. An increased production and consumption of vegetables by participants of a garden project as compared to non-gardeners has also been reported from Senegal (REYNAUD et al., 1989). In Puerto Rico, sufficiency levels of energy, protein, and certain vitamin and mineral intakes of preschoolers improved with the number of crops cultivated in the homegardens of their mothers (IMMINK et al., 1981). Concerning monetary values of total homegarden produce, only few authors presented precise figures, e.g. nearly 7 per $100 \mathrm{~m}^{2}$ and growing season in South Africa (HigH \& SHACKLETON, 2000) or 14 $\$ / 100 \mathrm{~m}^{2}$ in Peru (NiÑEZ, 1985).

The advantage of homegarden produce to be continuously available was frequently mentioned in the literature (e.g. Alvarez-Buylla Roches et al., 1989; Christanty et al., 1986; KARYONO, 1990; KimBer, 1966; Michon \& MARY, 1994; SOEMARWOTO \& CONWAY, 1992). Besides, homegardens were said to contribute to food security by providing usually neglected food sources such as tuber crops in times of scarcity (CHRISTANTY, 1990; SOEMARWOTO \& CONWAY, 1992). This feature was also found in the Napu valley, where gardeners presently used much of the staple tuber crops only as fodder, but mentioned their value for human nutrition if rice harvest would not be sufficient (see 3.5.1). Homegarden produce, including livestock and valuable timber, might also serve as a kind of insurance or saving for purchasing food or holding important ceremonies in times of need (MonTAGNINI, 2006; Soemarwoto, 1987). In the Napu valley, for example, pigs or even cattle raised in the homegardens were sold to pay for school fees, religious ceremonies, or medical doctor bills.

In summary, the homegardens surveyed could be rated as sustainable with regard to their outputs used for family consumption, cash income generation, or exchange within the community, although only few quantitative data were available to support this statement. However, there appeares to be much productive potential of homegardens not sufficiently exploited by the gardeners in the Napu valley.

\subsection{Is soil quality in homegardens managed in a sustainable manner?}

Maintaining soil fertility as basis for conservation of long-term productivity is widely accepted as one of the most important features of sustainable agricultural systems, thus, being frequently mentioned in the literature (HuXLEY, 1999; KuMAR \& NAIR, 2004; TORQUEBIAU, 1992). These authors described different aspects of soil fertility maintenance, e.g. low rates of soil erosion, high soil organic matter content, low soil bulk density, high soil moisture content, and low soil temperature. In homegardens of the Napu valley, not all physicochemical soil parameter could be rated as favourable. Particularly $\mathrm{C}$ content (that is directly related to soil organic matter content) as well as $\mathrm{N}$ and $\mathrm{K}$ contents were frequently too low (see 3.6.3 and 3.6.4), thus, most likely restricting the level of production, especially for $\mathrm{N}$ demanding vegetables. Cacao production that was very important for gardeners as a source of cash income might also have suffered from low $\mathrm{N}$ and $\mathrm{K}$ contents of soil in cacao production 
zones, as already indicated by severe deficiencies of $\mathrm{N}$ and $\mathrm{K}$ detected in cacao leaves (see 3.6.6 and 3.7). The analysis of cacao leaf nutrient contents could not replace soil nutrient analysis, as only $\mathrm{K}$ contents of leaves were correlated to K contents of soil (see 3.7), a result consistent with findings of SCHAFFERS (2002). Some gardeners in the Napu valley initiated to improve unfavourable soil conditions by specifically fertilising certain crops (that, however, made soil quality assessment more difficult due to patchiness). For example, the migrant gardener of the case study homegarden improved the soil of his cacao zone markedly in terms of $\mathrm{pH}$ value and $\mathrm{CEC}_{\text {eff. }}$ (see 3.8.3, Table 3.31); other gardeners regularly fertilised vegetable zones with ash, improving or at least maintaining soil $\mathrm{pH}$ values as well as available $\mathrm{P}$ and exchangeable cation contents (see 3.6.5, Table 3.25). For extremely P-deficient soils, like those of Tamadue (see 3.6.5, Table 3.21), industrial P-fertiliser may cautiously be applied in addition to measures for rising the availability of $\mathrm{P}$ in the soil (e.g. liming, adding organic matter). Nevertheless, unsuitable types of P-fertiliser should be avoided (e.g. Triple Super Phosphate on acid soils in Siliwanga).

$\mathrm{C}$ and $\mathrm{N}$ contents were markedly lower in vegetable than in adjacent cacao zones (Table 3.24). Considering the significant decrease in $\mathrm{C}$ and $\mathrm{N}$ contents over time (see 3.10.4, Table 3.40 ), crop production may become more constrained in the near future, particularly in Wuasa and Rompo, where $\mathrm{C}$ and $\mathrm{N}$ contents were already very low in many garden soils. Gardeners caused this alarming situation by insufficient soil quality management. For example, only about $20-50 \%$ of the gardeners in a village used farm yard manure as a fertiliser, although it was available to most of them (see 4.1.2). Many gardeners removed weeds including their roots for burning or depositing in garbage pits instead of using them for compost preparation. Soil quality deterioration was further accelerated by the habit of many gardeners to remove the litter layer by daily sweeping and burning, as mentioned in 4.1.2. Typical reasons given by the gardeners for this practice were keeping away snakes and insects from the house as well as their aesthetical perception. Sweeping and total weeding was carried out in all front gardens, in most vegetable and ornamental zones and also in some cacao or fruit tree zones. Together with frequent hoeing, particularly of vegetable and ornamental zones, this habit has contributed to severe soil erosion in some homegardens (see 3.8.3). Additionally, removing the litter layer and all weeds in non-shaded zones exposed the soil surface to direct sunlight that caused fairly high soil temperatures, particularly mean maximum temperatures (see Table 3.33 and Figure 3.30). High soil temperatures accelerate the breakdown and turn over rate of organic matter and mineralisation by soil microorganisms (SANCHEZ, 1976; SCHEFFER, 1998), thus, contributing to the lower $\mathrm{C}$ and $\mathrm{N}$ contents in vegetable as compared to cacao zones (see 3.8.3, Table 3.29 and Table 3.30 as well as 3.6.5, Table 3.24). However, if soil temperature exceeds the optimum for organic matter decomposition, its turn over rate may decrease, as observed by STEFFAN-DEWENTER et al. (2007) in cacao agroforestry systems of different shading levels in the same area of Sulawesi. They reported an increasing soil temperature with decreasing canopy cover, accompanied by decreasing rates of litter decomposition and abundance of certain soil arthropods. Cultivation of annual crops such as vegetables and spices on separate plots of homegardens seemed to reduce certain soil quality parameters over time much more than cultivation of perennials. A similar result was reported by DECHERT et al. (2004), who compared soil quality of maize fields and agroforestry plantations of different cultivation times in the same study region of Sulawesi. They revealed that $\mathrm{C}$ and $\mathrm{K}$ contents in maize fields decreased significantly over time, but did not change in agroforestry plots. 
Contrary to maize cultivation, agroforestry was, therefore, regarded as sustainable by the authors, although soils of the agroforestry plots had significantly lower $\mathrm{N}$ and $\mathrm{C}$ contents as compared to adjacent primary forest plots. BRODBECK (2004) reported a similar situation when comparing soil quality in forest gardens and primary forest in the same region. In two of three study sites, soil C and N contents in forest gardens were $20-40 \%$ lower than those of adjacent primary forest. By comparing soil quality of sun- and shade-grown cacao in plantations adjacent to the Lore Lindu National Park, SIEBERT (2002) described lower soil organic matter and nitrate contents in the non-shaded than in the shaded plantations, due to lower litter production and significantly higher soil temperature in the non-shaded plantation.

Insufficient soil fertility management in homegardens of the Napu valley, however, also needs to be seen in the context of changing traditional land use in this region (see 2.1.3). The previously dominant shifting cultivation has been replaced by permanent agriculture such as paddy rice or upland maize fields as well as cash crop plantations only about 10-30 years ago (BURKARD, 2002b). Therefore, indigenous as well as newly arrived migrant farmers may not be familiar with appropriate sustainable land management practices. Concerning soil fertility management, for example, nearly $98 \%$ of the gardeners mentioned fertilising (related mostly to industrial fertiliser) as best measure to improve soil fertility (see 3.4.3). Only $8 \%$ of the gardeners referred to mulching, one gardener to growing cover crops in addition (see Appendix 10). No gardener mentioned deliberate crop rotation or mixed cultivation including leguminous crops as advantageous. Negative environmental consequences have similarly been documented for other cases of resettlement, e.g. in Ethiopia (WoOD, 1993), Tanzania (CHARNLeY, 1997), or Sumatra, Indonesia (HoldEN \& HVOSLEF, 1995).

In general, soil fertility in homegardens has been said to be maintained in the long-term due to, for example, dense soil cover by herbs and litter, low soil temperature, low nutrient export by harvested products, or close nutrient cycling as well as application of locally available fertilisers (GAJASEnI \& GAJASEni, 1999; Drescher et al., 1999; Kumar \& NAIR, 2004; Montagnini, 2006; TChAtAT et al., 2004; WiCKRAMASINGHe, 1992). Several authors emphasised particularly that dense herbal, litter, and root layers in multi-storied homegardens reduce soil erosion rates markedly (DEL ANGEL-PÉrez \& MENDOZA B., 2004; HocheGGer, 1998; Jensen, 1993a; Jose \& Shanmugaratnam, 1993; Karyono, 1990; Soemarwoto \& CONWAY, 1991). However, some reports stated problems of soil deterioration and erosion due to insufficient management practices similar to those identified in the Napu valley. Soil erosion, partly caused by lacking vegetation or litter cover was reported from homegardens in Mexico (ANDRIST, 2003) as well as from Indonesia (HoLDEN et al., 1995; HVOSLEF, 1994). SOEMARWOTO (1987) pointed out that lack of litter caused high rates of soil erosion in homegardens dominated either by fruit and clove trees or by vegetables. Regular sweeping and removing of litter leading probably to a decline in soil fertility was observed in Indonesian urban homegardens (CHRISTANTY, 1990) as well as in those of Maya groups in Mexico (BENJAMIN et al., 2001). Declining soil fertility in terms of bulk density and C content was also reported from a South African homegarden (WICHERN et al., 2003). JENSEN (1993b) recognised negative nutrient budgets for $\mathrm{N}, \mathrm{P}, \mathrm{K}, \mathrm{Ca}$, and $\mathrm{Mg}$ in an Indonesian homegarden, partly related to insufficient fertilising and high nutrient export rates (e.g. by harvested products or leaching). In Sri Lanka, soil C and N contents were considerably lower in speciespoor, commercialised homegardens as compared to extensively managed, forest-like ones (Hochegger, 1998). Drescher et al. (1999) stated low soil C and N contents in 
homegardens of Zimbabwe, although soil fertility was found to be markedly lower in adjacent annual crop fields. Many authors suggested to improve soil fertility management in homegardens, e.g. by promoting the utilisation of farm yard manure (HVOSLEF, 1994; RUGALEMA et al., 1994); by mulching and composting organic residues (BENJAMIN et al., 2001; JENSEN, 1993b; MonTAGNini, 2006); by growing leguminous cover crops (also against soil erosion) (HVOSLEF, 1994); or by a general claim for better extension services (DRESCHER, 1996).

Spreading of partly non-biodegradable household waste materials in homegardens might cause a new problem affecting long-term soil quality and, consequently, productivity of the system. This has never been mentioned in the homegarden literature. Due to lack of opportunities for waste disposal, many gardeners in the Napu valley spread all garbage on the soil of the backyard, others used their homegardens for burying it in garbage pits, or they simply threw it into the pond (pers. obs., see Figure 4.1). Due to increasing wealth status and market access, this garbage consisted of more and more non-biodegradable items such as glass and plastic bottles, tins, plastic bags, broken plastic toys, household appliances and electronics, as well as old batteries. Mixed with organic wastes from the kitchen, this garbage formed the 'litter' layer in many backyard gardens. This practice will probably cause soil contamination in the near future. On the other hand, the traditional spreading of biodegradable waste on homegarden soil certainly contributes to better nutrient cycling and reduces soil erosion. Thus, proper waste recycling in homegardens has often been mentioned as a positive feature in the literature (MONTAGNINI, 2006), particularly in urban or peri-urban settings (DRESCHER et al., 2006).

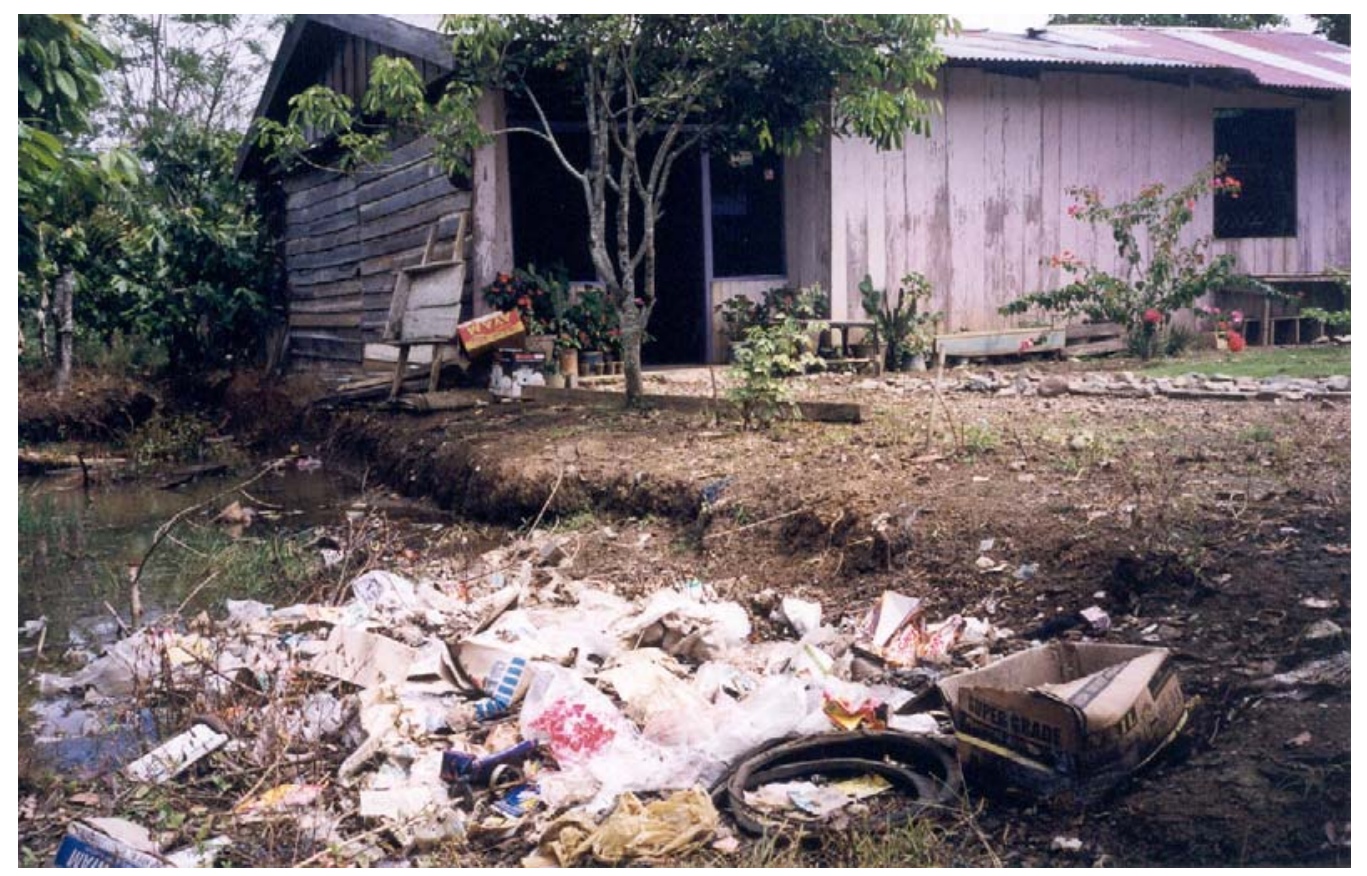

Figure 4.1. An example for waste disposal in homegardens. Here, garbage was thrown into a pond in a garden in Tamadue, Napu valley, Central Sulawesi, 2004.

In summary, the homegardens surveyed did not seem to be managed in a sustainable manner in terms of soil quality maintenance, particularly concerning $\mathrm{C}$ and $\mathrm{N}$ contents. Efficient use of locally available fertilisers should largely be improved, utilisation of compost, mulch, and 
leguminous cover crops should be promoted. Application of industrial fertiliser in an excessive (see 4.1.2) or inadequate manner ought to be avoided. Simultaneously, unfavourable habits such as removing the litter layer by sweeping or frequent hoeing should be given up as a result of explaining the gardeners their disadvantages. Extension services might play a major role in this effort. Similar suggestions were made by several scientists that claimed for improving soil fertility management in homegardens (see above).

\subsection{Is the resource 'light' used efficiently in homegardens?}

In a sustainable agricultural system, light should be used efficiently by several vegetation layers to increase the overall yield (TORQUEBIAU, 1992). A multi-storied vegetation structure further contributes to sustainability, e.g. by adding litter and reducing soil erosion as well as soil temperature (see 4.2), thus, it plays a role in maintaining soil fertility. In addition, a complex vegetation structure offers a habitat for wild flora and fauna, including rare and endangered plant species (see 4.6) as well as beneficial organism such as birds and insects for crop pest control (see 4.1.2). Consequently, homegardens with only few vegetation strata were rated as less sustainable than those with a complex, multi-layered structure (CECCOLINI, 2002; HoCHEGGER, 1998).

In the Napu valley, vegetation was stratified into at least four strata in most of the homegardens surveyed (see 3.5.2). However, complexity of the vertical structure differed among gardens. The strata of more than $5 \mathrm{~m}$ height were often reached by low or very low portions of species (see Figure 3.17) or individuals, respectively. Particularly in the migrant village Siliwanga, the higher vegetation strata were only sparsely or even not occupied, possibly due to the relative young age of the gardens or the poor soil conditions (see 3.6). Rather small homegardens, e.g. those of cluster 4 (see 3.5.4, Figure 3.20) mostly lacked the upper stratum (i.e. more than $10 \mathrm{~m}$ height), not only in 2001 (KEHLENBECK \& MAASS, 2004), but still in 2004. On the other hand, the lowest stratum of plants $(<1 \mathrm{~m}$ height) was rather poorly developed in the large, cash crop dominated homegardens of cluster 1 that harboured only few vegetables and spices (see 3.5.4, Figure 3.19).

Measurement of Photosynthetic Active Radiation (PAR) in the three case study gardens revealed differences in light use efficiency by the vegetation (see 3.8.4). In the small spice garden, light was efficiently used in the fruit tree zone, where only $17 \%$ of the total light reached the herbal layer of $0.3 \mathrm{~m}$ height (see Table 3.35). However, the cacao zone received much light $(96 \%)$ at the top of the cacao trees and, at the same time, let much light through $(30 \%)$ that was not used at the ground due to the mostly bare, regularly swept soil. Shading of cacao was highly recommended as photosynthesis of cacao leaves occurs at rather low rates, even under full sun light (HARDY, 1958). Shading of cacao is said to reduce nutritional imbalances and buffer adverse climatic conditions (BEER et al., 1998; MIYAJI et al., 1997). The authors mentioned suggested that the optimal shading for cacao trees should be $40-70 \%$ of full light. Therefore, shading of cacao only seemed to be optimal in the fruit and the migrant gardens with $40 \%$ and $62 \%$ of full light in $3 \mathrm{~m}$ height, respectively, but not in the spice garden. In the cacao zone of the migrant garden, however, only $2 \%$ of the full light reached $0.3 \mathrm{~m}$ height, resulting in a very sparse herbal layer of only scattered weedy plants. The high density of cacao trees in this garden did not allow an efficient use of light by growing shade-tolerant crops in the lowest layer. Besides, in too heavily shaded cacao, 
outbreaks of severe diseases such as Phytophthora pod rot are enhanced (BEER et al., 1998; MIYAJI et al., 1997). In contrast, the lowest layer in the fruit tree garden was reached by $15 \%$ of total light (see Table 3.35), thus, enabling cultivation of shade-tolerant taro, cocoyam, and Helioconia under some of the cacao trees. When comparing sun- and shade-grown cacao, SIEBERT (2002) suggested that about 5-15\% of full PAR reaching $1 \mathrm{~m}$ height was optimal for meeting both soil fertility maintenance (by low soil temperature) and overall productivity (by cultivation of some useful plants under the cacao trees).

In the fruit garden, light was also efficiently used in the vegetable zone because still $25 \%$ of the full light reached the lowest layer, where ginger and other spices were grown between some maize and climbing french bean plants. In the cassava zone of the migrant garden, however, light was not used efficiently. More than $50 \%$ of full light reached $1.3 \mathrm{~m}$ and $0.3 \mathrm{~m}$ (see Table 3.35), but only very dense weedy plants were found in the herbal layer (see Figure 3.31). However, the poor soil conditions in the backyard of the migrant garden (see Table 3.31) might have limited the cultivation of other crop species. Finally, PAR data presented in this study might not be representative for the three homegardens studied because, due to time scarcity, measurements were carried out only at a single spot per production zone (see 2.8.3), instead of moving around the equipment in the whole zone to allow calculation of means.

Vegetation structure in homegardens has been mostly described as consisting of 3-5 strata and resembling a forest (AlBUQUerque et al., 2005; DAS \& DAS, 2005; HEMP, 2006; JOSE \& ShanMUgaratnAM, 1993; MichON \& MARY, 1994; NiÑEZ, 1987; SOEMARWOTO \& SOEMARWOTO, 1982; WiCKRAMASINGHE, 1995). However, neither tree height nor species diversity or structural complexity of a homegarden might reach the respective levels of primary forests (GAJASENI \& GAJASENI, 1999; HochEGGER, 1998). In the homegardens surveyed in the Napu valley, tree height with a maximum of about $15 \mathrm{~m}$ (personal observation) was far below the $35 \mathrm{~m}$ and even $50 \mathrm{~m}$ reported for emergent trees in primary forests of the Lore Lindu National Park by KESSLER et al. (2005) and BRODBECK (2004), respectively. Also, species richness and diversity were much lower in homegardens as compared to primary forests (see 4.4). Consequently, JENSEN'S (1993a) statement that homegarden structure rather resembles a young secondary forest, kept in a permanent early successional stage, might be more applicable.

Many authors argued that light is used efficiently by the multi-layered structure in homegardens, e.g. by cultivating rather few very tall species in the highest layers (to avoid excessive shading) and shade-tolerant crops such as ginger, taro, cocoyam, and pineapple in the lowest stratum (De ClercK \& Negreros-Castillo, 2000; Esquivel \& Hammer, 1992; John \& NAIR, 1999; KARYONO, 1990; Millat-e-Mustafa et al., 1996; OKAFOR \& FERNANDES, 1987; SHRESTHA et al., 2002). However, only few scientists have carried out light intensity measurements in homegardens to prove efficient light utilisation. ALLISON (1983, cited in GLIESSMAN, 1990b) documented a rather low light transmission of only $21 \%$ in a tree-rich, but $31 \%$ in a tree-poor homegarden in Mexico. In a homegarden of West Java, CHRISTANTY (1981, cited in CHRISTANTY et al., 1986) measured only $6 \%$ of light reaching the bottom layer (i.e. less than $1 \mathrm{~m}$ height), where, however, photosynthetic rates were partly still as high as in the upper strata. GAJASENI \& GAJASENI (1999) reported continuously decreasing light intensities from crown to ground levels in three homegardens of Thailand, where the ground level was reached on average over one day by $84 \%$ of the full light in a species-poor, 
but by only $33-41 \%$ in a species-rich garden. In three multi-storied homegardens in Guatemala, GILLESPIE et al. (1993) measured on single spots at the ground $45-50 \%$ of the PAR in full sun; however, on average over the whole transect area, only $7-14 \%$ of the PAR reached the ground. Thus, results of PAR measurement at ground level in three homegardens of the Napu valley corresponded well with data from the literature, although measurements were carried out only for few days at a single spot per production zone (see above). In cacao zones of the fruit and the migrant homegardens, PAR at ground level was similar or even less as compared to $11.5-14 \%$ of full light reported by BRODBECK (2004) at the same height in two forest gardens in the same region of Sulawesi. However, PAR at $3 \mathrm{~m}$ height was much higher in all cacao zones surveyed (40-96\%) as compared to that in the forest gardens (less than 23\%). For primary forests, BRODBECK (2004) documented quite low PAR at ground level (only about $1 \%$ of full light) as well as at $4.5 \mathrm{~m}$ height (about $3 \%$ ). Thus, contrary to many statements in the literature, the homegardens surveyed were not comparable to adjacent forests concerning not only tree height and species diversity (see above), but also concerning light use efficiency.

A decrease in complexity of vegetation structure similar to that observed in certain homegardens of the Napu valley (i.e. less complex in small or cash crop dominated homegardens, see above) was similarly observed by other scientists. ARIFIN et al. (1998) as well as ABDOELLAH et al. (2002) found that the upper strata (i.e. more than $5 \mathrm{~m}$ height) were mostly lacking in small homegardens. In Kerala, India, most of the trees in small homegardens were less than 5 years old, whereas in large homegardens 10-15 year old trees dominated (Jose \& Shanmugaratnam, 1993). ABdoellah et al. (2006) reported that only about $6 \%$ of the cultivated species reached the stratum higher than $10 \mathrm{~m}$ in small Javanese homegardens with a mean size of $270 \mathrm{~m}^{2}$. HoCHEGGER (1998), on the other hand, noted as much as $32 \%$ of the cultivated species in the strata above $10 \mathrm{~m}$ for very large (mean size about 5,000 $\mathrm{m}^{2}$ ) homegardens in Vietnam. Besides size, also commercialisation of homegardens was said to influence the complexity of vegetation structure negatively (Christanty et al., 1986; Hochegger, 1998). The type of cash crop (annual or perennial) determines which vegetation strata will impoverish. JOHN \& NAIR (1999) claimed that perennial cash crops in homegardens dominate on the expense of vegetable crops in the lowest stratum. A similar observation was made in the cacao- and coffee-dominated homegardens of cluster 1 in the Napu valley (see above). However, when annual, lightdemanding cash crops predominate, homegardens lack the upper strata as a consequence of removing for example tall forest trees or minor fruit tree species to avoid shading (ABdoellah et al., 2006; CeCCOLINI, 2002; MichON \& MARY, 1994). In homegardens of the Napu valley, also high altitude might have contributed to the rather poorly developed upper vegetation strata, as similarly reported from other regions. SHRESTHA et al. (2002) noted no or very few trees in highland homegardens of Nepal, referring, however, to very high altitudes of more than 3,000 $\mathrm{m}$ asl. In West Java, homegardens at altitudes of more than 1,300 $\mathrm{m}$ asl. were dominated only by vegetables (grown mostly as cash crops), whereas those in the lowlands by fruit trees (ARIFIN et al., 2005; KEHLENBECK et al., 2007).

Finally, results of vertical structure analysis suggested that not all homegardens surveyed in the Napu valley fulfilled the sustainability requirement/characteristic of maintaining a multilayered structure. In the large cacao- and coffee-dominated migrant gardens, light use efficiency could be improved by cultivating more shade-tolerant herbal crops in the lowest 
stratum, accompanied by slightly reducing the density of cacao and coffee trees in some gardens. On the other hand, in the small gardens as well as in most of the separate vegetable zones of medium-sized ones, structural complexity could be increased by integrating some suitable tree crops. In the future, the observed trend towards more cash crops (see 4.5) might further threaten the sustainability of the homegardens surveyed in terms of structural complexity. As example from the research area, Figure 4.2 shows extreme impoverishments of the vertical structure in homegardens as an ultimate consequence of commercialisation.
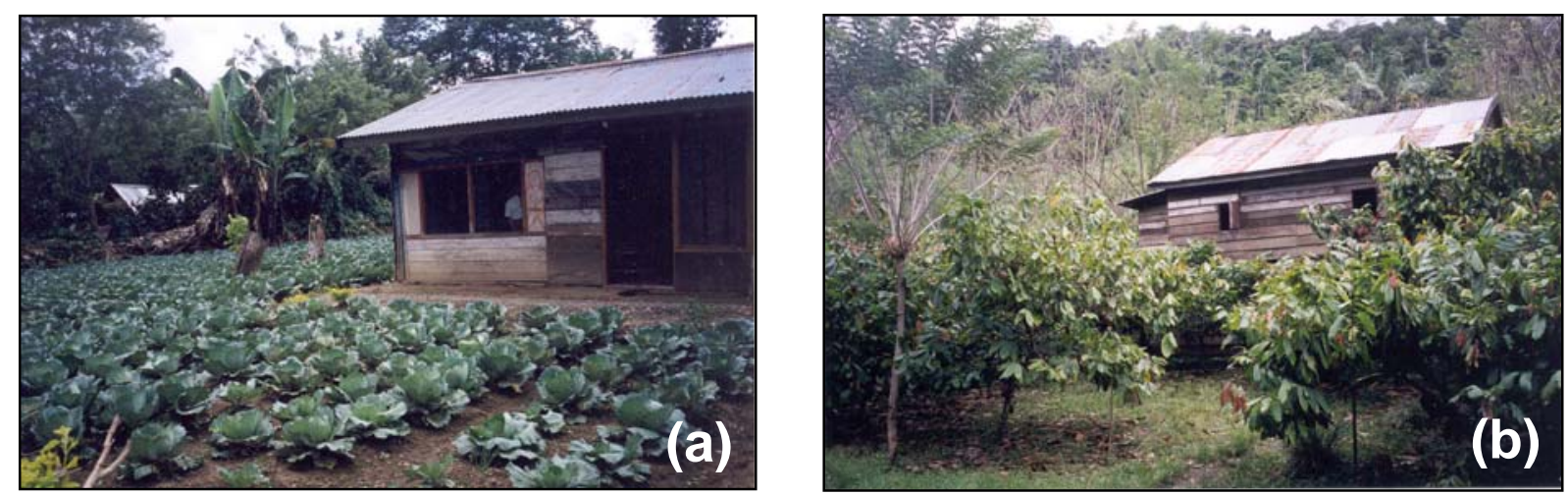

Figure 4.2. Highly commercialised homegardens lacking a multi-layered vegetation structure, managed by migrant families in the Napu valley, Central Sulawesi, 2004. (a) Cabbage garden in Tamadue. (b) Cacao garden with scattered shade trees, south of Wuasa. Note: These homegardens were not included in the sample gardens of this study.

\subsection{How valuable and how variable is crop diversity in the homegardens?}

Biodiversity, especially of useful plants, but sometimes also including wild plant species or even domestic animals, is frequently considered an important sustainability indicator of agroecosystems (Gliessman, 1990a; Torquebiau, 1992; TORQuebiau \& PenOT, 2006). This is related to the contribution of agro-biodiversity to the overall agro-ecosystem functioning, presented in detail in 1.3. To briefly summarise, plant diversity is seen as a major factor towards sustainability and productivity of a system because it reduces the risk of attacks by pests or diseases and contributes to a favourable microclimate, efficient use of resources, year-round availability of diverse and valuable products, long-term stability of yields, provision of genetic resources for future crop development and improvement, and soil fertility maintenance, among others (SOEMARWOTO \& CONWAY, 1992; TORQUEBIAU, 1992). Some of these attributes were not assigned to species diversity per se, but rather to a multi-layered structure (discussed in 4.3) or to the presence of certain keystone species or functional groups (NAIR, 2006). However, the strong influence of different factors on the state of crop diversity as well as its temporal changes (see 4.5) should be considered while assessing the sustainability of homegardens by using the indicator 'biodiversity'.

In the Napu valley, crop species richness was high, as 206 species were cultivated in the 48 homegardens studied in 2004 (see 3.5.1). Many of these crops were grown as vegetable, medicine, fuel wood, fruit, or spice, few ones as staple, stimulant, or for multi-purpose- or 
other uses (see Table 3.6). Therefore, diverse homegarden crops provide a diverse range of valuable produce for fulfilling the daily needs (both for subsistence and cash) of gardeners and their families, as discussed in more detail in 4.1.3. It should be stresses that, in general, homegarden produce contributes much more to meet the demands of protein and micronutrients than that of energy because the respondents stated to consume rather fruits, vegetables, and spices from their gardens, whereas staple crops were mainly used as animal feed (see 3.5.1). However, the potential for production of neither subsistence nor cash crops was fully exploited in the homegardens of the Napu valley (see 3.4.6 and 4.1.3). Additionally, many gardeners did not recognise the high nutritional value of their homegarden products, stating that the nutrients contained in cooked white rice, served three times a day, already fulfilled completely their nutritional requirements. In many households surveyed, fruits and vegetables were consumed only in very small quantities. Parts of the homegarden produce was left unharvested (e.g. pummelo, water apple) or only fed to pigs (e.g. cassava, sweet potato, taro) in these households. According to the gardeners, this was partly due to relatively low food quality of some local varieties (e.g. fibrous or bitter citrus fruits), but mostly due to disregard and acculturation (e.g. tuber crops, the former main staple, are now replaced by white rice and only recognised as 'food of the poor and the pigs'). Consequently, not only the homegarden productivity could be increased in the research area, as discussed in detail in 4.8 , but also the awareness about the nutritional value of homegarden produce should be raised (see also 4.6).

Concerning medicinal plants, richness in this use category found in homegardens of the Napu valley was highly valuable, including not only the 30 species with a main medicinal use, but also 83 species with a secondary medicinal use (see Appendix 12) as well as 36 weed species regarded potentially useful as medicine (see Appendix 14). This high number of 149 medicinally usable plant species was associated with large indigenous knowledge about the utilisation of each single species. However, the traditional knowledge was not evenly distributed among the sample households. Older respondents were mostly still able to list many medicinal plants together with the respective applications and recipes, whereas younger gardeners often stated to know only little about such plants and to prefer 'modern' medicine (see 3.4.6). Thus, genetic as well as cultural erosion might threaten diversity of and knowledge about medicinal plants in the future due to the ongoing process of 'modernisation'. On the other hand, awareness and appreciation concerning, for example, the conservation of medicinal plants and the related traditional knowledge could be raised by promotion and information campaigns as already observed in Wuasa, where the number of medicinal plants increased over time due to the activities by a development project (see 3.10.3 and Figure 3.40).

Varietal diversity was very high in the homegardens of the Napu valley, where altogether 329 species and/or varieties were cultivated (see 3.5.1). However, a high value, with regard to future development and improvement of crops, might be only assigned to rather few species with high numbers of varieties, e.g. banana, mango, chilli, and common eggplant, whereas 180 crop species (out of 206 spp.) only occurred with a single variety each (see Appendix 12). Future research concerning varietal diversity should, therefore, rather focus on such 'keyspecies'. On the other hand, homegardens seemed to be the only production system for cultivation and reproduction of some varieties, particularly of staple crops. At the field level, for example, nearly exclusively improved varieties of rice were grown (i.e. $95 \%$ of the 40 
different paddy rice plots cultivated by 49 respondent households were planted with improved varieties; pers. obs.). In contrast, the local rice variety 'mpulumaeta' (black-coulored seeds, having a very sticky cooking quality), used to make the local sweet 'onde-onde', was exclusively found in homegarden no. 45 in Wanga, but not in any of the paddy rice fields. Besides, the local maize variety 'pulut', used for making a special soup called 'binte', was grown in three homegardens, but was not mentioned by any of the respondents concerning the 22 maize fields cultivated by their households. Therefore, the homegardens studied showed to have a high value for in situ conservation of plant genetic resources, although this function might be threatened in the future, as discussed in more detail in 4.6.

As compared to other agro-ecosystems in the same research area, homegardens harboured a very high crop diversity. The homegardens surveyed covered on average only about $4 \%$ of the total agricultural farm land owned by the respondents' households in the Napu valley (see Appendix 4) (portion of homegardens in the whole STORMA research area: $7 \%$ of the total agricultural land, according to MAERTENS et al., 2002). Nevertheless, nearly all crop species cultivated in plantations and fields of the Napu valley were also grown in homegardens (pers. obs.). For many crops, on the other hand, homegardens seemed to be the most important production system, as they were only rarely found in fields or plantations of the region (pers. obs.). Homegardens should, thus, be appreciated as a key reservoir for cultivated plant species, important particularly as a source of planting material for plantations and upland fields (COOMES \& BAN, 2004; NiÑEZ, 1987). In addition, also some of the wild plant species recorded for the research area were found in the homegardens surveyed (see 4.6). The high crop species richness of homegardens was only comparable to that of forest gardens in and around the same area of Sulawesi, where BRODBECK (2004) documented 183 crop and wild species on three plots of 1 ha size each. A similar total species richness of forest gardens (maximum no. about $140 \mathrm{spp}$.), however, only concerning tree species on 4 plots of 2,500 $\mathrm{m}^{2}$ size each in the Napu valley, was estimated by KESSLER et al. (2005). For a simple agroforestry system in the same area (i.e. a cacao plantation, shaded by Gliricidia sepium), on the other hand, Schulze et al. (2004) reported only about 4 tree and 7 understorey plant species, for a maize field no tree and about 10 understorey plant species, however, determined on only 4 plots of $600 \mathrm{~m}^{2}$ each. SIEBERT (2002) identified 17 plant species (mostly weeds) in a simple full-sun grown cacao plantation and 21 (mostly useful ones) in a more complex agroforestry system of about 1 ha sizes each, located around the research area. The superiority of homegardens to all other agro-ecosystems concerning their biodiversity has also been emphasised for other regions or even worldwide (COOMES \& BAN, 2004; SWIFT \& ANDERSON, 1993 in NAIR, 2006; WEZEL \& OHL, 2005).

Plant species richness in homegardens of the Napu valley was comparable to those of other regions, when a similar sample size was considered (Table 4.1). If ornamentals were included in the Napu study, the combined species number of 368 (see 3.5.1) even exceeded many of the species numbers recorded for other regions. Particularly in African homegardens, the few studies available documented relatively low species richness as compared to Mesoamerican or Asian ones, possibly due to long dry periods in many parts of Africa, which are said to reduce crop diversity (see 1.4). In African regions of higher humidity, such as the slopes of Mt. Kilimanjaro, relatively high species diversity was recorded (HEMP, 2006), however, including many forest and weedy species (Table 4.1). 
Table 4.1. Plant species richness in homegardens (including ornamentals, but excluding weeds, if not differently indicated) as total number per study area and/or mean per garden in different regions of the world. Garden sizes are given in means (ranges in brackets).

\begin{tabular}{|c|c|c|c|c|c|c|}
\hline $\begin{array}{l}\text { Country/ } \\
\text { region }\end{array}$ & $\mathrm{N}$ & $\begin{array}{l}\text { Elevation } \\
\text { (m asl.) }\end{array}$ & $\begin{array}{c}\text { Mean } \\
\text { garden } \\
\text { size }\left(\mathrm{m}^{2}\right)\end{array}$ & $\begin{array}{l}\text { Total } \\
\text { spp. no. }\end{array}$ & $\begin{array}{c}\text { Mean } \\
\text { spp./ } \\
\text { HG }\end{array}$ & Reference \\
\hline \multicolumn{7}{|l|}{ Indonesia } \\
\hline C Sulawesi & 50 & 1100 & $600-2300$ & $206^{\dagger}$ & $33-49^{\dagger}$ & This study \\
\hline W Java & 94 & 1250 & 340 & 199 & $15-16$ & ABDOELLAH et al. (2006) \\
\hline W Java & 90 & $300-1300$ & $190-560$ & - & $27-44$ & KEHLENBECK et al. (2007) \\
\hline W Java & 351 & $0-1000$ & 230 & $602^{\pi}$ & $19-24^{\pi}$ & $\begin{array}{l}\text { KARYONO (1981) in SOEMARWOTO } \\
(1987)\end{array}$ \\
\hline W Java & 41 & - & - & 272 & 56 & SOEMARWOTO (1987) \\
\hline Sumatra & 68 & - & 2500 & $118^{\dagger}$ & - & HVOSLEF (1994) \\
\hline \multicolumn{7}{|c|}{ Asia without Indonesia } \\
\hline Thailand & 4 & - & 1590 & - & 34 & GAJASENI \& GAJASENI (1999) \\
\hline Vietnam & 100 & $<1010$ & 3050 & $646^{+\pi}$ & $68^{+\pi}$ & HoDEL et al. (1999) \\
\hline Vietnam & 116 & $<100$ & $1400-7500$ & 202 & $23-54$ & TRINH et al. (2003) \\
\hline Bangladesh & 32 & - & $(100-2200)$ & 86 & $10-32$ & ALI (2005) \\
\hline Bangladesh & 80 & - & $200-2000$ & $92^{\dagger \dagger}$ & $23^{\dagger \dagger}$ & MILLAT-E-MUSTAFA et al. (1996) \\
\hline Nepal & 134 & $100-1500$ & 400 & $165^{\dagger}$ & $31^{\dagger}$ & SUNWAR et al. (2006) \\
\hline S India & 30 & - & 4800 & 132 & 27 & PEYRE et al. (2006) \\
\hline S India & 400 & $0-1500$ & 3300 & $107^{\dagger}$ & $15^{\dagger}$ & JOHN \& NAIR (1999) \\
\hline NE India & 50 & - & 3000 & $122^{\|}$ & $20^{\|}$ & DAS \& DAS (2005) \\
\hline Sri Lanka & 158 & $<700$ & 5250 & 640 & $53^{\dagger}$ & HOCHEGGER (1998) \\
\hline SW China & 9 & - & 230 & 126 & 32 & Fu et al. (2003) \\
\hline Iran & 80 & $0->1500$ & 930 & $78^{\dagger}$ & $7-18$ & KHOSHBAKHT (2005) \\
\hline \multicolumn{7}{|l|}{ Mesoamerica } \\
\hline SE Mexiko & 8 & $<400$ & $(225-3400)$ & 338 & - & ALVAREZ-BUYLLA ROCES et al. (1989 \\
\hline SE Mexiko & 40 & 300 & - & 223 & 45 & DEL ANGEL-PÉREZ \& MENDOZA (200 \\
\hline Cuba & 31 & - & 875 & $101^{*}$ & $18-24^{\ddagger}$ & WEZEL \& BENDER (2003) \\
\hline Cuba & 107 & - & - & 508 & - & CASTIÑEIRAS et al. (2002) \\
\hline SE Guatemala & 46 & - & $(90-2500)$ & 276 & 33 & AZURDIA \& LEIVA (2004) \\
\hline C Guatemala & - & $20-1200$ & $1000-1900$ & 414 & $50-56$ & AZURDIA \& LEIVA (2004) \\
\hline Venezuela & 150 & $0-2400$ & - & 591 & $52-70$ & QUIROZ et al. (2004) \\
\hline Costa Rica & 1 & - & 1240 & 83 & - & GLIESSMAN (1990a) \\
\hline Nicaragua & 20 & 450 & 3240 & 324 & 70 & MENDEZ et al. (2001) \\
\hline SE Peru & 19 & $<500$ & - & $71^{+}$ & $14-20^{+}$ & WEZEL \& OHL (2005) \\
\hline NE Peru & 51 & - & 390 & $161^{\dagger}$ & $30^{\dagger}$ & LAMONT et al. (1999) \\
\hline NE Peru & 21 & - & 1280 & 168 & 35 & PADOCH \& JONG (1991) \\
\hline \multicolumn{7}{|l|}{ Africa } \\
\hline Sudan & 81 & 570 & $(40-150)$ & 32 & 3 & GEBAUER (2005) \\
\hline Ethiopia & 36 & $1200-2100$ & 560 & 133 & 8 & BELACHEW WASSIHUN et al. (2003) \\
\hline Ethiopia & 141 & $<2300$ & 9000 & 198 & 37 & TESFAYE ABEBE et al. (2006) \\
\hline Ghana & 250 & $<750$ & $1600-5900$ & $40-104$ & - & BENNETT-LARTEY et al. (2004) \\
\hline Tanzania & 62 & $1000-1800$ & $\begin{array}{c}1000 \\
\text { (sampled) }\end{array}$ & $523^{\pi}$ & $54^{\pi}$ & HEMP (2006) \\
\hline Zimbabwe & 14 & $<1000$ & - & $27^{*}$ & - & DRESCHER et al. (1999) \\
\hline
\end{tabular}

Note: $-=$ Not available.

${ }^{\dagger}$ : Without ornamental species.

\$: Without tree/timber and ornamental species.

ף: Including also useful weed species.

${ }^{+}$: Including also varieties.

"I: Only woody species.

${ }^{\dagger}$ : Only perennial species. 
To compare crop species diversity among homegardens or between homegardens and other agricultural systems, not only species richness, but also some diversity and evenness indices should be considered (see 1.2.2). However, such indices have only rarely been recorded in the literature, possibly because a time-consuming assessment of species abundances is necessary for their calculation. In the Napu valley, the mean Shannon index per village varied from 2.3 to 3.1 (see 3.5.3, Table 3.11), thus, reflecting the range of this index given by KARYONO (1990) as 2.8-3.0 for Indonesian homegardens, 1.9-2.7 by GAJASENI \& GAJASENI (1999) for Thai homegardens, or 3.2 (pooled and for tree species only) by SHASTRI et al. (2002) and 1.13.0 (tree species only) by KUMAR et al. (1994) for homegardens of Southwest India. GLIESSMAN (1990a), however, reported a higher Shannon index (i.e. 3.6) for only one homegarden in Costa Rica, whereas lower indices were documented by ABDOELLAH et al. (2006) for homegardens of West Java (i.e. on average 1.1 and 2.0 for commercialised and non-commercialised gardens, respectively) and by WEZEL \& BENDER (2003) for those of Cuba (on average 1.6-1.8 for three villages).

Not only plant species richness, but also diversity is generally said to be higher in homegardens as compared to other agro-ecosystems; sometimes it might even be similar or higher than that of natural ecosystems. For fallow plots covered with secondary forest ( 5 plots of $400 \mathrm{~m}^{2}$ size each) in the Napu valley, PITOPANG et al. (2004) calculated Shannon indices of 2.0-2.9 for tree species. According to KAYA et al. (2002), tree species diversity of four forest gardens of Central Maluku, Indonesia, was found to be nearly as high as that of adjacent primary forest (2.7-3.1 vs. 3.2, respectively). In homegardens of Southwest India, SHASTRI et al. (2002) reported an even higher tree diversity than in adjacent reserve forest (3.2 vs. 2.5, respectively). Nevertheless, the Shannon indices of these forest areas might have been considerably higher if herbaceous plants were included as the references only referred to the tree components.

Crop species composition, associated with the complexity of vertical structure as well as crop diversity parameters differed markedly among the homegardens. Cluster analysis based on crop species abundances revealed certain spatial patterns and some of the possible underlying reasons (see 3.5.4). The grouping occurred firstly along village differences, determined, on the other hand, by differences in ethnicity of the inhabitants and/or soil quality (see Figure 3.18, Table 3.18). The subsequent separation of the two migrant villages was much more distinct as that of the three local villages. Besides, the results of the cluster analysis reflected the marked differences existing in garden sizes, vertical vegetation structure, and socioeconomic characteristics as well as overall crop species richness and diversity parameters (see Table 3.16 and Table 3.17). Some of these factors were also revealed as important for influencing crop diversity by multiple regression analyses (discussed in more detail in 4.5), thus, supporting the cluster analysis. However, PCA of the 48 gardens did not add much information towards classification, as groups were not sufficiently separated (Figure 3.22). KUMAR \& NAIR (2004) challenged the search for classification schemes, e.g. by cluster analysis, by stating that it would not get homegarden research any further. However, different from regression analysis of factors determining crop diversity, classification by cluster analysis revealed structural and compositional differences among homegarden types. Therefore, it might help to identify those homegarden types that contain certain key species (important for in situ conservation of plant genetic resources) or that are, in general, more 
sustainable (related to the advantages of a complex vegetation structure or a well-balanced mix of different crop use categories, among others).

Multivariate statistical methods such as cluster analysis or Principal Component Analysis (PCA) based on species abundance or simply presence/absence have only been recently and rarely recorded in the homegarden literature (e.g. AlBUQUERQUE et al, 2005, for PCA), possibly due to the time-consuming data assessment and computing. Such multivariate methods were used mainly in studies focussing on in situ conservation of plant genetic resources (e.g. BLANCKAERT et al., 2004; LEIVA et al., 2002; QUIROZ et al., 2002) or on the structural and functional dynamics of crop species diversity (PEYRE et al., 2006; TESFAYE ABEBE et al., 2006). Similar to findings from the Napu valley, a clear division of homegarden clusters along cultural/ethnic lines as well as along an environmental gradient (climate zones) was also reported by LEIVA et al. (2002), a division according to differences in garden sizes and/or commercialisation level by PEYRE et al. (2006) and VogL et al. (2002; based on Correspondence Analysis).

In the Napu valley, the 30 homegardens surveyed in 2001 had been classified by cluster analysis based on species presence/absence data (KEHLENBECK \& MAASS, 2004). The resulting three main garden types also differed markedly with regard to garden age and size, species richness and diversity, and gardener's origin. When re-classifying the same gardens in the 2004-study, 20 more gardens were included, but four of the former study were not available anymore (see Figure 3.18). Many similarities were revealed between these two classifications, although clustering methods were slightly different (i.e. on species abundance in 2004). The former 'small, species-poor spice gardens' $(\mathrm{N}=7)$ were now mostly grouped in cluster 4, but two in cluster 3. Of the 'medium-sized, species-rich fruit tree gardens' $(\mathrm{N}=7)$, most were grouped in cluster 3, whereas two were among the outliers. Finally, the 'large, species-poor migrant gardens' $(\mathrm{N}=9)$ largely corresponded to cluster 2 of the present analysis, but three gardens were moved to cluster 3. Some of the inconsistencies between the two groupings can be explained with the help of the PCA. For example garden no. 5, formerly classified as 'migrant garden', was now put into cluster 3, however, it is located relatively close to gardens from cluster 2 by the PCA (Figure 3.22). In conclusion, different classifications based on species composition consistently grouped the gardens following stable criteria such as garden sizes, species richness, main use categories, or gardener's origin; but they also reflect the development of certain gardens.

In summary, homegardens in the Napu valley harboured high crop species richness and diversity, clearly exceeding those of other agricultural systems in the region. A high varietal diversity, however, was found only for certain key species. Homegardens provided the gardeners' families with a multitude of valuable produce, used not only as highly nutritional food or for cash income generation, but partly also as a medicine. Nevertheless, certain crops were neglected by the gardeners. Both crop species richness or diversity and the associated traditional knowledge about its utilisation was not evenly distributed among the homegardens studied and the gardeners interviewed. 


\subsection{Can crop diversity be maintained in homegardens? Which factors are responsible?}

In a sustainable agricultural system, crop diversity should be high and maintained over time to ensure the ecological, economic, and social functions of the system in the long-term (TORQUEBIAU, 1992). Although stability is requested in such a system, it should, at the same time, also be able to react in a flexible manner to changing household needs and changing environmental or socio-economic conditions (HUXLEY, 1999).

In homegardens of the Napu valley, crop species richness was not only maintained, but even increased over time, particularly that of vegetable and medicinal plants (see 3.10.3, Figure 3.40 and Figure 3.41). Activities of development projects partly might be responsible for this improvement (see below), however, their impact was not perceptible in the migrant village Siliwanga, where crop species richness still increased. Gardeners most likely followed new fashions in growing cash crops only recently in their homegardens, thus, introducing certain species such as cacao, vanilla, clove, teak, or Gmelina arborea. Often, homegardens serve as a kind of 'experimental station', where the suitability of new crops is tested. The planting material for many of these new crops was mostly not provided by formal, but informal sources (see 3.4.1). Principal Component Analysis of changes in crop diversity (Figure 3.38) confirmed the mentioned trend towards more cash crops in the two villages with rather good market access (i.e. Wuasa and Siliwanga), whereas in the remote village Rompo, such a trend was not detected. These results correspond to other studies, which reported increasing importance of cash crop production, including fruits and ornamentals, in homegardens located close to market opportunities such as large cities or tourist centres (KARYONO, 2000; MÉNDEZ et al., 2001; SOEMARWOTO \& CONWAY, 1992; see also 1.4).

Another reason for increasing crop species richness over time in the homegardens studied might have been the author's own research activities in the year 2001 (KEHLENBECK \& MAASS, 2004). Nearly all respondents perceived as an honour to be included in the sample households. Recognition of their homegardens by a foreign scientist might have raised pride and ambition of gardeners and possibly stimulated their interest in crop diversity. As a result, gardeners might have revived networks of seed and plant exchange within their neighbourhoods and were more open for experimental cultivation of new crops. Besides, during the intensive interviews concerning utilisation of plants in the 2001-survey, some gardeners might have learned from the author about the use potential of some of their spontaneously occurring homegarden species, which they might have perceived only as weeds before. Consequently, gardeners might have mentioned these plants as useful crops in their homegardens during the 2003/2004-survey. WEZEL \& BENDER (2003) reported a similar positive effect of a previous survey concerning medicinal plants on gardeners' knowledge, which might have biased the results of a study on species richness in the respective homegardens. In addition, due to the extended sample of homegardens in the Napu valley, a larger pool of gardeners' knowledge about useful plants was available in the 2003/2004survey. As a result, plant species mentioned as useful by 'new' respondents might already have occurred in the homegardens surveyed in 2001, but neither the former respondents nor the author had recognised these plants before. However, probably only few, mostly 'weedy' plant species with, for example, medicinal or mystic values, might have been overseen in this way. 
Raised pride of gardeners on a well-tended homegarden, caused probably by the research activity itself, might have affected not only the diversity of crops, but also of ornamentals. As compared to the 2001-survey, species number of ornamentals increased markedly in many homegardens in 2004 (data in Appendix 15)

Particularly in Wuasa, which was classified as the village being rather close to markets and most 'urbanised' (see 2.2), some gardeners raised the number of ornamental species substantially (e.g. from 9 to 52 species in garden no. 6). Also, the abundance of ornamentals was high in Wuasa, thus, numbers of ornamental individuals (and species) in a homegarden sometimes even exceeded those of crops (gardens no. 4 and 6). An increasing importance of ornamentals at the expense of subsistence crops together with urbanisation or the raise in social stratum and living standard has frequently been mentioned in the literature (KARYONO, 1990; Kehlenbeck et al., 2007; Rico-Gray et al., 1990; Soemarwoto \& Soemarwoto, 1982; see also 1.4). In the study area, however, a decrease of crop species richness over time was not observed, even not in homegardens, where ornamentals largely increased in species number and abundance.

Besides urbanisation, mainly commercialisation, fragmentation, and time scarcity were said to negatively influence crop diversity in homegardens, whereas garden size and age might positively affect it (see 1.4). For homegardens of the Napu valley, multiple regression analysis revealed a negative influence of commercialisation and household's migration background on crop species richness, but a positive influence of garden size, household age, and soil quality expressed as soil available P content (see 3.9.2, Table 3.38). Migration background and mean household age might partly have been related to time scarcity issues (i.e. migrant households mostly were rather small and focussing on staple or plantation crops; in households with a high mean age of adults, some of the older members invested more time into homegardening). Overall, results of regression analysis correlated well with general assertions in the literature (e.g. Christanty et al., 1986; HoogerbrugGe \& Fresco, 1993; see also 1.4). Nevertheless, most of the previous studies were rather descriptive, at best comparing, for example, differences between means separately for every factor. Only few scientists carried out multiple regression analysis to reveal the relative importance of different factors and their interactions in influencing crop diversity (BAN \& COOMES, 2004; COOMES \& BAN, 2004; TESFAYE ABEBE et al., 2006). Possible problems related to multiple regression analysis were relatively low numbers of cases (e.g. 13-48 cases per regression model in BAN \& COOMES, 2004) or low $\mathrm{R}^{2}$-values (e.g. adjusted $\mathrm{R}^{2}$ only 0.13 for crop species richness in TESFAYE ABEBE et al., 2006). The results of this study might have partly suffered from such weaknesses, as case number was 48 and adjusted $R^{2}$ values ranged from 0.45 to 0.60 for species richness, density, and Margalef index (see Table 3.38). On the other hand, factors found to be of significant influence in the regression analysis were supported by theoretical considerations and findings in the literature. In addition, the large influence of garden size and household's migration background was also demonstrated by Figure 3.15 in chapter 3.5.1, that of commercialisation by the PCA (see 3.10.3, Figure 3.38). Therefore, results of multiple regression analysis can be considered as reliable.

An important finding of the final regression analysis in this study was the lack of influence of market access on crop diversity. Instead, a slightly positive influence of this factor could be derived from the separate regression analysis restricted only to socio-economic factors (see 
3.9.1, Table 3.37). This phenomenon partly might have resulted from activities of development agencies that focussed mainly on Wuasa. Due to a planned village competition in autumn 2004 that also considered the appearance of homegardens, the mayor of Wuasa forced gardeners to plant a certain number of medicinal species in their homegardens as recommended by the village development programme. In addition, inhabitants of Wuasa, which is the administrative and commercial centre of the Napu valley (see 2.2), had a higher possibility to gather new planting material by travelling around, by meeting people from outside, or by taking advantage of available training and information opportunities as compared to the other, rather small villages studied. The finding of the present study that a higher crop diversity could be expected in homegardens with intermediately good market access supports the rather few studies postulating the same (HODEL et al., 1999; QUIROZ et al., 2004; Sunwar et al., 2006). Good market access also not necessarily resulted in commercialisation of homegardens. In Wuasa, only $30 \%$ of the gardeners mentioned generation of cash income as a main or second function of their homegardens (see Appendix 8 ). In contrast, $90 \%$ of the gardeners in Tamadue did so, although access to this village was difficult due to the very poor road and bridge conditions (see 2.2).

A strong negative influence of a household's migration background on crop diversity, similarly to the findings in the present study, has not yet been mentioned in quantitative measures in the homegarden literature (see 1.4). In contrast, SOEMARWOTO (1987) reported markedly higher species richness in homegardens of migrants in Sumatra as compared to those in their village of origin in East Java (138 species/village vs. 69, respectively). However, KUSUMANINGTYAS et al. (2006) documented a lower species richness in mixed plantations of migrants than in those of their village of origin (38 species vs. 55, respectively). In Thailand, OKUBO et al. (2003) reported a lower diversity of tall trees in migrant homegardens located on beach ridges with poor soil as compared to those in their village of origin on the nearby foot slopes. Probably, a household's migration background is frequently connected with socio-economic constraints such as labour and land scarcity, poverty, or discrimination (HODEL et al., 1999). In addition, migrants were often settled in areas with poor soil quality (Holden \& Hvoslef, 1995), as also observed in the Napu valley (see 3.6, Tab. 3.20 and 3.22).

Quantitative studies of the influence of soil quality parameters on crop diversity in homegardens are still lacking. For natural systems, the influence of soil characteristics on plant diversity is debated controversially (SOLLINS, 1998; WRIGHT, 1992). On poor soil, some studies noted rather low (GENTRY, 1988; GENTRY \& EMMONS, 1987), others high plant species diversity (FABER-LANGENDOEN \& GENTRY, 1991; Huston, 1980; PAOLI et al., 2006) or even no influence at all (CLINEBELL II et al., 1995). Some authors postulated the highest plant diversity at sites with intermediate soil fertility, e.g. for trees and shrubs in a temperate forest (FU et al., 2004). Of the soil fertility parameters, particularly $\mathrm{P}, \mathrm{K}$, and $\mathrm{Mg}$ contents were said to have an influence on plant species composition and diversity (ASHTON, 1988; GARTLAN et al., 1986). Concerning cultivated plant species, poor soil conditions such as very low $\mathrm{P}$, but high $\mathrm{Al}$ contents, high soil acidity, or waterlogging certainly reduce crop diversity because only few species are able to cope with such adverse situations.

Unfortunately, the overlapping of poor soil quality and a household's migration background in the present study hindered a clear separation of influence of these two factors on 
homegarden crop diversity. Although the extension of the sample size beyond that of the 2001-study (see 2.2) aimed at clarifying exactly this question, among others, a clear answer might not be possible. In the Napu valley, the local villages occupied the most fertile soils and the few local families living in the migrant villages might have suffered from similar socioeconomic and environmental constraints as their migrant neighbours. However, the only slightly negative influence of relatively low available P content of soils as compared to the strong one of the factor 'migrant' detected by multiple regression analysis (see 3.9.2, Tab. 3.35), suggested a primary influence of a household's migration background. This assumption was supported also by the results of the cluster analysis as well as PCA based on species composition in homegardens (see 3.5.4, Figure 3.18 and Figure 3.22). Two homegardens from Siliwanga, but managed at least partly by household members of Central Sulawesian origin (i.e. gardens no. 21 and 25) were not grouped together with the other gardens of Siliwanga, but in cluster 3 (see Figure 3.18), indicating a higher degree of similarity with the other local, rather species-rich homegardens of this cluster. The soil quality parameters examined in this study showed only minor influences on crop diversity. Reasons for this could be that, (i) the actually underlying soil parameters have not been included in the analysis, (ii) the level of soil quality determined still allowed the cultivation of a wide range of crops, and/or (iii) a few gardeners had improved soil quality sufficiently to enable the cultivation of sensitive crop species.

In summary and by combining results of cluster analysis as well as multiple regression and principal component analyses, a homegarden with the following characteristics might harbour and maintain a high crop diversity: intermediate to large garden size, complex vegetation structure, managed by a female of a local household with some rather old family members, production mainly focussing on subsistence, and located in a village with relatively good market access and high soil quality. In the future, however, the maintenance of crop diversity in homegardens might be threatened by attempts of modernisation that include increasing commercialisation of garden products and ornamentalisation.

\subsection{Are homegardens suitable for in situ conservation of PGR?}

Maintenance of species and genetic diversity is considered to be crucial for long-term sustainability of agricultural production systems (see 1.3). Concerning crops, their wild ancestors as well as traditional varieties and landraces are important resources for further development and improvement by breeding activities (BROOKFIELD, 2001). Besides, a high inter- and intra-specific diversity enables a system to adapt to changing environmental and socio-economic conditions (ATTA-KRAH et al., 2004; MAIN, 1999; WIERSUM, 2004).

Homegardens are generally considered as suitable for in situ conservation of genetic resources of both wild and cultivated plant species (BENNETT-LARTEY et al., 2004; ESQUIVEL \& HAMMER, 1992; Fu et al., 2003; MAXTED et al., 1997; Montagnini, 2006; Moreno-Black et al., 1996; SMITH et al., 1992; ZEMEDE ASFAW, 2004). Some authors particularly stress the conservation of traditional varieties as well as endangered, neglected, and underutilised crops in homegardens (ESQUiVEL \& HAMMER, 1992; LEIVA et al., 2002; OAKLEY, 2004; QUALSET et al., 1997; SHRESTHA et al., 2004; STHAPIT et al., 2004). Particularly women are said to play an important role in conserving both wild and cultivated traditional plant species in homegardens, whereas men often were interested only in the introduction of exotic cash crops 
(Del Angel-Pérez \& Mendoza B., 2004; Wilson, 2003). Concerning the conservation of wild species, however, homegardens in the study area seemed to play a minor role. Admittedly, about $24 \%$ of the 206 useful plant species found in homegardens of the Napu valley in 2004 could be considered as wild species (see 3.5.1), but in their majority these seemed not to be rare or endangered in the region. Instead, many wild species occurring in the homegardens studied might belong to a type of fast-growing pioneer vegetation, covering large areas of surrounding fallows and secondary forests. Of the 46 tree species recorded by PITOPANG et al. (2004) for young secondary forest in the Napu valley (i.e. forest less than 10 years old; overall plot size $2000 \mathrm{~m}^{2}$ ), 12 species or $26 \%$ were also found in the homegardens surveyed. Compared with 1 ha primary forest near the village Rompo, studied by BRODBECK (2004), only 5 tree species or $5.6 \%$ of the 89 forest trees occurred in homegardens. Also SCHROTH et al. (2004) criticised simple counting of wild species in agroforestry systems for evaluating their role for conservation because weedy and pioneer species that do not need any special protection will be included. On the other hand, the same authors stressed the importance of species diverse agroforestry systems for buffering and connecting isolated patches of natural vegetation such as primary forests.

Homegardens as a place for in situ conservation of wild species might play a more important role in largely deforested regions, where species of the natural flora lost their habitat. In the semi-arid zone of Guatemala, for example, about $37 \%$ of the native flora was also found in homegardens (ALARCón, 1992, cited in AZURDIA \& LEIVA, 2004). As much as 40\% of the perennial native flora of semi-arid north-eastern Brazil was documented in homegardens (AlBuQUERQUE et al., 2005). Native perennial species occurring in homegardens of Mexico, Kenya, and Tanzania made up $15-30 \%$ of the natural perennial vegetation of the particular regions (Alvarez-Buylla Roches et al., 1989; BACKeS, 2001; HeMP, 2006, respectively). However, in view of the often very small populations of wild species in homegardens, their suitability for in situ conservation of these plants might be questionable (ALVAREZ-BUYLLA RocHES et al., 1989). In homegardens of the Napu valley, $64-88 \%$ of the wild species were also represented by less than ten individuals each per village, $24-41 \%$ actually by only a single individual per village (see Appendix 12 and Appendix 13).

Even for cultivated species, the problems and risks of rather low intra-specific diversity due to small population sizes and low numbers of varieties in homegardens are sometimes mentioned in the literature (DAMANIA, 1996; Esquivel \& HAMMER, 1992; GUARINO \& HoOGENDIJK, 2004; Hodel et al., 1999). In the homegardens surveyed in the Napu valley, $41 \%$ of the 156 cultivated crop species were represented each by less than 10 individuals (in a sum of all five villages), $74 \%$ of the crop species were grown in one variety only (see Appendix 12 and Appendix 13). On the other hand, many varieties were named by the gardeners for certain crop species, such as banana, mango, chilli, or common eggplant (see 3.5.1). Possibly, in situ conservation of crop species in the homegardens surveyed should more focus on such diverse key species than on the whole species diversity, an approach suggested in the literature (BENNETT-LARTEY et al., 2004; GESSLER \& HodEL, 2004; STHAPIT et al., 2004; WiLliAMS, 2004). On the other hand, problems possibly arising from low intraspecific diversity of small populations, such as danger of genetic drift or inbreeding depression, might be overcome by different strategies. First, many homegardens should be included into one conservation unit and several regions combined for conservation issues (DAmANiA, 1996; GuARINO \& HoOGENDIJK, 2004; TRINH et al., 2003). Secondly, exchange of 
planting material within and between communities could enhance and maintain genetic diversity and should further be promoted (GUARINO \& HOOGENDIJK, 2004; MiLlat-EMUSTAFA et al., 2000; OAKLEY, 2004). However, conservation strategies and identification of minimum sizes of populations have to be adjusted for each single species according to its special characteristics such as mating system (e.g. self- or cross-pollinated), distribution type (e.g. common/rare, widely/locally distributed), propagation method, and extend of germplasm exchange (FundorA MAYOR et al., 2004; GUARINO \& HOOGENDIJK, 2004; STHAPIT et al., 2004).

The general suitability of homegardens for in situ conservation of crop genetic resources might be threatened in the future by cultural and socio-ecomomic changes, such as introduction of exotic species or improved varieties, increase of cash or staple crop production, migration followed by scarcity of labour force, adoption of 'western' lifestyle, or loss of tribal culture and knowledge (FUNDORA MAYOR et al., 2004; GUARINO \& HoogendiJK, 2004; Quiroz et al., 2004; SMith et al., 1992; ZEMEDE ASFAw, 2004). Some of these threats have already reached the relatively remote Napu valley and its homegardens, e.g. by increasing importance of cash crops (see 3.10.3); by low appreciation of local varieties (see 3.4.5); or by little use of and knowledge about medicinal plants or weeds by migrant or young gardeners (see 3.4.6 and 3.5.1, Table 3.10), discussed in 4.4 and 4.5. Loss of interest in and knowledge about medicinal plants was reported also from Ethiopia, where many traditional medicinal plants in homegardens recently were only regarded as shade plants, ornamentals, or even weeds due to acculturation and modernisation, thus, causing both genetic and cultural erosion (BELACHEW WASSIHUN et al., 2003). For Totonac homegardens in Mexico, Del ANGEL-PÉREZ \& MENDOZA B. (2004) reported that gardeners younger than 40 years already lacked the knowledge about names and uses of many plant species as a result of cultural changes. However, homegardens (as well as other agricultural systems) are not static over time, but dynamic. They continue to steadily be transformed by changing environmental, cultural, and socio-economic conditions, resulting in loss of some, but also evolution of other single species or varieties (BROOKFIELD, 2001; MORENO-BLACK et al., 1996; WilliaMs, 2004). Decrease or loss of traditional varieties and locally used species due to different consequences of 'modernisation' were reported also for other agricultural systems all over the world, e.g. for potatoes in Peru and wheat in Turkey (BRUSH, 1995), for French beans in Cuba (ESQUivel \& HAMMER, 1992), for African vegetables (Keller et al., 2006), or for rice replacing minor field crops in Bangladesh (OAKLEY \& MOMSEN, 2005). However, improved varieties did not necessarily displace traditional varieties because the latter might be better adapted to marginal environments, used for special dishes, or simply have a better taste (Brush \& Meng, 1998; OAKLey \& Momsen, 2005; SMith et al., 1992).

According to HoDEL et al. (1999) and SUNWAR et al. (2006), conservation of crop genetic resources is closely linked to their utilisation. Maintenance of diverse traditional species and varieties can be further enhanced by several approaches such as developing consumer markets for special unique attributes of such varieties, increasing their prestige (e.g. by seed fairs, competitions), increasing and maintaining knowledge, improving seed supply (e.g. by community seedbanks, seed exchange, seed propagation in demonstration gardens, registration of varieties, seed savers programmes), or by improving the quality of traditional varieties, e.g. by participatory breeding (BRUSH, 1995; BRUSH \& MENG, 1998; DAMANIA, 1996; Hodel et al., 1999; Qualset et al., 1997; RHOAdes \& NAZAREA, 1999; SMAle et al., 
2004; Sunwar et al., 2006; WiLliams, 2004). In addition, SMiTh et al. (1992) discussed the designation of target zones or museum farms, where subsidies compensate for not adopting modern varieties. Economic benefits for farmers maintaining such genetic diversity that is of high significance for the global community but not being valued up to now, were claimed also by CORREA (1999) and RHOADES \& NAZAREA (1999).

However, for the Napu valley, only some of these approaches seem to be practicable for enhancing the maintenance of traditional species and varieties. For example, competitions among villages already exist that focus on village development and appearance, including ornamentals and medicinal plants in homegardens. Seed supply could be improved by extending the aim of the already existing village demonstration gardens for medicinal plants to also propagate these (and other useful) species and to provide interested gardeners with planting material. More important might be to inform gardeners about the nutritional and cultural value of traditional species and varieties as compared to exotic and modern ones (e.g. young cassava leaves contain $7 \mathrm{~g}$ protein, 10,000 IU Vitamin A, and $5.6 \mathrm{mg}$ iron per $100 \mathrm{~g}$ fresh weight, but chinese cabbage, promoted by the CARE project, only $1.5 \mathrm{~g}, 4,470 \mathrm{IU}$, and $0.8 \mathrm{mg}$, respectively (REHM \& ESPIG, 1991; USDA, 2006)). Raising and dissemination of the still existing traditional knowledge within the region as well as strengthening cultural identity are further issues. By this research that started already in 2001, awareness of the sample gardeners concerning species diversity in their homegardens was already raised markedly. Many gardeners were very proud to be included in the sample households and, possibly, tried to satisfy the implied wishes of the author by creating a better tended homegarden and increasing its species richness. The overall increase of crop diversity over time (see 3.10.3), discussed in more detail in 4.5, partly might have resulted from these distortions (KEHLENBECK \& MAASS, 2006).

In summary, the homegardens surveyed de facto were loci of in situ conservation of plant genetic resources. They maintained high species richness over time. However, this attribute might decrease in the future due to more market-oriented production. Besides, not all homegardens seemed to be equally suitable for conservation issues. Small homegardens or those of migrants harboured less crop species (see 3.9.2 and 4.5). To ensure the suitability of homegardens for conservation of plant genetic resources, a detailed participatory strategy must be developed together with the gardeners as an active part in the whole process.

\subsection{Can productivity of homegardens be improved?}

The production potential of homegardens in the Napu valley was not fully exploited neither for subsistence production nor for cash income generation (see 3.4.6 and 4.1.3). Parts of some gardens were fallowed, others overgrown with weeds (pers. obs., Figure 4.3). Low-valued species were frequently not harvested, but their fruits were left to rot or only used for feeding pigs. Consumption of fruits and vegetables, although available, was alarmingly low due to their low appreciation and, at the same time, overestimation of the nutritional value of white rice (see 4.4). Lack both of knowledge and extension service caused insufficient management of demanding crops (e.g. not pruning cacao, not pollinating vanilla flowers by hand). It also led to the cultivation of some unsuitable crop species such as salak palm or rambutan, whose growth and production are known to suffer at higher elevations in the tropics (VERHEIJ \& CORONEL, 1992). 


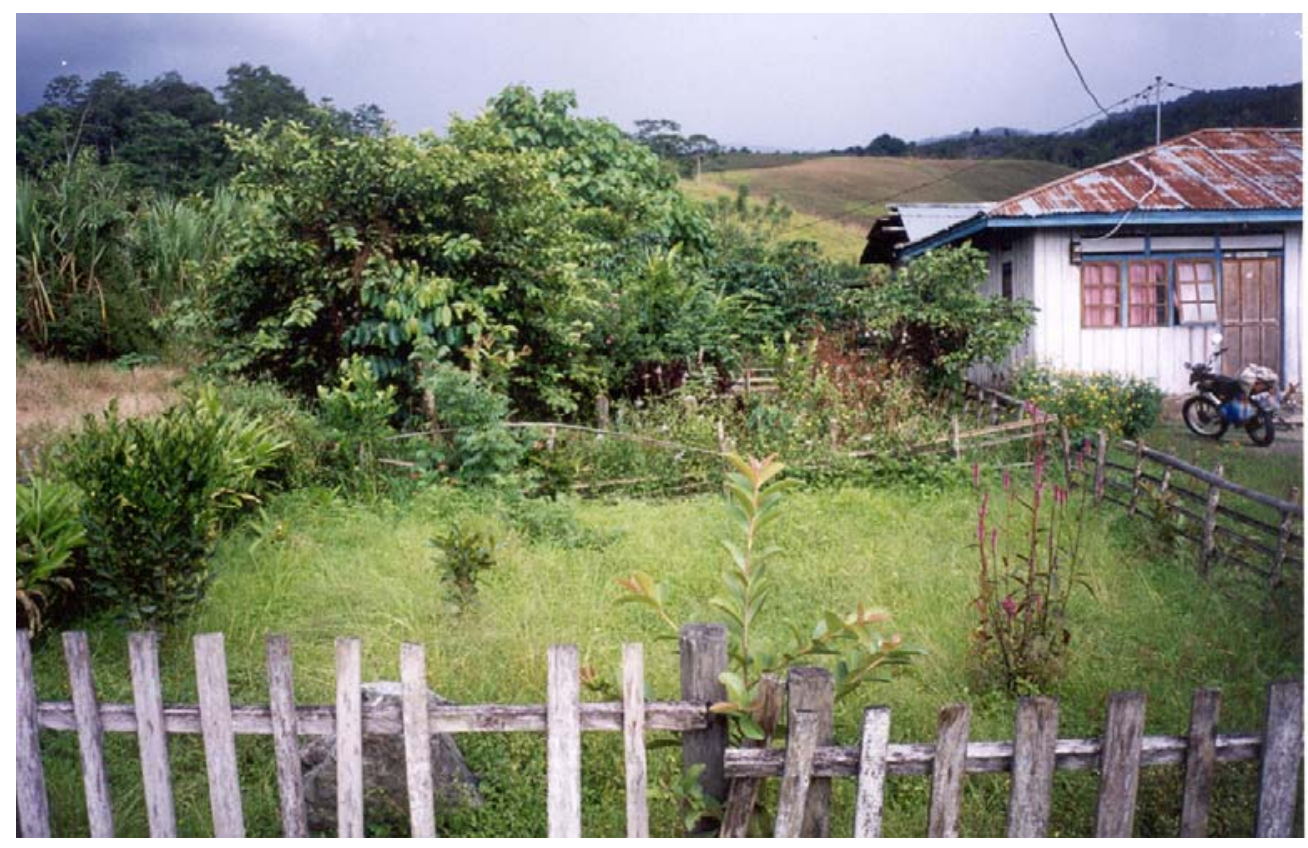

Figure 4.3. Fallowed vegetable zone in a homegarden of Wanga, Napu valley, Central Sulawesi, 2004.

A relatively low productivity of homegardens has frequently been recorded in the literature (FERnANDes et al., 1984; Millat-E-Mustafa et al., 2000). Their production potentials were not fully exploited due to, for example, poor management concerning soil fertility maintenance and weed as well as pest control (BENJAMIN et al., 2001; DHARMASENA \& Wijeratne, 1996; Gebauer, 2005; Rugalema et al., 1994) or labour scarcity resulting in partly fallowed gardens (DHARMASENA \& WIJERATNE, 1996; JOHN \& NAIR, 1999). Also in the Napu valley, gardeners mainly mentioned labour scarcity as a reason for fallowed garden parts, besides soil quality constraints (migrant gardeners) or simply laziness (local gardeners).

In many studies, a large potential for improving productivity of homegardens has been detected (KARYONO, 1990; SOEMARWOTO \& CONWAY, 1992), e.g. by integrated pest management or an increased use of compost or other organic fertilisers readily available (BEnjamin et al., 2001; DAsh \& Misra, 2001; Drescher, 1996; Rugalema et al., 1994). Besides, introducing suitable species or improved varieties of established species as well as promoting cultivation of leguminous and/or perennial crops have been suggested (DASH \& Misra, 2001; Gebauer, 2005; Karyono, 2000; Millat-e-Mustafa et al., 2000; SOEMARWOTO, 1987). The involvement of an effective extension service focussing on homegardens has frequently been claimed to be important for improving their productivity (Dharmasena \& Wijeratne, 1996; Drescher, 1996; Holden \& HvosleF, 1995; Holden et al., 1995; MiLLAT-E-MustafA et al., 2000). Indirectly, homegarden productivity could also be raised by processing homegarden products to create added value, e.g. by the processing of fruits to jams (KARYONO, 2000; SOEMARWOTO \& CONWAY, 1992).

Many well-meaning development projects with a focus on improving of homegardens, unintentionally have threatened the ecological, economic, and socio-cultural sustainability of this agro-ecosystem, for example, by introducing light-demanding exotic vegetable species for sale that need a continuous supply of exogenous inputs and may not automatically improve the nutrition situation of the gardeners' families (DRESCHER et al., 1999; SHRESTHA 
et al., 2002; SoEMARWOTO, 1987). To minimise such negative effects of modernisation and intensification that may accompany efforts towards improving homegarden productivity, the overall species richness ought to be maintained, including useful tree species in order to retain the multi-layered vegetation structure (CHRISTANTY, 1990; DRESCHER, 1999; MARTEN \& ABdoellah, 1988; Soemarwoto, 1987). Besides, only such species or varieties should be introduced or promoted that fulfil most of the following requirements:

- Being rich in micronutrients and well adapted to the local environment as well as to the extensive level of traditional management (MARTEN \& ABDOELLAH, 1988; Midmore et al., 1991; Millat-E-MustafA et al., 2000; NiÑEZ, 1985).

- Meeting the traditional food preferences instead of urban demands for exotic crops that need many exogenous inputs and may largely not be consumed by the family, but sold (NIÑEZ, 1987).

- Being easily to reproduce by gardeners instead of being dependent on an external seed supply system (NIÑEZ, 1985).

Such development projects, however, should not solely focus on individual crops, but apply an integrated, holistic approach for improving not only homegarden productivity but also family nutrition and well-being (FERNANDES et al., 1984; TALUKDER et al., 2000). Promotion of the cultivation of micronutrient-rich crops in homegardens should, for example, be accompanied by nutrition education of gardeners and their families via training courses, visits in schools, or public media campaigns (NIÑEZ, 1985). Establishing model gardens and extension centres that provide gardeners with information and planting material most likely would support such efforts (NIÑEZ, 1985). The gardeners' knowledge about costs and risks associated with the participation in a market economy should be strengthened (HoDEL et al., 1999). However, as the concept of sustainable agro-ecosystems also includes their ability to adjust to changing socio-economic conditions (PEYRE et al., 2006; WIERSUM, 2004), modernisation and commercialisation of homegardens should not generally be rejected. Therefore, the aim of fulfilling both the subsistence and cash income needs of the gardeners' families without destroying structure or functioning of their homegardens and further development of this system should be integrated in comprehensive homegarden projects.

In the Napu valley, the subsistence function of homegardens may be supported by promoting vegetable production and consumption. Traditional, perennial leafy vegetables such as cassava, Abelmoschus manihot, or Clerodendron minahassae should be preferred because they are mostly shade-tolerant, rich in micronutrients, and less susceptible than annual vegetables to damages caused by free-roaming chicken. Even in small gardens, such perennials can easily be planted along the borders as living fences. Concerning cash income generation, promotion of vanilla may be more suitable than that of cacao because vanilla can easily be integrated in the existing multi-layered vegetation structure of many homegardens. Besides, vanilla obtains higher and more stable prices than cacao. Extension would be essential for a successful vanilla production, and providing such a service will most likely simultaneously benefit the overall productivity in homegardens as well as in plantations. 


\subsection{Did the methods applied in this study serve the research questions?}

\section{Assessment of socio-economic sustainability}

The first research question concerned socio-economic sustainability of homegardens that was exclusively investigated by interviewing the gardeners. Overall, the interview results could be rated as reliable. For example, respondents remembered surprisingly well the seed sources of every single plant species occurring in their garden; often they provided much more information than requested (e.g. by naming the village or market of seed origin, or by giving the name of the 'donor' of the material). However, some differences were found when homegarden functions as given by the respondents were compared to the own classification into market or subsistence-oriented gardens (based on the dominance of cash crop individuals), where only about 50\% agreement was found (see Appendix 8). Some respondents also had problems in estimating working time per single management activity, related partly to the fact that he or she was not responsible for the plant type requiring that specific work (see Appendix 8). In such situations, probably respondents rather underestimated their time investments. For the three case study gardens, where intensive interviews concerning daily working time allocation were conducted every evening, the calculated monthly working time for homegardening (see Figure 3.24) was markedly higher than the medians of the respective villages given in Table 3.1. On the other hand, during the time of the investigation, some working activities were performed in the case study gardens that were rather extraordinary (e.g. fencing in the spice garden) and/or not included in the 'normal' perception of homegarden work (e.g. cutting fodder in the migrant garden).

Concerning soil quality management, many respondents could easily list the fertiliser types used in their homegardens, including recipient crops, fertiliser sources, and application procedure, but they had problems to quantify frequencies and applied amounts. Ash from the kitchen, for example, was applied, when the bucket used for its gathering simply was full or was needed for something else. Concerning purchased industrial fertiliser, on the other hand, respondents were frequently able to remember applied amounts (see Appendix 10). For a more detailed assessment of fertiliser utilisation and its efficiency, an exact measurement of the amounts of applied fertiliser would be necessary that, however, would be difficult and time-consuming to perform. The same applies concerning the assessment of homegarden outputs. Most respondents were only able to give rough quantitative estimates about the yields in their homegardens (see 3.4.6), a problem also mentioned in the literature (e.g. NIÑEZ, 1987, see also 4.1.3). Data obtained for the case study homegardens by daily interviews were considered to be more reliable because the household members still remembered the produce that they had harvested from their garden the same day (see 3.8.1, Figure 3.26). However, such detailed daily interviews would not be feasible for investigating 50 households.

To quantitatively assess productivity and efficiency of homegarden management, exact measurements of the amounts of in- and outputs would be essential. However, for a qualitative evaluation of the two features, the methods applied in this study were rated as suitable. The combination of investigating a considerable number of gardens relatively longterm and a few representative cases intensively, but over short time only, hence, produced complementary results. 


\section{Assessment of the soil-based sustainability}

To answer the second research question on soil quality maintenance, both interviews as well as physical and chemical soil analyses were performed. Concerning both present conditions and changes of soil quality, assessments by the gardeners mainly did not match the results of soil quality analyses. When gardeners, for example, mentioned soil fertility deterioration in their homegardens, in $58 \%$ and $67 \%$ of these cases, $\mathrm{N}$ and $\mathrm{C}$ contents, respectively, decreased according to soil analyses, but only in $42 \%$ and $25 \%$ concerning $\mathrm{pH}\left(\mathrm{H}_{2} \mathrm{O}\right)$ value and $\mathrm{P}-\mathrm{Olsen}$ content, respectively. For amelioration, on the other hand, gardeners' assessments only matched the analyses in $0-22 \%$ of the cases for $\mathrm{C}, \mathrm{N}$, and P-Olsen contents, and in $56 \%$ for $\mathrm{pH}\left(\mathrm{H}_{2} \mathrm{O}\right)$ value (Appendix 24). Thus, soil quality estimation of gardeners could not substitute physico-chemical analyses of soil quality parameters. Probably, the gardeners' estimations referred back to longer time periods than that of this study. Nutrient content analysis of cacao leaves could also not substitute soil analyses because a correlation was only detected for $\mathrm{K}$ contents (see 4.2).

Overall, the soil quality parameters analysed in this study were considered to be sufficient for assessing soil-based sustainability of homegardens. Only the assessment of soil erosion by analysing Caesium-137 was not adequate, and further studies should should use other methods. Concerning bulk density assessment, the sampling method applied in this study could be improved referring to the soil corer utilised. As a standard soil corer designed for bulk density sampling was not available during the field research (i.e. the corer was stolen), the one used instead had a rather small diameter (see 2.6.1). This might have caused slight distortions of the respective results. In addition, it rained unusually much in the Napu valley during the period of soil sampling in the village Tamadue, which resulted in wet and muddy soils. These sampling problems may have distorted some results towards very low bulk density of homegarden soils in Tamadue (see Table 3.20).

Another point of improvement concerns analysis of plant available P. According to LANDON (1991), the P-Olsen method should be applied for analysis of soil with a $\mathrm{pH}$ value $>7$. Although most soils were slightly acid in the Napu valley (see 3.6.2, Table 3.21), in the POlsen method was used the 2001-study as a concession to the standard measures of the STORMA-laboratory that were set in advance. To compare soil quality parameters of 2001 and 2004, the P-Olsen method, consequently, was also applied in the 2004-study, in addition to the P-Bray method that is recommended for slightly acid soils (LANDON, 1991). Results of the two methods showed similar trends concerning differences among villages, apart from the village Wanga (see 3.6.2, Table 3.21), whereas the rating of available P contents differed strongly. Garden soils of the villages Wanga, Siliwanga, and Tamadue were mostly rated as 'very low' to 'medium' concerning P-Olsen content, but P-Bray assessments resulted in rating all garden soils as 'high'. However, $50 \%$ of the cacao leaf samples contained less than 'normal' amounts of P. In addition, maize grown in some homegardens in Wanga and Siliwanga often showed typical symptoms of $\mathrm{P}$ deficiency (i.e. purple-coloured stripes on older leaves near the vines and on the stems (pers. obs.). Thus, results of P-Bray analysis corresponded less than those of P-Olsen to the P deficiencies observed in cacao and maize. Probably, neither the Bray, nor the Olsen method sufficiently reflected the real situation of available $\mathrm{P}$ content in the soils analysed. Instead, the anion exchange resin method, as described by TIESSEN \& MOIR (1993), might be more suitable for further studies of plant 
available $\mathrm{P}$ in garden soils. Nevertheless, for assessing temporal changes of available $\mathrm{P}$ contents in soils (see 3.10.4, Table 3.41), the results of the applied P-Olsen analysis were considered to reflect best the possible supply to plants.

Giving soil nutrient concentrations (e.g. percentages, ppm) instead of soil nutrient stocks in $\mathrm{kg} / \mathrm{ha}$ was chosen because also in the few homegarden studies that included soil analyses, nutrient concentrations were given (e.g. DRESCHER et al., 1999; GAJASENI \& GAJASENI, 1999; JENSEN, 1993a), thus, allowing for comparisons. In addition, rating of nutrient levels was done according to literature that also referred to nutrient concentrations (e.g. LANDON, 1991; OLSEN \& SOMMERS, 1982). In this study, statistical analyses of $\mathrm{C}$ and $\mathrm{N}$ as well as P-Olsen and P-Bray soil nutrient stocks (calculated from the available nutrient concentrations and bulk density data) revealed similar trends of soil quality differences among villages as the respective analyses of nutrient concentrations. Therefore, the results of the former analyses and calculations were not given. Concerning the severe soil fertility problem combined with poor crop performances in the migrant village Siliwanga, the analyses of the soil quality parameters chosen in this study did not reveal the underlying causes. Including additional analyses of the subsoil and/or investigations of the level and possible fluctuations of the water table may contribute to uncover the causes and, consequently, lead to recommendations of suitable measures for improving these gardeners' situations.

\section{Assessment of light-use efficiency}

The third research question dealt with light use efficiency. The analysis of vertical stratification of the vegetation only allowed for a rough estimate of light use efficiency in the homegardens surveyed, but it could not substitute exact measurements of light transmission because the former does not consider density or cover of the canopy, even if plant individual numbers per stratum would habe been assessed.

Measurement of Photosynthetic Active Radiation (PAR) could be improved in further studies, if more time and larger numbers of measurement units would be available. More homegardens and production zones should then be investigated and the equipment should be moved around in every garden to cover also small-scale differences of PAR within zones. BRODBECK (2004), for example, suggested to measure daily courses of PAR in a 1 ha plot for a period of 25 days by moving the equipment every day, followed by calculation of mean daily courses of PAR. For estimating light use efficiency, alternative methods for indirect mesurement of the light regime are available, including assessments of canopy closure by using, for example, a spherical densiometer, as documented by STEFFAN-DEWENTER et al. (2007). Performance of these alternative methods might be faster, easier, and cheaper than PAR measurements, but they are not suitable for recording daily courses of light transmission or light flecks of direct solar radiation in the different vegetation strata.

\section{Assessment of crop species diversity and its maintenance}

The fourth and fifth research questions considered the assessment of spatial differences and temporal changes of crop diversity. When asked for 'lost' crops in the interviews, most gardeners remembered no or only few species, particularly valuable tree crops. The results of these interviews did not correspond so well to the results of species inventories, where mostly many more 'lost' species were detected per garden (data not shown). Thus, results of studies concerning changes of species composition in homegardens over time, but exclusively relying 
on information gathered by interviews (e.g. PEYRE et al., 2006) might underestimate species loss, particularly concerning non-marketable species such as vegetables or medicinal plants.

In contrast, the detailed species inventories carried out in homegardens of the Napu valley over a time period of three years yielded highly reliable results and revealed marked differences, both in space and time (see 3.5.1; Table 3.8 and 3.10.3, Figure 3.41). The claim of Huston (1994), LUDWIG \& REYNOLDS (1988), and PIEPHO (1996), among others, for using not only species richness, but also different diversity and evenness indices for assessing biodiversity (see also 1.2.2) can be supported by this study. Calculating such indices revealed opposing trends as compared to species richness in some homegardens, e.g. in garden no. 9, where species richness increased markedly from 2001 to 2004, but values of diversity and evenness indices decreased in the same time (see Appendix 15 and Appendix 16), caused by a shift towards large scale cultivation of groundnuts for sale.

However, using many of the recommended diversity and evenness indices did not completely satisfy the expectations of the author on a measure that would integrate all aspects of crop diversity (including also structure and function) among the homegardens studied. For example, the applied indices valued a single spring onion plant exactly the same as a large single mango tree. Apart from differences in sizes, the mango tree most likely contributes much more than the onion to the ecological functioning of the agro-ecosystem (e.g. by supplying litter, shade, and habitat for other organisms) and to its socio-economic functions (e.g. by providing the gardener not only with lots of fruits, but also with fuel wood and timber). These differences among species are not reflected by the diversity and evenness indices applied in this study. A theoretically possible solution considering size differences may be to calculate these indices not on the basis of individuals per species, but of total biomass per species, as suggested by BAUMGÄRTNER (2005). However, this method requires time-consuming assessments of biomass, either destructive (which would not be feasible in homegardens), or by measurements of tree heights and diameters for a calculation of tree biomass, combined with weighing sub samples of cut herbs and shrubs (as performed by JENSEN, 1993a). Such measure would be practicable only on the scale of case studies. A relatively easy solution could be to calculate separate indices for different size classes (Cousins, 1991), e.g. for trees, shrubs, and herbaceous plant species each, or to weigh the different strata differently (ANAND \& ORLÓCI, 2000). The suitability of such indices calculated differently should be tested in further homegarden studies.

Structural and functional components of biodiversity could be included, if taxonomic dissimilarities of species would be considered in the calculation of indices, based on the idea that, for example, three different Citrus species in a garden may be less valuable than one species of Citrus, Manihot, and Allium each. The calculation of a 'taxonomic information index' like the Weitzman index includes an aggregate measure of the dissimilarity among all species in a system (BAUMGÄRTNER, 2005). This calculation is mostly performed based on taxonomic and phylogenetic dissimilarities, but such information is still limited (WEIKARD, 2002). Instead taxonomical, also functional or even morphological dissimilarities could be used for calculating the Weitzman index (BAUMGÄRTNER, 2005), a method that might be useful (but very time-consuming) also for the investigation of plant species diversity in homegardens. 
The choice of the 'right' index or indicator for assessing biodiversity depends much on the objective of a study (BAUMGäRTNER, 2005; Cousins, 1991; DUElli \& OBRIST, 2003), resulting in different perceptions of the value of biodiversity. According to WEIKARD (2002), the overall value of biodiversity consists of the direct value of single species (e.g. as food, medicine, raw material), the instrumental value of biodiversity (e.g. its contribution to ecosystem functioning, but also its 'option' value for future demands), and its intrinsic value (e.g. forming a beautiful landscape). If conservation of plant genetic resources or of certain rare/endangered or endemic species is the main task, target species ought to be valued higher than abundant species. The importance of a system for conservation issues could then simply be assessed by counting target species richness, but not by calculating diversity and evenness indices. However, high richness of target species in a system is not necessarily correlated to its overall species richness (DUELLI \& OBRIST, 2003). If not conservation, but rather ecological resilience and functioning of a system is the motivation of a study, the diversity of functional groups should be assessed. Abundant species may be more important for the system functioning than rare species that could even be ecologically redundant (DUELLI \& OBRIST, 2003). Therefore, not only species richness per se, but also species composition and dominance patterns may be relevant to assess, e.g. by calculating diversity indices. If an assessment of biodiversity is oriented economically, quite different characteristics should be assessed than for ecologically oriented studies, resulting in a different set of suitable indicators or indices (BAUMGÄRTNER, 2005). Until now, no single index has been developed, which combines not only species numbers and abundances, but also species functions or other characteristics.

However, for answering the research question concerning spatial differences and temporal changes of crop diversity in the homegardens studied, the chosen combination of assessing species richness, density, diversity, and evenness was considered to be useful.

\section{Revealing factors causing spatial differences and/or temporal changes of crop diversity}

To answer the last research question concerning the factors triggering spatial differences and/or temporal changes of crop diversity in homegardens, multiple regression analyses as well as Principal Component Analysis (PCA) were carried out. The results of multiple regression analyses were considered as reliable because influences of several factors revealed by this method were also mentioned in the literature, although the analyses in this study might have slightly suffered from small case numbers (see 4.5). The PCA, used for detecting temporal changes of crop diversity, was considered as a useful tool for this purpose, as it clearly revealed those crop species out of the rather confusing total number of 196 species, which were responsible for most of the variation (see 3.10.3, Figure 3.38). Probably, this method was applied in homegarden research for the first time, as it has not yet been mentioned in the literature available.

Data recorded in this study could have been further analysed to confirm or even extend the findings of the regression analyses concerning influencing factors. For example, a constrained ordination such as Canonical Correspondence Analysis (CCA) might detect environmental variables that could be responsible for certain patterns/differences of species composition (MCCUNE et al., 2002), whereas the applied regression analysis refers only to those of total species richness or diversity indices. Another promising method for revealing more about spatial patterns of crop diversity might be the Mantel test that analyses the relationship 
between two distance matrices (MCCUNE et al., 2002). For example, the Mantel test allows to analyse the relationships between floristic similarities among homegardens and their geographical or ecological (e.g. concerning soil quality parameters) distances. However, such measures were not applied in the present study due to time scarcity, but they may be helpful for further investigations of crop diversity in homegardens.

Could the suitability of homegardens for in situ conservation of PGR be assessed by more easy and rapid methods than those applied in this study?

For a detailed assessment of crop diversity and a sound understanding of the factors causing its spatial and temporal dynamics, the combination of methods applied in this study was considered indispensable. In fact, even more analytical methods could have been applied for a more thorough understanding. However, for a large scale investigation of, for example, all homegardens of a region concerning their value as a conservation unit, a more rapid assessment measure would be required. The multi-layered vegetation structure was found to be a key factor towards sustainability of homegardens (see 1.3, 4.3, and 4.4). Consequently, the number of vertical strata and their coverage must primarily be considered as a critical measure. Remote sensing could help to analyse vegetation patterns of homegardens in a large scale, if high resolution satellite images are available and, at the same time, detailed, GPSbased species mapping of certain homegardens of the target region is performed to enable classification of the respective images. However, analysis of satellite images may result only in a pre-selection of 'valuable' homegardens. A rapid assessment of such 'pre-selected' gardens should follow, for example, by evaluating certain key indicators for crop diversity and its maintenance. Based on the homegardens studied in detail in the Napu valley, such key indicators (and their rough assessment) should include:

- Garden size (intermediate size of about $1000 \mathrm{~m}^{2}$ would be optimal).

- Number of vegetation strata (the more, the better).

- Dominance of single crop species, particularly cash crop species (negative).

- Main gardener is female and of indigenous origin (positive).

- Presence of relatively old members in the household (positive).

- Regular application of purchased industrial fertilisers and pesticides (negative because related to market-oriented production).

The suggested key indicators could be assessed during a short visit of a garden, including an interview of the gardener. Depending on project objectives, the presence of certain plant species groups, previously identified as target species, can be recorded in addition, e.g. medicinal plant species or traditional leafy vegetables. However, detailed studies are necessary for adjusting these key indicators to the particular conditions of a research/project region.

\subsection{Do homegardens have a future? What kind of research is necessary for better understanding this agro-ecosystem?}

Despite the threats of modernisation and commercialisation, homegardens have a future, not only in the research area, but also worldwide (NAIR, 2006). Managing homegardens is deeply 
rooted in the traditions of so many people, who appreciate the ecological, economic, and socio-cultural benefits of this agro-ecosystem. In addition, homegardens serve as an important back-up resource for gardeners in cases of 'emergency' (MARSH, 1996). Homegardens can easily and quickly be changed from 'leisure' or 'supplement' gardens into subsistence gardens whenever necessary. Such situations may occur due to harvest failure, prolonged unemployment or events of illness suffered by household members, or a more general economic crisis (MARSH, 1996; WEZEL \& BENDER, 2003). However, homegardens have ever been and will continuously be subjects of changes related to ecology, economics, and culture (NAIR, 2006).

In the Napu valley, particularly socio-economic factors have been causing such changes. Modernisation and commercialisation have been threatening the sustainability and functioning of homegardens by an increased and indiscriminate use of industrial fertiliser and pesticides (see 4.1.2), by an impoverishment of structural complexity (see 4.3), and by cultural and genetic erosion (see 4.4, 4.5, and 4.6). In addition, gardeners failed to manage soil quality in a sustainable manner (see 4.2). In the future, the mentioned threats to sustainability and functioning of the homegardens studied may further increase because most gardeners only recognise the short-term benefits of commercialisation, but not its potential long-term disadvantages. A well thought-out concept for improving productivity of homegardens without destroying their manifold ecological, economic, and socio-cultural functions most likely contributes to minimise the negative effects of intensification and modernisation (see 4.7).

Despite a recently increasing body of homegarden literature (e.g. KUMAR \& NAIR, 2006; EYZAGUIRRE \& LINARES, 2004) that reflects the growing importance of this agro-ecosystem in science, its functioning and potentials have not been satisfactorily investigated and understood. Research is needed, particularly, concerning nutrient and water balances, interactions between garden components, seed supply systems, the value of non-conventional products and services (e.g. carbon sequestration), system productivity, and its sustainability, including temporal changes and factors driving them (KUMAR \& NAIR, 2004; MENDEZ, 2001; Midmore et al., 1991; Millat-E-MuSTAFA et al., 2000; NAIR, 2006).

In the Napu valley, future research should particularly cover the problems related to soil quality/erosion and identify possible solutions. For assessing economic efficiency in homegarden production, inputs and outputs should be investigated in more detail. The suitability of certain cash and subsistence crops for improving the productivity of homegardens should be tested. Concerning plant diversity, key species responsible for maintaining the system's functioning and target species for in situ conservation of plant genetic resources should be identified and promoted. The role of plant diversity located in the homegardens, as a model agroforestry system, also needs to be investigated in the overall landscape context as it may provide important reservoirs for recolonisation of the agricultural landscape by many organisms (TSCHARNTKE et al., 2005) and, therefore, assist in important agro-ecosystem functions. Finally, the initiated time-series study of crop diversity dynamics and their underlying factors should be continued in the same homegardens because they provide an unique opportunity for a long-term study. 


\section{$5 \quad$ Conclusions and Recommendations}

In the previous chapters, crop diversity, soil quality, and management of rural homegardens in Central Sulawesi have been presented and assessed with regard to the sustainability of this agro-ecosystem and its suitability for in situ conservation of plant genetic resources. Integrating all results, it can be concluded that:

- The homegardens surveyed were managed by family members that mostly used endogenous inputs for producing year-round available food and non-food items as well as cash crops with relatively low labour investment.

- Productivity of homegardens was not fully exploited neither in cash nor in subsistence-oriented gardens.

- Soil quality maintenance was not adequate over time, and soil erosion was considered problematic in some homegardens.

- The homegardens surveyed harboured a high crop diversity that is not only maintained, but slightly increased over time, partly due to activities of development projects.

- Crop diversity and species composition in homegardens showed spatial differences and was mainly influenced by garden size, commercialisation, mean age of adults in the household, and origin of the gardener.

- Homegardens are suitable for in situ conservation of plant genetic resources, but crop diversity was found to be highly dynamic over time and may, in future, be threatened by modernisation and commercialisation.

- The homegardens surveyed were sustainable concerning socio-economic dimensions and the resource 'crop diversity', but not regarding the resource 'soil'.

The following main recommendations are given to improve the sustainability of homegardens in the Napu valley as well as their suitability for in situ conservation of plant genetic resources:

- To achieve sustainable soil quality management, gardeners should be trained to use compost, mulch, and farm yard manure as well as to grow $\mathrm{N}_{2}$-fixing cover crops, not only in homegardens, but also in their other cropping systems.

- The existing extension service should not exclusively focus on paddy rice production, but also on proper management and improvement of agroforestry systems (including homegardens) with their great significance for cash income generation and the ecological sustainability of the overall landscape.

- Suitable subsistence and cash crops for improving homegarden productivity without destroying its structure and functioning should be identified and promoted. Gardeners should be integrated as an active part in the whole process of developing a holistic approach for raising and maintaining the sustainability of homegardens together with conserving its agro-biodiversity. 


\section{Summary}

Homegardens are generally regarded as a very complex, species-rich agro-ecosystem managed in a sustainable manner over decades or even centuries. The major purposes of homegardens are subsistence production and income generation, particularly in rural areas. In addition, they fulfil important ecological, social, and cultural functions. Furthermore, homegardens should be considered as a model for sustainable agricultural production systems that integrate both economic and ecological advantages. Sustainability of agro-ecosystems refers to maintaining production levels that meet the needs of present and future generations without destroying the natural resource base on which the production depends. The concept of sustainability includes not only ecological, but also economic and social dimensions. As sustainability can not be assessed per se, certain descriptors and indicators have been used instead, e.g. soil fertility parameters or biodiversity. Plant diversity is considered as a basis for homegarden productivity and sustainability, however, it is not static over time. Both plant diversity and species composition are largely influenced by a combination of agro-ecological and socio-economic factors, whose complex interactions are not yet fully understood. In addition, the sustainability of homegardens has rarely been examined in a quantitative way or in a time series.

The main objective of this study was to assess the sustainability of selected rural homegardens in Central Sulawesi, Indonesia, with the help of certain sustainability indicators. The study aimed at determining spatial and temporal differences of resource quality in homegardens and the underlaying driving forces, focussing on plant species diversity, soil quality, microclimate, and homegarden management. Finally, potentials for improving homegarden productivity and their suitability for in situ conservation of plant genetic resources were assessed.

The research was carried out in the Napu valley, Central Sulawesi, located at the eastern margins of the Lore Lindu National Park at an elevation of about 1,100 m asl. Five villages were chosen that differ in their market access, origin of inhabitants, and soil quality, among others. Ten households with homegardens were randomly selected per village and sizes of homegardens were measured. Complete plant species inventories were carried out to assess the number and abundance of crop species (i.e. all useful plant species) and ornamentals. Tree height was also estimated. For assessing temporal dynamics of crop diversity, 30 homegardens in the villages Wuasa, Rompo, and Siliwanga, which had been previously investigated in 2001, were re-inventoried in 2003 and 2004. Top soil samples $(0-15 \mathrm{~cm}$ depth) were randomly taken in all homegardens for analysis of soil texture, bulk density, $\mathrm{pH}$ value, total $\mathrm{C}$ and $\mathrm{N}$ contents, plant available $\mathrm{P}$ content, effective $\mathrm{CEC}$, and base saturation. Parts of these soil analyses were performed also in the 2001-study. All gardeners were individually interviewed about homegarden management and plant utilisation, among others. Secondary data concerning household and farm characteristics were gathered through additional interviews. Microclimate (i.e. air and soil temperature as well as photosynthetic 
active radiation) and soil erosion were investigated only in a subsample of three homegardens, where also more detailed management data were recorded. In addition to crop species richness and density, several diversity and similarity indices were calculated. Cluster analysis was performed to detect spatial patterns of crop diversity and, hence, classify different homegarden types based on their plant species composition. To identify factors that influence crop diversity, multiple linear regression analysis was applied. Principal component analysis (PCA) based on species abundance data was carried out to detect and visualise changes of plant species composition over time.

In the Napu valley, homegardens were cultivated for periods between 2 and 40 years, their cropped area varied from 300 to $2,400 \mathrm{~m}^{2}$ (on average $600-2,300 \mathrm{~m}^{2}$ ). The primary function of homegardens was subsistence-oriented production of non-staple food (e.g. fruits, vegetables, spices) as well as non-food items (e.g. medicine, fodder, fuel wood). Homegarden produce was available year-round. Some gardens were largely used for income generation by cultivating cash crops (particularly cacao, arabica coffee, and vanilla). In both subsistence and market-oriented homegardens, the production potential was not fully exploited. Homegardens were mainly worked by women, but fruit trees and cash crops were mostly managed by men. According to the gardeners, monthly working hours per $100 \mathrm{~m}^{2}$ garden area ranged from 0.2 to 10.1 hours (on average 1-2 hours). Planting material was largely of endogenous origin, e.g. saved from own seeds, requested from relatives and friends, or self-established. Concerning soil quality management, local gardeners reported to apply mostly ash, manure, or no fertiliser, whereas many migrant gardeners also used industrial fertiliser. Gardeners mainly controlled weeds by spraying herbicides, although hoeing or cutting weeds was still performed, particularly in the local villages. Application of insecticides was reported mainly by gardeners managing cash crop-dominated gardens.

In 2004, a combined total of 206 crop species belonging to 71 plant families were cultivated in the 50 homegardens surveyed. Besides, 162 ornamental and 58 weedy species were found in the gardens. On average, 33-49 crop species were cultivated per garden; crop species density varied from 30 to 51 species per $1000 \mathrm{~m}^{2}$ cultivated garden area. Composition as well as richness and diversity of crops differed markedly among villages, reflected partly also in differences of structural complexity. In the three local villages Wuasa, Rompo, and Wanga, species richness and diversity were rather high and vegetation structure more complex as compared to the migrant villages Siliwanga and Tamadue. In Wuasa, the administrative and commercial centre of the Napu valley, homegardens harboured many spices, partly cultivated also for sale. On the other hand, homegardens in Rompo and Wanga were characterised by a mixture of crops not dominated by any use category. In the migrant village Siliwanga, homegardens were largely used for staple crop production, as suitable fields for staples were limited around this village. Due to the poor soil quality in Siliwanga, only few trees reached the higher vegetation layers. In the migrant village Tamadue, many gardens were dominated by the cash crops cacao and arabica coffee as well as some shade trees. Shading and regular herbicide application resulted in a poorly developed herbaceous vegetation layer. Cluster analysis based on species abundances partly reflected these differences between migrant and 
local gardens as well as villages. However, local gardens were not separated according to villages, indicated also by high similarity coefficients among the local villages.

Soil quality parameters were highly variable both within and among homegardens. Total C and $\mathrm{N}$ contents were mostly rated as low to intermediate. In garden zones used for vegetable production, $\mathrm{C}$ and $\mathrm{N}$ contents were significantly lower than in adjacent parts of the same garden used for cacao/coffee production. Among other reasons, this could be caused by the higher soil temperature in the vegetable zones as recorded in the case study gardens. Average soil $\mathrm{pH}$ values ranged from 5.6 to 5.8, being slightly lower in Siliwanga. Plant available PBray contents varied largely from 26 to $440 \mathrm{ppm}$, being on average very low in Tamadue and high in Wuasa. When vegetable zones were regularly fertilised with ash, P-Bray contents of their soils were significantly higher than in adjacent cacao/coffee zones of the same garden, but lower, when vegetable zones were not fertilised. Effective cation exchange capacity was rated as high in Tamadue, very low in Siliwanga, and low to intermediate in the other three villages. Soil erosion was considered as problematic in some of the homegardens surveyed, particularly in the vegetable and ornamental zones.

Multiple regression analysis applied to all gardens revealed the most important factors influencing crop species richness and diversity. A negative influence was detected for the characteristics 'low soil P content', 'cash-oriented production', and 'migrant gardener'. Garden size and mean age of adults in the gardener's household influenced crop species richness and diversity positively. PCA applied to the 30 re-inventoried gardens showed that crop species composition shifted in the two villages with relatively good market access, Wuasa and Siliwanga, towards more cash crops, whereas in the remote village Rompo, no such changes were detected over time. In these three villages, overall crop species richness and diversity slightly increased from 2001 to 2004. This increase partly might have been caused by activities of development projects in the area and by the previous homegarden research in the year 2001, which stimulated the interest of gardeners in crop diversity. Soil pH values as well as $\mathrm{C}$ and $\mathrm{N}$ contents decreased significantly over time; although not significant, $\mathrm{P}$ content showed a similar trend. This was, most likely, due to insufficient soil quality management.

In conclusion, the homegardens surveyed were considered to be sustainable in socioeconomic dimensions and also concerning the resource 'crop diversity', but not in terms of appropriate management for the maintenance of soil quality. In the future, sustainability of these homegardens may additionally be threatened by different aspects of 'modernisation', such as an increased use of external inputs and a shift towards cash-oriented production. Particularly, when commercialisation was possible, crop diversity was shown to be fairly dynamic over time. To maintain the sustainability of these homegardens and their suitability for in situ conservation of plant genetic resources, any promotion to intensify production should consider to keep the structure and overall functioning of this agro-ecosystem in a landscape context. 



\section{$7 \quad$ Zusammenfassung}

Hausgärten gelten allgemein als sehr komplexes, artenreiches Agrar-Ökosystem, das auf nachhaltige Weise über Jahrzehnte oder gar Jahrhunderte hinweg bewirtschaftet wird. Die wichtigsten Funktionen von Hausgärten sind neben der Subsistenz-Produktion auch die Einkommensschaffung, besonders im ländlichen Raum. Zusätzlich erfüllen Hausgärten aber auch wichtige ökologische, soziale und kulturelle Funktionen. Darüberhinaus können Hausgärten als ein Modell für ein nachhaltiges landwirtschaftliches Produktionssystem angesehen werden, das sowohl ökonomische, als auch ökologische Vorteile vereinigt. Die Nachhaltigkeit von Agrar-Ökosystemen besteht darin, dass ein Produktionsniveau erhalten wird, welches die Bedürfnisse jetziger und zukünftiger Generationen erfüllt, ohne dabei die natürlichen Ressourcen zu zerstören, auf denen diese Produktion basiert. Das Konzept der Nachhaltigkeit beinhaltet nicht nur ökologische, sondern auch ökonomische und soziale Dimensionen. Da Nachhaltigkeit per se nicht erfasst und bewertet werden kann, kommen stattdessen bestimmte Deskriptoren und Indikatoren zum Einsatz, z.B. BodenfruchtbarkeitsParameter oder Biodiversität. Als Grundlage für die Produktivität und Nachhaltigkeit von Hausgärten wird pflanzliche Diversität angesehen, die jedoch über die Jahre nicht stabil bleibt. Sowohl Diversität als auch Zusammensetzung von Pflanzengemeinschaften werden weitgehend von einer Kombination verschiedenster agro-ökologischer wie auch sozioökonomischer Faktoren beeinflusst, deren komplexe Interaktionen bisher aber nicht vollständig verstanden werden. Darüberhinaus wurde die behauptete Nachhaltigkeit von Hausgärten nur selten in quantitativer Art oder in Zeitreihen überprüft.

Das Hauptziel der vorliegenden Arbeit war die Bewertung der Nachhaltigkeit ausgewählter ländlicher Hausgärten in Zentral-Sulawesi, Indonesien. Dabei wurden räumliche Unterschiede und zeitliche Veränderungen der Ressourcenqualität in Hausgärten sowie die dafür verantwortlichen Faktoren erfasst. Besonderer berücksichtigt wurden Nutzpflanzendiversität, Bodenqualität, Mikroklima und Management dieser Gärten. Schließlich wurden mögliche Potentiale für die Produktivitätssteigerung in Hausgärten und ihre Eignung für die in situKonservierung pflanzengenetischer Ressourcen abgeschätzt.

Die Untersuchung wurde im Napu-Tal, Zentral-Sulawesi, durchgeführt. Dieses Tal liegt am östlichen Rand des Lore Lindu Nationalparks auf einer Höhe von ca. 1.100 m über NN. In fünf Dörfern, die sich unter anderem hinsichtlich Marktzugang, Herkunft ihrer Bewohner und Bodenqualität unterschieden, wurden jeweils 10 Haushalte mit Hausgärten randomisiert ausgewählt. Die Gärten wurden vermessen und in jedem eine Inventur sämtlicher Pflanzenarten durchgeführt, bei der Anzahl und Abundanz aller Nutz- und Zierpflanzen ermittelt wurden. Für Bäume wurde zusätzlich deren Höhe abgeschätzt. Um die zeitliche Dynamik der Nutzpflanzendiversität zu erfassen, wurden 30 Hausgärten in den Dörfern Wuasa, Rompo und Siliwanga, die schon im Jahr 2001 untersucht worden waren, in den Jahren 2003 und 2004 erneut inventarisiert. In allen Hausgärten wurde der Oberboden (0-15 $\mathrm{cm}$ tief) randomisiert beprobt und dessen Textur, Bodendichte, $\mathrm{pH}-$ Wert, Gehalt an $\mathrm{C}, \mathrm{N}$, und pflanzenverfügbarem $\mathrm{P}$, sowie dessen effektive Kationenaustauschkapazität und Basensättigung analysiert. Einige dieser Analysen wurden mit denen des Jahres 2001 
verglichen. Außerdem wurden Interviews mit den Gartenbetreibern u.a. zu den Themen Gartenmanagement sowie Nutzung der angebauten Pflanzen durchgeführt. Mit Hilfe weiterer Interviews wurden Sekundärdaten zu Haushalt und Hof dokumentiert. In einer Fallstudie wurden in drei der Gärten Bodenerosion und Mikroklima (d.h. Luft- und Bodentemperaturen sowie photosynthetisch-aktive Strahlung (PAR)) untersucht sowie detaillierte Managementdaten ermittelt. Neben der Erfassung von Nutzpflanzenanzahl und -dichte wurden zusätzlich mehrere Diversitäts- und Ähnlichkeitsindices berechnet. Mit Hilfe einer Clusteranalyse wurden räumliche Diversitätsmuster aufgedeckt und unterschiedliche Gartentypen auf der Grundlage ihrer Artenzusammensetzung klassifiziert. Zur Identifizierung der Faktoren, die die Nutzpflanzendiversität beeinflussen, wurden multiple, lineare Regressionsanalysen eingesetzt. Hauptkomponentenanalyse (PCA) auf der Basis von Artenabundanzen wurde zur Aufdeckung und Visualisierung zeitlicher Veränderungen der Artenzusammensetzung durchgeführt.

Die Hausgärten im Napu-Tal wurden 2 bis 40 Jahre lang kontinuierlich bewirtschaftet und verfügten über eine Anbaufläche zwischen 300 und 2.400 m² (im Mittel 600-2.300 m²). Die Gärten dienten in erster Linie der subsistenzorientierten Produktion von Nahrungsmitteln (aber nicht von Grundnahrungsmitteln, sondern eher von Obst, Gemüse und Gewürzen) und von Nicht-Nahrungsmitteln wie Medizinalpflanzen, Futter oder Brennholz. Die Hausgartenerzeugnisse waren ganzjährig verfügbar. Einige Gärten trugen durch den Anbau von cash crops (besonders von Kakao, Arabika-Kaffee und Vanille) weitgehend zur Einkommensschaffung ihrer Besitzer bei. Das Produktionspotential wurde jedoch sowohl in den subsistenz- wie auch den markt-orientierten Hausgärten nicht vollständig ausgenutzt. Die Gärten wurden überwiegen von Frauen bewirtschaftet, doch lag die Pflege von Obstbäumen und cash crops meistens im Verantwortungsbereich der Männer. Die Gartenbetreiber gaben an, pro $100 \mathrm{~m}^{2}$ Gartenfläche monatlich zwischen 0,2 und 10,1 Stunden ihrer Arbeitszeit für Gartenarbeiten zu investieren (im Mittel 1-2 Stunden). Das verwendete Pflanzmaterial war größtenteils endogener Herkunft, z.B. aus eigener Nachzucht, von Verwandten und Freunden erbeten oder von selbst gekeimt. Befragt zu Management und Erhaltung der Bodenqualität nannten einheimische Gartenbetreiber u.a. die Anwendung von Asche oder Mist bzw. keinerlei Düngeranwendung, zugewanderte dagegen auch die von synthetischem Dünger. Als Maßnahme zur Unkrautbekämpfung wurde vorwiegend die Herbizidanwendung genannt, jedoch erwähnten besonders die einheimischen Gartenbetreiber auch Hacken und Schneiden zur Unkrautkontrolle. Insektizide wurden hauptsächlich von solchen Gartenbetreibern eingesetzt, die einen markt-orientierten Garten bewirtschafteten.

Im Jahr 2004 wurden insgesamt 206 Nutzpflanzenarten aus 71 Pflanzenfamilien in den 50 untersuchten Gärten angebaut. Zusätzlich kamen 162 Zier- und 58 Unkrautarten in den Gärten vor. Pro Garten fanden sich im Mittel 33 bis 49 Nutzpflanzenarten, ihre Dichte schwankte zwischen 30 und 51 Arten pro $1000 \mathrm{~m}^{2}$ Gartenfläche. Sowohl Artenzusammensetzung als auch Artenzahl und -dichte in Hausgärten wiesen deutliche Unterschiede zwischen den Dörfern auf, die sich auch in einer unterschiedlichen strukturellen Komplexität der Vegetation widerspiegelten. In den drei überwiegend von Einheimischen bewohnten Dörfern Wuasa, Rompo und Wanga fand sich eine höhere Artenzahl und -diversität sowie eine komplexere Vegetationsstruktur als in den Migrantendörfern Siliwanga und Tamadue. In Wuasa, dem administrativen und kommerziellen Zentrum des Napu-Tales, kamen viele Gewürzarten in den Hausgärten vor, die teilweise zu Verkaufszwecken angebaut wurden. Dagegen zeichneten 
sich die Gärten in Rompo und Wanga durch eine ausgewogene Mischung von Nutzpflanzen aus, ohne dass einzelne Nutzungsklassen dominierten. Im Migrantendorf Siliwanga dienten die Gärten weitgehend der Produktion von Grundnahrungsmitteln, da in der Nähe dieses Dorfes nur wenige dafür geeignete Felder zur Verfügung standen. Aufgrund der nur geringen Bodenqualität in Siliwanga erreichten nur wenige Bäume die obersten Vegetationsschichten. In den Hausgärten des Migrantendorfes Tamadue dominierten die cash crops Kakao und Kaffee sowie deren Schattenbäume. Aufgrund der Beschattung und regelmäßiger Herbizidanwendung war in diesen Gärten die Krautschicht nur sehr spärlich entwickelt. Diese Unterschiede zwischen von Einheimischen und Migranten bewirtschafteten Gärten sowie zwischen deren Dörfern bestätigte teilweise auch die auf der Artenabundanz basierende Clusteranalyse. Die Gärten der von Einheimischen bewohnten Dörfer wurden allerdings durch die Clusteranalyse nicht deutlich getrennt, was aufgrund der relativ hohen Ähnlichkeitskoeffizienten dieser drei Dörfer auch nicht zu erwarten war.

Die erfassten Bodenqualitätsparameter schwankten sowohl innerhalb einzelner Gärten als auch zwischen verschiedenen Gärten stark. Die Gehalte an C und N wurden zumeist als niedrig bis mittel bewertet. Boden von vorwiegend der Gemüseproduktion dienender Bereiche innerhalb eines Gartens enthielt signifikant weniger $\mathrm{C}$ und $\mathrm{N}$ als derjenige angrenzender, aber für Kakao- und/oder Kaffeeproduktion genutzter Zonen desselben Gartens. Diese Unterschiede könnten u.a. mit der höheren Bodentemperatur von Gemüse- gegenüber Kakao/Kaffeezonen begründet werden, die in den Fallstudien dreier Gärten festgestellt wurde. Die mittleren $\mathrm{pH}$-Werte schwankten zwischen 5,6 und 5,8, wobei sie in Siliwanga eher niedrig waren. Gehalte an pflanzenverfügbarem P (Bray) variierten sehr stark von 26 bis 440 ppm; im Mittel waren sie in Tamadue sehr niedrig, aber in Wuasa relativ hoch. Gemüsezonen, die regelmäßig mit Asche gedüngt wurden, verfügten über einen höheren Bodengehalt an $\mathrm{P}$ (Bray) als angrenzende Kakao/Kaffeezonen desselben Gartens, aber über einen niedrigeren, wenn sie nicht gedüngt wurden. Die effektive Kationenaustauschkapazität wurde in Tamadue als hoch, in Siliwanga als sehr niedrig und in den drei anderen Dörfern als niedrig bis mittel bewertet. In einigen Gärten wurde die Bodenerosion als problematisch eingeschätzt, besonders in Gemüse- und Zierpflanzenzonen.

Die multiple Regressionsanalyse der Daten aller 50 untersuchten Gärten ermittelte die wesentlichen, die Nutzpflanzenartenzahl und -diversität beeinflussenden Faktoren. Ein negativer Einfluß wurde für die Merkmale ,geringer P-Gehalt des Bodens“, ,,markt-orientierte Produktion“ und „Zugewanderter Gartenbetreiber" nachgewiesen. Dagegen beinflussten Gartengröße und mittleres Alter der Erwachsenen im Haushalt des Gartenbetreibers die Nutzpflanzenartenzahl und -diversität positiv. Die Hauptkomponentenanalyse der Daten der 30 in einer Zeitreihe untersuchten Gärten zeigte, dass sich die Artenzusammensetzung in den Gärten der zwei Dörfer mit relativ gutem Marktzugang (d.h. Wuasa und Siliwanga) zugunsten der cash crops verschoben hatte. Im abgelegenen Dorf Rompo wurde dagegen keine derartige Veränderung über die Jahre nachgewiesen. Insgesamt nahmen sowohl Artenzahl als auch diversität der Nutzpflanzen in allen drei Dörfern im Untersuchungszeitraum von drei Jahren zu. Zum Teil mag dieser Anstieg mit regionalen Aktivitäten von Dorfentwicklungsprojekten zusammenhängen, zum Teil aber auch mit der im Jahr 2001 durchgeführten Studie in denselben Hausgärten, die das Interesse der Gartenbetreiber an einer hohen Nutzpflanzendiversität gesteigert haben könnte. Sowohl pH-Werte als auch C- und N-Gehalte der Gartenböden nahmen von 2001 bis 2004 signifikant ab. Auch für den P-Gehalt der Böden 
konnte eine solche Tendenz, die jedoch nicht signifikant war, festgestellt werden. Dieser Rückgang wurde höchstwahrscheinlich durch unzureichendes BodenfruchtbarkeitsManagement verursacht.

Abschließend lassen sich die untersuchten Hausgärten als nachhaltig in Bezug auf sozioökonomische Kriterien und auf die Ressource „Nutzpflanzendiversität“ bewerten, nicht jedoch bezüglich einer angemessenen, auf Erhaltung der Bodenqualität ausgerichteten Bodenbewirtschaftung. Zusätzlich könnte die Nachhaltigkeit dieser Hausgärten durch verschiedene Auswirkungen der „Modernisierung“ beeinträchtigt werden, z.B. durch steigende Nutzung exogener Inputs oder stärkere Marktorientierung der Produktion. Die Nutzpflanzendiversität erwies sich besonders dort als sehr veränderlich über die Zeit, wo eine Kommerzialisierung von Gärten leicht möglich war. Damit die Nachhaltigkeit dieser Hausgärten sowie ihre Eignung für in situ-Konservierung pflanzengenetischer Ressourcen erhalten bleibt, sollten jegliche Maßnahmen zur Produktionsintensivierung die Struktur und Gesamtfunktion dieses Agrar-Ökosystems auch im jeweiligen landschaftlichen Kontext berücksichtigen. 


\section{References}

ABDoellah, O.S.; MARTEN, G.G. (1986). The complementary roles of homegardens, upland fields, and rice fields for meeting nutritional needs in West Java. In: MARTEN, G.G. (ed.). Traditional Agriculture in Southeast Asia. Boulder, Colorado, USA, p. 293-325.

Abdoellah, O.S.; HadikUSUmah, H.Y.; TAKeUChi, K.; OKUBO, S.; Parikesit (2006). Commercialization of homegardens in an Indonesian village: Vegetation composition and functional changes. Agroforestry Systems 68: 1-13.

AbDOellah, O.S.; PARIKEsit; Gunawan, B.; Hadikusumah, H.Y. (2002). Home gardens in the upper Citarum watershed, West Java: A challenge for in situ conservation of plant genetic resources. In: WATSON, J.W.; EYZAGUIRRE, P.B. (eds.). Home gardens and in situ conservation of plant genetic resources in farming systems. Proceedings of the Second International Home Gardens Workshop, 17-19 July 2001, Witzenhausen, Germany. IPGRI, Rome, Italy, p. 140-147.

ABDULKADIR-SUNITO, M. (2004). Orang kampung and pendatang: Analysis of demographic structure and migration in two forest-margin villages, Central Sulawesi. In: GEROLD, G.; Fremerey, M.; GuHARDJA, E. (eds.). Land Use, Nature Conservation and the Stability of Rain Forest Margins in Southeast Asia. Springer, Berlin, Germany, p. 89-104.

ACQUAYE, D.K. (1964). Foliar analysis as a diagnostic technique in cocoa nutrition. Part I: Sampling procedure and analytical methods. J. Sci. Food Agric. 15: 855-863.

Albuquerque, U.P.; ANDRAde, L.H.C.; CABAllero, J. (2005). Structure and floristics of homegardens in Northeastern Brazil. Journal of Arid Environments 62: 491-506.

ALI, A.M.S. (2005). Homegardens in smallholder farming systems: Examples from Bangladesh. Human Ecology 33: 245-270.

AltiERI, M.A. (2002). Agroecological principles for sustainable agriculture. In: UPHOFF, N. (ed.). Agroecological Innovations: Increasing Food Production with Participatory Development. Earthscan, London, UK, p. 40-46.

AltiERI, M.A.; NiCHOLls, C.I. (1999). Biodiversity, ecosystem function, and insect pest management in agricultural systems. In: COLLINS, W.W.; QuALSET, C.O. (eds.). Biodiversity in Agroecosystems. CRC Press, Boca Raton, USA, pp. 69-84.

Alvarez-Buylla Roches, M.E.; Lazos Chavero, E.; García-BArrios, J.R. (1989). Homegardens of a humid tropical region in Southeast Mexico: An example of an agroforestry cropping system in a recently established community. Agroforestry Systems 8: 133-156.

ANAND, M.; ORLOCI, L. (2000). On hierarchical partitioning of an ecological complexity function. Ecological Modelling 132: 51-62.

ANDRIST, Y. (2003). Investigation of soils, vegetation and management of homegardens in the Henequen region, Yucatan, Mexico. Minor Field Studies No. 245, Uppsala, Sweden.

ANONYMOUS (1979). Selected Methods for Soil and Plant Analysis. International Institute of Tropical Agriculture IITA, Ibadan, Nigeria. Manual Series No. 1.

ARIFIn, H.S.; ChOzIn, M.A.; SARMA, M.; SAKAmoto, K. (2005). The farming system of Indonesian home garden (pekarangan) in Cianjur watershed, Cianjur district - West Java. Japanese Journal of Tropical Agriculture (submitted).

ARIFIN, H.S.; SAKAMOTO, K.; CHIBA, K. (1998). Effects of urbanisation on the vegetation structure of home gardens in West Java, Indonesia. Japanese Journal of Tropical Agriculture 42: 94-102. 
ARIFIn, H.S.; SAKAMOTO, K.; CHIBA, K. (1997). Effects of the fragmentation and the change of the social and economical aspects on the vegetation structure in the rural home gardens of West Java, Indonesia. Journal of the Japanese Institute of Landscape Architecture 60: 489-494.

ASHTON, P.S. (1988). Dipterocarp biology as a window to the understanding of tropical forest structure. Annual Review of Ecology and Systematics 19: 347-370.

AtTA-Krah, K.; Kindt, R.; Skilton, J.N.; Amaral, W. (2004). Managing biological and genetic diversity in tropical agroforestry. Agroforestry Systems 61: 183-194.

AZURDIA, C.; LEIVA, J.M. (2004). Home-garden biodiversity in two contrasting regions of Guatemala. In: EyZAGUiRRE, P.B.; LinARES, O.F. (eds.). Home Gardens and Agrobiodiversity. Smithsonian Books, Washington, USA, p. 168-184.

BACKES, M.M. (2001). The role of indigenous trees for the conservation of biocultural diversity in traditional agroforestry land use systems: The Bungoma case study. Agroforestry Systems 52: 119-132.

Backhaus, K.; Erichson, B.; Plinke, W.; WeIBER, R. (2006). Multivariate Analysemethoden. Eine anwendungsorientierte Einführung. Springer, Berlin, Germany, 830 pp.

BÄRTELS, A. (1993). Farbatlas Tropenpflanzen: Zier- und Nutzpflanzen. Ulmer, Stuttgart, Germany, $384 \mathrm{pp}$.

Balvanera, P.; Pfisterer, A.B.; Buchmann, N.; He, J.S.; NAKashizuKa, T.; Raffaelli, D.; SCHMID, B. (2006). Quantifying the evidence for biodiversity effects on ecosystem functioning and services. Ecology Letters 9: 1146-1156.

Ban, N.; CoOmes, O.T. (2004). Home gardens in Amazonian Peru: Diversity and exchange of planting material. The Geographical Review 94: 348-367.

BAUMGÄRTNER, S. (2005). Measuring the diversity of what? And for what purpose? A conceptual comparison of ecological and economic biodiversity indices. $<$ http://www.eco.uni-heidelberg.de/ng-oeoe/research/papers/DivMeas.pdf $>$ [09.02.2006].

BeER, J.; Muschler, R.; KASS, D.; SoMARRIBA, E. (1998). Shade management in coffee and cacao plantations. Agroforestry Systems 38: 139-164.

Belachew Wassinun; Zemede Asfaw; Sebsebe Demissew (2003). Ethnobotanical study of useful plants in Daniio Gade (home-gardens) in Southern Ethiopia. Ethiop. J. Biol. Sci. 2(2): 119-141.

Belsley, D.A.; KuH, E.; Welsch, R.E. (1980). Regression Diagnostics: Identifying Influential Data and Sources of Collinearity. John Wiley and Sons, New York, USA, 292 pp.

Benjamin, T.J.; Montañez, P.I.; JimÉnez, J.J.M.; Gillespie, A.R. (2001). Carbon, water and nutrient flux in Maya homegardens in the Yucatán peninsula of México. Agroforestry Systems 53: 103-111.

Bennett-Lartey, S.O.; Ayernor, G.S.; Markwei, C.M.; Asante, I.K.; AbBiW, D.K.; BOATENG, S.K.; ANCHIRINAH, V.M.; EKPE, P. (2004). Aspects of home-garden cultivation in Ghana: Regional differences in ecology and society. In: EYZAGUIRRE, P.B.; LINARES, O.F. (eds.). Home Gardens and Agrobiodiversity. Smithsonian Books, Washington, USA, p. 148-167.

Blanckaert, I.; Swennen, R.L.; Paredes Flores, M.; Rosas LóPez, R.; Lira SAAde, R. (2004). Floristic composition, plant uses and management practices in homegardens of San Rafael Coxcatlán, Valley of Tehuacán-Cuicatlán, Mexico. Journal of Arid Environment 57: 39-62. 
Bloem, M.W.; HuQ, N.; Gorstein, J.; Burger, S.; Kahn, T.; Islam, N.; BaKer, S.; DAVIDSON, F. (1996). Production of fruits and vegetables at the homestead is an important source of vitamin A among women in rural Bangladesh. European Journal of Clinical Nutrition 50, Supplement 3: S62-S67.

BPS Statistics Indonesia (2004). Social welfare statistics: Education. $<$ http://www.bps.go.id/sector/socwel/table2.shtml $>$ [01.10.2006].

BRodBeCK, F. (2004). Structure and Processes in Traditional Forest Gardens of Central Sulawesi, Indonesia. Dissertation, University of Goettingen, Faculty of Forest Science and Forest Ecology. Cuvillier Verlag, Goettingen, Germany, 197 pp.

Brookfield, H. (2001). Exploring Agrodiversity: Issues, Cases, and Methods in Biodiversity Conservation. Columbia University Press, New York, USA, 348 pp.

BRUSH, S.B. (1995). In situ conservation of landraces in centers of crop diversity. Crop Science 35: 346-354.

BRUSH, S.B.; MENG, E. (1998). Farmers' valuation and conservation of crop genetic resources. Genetic Resources and Crop Evolution 45: 139-150.

BURKARD, G. (2002a). Stability or sustainability? Dimensions of socio-economic security in a rain forest margin. STORMA Discussion Paper Series No. 7. Universities of Goettingen/Kassel, Germany; Institut Pertanian Bogor/Universitas Tadulako, Indonesia. $<$ http://ufgb989.uni-forst.gwdg.de/DPS/pdf/SDP7_160902.pdf $>$ [06.02.2007].

BurKard, G. (2002b). Natural Resource Management in Central Sulawesi: Past Experiences and Future Prospects. STORMA Discussion Paper Series No. 8. Universities of Goettingen/Kassel, Germany; Institut Pertanian Bogor/Universitas Tadulako, Indonesia. $<$ http://ufgb989.uni-forst.gwdg.de/DPS/pdf/SDP8.pdf > [06.02.2007].

BurkiLl, I.H. (1966). A Dictionary of the Economic Products of the Malay Peninsula. Second Edition, Kuala Lumpur, Malaysia, 2444 pp.

Cardinale, B.J.; Srivastava, D.S.; Duffy, J.E.; Wright, J.P.; Downing, A.L.; SANKARAN, M.; JouSEAU, C. (2006). Effects of biodiversity on the functioning of trophic groups and ecosystems. Nature 443: 989-992.

CARON, C.M. (1995). The role of nontimber tree products in household food procurement strategies: Profile of a Sri Lankan village. Agroforestry Systems 32: 99-117.

Castiñeiras, L.; Fundora Mayor, Z.; Shagarodsky, T.; Moreno, V.; Barrios, O.; FERNÁNDEZ, L.; CRISTÓBAL, R. (2002). Contribution of home gardens to in situ conservation of plant genetic resources in farming systems - Cuban component. In: Watson, J.W.; EyZAguirre, P.B. (eds.). Home Gardens and In Situ Conservation of Plant Genetic Resources in Farming Systems. Proceedings of the Second International Home Gardens Workshop, 17-19 July 2001, Witzenhausen, Germany. IPGRI, Rome, Italy, p. 4255 .

Ceccolini, L. (2002). The homegardens of Soqotra island, Yemen: An example of agroforestry approach to multiple land-use in an isolated location. Agroforestry Systems 56: 107-115.

CHARNLEY, S. (1997). Environmentally-displaced peoples and the cascade effect: Lessons from Tanzania. Human Ecology 25: 593-618.

Christanty, L. (1990). Home gardens in tropical Asia, with special reference to Indonesia. In: LANDAuer, K.; BRAZIL, M. (eds.). Tropical Home Gardens. The United Nations University, Tokyo, Japan, p. 9-20. 
Christanty, L.; Abdoellah, O.S.; Marten, G.G.; IsKandar, J. (1986). Traditional agroforestry in West Java: the pekarangan (homegardens) and kebun-talun (annualperennial rotation) cropping system. In: MARTEN, G.G. (ed.). Traditional Agriculture in Southeast Asia. Boulder, Colorado, USA, p. 132-158.

Clergue, B.; Amiaud, B.; Pervanchon, F.; Lasserre-Joulin, F.; PlantureuX, S. (2005). Biodiversity: function and assessment in agricultural areas. A review. Agron. Sustain. Dev. 25: 1-15.

Clinebell II, R.R.; Phillips, O.L.; Gentry, A.H.; StARK, N.; ZuURING, H. (1995). Prediction of neotropical tree and liana species richness from soil and climatic data. Biodiversity and Conservation 4: 56-90.

Cohan, N.; Jalil, M.A.; Rahman, H.; Matin, M.A.; Sprague, J.; Islam, J.; Davison, J.; LEEMHUIS DE REGT, E.; MitRA, M. (1985). Landholding, wealth and risk of blinding malnutrition in rural Bangladeshi households. Social Science and Medicine 21: 1269-1272.

CoOMES, O.T.; BAN, N. (2004). Cultivated plant species diversity in home gardens of an Amazonian peasant village in Northeastern Peru. Economic Botany 59: 420-434.

CORREA, C.M. (1999). In situ conservation and intellectual property rights. In: BRUSH, S.B. (ed.). Genes in the Field. On-farm Conservation of Crop Diversity. Lewis, Boca Raton, USA, p. 239-260.

Cousins, S.H. (1991). Species diversity measurement: Choosing the right index. Tree 6: 190192.

DAMANIA, A.B. (1996). Biodiversity conservation: A review of options complementary to standard ex situ methods. Plant Genetic Resources Newsletter 107: 1-18.

DAS, T.; DAS, A.K. (2005). Inventorying plant biodiversity in homegardens: A case study in Barak Valley, Assam, North East India. Current Science 89: 155-163.

DASH, S.S.; MisRA, M.K. (2001). Studies on hill agro-ecosystems of three tribal villages on the Eastern Ghats of Orissa, India. Agriculture, Ecosystems and Environment 86: 287-302.

Dechert, G. (2003). Nutrient Dynamics and their Control in Land Use Systems of Forest Margins in Central Sulawesi, Indonesia. Dissertation, University of Goettingen, Germany, $111 \mathrm{pp}$.

DECHERT, G.; VELDKAMP, E.; ANAS, I. (2004). Is soil degradation unrelated to deforestation? Examining soil parameters of land use systems in upland Central Sulawesi, Indonesia. Plant and Soil 265: 197-209.

De Clerck, F.A.J.; Negreros-Castillo, P. (2000). Plant species of traditional Mayan homegardens of Mexico as analogs for multistrata agroforests. Agroforestry Systems 48: 303-317.

Del Angel-PÉrez, A.L.; Mendoza B., M.A. (2004). Totonac homegardens and natural resources in Veracruz, Mexico. Agriculture and Human Values 21: 329-346.

Dharmasena, K.H.; WiJeratne, M. (1996). Analysis of nutritional contribution of homegardening. Der Tropenlandwirt 96: 149-158.

DiERßEN, K. (1990). Einführung in die Pflanzensoziologie (Vegetationskunde). Wissenschaftliche Buchgesellschaft, Darmstadt, Germany, 241 pp.

DRESCHER, A.W. (1996). Management strategies in African homegardens and the need for new extension approach. In: HeIDHUES, F.; FADANI, A. (eds.). Food Security and Innovations - Successes and Lessons learned. Peter Lang, Frankfurt, Germany, p. 231-246. 
Drescher, A.W.; Holmer, R.J.; IAQUINTA, D.L. (2006). Urban homegardens and allotment gardens for sustainable livelihoods: Management strategies and institutional environments. In: KUMAR, B.M.; NAIR, P.K.R. (eds.). Tropical Homegardens: A Time-Tested Example of Sustainable Agroforestry. Advances in Agroforestry, Vol. 3, Springer Science, Dordrecht, The Netherlands, pp. 317-338.

Drescher, A.W.; Hagmann, J.; ChUMA, E. (1999). Homegardens - a neglected potential for food security and sustainable land management in the communal lands of Zimbabwe. Der Tropenlandwirt 100: 163-180.

DuelLi, P.; OBRIST, M.K. (2003). Biodiversity indicators: The choice of values and measures. Agriculture, Ecosystems and Environment 98: 87-98.

Esquivel, M.; HAMmer, K. (1992). The Cuban homegarden 'conuco': A perspective environment for evolution and in situ conservation of plant genetic resources. Genetic Resources and Crop Evolution 39: 9-22.

Evans, F.C.; Clark, P.J.; BRAND, R.H. (1955). Estimation of the number of species present in a given area. Ecology 36: 342-343.

EyzAguiRRE, P.B.; LinARES, O.F. (eds.). Home Gardens and Agrobiodiversity. Smithsonian Books, Washington, USA, $296 \mathrm{pp}$.

FABER-LANGENDOEN, D.; GENTRY, A.H. (1991). The structure and diversity of rain forests at Bajo Calima, Chocó region, Western Colombia. Biotropica 23: 2-11.

FAO (2001). Improving Nutrition through Home Gardening. A Training Package for Preparing Field Workers in Africa. <http://www.fao.org/DOCREP/003/X3996E/x3996e04.htm\#P0_00> [19.09.2006].

FARIDAH HANUM, I.; MAESEN, L.J.G. VAN DER (eds.) (1997). Plant Resources of South-East Asia No. 11: Auxiliary Plants. PROSEA, Bogor, Indonesia, 389 pp.

Faust, H.; Maertens, M.; Weber, R.; Nuryartono, N.; Rheenen, T. VAn; Birner, R. (2003). Does migration lead to destabilization of forest margins? Evidence from an interdisciplinary field study in Central Sulawesi. STORMA Discussion Paper Series No. 11. Universities of Goettingen/Kassel, Germany; Institut Pertanian Bogor/Universitas Tadulako, Indonesia. <http://ufgb989.uni-forst.gwdg.de/DPS/pdf/SDP11_Migration.pdf> [06.02.2007].

FERNANDES, E.C.M.; NAIR, P.K.R. (1986). An evaluation of the structure and function of tropical homegardens. Agricultural Systems 21: 279-310.

Fernandes, E.C.M.; A. OKTingati; J. Maghembe (1984). The Chagga homegardens: A multistoried agroforestry cropping system on Mt. Kilimanjaro (Northern Tansania). Agroforestry Systems 2: 73-86.

Flach, M.; Rumawas, F. (eds.) (1996). Plant Resources of South-East Asia No. 9: Plants Yielding Non-Seed Carbohydrates. PROSEA, Bogor, Indonesia, 237 pp.

FRANKE, W. (1992). Nutzpflanzenkunde: Nutzbare Gewächse der gemäßigten Breiten, Subtropen und Tropen. Thieme, Stuttgart, Germany, $490 \mathrm{pp}$.

FU, B.J.; LIU, S.L.; MA, K.M.; ZHU, Y.G. (2004). Relationship between soil characteristics, topography and plant diversity in a heterogeneous deciduous broad-leaved forest near Beijing, China. Plant and Soil 261: 47-54.

Fu, Y.; GuO, H.; Chen, A.; CuI, J.; PADOCH, C. (2003). Relocating plants from swidden fallows to gardens in southwestern China. Economic Botany 57: 389-402.

Fundora Mayor, Z.; Shagarodsky, T.; CASTIÑEIRAS, L. (2004). Sampling methods for the study of genetic diversity in home gardens of Cuba. In: EYZAGUIRRE, P.B.; LINARES, O.F. (eds.). Home Gardens and Agrobiodiversity. Smithsonian Books, Washington, USA, p. 5677 . 
GAJASENI, J.; GAJASENI, N. (1999). Ecological rationalities of the traditional homegarden system in the Chao Phraya Basin, Thailand. Agroforestry Systems 46: 3-23.

Gartlan, J.S.; Newbery, D.M.; Thomas, D.W.; WAterman, P.G. (1986). The influence of topography and soil phosphorus in the vegetation of Korup Forest Reserve, Cameroun. Vegetatio 65: 131-148.

GeBAuer, J. (2005). Plant species diversity of home gardens in El Obeid, Central Sudan. Journal of Agriculture and Rural Development in the Tropics and Subtropics 106: 97-103.

GENTRY, A.H. (1988). Changes in plant community diversity and floristic composition on environmental and geographical gradients. Annals of the Missouri Botanical Garden 75: 134.

GENTRY, A.H.; EMmONS, L.H. (1987). Geographical variation in fertility, phenology, and composition of the understory of neotropical forests. Biotropica 19: 216-227.

GeSsler, M.; Hodel, U. (2004). A case study of key species in Southern Vietnam: Farmer classification and management of agrobiodiversity in home gardens. In: EYZAGUIRRE, P.B.; LinARES, O.F. (eds.). Home Gardens and Agrobiodiversity. Smithsonian Books, Washington, USA, p. 215-233.

GiLlesPie, A.R.; KNUDSOn, D.M.; GeILfus, F. (1993). The structure of four home gardens in the Petén, Guatemala. Agroforestry Systems 24: 157-170.

GLIESSMAN, S.R. (2001). The ecological foundations of agroecosystem sustainability. In: Gliessman, S.R. (ed.). Agroecosystem Sustainability. Developing Practical Strategies. CRC Press, Boca Raton, USA, p. 3-14.

Gliessman, S.R. (2000). Agroecology: Ecological Processes in Sustainable Agriculture. CRC Press, Boca Raton, USA, 357 pp.

GLIESSMAN, S.R. (1990a). Understanding the basis of sustainability for agriculture in the tropics: Experiences in Latin America. In: EdWARDS, C.A.; LAL, R.; MADDEN, P.; MiLler, R.H.; House, G. (eds.). Sustainable Agricultural Systems. Soil and Water Conservation Society, Iowa, USA, p. 378-389.

GLIESSMAN, S.R. (1990b). Integrating trees into agriculture: The home garden agroecosystem as an example of agroforestry in the tropics. In: GLIESSMAN, S.R. (ed.). Agroecology. Researching the Ecological Basis for Sustainable Agriculture. Springer, New York, USA, p. 160-168.

Grubauer, A. (1923). Celebes: Ethnologische Streifzüge in Südost- und Zentral-Celebes. Folkwang-Verlag, Hagen, Germany, 72 pp.

GuARINO, L.; HoOgENDIJK, M. (2004). Microenvironments. In: EYZAGUIRRE, P.B.; LiNARES, O.F. (eds.). Home Gardens and Agrobiodiversity. Smithsonian Books, Washington, USA, p. 31-40.

GuZman, C.C. DE; Siemonsma, J.S. (eds.) (1999). Plant Resources of South-East Asia No. 13: Spices. PROSEA, Bogor, Indonesia, 400 pp.

Halliday, D.J.; TRENKEL, M.E. (eds.) (1992). IFA World Fertilizer Use Manual. International Fertilizer Industry Association, Paris, France, 632 pp.

Hardy, F. (1958). Cacao soils. Proceedings of the Soil and Crop Science Society of Florida 18: $75-87$.

HarteminK, A.E. (2003). Soil Fertility Decline in the Tropics with Case Studies on Plantations. CABI Publishing, Wallingford, UK, 360 pp.

HaWkins, B.A.; Field, R.; CORNELl, H.V.; CuRrie, D.J.; GuÉGAN, J.F.; KAUfMAN, D.M.; Kerr, J.T.; Mittelbach, G.G.; OberdorfF, T.; O’Brien, E.M.; Porter, E.E.; TuRner, J.R.G. (2003). Energy, water, and broad-scale geographic patterns of species richness.

Ecology 84: 3105-3117. 
HELEN KELLER INTERNATIONAL (2004). Research and publications. $<\mathrm{http}: / / w w w . h k i . o r g /$ research/index.html $>$ [03.11.2005].

HEMP, A. (2006). The banana forests of Kilimanjaro: Biodiversity and conservation of the Chagga homegardens. Biodiversity and Conservation 15: 1193-1217.

HENDRIAN; TRI HADIAH, J. (eds.) (1999). Koleksi Tumbuhan Obat Kebun Raya Bogor. Seri Koleksi Kebun Raya-Lipi, Vol. 1, No. 3. UPT Bakai Pengembangan Kebun Raya-LIPI, Bogor, Indonesia, 79 pp.

Henry, C.; Sharma, M.; LaPenu, C.; Zeller, M. (2003). Microfinance Poverty Assessment Tool. CGAP, Technical Tools Series No. 5., Washington, DC, USA. $<$ http://www.cgap.org/publications/technical_tools.html $>$ [06.07.2005].

HeYNe, K. (1927). De Nuttige Planten van Nederlandsch-Indie. Department van Landbouw, Nijverheid \& Handel in Nederlandsch-Indie, Batavia, Nederlandsch-Indie, 1662 pp.

High, C.; Shackleton, C.M. (2000). The comparative value of wild and domestic plants in home gardens of a South African rural village. Agroforestry Systems 48: 141-156.

Hochegger, K. (1998). Farming Like the Forest - Traditional Home Garden Systems in Sri Lanka. Margraf Verlag, Weikersheim, Germany, 203 pp.

Hodel, U.; Gessler, M.; Cai H.H.; Thoan, V.V.; Ha, N.V.; Thu, N.X.; BA, T. (1999). In situ Conservation of Plant Genetic Resources in Home Gardens of Southern Vietnam. IPGRI, Rome, Italy, $106 \mathrm{pp}$.

Holden, S.; Hvoslef, H. (1995). Transmigration settlements in Seberida: Causes and consequences of the deterioration of farming systems of settlers in a rain forest environment. In: SANDBUKT, O. (ed.). Management of Tropical Forests: Towards an Integrated Perspective. Centre for Development and Environment, University of Oslo, Norway, p. 107-125.

Holden, S.; Hvoslef, H.; Simanjuntak, R. (1995). Transmigration settlements in Seberida, Sumatra: Deterioration of farming systems in a rain forest environment. Agricultural Systems 49: 237-258.

HoOgerbrugge, I.D.; Fresco, L.O. (1993). Homegarden Systems: Agricultural Characteristics and Challenges. Gatekeeper Series 39. IIED (Intern. Inst. for Environment and Development), London, UK, 23 pp.

HoOPER, D.U.; VitouseK, P.M. (1997). The effects of plant composition and diversity on ecosystem processes. Science 277: 1302-1305.

HoPPE, M.; FAUST, H. (2004). Transmigration and integration in Indonesia - Impacts on resource use in the Napu valley, Central Sulawesi. STORMA Discussion Paper Series No. 13. Universities of Goettingen/Kassel, Germany; Institut Pertanian Bogor/Universitas Tadulako, Indonesia. <http://www.storma.de/DPS/pdf/SDP13.pdf> [18.07.2004].

HowARD, P.L. (2006). Gender and social dynamics in swidden and homegardens in Latin America. In: KUMAR, B.M.; NAIR, P.K.R. (eds.). Tropical Homegardens: A Time-Tested Example of Sustainable Agroforestry. Advances in Agroforestry, Vol. 3, Springer Science, Dordrecht, The Netherlands, pp. 159-182.

Huston, M. (1980). Soil nutrients and tree species richness in Costa Rican forests. Journal of Biogeography 7: 147-157.

Huston, M.A. (1994). Biological Diversity: The Coexistence of Species on Changing Landscapes. Cambridge University Press, Cambrigde, UK, 681 pp.

HuXLeY, P. (1999). Tropical Agroforestry. Blackwell Science, Oxford, UK, 371 pp. 
Hvoslef, H. (1994). Homegardens of Javanese transmigrants in Seberida subdistrict: description, agroecological constraints and evaluation of potential solutions to declining productivity. In: SANDBUKT, O.; WIRIADINATA, H. (eds.). Rain Forest and Resource Management. NORINDRA Seminar, Jakarta, 1994. Indonesian Institute of Sciences (LIPI), Indonesia, p. 127-136.

IMMINK, M.D.C.; SANJUR, D.; COLON, M. (1981). Home gardens and the energy and nutrient intakes of women and preschoolers in rural Puerto Rico. Ecology of Food and Nutrition 11: 191-199.

IZAC, A.M.N.; SwIFT, M.J. (1994). On agricultural sustainability and its measurement in small-scale farming in sub-Saharan Africa. Ecological Economics 11: 105-125

JANSSEN, J.; LAATZ, W. (2003). Statistische Datenanalyse mit SPSS für Windows: Eine anwendungsorientierte Einführung in das Basissystem und das Modul Exakte Tests. Springer, Berlin, Germany, 722 pp.

JENSEN, M. (1993a). Soil conditions, vegetation structure and biomass of a Javanese homegarden. Agroforestry Systems 24: 171-186.

JENSEN, M. (1993b). Productivity and nutrient cycling of a Javanese homegarden. Agroforestry Systems 24: 187-201.

JoHN, J.; NAIR, M.A. (1999). Crop-tree inventory of the home gardens of Southern Kerala. Journal of Tropical Agriculture 37: 110-114.

Jose, D.; Shanmugaratnam, N. (1993). Traditional homegardens of Kerala: A sustainable human ecosystem. Agroforestry Systems 24: 203-213.

KARYONO (2000). Traditional homegarden and its transforming trend. Jurnal Bionatura 2: $117-124$.

KARYONO (1990). Home Gardens in Java. Their Structure and Function. In: LANDAUER, K.; BrAZIL, M. (eds.). Tropical Home Gardens. The United Nations University, Tokyo, Japan, p. 138-146.

KAYA, M.; KAMmeSheidT, L.; WeIDELT, H.J. (2002). The forest garden system of Saparua island, Central Maluku, Indonesia, and its role in maintaining tree species diversity. Agroforestry Systems 54: 225-234.

KEHLENBECK, K. (2002). Nutzpflanzendiversität, Bodenfruchtbarkeit und Management von Hausgärten in Zentral-Sulawesi, Indonesien. Unpublished M.Sc. thesis, Institute for Crop and Animal Production in the Tropics, University of Goettingen, Germany, $179 \mathrm{pp}$.

KeHLEnBECK, K.; MAAss, B.L. (2006). Are tropical homegardens sustainable? Some evidence from Central Sulawesi, Indonesia. In: KUMAR, B.M.; NAIR, P.K.R. (eds.). Tropical Homegardens: A Time-Tested Example of Sustainable Agroforestry. Advances in Agroforestry, Vol. 3, Springer Science, Dordrecht, The Netherlands, pp. 339-354.

KeHLENBECK, K.; MAASS, B.L. (2004). Crop diversity and classification of homegardens in Central Sulawesi, Indonesia. Agroforestry Systems 63: 53-62.

KeHLEnBECK, K.; ARIFIn, H.S.; MAAsS, B.L. (2007). Plant diversity in homegardens in a socio-economic and agro-ecological context. In: TSCHARNTKE, T.; LEUSCHNER, C.; ZELLER, M.; GUHARDJA, E.; BIDIN, A. (eds.). The Stability of Tropical Rainforest Margins: Linking Ecological, Economic and Social Constraints of Land Use and Conservation. Springer, Berlin, Germany, p. 297-319.

Keller, G.B.; Mndiga, H.; MAAss, B.L. (2006). Diversity and genetic erosion of traditional vegetables in Tanzania from the farmer's point of view. Plant Genetic Resources 3: 400413. 
Kessler, M. (2002). Plant species richness and endemism of upper montane forests and timberline habitats in the Bolivian Andes. In: KÖRNER, C.; SPEHN, E.M. (eds.). Mountain Biodiversity: A Global Assessment. Parthenon Publishing, London, UK, pp. 59-73.

Kessler, M.; Keßler, P.J.A.; Gradstein, S.R.; Bach, K.; Schmull, M.; Pitopang, R. (2005). Tree diversity in primary forest and different land use systems in Central Sulawesi, Indonesia. Biodiversity and Conservation 14: 547-560.

Khoshbakht, K. (2005). Agrobiodiversity of Plant Genetic Resources in Savadhkouh/Iran with Emphasis on Plant Uses and Socioeconomic Aspects. Kassel University Press, Kassel, Germany, $87 \mathrm{pp}$.

KIMBER, C. (1978). A folk context for plant domestication: Or the dooryard garden revisited. Anthropological Journal of Canada 16 (4): 2-11.

KIMBER, C. (1973). Spatial patterning in the dooryard gardens of Puerto Rico. The Geographical Review 63: 6-26.

KIMBER, C. (1966). Dooryard gardens of Martinique. Yearbook of the Association Pacific Coast Geographers 28: 97-118.

Klein, A.M.; StefFan-Dewenter, I.; TsChaRnTKe, T. (2006). Rain forest promotes trophic interactions and diversity of trap nesting Hymenoptera in adjacent agroforestry. Ecology 75: 315-323.

Kluge, J.; Kessler, M.; DunN, R.R. (2006). What drives elevational patterns of diversity? A test of geometric constraints, climate and species pool effects for pteridophytes on an elevational gradient in Costa Rica. Global Ecology and Biogeography 15: 358-371.

Kovach COMPUTING SERVICES (2006). MVSP Information. $<$ http://www.kovcomp.com/mvsp/index.html > [29.03.2007].

KREBS, C. J. (1999). Ecological Methodology. Benjamin/Cummings, Menlo Park, USA, $620 \mathrm{pp}$.

KUMAR, B.M. (2006). Carbon sequestration potential of tropical homegardens. In: KUMAR, B.M.; NAIR, P.K.R. (eds.). Tropical Homegardens: A Time-Tested Example of Sustainable Agroforestry. Advances in Agroforestry, Vol. 3, Springer Science, Dordrecht, The Netherlands, pp. 185-204.

KuMAR, B.M.; NAIR, P.K.R. (2006) (eds.). Tropical Homegardens: A Time-Tested Example of Sustainable Agroforestry. Advances in Agroforestry, Vol. 3, Springer Science, Dordrecht, The Netherlands, $377 \mathrm{pp}$.

KUMAR, B.M.; NAIR, P.K.R. (2004). The enigma of tropical homegardens. Agroforestry Systems 61: 135-152.

Kumar, B.M.; GeORGE, S.J.; ChINNAMANI, S. (1994). Diversity, structure and standing stock of wood in the homegardens of Kerala in peninsular India. Agroforestry Systems 25: 243262.

Kusumaningtyas, R.; Kobayashi, S.; TAKedA, S. (2006). Mixed species gardens in Java and the transmigration areas of Sumatra, Indonesia: A comparison. Journal of Tropical Agriculture 44: 15-22.

LAMONT, S.R.; EshBAUGH, W.H.; GREENBERG, A.M. (1999). Species composition, diversity, and use of homegardens among three Amazonian villages. Economic Botany 53: 312-326.

LANDON, J.R. (ed.) (1991). Booker Tropical Soil Manual: A Handbook for Soil Survey and Agricultural Land Evaluation in the Tropics and Subtropics. Longman Scientific \& Technical, Essex, Great Britain, 474 pp. 
Leiva, J.M.; Azurdia, C.; Ovando, W.; LóPez, E.; Ayala, H. (2002). Contributions of home gardens to in situ conservation in traditional farming systems - Guatemalan component. In: Watson, J.W.; EyzaguirRe, P.B. (eds.). Home Gardens and In Situ Conservation of Plant Genetic Resources in Farming Systems. Proceedings of the Second International Home Gardens Workshop, 17-19 July 2001, Witzenhausen, Germany. IPGRI, Rome, Italy, p. 56-72.

LEMmEns, R.H.M.J. (ed.) (2003). Plant Resources of South-East Asia No. 12(3): Medicinal and Poisonous Plants 3. Backhuys Publishers, Leiden, The Netherlands, 664 pp.

LEPŠ, J.; ŠMILAUER, P. (2003). Multivariate Analysis of Ecological Data Using CANOCO. Cambridge University Press, Cambridge, United Kingdom, 269 pp.

LeVAng, P.; Foresta, H. DE (1991). Economic Plants of Indonesia: A Latin, Indonesian, French and English Dictionary of 728 Species. ORSTOM und SEAMEO BIOTROP, Bogor, Indonesia, $180 \mathrm{pp}$.

LOREAU, M.; HeCtOR, A. (2001). Partitioning selection and complementarity in biodiversity experiments. Nature 412: 72-76.

Loreau, M.; Naeem, S.; Inchausti, P.; Bengtsson, J.; Grime, J.P.; Hector, A.; Hooper, D.U.; Huston, M.A.; Raffaelli, D.; Schmid, B.; Tilman, D.; Wardle, D.A. (2001). Biodiversity and ecosystem functioning: current knowledge and future challenges. Science 294: 804-808.

Ludwig, J.A.; REYNOLDS, J.F. (1988). Statistical Ecology: A Primer on Methods and Computing. Wiley-Interscience, New York, USA, 337 pp.

LÜER, B.; BÖHMER, A. (2000). Vergleich zwischen Perkolation und Extraktion mit $1 \mathrm{M}$ $\mathrm{NH}_{4}$ Cl-Lösung zur Bestimmung der effektiven Kationenaustauschkapazität (KAK eff) von Böden. J. Plant Nutr. Soil Sci. 163: 555-557.

Mackensen, J.; Ampt, J.; Garrelts, A.; KortekaAs, M.; VeldKamp, A. (1999). Report on reconnaissance soil survey in the Napu and Sopu-valley, Central Sulawesi, Indonesia. Submitted to SFB 1687, Göttingen on December, 10, 1999.

MAertens, M.; ZelLer, M.; BIRner, R. (2002). Explaining agricultural land use in villages surrounding the Lore Lindu National Park in Central Sulawesi, Indonesia. STORMA Discussion Paper Series No. 4. Universities of Goettingen/Kassel, Germany; Institut Pertanian Bogor/Universitas Tadulako, Indonesia. <http://www.storma.de/DPS/index.htm> [27.07.2004].

MAESEN, L.J.G. VAN DER; SOMAATMADJA, S. (eds.) (1992). Plant Resources of South-East Asia No. 1: Pulses. PROSEA, Bogor, Indonesia, 106 pp.

MagurRAn, A.E. (1988). Ecological Diversity and its Measurement. Croom Helm, London, UK, 179 pp.

MAIN, A.R. (1999). How much biodiversity is enough? Agroforestry Systems 45: 23-41.

MARSH, R. (1996). Household food security through home gardening - Evidence from Bangladesh. In: HEIDHUES, F.; FADANI, A. (eds.). Food Security and Innovations Successes and Lessons Learned. Peter Lang, Frankfurt, Germany, p. 247-260.

Marten, G.G.; ABDOELlah, O.S. (1988). Crop diversity and nutrition in West Java. Ecology of Food and Nutrition 21: 17-43.

Mathias-Mundy, E.; Muchena, O.; McKiernan, G.; Mundy, P. (1992). Indigenous Technical Knowledge of Private Tree Management: A Bibliographic Report. Studies in Technology and Social Change 22, Ames, Iowa, USA.

$<$ http://www.ciesin.columbia.edu/docs/004-175/004-175.html $>$ [29.03.2007]. 
MAXTED, N.; Ford-Lloyd, B.V.; HAWKes, J.G. (1997). Complementary conservation strategies. In: MAXTED, N.; Ford-Lloyd, B.V.; HAwKes, J.G. (eds.). Plant Genetic Conservation: The in situ Approach. Kluwer, Dordrecht, The Netherlands, p. 15-39.

MCCANN, K.S. (2000). The diversity-stability debate. Nature 405: 228-233.

McCunE, B.; Grace, J.B.; Urban, D.L. (2002). Analysis of Ecological Communities. MjM Software Design, Gleneden Beach, USA, 300 pp.

MENDEZ, V.E. (2001). An assessment of tropical homegardens as examples of sustainable local agroforestry systems. In: GLIESSMAN, S.R. (ed.). Agroecosystem Sustainability. Developing Practical Strategies. CRC Press, Boca Raton, USA, p. 51-66.

MÉNDEZ, V.E.; LOK, R.; SOMARRIBA, E. (2001). Interdisciplinary analysis of homegardens in Nicaragua: Micro-zonation, plant use and socioeconomic importance. Agroforestry Systems 51: 85-96.

MiCHON, G.; MARY, F. (1994). Conversion of traditional village gardens and new economic strategies of rural households in the area of Bogor, Indonesia. Agroforestry Systems 25: 31-58.

MidMORE, D.J.; NiÑEZ, V.; VenKATARAMAN, R. (1991). Household gardening projects in Asia: Past experiences and future directions. Asian Vegetable Research and Development Center, Technical Bulletin No. 19, 28 pp.

Millat-e-Mustafa, M.D.; Hall, J.B.; Teklehaimanot, Z. (2000). Indigenous management techniques in Bangladesh homegardens. International Tree Crops Journal 10: 215-228.

Millat-e-Mustafa, M.D.; Hall, J.B.; Teklehaimanot, Z. (1996). Structure and floristics of Bangladesh homegardens. Agroforestry Systems 33: 263-280.

MiLleR, R.P.; NAIR, P.K.R. (2006). Indigenous agroforestry systems in Amazonia: From prehistory to today. Agroforestry Systems 66: 151-164.

MiYAJI, K.; Silva, W.S. DA; AlviM, P. DE T. (1997). Productivity of leaves of a tropical tree, Theobroma cacao, grown under shading, in relation to leaf age and light conditions within the canopy. New Phytologist 137: 463-472.

Montagnini, F. (2006). Homegardens of Mesoamerica: Biodiversity, food security, and nutrient management. In: KUMAR, B.M.; NAIR, P.K.R. (eds.). Tropical Homegardens: A Time-Tested Example of Sustainable Agroforestry. Advances in Agroforestry, Vol. 3, Springer, Dordrecht, The Netherlands, p. 61-84.

Moreno-Black, G.; Somnasang, P.; Thamathawan, S. (1996). Cultivating continuity and creating change: Woman's home garden practices in Northeastern Thailand. Agriculture and Human Values 13: 3-11.

NAIR, P.K.R. (2006). Whither homegardens. In: KUMAR, B.M.; NAIR, P.K.R. (eds.). Tropical Homegardens: A Time-Tested Example of Sustainable Agroforestry. Advances in Agroforestry, Vol. 3, Springer, Dordrecht, The Netherlands, p. 355-370.

NAIR, P.K.R.; KUMAR, B.M. (2006). Introduction. In: KUMAR, B.M.; NAIR, P.K.R. (eds.). Tropical Homegardens: A Time-Tested Example of Sustainable Agroforestry. Advances in Agroforestry, Vol. 3, Springer, Dordrecht, The Netherlands, p. 1-10.

NiÑEZ, V. (1987). Household gardens: Theoretical and policy considerations. Agricultural Systems 23: 167-186.

NIÑEZ, V. (1985). Working at half-potential: Constructive analysis of home garden programmes in the Lima slums with suggestions for an alternative approach. Food and Nutrition Bulletin 7: 6-14. <http://www.unu.edu/unupress/food/8F073e/8F073E02.htm> [04.07.2005].

OAKLEY, E. (2004). Home gardens: A cultural responsibility. Leisa Magazine 20: 22-23. 
OAKLEY, E.; Momsen, J.H. (2007). Women and seed management: A study of two villages in Bangladesh. Singapore Journal of Tropical Geography 28: 90-106.

OAKLEY, E.; MOMSEN, J.H. (2005). Gender and agrobiodiversity: A case study from Bangladesh. The Geographical Journal 171: 195-208.

OKAFOR, J.C.; FERNANDES, E.C.M. (1987). Compound farms of southeastern Nigeria: A predominant agroforestry homegarden system with crops and small livestock. Agroforestry Systems 5: 153-168.

OKigBo, B.N. (1990). Home gardens in tropical Africa. In: LANDAUER, K.; BrAZIL, M. (eds.). Tropical Home Gardens. The United Nations University, Tokyo, Japan, p. 21-40.

OKubo, S.; TAKeuChi, K.; ChaKranon, B.; Jongskul, A. (2003). Land characteristics and plant resources in relation to agricultural land-use planning in a humid tropical strand plain, southeastern Thailand. Landscape and Urban Planning 65: 133-148.

Olsen, S.R.; Sommers, L.E. (1982). Phosphorus. In: Page, A.L.; Miller, R.H.; Keeney, D.R. (eds.). Methods of Soil Analysis. Part 2. ASA, Madison, Wisconsin, USA, p. 403430.

OOMEN, H.A.P.C.; GRUBBEN, G.J.H. (1977). Tropical Leaf Vegetables in Human Nutrition. Communication 69, Dept. Agr. Res., Royal Tropical Institute, Amsterdam, The Netherlands, 133 pp.

PAdoch, C.; DE Jong, W. (1991). The house gardens of Santa Rosa: Diversity and variability in an Amazonian agriculture system. Economic Botany 45 (2): 166-175.

PAdUA, L.S. DE; BunYAPRAPhATSARA, N.; LEMmens, R.H.M.J. (eds.) (1999). Plant Resources of South-East Asia No. 12(1): Medicinal and Poisonous Plants 1. PROSEA, Bogor, Indonesia, $711 \mathrm{pp}$.

PAOLI, G.D.; CURRAN, L.M.; ZAK, D.R. (2006). Soil nutrients and beta diversity in the Bornean Dipterocarpaceae: Evidence for niche partitioning by tropical rain forest trees. Journal of Ecology 94: 157-170.

PEET, R.K. (1974). The measurement of species diversity. Annual Review of Ecology and Systematics 5, 285-307.

Perry, L.M. (1980). Medicinal Plants of East and Southeast Asia: Attributed Properties and Uses. MIT Press, Cambridge, Massachusetts, USA, 620 pp.

PERZ, S.G. (2005). The effects of household asset endowments on agricultural diversity among frontier colonists in the Amazon. Agroforestry Forum 63: 263-279.

Peyre, A.; GuidAl, A.; Wiersum, K.F.; Bongers, F. (2006). Dynamics of homegarden structure and function in Kerala, India. Agroforestry Systems 66: 101-115.

PIEPHO, H.P. (1996). Einige Überlegungen zur Quantifizierung von Nachhaltigkeit unter besonderer Berücksichtigung von Biodiversität und Stabilität. Der Tropenlandwirt, Beiheft Nr. 56: 137-162.

Pitopang, R.; KeßLER, P.J.A.; GRAdstein, S.R.; GuhardJa, E.; TJITROSUdirdjo, S.S.; WiriadinatA, H. (2004). Tree composition in secondary forest of Lore Lindu National Park, Central Sulawesi, Indonesia. In: Gerold, G.; FrEMEREY, M.; GuHARDJA, E. (eds.). Land Use, Nature Conservation and the Stability of Rain Forest Margins in Southeast Asia. Springer, Berlin, Germany, p. 269-279.

Power, A.G.; KeNMORE, P. (2002). Exploiting interactions between planned and unplanned diversity in agroecosystems: What do we need to know?. In: UPHOFF, N. (ed.).

Agroecological Innovations: Increasing Food Production with Participatory Development. Earthscan, London, UK, p. 233-242. 
Qualset, C.O.; DAmania, A.B.; ZanATtA, A.C.A.; BRush, S.B. (1997). Locally based crop plant conservation. In: MAXTED, N.; ForD-Lloyd, B.V.; HAWKeS, J.G. (eds.). Plant Genetic Conservation. The in situ Approach. Kluwer, Dordrecht, The Netherlands, p. 160175.

Quiroz, C.; Gutierrez, M.; Perez de Fernandez, T. (2004). Venezuelan conucos: Reversing threats to a traditional system. In: EYZAGUIRRE, P.B.; LiNARES, O.F. (eds.). Home Gardens and Agrobiodiversity. Smithsonian Books, Washington, USA, p. 185-197.

Quiroz, C.; Gutierrez, M.; Rodriguez, D.; Perez, D.; Ynfante, J.; Gamez, J.; Perez de Fernandez, T.; Marquez, A. \& PaCheCo, W. (2002). Home gardens and in situ conservation of agrobiodiversity - Venezuelan component. In: WATSON, J.W. \& EYZAGUIRRE, P.B. (eds.). Home gardens and in situ conservation of plant genetic resources in farming systems. Proceedings of the Second International Home Gardens Workshop, 17-19 July 2001, Witzenhausen, Germany. IPGRI, Rome, Italy, p. 73-82.

Rehm, S.; EsPIG, G. (1991). The Cultivated Plants of the Tropics and Subtropics: Cultivation, Economic Value, Utilization. Margraf, Weikersheim, Germany, 552 pp.

REYNAUD, J.; BRUN, T.; MAREK, T. (1989). Impact of a women's garden project on nutrition and income in Senegal. Arid Lands Newsletter 29: 15-20.

Rheenen, T. van; Elbel, C.; Schwarze, S.; Nuryartono, N.; Zeller, M; Sanim, B. (2004). Encroachments on primary forest: Are they really driven by despair? In: GEROLD, G.; Fremerey, M.; Guhardja, E. (eds.). Land Use, Nature Conservation and the Stability of Rain Forest Margins in Southeast Asia. Springer, Berlin, Germany, p. 199-213.

RHOADES, R.E.; NAZAREA, V.D. (1999). Local management of biodiversity in traditional agroecosystems. In: COLLINS, W.W.; QUALSET, C.O. (eds.). Biodiversity in Agroecosystems. CRC Press, Boca Raton, USA, pp. 215-236.

Rico-Gray, V.; Garcia-Franco, J.G.; Chemas, A.; Puch, A.; Sima, P. (1990). Species composition, similarity, and structure of Mayan homegardens in Tixpeual and Tixcacaltuyub, Mexico. Economic Botany 44: 470-487.

RoshetKo, M.; Delaney, M.; Hairiah, K.; PuRnOMOsidhi, P. (2002). Carbon stocks in Indonesian homegarden systems: Can smallholder systems be targeted for increased carbon storage? American Journal of Alternative Agriculture 17: 138-148.

Rugalema, G.H.; A. OKTING`ATi; F.H. Johnsen (1994). The homegarden agroforestry system of Bukoba district, North-Western Tanzania. 1. Farming system analysis. Agroforestry Systems 26: 53-64.

SANCHEZ, P.A. (1976). Properties and Management of Soils in the Tropics. Wiley, New York, USA, $618 \mathrm{pp}$.

SCHAFFERS, A.P. (2002). Soil, biomass, and management of semi-natural vegetation. Part I. Interelationships. Plant Ecology 158: 229-246.

SCHEFFER, F. (1998). Lehrbuch der Bodenkunde: Scheffer; Schachtschabel. 14. Aufl., Enke, Stuttgart, Germany, 494 pp.

Schroth, G.; FonseCA, G.A.B. DA; HarVeY, C.A.; VAsconcelos, H.L.; Gascon, C.; IZAC, A.M.N. (2004). Introduction: The role of agroforestry in biodiversity conservation in tropical landscapes. In: SCHROTH, G.; FonseCA, G.A.B. DA; HARVEY, C.A.; GASCON, C.; VASCONCELOS, H.L.; IZAC, A.M.N. (eds.). Agroforestry and Biodiversity Conservation in Tropical Landscapes. Island Press, Washington, USA, p. 1-12.

Schroth, G.; Lehmann, J.; Rodrigues, M.R.L.; BARros, E.; MACÊdO, J.L.V. (2001). Plantsoil interactions in multistrata agroforestry in the humid tropics. Agroforestry Systems 53: 85-102. 
SCHÜLlER, H. (1969). Die CAL-Methode, eine neue Methode zur Bestimmung des pflanzenverfügbaren Phosphates in Böden. Z. Pflanzenernähr. Bodenk. 123, 48-63.

Schulze, C.H.; Waltert, M.; Kessler, P.J.A.; Pitopang, R.; Shahabuddin; Veddeler, D.; MÜHlenberG, M.; Gradstein, S.R.; Leuschner, C.; StefFAn-DeWEnTER, I.; TSCHARNTKE, T. (2004). Biodiversity indicator groups of tropical land-use systems: Comparing plants, birds, and insects. Ecological Applications 15: 1321-1333.

Schwartz, M.W.; Brigham, C.A.; Hoeksema, J.D.; Lyons, K.G.; Mills, M.H.; VAN MANTGEM, P.J. (2000). Linking biodiversity to ecosystem function: Implications for conservation ecology. Oecologia 122: 297-305.

SchWARZE, S. (2004). Determinants of Income Generation Activities of Rural Households. A Quantitative Study in the Vicinity of the Lore Lindu National Park in Central Sulawesi/Indonesia. Dissertation, University of Goettingen, Germany, 127 pp.

Shastri, C.M.; Bhat, D.M.; NAGARAJa, B.C.; Murali, K.S.; RAVINDRANATH, N.H. (2002). Tree species diversity in a village ecosystem in Uttara Kannada district in Western Ghats, Karnataka. Current Science 82: 1080-1084.

Shrestha, P.; GAUTAM, R.; RANA, R.B.; SthaPIT, B. (2004). Managing diversity in various ecosystems: Home gardens of Nepal. In: Eyzaguirre, P.B.; LinARES, O.F. (eds.). Home Gardens and Agrobiodiversity. Smithsonian Books, Washington, USA, p. 95-122.

Shrestha, P.; GaUtAm, R.; RANA, R.B.; Sthapit, B. (2002). Home gardens in Nepal: Status and scope for research and development. In: WATSON, J.W.; EYZAGUIRRE, P.B. (eds.). Home Gardens and In Situ Conservation of Plant Genetic Resources in Farming Systems. Proceedings of the Second International Home Gardens Workshop, 17-19 July 2001, Witzenhausen, Germany. IPGRI, Rome, Italy, p. 105-118.

SIEBERT, S.F. (2002). From shade- to sun-grown perennial crops in Sulawesi, Indonesia: Implications for biodiversity conservation and soil fertility. Biodiversity and Conservation 11: 1889-1902.

Siemonsma, J.S.; Kasem PilueK (eds.) (1994). Plant Resources of South-East Asia No.8: Vegetables. PROSEA, Bogor, Indonesia, $412 \mathrm{pp}$.

SMAle, M.; Bellon, M.R.; JARVIS, D.; SthaPIT, B. (2004). Economic concepts for designing policies to conserve crop genetic resources on farms. Genetic Resources and Crop Evolution 51: 121-135.

SMITH, N.J.H. (1996). Home gardens as a springboard for agroforestry development in Amazonia. International Tree Crop Journal 9: 11-30.

Smith, N.J.H.; Williams, J.T.; PluckNetT, D.L.; TALBOT, J.P. (1992). Tropical Forests and their Crops. Cornell University Press, Ithaca, USA, 568 pp.

SoEmARWOTO, O. (1987). Homegardens: A traditional agroforestry system with a promising future. In: STEPPLER, H.A.; NAIR, P.K.R. (eds.) : Agroforestry: A Decade of Development. International Council for Research and Agroforestry (ICRAF), Nairobi, Kenya, p. 157-170.

Soemarwoto, O.; Conway, G.R. (1992). The Javanese homegarden. Journal for Farming Systems Research-Extension 2: 95-118.

SoEmARWoto, O.; SoEMARWOTO, I. (1982). Homegarden: Its nature, origin and future development. Proceedings of the Workshop on Ecological Basis for Rational Resource Utilization in the Humid Tropics of South East Asia, 18-22 January 1982, Universitas Pertanian, Malaysia, p. 130-139.

Sollins, P. (1998). Factors influencing species composition in tropical lowland rain forest: Does soil matter? Ecology 79: 23-30. 
Steffan-Dewenter, I.; Kessler, M.; Barkmann, J.; Bos, M.M.; Buchori, D.; Erasmi, S.; Faust, H.; Gerold, G.; GlenK, K.; Gradstein, S.R.; Guhardua, E.; Harteveld, M.; Hertel, D.; Höhn, P.; Kappas, M.; Köhler, S.; Leuschner, C.; Maertens, M.; Marggraf, R.; Migge-Kleian, S.; Mogea, J.; Pitopang, R.; Schaefer, M.; Schwarze, S.; Sporn, S.G.; Steingrebe, A.; TJitrosoedirdjo, S.S.; TJitrosoemito, S.; Twele, A.; WeBer, R.; WoltMAnN, L.; Zeller, M.; TscharnTKe, T. (2007). Tradeoffs between income, biodiversity, and ecosystem functioning during tropical rainforest conversion and agroforestry intensification. PNAS (Proceedings of the National Academy of Sciences of the United States of America) 104: 4973-4978.

Sthapit, B.; RANA, R.B.; HuE, N.N.; RIJAL, D. (2004). The diversity of taro and sponge gourd in home gardens of Nepal and Vietnam. In: EYZAGUiRRE, P.B.; LinARES, O.F. (eds.). Home Gardens and Agrobiodiversity. Smithsonian Books, Washington, USA, p. 234-255.

StOLER, A. (1978). Garden use and household economy in rural Java. Bull. of Indonesian Economic Studies 14 (2): 85-101.

STORMA (2007). SFB 552 - STORMA: Stability of Rainforest Margins in Indonesia. $<$ http://www.uni-goettingen.de/de/sh/40515.htmlindex.html $>$ [29.03.2007].

Sunito, S. (2004). Robo and the water buffalo: The lost souls of the Pekurehua of the Napu Valley. In: Gerold, G.; Fremerey, M.; Guhardja, E. (eds.). Land Use, Nature Conservation and the Stability of Rain Forest Margins in Southeast Asia. Springer, Berlin, Germany, p. 67-88.

Sunwar, S.; Thornström, C.G.; Subedi, A.; Bystrom, M. (2006). Home gardens in western Nepal: Opportunities and challenges for on-farm management of agrobiodiversity. Biodiversity and Conservation 15: 4211-4238.

SuRYANA, A.; SimAtuPANG, P. (1992). Socio-economic aspects of pekarangan land in Java: A literature review. Indonesian Agricultural Research and Development Journal 14: 7-16.

Swift, M.J.; VANDERMEer, J.; RAMAKRIShnan, P.S.; Anderson, J.M.; OnG, C.K.; HAWKINS, B.A. (1996). Biodiversity and agroecosystems function. In: MoONEY, H.A.; Cushman, J.H.; Sala, O.E.; Medina, E.; Schulze, E.D. (eds.). Functional roles of biodiversity: A global perspective. John Wiley \& Sons, New York, USA, p. 261-298.

Talukder, A.; Kiess, L.; HuQ, N.; De Pee, S.; Darnton-Hill, I.; Bloem, M.W. (2000). Increasing the production and consumption of vitamin A-rich fruits and vegetables: Lessons learned in taking the Bangladesh homestead gardening programme to a national scale. Food and Nutrition Bulletin 21: 165-172.

TChatat, M.; AmBassa-Kiki, R.; MBIla, D.; FABre, A. (2004). Assessing soil chemical fertility in homegardens in forested areas of Southern Cameroon. African Crop Science Journal 12: 163-170.

TChatat, M.; Puig, H.; FABRE, A. (1996). Genèse et organisation des jardins de case des zones forestières humides du Cameroun. Revue d'Ècologie: La Terre et la Vie 51: 197221.

Tesfaye Abebe; Wiersum, K.F.; Bongers, F.; Sterck, F. (2006). Diversity and dynamics in homegardens of southern Ethiopia. In: KUMAR, B.M.; NAIR, P.K.R. (eds.). Tropical Homegardens: A Time-Tested Example of Sustainable Agroforestry. Advances in Agroforestry, Vol. 3, Springer, Dordrecht, The Netherlands, p. 123-142.

Tiessen, H.; MoIR, J.O. (1993). Characterisation of available P by sequential extraction. In: CARTER, M.R. (ed.). Soil Sampling and Methods of Analysis. Lewis, Boca Raton, USA, p. 75-86. 
TIMISCHL, W. (2000). Biostatistik: Eine Einführung für Biologen und Mediziner. Springer, Vienna, Austria, 340 pp.

TORQUeBIAU, E. (1992). Are tropical agroforestry home gardens sustainable? Agriculture, Ecosystems and Environment 41: 189-207.

Torquebiau, E.; PenOt, E. (2006). Ecology versus economics in tropical multistrata agroforests. In: KUMAR, B.M.; NAIR, P.K.R. (eds.). Tropical Homegardens: A Time-Tested Example of Sustainable Agroforestry. Advances in Agroforestry, Vol. 3, Springer, Dordrecht, The Netherlands, p. 269-282.

Trinh, L.N.; Watson, J.W.; Hue, N.N.; De, N.N.; Minh, N.V.; Chu, P.; SthaPit, B.R.; EYZAguiRRE, P.B. (2003). Agrobiodiversity conservation and development in Vietnamese home gardens. Agriculture, Ecosystems and Environment 97: 317-344.

TscharntKe, T.; Klein, A.M.; Kruess, A.; StefFan-Dewenter, I.; ThIES, C. (2005). Landscape perspectives on agricultural intensification and biodiversity - ecosystem service management. Ecology Letters 8: 857-874.

UNESCO (2006). The MAB Programme.

$<$ http://www.unesco.org/mab/BRs/AsiaBRlist.shtml > [30.03.2007].

USDA (U.S. Department of Agriculture) (2006). Sustainable Agriculture. $<$ http://www.csrees.usda.gov/nea/ag_systems/in_focus/sustain_ag_if_legal.html> [19.03.2007].

USDA (U.S. Department of Agriculture, Agricultural Research Service) (2006). USDA National Nutrient Database for Standard Reference, Release 19. Nutrient Data Laboratory Home Page, $<\mathrm{http}: / /$ www.ars.usda.gov/ba/bhnrc/ndl $>$ [29.01.2007].

VALKENBURG, J.L.C.H. VAN; BUNYAPRAPHATSARA, N. (eds.) (2001). Plant Resources of South-East Asia No. 12(2): Medicinal and Poisonous Plants 2. Backhuys Publishers, Leiden, The Netherlands, $782 \mathrm{pp}$.

VERHEIJ, E.W.M.; Coronel, R.E. (eds.) (1992). Plant Resources of South-East Asia No. 2: Edible Fruits and Nuts. PROSEA, Bogor, Indonesia, 446 pp.

Vogl, C.R.; Vogl-LuKasser, B.N.; CABALlero, J. (2002). Homegardens of Maya migrants in the district of Palenque, Chiapas, Mexico. Implications for sustainable rural development. In: STEPP, J.R.; WyNDHAM, F.S.; ZARGER, R.K. (eds.). Ethnobiology and Biocultural Diversity. University of Georgia Press, Athens, USA, p. 631-647.

Vossen, H.A.M. VAN DER; WeSSEL, M. (eds.) (2000). Plant Resources of South-East Asia No. 16: Stimulants. PROSEA, Bogor, Indonesia, 201 pp.

Watson, J.W.; EyzaguirRe, P.B. (eds.) (2002). Home Gardens and In Situ Conservation of Plant Genetic Resources in Farming Systems. Proceedings of the Second International Home Gardens Workshop, 17-19 July 2001, Witzenhausen, Germany. IPGRI, Rome, Italy, 184 pp. <http://www.ipgri.cgiar.org/publications/pdf/753.pdf $>$ [29.03.2007].

WEBER, R. (2005). Kulturlandschaftswandel während des 20. Jh. in Zentralsulawesi - eine historisch-geographische Analyse der Lore-Lindu Bergregenwaldregion. Dissertation, University of Goettingen, Germany, 268 pp.

WeBER, R.; AKIB, M.; FAUST, H.; KREISEL, W. (2003). First results of sub-project A1: Historical development of the cultural landscape at the Lore Lindu region. In: FAUST, H.; Woellert, F.; MARBIANA, S.N. (eds.). Social and Economic Dynamics in the Rain Forest Margins of the Lore Lindu National Park in Central Sulawesi. Summaries of the STORMA Discussion Papers No. 1-11 of Sub-program A, 2001-2003. STORMA Discussion Paper Series No. 12. Universities of Goettingen/Kassel, Germany; Institut Pertanian Bogor/Universitas Tadulako, Indonesia, p. 31-43. $<$ http://www.storma.de/DPS/pdf/SDP12.pdf $>$ [27.07.2004]. 
WEIKARD, H.P. (2002). Diversity functions and the value of biodiversity. Land Economics 78: 20-27.

WeZel, A.; OHL, J. (2005). Does remoteness from urban centres influence plant diversity in homegardens and swidden fields?: A case study from the Matsiguenka in the Amazonian rain forest of Peru. Agroforestry Systems 65: 241-251.

WeZEL, A.; BENDER, S. (2003). Plant species diversity of homegardens of Cuba and its significance for household food supply. Agroforestry Systems 57: 39-49.

Whitten, A.J.; Mustafa, M.; Henderson, G.S. (1987). The Ecology of Sulawesi. Gadjah Mada University Press, Yogyakarta, Indonesia, $777 \mathrm{pp}$.

WiChERN, F.; Richter, C.; JOERGENSEN, R.G. (2003). Soil fertility breakdown in a subtropical South African vertisol site used as a home garden. Biol. Fertil. Soils 37: 288294.

WiCKRAMASINGHE, A. (1995). The evolution of Kandyan home-gardens: An indigenous strategy for conservation of biodiversity in Sri Lanka. In: HALlADAY, P.; GILMOUR, D.A. (eds.). Conserving Biodiversity Outside Protected Areas. IUNC Forest Conservation Programme, 20: 164-182.

WiCKRAMASINGHE, A. (1992). Soils of forest and agricultural systems: A case study in Sri Lanka. Malaysian Journal of Tropical Geography 23: 45-49.

WIERSUM, K.F. (2006). Diversity and change in homegarden cultivation in Indonesia. In: KUMAR, B.M.; NAIR, P.K.R. (eds.). Tropical Homegardens: A Time-Tested Example of Sustainable Agroforestry. Advances in Agroforestry, Vol. 3, Springer, Dordrecht, The Netherlands, p. 13-24.

WIERSUM, K.F. (2004). Forest gardens as an ,intermediate' land-use system in the natureculture continuum: Characteristics and future potential. Agroforestry Systems 61: 123-134.

WiLliAMS, D.E. (2004). The conservation and evolution of landraces of peanuts and peppers. In: EyZaguirRe, P.B.; LinARes, O.F. (eds.). Home Gardens and Agrobiodiversity. Smithsonian Books, Washington, USA, p. 256-265.

WILSON, M. (2003). Exchange, patriarchy and status: Women's homegardens in Bangladesh. In: HowARD, P.L. (ed.). Woman \& Plants. Gender Relations in Biodiversity Management and Conservation. Zed Books, London, England, p. 211-225.

WinkLerPrins, A.M.G.A. (2002). House-lot gardens in Santarém, Pará, Brazil: Linking rural with urban. Urban Ecosystems 6: 43-65.

WooD, A.P. (1993). Natural resource conflicts in south-west Ethiopia: State, communities, and the role of the National Conservation Strategy in the search for sustainable development. Nordic Journal of African Studies 2: 83-99.

WoOD, G.A.R.; LASS, R.A. (1985). Cocoa. Longman Scientific \& Technical, New York, USA, $620 \mathrm{pp}$.

WRIGHT, S.J. (1992). Seasonal drought, soil fertility and the species density of tropical forest plant communities. Trends in Ecology and Evolution 7: 260-263.

Wu, R.; TIESSEN, H. (2002). Effect of land use on soil degradation in alpine grassland soil, China. Soil Sci. Soc. Am. J. 66: 1648-1655.

YAMADA, M.; OSAQUI, H.M.L. (2006). The role of homegardens in agroforestry development: Lessons from Tomé-Açu, a Japanese-Brazilian settlement in the Amazon. In: KUMAR, B.M.; NAIR, P.K.R. (eds.). Tropical Homegardens: A Time-Tested Example of Sustainable Agroforestry. Advances in Agroforestry, Vol. 3, Springer, Dordrecht, The Netherlands, p. 299-316. 
Zaldivar, M.E.; Rocha, O.J.; CASTRO, E.; BARRANTES, R. (2002). Species diversity of edible plants grown in homegardens of Chibchan Amerindians from Costa Rica. Human Ecology 30: 301-316.

ZANDER, R.; ERHARD, W. (2002). Handwörterbuch der Pflanzennamen. Ulmer, Stuttgart, Germany, 990 pp.

ZELLER, M.; SCHWARZE, S.; RHEENEN, T. VAN (2001). Statistical sampling frame and methods used for the selection of villages and households in the scope of the research program on stability of rainforest margins in Indonesia (STORMA). STORMA Discussion Paper Series No. 1. Universities of Goettingen/Kassel, Germany; Institut Pertanian Bogor/Universitas Tadulako, Indonesia. <http://www.storma.de/DPS/pdf/SDP1.pdf $>$ [27.07.2004].

ZEMEDE ASFAW (2004). The enset-based home gardens of Ethiopia. In: EYZAGUIRRE, P.B.; LINARES, O.F. (eds.). Home Gardens and Agrobiodiversity. Smithsonian Books, Washington, USA, p. 123-147. 


\section{$9 \quad$ Appendices}

Appendix 1. Questionnaire for socio-economic data survey of 50 households with homegardens in five villages of the Napu valley, Central Sulawesi, designed by subproject A4 of STORMA.

\section{STORMA (Stability of Rainforest Margins) Household survey questionnaire}

\section{Household identification}

Kecamatan/village/dusun RT: Lore Utara/...............

Date of interview

Name of household head

Name of respondent

\section{Residence of parents/grandparents}

2.1. Residency table head of household

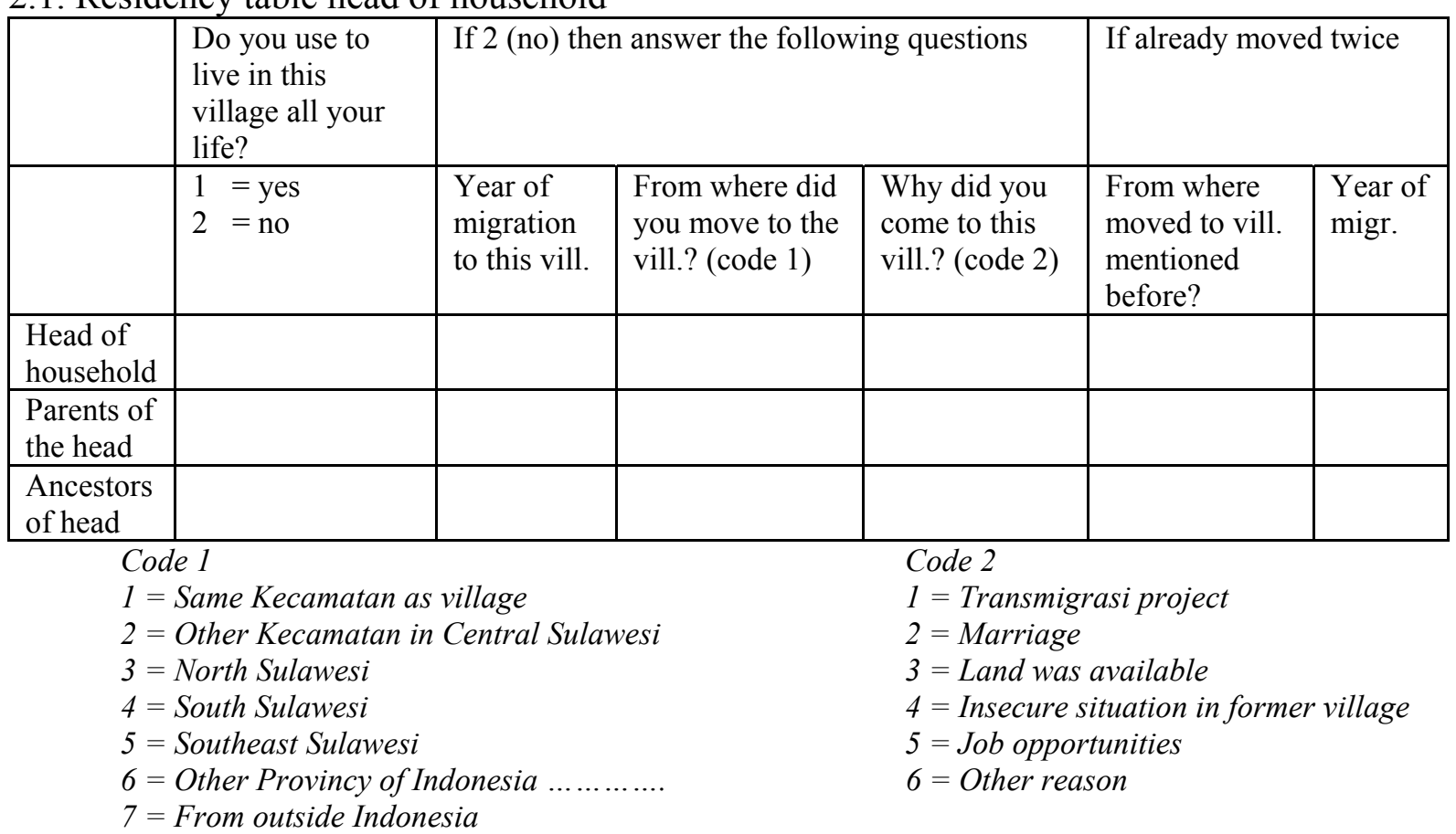

2.2. If the code 1 is 1 or 2 (same Kecamatan as village or other Kecamatan in Central Sulawesi) name of village/kec/kab : 


\subsection{Residency table spouse}

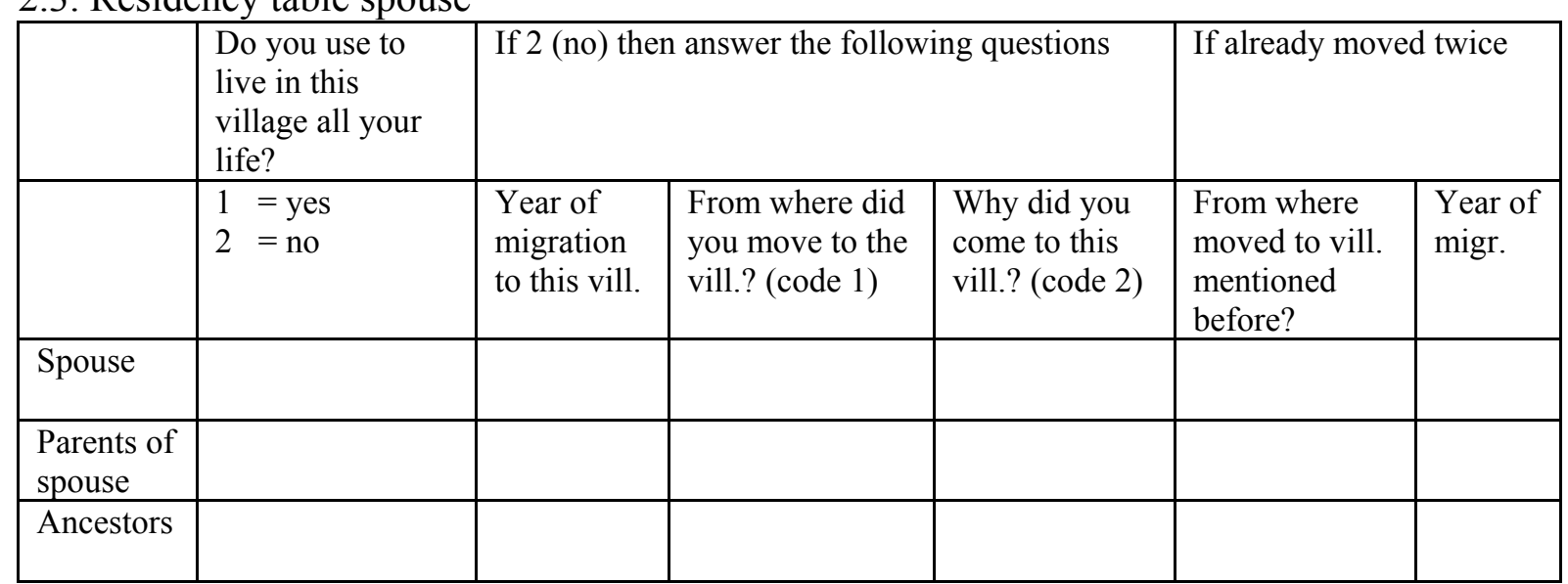

2.4 If code 1 is 1 or 2 (same Kecamatan as village or other Kecamatan in Central Sulawesi) name of village $/ \mathrm{kec} . / \mathrm{kab}$. :

\section{Religion of the head of the household:}

1. Muslim, 2. Catholic, 3. Protestant, 4. Others (Hindu) 


\section{Household composition}

Note: Members of household are all people, who usually eat from the same pot and sleep under the same roof. Include also members, who are absent for less than two months

\begin{tabular}{|c|c|c|c|c|c|c|c|c|c|c|}
\hline $\begin{array}{l}\text { Member } \\
\text { I.D. } \\
1=\text { head } \\
2=\text { spouse }\end{array}$ & Name & $\begin{array}{l}\text { Sex } \\
1=\text { male } \\
2=\text { female }\end{array}$ & $\begin{array}{l}\text { Age in } \\
\text { years }\end{array}$ & $\begin{array}{l}\text { Relation } \\
\text { with head } \\
\text { Code } 1 \\
\end{array}$ & $\begin{array}{l}\begin{array}{l}\text { Marital } \\
\text { status }\end{array} \\
\text { Code } 2 \\
\end{array}$ & $\begin{array}{l}\text { Able to } \\
\text { write? } \\
1=\text { yes } \\
2=\text { no }\end{array}$ & \begin{tabular}{|l}
$\begin{array}{l}\text { Level of } \\
\text { schooling }\end{array}$ \\
Code 3 \\
\end{tabular} & $\begin{array}{l}\text { Professional } \\
\text { training } \\
1=\text { yes } \\
2=\text { no } \\
\end{array}$ & $\begin{array}{l}\text { Main occupation } \\
\text { in the current year } \\
\text { Code } 4\end{array}$ & $\begin{array}{l}\text { Clothes/footwear } \\
\text { expenses in last } \\
12 \text { months (Rp) }\end{array}$ \\
\hline \multicolumn{11}{|l|}{1} \\
\hline \multicolumn{11}{|l|}{2} \\
\hline \multicolumn{11}{|l|}{3} \\
\hline \multicolumn{11}{|l|}{4} \\
\hline \multicolumn{11}{|l|}{5} \\
\hline \multicolumn{11}{|l|}{6} \\
\hline \multicolumn{11}{|l|}{7} \\
\hline \multicolumn{11}{|l|}{8} \\
\hline $\begin{array}{l}\text { Code } 1 \\
1=\text { Son or } d \\
2=\text { Father } 0 \\
3=\text { Grandch } \\
4=\text { Grandpc } \\
5=\text { Father } / n \\
6=\text { Other re } \\
7=\text { Other no }\end{array}$ & $\begin{array}{l}\text { ughter } \\
\text { mother } \\
\text { ild } \\
\text { rents } \\
\text { other/son } \\
\text { ative } \\
\text { n relative }\end{array}$ & in law & & $\begin{array}{l}\text { Oode } 2 \\
=\text { Unmarried } \\
=\text { Married } \\
=\text { Widow/wid } \\
=\text { Divorced }\end{array}$ & wer & $\begin{array}{l}4 \\
5 \\
6\end{array}$ & $\begin{array}{l}\text { de } 3 \\
\text { Never atten } \\
\text { Some SD } \\
\text { Completed } \\
\text { Attended SN } \\
\text { Completed } \\
\text { Attended SN } \\
\text { Completed } \\
\text { Attended ac }\end{array}$ & $\begin{array}{l}\text { ed } \\
D \\
P \\
M P \\
A \\
M A \\
\text { demy or Univ. }\end{array}$ & $\begin{array}{l}\text { Code } 4 \\
1=\text { Self-employed } \\
2=\text { Self-employed } \\
3=\text { Government } \\
4=\text { Casual worke } \\
5=\text { Salaried work } \\
6=\text { Salaried work } \\
7=\text { Domestic wor } \\
8=\text { Student } \\
9=\text { Unemployed }, \\
10=\text { Unwilling } \text { to } \\
11=\text { Unable to } w\end{array}$ & $\begin{array}{l}\text { in agriculture } \\
\text { in non farm enterprise } \\
\text { iployee } \\
r \text { in agriculture } \\
r \text { in non-agriculture } \\
\text { er } \\
\text { oking for a job } \\
\text { vork or retired } \\
k \text { (handicapped) }\end{array}$ \\
\hline
\end{tabular}




\section{Land and livestock possession}

5.1 Current possession of livestock

Please do not include animals that are younger than two months (poultry) or 6 months (all other animals)

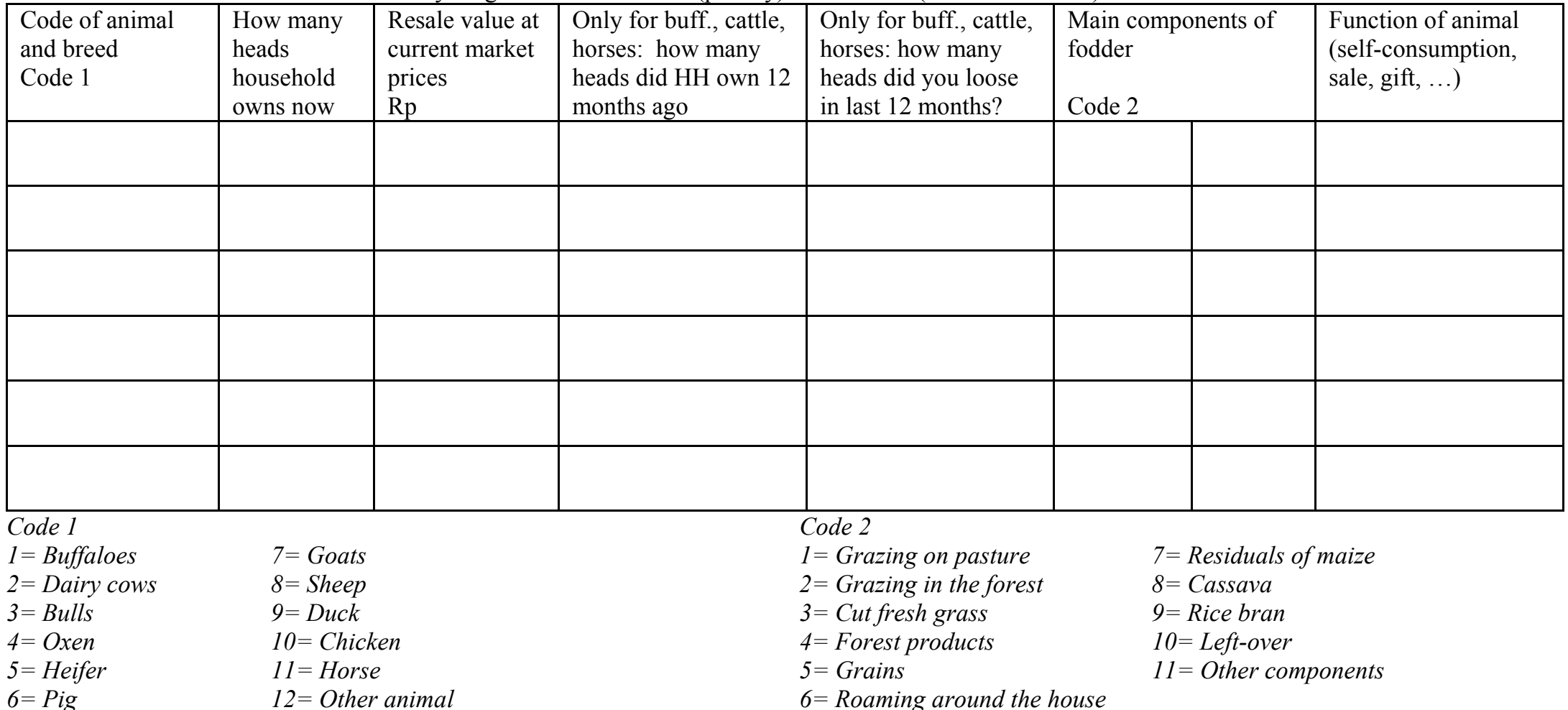

$=$ Roaming around the house 
5.2 Do you own any land at present? $(1=$ yes, $2=$ no $)$ If 2 (no) skip to question 5.4

5.3 Current possession of land (land owned at present)

Please fill out for each parcel of land owned. Begin with homestead/home garden (lahan pekarangan)

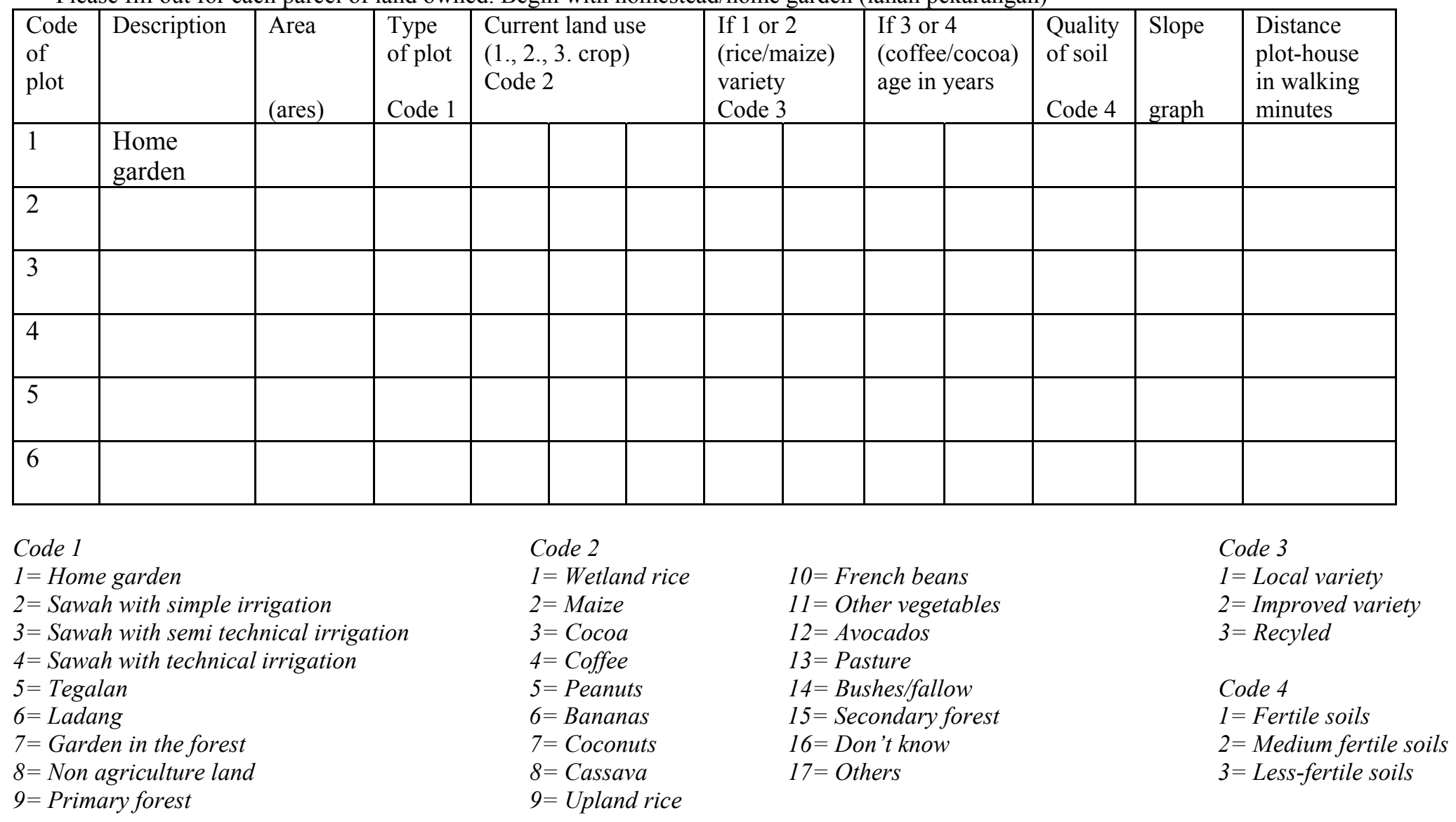


5.4 Does your household rent in or borrow any land at present? (1=yes, $2=n$ ) If 2 (no) skip to question 6

\subsection{Land rented in/borrowed}

Please fill out for each parcel for each rented in or borrow

\begin{tabular}{|c|c|c|c|c|c|c|c|c|c|c|}
\hline $\begin{array}{l}\text { Code } \\
\text { of } \\
\text { plot }\end{array}$ & Description & $\begin{array}{l}\text { Area } \\
\text { (ares) }\end{array}$ & $\begin{array}{l}\text { Type } \\
\text { of plot } \\
\text { Code 1 }\end{array}$ & $\begin{array}{l}\text { Current land use } \\
(1 ., 2 ., 3 \text {. crop) } \\
\text { Code } 2\end{array}$ & $\begin{array}{l}\text { If } 1 \text { or } 2 \\
\text { (rice/maize) } \\
\text { variety } \\
\text { Code } 3 \\
\end{array}$ & $\begin{array}{l}\text { If } 3 \text { or } 4 \\
\text { (coffee/cocoa) } \\
\text { age in years }\end{array}$ & $\begin{array}{l}\text { Quality } \\
\text { of soil } \\
\text { Code } 4\end{array}$ & $\begin{array}{l}\text { Slope } \\
\text { graph }\end{array}$ & $\begin{array}{l}\text { Distance } \\
\text { plot-house } \\
\text { in walking } \\
\text { minutes } \\
\end{array}$ & $\begin{array}{l}\text { How much } \\
\text { do you pay } \\
\text { (Rp/year) }\end{array}$ \\
\hline 1 & $\begin{array}{l}\text { Home } \\
\text { garden }\end{array}$ & & & & & & & & & \\
\hline 2 & & & & & & & & & & \\
\hline 3 & & & & & & & & & & \\
\hline 4 & & & & & & & & & & \\
\hline 5 & & & & & & & & & & \\
\hline 6 & & & & & & & & & & \\
\hline
\end{tabular}

Code 1

$1=$ Home garden

$2=$ Sawah with simple irrigation

$3=$ Sawah with semi technical irrigation

$4=$ Sawah with technical irrigation

$5=$ Tegalan

$6=$ Ladang

$7=$ Garden in the forest

$8=$ Non agriculture land

$9=$ Primary forest
Code 2

$1=$ Wetland rice

2= Maize

$3=$ Cocoa

$4=$ Coffee

$5=$ Peanuts

$6=$ Bananas

$7=$ Coconuts

$8=$ Cassava

$9=$ Upland rice
Code 3

$1=$ Local variety

$2=$ Improved variety

$3=$ Recyled

$12=$ Avocados

$13=$ Pasture

$14=$ Bushes/fallow

$15=$ Secondary forest

$16=$ Don't know

$17=$ Others

Code 4

$1=$ Fertile soils

$2=$ Medium fertile soils

$3=$ Less-fertile soils 


\section{Plot-specific output and input data}

Note for enumerator: the next questions concern the plots from table 5.1, but refers only to the last crop harvested (annual crops) and to the last twelve months for all perennial crops respectively. The input use refers to the time before the last harvest (annuals) and to the last twelve months for all perennials respectively

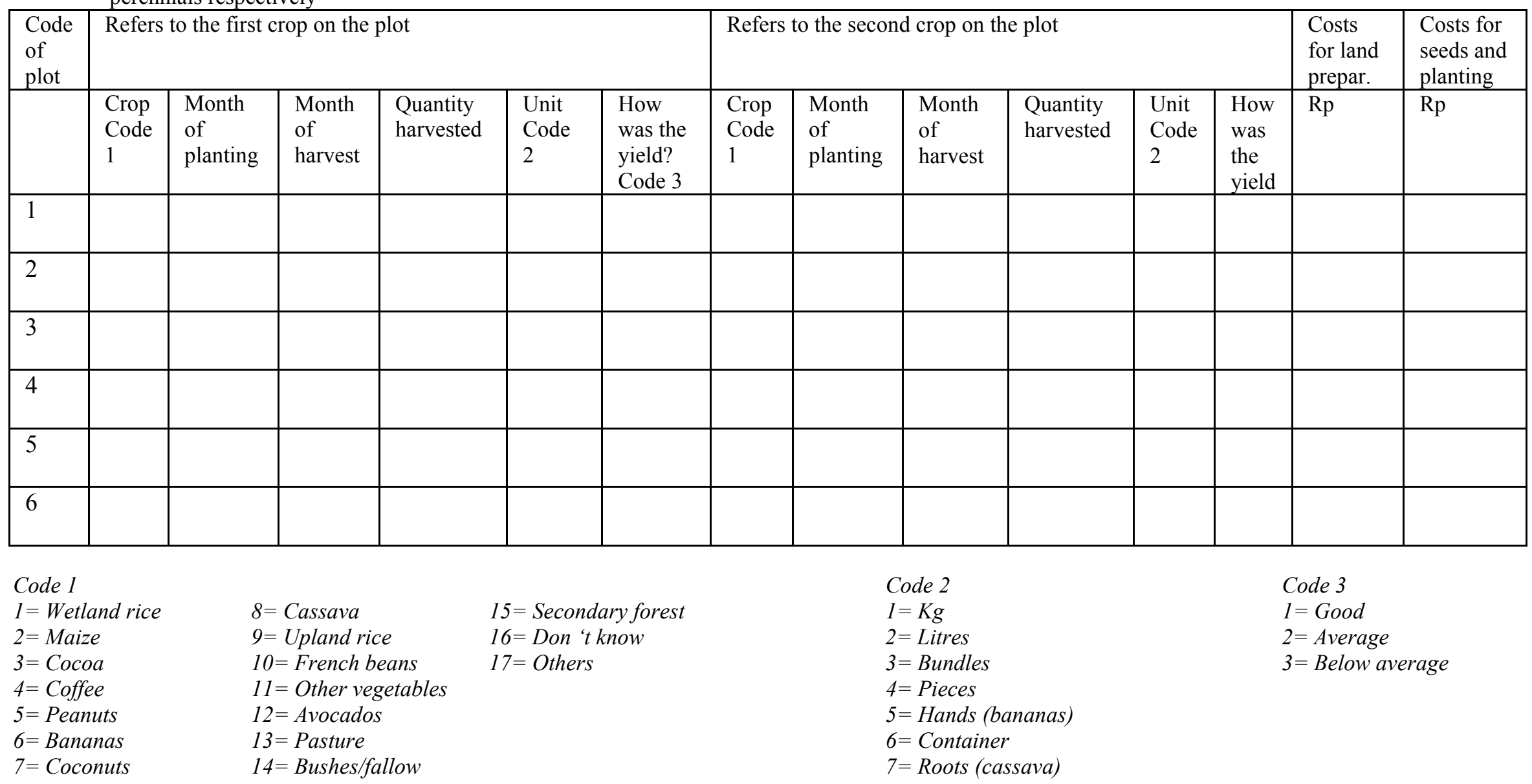


6. Plot-specific output and input data (continued)

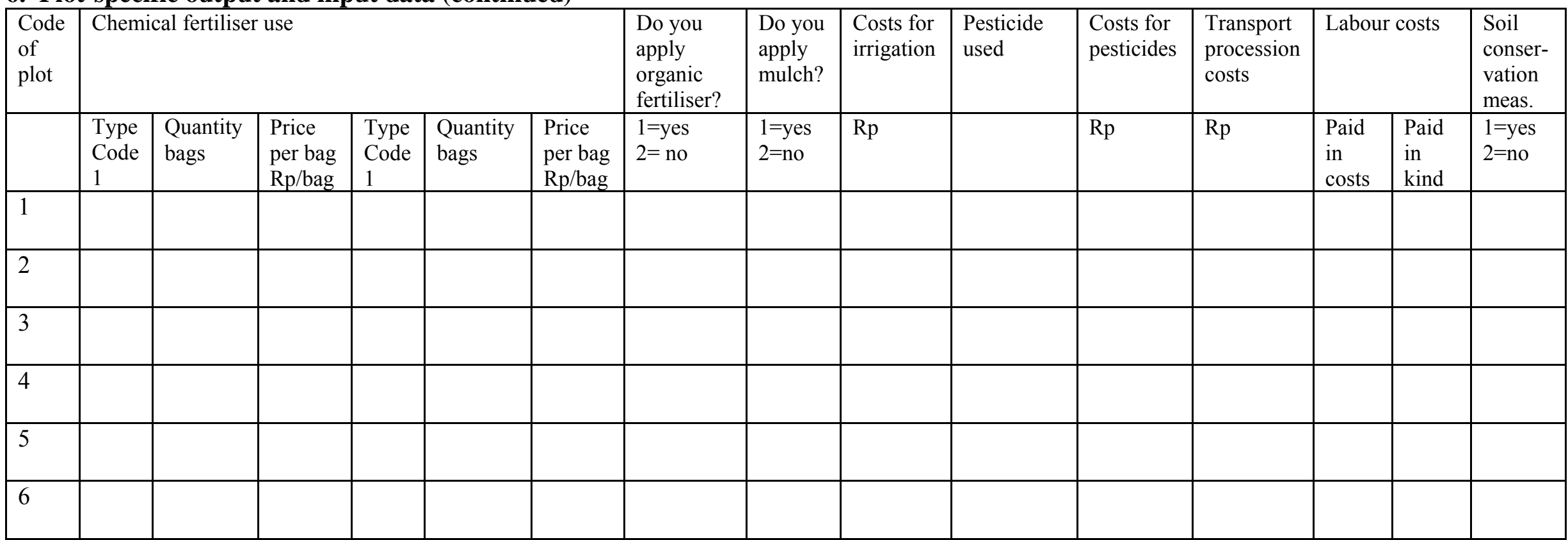

Code 1

$1=$ Urea

$2=$ Triple super phosphate

$4=K C L$

$5=N P K$

$3=Z A$ 


\section{Food-related indicators}

Note : Both the head of the household and his or her spouse should be present when answering for this section.

7.1. How many meals were served to the household members during the last 2 days? ....

7.2. During the last seven days, for how many days were the following foods served in a main meal eaten by the household?

\begin{tabular}{|l|l|}
\hline Luxury food & Number of days served \\
\hline Poultry & \\
\hline Beef & \\
\hline Pork & \\
\hline Fish & \\
\hline
\end{tabular}

7.3. During the last 12 months, for how many days did your household not have enough to eat everyday?

7.4. How often do you purchase the following?

\begin{tabular}{|l|l|}
\hline Staple & Frequency served (Code 1) \\
\hline Rice & \\
\hline Cooking oil & \\
\hline Sugar & \\
\hline
\end{tabular}

$\begin{array}{lll}\begin{array}{ll}\text { Code 1: } \\ \text { l=Daily }\end{array} & 2=\text { Twice a week } & 3=\text { Weekly } \\ 4=\text { Fortnightly } & 5=\text { Monthly } & 6=\text { Less frequent than a month }\end{array}$

7.5. For how many weeks do you have a stock of rice in your house?

\section{Dwelling-related indicators}

Note: Information should be collected about the dwelling in which the family currently resides.

8.1. What is the ownership status of dwelling? ..........
$1=$ Built on squatter land
$2=$ Owned
$3=$ Given by relative or other to use
$4=$ Provided by government
$5=$ Rented

8.2. How many rooms does the dwelling have? ..........

Note: Include detached rooms in same compound if same household.

8.3. What type of roofing material is used in main house?
$1=$ Straw
$2=$ Clay bricks
$5=$ Corrugated iron
$3=$ Pressed bricks
$4=$ Asbestos
$6=$ Concrete

8.4. What type of exterior walls does the dwelling have?
$1=$ Bamboo
$2=$ Wooden plates
3=Brick or stone with mud
$4=$ Brick or stone with cement plaster

8.5. What type of flooring does the dwelling have?
$1=$ Earth
$2=$ Wood
$3=$ Stones
$4=$ Stone plates
$5=$ Cement
$6=$ Cement with additional covering

Note: You must not ask the next question to the respondent. Please give your own estimation.

8.6. What is the observed structural condition of main dwelling?

$1=$ Seriously dilapidated $\quad 2=$ Need for major repairs $\quad 3=$ Sound structure 
8.7. What is the electricity supply?
$1=$ No connection

8.8. What type of cooking fuel source primarily is used?
$1=$ Dung
$2=$ Collected wood
$3=$ Purchased wood or sawdust
5=Kerosene
$6=$ Gas
$7=$ Electricity

8.9. What is the source of drinking water?
$1=$ Rainwater
$2=$ Dam
$3=$ Pond or lake
$4=$ River or stream
$5=$ Spring $\quad 6=$ Public well-open $7=$ Public well-sealed by pump
$8=$ Well in residence yard
$9=$ Piped public water
$10=$ Bore hole in residence

8.10. What type of toilet facility is available?
$1=$ Bush, field, or no facility
$2=$ Shared pit toilette
$5=$ Own improved latrine
$3=$ Own pit toilette
$4=$ Shared improved latrine
$6=$ Flush toilet

\section{Other asset-based indicators}

Number and value of selected assets owned by household.

\begin{tabular}{|l|l|l|}
\hline Asset type and code & Number owned & Resale value at current market price \\
\hline Transportation & & \\
\hline 1. Cars & & \\
\hline 2. Motorcycles & & \\
\hline 3. Bicycles & & \\
\hline 4. Tractor & & \\
\hline 5. Carts & & \\
\hline Appliances and electronics & & \\
\hline 6. Radios, Tape & & \\
\hline 7. Television & & \\
\hline 8. Kerosene cooker & & \\
\hline 9. Electric or gas cookers & & \\
\hline 10. Knapsack sprayer & & \\
\hline 11. Water pump & & \\
\hline 12. Chainsaw & & \\
\hline 13. Sewing machine & & \\
\hline 14. Fans & & \\
\hline
\end{tabular}


Appendix 2. Questionnaire for homegarden-specific data, used for a survey of 50 households with homegardens in five villages of the Napu valley, Central Sulawesi, in 2001 and 2004.

\section{Homegarden Questionnaire}

1. Name of gardener:

Date of interview:

2. When did you establish the garden?

3. How was the land used before?

4. If it was used as a homegarden before, who was the owner and what kind of plants were already grown?

\section{Biodiversity}

5. What kind of weeds do you have in your garden? Please give the local names!

6. Do you use some of the weeds? If yes, which species and how?

7. In the past, do you remember growing some plants that are presently not grown? If yes, which species and why did you stop growing them?

8. In the future, would you like to grow some more plant species? If yes, which species or varieties, what is the purpose and why did you not grow them up to now?

9. If seeds of modern varieties would be available, would you like to replace your local varieties with the modern ones? Why and which species first?

10. Do you keep any livestock in your garden?

Which species and breeds?

\section{Soil}

11. What do you think about the quality of the soil in your garden?

12. Has the soil quality changed in the past? How?

13. Are there local names given to the different soil types? Please list and describe!

14. Do you have an idea how to improve the soil?

15. How do you work the land?

16. How many times a week/a month do you hoe your garden?

17. How deep (in $\mathrm{cm}$ ) do you hoe usually?

18. Do you work the whole garden in the same manner or differently according to different plants?

$\begin{array}{ll}\text { Ornamentals } & : \\ \text { Vegetables } & : \\ \text { Coffee and cacao trees } & : \\ \text { Fruit trees } & :\end{array}$

19. Do you use fertiliser in your garden?

\begin{tabular}{|l|l|l|l|l|l|l|}
\hline Fertiliser & Frequency & $\begin{array}{l}\text { Last } \\
\text { application }\end{array}$ & Amount & $\begin{array}{l}\text { For which } \\
\text { plants }\end{array}$ & $\begin{array}{l}\text { Application } \\
\text { procedure }\end{array}$ & Fertiliser source \\
\hline NPK & & & & & & \\
\hline Manure & & & & & & \\
\hline Ashes & & & & & & \\
\hline Compost & & & & & & \\
\hline Mulch & & & & & & \\
\hline Other & & & & & & \\
\hline
\end{tabular}

If not, why not? Would you like to use fertiliser? What kind of fertiliser? 


\section{Management}

20. What kind of work do you do in your garden throughout the year?

\begin{tabular}{|l|l|l|l|l|l|}
\hline Work & Frequency & $\begin{array}{l}\text { Last } \\
\text { performing }\end{array}$ & $\begin{array}{l}\text { Person } \\
\text { working }\end{array}$ & $\begin{array}{l}\text { Plant species/ } \\
\text { production zone }\end{array}$ & Time needed \\
\hline Hoeing & & & & & \\
\hline Sowing/planting & & & & & \\
\hline Fertilising & & & & & \\
\hline Spraying & & & & & \\
\hline Weeding & & & & & \\
\hline Cutting trees & & & & & \\
\hline Harvesting & & & & & \\
\hline Other & & & & & \\
\hline
\end{tabular}

21. In general, who carries out most of the work in your homegarden (e.g. farmer, his wife, children, relatives, neighbours, ...)?

22. Who is responsible for the following kinds of plants?
Ornamentals
Vegetables
Spices
Medicals
Coffee/cacao
Trees

23. If you compare the work in your homegarden, your paddy rice fields and your coffee/cacao plantation:

- where do you work the most time

- where is the work hardest

1.

2.

3.

1.

2.

3.

24. If you compare the costs for fertiliser, pesticides or farm worker in your homegarden,

- your paddy rice fields and your coffee/cacao plantation:

- where do you have to pay most 1.

3.

\section{Function}

25. What is the main function of your garden? What is the second function?

26. For the life of you and your family, is your homegarden very important or not important at all?

27. If you compare the yield of food stuffs for home consumption coming from your homegarden, your paddy rice fields and your coffee/cacao plantation:

from where comes the highest portion 1.

2.

3.

28. If you compare the yield of cash crops for sale coming from your homegarden, your paddy rice fields and your coffee/cacao plantation:

from where comes the highest portion 1.

2.

3.

If possible, can you please give the portion in percent of cash income coming from your: garden $\%$, paddy rice field $\%$, plantation $\%$, other $\%$

\section{Problems}

29. Are there any problems with weeds or pests and diseases?

\begin{tabular}{|c|c|c|c|c|c|c|}
\hline Problem & $\begin{array}{l}\text { Plants/production } \\
\text { zones attacked }\end{array}$ & Description & $\begin{array}{l}\text { Controlling } \\
\text { procedure }\end{array}$ & $\begin{array}{l}\text { Name of } \\
\text { pesticide }\end{array}$ & $\begin{array}{l}\text { Last } \\
\text { application }\end{array}$ & Success \\
\hline \multicolumn{7}{|l|}{ Weeds } \\
\hline \multicolumn{7}{|l|}{ Pests: } \\
\hline & & & & & & \\
\hline & & & & & & \\
\hline \multicolumn{7}{|l|}{ Diseases: } \\
\hline & & & & & & \\
\hline & & & & & & \\
\hline
\end{tabular}


30. Please rate the importance of following problems in managing your homegarden (very serious, serious, medium, no problem):

Weeds

Pests and diseases

Poor soil

Time shortage

Poor varieties/lack of seeds

Free roaming livestock

Other

31. If you sell products of your homegarden, do you have any problems with sale? If yes, please name and describe these problems!

32. Was there ever any extension service for home gardens? If yes:

What organisation gave the extension?

How often/when the last time?

Was it helpful for you?

33. Would you like to improve your homegarden? How?

34. Did you and your family ever get some agricultural support from NGO's or the government? If yes, please describe what kind, how often, from whom?

35. If there was some agricultural support from NGO's or the government, what kind of assistance would you need? Please rate the importance of the item (very important, important, medium, useless)!

Fertiliser

Seeds/seedlings

Livestock

Extension service/training

Pesticides and sprayer

Other

Note: Questions no. 4, 9, 22-24, 26-28, 34, and 35 were not asked in 2001, no.18-20, 29, 30, and 32 not in such detail. 
Appendix 3. Basic socio-economic data of 50 households $(H H)$ with homegardens surveyed in five villages of the Napu valley, Central Sulawesi, in 2004. (HH-H = Household head).

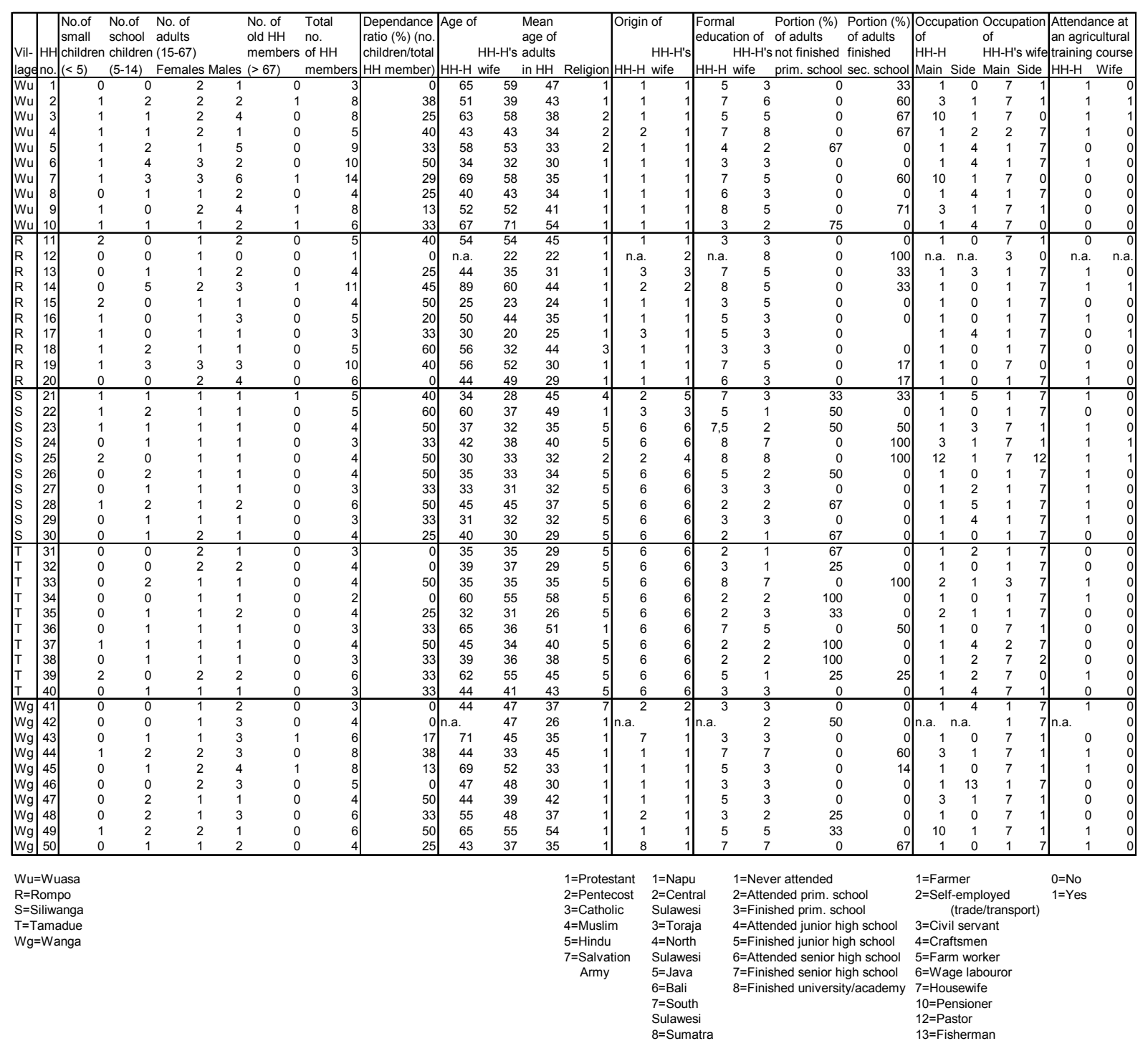


Appendix 4. Farm-specific data of 50 households $(H H)$ with homegardens $(H G)$ surveyed in five villages of the Napu valley, Central Sulawesi, in 2004. (IR = Indonesian Rupiah; exchange rate in 2004: 10,000 $I R \approx 1$ Euro).

\begin{tabular}{|c|c|c|c|c|c|c|c|c|c|c|c|c|c|c|c|c|c|c|c|}
\hline Village & $\mid \begin{array}{ll}\mathrm{HH} \\
\text { no. }\end{array}$ & $\begin{array}{l}\text { Buffaloes Cattle } \\
\text { No. No. }\end{array}$ & $\begin{array}{l}\text { le Horse } \\
\text { No. }\end{array}$ & $\begin{array}{l}\text { es Pig } \\
\text { No. }\end{array}$ & $\begin{array}{l}\text { Dog } \\
\text { No. }\end{array}$ & $\begin{array}{l}\text { gs Duc } \\
\text { No. }\end{array}$ & & $\begin{array}{l}\text { hicken Rabbits } \\
\text { lo. No. }\end{array}$ & \begin{tabular}{|l|} 
Tropical \\
Livestock I \\
Units
\end{tabular} & $\begin{array}{l}\text { Value of } \\
\text { livestock } \\
(1,000 \mathrm{IR})\end{array}$ & $\begin{array}{l}\text { Land hol } \\
\text { Sizes } \\
\mathrm{HG} \\
{\left[\mathrm{m}^{2}\right]}\end{array}$ & $\begin{array}{l}\text { oldings } \\
\text { of } \\
\text { Paddy rice } \\
{\left[\mathrm{m}^{2}\right]}\end{array}$ & $\begin{array}{l}\text { Annual } \\
\text { crops }\left[\mathrm{m}^{2}\right]\end{array}$ & $\begin{array}{l}\text { Plantation } \\
{\left[\mathrm{m}^{2}\right]}\end{array}$ & $\begin{array}{l}\text { n Fallow } \\
{\left[\mathrm{m}^{2}\right]}\end{array}$ & \begin{tabular}{|l} 
Total \\
farm size \\
[ha]
\end{tabular} & $\begin{array}{l}\text { Cropped } \\
\text { area } \\
\text { [h] }\end{array}$ & $\begin{array}{l}\text { Cropped areal } \\
\mathrm{HH} \text { member } \\
{\left[\mathrm{m}^{2}\right]}\end{array}$ & $\begin{array}{l}\text { / Proportion } \\
\text { total } \mathrm{HG} / \\
\text { total farm (\%) }\end{array}$ \\
\hline Wuasa & 1 & 0 & 0 & 0 & 2 & 0 & 13 & 2 & 0.94 & 835 & 1,800 & 5,000 & 0 & 0 & $0 \quad 4,000$ & 1.1 & 0.6 & 1,880 & $\begin{array}{ll}5 & 16.7\end{array}$ \\
\hline Wuasa & 2 & 0 & 0 & 0 & 2 & 3 & 6 & 21 & 1.44 & 905 & 1,200 & 5,800 & 0 & 12,000 & 2,000 & 3.3 & 1.9 & 2,359 & 3.6 \\
\hline Wuasa & 3 & 0 & 0 & 0 & 3 & 4 & 7 & 0 & 1.44 & 2,010 & 450 & 10,000 & 5,000 & 15,000 & $\begin{array}{ll}0 & 30,000\end{array}$ & 7.5 & 3.0 & 3,789 & 0.6 \\
\hline Wuasa & 4 & 0 & 0 & 0 & 1 & 2 & 20 & 8 & 1.06 & 1,620 & 1,000 & 7,000 & 5,000 & 15,000 & $\begin{array}{ll}0 & 20,000\end{array}$ & 6.3 & 2.7 & 5,494 & 1.6 \\
\hline Wuasa & 5 & 0 & 0 & 0 & 6 & 0 & 0 & 23 & 2.26 & 1,750 & 700 & 0 & 10,000 & 15,000 & $\begin{array}{r}0 \\
0\end{array}$ & 4.6 & 2.6 & 2,849 & 1.5 \\
\hline Wuasa & 6 & 0 & 0 & 0 & 2 & 1 & 3 & 0 & 0.76 & 680 & 400 & 0 & 5,000 & 15,000 & & 3.5 & 2.0 & 2,028 & 1.1 \\
\hline Wuasa & 7 & 0 & 5 & 0 & 5 & 1 & 1 & 12 & 5.42 & 15,515 & 1,000 & 10,000 & 12,000 & 10,000 & $\begin{array}{l}0 \\
05,000\end{array}$ & 9.8 & 3.3 & 2,347 & 1.0 \\
\hline Wuasa & 8 & 0 & 0 & 0 & 1 & 0 & 0 & 5 & 0.40 & 225 & 600 & 3,000 & 0 & 3,000 & $\begin{array}{ll}0 & 2,000\end{array}$ & 1.2 & 0.7 & 1,633 & 5.2 \\
\hline Wuasa & 9 & 5 & 0 & 3 & 2 & 3 & 9 & 12 & 8.72 & 26,570 & 1,000 & 12,000 & 5,000 & 15,000 & 7,000 & 5.5 & 3.3 & 4,108 & 1.8 \\
\hline Wuasa & 10 & 0 & 0 & 0 & 1 & 0 & 5 & 0 & 0.40 & 290 & 1,100 & 5,000 & 2,000 & 2,000 & 0 & 1.2 & 1.0 & 1,650 & 9.1 \\
\hline Rompo & 11 & 0 & 0 & 0 & 1 & 6 & 0 & 19 & 1.28 & 1,170 & 1,500 & 3,000 & 0 & 400 & \begin{tabular}{ll|}
0 & 30,000 \\
\end{tabular} & 3.5 & 0.5 & 968 & 4.2 \\
\hline Rompo & 12 & 0 & 0 & 0 & 0 & 0 & 0 & 3 & 0.06 & 90 & $700^{*}$ & n.a. & n.a. & n.a. & n. n. & n.a. & n.a. & n.a. & n.a. \\
\hline Rompo & 13 & 0 & 0 & 0 & 0 & 8 & 0 & 27 & 1.34 & 710 & $500^{*}$ & 0 & 5,000 & 13,000 & $0 \quad 40,000$ & 7.1 & 1.8 & 4,613 & 0.9 \\
\hline Rompo & 14 & 0 & 0 & 0 & 3 & 4 & 0 & 21 & 1.72 & 1,500 & 1,500 & 7,500 & 3,000 & 9,000 & $\begin{array}{ll}0 & 25,000\end{array}$ & 5.5 & 2.1 & 1,893 & 2.7 \\
\hline Rompo & 15 & 0 & 0 & 0 & 3 & 0 & 7 & 10 & 1.24 & 1,125 & 700 & 3,000 & 0 & 13,000 & & 3.0 & 1.7 & 4,128 & 2.4 \\
\hline Rompo & 16 & 1 & 0 & 0 & 4 & 0 & 4 & 21 & 2.70 & 2,455 & 500 & 0 & 3,000 & 3,000 & $\begin{array}{ll}0 & 65,000\end{array}$ & 7.5 & 0.6 & 1,274 & 0.7 \\
\hline Rompo & 17 & 0 & 0 & 0 & 0 & 0 & 0 & 11 & 0.22 & 45 & 350 & 0 & 10,000 & 10,000 & $0 \quad 40,000$ & 7.0 & 2.0 & 6,760 & 0.5 \\
\hline Rompo & 18 & 2 & 0 & 0 & 2 & 0 & 0 & 0 & 2.60 & 11,200 & 1,000 & 5,000 & 0 & 8,500 & $\begin{array}{ll}0 & 10,000\end{array}$ & 3.3 & 1.4 & 2,828 & 3.0 \\
\hline Rompo & 19 & 0 & 0 & 0 & 2 & 1 & 0 & 22 & 1.14 & 2,225 & 2,000 & 10,000 & 15,000 & 16,000 & $\begin{array}{ll}0 & 72,000\end{array}$ & 13.1 & 4.2 & 4,193 & 1.5 \\
\hline Rompo & 20 & 0 & 0 & 0 & 3 & 5 & 0 & 9 & 1.58 & 1,520 & 800 & 10,000 & 5,000 & 10,000 & $\begin{array}{lll}0 & 45,000 \\
\end{array}$ & 8.1 & 2.6 & 4,278 & 1.0 \\
\hline Siliwanga & 21 & 0 & 0 & 0 & 0 & 0 & 0 & 19 & 0.38 & 70 & 2,500 & 13,000 & 7,000 & 5,000 & \begin{tabular}{|c|}
0 \\
\end{tabular} & 5.0 & 2.6 & 5,142 & 5.0 \\
\hline Siliwanga & 22 & 0 & 1 & 0 & 1 & 4 & 0 & 9 & 1.58 & 2,725 & 2,500 & 3,000 & 0 & 0 & $\begin{array}{ll}0 & 15,000\end{array}$ & 2.1 & 0.3 & 694 & 12.2 \\
\hline Siliwanga & 23 & 0 & 3 & 0 & 0 & 0 & 0 & 15 & 2.40 & 6,800 & 2,500 & 0 & 2,500 & 17,500 & $\begin{array}{ll}0 & 65,000\end{array}$ & 10.5 & 2.2 & 5,553 & 2.4 \\
\hline Siliwanga & 24 & 0 & 4 & 0 & 1 & 1 & 0 & 19 & 3.58 & 9,475 & 2,500 & 5,000 & 0 & 0 & $\begin{array}{ll}0 & 11,500\end{array}$ & 1.9 & 0.6 & 1,977 & 13.2 \\
\hline Siliwanga & 25 & 0 & 0 & 0 & 0 & 2 & 0 & 12 & 0.44 & 150 & 2,500 & 0 & 2,500 & 2,500 & $0 \quad 20,000$ & 3.0 & 0.6 & 1,398 & 8.3 \\
\hline Siliwanga & 26 & 0 & 7 & 0 & 0 & 1 & 0 & 17 & 5.34 & 20,340 & 2,500 & 0 & 10,000 & 25,000 & $\begin{array}{l}0 \\
0\end{array}$ & 8.0 & 3.6 & 8,908 & 3.1 \\
\hline Siliwanga & 27 & 0 & 6 & 0 & 1 & 1 & 0 & 11 & 4.82 & 10,210 & 2,500 & 0 & 0 & 17,500 & 0 & 3.8 & 2.0 & 6,627 & 6.7 \\
\hline Siliwanga & 28 & 0 & 0 & 0 & 0 & 0 & 2 & 1 & 0.06 & 75 & 2,500 & 0 & 5,000 & 15,000 & 20,000 & 5.8 & 2.1 & 3,500 & 4.3 \\
\hline Siliwanga & 29 & 0 & 5 & 0 & 1 & 2 & 0 & 6 & 4.12 & 11,660 & 2,500 & 9,000 & 5,000 & 2,500 & 15,000 & 3.7 & 1.9 & 6,307 & 6.8 \\
\hline Siliwanga & 30 & 0 & 3 & 0 & 0 & 1 & 0 & 2 & 2.24 & 7,600 & 2,500 & 5,000 & 0 & 5,000 & 7,500 & 2.5 & 1.1 & 2,718 & 10.0 \\
\hline Tamadue & \begin{tabular}{l|}
31 \\
\end{tabular} & 0 & 2 & 0 & 9 & 10 & 13 & 50 & 6.36 & 12,745 & 2,000 & 40,000 & 0 & 5,000 & 13,000 & 6.5 & 4.7 & 15,633 & 3.1 \\
\hline Tamadue & 32 & 0 & 0 & 0 & 1 & 0 & 0 & 5 & 0.40 & 550 & 2,500 & 9,500 & 0 & 10,000 & 0 & 3.2 & 2.2 & 5,445 & 7.8 \\
\hline Tamadue & 33 & 0 & 0 & 11 & 13 & 0 & 0 & 0 & 4.70 & 5,450 & 2,500 & 0 & 10,000 & 50,000 & 230,000 & 34.3 & 6.2 & 15,555 & 0.7 \\
\hline Tamadue & 34 & 0 & 0 & 0 & 2 & 3 & 0 & 0 & 0.90 & 570 & 2,500 & 7,500 & 0 & 7,500 & & 2.5 & 1.7 & 8,650 & 10.0 \\
\hline Tamadue & 35 & 0 & 0 & 0 & 2 & 0 & 3 & 3 & 0.72 & 710 & 2,500 & 10,000 & 0 & 17,500 & $\begin{array}{l}0 \\
0\end{array}$ & 5.8 & 3.0 & 7,453 & 4.3 \\
\hline Tamadue & 36 & 0 & 0 & 0 & 4 & 0 & 7 & 0 & 1.34 & 2,175 & 2,500 & 6,000 & 0 & 25,000 & 40,000 & 9.9 & 3.2 & 10,655 & 2.5 \\
\hline Tamadue & 37 & 0 & 0 & 0 & 2 & 1 & 0 & 5 & 0.80 & 100 & 2,500 & 0 & 0 & 10,000 & 7,500 & 3.0 & 1.1 & 2,680 & 8.3 \\
\hline Tamadue & 38 & 0 & 0 & 0 & 2 & 0 & 4 & 13 & 0.94 & 760 & 2,500 & 7,500 & 0 & 20,000 & & 5.0 & 3.0 & 9,907 & 5.0 \\
\hline Tamadue & 39 & 0 & 0 & 0 & 0 & 1 & 0 & 4 & 0.18 & 95 & 2,500 & 0 & 0 & 50,000 & $\begin{array}{l}0 \\
0\end{array}$ & 11.3 & 5.2 & 8,725 & 2.2 \\
\hline Tamadue & 40 & 0 & 0 & 0 & 3 & 0 & 3 & 5 & 1.06 & 1,195 & 2,500 & 0 & 10,000 & 27,500 & & 6.8 & 4.0 & 13,317 & 3.7 \\
\hline Wanga & 41 & 0 & 2 & 0 & 2 & 2 & 0 & 6 & 2.32 & 7,440 & 1,400 & 0 & 4,000 & 6,000 & 10,000 & 2.7 & 1.1 & 3,760 & 5.1 \\
\hline Wanga & 42 & 0 & 0 & 0 & 1 & 1 & 0 & 1 & 0.42 & 340 & 600 & 2,000 & 9,500 & 1,500 & $\begin{array}{l}0 \\
0\end{array}$ & 2.7 & 1.4 & 3,385 & 2.2 \\
\hline Wanga & 43 & 0 & 4 & 0 & 2 & 3 & 0 & 0 & 3.70 & 10,630 & 350 & 5,000 & 60,000 & 40,000 & 90,000 & 23.5 & 10.5 & 17,542 & 0.1 \\
\hline Wanga & 44 & 0 & 0 & 0 & 2 & 5 & 2 & 10 & 1.34 & 2,060 & 900 & 7,500 & 7,000 & 25,000 & 33,000 & 9.8 & 4.0 & 5,019 & 0.9 \\
\hline Wanga & 45 & 0 & 3 & 0 & 2 & 3 & 0 & 11 & 3.22 & 7,645 & 450 & 3,000 & 9,000 & 6,000 & 20,000 & 4.4 & 1.8 & 2,289 & 1.0 \\
\hline Wanga & 46 & 0 & 0 & 0 & 2 & 0 & 0 & 0 & 0.60 & 450 & 550 & 5,000 & 1,500 & 1,500 & 27,000 & 3.7 & 0.8 & 1,688 & 1.5 \\
\hline anga & 47 & 0 & 0 & 0 & 2 & 3 & 0 & 1 & 0.92 & 870 & 500 & 3,000 & 0 & 0 & 35,000 & 3.9 & 0.3 & 858 & 1.3 \\
\hline Wanga & 48 & 0 & 0 & 0 & 1 & 4 & 0 & 6 & 0.82 & 960 & 750 & 3,900 & 3,500 & 5,000 & 26,500 & 4.5 & 1.3 & 2,180 & 1.7 \\
\hline Wanga & 49 & 0 & 2 & 0 & 8 & 8 & 0 & 5 & 4.70 & 9,360 & 1,600 & 10,000 & 10,000 & 7,500 & 20,000 & 5.7 & 2.9 & 4,817 & 2.8 \\
\hline Wanga & 50 & 0 & 0 & 0 & 2 & 0 & 0 & 7 & 0.74 & 700 & 2,000 & 0 & 0 & 21,000 & 10,000 & 5.4 & 2.3 & 5,680 & 3.7 \\
\hline
\end{tabular}


Appendix 5. Asset-specific data of 50 households with homegardens surveyed in five villages of the Napu valley, Central Sulawesi, in 2004. (IR = Indonesian Rupiah; exchange rate in 2004: 10,000 IR $\approx 1$ Euro).

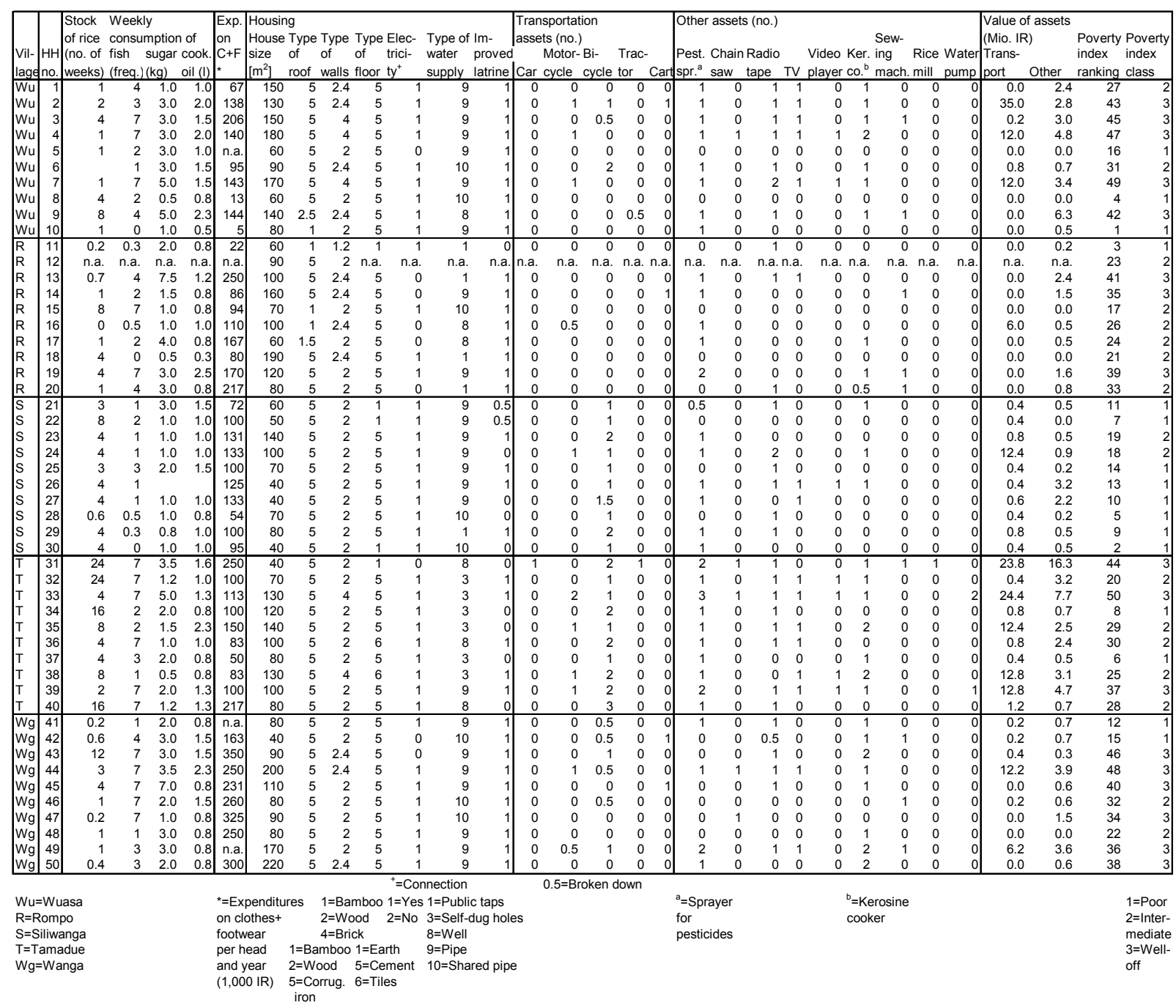

Appendix 6. Poverty indicators and their weights, resulting from Principal Component Analysis based on data of 50 households in five villages of the Napu valley, Central Sulawesi, 2004.

\begin{tabular}{llc}
\hline Dimension & Indicator & Weight \\
\hline Human resources & Per capita expenditures on clothes/footwear & 0.532 \\
& No. of household members & 0.444 \\
\multirow{4}{*}{ Food security } & Percentage of adults who did not complete elementary school & -0.413 \\
& Days of fish consumption per week & 0.691 \\
Dwelling & Amount of weekly sugar purchase & 0.649 \\
& Size of the house & 0.564 \\
Assets & Type of walls & 0.691 \\
& Farm size & 0.645 \\
& Total value of transportation assets & 0.541 \\
& Total value of other assets & 0.575 \\
\hline
\end{tabular}


Appendix 7. Sizes and micro-zonation of 50 homegardens surveyed in five villages of the Napu valley, Central Sulawesi, in 2004.

\begin{tabular}{|c|c|c|c|c|c|c|c|c|c|c|c|c|c|c|c|c|}
\hline \multirow[b]{2}{*}{ Village } & \multirow[b]{2}{*}{$\begin{array}{l}\mathrm{HH} \\
\text { no. }\end{array}$} & \multirow{2}{*}{\begin{tabular}{|l|} 
Garden size \\
measured \\
$\left(\mathrm{m}^{2}\right)$
\end{tabular}} & \multicolumn{6}{|c|}{ Proportion of cultivated zones (\%) } & \multicolumn{6}{|c|}{ Proportion of non-cultivated zones (\%) } & \multirow{2}{*}{$\begin{array}{l}\text { HG open } \\
\text { space } \\
\left(\mathrm{m}^{2}\right)\end{array}$} & \multirow{2}{*}{$\begin{array}{l}\text { Additionally } \\
\text { excluded } \\
\text { area/zone }\end{array}$} \\
\hline & & & $\begin{array}{l}\text { Orna- } \\
\text { mentals }\end{array}$ & $\begin{array}{l}\text { Vege- } \\
\text { tables }\end{array}$ & $\begin{array}{l}\text { Coffee/ } \\
\text { Cacao }\end{array}$ & $\begin{array}{l}\text { Fruit } \\
\text { trees }\end{array}$ & $\begin{array}{l}\text { Mixed } \\
\text { vegetation }\end{array}$ & \begin{tabular}{l|} 
Tree \\
nursery
\end{tabular} & Fallow & House & $\begin{array}{l}\text { Yard, } \\
\text { toilet }\end{array}$ & Stable & Pond & Other & & \\
\hline Wuasa & 1 & 1,800 & 4.7 & 5.4 & 6.2 & 8.4 & 14.9 & 0.06 & 25.4 & 8.3 & 4.8 & 0.2 & 21.7 & 0.0 & 803 & 3 Fallow+pond \\
\hline Wuasa & 2 & 1,260 & 2.7 & 3.5 & 51.5 & 9.0 & 0.0 & 0.16 & 0.0 & 10.3 & 19.9 & 0.3 & 0.0 & 2.5 & 1,130 & \\
\hline Wuasa & 3 & 460 & 3.7 & 2.6 & 0.0 & 2.2 & 5.4 & 0.11 & 34.6 & 32.6 & 18.7 & 0.0 & 0.0 & 0.0 & 310 & \\
\hline Wuasa & 4 & 930 & 20.9 & 4.7 & 12.8 & 3.9 & 0.0 & 0.22 & 0.0 & 19.4 & 7.6 & 0.0 & 0.0 & 30.5 & 466 & Kiosk \\
\hline Wuasa & 5 & 730 & 2.1 & 0.0 & 73.7 & 0.0 & 0.0 & 0.00 & 0.0 & 8.2 & 16.0 & 0.0 & 0.0 & 0.0 & 670 & \\
\hline Wuasa & 6 & 370 & 7.3 & 39.2 & 2.7 & 8.1 & 0.0 & 0.00 & 0.0 & 24.3 & 17.6 & 0.8 & 0.0 & 0.0 & 280 & \\
\hline Wuasa & 7 & 1,030 & 4.7 & 3.6 & 16.5 & 4.7 & 0.0 & 0.58 & 21.2 & 16.5 & 29.9 & 1.0 & 1.0 & 0.5 & 860 & \\
\hline Wuasa & 8 & 640 & 6.3 & 13.0 & 26.1 & 3.1 & 6.3 & 0.00 & 0.0 & 9.4 & 33.6 & 0.5 & 1.9 & 0.0 & 580 & \\
\hline Wuasa & 9 & 1,000 & 8.1 & 22.7 & 36.6 & 5.0 & 0.0 & 0.00 & 0.0 & 14.0 & 11.8 & 0.2 & 0.0 & 1.6 & 860 & \\
\hline Wuasa & 10 & 1,130 & 2.0 & 2.8 & 65.8 & 0.0 & 0.0 & 0.04 & 0.0 & 7.1 & 19.8 & 0.0 & 2.2 & 0.2 & 1,050 & \\
\hline Rompo & 11 & 1,500 & 1.1 & 1.2 & 22.7 & 0.0 & 0.0 & 0.07 & 61.6 & 4.0 & 9.3 & 0.0 & 0.0 & 0.0 & 1,440 & \\
\hline Rompo & 12 & 675 & 3.7 & 4.1 & 0.1 & 0.7 & 0.0 & 0.00 & 72.9 & 13.3 & 5.0 & 0.0 & 0.0 & 0.0 & 585 & \\
\hline Rompo & 13 & 540 & 2.6 & 2.0 & 38.0 & 15.0 & 0.0 & 0.19 & 0.0 & 18.5 & 23.7 & 0.0 & 0.0 & 0.0 & 440 & \\
\hline Rompo & 14 & 1,490 & 0.4 & 21.3 & 0.0 & 28.7 & 28.7 & 0.27 & 0.0 & 10.7 & 8.4 & 1.2 & 0.0 & 0.3 & 1,330 & \\
\hline Rompo & 15 & 580 & 2.2 & 56.2 & 9.5 & 0.0 & 0.0 & 0.09 & 6.9 & 12.1 & 10.9 & 0.2 & 0.0 & 1.9 & 510 & \\
\hline Rompo & 16 & 470 & 2.1 & 10.4 & 41.7 & 0.0 & 0.0 & 0.11 & 0.0 & 21.3 & 24.3 & 0.0 & 0.0 & 0.0 & 370 & \\
\hline Rompo & 17 & 330 & 1.2 & 10.3 & 0.0 & 0.0 & 0.0 & 0.61 & 1.8 & 18.2 & 67.9 & 0.0 & 0.0 & 0.0 & 270 & \\
\hline Rompo & 18 & 830 & 1.2 & 13.0 & 45.4 & 0.0 & 0.0 & 0.00 & 0.0 & 22.9 & 17.5 & 0.0 & 0.0 & 0.0 & 640 & \\
\hline Rompo & 19 & 1,570 & 0.0 & 0.0 & 32.7 & 0.0 & 0.0 & 0.00 & 31.5 & 7.6 & 19.6 & 1.2 & 0.0 & 7.4 & 956 & Fallow \\
\hline Rompo & 20 & 750 & 1.9 & 9.6 & 8.0 & 0.0 & 52.9 & 0.13 & 0.0 & 10.7 & 16.8 & 0.0 & 0.0 & 0.0 & 670 & \\
\hline Siliwanga & 21 & 770 & 2.5 & 19.5 & 4.0 & 0.0 & 14.3 & 0.06 & 13.5 & 7.8 & 31.3 & 0.8 & 0.0 & 6.2 & 710 & \\
\hline Siliwanga & 22 & 520 & 0.0 & 2.7 & 1.0 & 8.5 & 0.0 & 0.38 & 61.5 & 9.6 & 8.5 & 1.3 & 0.0 & 6.5 & 470 & \\
\hline Siliwanga & 23 & 2,350 & 0.5 & 0.0 & 1.3 & 1.1 & 41.0 & 0.00 & 41.0 & 6.0 & 8.0 & 0.5 & 0.0 & 0.7 & 2,210 & \\
\hline Siliwanga & 24 & 1,030 & 2.3 & 2.4 & 8.4 & 4.6 & 0.0 & 0.00 & 53.0 & 9.7 & 17.0 & 0.5 & 0.0 & 2.0 & 930 & \\
\hline Siliwanga & 25 & 750 & 5.6 & 3.6 & 0.0 & 0.0 & 3.3 & 1.33 & 26.9 & 9.3 & 22.4 & 0.0 & 7.2 & 20.3 & 528 & 3 Church building \\
\hline Siliwanga & 26 & 670 & 0.1 & 0.1 & 24.9 & 9.0 & 12.5 & 0.00 & 12.5 & 6.0 & 26.1 & 0.0 & 3.4 & 5.2 & 630 & \\
\hline Siliwanga & 27 & 2,420 & 1.1 & 0.1 & 3.6 & 2.7 & 42.0 & 0.00 & 42.0 & 1.7 & 5.5 & 0.3 & 0.0 & 1.0 & 2,380 & \\
\hline Siliwanga & 28 & 1,060 & 1.0 & 0.5 & 35.9 & 2.5 & 18.0 & 0.05 & 18.0 & 6.6 & 15.3 & 0.0 & 0.0 & 2.0 & 990 & \\
\hline Siliwanga & 29 & 2,500 & 1.4 & 0.2 & 4.9 & 2.6 & 38.9 & 0.00 & 38.9 & 3.2 & 7.3 & 1.2 & 0.0 & 1.4 & 2,420 & \\
\hline Siliwanga & 30 & 910 & 1.6 & 0.5 & 38.9 & 0.0 & 19.5 & 0.00 & 19.5 & 4.4 & 8.6 & 0.0 & 4.7 & 2.3 & 870 & \\
\hline Tamadue & 31 & 2,000 & 3.9 & 0.0 & 5.0 & 23.0 & 0.0 & 0.00 & 41.3 & 2.0 & 8.8 & 3.9 & 0.0 & 12.3 & 1,960 & \\
\hline Tamadue & 32 & 2,350 & 1.5 & 0.0 & 64.0 & 0.0 & 0.0 & 0.00 & 17.4 & 3.0 & 11.3 & 1.0 & 0.0 & 1.8 & 2,280 & \\
\hline Tamadue & 33 & 2,350 & 1.0 & 0.3 & 56.7 & 2.3 & 0.0 & 0.00 & 0.0 & 5.5 & 15.6 & 1.8 & 14.9 & 1.7 & 1,869 & Pond \\
\hline Tamadue & 34 & 2,420 & 1.0 & 0.6 & 73.3 & 1.5 & 0.0 & 0.00 & 11.0 & 5.0 & 6.3 & 0.5 & 0.0 & 0.9 & 2,300 & \\
\hline Tamadue & 35 & 2,450 & 0.4 & 0.2 & 80.4 & 0.0 & 0.0 & 0.04 & 0.0 & 5.7 & 8.4 & 1.0 & 2.5 & 1.3 & 2,310 & \\
\hline Tamadue & 36 & 1,070 & 4.6 & 0.6 & 1.4 & 0.8 & 26.1 & 0.28 & 26.1 & 9.3 & 12.2 & 1.1 & 14.5 & 3.0 & 815 & Pond \\
\hline Tamadue & 37 & 800 & 1.5 & 0.1 & 0.0 & 2.3 & 13.8 & 0.00 & 41.4 & 10.0 & 28.3 & 0.6 & 0.0 & 2.1 & 720 & \\
\hline Tamadue & 38 & 2,350 & 0.8 & 0.6 & 79.9 & 0.5 & 0.0 & 0.00 & 0.0 & 5.5 & 10.3 & 0.8 & 0.6 & 1.0 & 2,220 & \\
\hline Tamadue & 39 & 2,450 & 1.8 & 0.0 & 80.9 & 0.0 & 0.0 & 0.00 & 0.0 & 4.1 & 12.4 & 0.0 & 0.0 & 0.9 & 2,350 & \\
\hline Tamadue & 40 & 2,500 & 1.6 & 0.0 & 88.5 & 0.0 & 0.0 & 0.16 & 0.0 & 3.2 & 5.6 & 0.3 & 0.0 & 0.6 & 2,420 & \\
\hline Wanga & 41 & 1,360 & 2.2 & 1.0 & 28.2 & 0.0 & 25.0 & 0.44 & 25.0 & 5.9 & 11.5 & 0.0 & 0.0 & 0.7 & 1,280 & \\
\hline Wanga & 42 & 590 & 3.4 & 2.0 & 3.4 & 0.0 & 67.8 & 0.51 & 0.0 & 6.8 & 14.9 & 0.0 & 0.0 & 1.2 & 550 & \\
\hline Wanga & 43 & 340 & 5.0 & 2.6 & 10.6 & 0.0 & 0.0 & 0.88 & 0.0 & 26.5 & 54.4 & 0.0 & 0.0 & 0.0 & 250 & \\
\hline Wanga & 44 & 880 & 4.1 & 6.6 & 43.6 & 0.0 & 0.0 & 0.00 & 0.0 & 22.7 & 19.3 & 0.0 & 0.0 & 3.6 & 648 & 3 Barn \\
\hline Wanga & 45 & 420 & 2.9 & 2.1 & 0.0 & 0.0 & 6.2 & 0.12 & 31.2 & 26.2 & 31.2 & 0.0 & 0.0 & 0.0 & 310 & \\
\hline Wanga & 46 & 520 & 2.1 & 2.3 & 30.2 & 0.0 & 15.0 & 0.00 & 0.0 & 15.4 & 34.0 & 1.0 & 0.0 & 0.0 & 440 & \\
\hline Wanga & 47 & 520 & 7.3 & 4.6 & 21.7 & 0.0 & 21.7 & 0.00 & 0.0 & 17.3 & 24.6 & 2.7 & 0.0 & 0.0 & 430 & \\
\hline Wanga & 48 & 750 & 0.1 & 14.4 & 40.1 & 0.0 & 17.9 & 0.67 & 0.0 & 10.7 & 14.3 & 0.5 & 0.0 & 1.3 & 670 & \\
\hline Wanga & 49 & 1,610 & 2.7 & 6.0 & 28.7 & 0.0 & 28.7 & 0.43 & 0.0 & 10.6 & 21.1 & 0.6 & 0.0 & 1.4 & 1,440 & \\
\hline Wanga & 50 & 1,940 & 0.0 & 0.0 & 59.9 & 0.0 & 0.0 & 0.00 & 17.7 & 11.3 & 11.0 & 0.0 & 0.0 & 0.0 & 1,377 & Fallow \\
\hline
\end{tabular}


Appendix 8. Data on age and function as well as management characteristics of 50 homegardens (HG) surveyed in five villages of the Napu valley, Central Sulawesi, in 2004.

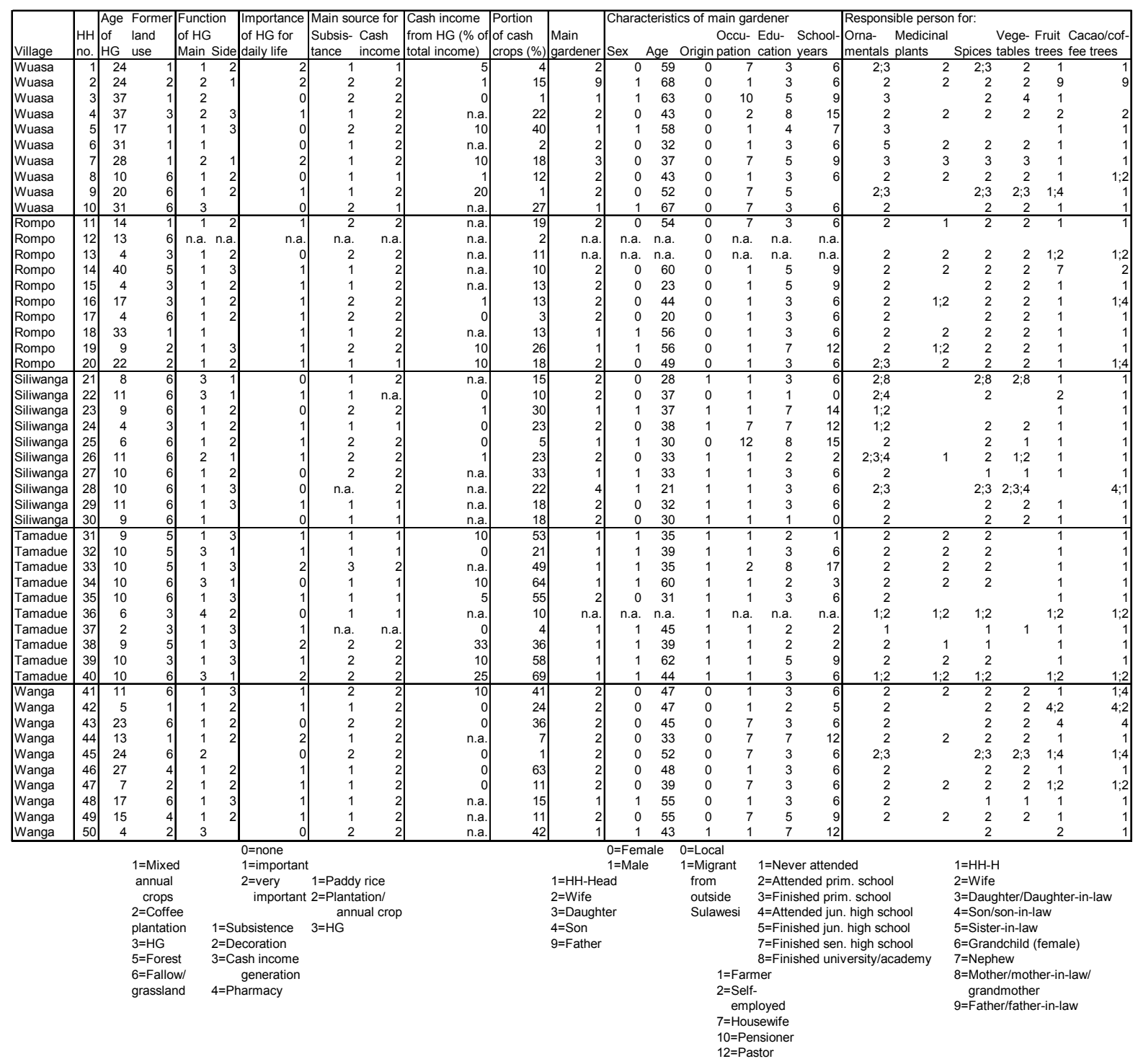


Appendix 9. Labour management in 50 homegardens $(H G)$ surveyed in five villages of the Napu valley, Central Sulawesi, in 2004. (HH-H = Household head).

\begin{tabular}{|c|c|c|c|c|c|c|c|c|c|c|c|c|c|c|c|c|}
\hline \multirow[b]{3}{*}{ Village } & \multirow{3}{*}{$\begin{array}{l}\mathrm{HH} \\
\text { no. }\end{array}$} & \multicolumn{6}{|c|}{ Monthly working time (h) } & \multirow{3}{*}{$\begin{array}{l}\text { Daily working } \\
\text { time per } 100 \mathrm{~m}^{2} \\
\text { (minutes) }\end{array}$} & \multicolumn{8}{|c|}{ Portion of HG|Working hours spent per month for: } \\
\hline & & & $+-H$ 's & & Other & & per $100 \mathrm{~m}^{2} \mid \mathrm{t}$ & & work done by & & & & & & & \\
\hline & & HH-Head wi & & Children & relatives T & & $\mathrm{HG}$ area & & females $(\%)$ & Hoeing 1 & Weeding & Harvesting & Spraying & Fertilising & Planting & Pruning \\
\hline Wuasa & 1 & 2.8 & 19.3 & 20.3 & 0.0 & 42.3 & 5.3 & 10.5 & 93.3 & 6.0 & 30.0 & 3.0 & 0.13 & 2.00 & 0.75 & 0.44 \\
\hline Wuasa & 2 & 0.5 & 0.7 & 0.7 & 1.5 & 3.4 & 0.3 & 0.6 & 41.6 & 1.0 & 0.2 & 0.7 & 0.25 & 0.96 & 0.02 & 0.28 \\
\hline Wuasa & 3 & 4.4 & 2.4 & 0.0 & 0.0 & 6.8 & 2.2 & 4.4 & 35.4 & 4.0 & 0.0 & 2.4 & 0.09 & 0.24 & 0.05 & 0.00 \\
\hline Wuasa & 4 & 0.7 & 32.0 & 14.8 & 0.0 & 47.4 & 10.2 & 20.4 & 98.6 & 36.0 & 6.0 & 2.4 & 0.15 & 0.08 & 2.25 & 0.55 \\
\hline Wuasa & 5 & 2.9 & 0.6 & 1.6 & 0.0 & 5.1 & 0.8 & 1.5 & 11.7 & 0.0 & 0.0 & 1.8 & 1.80 & 0.00 & 0.96 & 0.51 \\
\hline Wuasa & 6 & 0.1 & 2.6 & 0.0 & 2.1 & 4.9 & 1.7 & 3.5 & 54.3 & 2.0 & 2.0 & 0.5 & 0.13 & 0.10 & 0.03 & 0.10 \\
\hline Wuasa & 7 & 0.1 & 0.0 & 15.2 & 0.0 & 15.3 & 1.8 & 3.6 & 99.4 & 12.0 & 0.0 & 2.4 & 0.00 & 0.50 & 0.30 & 0.09 \\
\hline Wuasa & 8 & 0.0 & 9.2 & 0.1 & 0.0 & 9.3 & 1.6 & 3.2 & 99.6 & 6.0 & 0.5 & 2.4 & 0.00 & 0.00 & 0.30 & 0.13 \\
\hline Wuasa & 9 & 11.6 & 13.7 & 3.1 & 0.0 & 28.3 & 3.3 & 6.6 & 59.2 & 6.0 & 15.0 & 0.3 & 0.60 & 0.04 & 6.12 & 0.25 \\
\hline Wuasa & 10 & 23.1 & 2.4 & 0.0 & 0.0 & 25.5 & 2.4 & 4.9 & 9.4 & 7.5 & 15.0 & 2.4 & 0.00 & 0.04 & 0.17 & 0.38 \\
\hline Rompo & 11 & 4.1 & 4.4 & 1.0 & 0.0 & 9.5 & 0.7 & \begin{tabular}{l|}
1.3 \\
\end{tabular} & \begin{tabular}{l|l}
46.3 \\
\end{tabular} & 4.0 & 2.0 & 2.4 & 0.00 & 0.00 & 1.02 & 0.09 \\
\hline Rompo & 12 & n.a. & n.a. & n.a. & n.a. & n.a. & n.a. & n.a. & n.a. & n.a. & n.a. & n.a. & n.a. & n.a. & n.a. & n.a. \\
\hline Rompo & 13 & 1.1 & 10.4 & 0.0 & 6.0 & 17.5 & 4.0 & 8.0 & 59.3 & 12.0 & 1.9 & 2.4 & 0.04 & 0.50 & 0.51 & 0.12 \\
\hline Rompo & 14 & 0.0 & 4.5 & 0.0 & 0.1 & 4.6 & 0.3 & 0.7 & 98.3 & 1.0 & 0.3 & 2.4 & 0.00 & 0.32 & 0.13 & 0.40 \\
\hline Rompo & 15 & 0.0 & 10.1 & 0.0 & 0.0 & 10.1 & 2.0 & 3.9 & 100.0 & 6.0 & 1.2 & 2.4 & 0.00 & 0.16 & 0.30 & 0.00 \\
\hline Rompo & 16 & 0.5 & 4.6 & 0.0 & 0.0 & 5.1 & 1.4 & 2.8 & 89.9 & 2.0 & 0.5 & 2.4 & 0.01 & 0.00 & 0.17 & 0.01 \\
\hline Rompo & 17 & 0.2 & 5.7 & 0.0 & 0.0 & 5.9 & 2.2 & 4.3 & 97.1 & 2.0 & 1.0 & 2.4 & 0.17 & 0.17 & 0.13 & 0.00 \\
\hline Rompo & 18 & 22.0 & 14.6 & 0.0 & 0.0 & 36.6 & 5.7 & 11.4 & 40.0 & 24.0 & 6.0 & 2.4 & 0.00 & 0.00 & 0.24 & 3.96 \\
\hline Rompo & 19 & 10.4 & 0.2 & 5.7 & 0.1 & 16.4 & 1.7 & 3.4 & 1.4 & 10.8 & 0.6 & 4.0 & 0.09 & 0.19 & 0.04 & 0.66 \\
\hline Rompo & 20 & 1.0 & 19.3 & 12.0 & 0.0 & 32.2 & 4.8 & 9.6 & 97.0 & 4.0 & 24.0 & 2.4 & 0.17 & 0.68 & 0.17 & 0.79 \\
\hline Siliwanga & 21 & 3.8 & 4.0 & 0.0 & 0.0 & 7.7 & 1.1 & 2.2 & \begin{tabular}{l|}
51.5 \\
\end{tabular} & 0.5 & 3.0 & 2.4 & 0.08 & 0.68 & 0.90 & $\begin{array}{l}0.17 \\
\end{array}$ \\
\hline Siliwanga & 22 & 4.6 & 7.1 & 0.0 & 0.0 & 11.7 & 2.5 & 5.0 & 60.9 & 0.5 & 7.2 & 0.0 & 0.48 & 3.00 & 0.48 & 0.00 \\
\hline Siliwanga & 23 & 12.2 & 0.5 & 0.0 & 0.0 & 12.7 & 0.6 & 1.1 & 4.0 & 6.1 & 2.0 & 0.5 & 0.51 & 3.00 & 0.48 & 0.00 \\
\hline Siliwanga & 24 & 0.5 & 4.3 & 0.0 & 0.0 & 4.8 & 0.5 & 1.0 & 89.3 & 0.2 & 1.0 & 2.4 & 0.50 & 0.68 & 0.04 & 0.01 \\
\hline Siliwanga & 25 & 4.0 & 2.7 & 0.0 & 0.0 & 6.7 & 1.3 & 2.5 & 39.7 & 0.8 & 0.8 & 2.4 & 0.04 & 2.40 & 0.25 & 0.08 \\
\hline Siliwanga & 26 & 1.2 & 4.8 & 0.0 & 0.0 & 6.0 & 0.9 & 1.9 & 80.3 & 0.0 & 0.1 & 2.4 & 1.00 & 2.40 & 0.00 & 0.09 \\
\hline Siliwanga & 27 & 7.5 & 2.0 & 0.0 & 0.0 & 9.5 & 0.4 & 0.8 & 21.1 & 0.2 & 5.4 & 2.0 & 0.51 & 0.32 & 0.04 & 1.02 \\
\hline Siliwanga & 28 & 0.0 & 0.2 & 28.0 & 0.0 & 28.2 & 2.8 & 5.7 & 50.4 & 9.0 & 18.0 & 0.3 & 0.51 & 0.17 & 0.04 & 0.13 \\
\hline Siliwanga & 29 & 20.0 & 22.9 & 9.0 & 0.0 & 51.9 & 2.1 & 4.3 & 44.2 & 2.0 & 45.0 & 3.0 & 0.90 & 0.68 & 0.01 & 0.32 \\
\hline Siliwanga & 30 & 2.1 & 2.7 & 2.3 & 0.0 & 7.1 & 0.8 & 1.6 & 38.2 & 1.4 & 2.0 & 2.4 & 0.08 & 0.64 & 0.48 & 0.09 \\
\hline \begin{tabular}{|l|} 
Tamadue \\
\end{tabular} & 31 & n.a. & n.a. & n.a. & n.a. & n.a. & $\begin{array}{ll}\text { n.a. } \\
\end{array}$ & $\begin{array}{ll}\text { n.a. } \\
\end{array}$ & n.a. & n.a. & n.a. & n.a. & n.a. & n.a. & n.a. & n.a. \\
\hline Tamadue & 32 & n.a. & n.a. & n.a. & n.a. & n.a. & n.a. & n.a. & n.a. & n.a. & n.a. & n.a. & n.a. & n.a. & n.a. & n.a. \\
\hline Tamadue & 33 & n.a. & n.a. & n.a. & n.a. & n.a. & n.a. & n.a. & n.a. & n.a. & n.a. & n.a. & n.a. & n.a. & n.a. & n.a. \\
\hline Tamadue & 34 & n.a. & n.a. & n.a. & n.a. & n.a. & n.a. & n.a. & n.a. & n.a. & n.a. & n.a. & n.a. & n.a. & n.a. & n.a. \\
\hline Tamadue & 35 & n.a. & n.a. & n.a. & n.a. & n.a. & n.a. & n.a. & n.a. & n.a. & n.a. & n.a. & n.a. & n.a. & n.a. & n.a. \\
\hline Tamadue & 36 & n.a. & n.a. & n.a. & n.a. & n.a. & n.a. & n.a. & n.a. & n.a. & n.a. & n.a. & n.a. & n.a. & n.a. & n.a. \\
\hline Tamadue & 37 & n.a. & n.a. & n.a. & n.a. & n.a. & n.a. & n.a. & n.a. & n.a. & n.a. & n.a. & n.a. & n.a. & n.a. & n.a. \\
\hline Tamadue & 38 & n.a. & n.a. & n.a. & n.a. & n.a. & n.a. & n.a. & n.a. & n.a. & n.a. & n.a. & n.a. & n.a. & n.a. & n.a. \\
\hline Tamadue & 39 & n.a. & n.a. & n.a. & n.a. & n.a. & n.a. & n.a. & n.a. & n.a. & n.a. & n.a. & n.a. & n.a. & n.a. & n.a. \\
\hline Tamadue & 40 & n.a. & n.a. & n.a. & n.a. & n.a. & n.a. & n.a. & n.a. & n.a. & n.a. & n.a. & n.a. & n.a. & n.a. & n.a. \\
\hline $\begin{array}{l}\text { Wanga } \\
\end{array}$ & 41 & 0.0 & 8.7 & 1.2 & 00 & 9.9 & 0.8 & 1.6 & 87.6 & 6.0 & 0 & & 0 . & 0.00 & 0.01 & 10 \\
\hline War & 42 & n.a. & 20.9 & 0.2 & 0. & 21 & 3.8 & 7.7 & 99.0 & 12.0 & 4.0 & 2.4 & 0.08 & 2.40 & 0.05 & 0.12 \\
\hline Wanga & 43 & 2.0 & 12.3 & 0.5 & 0.0 & 14.8 & 5.9 & 11.9 & 83.2 & 12.0 & 0.3 & 2.0 & 0.50 & 0.00 & 0.04 & 0.00 \\
\hline Wanga & 44 & 0.8 & 18.8 & 8.0 & 0.0 & 27.6 & 4.3 & 8.5 & 97.0 & 9.0 & 15.0 & 2.4 & 0.2 & 0.04 & 0.34 & 0.58 \\
\hline Wanga & 45 & 0.0 & 3.1 & 5. & 0 & 8.6 & 28 & 5 & 100.0 & 4.0 & 2.0 & 2.4 & $0 . C$ & 0.08 & 0.05 & 0.0 \\
\hline Wanga & 46 & 0.3 & 6.5 & 0.0 & 0.0 & 6.8 & 1.5 & 3.1 & 95.7 & 4.0 & 0.1 & 2.4 & 0.25 & 0.00 & 0.04 & 0.04 \\
\hline Wanga & 47 & 0.4 & 6.5 & 0.0 & 0.0 & 6.9 & 1.6 & 3.2 & 94.5 & 0.5 & 1.0 & 2.4 & 0.30 & 2.40 & 0.17 & 0.08 \\
\hline Wanga & 48 & 19.0 & 0.0 & 0.0 & 0.0 & 19.0 & 2.8 & 5.7 & 0.2 & 6.0 & 8.0 & 4.0 & 0.1 & 0.04 & 0.34 & 0.49 \\
\hline Wa & 49 & 0.7 & 7.7 & 0.0 & 0.1 & 8.5 & 0.6 & 1.2 & 91.1 & 3.0 & 1.0 & 2.4 & 0.0 & 0.30 & 1.02 & 0.67 \\
\hline Wanga & 50 & 1.7 & 1.1 & 0.0 & 0.0 & 2.8 & 0.2 & 0.4 & 39.6 & 0.0 & 0.6 & 0.5 & 0.30 & 0.00 & 0.00 & 1.38 \\
\hline
\end{tabular}


Appendix 10. Soil fertility management in 50 homegardens surveyed in five villages of the Napu valley, Central Sulawesi, in 2004.

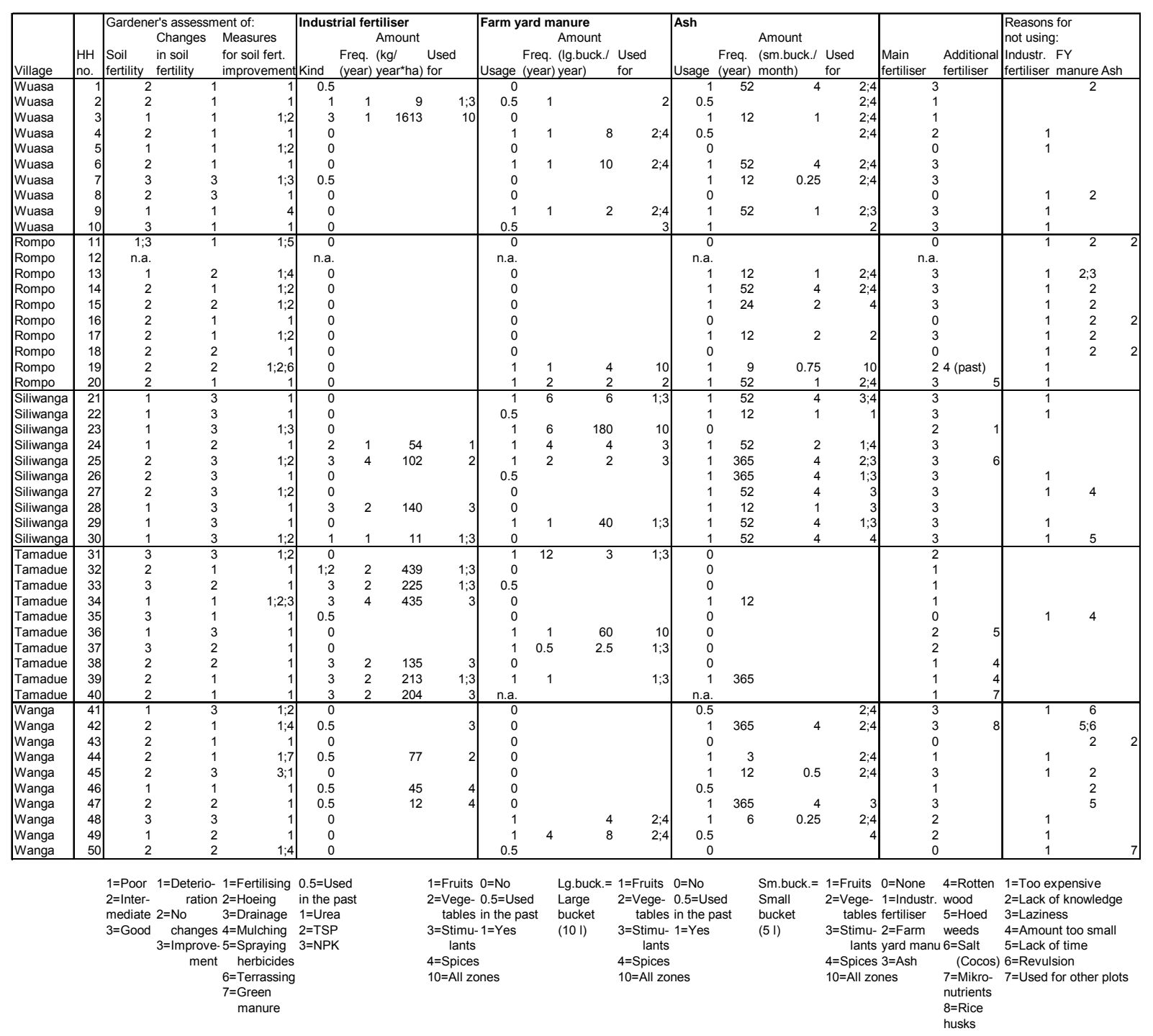


Appendix 11. Use of pesticides and alternatives as well as rating of management problems in 50 homegardens surveyed in five villages of the Napu valley, Central Sulawesi, in 2004.

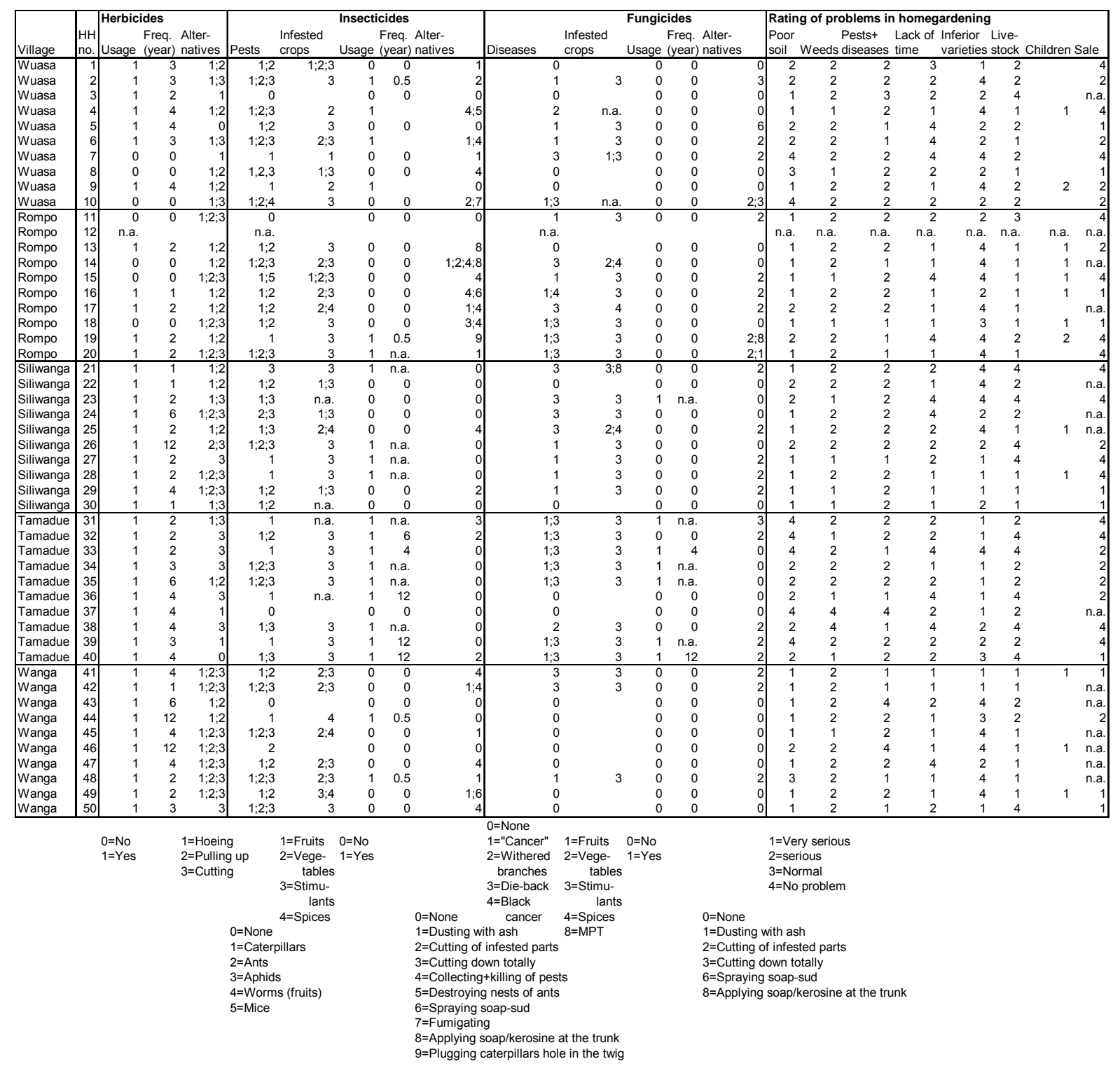


Appendix 12. Combined list of crop plant species (ordered by main use categories) cultivated in 30-50 homegardens in 3-5 villages of the Napu valley, Central Sulawesi, in 2001, 2003, and 2004. Besides scientific, common, Indonesian, and local species names, also numbers of cultivated varieties in the year 2003 (Var no.), domestication status (Wild), life form (Ann.), origin, and main and secondary uses are given. (For coding see footnotes).

\begin{tabular}{|c|c|c|c|c|c|c|c|c|c|c|}
\hline No. & Species name & Family & Common name & $\begin{array}{l}\text { Indonesian name } \\
\text { (local name) }\end{array}$ & $\begin{array}{l}\text { Var } \\
\text { no. }\end{array}$ & Wild & Ann. & $\begin{array}{l}\text { Ori- } \\
\text { gin }\end{array}$ & $\begin{array}{l}\text { Main } \\
\text { use }\end{array}$ & $\begin{array}{l}\text { Secondary } \\
\text { uses }\end{array}$ \\
\hline 1 & Anacardium occidentale L. & Anacardiaceae & Cashew & Jambu monyet & 1 & 0 & 0 & 5 & 1 & \\
\hline 2 & Ananas comosus (L.) Merr. & Bromeliaceae & Pineapple & Nanas & 2 & 0 & 0 & 5 & 1 & $\begin{array}{l}5 ; 13 ; 14 ; 15 \\
16\end{array}$ \\
\hline 3 & Annona muricata L. & Annonaceae & Soursop & Sirsak & 2 & 0 & 0 & 5 & 1 & 5 \\
\hline 4 & Carica papaya L. & Caricaceae & Papaya & Pepaya & 2 & 0 & 0 & 5 & 1 & $2 ; 5 ; 10 ; 13$ \\
\hline 5 & $\begin{array}{l}\text { Citrullus lanatus ssp. vulgaris Dessert } \\
\text { Group }\end{array}$ & Cucurbitaceae & Watermelon & Semangka & 1 & 0 & 1 & 3 & 1 & \\
\hline 6 & $\begin{array}{l}\text { Citrus aurantiifolia (Christm. \& Panz.) } \\
\text { Swingle }\end{array}$ & Rutaceae & Lime & Jeruk nipis kuning & 1 & 0 & 0 & 1 & 1 & $4 ; 5 ; 13$ \\
\hline 7 & Citrus maxima (Burm.) Merr. & Rutaceae & Pummelo & Jeruk besar & 3 & 0 & 0 & 1 & 1 & $5 ; 13 ; 15$ \\
\hline 8 & Citrus medica L. & Rutaceae & Citron & Jeruk sukade (doku) & 1 & 0 & 0 & 2 & 1 & 4 \\
\hline 9 & Citrus reticulata Blanco & Rutaceae & Mandarin & Jeruk manis & 4 & 0 & 0 & 1 & 1 & $4 ; 5 ; 13 ; 15$ \\
\hline 10 & Citrus sinensis (L.) Osbeck & Rutaceae & Sweet orange & Jeruk cina & 3 & 0 & 0 & 2 & 1 & $13 ; 15$ \\
\hline 11 & Citrus sp. & Rutaceae & & Jeruk nipis oranye & 1 & 0 & 0 & & 1 & 4 \\
\hline 12 & Clausena sp.? & Rutaceae & & Jeruk baru & 1 & 0 & 0 & 1 & 1 & 5 \\
\hline 13 & Cocos nucifera L. & Arecaceae & Coconut palm & Kelapa & 4 & 0 & 0 & 1 & 1 & $\begin{array}{l}2 ; 5 ; 11 ; 13 ; 1 \\
4 ; 15\end{array}$ \\
\hline 14 & Dimocarpus longan Lour. & Sapindaceae & Longan & Klengkeng & 2 & 0 & 0 & 2 & 1 & \\
\hline 15 & Durio zibethinus Murray & Bombacaceae & Durian & Durian & 4 & 0 & 0 & 1 & 1 & $5 ; 13$ \\
\hline 16 & Garcinia mangostana L. & Clusiaceae & Mangosteen & Manggis & 1 & 0 & 0 & 1 & 1 & \\
\hline 17 & Lansium domesticum Correa & Meliaceae & Langsat & Langsat & 1 & 0 & 0 & 1 & 1 & $5 ; 13$ \\
\hline 18 & Mangifera indica L. & Anacardiaceae & Mango & Mangga & 11 & 0 & 0 & 2 & 1 & $5 ; 13 ; 15$ \\
\hline 19 & Manilkara zapota (L.) van Royen & Sapotaceae & Sapodilla & Sawo & 1 & 0 & 0 & 5 & 1 & \\
\hline 20 & Musa $x$ paradisiaca $\mathrm{L}$. & Musaceae & Banana & Pisang & 28 & 0 & 0 & 1 & 1 & $\begin{array}{l}2 ; 5 ; 10 ; 11 ; 1 \\
3 ; 15\end{array}$ \\
\hline 21 & Nephelium lappaceum L. & Sapindaceae & Rambutan & Rambutan & 4 & 0 & 0 & 1 & 1 & 13 \\
\hline 22 & Passiflora edulis Sims & Passifloraceae & Passionfruit & Markisa hitam & 1 & 0 & 0 & 5 & 1 & 15 \\
\hline 23 & Passiflora ligularis Juss. & Passifloraceae & Sweet granadilla & Markisa kuning & 1 & 0 & 0 & 5 & 1 & 15 \\
\hline 24 & Persea americana Miller & Lauraceae & Avocado & Adpukat & 3 & 0 & 0 & 5 & 1 & $5 ; 13$ \\
\hline 25 & $\begin{array}{l}\text { Pometia pinnata J.R. Forster \& G. } \\
\text { Forster }\end{array}$ & Sapindaceae & Kasai tree & Matoa & 1 & 1 & 0 & 1 & 1 & \\
\hline 26 & Psidium guajava L. & Myrtaceae & Guava & Jambu biji & 4 & 0 & 0 & 5 & 1 & $4 ; 5 ; 10$ \\
\hline 27 & Rubus rosifolius Sm. & Rosaceae & Queensland raspberry & Arbei (lole-lole) & 1 & 1 & 0 & 1 & 1 & 5 \\
\hline 28 & Salacca zalacca (Gaertner) Voss & Arecaceae & Salak palm & Salak & 1 & 0 & 0 & 1 & 1 & $14 ; 15$ \\
\hline 29 & Syzygium aqueum (Burm.f.) Alston & Myrtaceae & Water apple & Jambu air & 3 & 0 & 0 & 1 & 1 & $\begin{array}{l}5 ; 10 ; 13 ; 14 ; \\
15\end{array}$ \\
\hline 30 & Syzygium malaccense (L.) Merr. \& Perry & Myrtaceae & Malay apple & Jambu bol (gora) & 2 & 0 & 0 & 1 & 1 & $13 ; 15$ \\
\hline 31 & Abelmoschus manihot (L.) Medik. & Malvaceae & Sunset hibiscus & Sayur gedi & 1 & 0 & 0 & 1 & 2 & 5 \\
\hline 32 & Amaranthus tricolor $\mathrm{L}$. & Amaranthaceae & Amaranth & Bayam & 2 & 0 & 1 & 1 & 2 & $5 ; 13$ \\
\hline 33 & Artocarpus altilis (Park.) Fosberg & Moraceae & Breadfruit & Sukun & 1 & 0 & 0 & 1 & 2 & \\
\hline 34 & Artocarpus heterophyllus Lam. & Moraceae & Jackfruit & Nangka & 5 & 0 & 0 & 2 & 2 & $1 ; 5 ; 6 ; 10$ \\
\hline 35 & Athyrium esculentum (Retz.) Copel. & Woodsiaceae & Fern & Sayur paku & 1 & 1 & 0 & 1 & 2 & 13 \\
\hline 36 & Brassica juncea (L.) Czernjaew & Brassicaceae & Indian mustard & Sawi & 1 & 0 & 1 & 2 & 2 & 13 \\
\hline 37 & $\begin{array}{l}\text { Brassica oleracea L. ssp. oleracea } \\
\text { convar. capitata (L.) Alef. var. capitata } \\
\text { L. forma alba }\end{array}$ & Brassicaceae & White cabbage & Kol & 1 & 0 & 1 & 4 & 2 & 13 \\
\hline 38 & $\begin{array}{l}\text { Brassica rapa ssp. chinensis (L.) Hanelt } \\
\text { in J.Schultze-Motel }\end{array}$ & Brassicaceae & Pak choi & Sayur putih & 1 & 0 & 1 & 2 & 2 & \\
\hline 39 & $\begin{array}{l}\text { Brassica rapa ssp. pekinensis (Lour.) } \\
\text { Hanelt in J.Schultze-Motel }\end{array}$ & Brassicaceae & Chinese cabbage & Sayur sekatar & 1 & 0 & 1 & 2 & 2 & \\
\hline 40 & Cajanus cajan (L.) Millsp. & Fabaceae & Pigeonpea & Kacang kayu (undis) & 1 & 0 & 0 & 3 & 2 & \\
\hline 41 & Canavalia ensiformis (L.) DC. & Fabaceae & Sword bean & Kacang parang & 1 & 0 & 0 & 5 & 2 & \\
\hline 42 & $\begin{array}{l}\text { Clerodendron minahassae Teijsm. \& } \\
\text { Binn. }\end{array}$ & Verbenaceae & & (Dongato/leilem) & 1 & 1 & 0 & 1 & 2 & 5 \\
\hline 43 & Cosmos caudatus H.B. K.H.B.K. & Asteraceae & Cosmos & Kenikir & 1 & 1 & 1 & 5 & 2 & 12 \\
\hline 44 & Cucumis sativus $\mathrm{L}$. & Cucurbitaceae & Cucumber & Ketimun & 1 & 0 & 1 & 2 & 2 & 5 \\
\hline 45 & Cucurbita pepo L. & Cucurbitaceae & Pumpkin & Labu & 3 & 0 & 1 & 5 & 2 & $5 ; 10$ \\
\hline 46 & $\begin{array}{l}\text { Daucus carota ssp. sativus (Hoffn.) } \\
\text { Schübl. \& Mart. }\end{array}$ & Apiaceae & Carrot & Wortel & 2 & 0 & 1 & 4 & 2 & 5 \\
\hline 47 & Enydra fluctuans Lour. & Asteraceae & Buffalo spinach & (Sayur taugaruk) & 1 & 1 & 0 & 2 & 2 & \\
\hline 48 & Etlingera elatior (Jack) R.M. Sm. & Zingiberaceae & Torch ginger & Combrang (cicang) & 1 & 0 & 0 & 1 & 2 & 12 \\
\hline 49 & Glycine max (L.) Merr. & Fabaceae & Soya bean & Kedelai & 1 & 0 & 1 & 2 & 2 & \\
\hline 50 & Hedychium coronarium Koenig in Retz. & Zingiberaceae & Butterfly ginger & Gandasuli (pambuku) & 1 & 1 & 0 & 1 & 2 & 5 \\
\hline 51 & Ipomoea aquatica Forsskal & Convolvulaceae & Water spinach & Kangkung & 2 & 0 & 0 & 2 & 2 & $4 ; 5 ; 10$ \\
\hline 52 & Lablab purpureus (L.) Sweet & Fabaceae & Hyacinth bean & Kacang komak & 1 & 0 & 1 & 3 & 2 & \\
\hline 53 & Lagenaria siceraria (Molina) Standl. & Cucurbitaceae & Bottle gourd & Labu air & 1 & 0 & 1 & 3 & 2 & \\
\hline 54 & Limnocharis flava (L.) Buchenau & Butomaceae & Sawah lettuce & Genjer & 1 & 1 & 0 & 5 & 2 & 12 \\
\hline
\end{tabular}




\begin{tabular}{|c|c|c|c|c|c|c|c|c|c|c|}
\hline No. & Species name & Family & Common name & $\begin{array}{l}\text { Indonesian name } \\
\text { (local name) }\end{array}$ & $\begin{array}{l}\text { Var } \\
\text { no. }\end{array}$ & Wild & Ann. & $\begin{array}{l}\text { Ori- } \\
\text { gin }\end{array}$ & $\begin{array}{l}\text { Main } \\
\text { use }\end{array}$ & $\begin{array}{l}\text { Secondary } \\
\text { uses }\end{array}$ \\
\hline 55 & Luffa acutangula (L.) Roxb. & Cucurbitaceae & Ridged gourd & Gambas & 1 & 0 & 1 & 2 & 2 & \\
\hline 56 & Luffa aegyptiaca Mill. & Cucurbitaceae & Sponge gourd & Blustru & 1 & 0 & 1 & 1 & 2 & \\
\hline 57 & Lycopersicon esculentum Miller & Solanaceae & Tomato & Tomat & 4 & 0 & 1 & 5 & 2 & $4 ; 5 ; 13$ \\
\hline 58 & Moringa oleifera Lam. & Moringaceae & Horseradish tree & Kelor & 1 & 0 & 0 & 2 & 2 & 5 \\
\hline 59 & Phaseolus lunatus L. & Fabaceae & Lima bean & Kacang manis & 2 & 0 & 1 & 5 & 2 & \\
\hline 60 & $\begin{array}{l}\text { Phaseolus vulgaris L. ssp. vulgaris var. } \\
\text { Nanus (L.) Asch. }\end{array}$ & Fabaceae & French bean & Kacang merah/buncis & 1 & 0 & 1 & 5 & 2 & \\
\hline 61 & $\begin{array}{l}\text { Psophocarpus tetragonolobus (Stickm.) } \\
\text { DC. }\end{array}$ & Fabaceae & Winged bean & Kecipir & 1 & 0 & 0 & 1 & 2 & \\
\hline 62 & Sauropus androgynus (L.) Merr. & Euphorbiaceae & Star gooseberry & Katuk & 1 & 0 & 0 & 1 & 2 & 5 \\
\hline 63 & Sechium edule (Jacq.) Swartz & Cucurbitaceae & Chayote & Labu siam & 3 & 0 & 0 & 5 & 2 & $5 ; 10$ \\
\hline 64 & Solanum aethiopicum L. & Solanaceae & Bitter tomato & (Palolakao) & 1 & 0 & 0 & 3 & 2 & 5 \\
\hline 65 & Solanum macrocarpon L. & Solanaceae & African eggplant & Terong cina/kelapa & 1 & 0 & 0 & 3 & 2 & $5 ; 13$ \\
\hline 66 & Solanum melongena L. & Solanaceae & Eggplant & Terong biasa/kuning & 8 & 0 & 0 & 3 & 2 & $13 ; 15$ \\
\hline 67 & Solanum nigrum L. & Solanaceae & Black nightshade & Kampai & 1 & 0 & 1 & 4 & 2 & 5 \\
\hline 68 & Solanum torvum Sw. & Solanaceae & Devil's fig & Terong hutan & 1 & 1 & 0 & 5 & 2 & \\
\hline 69 & Solanum tuberosum L. & Solanaceae & Potato & Kentang & 1 & 0 & 0 & 5 & 2 & 13 \\
\hline 70 & Vigna angularis (Willd.) Ohwi \& Ohashi & Fabaceae & Adzuki bean & Kacang cina & 1 & 0 & 1 & 2 & 2 & \\
\hline 71 & Vigna radiata (L.) R. Wilczek & Fabaceae & Mung bean & Kacang hijau & 1 & 0 & 1 & 2 & 2 & \\
\hline 72 & Vigna sp. & Fabaceae & & Kacang duduk & 1 & 0 & 1 & 2 & 2 & 13 \\
\hline 73 & $\begin{array}{l}\text { Vigna unguiculata (L.) Walp. ssp. } \\
\text { sesquipedalis }\end{array}$ & Fabaceae & Yard-long bean & Kacang panjang & 3 & 0 & 1 & 2 & 2 & $5 ; 13$ \\
\hline 74 & Youngia japonica (L.) DC. (=Crepis jap.) & Asteraceae & & Sayur sawi bunga & 1 & 1 & 1 & & 2 & \\
\hline 75 & Areca catechu L. & Arecaceae & Betelnut palm & Palem pinang & 1 & 0 & 0 & 1 & 3 & 5 \\
\hline 76 & Areca sp. & Arecaceae & & Pinang hutan (harao) & 1 & 1 & 0 & 1 & 3 & 5 \\
\hline 77 & Arenga pinnata (Wurmb.) Merr. & Arecaceae & Sugar palm & Enau & 1 & 0 & 0 & 1 & 3 & $1 ; 2 ; 13 ; 14$ \\
\hline 78 & Camellia sinensis (L.) Kuntze & Theaceae & Tea & Teh & 1 & 0 & 0 & 2 & 3 & $5 ; 12 ; 16$ \\
\hline 79 & Coffea arabica L. & Rubiaceae & Arabica coffee & Kopi arabika & 3 & 0 & 0 & 3 & 3 & $5 ; 13$ \\
\hline 80 & Coffea canephora Pierre ex Froehner & Rubiaceae & Robusta coffee & Kopi robusta & 1 & 0 & 0 & 3 & 3 & $5 ; 14$ \\
\hline 81 & Coffea liberica Bull. & Rubiaceae & Liberica coffee & Kopi besar (belulang) & 1 & 0 & 0 & 3 & 3 & \\
\hline 82 & Nicotiana tabacum L. & Solanaceae & Tobacco & Tembakau & 2 & 0 & 0 & 5 & 3 & $5 ; 12$ \\
\hline 83 & Piper betle L. & Piperaceae & Betel pepper & Sirih & 1 & 0 & 0 & 1 & 3 & $5 ; 15$ \\
\hline 84 & Saccharum officinarum L. & Poaceae & Sugar cane & Tebu & 3 & 0 & 0 & 2 & 3 & $5 ; 13 ; 15 ; 16$ \\
\hline 85 & Theobroma cacao L. & Sterculiaceae & Cacao & Coklat & 7 & 0 & 0 & 5 & 3 & 13 \\
\hline 86 & Aleurites moluccana (L.) Willd. & Euphorbiaceae & Candle nut tree & Kemiri & 1 & 0 & 0 & 1 & 4 & $5 ; 7 ; 8 ; 13$ \\
\hline 87 & $\begin{array}{l}\text { Allium cepa L. Aggregatum Group (var. } \\
\text { ascalonicum) }\end{array}$ & Alliaceae & Shallot & Bawang merah & 1 & 0 & 0 & 2 & 4 & \\
\hline 88 & Allium fistulosum $\mathrm{L}$. & Alliaceae & Spring onion & Bawang daun & 2 & 0 & 0 & 2 & 4 & $5 ; 13$ \\
\hline 89 & Allium schoenoprasum L. & Alliaceae & Chives & Bawang piara/nkundu & 1 & 0 & 0 & 4 & 4 & 5 \\
\hline 90 & Alpinia galanga (L.) Willd. & Zingiberaceae & Great galanga & Lengkuas & 1 & 0 & 0 & 1 & 4 & 5 \\
\hline 91 & Alpinia sp. & Zingiberaceae & & (Bumbu talas) & 1 & 0 & 0 & 2 & 4 & 5 \\
\hline 92 & Apium graveolens L. var. secalinum Alef. & Apiaceae & Celery & Seledri & 1 & 0 & 0 & & 4 & 5 \\
\hline 93 & Arachis hypogaea L. & Fabaceae & Groundnut & Kacang tanah & 2 & 0 & 1 & 5 & 4 & 13 \\
\hline 94 & Capsicum annuum L. & Solanaceae & Chilli & Cabe & 10 & 0 & 0 & 5 & 4 & $2 ; 5 ; 13 ; 15$ \\
\hline 95 & Cinnamomum burmanii (Nees) Blume & Lauraceae & Indonesian cassia & Kayu manis & 1 & 0 & 0 & 1 & 4 & \\
\hline 96 & Citrus hystrix DC. & Rutaceae & Kaffir lime & Jeruk ikan/purut & 1 & 0 & 0 & 1 & 4 & 1 \\
\hline 97 & Curcuma longa L. & Zingiberaceae & Turmeric & Kunyit & 1 & 0 & 0 & 1 & 4 & $5 ; 13$ \\
\hline 98 & Cymbopogon citratus (DC.) Stapf & Poaceae & Lemon grass & Daun serai & 1 & 0 & 0 & 1 & 4 & 5 \\
\hline 99 & Cymbopogon flexuosus (Steud.) Stapf & Poaceae & Malabar lemon grass & Daun serai belanda & 1 & 0 & 0 & 2 & 4 & 5 \\
\hline 100 & Etlingera sp. & Zingiberaceae & & (Bongkot) & 1 & 0 & 0 & 2 & 4 & \\
\hline 101 & Foeniculum vulgare Mill. & Apiaceae & Fennel & Adas & 1 & 0 & 0 & 4 & 4 & $2 ; 5$ \\
\hline 102 & Kaempferia galanga L. & Zingiberaceae & East Indian galangal & Kencur & 1 & 0 & 0 & 2 & 4 & 5 \\
\hline 103 & Mentha $x$ piperita $\mathrm{L}$. & Lamiaceae & Peppermint & Daun solasi & 1 & 0 & 0 & 4 & 4 & 5 \\
\hline 104 & Momordica charantia L. & Cucurbitaceae & Bitter gourd & Paria & 1 & 0 & 1 & 2 & 4 & $2 ; 5$ \\
\hline 105 & Ocimum basilicum L. & Lamiaceae & Basil & Kemangi & 1 & 0 & 1 & & 4 & $5 ; 13$ \\
\hline 106 & Pandanus amaryllifolius Roxb. & Pandanaceae & Fragant screw pine & Pandan & 1 & 0 & 0 & & 4 & $5 ; 11 ; 15$ \\
\hline 107 & Piper nigrum L. & Piperaceae & Pepper & Merica & 1 & 0 & 0 & 2 & 4 & $5 ; 13$ \\
\hline 108 & Sesamum indicum L. & Pedaliaceae & Sesame & Wijen & 1 & 0 & 1 & 2 & 4 & \\
\hline 109 & Suaeda sp. & Chenopodiaceae & & $\begin{array}{l}\text { Bumbu tinotuan } \\
\text { (pasote) }\end{array}$ & 1 & 1 & 0 & & 4 & 5 \\
\hline 110 & Syzygium aromaticum (L.) Merr. \& Perry & Myrtaceae & Clove & Cengkeh & 1 & 0 & 0 & 1 & 4 & 13 \\
\hline 111 & Syzygium polyanthum (Wight) Walp. & Myrtaceae & Indonesian bay-leaf & Salam & 1 & 0 & 0 & 2 & 4 & $2 ; 7$ \\
\hline 112 & Tamarindus indica L. & Fabaceae/Caes. & Tamarind & Asam jawa & 1 & 0 & 0 & 3 & 4 & 5 \\
\hline 113 & Vanilla planifolia Andr. & Orchidaceae & Vanilla & Vanili & 1 & 0 & 0 & 5 & 4 & 13 \\
\hline 114 & Zingiber officinale Roscoe & Zingiberaceae & Ginger & Jahe & 2 & 0 & 0 & 2 & 4 & $5 ; 13$ \\
\hline 115 & Acorus calamus L. & $\begin{array}{l}\text { Araceae/Acorace } \\
\text { ae }\end{array}$ & Sweet flag & Dringo (kariango) & 1 & 0 & 0 & 2 & 5 & 17 \\
\hline 116 & $\begin{array}{l}\text { Allium ramosum L. (= A. tuberosum } \\
\text { Rottler ex Sprengel) }\end{array}$ & Alliaceae & Chinese chives & $\begin{array}{l}\text { Bawang kucai (lehune } \\
\text { mpipi) }\end{array}$ & 1 & 0 & 0 & 2 & 5 & 4 \\
\hline 117 & Aloe barbadensis Mill. & Asphodelaceae & True aloe & Lidah boaya & 1 & 0 & 0 & 3 & 5 & 12 \\
\hline 118 & Blumea balsamifera (L.) DC. & Asteraceae & Camphor plant & Sembung (tobuburi) & 1 & 0 & 0 & 1 & 5 & \\
\hline 119 & Celosia argentea L. & Amaranthaceae & Green soko & (Bunga imba) & 1 & 0 & 1 & & 5 & \\
\hline 120 & Centella asiatica (L.) Urb. in Mart. & Apiaceae & Asiatic pennywort & Tapu kuda & 1 & 1 & 0 & 1 & 5 & \\
\hline 121 & Clematis smilacifolia Wall. & Ranunculaceae & & Obat gigi & 1 & 1 & 0 & 1 & 5 & \\
\hline
\end{tabular}




\begin{tabular}{|c|c|c|c|c|c|c|c|c|c|c|}
\hline No. & Species name & Family & Common name & $\begin{array}{l}\text { Indonesian name } \\
\text { (local name) }\end{array}$ & $\begin{array}{l}\text { Var } \\
\text { no. }\end{array}$ & Wild & Ann. & $\begin{array}{l}\text { Ori- } \\
\text { gin }\end{array}$ & $\begin{array}{l}\text { Main } \\
\text { use }\end{array}$ & $\begin{array}{l}\text { Secondary } \\
\text { uses }\end{array}$ \\
\hline 122 & Clerodendron sp. & Verbenaceae & & $\begin{array}{l}\text { Patah tulang } \\
\text { (lelimbanua) }\end{array}$ & 1 & 1 & 0 & 1 & 5 & \\
\hline 123 & Cordyline fruticosa (L.) Goepp. & Asteliaceae & Palm lily & $\begin{array}{l}\text { Andong (bunga } \\
\text { tabang) }\end{array}$ & 1 & 0 & 0 & 1 & 5 & $12 ; 17$ \\
\hline 124 & $\begin{array}{l}\text { Costus speciosus (Koenig in Retz.) J.E. } \\
\text { Sm. }\end{array}$ & Zingiberaceae & Crepe ginger & Pacing (tuwu-tuwu) & 1 & 0 & 0 & 1 & 5 & \\
\hline 125 & Curcuma xanthorrhiza Roxb. & Zingiberaceae & & Temu lawak & 1 & 0 & 0 & 1 & 5 & \\
\hline 126 & Cyperus rotundus L. & Cyperaceae & Purple nut grass & Rumput tekih & 1 & 1 & 0 & 3 & 5 & \\
\hline 127 & Dichrocephala integrifolia (L.f.) Kuntze & Asteraceae & & (Panaramanu) & 1 & 1 & 1 & 1 & 5 & \\
\hline 128 & Eleutherine palmifolia (L.) Merr. & Iridaceae & & $\begin{array}{l}\text { Bawang kapal (lehune } \\
\text { topeole) }\end{array}$ & 1 & 1 & 0 & 5 & 5 & \\
\hline 129 & Equisetum debile Roxb. & Equisetaceae & & $\begin{array}{l}\text { (Uhouhou/tikel } \\
\text { balung) }\end{array}$ & 1 & 1 & 0 & 1 & 5 & \\
\hline 130 & Graptophyllum pictum (L.) Griff. & Acanthaceae & Carricature plant & Daun teman/ungu & 1 & 0 & 0 & 3 & 5 & 15 \\
\hline 131 & Gynura procumbens (Lour.) Merr. & Asteraceae & & Sambung myawa & 1 & 0 & 0 & 3 & 5 & \\
\hline 132 & Hemigraphis bicolor Boerl. & Acanthaceae & & Kembang & 1 & 0 & 0 & & 5 & 17 \\
\hline 133 & Hibiscus acetosella Welw. ex Hierr. & Malvaceae & False roselle & Obat bunga merah & 1 & 0 & 0 & 3 & 5 & \\
\hline 134 & Hippeastrum puniceum (Lam.) Voss & Amaryllidaceae & Barbados lily & Bunga oktober & 1 & 0 & 0 & 5 & 5 & 12 \\
\hline 135 & Homalomena cordata Schott & Araceae & & (Kalomba) & 1 & 1 & 0 & 1 & 5 & 17 \\
\hline 136 & Jatropha curcas L. & Euphorbiaceae & Purging nut & Jarak pagar (belacair) & 1 & 0 & 0 & 5 & 5 & $7 ; 16$ \\
\hline 137 & Kalanchoe pinnata (Lam.) Pers. & Crassulaceae & Floppers & $\begin{array}{l}\text { Sosor bebek (lompo- } \\
\text { lompo) }\end{array}$ & 2 & 0 & 0 & 3 & 5 & 12 \\
\hline 138 & Morinda citrifolia L. & Rubiaceae & Indian mulberry & Mengkudu & 1 & 0 & 0 & 1 & 5 & \\
\hline 139 & Orthosiphon aristatus (Blume) Miq. & Lamiaceae & Cat's whizkers & Kumis kucing & 1 & 0 & 0 & 1 & 5 & 16 \\
\hline 140 & Picria felterrae Lour. & $\begin{array}{l}\text { Scrophulariacea } \\
\text { e }\end{array}$ & & (Lubi-lubi) & 1 & 1 & 1 & 1 & 5 & \\
\hline 141 & Piper caninum Blume & Piperaceae & & Sirih hutan & 1 & 1 & 0 & 1 & 5 & \\
\hline 142 & Plectranthus amboinicus (Lour.) Spreng. & Lamiaceae & Indian borage & Daun tebal/jinten & 1 & 0 & 0 & 1 & 5 & 4 \\
\hline 143 & Premna trichostoma Miq. & Verbenaceae & & (Daluman) & 1 & 0 & 0 & 1 & 5 & \\
\hline 144 & Ricinus communis L. & Euphorbiaceae & Castor bean & Jarak & 1 & 0 & 0 & 2 & 5 & \\
\hline 145 & Sansevieria trifasciata Prain & Dracaenaceae & Bowstring hemp & $\begin{array}{l}\text { Lidah mertua (bunga } \\
\text { pedang) }\end{array}$ & 1 & 0 & 0 & 3 & 5 & \\
\hline 146 & Senna alata (L.) Roxb. & Fabaceae/Caes. & Ringworm bush & Ketepeng & 1 & 0 & 0 & 5 & 5 & \\
\hline 147 & Solenostemon scutellarioides (L.) Codd & Lamiaceae & Painted nettle & Bunga mayana & 2 & 0 & 0 & 1 & 5 & $2 ; 12$ \\
\hline 148 & Strobilanthes crispa (L.) Blume & Acanthaceae & Cone head & Pijahbeling & 1 & 0 & 0 & & 5 & 12 \\
\hline 149 & Symphytum officinale L. & Boraginaceae & Common Comfrey & Obat jamur/komfrey & 1 & 0 & 0 & 4 & 5 & \\
\hline 150 & Synadenium grantii Hook.f. & Euphorbiaceae & African milk bush & Obat panas & 1 & 0 & 0 & 3 & 5 & \\
\hline 151 & Talinum paniculatum (Jacq.) Gaertn. & Portulacaceae & Fame flower & Rumput ginseng & 1 & 0 & 0 & 5 & 5 & \\
\hline 152 & Talinum triangulare (Jacq.) Willd. & Portulacaceae & Surinam purslane & Ginseng poslen & 1 & 0 & 0 & 5 & 5 & 12 \\
\hline 153 & Tinospora crispa Miers & Menispermaceae & & $\begin{array}{l}\text { Bratawali (pancar } \\
\text { sona) }\end{array}$ & 1 & 0 & 0 & 1 & 5 & \\
\hline 154 & Zingiber aromaticum Val. & Zingiberaceae & & $\begin{array}{l}\text { Lempuyang wangi } \\
\text { (gambongan) }\end{array}$ & 1 & 0 & 0 & 1 & 5 & $4 ; 15 ; 17$ \\
\hline 155 & Zingiber purpureum Roscoe & Zingiberaceae & Cassumunar ginger & Banglai & 1 & 0 & 0 & 2 & 5 & 2 \\
\hline 156 & Canna edulis Ker-Gawl. & Cannaceae & Queensland arrowroot & Ganyong & 1 & 0 & 0 & 5 & 6 & \\
\hline 157 & $\begin{array}{l}\text { Colocasia esculenta (L.) Schott ex } \\
\text { Schott \& Endl. }\end{array}$ & Araceae & Taro & Keladi (upe) & 2 & 0 & 0 & 1 & 6 & $2 ; 10$ \\
\hline 158 & Dioscorea bulbifera L. & Dioscoreaceae & Aerial yam & Sekapo & 1 & 0 & 0 & 3 & 6 & \\
\hline 159 & Ipomoea batatas (L.) Lam. & Convolvulaceae & Sweet potato & Ubi jalar/ubi merah & 3 & 0 & 0 & 5 & 6 & $2 ; 5 ; 10 ; 13$ \\
\hline 160 & Manihot esculenta Crantz & Euphorbiaceae & Cassava & Ubi kayu & 4 & 0 & 0 & 5 & 6 & $2 ; 10 ; 13 ; 16$ \\
\hline 161 & Maranta arundinacea L. & Marantaceae & Arrowroot & Garut (parus) & 1 & 0 & 0 & 5 & 6 & 10 \\
\hline 162 & Oryza sativa L. & Poaceae & Rice & Padi & 2 & 0 & 1 & 2 & 6 & \\
\hline 163 & $\begin{array}{l}\text { Xanthosoma sagittifolium (L.) Schott ex } \\
\text { Schott \& Endl. }\end{array}$ & Araceae & New cocoyam & Keladi putih & 1 & 0 & 0 & 5 & 6 & $5 ; 10$ \\
\hline 164 & Xanthosoma violaceum Schott & Araceae & Blue taro/cocoyam & Keladi hitam & 1 & 0 & 0 & 5 & 6 & 10 \\
\hline 165 & Zea mays L. & Poaceae & Maize & Jagung & 3 & 0 & 1 & 5 & 6 & $2 ; 5 ; 10 ; 13$ \\
\hline 166 & Acalypha caturus Blume & Euphorbiaceae & & (Beranahe) & 1 & 1 & 0 & & 7 & 5 \\
\hline 167 & Acalypha marginata Spreng. & Euphorbiaceae & & (Ampana) & 1 & 1 & 0 & & 7 & 16 \\
\hline 168 & Bischofia javanica Blume & Euphorbiaceae & Bishop wood & Pepolo & 1 & 1 & 0 & 1 & 7 & $5 ; 16$ \\
\hline 169 & $\begin{array}{l}\text { Breynia microphylla (Kurz. ex Teijsm. \& } \\
\text { Binn.) Muell. Arg. }\end{array}$ & Euphorbiaceae & & Kayu rumput (teturu) & 1 & 1 & 0 & & 7 & \\
\hline 170 & $\begin{array}{l}\text { Cananga odorata (Lam.) Hook.f. \& } \\
\text { Thoms. }\end{array}$ & Annonaceae & Ilang-ilang & Kenanga (sandat) & 1 & 1 & 0 & 1 & 7 & 15 \\
\hline 171 & Crescentia cujete L. & Bignoniaceae & Calabash tree & Kayu tabu (bila) & 1 & 0 & 0 & 5 & 7 & $14 ; 16$ \\
\hline 172 & Dendrocalamus sp. & Poaceae & Giant bamboo & Bambu & 1 & 0 & 0 & 1 & 7 & $2 ; 14 ; 16$ \\
\hline 173 & Elmerrillia ovalis (Miq.) Dandy & Magnoliaceae & & Uru/cempaka & 1 & 1 & 0 & 1 & 7 & \\
\hline 174 & Euonymus javanicus Blume & Celastraceae & & (Patingka) & 1 & 1 & 0 & 1 & 7 & 16 \\
\hline 175 & Ficus septica Burm.f. & Moraceae & & (Leboni/lewunu) & 1 & 1 & 0 & 1 & 7 & $5 ; 11$ \\
\hline 176 & Ficus sp. 1 & Moraceae & & (Dodonga) & 1 & 1 & 0 & & 7 & \\
\hline 177 & Ficus sp. 2 & Moraceae & & (Lamba) & 1 & 1 & 0 & & 7 & 14 \\
\hline 178 & $\begin{array}{l}\text { Flemingia strobilifera (L.) Aiton \& W.T. } \\
\text { Aiton }\end{array}$ & Fabaceae & & (Soa-soa) & 1 & 1 & 0 & 1 & 7 & 5 \\
\hline 179 & Globba sp.? & Zingiberaceae & & (Kahimpo) & 1 & 1 & 0 & & 7 & 5 \\
\hline 180 & Glochidion rubrum Blume & Euphorbiaceae & & (Kahio) & 1 & 1 & 0 & & 7 & $1 ; 5$ \\
\hline 181 & Glochidion sp. & Euphorbiaceae & & (Bure-bure, tambone) & 1 & 1 & 0 & & 7 & $5 ; 16$ \\
\hline 182 & Gmelina arborea Roxb. & Verbenaceae & & Jati putih & 1 & 0 & 0 & 2 & 7 & 13 \\
\hline
\end{tabular}




\begin{tabular}{|c|c|c|c|c|c|c|c|c|c|c|}
\hline No. & Species name & Family & Common name & $\begin{array}{l}\text { Indonesian name } \\
\text { (local name) }\end{array}$ & $\begin{array}{ll}\text { Var } \\
\text { no. }\end{array}$ & Wild & Ann. & $\begin{array}{l}\text { Ori- } \\
\text { gin }\end{array}$ & $\begin{array}{l}\text { Main } \\
\text { use }\end{array}$ & $\begin{array}{l}\text { Secondary } \\
\text { uses }\end{array}$ \\
\hline 183 & Grewia laevigata Vahl. & Tiliaceae & & (Bonoh) & 1 & 1 & 0 & & 7 & \\
\hline 184 & Hibiscus macrophyllus Roxb. & Malvaceae & & (Tawe meapo) & 1 & 1 & 0 & & 7 & 11 \\
\hline 185 & Homalanthus populneus Pax & Euphorbiaceae & & (Belante) & 1 & 1 & 0 & & 7 & $5 ; 16$ \\
\hline 186 & Leucosyke condissima Wedd. & Urticaceae & & (Balowira) & 1 & 1 & 0 & & 7 & 1 \\
\hline 187 & Litsea sp. 1 & Lauraceae & & (Bitiahu) & 1 & 1 & 0 & & 7 & 3 \\
\hline 188 & Litsea sp. 2 & Lauraceae & & (Salamate) & 1 & 1 & 0 & & 7 & 5 \\
\hline 189 & Macaranga tanarius (L.) Muell. Arg. & Euphorbiaceae & & (Potimata) & 1 & 1 & 0 & 1 & 7 & 11 \\
\hline 190 & Macaranga triloba (Thunb.) Muell. Arg. & Euphorbiaceae & & (Lengkobu) & 1 & 1 & 0 & & 7 & 11 \\
\hline 191 & Melastoma malabathricum L. & $\begin{array}{l}\text { Melastomata- } \\
\text { ceae }\end{array}$ & $\begin{array}{l}\text { Singapore } \\
\text { rhododendron }\end{array}$ & (Wua-wua) & 1 & 1 & 0 & 1 & 7 & $1 ; 5$ \\
\hline 192 & Melochia umbellata (Wight) Stapf & Sterculiaceae & & (Bentunu) & 1 & 1 & 0 & 2 & 7 & 8 \\
\hline 193 & Morus alba L. & Moraceae & White mulberry & Murbei & 1 & 0 & 0 & 2 & 7 & $1 ; 2 ; 16$ \\
\hline 194 & Nauclea orientalis (L.) L. & Rubiaceae & & Kayu telur (towote) & 1 & 1 & 0 & 2 & 7 & \\
\hline 195 & Pinus merkusii Jungh. \& de Vriese & Pinaceae & Sumatra pine & Pinus & 1 & 0 & 0 & 1 & 7 & 12 \\
\hline 196 & $\begin{array}{l}\text { Pisonia umbellifera (J.R. \& G. Forst.) } \\
\text { Seem. }\end{array}$ & Nyctaginaceae & & (Berombo) & 1 & 1 & 0 & 2 & 7 & \\
\hline 197 & Platea sp. & Icacinaceae & & (Nkanona) & 1 & 1 & 0 & & 7 & \\
\hline 198 & Pothomorphe umbellata (L.) Miq. & Piperaceae & & (Lepo-lepo) & 1 & 1 & 0 & 5 & 7 & $4 ; 5$ \\
\hline 199 & Premna serratifolia L. & Verbenaceae & & (Arogo) & 1 & 1 & 0 & 2 & 7 & $2 ; 5 ; 16$ \\
\hline 200 & Sambucus canadensis L. & Caprifoliaceae & Canadian elder & (Doda) & 1 & 1 & 0 & 5 & 7 & 15 \\
\hline 201 & Tectona grandis L.f. & Verbenaceae & Teak wood & Jati mas & 1 & 0 & 0 & 1 & 7 & 13 \\
\hline 202 & Trema orientalis (L.) Blume & Ulmaceae & Indian charcoal tree & (Bolah) & 1 & 1 & 0 & 1 & 7 & \\
\hline 203 & Trema sp. & Ulmaceae & & (Ntowiroe) & 1 & 1 & 0 & & 7 & \\
\hline 204 & Wendlandia paniculata (Roxb.) DC. & Rubiaceae & & (Parahoa) & 1 & 1 & 0 & & 7 & 5 \\
\hline 205 & Wendlandia sp. & Rubiaceae & & (Urio) & 1 & 1 & 0 & & 7 & \\
\hline 206 & $\begin{array}{l}\text { Erythrina subumbrans (Hassk.) Merrill } \\
\text { (=variegata) (orientalis?) }\end{array}$ & Fabaceae & December coral tree & Dadap & 1 & 0 & 0 & 2 & 8 & \\
\hline 207 & $\begin{array}{l}\text { Flemingia macrophylla (Willd.) Blume ex } \\
\text { Miq. }\end{array}$ & Fabaceae & & (Ingan-ingan) & 1 & 0 & 0 & 1 & 8 & 16 \\
\hline 208 & Gliricidia sepium (Jacq.) Kunth ex Walp. & Fabaceae & Mother of cocoa & Gamal & 1 & 0 & 0 & 5 & 8 & $2 ; 5 ; 10 ; 16$ \\
\hline 209 & Leucaena leucocephala (Lam.) De Wit & Fabaceae/Mim. & Horse tamarind & Lamtoro & 1 & 0 & 0 & 5 & 8 & $2 ; 4 ; 5 ; 10$ \\
\hline 210 & Manihot glaziovii Müll. Arg. in Mart. & Euphorbiaceae & Tree cassava & Ubi karet & 1 & 0 & 0 & 5 & 8 & $2 ; 5 ; 10$ \\
\hline 211 & Mucuna pruriens cv. group utilis (L.) DC. & Fabaceae & Velvet bean & Kacang benguk & 1 & 0 & 1 & & 8 & 2 \\
\hline 212 & Paraserianthes falcataria (L.) Nielsen & Fabaceae/Mim. & White albizia & Sengon & 1 & 0 & 0 & & 8 & \\
\hline 213 & Tephrosia vogelii Hook.f. in Hook. & Fabaceae & Fish poison bean & (Gereng-gereng) & 1 & 0 & 0 & 3 & 8 & \\
\hline 214 & Calamus sp. & Arecaceae & Rattan cane & Rotan & 1 & 1 & 0 & 1 & 9 & $13 ; 14$ \\
\hline 215 & Ceiba pentandra (L.) Gaertn. & Bombacaceae & Silk-cotton tree & Pohon kapuk & 1 & 0 & 0 & 5 & 9 & 14 \\
\hline 216 & Coix lacryma-jobi L. & Poaceae & Job's tears & Jali (kalide) & 1 & 0 & 0 & 2 & 9 & $12 ; 15$ \\
\hline 217 & Gossypium barbadense L. & Malvaceae & Cotton & Kapok/kapas & 1 & 0 & 0 & & 9 & $12 ; 14 ; 15$ \\
\hline 218 & Heliconia indica Lam. & Heliconiaceae & False bird-of-paradise & Daun bungkus & 1 & 0 & 0 & & 9 & $5 ; 11$ \\
\hline 219 & Pennisetum purpureum Schum. & Poaceae & Napier grass & Rumput gadjah & 1 & 0 & 0 & & 9 & 10 \\
\hline 220 & Phrynium pubinerve Blume & Marantaceae & & (Malanipa) & 1 & 1 & 0 & 1 & 9 & 11 \\
\hline 221 & Stephania corymbosa (Blume) Spreng. & Menispermaceae & & Cincau (daluman) & 1 & 0 & 0 & 1 & 9 & 5 \\
\hline
\end{tabular}

Note: Coloured cells $=$ Species cultivated only in 2001 and/or 2003.

Coding:

Domestication status:

$0=$ Domesticated

$1=$ Wild
Life form :

$0=$ Perennial

$1=$ Annual
Origin:

$1=S E-A s i a$

$2=$ Asia

$3=$ Africa

$4=$ Europe

$5=$ America
Main and secondary uses:

$\begin{array}{ll}1=\text { Fruit } & 10=\text { Fodder } \\ 2=\text { Vegetable } & 11=\text { Wrapping } \\ 3=\text { Stimulant } & 12=\text { Ornament } \\ 4=\text { Spice } & 13=\text { Cash } \\ 5=\text { Medicine } & 14=\text { Handicraft } \\ 6=\text { Staple } & 15=\text { Sacrifices } \\ 7=\text { Wood } & 16=\text { Fence } \\ 8=\text { MPU } & 17=\text { Mystic }\end{array}$


Appendix 13. Individual numbers and frequencies of crop plant species (ordered by main use categories) cultivated in 30-50 homegardens in 3-5 villages of the Napu valley, Central Sulawesi, in 2001, 2003, and 2004. N per village $=10$, apart from Rompo 2004: $N=8$; Siliwanga 2003: $N=9$, Siliwanga 2004: $N=8$. (Sili. = Siliwanga; Sili. new = Siliwanga including two 'new' homegardens to replace the abandoned ones; Ta. $=$ Tamadue; Wg. $=$ Wanga).

\begin{tabular}{|c|c|c|c|c|c|c|c|c|c|c|c|c|c|c|c|c|c|c|c|c|c|c|c|c|}
\hline \multirow[b]{3}{*}{ Species name } & \multicolumn{9}{|c|}{ Number of individuals } & \multicolumn{3}{|l|}{ Sili. } & \multicolumn{9}{|c|}{ Frequencies (\%) } & \multicolumn{3}{|l|}{ Sili. } \\
\hline & Wua & asa & & Rom & npo & & Sili. & & & new & Ta. & Wg. & Wua & & & Rom & nро & & Sili. & & & new & Ta. & Wg. \\
\hline & 01 & 03 & 04 & 01 & 03 & 04 & 01 & 03 & 04 & 04 & 04 & 04 & 01 & 03 & 04 & 01 & 03 & 04 & 01 & 03 & 04 & 04 & 04 & 04 \\
\hline Anacardium occidentale & 0 & 0 & 0 & 0 & 0 & 0 & 1 & 1 & 1 & 1 & 0 & 0 & 0 & 0 & 0 & 0 & 0 & 0 & 10 & 11 & 13 & 10 & 0 & 0 \\
\hline Ananas comosus & 210 & 169 & 267 & 63 & 69 & 33 & 244 & 171 & 248 & 262 & 0 & 23 & 60 & 60 & 70 & 50 & 60 & 63 & 70 & 89 & 88 & 80 & 0 & 30 \\
\hline Annona muricata & 0 & 0 & 0 & 1 & 3 & 2 & 0 & 0 & 0 & 0 & 2 & 1 & 0 & 0 & 0 & 10 & 20 & 25 & 0 & 0 & 0 & 0 & 20 & 10 \\
\hline Carica papaya & 9 & 15 & 19 & 31 & 25 & 35 & 15 & 8 & 9 & 10 & 12 & 26 & 50 & 50 & 60 & 80 & 70 & 75 & 50 & 44 & 63 & 60 & 20 & 80 \\
\hline $\begin{array}{l}\text { Citrullus lanatus ssp. vulgaris } \\
\text { Dessert Group }\end{array}$ & 0 & 0 & 1 & 0 & 2 & 0 & 0 & 0 & 0 & 0 & 0 & 1 & 0 & 0 & 10 & 0 & 20 & 0 & 0 & 0 & 0 & 0 & 0 & 10 \\
\hline Citrus aurantiifolia & 0 & 0 & 0 & 1 & 1 & 1 & 0 & 0 & 0 & 0 & 0 & 3 & 0 & 0 & 0 & 10 & 10 & 13 & 0 & 0 & 0 & 0 & 0 & 20 \\
\hline Citrus maxima & 10 & 23 & 15 & 12 & 18 & 16 & 3 & 3 & 2 & 2 & 4 & 6 & 60 & 80 & 70 & 80 & 70 & 75 & 20 & 22 & 25 & 20 & 40 & 50 \\
\hline Citrus medica & 0 & 0 & 2 & 0 & 0 & 2 & 0 & 1 & 6 & 7 & 2 & 9 & 0 & 0 & 20 & 0 & 0 & 13 & 0 & 11 & 38 & 40 & 10 & 50 \\
\hline Citrus reticulata & 23 & 23 & 24 & 5 & 52 & 38 & 47 & 87 & 86 & 121 & 43 & 23 & 50 & 50 & 60 & 40 & 90 & 88 & 80 & 89 & 88 & 90 & 80 & 50 \\
\hline Citrus sinensis & 1 & 1 & 1 & 5 & 4 & 9 & 13 & 17 & 16 & 18 & 0 & 7 & 10 & 10 & 10 & 20 & 20 & 38 & 50 & 56 & 50 & 60 & 0 & 40 \\
\hline Citrus sp. & 6 & 5 & 2 & 1 & 3 & 4 & 1 & 2 & 4 & 4 & 1 & 10 & 20 & 30 & 20 & 10 & 20 & 38 & 10 & 22 & 38 & 30 & 10 & 50 \\
\hline Clausena sp.? & 0 & 0 & 2 & 0 & 0 & 0 & 0 & 0 & 0 & 0 & 0 & 0 & 0 & 0 & 20 & 0 & 0 & 0 & 0 & 0 & 0 & 0 & 0 & 0 \\
\hline Cocos nucifera & 10 & 10 & 13 & 12 & 10 & 7 & 13 & 11 & 11 & 11 & 50 & 9 & 60 & 60 & 60 & 40 & 40 & 50 & 60 & 67 & 75 & 60 & 80 & 40 \\
\hline Dimocarpus longan & 3 & 3 & 3 & 0 & 0 & 0 & 0 & 0 & 0 & 0 & 2 & 0 & 20 & 20 & 20 & 0 & 0 & 0 & 0 & 0 & 0 & 0 & 20 & 0 \\
\hline Durio zibethinus & 4 & 4 & 3 & 10 & 8 & 8 & 1 & 1 & 2 & 2 & 9 & 5 & 30 & 40 & 30 & 30 & 20 & 38 & 10 & 11 & 25 & 20 & 40 & 20 \\
\hline Garcinia mangostana & 0 & 1 & 1 & 0 & 0 & 2 & 0 & 0 & 0 & 0 & 0 & 2 & 0 & 10 & 10 & 0 & 0 & 13 & 0 & 0 & 0 & 0 & 0 & 10 \\
\hline Lansium domesticum & 5 & 6 & 9 & 2 & 2 & 2 & 0 & 0 & 0 & 0 & 0 & 1 & 10 & 20 & 30 & 10 & 10 & 13 & 0 & 0 & 0 & 0 & 0 & 10 \\
\hline Mangifera indica & 20 & 19 & 30 & 12 & 30 & 22 & 11 & 7 & 7 & 8 & 39 & 20 & 100 & 100 & 100 & 70 & 90 & 63 & 70 & 56 & 63 & 60 & 100 & 100 \\
\hline Manilkara zapota & 0 & 0 & 0 & 0 & 0 & 0 & 0 & 0 & 0 & 0 & 1 & 0 & 0 & 0 & 0 & 0 & 0 & 0 & 0 & 0 & 0 & 0 & 10 & 0 \\
\hline Musa $x$ paradisiaca & 195 & 186 & 184 & 161 & 116 & 143 & 295 & 187 & 268 & 300 & 128 & 29 & 100 & 100 & 80 & 90 & 90 & 100 & 90 & 89 & 88 & 90 & 90 & 50 \\
\hline Nephelium lappaceum & 2 & 8 & 10 & 3 & 3 & 4 & 2 & 3 & 2 & 4 & 15 & 9 & 20 & 50 & 50 & 20 & 30 & 38 & 20 & 33 & 25 & 30 & 60 & 30 \\
\hline Passiflora edulis & 0 & 1 & 2 & 2 & 0 & 0 & 7 & 6 & 2 & 2 & 9 & 1 & 0 & 10 & 10 & 20 & 0 & 0 & 40 & 33 & 13 & 10 & 50 & 10 \\
\hline Passiflora ligularis & 0 & 0 & 0 & 0 & 0 & 0 & 4 & 1 & 1 & 1 & 0 & 0 & 0 & 0 & 0 & 0 & 0 & 0 & 10 & 11 & 13 & 10 & 0 & 0 \\
\hline Persea americana & 17 & 17 & 25 & 1 & 0 & 0 & 9 & 9 & 8 & 8 & 5 & 7 & 60 & 90 & 90 & 10 & 0 & 0 & 40 & 56 & 50 & 40 & 30 & 40 \\
\hline Pometia pinnata & 4 & 3 & 3 & 0 & 0 & 0 & 0 & 0 & 0 & 0 & 0 & 0 & 10 & 10 & 10 & 0 & 0 & 0 & 0 & 0 & 0 & 0 & 0 & 0 \\
\hline Psidium guajava & 32 & 32 & 39 & 35 & 43 & 42 & 84 & 76 & 68 & 84 & 51 & 101 & 60 & 80 & 80 & 90 & 90 & 75 & 100 & 100 & 100 & 100 & 100 & 100 \\
\hline Rubus rosifolius & 0 & 0 & 8 & 0 & 9 & 16 & 0 & 0 & 0 & 0 & 0 & 32 & 0 & 0 & 10 & 0 & 10 & 13 & 0 & 0 & 0 & 0 & 0 & 30 \\
\hline Salacca zalacca & 2 & 1 & 2 & 2 & 2 & 3 & 1 & 1 & 1 & 1 & 2 & 0 & 10 & 10 & 20 & 10 & 10 & 13 & 10 & 11 & 13 & 10 & 10 & 0 \\
\hline Syzygium aqueum & 15 & 13 & 15 & 8 & 8 & 6 & 4 & 3 & 3 & 4 & 8 & 3 & 80 & 60 & 70 & 60 & 50 & 50 & 20 & 22 & 25 & 30 & 50 & 10 \\
\hline Syzygium malaccense & 0 & 0 & 0 & 1 & 1 & 1 & 0 & 0 & 0 & 0 & 4 & 0 & 0 & 0 & 0 & 10 & 10 & 13 & 0 & 0 & 0 & 0 & 20 & 0 \\
\hline Abelmoschus manihot & 8 & 1 & 2 & 1 & 0 & 0 & 0 & 0 & 2 & 2 & 0 & 7 & 30 & 10 & 20 & 10 & 0 & 0 & 0 & 0 & 13 & 10 & 0 & 10 \\
\hline Amaranthus tricolor & 63 & 19 & 84 & 40 & 123 & 29 & 77 & 29 & 10 & 19 & 9 & 21 & 20 & 50 & 50 & 50 & 80 & 50 & 40 & 78 & 50 & 60 & 30 & 60 \\
\hline Artocarpus altilis & 0 & 0 & 0 & 0 & 0 & 0 & 1 & 1 & 1 & 1 & 1 & 1 & 0 & 0 & 0 & 0 & 0 & 0 & 10 & 11 & 13 & 10 & 10 & 10 \\
\hline Artocarpus heterophyllus & 21 & 21 & 17 & 23 & 25 & 30 & 14 & 13 & 11 & 12 & 24 & 13 & 70 & 70 & 60 & 70 & 70 & 75 & 60 & 67 & 63 & 60 & 90 & 50 \\
\hline Athyrium esculentum & 0 & 16 & 28 & 0 & 0 & 6 & 0 & 0 & 0 & 0 & 11 & 0 & 0 & 30 & 40 & 0 & 0 & 25 & 0 & 0 & 0 & 0 & 30 & 0 \\
\hline Brassica juncea & 25 & 18 & 23 & 100 & 22 & 36 & 0 & 0 & 0 & 0 & 3 & 55 & 10 & 30 & 40 & 50 & 50 & 75 & 0 & 0 & 0 & 0 & 10 & 30 \\
\hline $\begin{array}{l}\text { Brassica oleracea ssp. } \\
\text { oleracea convar. capitata } \\
\text { var. capitata forma alba }\end{array}$ & 60 & 0 & 0 & 0 & 0 & 0 & 0 & 0 & 0 & 0 & 0 & 0 & 10 & 0 & 0 & 0 & 0 & 0 & 0 & 0 & 0 & 0 & 0 & 0 \\
\hline Brassica rapa ssp. chinensis & 0 & 0 & 0 & 1 & 0 & 0 & 0 & 0 & 0 & 0 & 0 & 0 & 0 & 0 & 0 & 10 & 0 & 0 & 0 & 0 & 0 & 0 & 0 & 0 \\
\hline Brassica rapa ssp. pekinensis & 0 & 0 & 0 & 1 & 25 & 0 & 0 & 0 & 0 & 0 & 0 & 0 & 0 & 0 & 0 & 10 & 10 & 0 & 0 & 0 & 0 & 0 & 0 & 0 \\
\hline Cajanus cajan & 0 & 0 & 0 & 0 & 0 & 0 & 0 & 0 & 0 & 1 & 0 & 0 & 0 & 0 & 0 & 0 & 0 & 0 & 0 & 0 & 0 & 10 & 0 & 0 \\
\hline Canavalia ensiformis & 0 & 0 & 0 & 0 & 0 & 0 & 0 & 0 & 0 & 0 & 0 & 4 & 0 & 0 & 0 & 0 & 0 & 0 & 0 & 0 & 0 & 0 & 0 & 10 \\
\hline Clerodendron minahassae & 7 & 15 & 17 & 138 & 99 & 160 & 0 & 0 & 0 & 0 & 0 & 5 & 20 & 30 & 40 & 40 & 40 & 38 & 0 & 0 & 0 & 0 & 0 & 30 \\
\hline Cosmos caudatus & 0 & 0 & 0 & 0 & 0 & 0 & 7 & 13 & 34 & 34 & 0 & 0 & 0 & 0 & 0 & 0 & 0 & 0 & 10 & 11 & 13 & 10 & 0 & 0 \\
\hline Cucumis sativus & 0 & 0 & 0 & 0 & 0 & 0 & 0 & 0 & 0 & 0 & 1 & 2 & 0 & 0 & 0 & 0 & 0 & 0 & 0 & 0 & 0 & 0 & 10 & 10 \\
\hline Cucurbita pepo & 24 & 45 & 76 & 20 & 30 & 20 & 9 & 32 & 27 & 27 & 8 & 36 & 80 & 90 & 70 & 60 & 50 & 50 & 40 & 78 & 100 & 80 & 30 & 80 \\
\hline Daucus carota ssp. sativus & 0 & 6 & 2 & 7 & 0 & 0 & 0 & 9 & 2 & 2 & 0 & 0 & 0 & 20 & 10 & 10 & 0 & 0 & 0 & 11 & 13 & 10 & 0 & 0 \\
\hline Enydra fluctuans & 0 & 0 & 0 & 0 & 0 & 0 & 25 & 65 & 45 & 45 & 0 & 0 & 0 & 0 & 0 & 0 & 0 & 0 & 10 & 11 & 13 & 10 & 0 & 0 \\
\hline Etlingera elatior & 0 & 0 & 0 & 0 & 0 & 0 & 1 & 3 & 1 & 1 & 0 & 0 & 0 & 0 & 0 & 0 & 0 & 0 & 10 & 11 & 13 & 10 & 0 & 0 \\
\hline Glycine max & 0 & 0 & 0 & 0 & 0 & 0 & 0 & 2 & 92 & 92 & 0 & 0 & 0 & 0 & 0 & 0 & 0 & 0 & 0 & 11 & 13 & 10 & 0 & 0 \\
\hline Hedychium coronarium & 0 & 0 & 0 & 0 & 0 & 1 & 0 & 0 & 0 & 0 & 0 & 1 & 0 & 0 & 0 & 0 & 0 & 13 & 0 & 0 & 0 & 0 & 0 & 10 \\
\hline Ipomoea aquatica & 13 & 34 & 8 & 40 & 16 & 12 & 130 & 28 & 46 & 46 & 49 & 0 & 30 & 50 & 30 & 10 & 20 & 25 & 40 & 56 & 63 & 50 & 40 & 0 \\
\hline Lablab purpureus & 0 & 0 & 0 & 0 & 0 & 0 & 0 & 0 & 0 & 0 & 3 & 0 & 0 & 0 & 0 & 0 & 0 & 0 & 0 & 0 & 0 & 0 & 20 & 0 \\
\hline Lagenaria siceraria & 0 & 0 & 0 & 0 & 0 & 2 & 0 & 0 & 0 & 0 & 0 & 0 & 0 & 0 & 0 & 0 & 0 & 13 & 0 & 0 & 0 & 0 & 0 & 0 \\
\hline Limnocharis flava & 0 & 0 & 0 & 0 & 0 & 0 & 0 & 0 & 0 & 0 & 15 & 0 & 0 & 0 & 0 & 0 & 0 & 0 & 0 & 0 & 0 & 0 & 10 & 0 \\
\hline Luffa acutangula & 0 & 0 & 0 & 0 & 0 & 4 & 0 & 2 & 0 & 0 & 0 & 0 & 0 & 0 & 0 & 0 & 0 & 13 & 0 & 11 & 0 & 0 & 0 & 0 \\
\hline Luffa aegyptiaca & 0 & 0 & 0 & 0 & 2 & 1 & 0 & 0 & 0 & 0 & 0 & 1 & 0 & 0 & 0 & 0 & 10 & 13 & 0 & 0 & 0 & 0 & 0 & 10 \\
\hline Lycopersicon esculentum & 77 & 87 & 163 & 79 & 110 & 30 & 30 & 35 & 26 & 26 & 7 & 35 & 70 & 100 & 100 & 90 & 100 & 75 & 60 & 56 & 75 & 60 & 20 & 70 \\
\hline Moringa oleifera & 0 & 0 & 0 & 0 & 2 & 2 & 0 & 0 & 0 & 0 & 2 & 0 & 0 & 0 & 0 & 0 & 10 & 25 & 0 & 0 & 0 & 0 & 10 & 0 \\
\hline Phaseolus lunatus & 0 & 0 & 0 & 0 & 0 & 0 & 3 & 12 & 33 & 36 & 1 & 0 & 0 & 0 & 0 & 0 & 0 & 0 & 10 & 33 & 50 & 50 & 10 & 0 \\
\hline $\begin{array}{c}\text { Phaseolus vulgaris ssp. } \\
\text { vulgaris var. nanus }\end{array}$ & 7 & 15 & 13 & 39 & 52 & 1 & 1 & 10 & 1 & 1 & 2 & 4 & 30 & 30 & 40 & 20 & 40 & 13 & 10 & 11 & 13 & 10 & 10 & 20 \\
\hline
\end{tabular}




\begin{tabular}{|c|c|c|c|c|c|c|c|c|c|c|c|c|c|c|c|c|c|c|c|c|c|c|c|c|}
\hline \multirow[b]{3}{*}{ Species name } & Num & aber o & ff indi & lividua & & & & & & Sili. & & & Fre & quenc & ies $(\%$ & & & & & & & & & \\
\hline & Wua & & & Rom & npo & & Sili. & & & new & Ta. & $\mathrm{Wg}$ & Wu & asa & & Rom & npo & & Sili. & & & new & Ta. & Wg. \\
\hline & 01 & 03 & 04 & 01 & 03 & 04 & 01 & 03 & 04 & 04 & 04 & 04 & 01 & 03 & 04 & 01 & 03 & 04 & 01 & 03 & 04 & 04 & 04 & 04 \\
\hline \begin{tabular}{|l|} 
Psophocarpus tetragonolobus \\
\end{tabular} & 0 & 2 & 0 & 3 & 1 & 10 & 0 & 0 & 0 & 0 & 0 & 0 & 0 & 10 & 0 & 10 & 10 & 25 & 0 & 0 & 0 & 0 & 0 & 0 \\
\hline Sauropus androgynus & 0 & 0 & 0 & 0 & 0 & 0 & 0 & 0 & 2 & 8 & 0 & 0 & 0 & 0 & 0 & 0 & 0 & 0 & 0 & 0 & 13 & 20 & 0 & 0 \\
\hline Sechium edule & 23 & 32 & 31 & 12 & 14 & 19 & 8 & 6 & 9 & 11 & 27 & 10 & 50 & 60 & 70 & 30 & 50 & 50 & 20 & 33 & 75 & 70 & 70 & 50 \\
\hline Solanum aethiopicum & 12 & 7 & 10 & 4 & 7 & 12 & 0 & 0 & 0 & 0 & 0 & 41 & 30 & 30 & 30 & 30 & 40 & 50 & 0 & 0 & 0 & 0 & 0 & 80 \\
\hline Solanum macrocarpon & 5 & 1 & 5 & 27 & 32 & 17 & 0 & 0 & 0 & 0 & 0 & 8 & 10 & 10 & 20 & 60 & 60 & 50 & 0 & 0 & 0 & 0 & 0 & 40 \\
\hline Solanum melongena & 24 & 25 & 39 & 59 & 104 & 68 & 6 & 17 & 23 & 24 & 2 & 30 & 30 & 60 & 80 & 80 & 70 & 75 & 20 & 33 & 50 & 50 & 10 & 20 \\
\hline Solanum nigrum & 0 & 0 & 0 & 5 & 1 & 0 & 0 & 0 & 0 & 0 & 0 & 0 & 0 & 0 & 0 & 10 & 10 & 0 & 0 & 0 & 0 & 0 & 0 & 0 \\
\hline Solanum torvum & 0 & 0 & 0 & 0 & 11 & 1 & 0 & 0 & 0 & 0 & 7 & 0 & 0 & 0 & 0 & 0 & 20 & 13 & 0 & 0 & 0 & 0 & 40 & 0 \\
\hline Solanum tuberosum & 6 & 1 & 17 & 0 & 0 & 1 & 0 & 0 & 0 & 0 & 0 & 0 & 20 & 10 & 10 & 0 & 0 & 13 & 0 & 0 & 0 & 0 & 0 & 0 \\
\hline Vigna angularis & 0 & 0 & 0 & 0 & 0 & 3 & 0 & 0 & 0 & 0 & 0 & 0 & 0 & 0 & 0 & 0 & 0 & 13 & 0 & 0 & 0 & 0 & 0 & 0 \\
\hline Vigna radiata & 0 & 0 & 0 & 0 & 0 & 0 & 0 & 0 & 21 & 21 & 0 & 0 & 0 & 0 & 0 & 0 & 0 & 0 & 0 & 0 & 13 & 10 & 0 & 0 \\
\hline Vigna sp. & 0 & 14 & 0 & 0 & 0 & 24 & 607 & 115 & 0 & 0 & 0 & 0 & 0 & 10 & 0 & 0 & 0 & 25 & 20 & 33 & 0 & 0 & 0 & 0 \\
\hline $\begin{array}{l}\text { Vigna unguiculata ssp. } \\
\text { sesquipedalis }\end{array}$ & 93 & 17 & 67 & 47 & 88 & 228 & 48 & 6 & 3 & 3 & 54 & 33 & 40 & 30 & 70 & 30 & 60 & 88 & 30 & 22 & 25 & 20 & 10 & 20 \\
\hline Youngia japonica & 0 & 0 & 0 & 0 & 0 & 0 & 0 & 0 & 0 & 0 & 1 & 0 & 0 & 0 & 0 & 0 & 0 & 0 & 0 & 0 & 0 & 0 & 10 & 0 \\
\hline Areca catechu & 0 & 0 & 0 & 1 & 1 & 1 & 0 & 0 & 0 & 0 & 0 & 0 & 0 & 0 & 0 & 10 & 10 & 13 & 0 & 0 & 0 & 0 & 0 & 0 \\
\hline Areca sp. & 0 & 0 & 0 & 1 & 0 & 0 & 0 & 0 & 0 & 0 & 0 & 0 & 0 & 0 & 0 & 10 & 0 & 0 & 0 & 0 & 0 & 0 & 0 & 0 \\
\hline Arenga pinnata & 1 & 0 & 9 & 4 & 1 & 11 & 0 & 0 & 0 & 0 & 0 & 0 & 10 & 0 & 10 & 30 & 10 & 25 & 0 & 0 & 0 & 0 & 0 & 0 \\
\hline Camellia sinensis & 0 & 0 & 0 & 0 & 0 & 0 & 36 & 36 & 30 & 30 & 1 & 0 & 0 & 0 & 0 & 0 & 0 & 0 & 40 & 67 & 63 & 50 & 10 & 0 \\
\hline Coffea arabica & 376 & 156 & 110 & 136 & 75 & 72 & 398 & 225 & 222 & 277 & 890 & 310 & 90 & 90 & 90 & 80 & 80 & 75 & 100 & 100 & 100 & 100 & 100 & 100 \\
\hline Coffea canephora & 44 & 42 & 55 & 146 & 115 & 173 & 120 & 139 & 150 & 150 & 168 & 54 & 70 & 80 & 70 & 80 & 80 & 88 & 60 & 78 & 75 & 60 & 80 & 70 \\
\hline Coffea liberica & 0 & 0 & 0 & 1 & 1 & 1 & 0 & 0 & 0 & 0 & 0 & 0 & 0 & 0 & 0 & 10 & 10 & 13 & 0 & 0 & 0 & 0 & 0 & 0 \\
\hline Nicotiana tabacum & 4 & 22 & 24 & 14 & 17 & 39 & 0 & 9 & 4 & 4 & 4 & 7 & 20 & 60 & 50 & 20 & 40 & 38 & 0 & 11 & 13 & 10 & 10 & 30 \\
\hline Piper betle & 0 & 1 & 3 & 0 & 0 & 1 & 0 & 0 & 0 & 0 & 3 & 0 & 0 & 10 & 30 & 0 & 0 & 13 & 0 & 0 & 0 & 0 & 20 & 0 \\
\hline Saccharum officinarum & 20 & 18 & 16 & 13 & 12 & 12 & 18 & 2 & 7 & 7 & 16 & 4 & 40 & 60 & 60 & 40 & 50 & 63 & 80 & 11 & 38 & 30 & 60 & 20 \\
\hline Theobroma cacao & 246 & 306 & 377 & 244 & 225 & 263 & 200 & 259 & 408 & 460 & 1028 & 204 & 90 & 100 & 100 & 90 & 100 & 100 & 80 & 89 & 100 & 100 & 100 & 100 \\
\hline Aleurites moluccana & 3 & 6 & 7 & 13 & 15 & 15 & 1 & 1 & 1 & 1 & 18 & 10 & 30 & 30 & 40 & 30 & 30 & 50 & 10 & 11 & 13 & 10 & 50 & 50 \\
\hline $\begin{array}{l}\text { Allium cepa L. Aggregatum } \\
\text { Group }\end{array}$ & 25 & 0 & 0 & 0 & 0 & 0 & 0 & 0 & 0 & 0 & 2 & 0 & 10 & 0 & 0 & 0 & 0 & 0 & 0 & 0 & 0 & 0 & 10 & 0 \\
\hline Allium fistulosum & 784 & 3490 & 661 & 566 & 343 & 296 & 35 & 94 & 221 & 221 & 7 & 279 & 80 & 90 & 80 & 80 & 80 & 88 & 20 & 11 & 25 & 20 & 10 & 70 \\
\hline Allium schoenoprasum & 29 & 12 & 12 & 142 & 23 & 8 & 0 & 0 & 0 & 0 & 0 & 18 & 50 & 30 & 40 & 70 & 50 & 25 & 0 & 0 & 0 & 0 & 0 & 10 \\
\hline Alpinia galanga & 19 & 27 & 52 & 7 & 9 & 10 & 43 & 11 & 21 & 21 & 6 & 33 & 50 & 60 & 50 & 20 & 50 & 50 & 50 & 56 & 63 & 50 & 50 & 60 \\
\hline Alpinia sp. & 0 & 0 & 0 & 0 & 0 & 0 & 0 & 0 & 0 & 0 & 2 & 0 & 0 & 0 & 0 & 0 & 0 & 0 & 0 & 0 & 0 & 0 & 10 & 0 \\
\hline $\begin{array}{l}\text { Apium graveolens var. } \\
\text { secalinum }\end{array}$ & 30 & 23 & 48 & 12 & 9 & 19 & 12 & 4 & 6 & 6 & 20 & 14 & 20 & 30 & 80 & 40 & 20 & 50 & 40 & 22 & 38 & 30 & 40 & 40 \\
\hline Arachis hypogaea & 520 & 28 & 2455 & 2 & 1 & 30 & 3 & 0 & 0 & 0 & 0 & 0 & 40 & 30 & 30 & 10 & 10 & 25 & 20 & 0 & 0 & 0 & 0 & 0 \\
\hline Capsicum annuum & 57 & 72 & 116 & 109 & 105 & 97 & 57 & 53 & 116 & 123 & 17 & 100 & 90 & 90 & 100 & 100 & 90 & 88 & 70 & 100 & 100 & 100 & 70 & 90 \\
\hline Cinnamomum burmanii & 1 & 1 & 1 & 0 & 0 & 0 & 0 & 0 & 0 & 0 & 0 & 0 & 10 & 10 & 10 & 0 & 0 & 0 & 0 & 0 & 0 & 0 & 0 & 0 \\
\hline Citrus hystrix & 1 & 4 & 4 & 0 & 0 & 0 & 1 & 0 & 1 & 1 & 0 & 0 & 10 & 30 & 30 & 0 & 0 & 0 & 10 & 0 & 13 & 10 & 0 & 0 \\
\hline Curcuma longa & 63 & 65 & 98 & 42 & 17 & 18 & 11 & 9 & 23 & 23 & 12 & 71 & 70 & 80 & 80 & 90 & 70 & 75 & 40 & 67 & 75 & 60 & 60 & 90 \\
\hline Cymbopogon citratus & 37 & 60 & 67 & 24 & 16 & 6 & 13 & 17 & 17 & 18 & 33 & 45 & 90 & 90 & 90 & 60 & 50 & 50 & 50 & 67 & 88 & 80 & 50 & 60 \\
\hline Cymbopogon flexuosus & 0 & 1 & 1 & 0 & 0 & 0 & 0 & 0 & 0 & 0 & 0 & 0 & 0 & 10 & 10 & 0 & 0 & 0 & 0 & 0 & 0 & 0 & 0 & 0 \\
\hline Etlingera sp. & 0 & 0 & 0 & 0 & 0 & 0 & 0 & 0 & 0 & 0 & 10 & 0 & 0 & 0 & 0 & 0 & 0 & 0 & 0 & 0 & 0 & 0 & 20 & 0 \\
\hline Foeniculum vulgare & 0 & 0 & 0 & 0 & 0 & 0 & 0 & 0 & 0 & 0 & 2 & 0 & 0 & 0 & 0 & 0 & 0 & 0 & 0 & 0 & 0 & 0 & 10 & 0 \\
\hline Kaempferia galanga & 0 & 3 & 11 & 2 & 11 & 2 & 1 & 0 & 0 & 0 & 2 & 4 & 0 & 30 & 30 & 20 & 20 & 13 & 10 & 0 & 0 & 0 & 10 & 20 \\
\hline Mentha $x$ piperita & 5 & 12 & 31 & 5 & 3 & 2 & 6 & 3 & 0 & 0 & 0 & 28 & 20 & 20 & 50 & 10 & 10 & 13 & 10 & 11 & 0 & 0 & 0 & 60 \\
\hline Momordica charantia & 0 & 1 & 0 & 0 & 0 & 16 & 1 & 0 & 0 & 0 & 2 & 5 & 0 & 10 & 0 & 0 & 0 & 63 & 10 & 0 & 0 & 0 & 10 & 30 \\
\hline Ocimum basilicum & 77 & 30 & 97 & 74 & 19 & 21 & 6 & 5 & 23 & 23 & 2 & 32 & 80 & 60 & 90 & 90 & 40 & 38 & 20 & 22 & 38 & 30 & 20 & 70 \\
\hline Pandanus amaryllifolius & 37 & 39 & 32 & 54 & 45 & 43 & 30 & 41 & 44 & 45 & 73 & 11 & 90 & 70 & 60 & 60 & 50 & 63 & 80 & 78 & 75 & 70 & 60 & 40 \\
\hline Piper nigrum & 4 & 1 & 1 & 0 & 0 & 0 & 2 & 2 & 6 & 6 & 3 & 3 & 10 & 10 & 10 & 0 & 0 & 0 & 10 & 11 & 25 & 20 & 20 & 20 \\
\hline Sesamum indicum & 0 & 0 & 0 & 0 & 0 & 0 & 490 & 0 & 0 & 0 & 0 & 0 & 0 & 0 & 0 & 0 & 0 & 0 & 10 & 0 & 0 & 0 & 0 & 0 \\
\hline Suaeda sp. & 0 & 0 & 0 & 0 & 0 & 0 & 0 & 0 & 0 & 0 & 0 & 1 & 0 & 0 & 0 & 0 & 0 & 0 & 0 & 0 & 0 & 0 & 0 & 10 \\
\hline Syzygium aromaticum & 0 & 0 & 0 & 0 & 0 & 0 & 0 & 0 & 1 & 1 & 0 & 0 & 0 & 0 & 0 & 0 & 0 & 0 & 0 & 0 & 13 & 10 & 0 & 0 \\
\hline Syzygium polyanthum & 0 & 0 & 0 & 0 & 0 & 0 & 1 & 1 & 1 & 1 & 0 & 0 & 0 & 0 & 0 & 0 & 0 & 0 & 10 & 11 & 13 & 10 & 0 & 0 \\
\hline Tamarindus indica & 0 & 0 & 1 & 0 & 0 & 0 & 0 & 0 & 0 & 0 & 1 & 2 & 0 & 0 & 10 & 0 & 0 & 0 & 0 & 0 & 0 & 0 & 10 & 10 \\
\hline Vanilla planifolia & 17 & 50 & 212 & 22 & 20 & 41 & 0 & 0 & 22 & 22 & 47 & 66 & 20 & 30 & 80 & 10 & 20 & 50 & 0 & 0 & 63 & 50 & 20 & 30 \\
\hline Zingiber officinale & 126 & 61 & 63 & 50 & 19 & 11 & 4 & 9 & 30 & 30 & 16 & 77 & 90 & 60 & 80 & 70 & 50 & 50 & 30 & 44 & 38 & 30 & 50 & 70 \\
\hline Acorus calamus & 8 & 40 & 58 & 1 & 27 & 25 & 0 & 3 & 8 & 8 & 34 & 7 & 20 & 50 & 50 & 10 & 50 & 50 & 0 & 22 & 38 & 30 & 10 & 20 \\
\hline Allium ramosum & 27 & 50 & 44 & 213 & 39 & 42 & 0 & 0 & 0 & 0 & 0 & 10 & 50 & 60 & 60 & 80 & 50 & 38 & 0 & 0 & 0 & 0 & 0 & 50 \\
\hline Aloe barbadensis & 0 & 0 & 1 & 0 & 0 & 0 & 0 & 0 & 0 & 0 & 0 & 2 & 0 & 0 & 10 & 0 & 0 & 0 & 0 & 0 & 0 & 0 & 0 & 10 \\
\hline Blumea balsamifera & 1 & 3 & 3 & 0 & 3 & 3 & 1 & 0 & 0 & 0 & 0 & 0 & 10 & 10 & 10 & 0 & 10 & 13 & 10 & 0 & 0 & 0 & 0 & 0 \\
\hline Celosia argentea & 0 & 0 & 0 & 1 & 29 & 2 & 0 & 0 & 0 & 0 & 0 & 0 & 0 & 0 & 0 & 10 & 10 & 13 & 0 & 0 & 0 & 0 & 0 & 0 \\
\hline Centella asiatica & 0 & 0 & 0 & 0 & 0 & 0 & 0 & 0 & 0 & 0 & 0 & 1 & 0 & 0 & 0 & 0 & 0 & 0 & 0 & 0 & 0 & 0 & 0 & 10 \\
\hline Clematis smilacifolia & 0 & 0 & 0 & 0 & 1 & 1 & 0 & 0 & 0 & 0 & 0 & 0 & 0 & 0 & 0 & 0 & 10 & 13 & 0 & 0 & 0 & 0 & 0 & 0 \\
\hline Clerodendron sp. & 4 & 2 & 5 & 35 & 32 & 49 & 0 & 0 & 0 & 0 & 0 & 0 & 20 & 10 & 10 & 20 & 20 & 25 & 0 & 0 & 0 & 0 & 0 & 0 \\
\hline Cordyline fruticosa & 0 & 0 & 0 & 6 & 9 & 12 & 0 & 0 & 0 & 0 & 0 & 0 & 0 & 0 & 0 & 20 & 20 & 25 & 0 & 0 & 0 & 0 & 0 & 0 \\
\hline Costus speciosus & 4 & 11 & 17 & 0 & 2 & 1 & 0 & 0 & 0 & 0 & 0 & 6 & 10 & 20 & 20 & 0 & 10 & 13 & 0 & 0 & 0 & 0 & 0 & 10 \\
\hline Curcuma xanthorrhiza & 1 & 1 & 6 & 4 & 0 & 3 & 0 & 0 & 2 & 2 & 7 & 23 & 10 & 10 & 30 & 20 & 0 & 13 & 0 & 0 & 13 & 10 & 30 & 40 \\
\hline Cyperus rotundus & 0 & 0 & 0 & 0 & 0 & 0 & 15 & 10 & 10 & 10 & 0 & 0 & 0 & 0 & 0 & 0 & 0 & 0 & 10 & 11 & 13 & 10 & 0 & 0 \\
\hline Dichrocephala integrifolia & 5 & 12 & 15 & 0 & 0 & 0 & 0 & 0 & 0 & 0 & 0 & 0 & 10 & 10 & 10 & 0 & 0 & 0 & 0 & 0 & 0 & 0 & 0 & 0 \\
\hline Eleutherine palmifolia & 21 & 30 & 32 & 90 & 139 & 150 & 0 & 0 & 0 & 0 & 0 & 0 & 20 & 20 & 20 & 40 & 40 & 38 & 0 & 0 & 0 & 0 & 0 & 0 \\
\hline Equisetum debile & 0 & 0 & 0 & 0 & 0 & 0 & 0 & 0 & 0 & 0 & 0 & 10 & 0 & 0 & 0 & 0 & 0 & 0 & 0 & 0 & 0 & 0 & 0 & 10 \\
\hline
\end{tabular}




\begin{tabular}{|c|c|c|c|c|c|c|c|c|c|c|c|c|c|c|c|c|c|c|c|c|c|c|c|c|}
\hline & Num & aber & of indi & lividue & & & & & & Sili. & & & Fre & quen & iies & & & & & & & Sili. & & \\
\hline & Wua & & & Rom & & & Sili. & & & new & va. & Wg. & Wu & asa & & Ron & npo & & Sili. & & & new & Ta. & $\mathrm{Wg}$ \\
\hline Species name & 01 & 03 & 04 & 01 & 03 & 04 & 01 & 03 & 04 & 04 & 04 & 04 & 01 & 03 & 04 & 01 & 03 & 04 & 01 & 03 & 04 & 04 & 04 & 04 \\
\hline Graptophyllum pictum & 0 & 0 & 0 & 0 & 0 & 0 & 0 & 0 & 0 & 0 & 3 & 0 & 0 & 0 & 0 & 0 & 0 & 0 & 0 & 0 & 0 & 0 & 20 & 0 \\
\hline Gynura procumbens & 0 & 1 & 4 & 0 & 0 & 0 & 0 & 0 & 0 & 0 & 0 & 0 & 0 & 10 & 20 & 0 & 0 & 0 & 0 & 0 & 0 & 0 & 0 & 0 \\
\hline Hemigraphis bicolor & 0 & 7 & 3 & 0 & 1 & 1 & 0 & 0 & 0 & 0 & 0 & 0 & 0 & 10 & 10 & 0 & 10 & 13 & 0 & 0 & 0 & 0 & 0 & 0 \\
\hline Hibiscus acetosella & 0 & 0 & 0 & 0 & 0 & 0 & 0 & 0 & 0 & 0 & 3 & 0 & 0 & 0 & 0 & 0 & 0 & 0 & 0 & 0 & 0 & 0 & 20 & 0 \\
\hline Hippeastrum puniceum & 2 & 1 & 5 & 0 & 0 & 0 & 0 & 0 & 0 & 0 & 0 & 0 & 10 & 10 & 10 & 0 & 0 & 0 & 0 & 0 & 0 & 0 & 0 & 0 \\
\hline Homalomena cordata & 0 & 0 & 0 & 1 & 2 & 2 & 0 & 0 & 0 & 0 & 0 & 0 & 0 & 0 & 0 & 10 & 20 & 25 & 0 & 0 & 0 & 0 & 0 & 0 \\
\hline Jatropha curcas & 16 & 28 & 38 & 4 & 9 & 1 & 2 & 5 & 5 & 5 & 1 & 14 & 50 & 60 & 60 & 10 & 40 & 13 & 10 & 33 & 38 & 30 & 10 & 40 \\
\hline Kalanchoe pinnata & 12 & 38 & 45 & 0 & 1 & 1 & 11 & 10 & 4 & 4 & 11 & 1 & 40 & 50 & 60 & 0 & 10 & 13 & 30 & 33 & 25 & 20 & 40 & 10 \\
\hline Morinda citrifolia & 0 & 1 & 1 & 0 & 0 & 0 & 0 & 0 & 0 & 0 & 0 & 0 & 0 & 10 & 10 & 0 & 0 & 0 & 0 & 0 & 0 & 0 & 0 & 0 \\
\hline Orthosiphon aristatus & 53 & 41 & 64 & 8 & 32 & 1 & 3 & 6 & 4 & 4 & 0 & 24 & 40 & 60 & 80 & 10 & 20 & 13 & 10 & 44 & 38 & 30 & 0 & 50 \\
\hline Picria felterrae & 0 & 0 & 0 & 0 & 0 & 3 & 0 & 0 & 0 & 0 & 0 & 0 & 0 & 0 & 0 & 0 & 0 & 13 & 0 & 0 & 0 & 0 & 0 & 0 \\
\hline Piper caninum & 0 & 0 & 0 & 0 & 0 & 1 & 0 & 0 & 0 & 0 & 0 & 0 & 0 & 0 & 0 & 0 & 0 & 13 & 0 & 0 & 0 & 0 & 0 & 0 \\
\hline Plectranthus amboinicus & 0 & 2 & 4 & 0 & 0 & 0 & 0 & 0 & 0 & 0 & 0 & 7 & 0 & 10 & 20 & 0 & 0 & 0 & 0 & 0 & 0 & 0 & 0 & 30 \\
\hline Premna trichostoma & 0 & 0 & 0 & 0 & 0 & 0 & 0 & 0 & 0 & 0 & 1 & 0 & 0 & 0 & 0 & 0 & 0 & 0 & 0 & 0 & 0 & 0 & 10 & 0 \\
\hline Ricinus communis & 0 & 0 & 1 & 0 & 0 & 0 & 1 & 0 & 0 & 0 & 0 & 13 & 0 & 0 & 10 & 0 & 0 & 0 & 10 & 0 & 0 & 0 & 0 & 10 \\
\hline Sansevieria trifasciata & 0 & 0 & 0 & 1 & 0 & 0 & 0 & 0 & 0 & 0 & 0 & 0 & 0 & 0 & 0 & 10 & 0 & 0 & 0 & 0 & 0 & 0 & 0 & 0 \\
\hline Senna alata & 0 & 0 & 0 & 1 & 4 & 0 & 0 & 0 & 0 & 0 & 0 & 0 & 0 & 0 & 0 & 10 & 20 & 0 & 0 & 0 & 0 & 0 & 0 & 0 \\
\hline Solenostemon scutellarioides & 3 & 32 & 32 & 1 & 37 & 2 & 14 & 29 & 20 & 20 & 3 & 15 & 10 & 60 & 60 & 10 & 30 & 13 & 40 & 33 & 38 & 30 & 10 & 20 \\
\hline Strobilanthes crispa & 1 & 1 & 1 & 0 & 0 & 0 & 0 & 0 & 0 & 0 & 0 & 2 & 10 & 10 & 10 & 0 & 0 & 0 & 0 & 0 & 0 & 0 & 0 & 10 \\
\hline Symphytum officinale & 5 & 2 & 5 & 0 & 0 & 0 & 0 & 0 & 0 & 0 & 2 & 0 & 10 & 10 & 20 & 0 & 0 & 0 & 0 & 0 & 0 & 0 & 20 & 0 \\
\hline Synadenium grantii & 0 & 0 & 0 & 0 & 0 & 0 & 0 & 0 & 0 & 0 & 0 & 3 & 0 & 0 & 0 & 0 & 0 & 0 & 0 & 0 & 0 & 0 & 0 & 20 \\
\hline Talinum paniculatum & 0 & 0 & 0 & 0 & 0 & 0 & 0 & 0 & 9 & 9 & 0 & 9 & 0 & 0 & 0 & 0 & 0 & 0 & 0 & 0 & 13 & 10 & 0 & 20 \\
\hline Talinum triangulare & 6 & 21 & 47 & 1 & 8 & 6 & 0 & 5 & 23 & 23 & 0 & 0 & 10 & 20 & 40 & 10 & 10 & 25 & 0 & 11 & 13 & 10 & 0 & 0 \\
\hline Tinospora crispa & 0 & 0 & 3 & 0 & 1 & 2 & 4 & 5 & 3 & 3 & 0 & 0 & 0 & 0 & 10 & 0 & 10 & 13 & 10 & 11 & 13 & 10 & 0 & 0 \\
\hline Zingiber aromaticum & 0 & 0 & 0 & 0 & 0 & 0 & 0 & 1 & 4 & 6 & 3 & 0 & 0 & 0 & 0 & 0 & 0 & 0 & 0 & 11 & 25 & 30 & 10 & 0 \\
\hline Zingiber purpureum & 4 & 17 & 21 & 7 & 1 & 2 & 5 & 3 & 4 & 8 & 0 & 2 & 10 & 30 & 40 & 50 & 10 & 13 & 30 & 33 & 38 & 50 & 0 & 10 \\
\hline Canna edulis & 0 & 0 & 0 & 0 & 0 & 0 & 0 & 0 & 0 & 0 & 6 & 0 & 0 & 0 & 0 & 0 & 0 & 0 & 0 & 0 & 0 & 0 & 10 & 0 \\
\hline Colocasia esculenta & 57 & 149 & 322 & 35 & 67 & 57 & 287 & 321 & 352 & 360 & 31 & 75 & 70 & 70 & 70 & 50 & 50 & 50 & 60 & 100 & 100 & 90 & 20 & 60 \\
\hline Dioscorea bulbifera & 0 & 0 & 0 & 0 & 0 & 0 & 0 & 1 & 0 & 0 & 1 & 0 & 0 & 0 & 0 & 0 & 0 & 0 & 0 & 11 & 0 & 0 & 10 & 0 \\
\hline Ipomoea batatas & 123 & 199 & 111 & 209 & 103 & 109 & 430 & 346 & 245 & 259 & 260 & 13 & 90 & 60 & 70 & 90 & 80 & 88 & 90 & 89 & 88 & 90 & 70 & 20 \\
\hline Manihot esculenta & 427 & 449 & 376 & 157 & 360 & 634 & 2766 & 993 & 828 & 1039 & 156 & 144 & 70 & 80 & 80 & 70 & 100 & 88 & 100 & 100 & 100 & 100 & 80 & 80 \\
\hline Maranta arundinacea & 0 & 0 & 0 & 0 & 0 & 0 & 0 & 5 & 4 & 4 & 0 & 0 & 0 & 0 & 0 & 0 & 0 & 0 & 0 & 11 & 13 & 10 & 0 & 0 \\
\hline Oryza sativa & 0 & 0 & 0 & 0 & 0 & 0 & 145 & 200 & 105 & 105 & 0 & 250 & 0 & 0 & 0 & 0 & 0 & 0 & 10 & 11 & 13 & 10 & 0 & 10 \\
\hline Xanthosoma sagittifolium & 106 & 157 & 196 & 119 & 219 & 376 & 206 & 182 & 147 & 156 & 413 & 101 & 60 & 90 & 80 & 90 & 100 & 88 & 80 & 100 & 88 & 90 & 90 & 90 \\
\hline Xanthosoma violaceum & 0 & 14 & 25 & 0 & 1 & 2 & 0 & 1 & 0 & 0 & 15 & 8 & 0 & 30 & 50 & 0 & 10 & 25 & 0 & 11 & 0 & 0 & 20 & 20 \\
\hline Zea mays & 125 & 41 & 233 & 206 & 35 & 66 & 23 & 8 & 30 & 30 & 0 & 2 & 20 & 20 & 60 & 50 & 30 & 38 & 10 & 11 & 13 & 10 & 0 & 10 \\
\hline Acalypha caturus & 1 & 3 & 2 & 2 & 2 & 1 & 0 & 0 & 0 & 0 & 2 & 2 & 10 & 20 & 20 & 20 & 20 & 13 & 0 & 0 & 0 & 0 & 10 & 20 \\
\hline Acalypha marginata & 0 & 0 & 6 & 0 & 0 & 0 & 0 & 0 & 0 & 0 & 0 & 0 & 0 & 0 & 10 & 0 & 0 & 0 & 0 & 0 & 0 & 0 & 0 & 0 \\
\hline Bischofia javanica & 2 & 1 & 0 & 3 & 2 & 3 & 0 & 0 & 0 & 0 & 2 & 0 & 20 & 10 & 0 & 10 & 20 & 25 & 0 & 0 & 0 & 0 & 20 & 0 \\
\hline Breynia microphylla & 0 & 0 & 0 & 0 & 0 & 0 & 1 & 3 & 5 & 5 & 0 & 0 & 0 & 0 & 0 & 0 & 0 & 0 & 10 & 11 & 13 & 10 & 0 & 0 \\
\hline Cananga odorata & 0 & 0 & 0 & 0 & 0 & 0 & 0 & 0 & 0 & 0 & 1 & 0 & 0 & 0 & 0 & 0 & 0 & 0 & 0 & 0 & 0 & 0 & 10 & 0 \\
\hline Crescentia cujete & 1 & 3 & 3 & 3 & 4 & 3 & 0 & 0 & 0 & 0 & 0 & 0 & 10 & 10 & 10 & 20 & 20 & 25 & 0 & 0 & 0 & 0 & 0 & 0 \\
\hline Dendrocalamus sp. & 2 & 3 & 3 & 3 & 3 & 3 & 0 & 0 & 0 & 0 & 0 & 5 & 10 & 20 & 20 & 20 & 20 & 25 & 0 & 0 & 0 & 0 & 0 & 30 \\
\hline Elmerrillia ovalis & 2 & 1 & 2 & 0 & 0 & 0 & 0 & 0 & 0 & 0 & 0 & 0 & 10 & 10 & 10 & 0 & 0 & 0 & 0 & 0 & 0 & 0 & 0 & 0 \\
\hline Euonymus javanicus & 0 & 0 & 0 & 0 & 0 & 0 & 1 & 1 & 1 & 1 & 0 & 0 & 0 & 0 & 0 & 0 & 0 & 0 & 10 & 11 & 13 & 10 & 0 & 0 \\
\hline Ficus septica & 1 & 1 & 1 & 2 & 4 & 2 & 0 & 0 & 0 & 0 & 1 & 12 & 10 & 10 & 10 & 20 & 20 & 25 & 0 & 0 & 0 & 0 & 10 & 60 \\
\hline Ficus sp. 1 & 0 & 2 & 1 & 0 & 1 & 5 & 0 & 0 & 0 & 0 & 2 & 1 & 0 & 10 & 10 & 0 & 10 & 38 & 0 & 0 & 0 & 0 & 20 & 10 \\
\hline Ficus sp. 2 & 0 & 0 & 0 & 1 & 0 & 0 & 0 & 0 & 0 & 0 & 0 & 0 & 0 & 0 & 0 & 10 & 0 & 0 & 0 & 0 & 0 & 0 & 0 & 0 \\
\hline Flemingia strobilifera & 0 & 0 & 0 & 0 & 2 & 7 & 0 & 0 & 0 & 0 & 0 & 0 & 0 & 0 & 0 & 0 & 10 & 13 & 0 & 0 & 0 & 0 & 0 & 0 \\
\hline Globba sp.? & 0 & 0 & 0 & 1 & 0 & 0 & 0 & 0 & 0 & 0 & 0 & 0 & 0 & 0 & 0 & 10 & 0 & 0 & 0 & 0 & 0 & 0 & 0 & 0 \\
\hline Glochidion rubrum & 0 & 0 & 0 & 0 & 0 & 0 & 1 & 1 & 1 & 1 & 0 & 0 & 0 & 0 & 0 & 0 & 0 & 0 & 10 & 11 & 13 & 10 & 0 & 0 \\
\hline Glochidion sp. & 0 & 1 & 1 & 1 & 7 & 2 & 3 & 3 & 3 & 3 & 0 & 1 & 0 & 10 & 10 & 10 & 20 & 25 & 30 & 33 & 25 & 20 & 0 & 10 \\
\hline Gmelina arborea & 0 & 2 & 4 & 0 & 5 & 5 & 0 & 0 & 0 & 0 & 0 & 0 & 0 & 10 & 10 & 0 & 20 & 25 & 0 & 0 & 0 & 0 & 0 & 0 \\
\hline Grewia laevigata & 0 & 0 & 0 & 0 & 1 & 0 & 0 & 0 & 0 & 0 & 1 & 0 & 0 & 0 & 0 & 0 & 10 & 0 & 0 & 0 & 0 & 0 & 10 & 0 \\
\hline Hibiscus macrophyllus & 0 & 0 & 0 & 0 & 1 & 1 & 0 & 0 & 0 & 0 & 0 & 0 & 0 & 0 & 0 & 0 & 10 & 13 & 0 & 0 & 0 & 0 & 0 & 0 \\
\hline Homalanthus populneus & 3 & 1 & 3 & 1 & 3 & 4 & 0 & 0 & 0 & 1 & 23 & 9 & 10 & 10 & 20 & 10 & 20 & 25 & 0 & 0 & 0 & 10 & 60 & 40 \\
\hline Leucosyke condissima & 0 & 0 & 0 & 1 & 6 & 3 & 0 & 0 & 0 & 0 & 0 & 0 & 0 & 0 & 0 & 10 & 20 & 38 & 0 & 0 & 0 & 0 & 0 & 0 \\
\hline Litsea sp. 1 & 0 & 0 & 0 & 1 & 0 & 0 & 0 & 0 & 0 & 0 & 0 & 0 & 0 & 0 & 0 & 10 & 0 & 0 & 0 & 0 & 0 & 0 & 0 & 0 \\
\hline Litsea sp. 2 & 0 & 0 & 0 & 1 & 0 & 0 & 0 & 0 & 0 & 0 & 0 & 0 & 0 & 0 & 0 & 10 & 0 & 0 & 0 & 0 & 0 & 0 & 0 & 0 \\
\hline Macaranga tanarius & 0 & 0 & 0 & 0 & 0 & 0 & 0 & 0 & 0 & 0 & 0 & 1 & 0 & 0 & 0 & 0 & 0 & 0 & 0 & 0 & 0 & 0 & 0 & 10 \\
\hline Macaranga triloba & 0 & 0 & 0 & 3 & 0 & 0 & 0 & 0 & 0 & 0 & 0 & 0 & 0 & 0 & 0 & 10 & 0 & 0 & 0 & 0 & 0 & 0 & 0 & 0 \\
\hline Melastoma malabathricum & 0 & 0 & 0 & 1 & 4 & 3 & 0 & 0 & 0 & 0 & 0 & 0 & 0 & 0 & 0 & 10 & 20 & 25 & 0 & 0 & 0 & 0 & 0 & 0 \\
\hline Melochia umbellata & 1 & 0 & 0 & 9 & 7 & 7 & 0 & 0 & 0 & 0 & 0 & 4 & 10 & 0 & 0 & 30 & 40 & 50 & 0 & 0 & 0 & 0 & 0 & 30 \\
\hline Morus alba & 0 & 0 & 0 & 0 & 0 & 0 & 0 & 0 & 0 & 0 & 0 & 12 & 0 & 0 & 0 & 0 & 0 & 0 & 0 & 0 & 0 & 0 & 0 & 30 \\
\hline Nauclea orientalis & 2 & 3 & 5 & 0 & 0 & 1 & 0 & 0 & 0 & 0 & 0 & 0 & 20 & 30 & 50 & 0 & 0 & 13 & 0 & 0 & 0 & 0 & 0 & 0 \\
\hline Pinus merkusii & 1 & 1 & 0 & 4 & 4 & 1 & 0 & 0 & 0 & 0 & 0 & 3 & 10 & 10 & 0 & 30 & 30 & 13 & 0 & 0 & 0 & 0 & 0 & 20 \\
\hline Pisonia umbellifera & 0 & 0 & 0 & 1 & 1 & 0 & 0 & 0 & 0 & 0 & 0 & 0 & 0 & 0 & 0 & 10 & 10 & 0 & 0 & 0 & 0 & 0 & 0 & 0 \\
\hline Platea sp. & 1 & 4 & 4 & 0 & 1 & 0 & 0 & 0 & 0 & 0 & 0 & 0 & 10 & 20 & 20 & 0 & 10 & 0 & 0 & 0 & 0 & 0 & 0 & 0 \\
\hline Pothomorphe umbellata & 0 & 0 & 0 & 0 & 1 & 1 & 0 & 0 & 0 & 0 & 0 & 4 & 0 & 0 & 0 & 0 & 10 & 13 & 0 & 0 & 0 & 0 & 0 & 30 \\
\hline Premna serratifolia & 0 & 0 & 0 & 1 & 3 & 2 & 0 & 0 & 0 & 0 & 0 & 3 & 0 & 0 & 0 & 10 & 20 & 25 & 0 & 0 & 0 & 0 & 0 & 20 \\
\hline Sambucus canadensis & 0 & 3 & 16 & 7 & 0 & 0 & 0 & 0 & 0 & 0 & 43 & 6 & 0 & 10 & 30 & 10 & 0 & 0 & 0 & 0 & 0 & 0 & 80 & 20 \\
\hline
\end{tabular}




\begin{tabular}{|c|c|c|c|c|c|c|c|c|c|c|c|c|c|c|c|c|c|c|c|c|c|c|c|c|}
\hline \multirow[b]{2}{*}{ Species name } & \multicolumn{9}{|c|}{ Number of individuals } & \multicolumn{3}{|l|}{ Sili. } & \multicolumn{9}{|c|}{ Frequencies (\%) } & \multicolumn{3}{|l|}{ Sili. } \\
\hline & \multicolumn{3}{|c|}{ Wuasa } & \multicolumn{3}{|c|}{ Rompo } & \multicolumn{3}{|l|}{ Sili. } & \multicolumn{2}{|c|}{ new Ta. } & $\begin{array}{l}W g . \\
04\end{array}$ & \multicolumn{3}{|c|}{ Wuasa } & \multicolumn{3}{|c|}{ Rompo } & \multicolumn{3}{|c|}{ Sili. } & \multicolumn{2}{|c|}{ new Ta. } & $\begin{array}{l}\text { Wg. } \\
04\end{array}$ \\
\hline Tectona grandis & 0 & 8 & 7 & 0 & 0 & 0 & 0 & 0 & 0 & 0 & 0 & 0 & 0 & 20 & 20 & 0 & 0 & 0 & 0 & 0 & 0 & 0 & 0 & 0 \\
\hline Trema orientalis & 0 & 0 & 0 & 0 & 0 & 0 & 0 & 0 & 0 & 0 & 1 & 0 & 0 & 0 & 0 & 0 & 0 & 0 & 0 & 0 & 0 & 0 & 10 & 0 \\
\hline Trema sp. & 0 & 0 & 0 & 3 & 3 & 1 & 1 & 1 & 1 & 1 & 0 & 0 & 0 & 0 & 0 & 10 & 20 & 13 & 10 & 11 & 13 & 10 & 0 & 0 \\
\hline Wendlandia paniculata & 0 & 0 & 0 & 2 & 3 & 2 & 0 & 0 & 0 & 0 & 0 & 0 & 0 & 0 & 0 & 10 & 10 & 25 & 0 & 0 & 0 & 0 & 0 & 0 \\
\hline Wendlandia sp. & 0 & 0 & 0 & 0 & 0 & 0 & 0 & 0 & 0 & 0 & 0 & 1 & 0 & 0 & 0 & 0 & 0 & 0 & 0 & 0 & 0 & 0 & 0 & 10 \\
\hline Erythrina subumbrans & 9 & 10 & 23 & 12 & 8 & 11 & 61 & 39 & 40 & 69 & 94 & 14 & 40 & 50 & 80 & 40 & 30 & 50 & 80 & 78 & 88 & 90 & 90 & 40 \\
\hline Flemingia macrophylla & 0 & 0 & 0 & 0 & 0 & 0 & 0 & 5 & 8 & 8 & 13 & 0 & 0 & 0 & 0 & 0 & 0 & 0 & 0 & 11 & 13 & 10 & 40 & 0 \\
\hline Gliricidia sepium & 175 & 154 & 441 & 113 & 126 & 163 & 228 & 130 & 171 & 199 & 392 & 197 & 80 & 90 & 100 & 80 & 100 & 100 & 70 & 78 & 88 & 90 & 100 & 100 \\
\hline Leucaena leucocephala & 0 & 0 & 0 & 0 & 0 & 0 & 2 & 4 & 9 & 21 & 16 & 0 & 0 & 0 & 0 & 0 & 0 & 0 & 20 & 22 & 38 & 40 & 20 & 0 \\
\hline Manihot glaziovii & 0 & 0 & 0 & 0 & 0 & 2 & 36 & 23 & 19 & 24 & 0 & 0 & 0 & 0 & 0 & 0 & 0 & 13 & 70 & 67 & 50 & 50 & 0 & 0 \\
\hline $\begin{array}{l}\text { Mucuna pruriens cv. group } \\
\text { utilis }\end{array}$ & 0 & 0 & 0 & 0 & 0 & 0 & 0 & 6 & 1 & 1 & 0 & 0 & 0 & 0 & 0 & 0 & 0 & 0 & 0 & 22 & 13 & 10 & 0 & 0 \\
\hline Paraserianthes falcataria & 0 & 0 & 0 & 6 & 5 & 3 & 4 & 1 & 1 & 1 & 0 & 0 & 0 & 0 & 0 & 10 & 10 & 13 & 10 & 11 & 13 & 10 & 0 & 0 \\
\hline Tephrosia vogelii & 0 & 0 & 0 & 0 & 0 & 0 & 14 & 40 & 19 & 33 & 0 & 0 & 0 & 0 & 0 & 0 & 0 & 0 & 30 & 33 & 25 & 40 & 0 & 0 \\
\hline Calamus sp. & 0 & 1 & 0 & 0 & 0 & 0 & 0 & 0 & 0 & 0 & 0 & 0 & 0 & 10 & 0 & 0 & 0 & 0 & 0 & 0 & 0 & 0 & 0 & 0 \\
\hline Ceiba pentandra & 0 & 0 & 0 & 0 & 0 & 0 & 0 & 0 & 0 & 1 & 1 & 0 & 0 & 0 & 0 & 0 & 0 & 0 & 0 & 0 & 0 & 10 & 10 & 0 \\
\hline Coix lacryma-jobi & 2 & 1 & 0 & 2 & 39 & 29 & 8 & 13 & 11 & 11 & 63 & 0 & 10 & 10 & 0 & 10 & 20 & 13 & 10 & 33 & 13 & 10 & 30 & 0 \\
\hline Gossypium barbadense & 1 & 2 & 2 & 1 & 0 & 1 & 4 & 2 & 1 & 1 & 1 & 1 & 10 & 20 & 20 & 10 & 0 & 13 & 20 & 22 & 13 & 10 & 10 & 10 \\
\hline Heliconia indica & 72 & 82 & 107 & 51 & 43 & 30 & 0 & 4 & 3 & 3 & 0 & 55 & 60 & 60 & 50 & 50 & 50 & 38 & 0 & 11 & 13 & 10 & 0 & 60 \\
\hline Pennisetum purpureum & 0 & 0 & 0 & 0 & 0 & 0 & 18 & 56 & 139 & 159 & 6 & 0 & 0 & 0 & 0 & 0 & 0 & 0 & 20 & 56 & 63 & 70 & 10 & 0 \\
\hline Phrynium pubinerve & 0 & 1 & 1 & 1 & 1 & 0 & 0 & 0 & 0 & 0 & 0 & 0 & 0 & 10 & 10 & 10 & 10 & 0 & 0 & 0 & 0 & 0 & 0 & 0 \\
\hline Stephania corymbosa & 0 & 0 & 0 & 0 & 0 & 0 & 0 & 0 & 0 & 0 & 1 & 0 & 0 & 0 & 0 & 0 & 0 & 0 & 0 & 0 & 0 & 0 & 10 & 0 \\
\hline
\end{tabular}


Appendix 14. List and potential use of weed species identified in 50 homegardens in five villages of the Napu valley, Central Sulawesi, in 2004.

\begin{tabular}{|c|c|c|c|c|c|c|c|}
\hline No. & Species name & Family & Common name & Indonesian name & \begin{tabular}{|l|} 
Local names \\
Napu/Behoa language
\end{tabular} & Usage & $\begin{array}{l}\text { Medically used } \\
\text { plant part }\end{array}$ \\
\hline \begin{tabular}{l|l}
1 \\
2
\end{tabular} & $\begin{array}{l}\text { Alternanthera sessilis (L.) DC. } \\
\text { Amaranthus lividus L. }\end{array}$ & $\begin{array}{l}\text { Amaranthaceae } \\
\text { Amaranthaceae }\end{array}$ & $\begin{array}{l}\text { Alligator weed } \\
\text { African spinach }\end{array}$ & \begin{tabular}{|l|} 
Daun rusa/tolod \\
Bayam itik/monyet
\end{tabular} & $\begin{array}{l}\text { Palantanga } \\
\text { Tantaimanu }\end{array}$ & M (livestock), F, V & \\
\hline & Cyathula prostrata (L.) Blume & Amaranthaceae & Sand spinach & Rumput jarang-jarang & Tomapolo & M, fishing & \\
\hline 4 & Centella asiatica (L.) Urb. & Apiaceae & Asiatic pennywort & Daun kaki kuda & Kaki kuda & M & \\
\hline 5 & Ageratum conyzoides $\mathrm{L}$. & Asteraceae & Billy goatweed & Babadotan & Behoa, putih sese & $\mathrm{M}$ & Leaves, sap \\
\hline & Bidens pilosa $\mathrm{L}$. & Asteraceae & $\begin{array}{l}\text { Black jack/Spanish } \\
\text { needles }\end{array}$ & Ketul & Karukahi & $\mathrm{M}, \mathrm{V}$ & $\begin{array}{l}\text { Leaves, seeds, } \\
\text { sap, young shoot }\end{array}$ \\
\hline & Crepis japonica Bth. & Asteraceae & & Rumput sawi & & V & \\
\hline & Dichrocephala bicolor (Roth.) Schlecht. & Asteraceae & & Wedahan & Panaramanu & M & Leaves, roots \\
\hline 9 & Eclipta prostrata (L.) L. & Asteraceae & Ink plant & Urang-aring & Nali bula & & \\
\hline 10 & Elephantopus scaber L. var sinuata Miq. & Asteraceae & $\begin{array}{l}\text { Prickly-leaved } \\
\text { elephant's foot }\end{array}$ & $\begin{array}{l}\text { Tapak liman, rumput } \\
\text { kelapa }\end{array}$ & Kaluku & $\mathrm{M}, \mathrm{F}$ & Roots \\
\hline 11 & Erechtites valerianifolia (Wolf.) DC. & Asteraceae & & & Nipo & $M, F, V$ & Leaves \\
\hline 12 & Erigeron sumatrensis Retz. & Asteraceae & & & Sulepe & M, F, C, soil improvement & Leaves, roots \\
\hline 13 & Galinsoga parviflora Cav. & Asteraceae & & & Hehito basmillan & M (livestock) & \\
\hline 14 & Sigesbeckia orientalis L. & Asteraceae & Yellow crown-beard & & Ranta-ranta & M & \\
\hline 15 & Spilanthes iabadicensis A.H. Moore & Asteraceae & & Karukahi kuning & Nali & $\mathrm{M}, \mathrm{F}$ & Leaves \\
\hline 16 & Synedrella nodiflora (L.) Gaertn. & Asteraceae & Pig's grass & Bruwan & Kaluku kecil, nali & $\mathrm{M}, \mathrm{F}$ & Leaves \\
\hline 17 & Drymaria cordata (L.) Willd. Ex R. \& S. & Caryophyllaceae & & & Sende-sende & $\mathrm{M}, \mathrm{F}$ & Leaves \\
\hline 18 & Commelina nudiflora L. (=C. diffusa) & Commelinaceae & Creeping dayflower & Rumput kupu-kupu & Lehoka & F, fishing & \\
\hline $\begin{array}{l}19 \\
20\end{array} \mid$ & $\begin{array}{l}\text { Cyperus kyllingia Endl. } \\
\text { Cyperus pilosus Vahl. }\end{array}$ & $\begin{array}{l}\text { Cyperaceae } \\
\text { Cyperaceae }\end{array}$ & Nut sedge & $\begin{array}{l}\text { Melaran } \\
\text { Rumput pisau }\end{array}$ & Hila & $\begin{array}{l}\mathrm{F}, \text { talisman } \\
\mathrm{M}, \mathrm{F}\end{array}$ & Roots \\
\hline 21 & Cyperus rotundus L. & Cyperaceae & Purple nut grass & Rumput teki & Kukuboe & M, F, C, soil improvement & Tubers \\
\hline 22 & Fimbristylis miliacea (L.) Vahl. & Cyperaceae & & & Tiu walehu & Weaving baskets/mats & \\
\hline 23 & Scleria purpurascens Steud. & Cyperaceae & & & Tatari, hihila & $\mathrm{M}, \mathrm{F}$ & Seeds \\
\hline 24 & Euphorbia hirta L. & Euphorbiaceae & Hairy spurge & Daun biji kacang & Pakuli-katuli & M & Leaves, fruits \\
\hline 25 & Phyllanthus urinaria L. & Euphorbiaceae & Leaf flower & Meniran & Hinuntu & $\mathrm{M}$, magic & Leaves \\
\hline 27 & $\begin{array}{l}\text { Dysophylla auricularia (L.) Blume } \\
\text { Hyptis brevipes Poit. }\end{array}$ & $\begin{array}{l}\text { Lamiaceae } \\
\text { Lamiaceae }\end{array}$ & & & $\begin{array}{l}\text { IKomeo } \\
\text { Sambuku }\end{array}$ & $M$ & J \\
\hline 28 & Hyptis rhomboidea Mart. \& Gal. & Lamiaceae & & & $\begin{array}{l}\text { Boa-boa malei/bula, } \\
\text { bimbing kalo }\end{array}$ & $\mathrm{M}$ & $\begin{array}{l}\text { Leaves, smoke of } \\
\text { flowers }\end{array}$ \\
\hline 29 & Scurula fusca (Blume) G.Don & Loranthaceae & & & Benalu & M & \\
\hline $\begin{array}{r}30 \\
31\end{array} \mid$ & $\begin{array}{l}\text { Cuphea balsamona Cham. \& Schlecht. } \\
\text { Sida rhombifolia L. }\end{array}$ & \begin{tabular}{|l} 
Lythraceae \\
Malvaceae
\end{tabular} & Queensland hemp & $\begin{array}{l}\text { Gunung colo } \\
\text { Sidaguri }\end{array}$ & & M, broome/toothbrush & Roots \\
\hline 32 & Urena lobata L. & Malvaceae & Indian mallow & Pulutan sapi & Delupa & M, ropes & \\
\hline $33 \mid$ & $\begin{array}{l}\text { Nephrolepis falcate (Cav.) C.Hr. } \\
\text { Ludwigia hyssopifolia (G.Don) Exell. (Jussiaea } \\
\text { linifolia Vahl.) }\end{array}$ & $\begin{array}{l}\text { Nephrolepidaceae } \\
\text { Onagraceae }\end{array}$ & Willow herb & $\begin{array}{l}\text { Jukut anggereman, } \\
\text { rica tikus }\end{array}$ & Luku/tongko & $\begin{array}{l}\text { Grave decoration } \\
\text { M }\end{array}$ & $\begin{array}{l}\text { Leaves, roots, } \\
\text { young fruits }\end{array}$ \\
\hline 35 & Oxalis corniculata L. & Oxalidaceae & Indian sorrel & Daun asam kecil & Sende-sende owai & M, fruit, spice & Leaves \\
\hline 36 & Plantago major $\mathrm{L}$. & Plantaginaceae & Great plantain & Daun sendok & & & \\
\hline $\begin{array}{l}37 \\
38\end{array}$ & $\begin{array}{l}\text { Dyrtococcum acrescens Stapf } \\
\text { Digitaria sanguinalis Scop. }\end{array}$ & \begin{tabular}{|l} 
Poaceae \\
Poaceae
\end{tabular} & & & $\begin{array}{l}\text { Hirero } \\
\text { Kere-kere }\end{array}$ & M (livestock), F & \\
\hline 39 & Eleusine indica (L.) Gaertn. & Poaceae & Dog's tail grass & Rumput belulang & Bisoa, barigi popenga & $\mathrm{M}, \mathrm{F}$, decoration & Roots \\
\hline 40 & Eragrostis sp. 1 & Poaceae & & & Tirangka & & \\
\hline 41 & Eragrostis sp. 2 & Poaceae & & & Gawu-gawu & $\mathrm{M}, \mathrm{F}$ & Roots \\
\hline 42 & Eragrostis unioloides (Retz.) Nees ex Steud. & Poaceae & & & Nkundu & & \\
\hline 43 & Imperata cylindrica (L.) Raeuschel & Poaceae & Imperata & Alang-alang & & $M, F$, thatching roofs & Rhizomes, buds \\
\hline $44 \mid i$ & Ischaemum indicum (Houtt.) Merrill & Poaceae & & & Luane bose & & \\
\hline 45 & Oplismenus compositus (L.) Beauv. & Poaceae & & & Holedena, palemba & $\mathrm{M}, \mathrm{F}$, making traps/snares & Leaves \\
\hline $46 \mid$ & Paspalum conjugatum Berg. & Poaceae & Buffalo grass & Rumput kerbau/pahit & Lepa & $\mathrm{M}, \mathrm{F}$ & Leaves \\
\hline 47 & Paspalum scrobiculatum L. & Poaceae & & & & & \\
\hline 48 & Pennisetum purpureum Schumach. & Poaceae & Napier grass & Rumput gadjah & Meo & $\mathrm{F}$ & \\
\hline 49 & Setaria palmifolia (Willd.) Stapf & Poaceae & & & Dinding kelapa & & \\
\hline 50 & $\begin{array}{l}\text { Sporobolus indicus (Linn.) R.Br. var. major } \\
\text { (Buse) Baaiiens }\end{array}$ & Poaceae & & & & Decoration & \\
\hline 51 & Polygonum chinense L. & Polygonaceae & & & Andeo kokou & & \\
\hline 52 & Polygonum perfoliatum L. & Polygonaceae & & & Sankada, tankada & M, fruit & Leaves \\
\hline $53 \mid$ & Polygonum barbatum L. & Polygoniaceae & & Rica kerbau & Mantilala & & \\
\hline 54 & Portulaca oleracea L. & Portulacaceae & Purslane & Krokok & Tontoru & $M, F, V$ & Leaves \\
\hline 55 & Borreria laevis (Lamk.) Griseb & Rubiaceae & Button weed & Jugul & Katuli & M & Leaves \\
\hline 56 & Borreria ocymoides (Burm.f.) DC. & Rubiaceae & Button weed & Balungan & Taunkada & $F, V$ & \\
\hline 57 & Hedyotis (=Oldenlandia) corymbosa (L.) Lamk. & Rubiaceae & & Pokok telur belangkas & Panangi & Fishing & \\
\hline 58 & Lindernia cordifolia Merr. (L. anagallis) & Scrophulariaceae & & & Topendele & M, F, ornan & Leaves \\
\hline 59 & Sphaerostephanos sp. & Thelypteridaceae & & & Poto & & \\
\hline 60 & Pouzolzia zeylanica Benn. & Urticaceae & Red eclipta & Daun deresan & Walugai towao & c & \\
\hline \multicolumn{6}{|c|}{ Coloured cells $=$ Species already counted as crop } & \multicolumn{2}{|l|}{$\begin{array}{l}\mathrm{M}=\text { Medicine } \\
\mathrm{F}=\text { Fodder } \\
\mathrm{V}=\text { Vegetable } \\
\mathrm{C}=\text { Cosmetic, hygiene }\end{array}$} \\
\hline
\end{tabular}


Appendix 15. Homegarden (HG) sizes, cluster numbers, species richness and individual numbers of crops and ornamentals as well as numbers of named and used weed species occurring in 50 homegardens in five villages of the Napu valley, Central Sulawesi, in 2001, 2003, and 2004.

\begin{tabular}{|c|c|c|c|c|c|c|c|c|c|c|c|c|c|c|c|c|c|c|c|c|c|c|c|c|c|}
\hline \multirow[b]{3}{*}{ Village } & \multicolumn{3}{|c|}{ HG size ${ }^{*}$} & \multirow{3}{*}{\begin{tabular}{|l} 
Clus- \\
ter \\
No.
\end{tabular}} & \multirow{2}{*}{\multicolumn{2}{|c|}{$\begin{array}{l}\text { Species } \\
\text { richness (no.) }\end{array}$}} & & & \multicolumn{4}{|c|}{ Individual } & \multicolumn{8}{|c|}{ Crop species per use category (no.) } & \multicolumn{3}{|c|}{ Ornamentals } & \multicolumn{2}{|c|}{ Weed species } \\
\hline & $\mathrm{HH}$ & 2001 & 2004 & & & & & & & & & & 2004 & & & & & & & & species & & Ind. no. & (no.) in 2 & 2004 \\
\hline & no. & $\left(\mathrm{m}^{2}\right)$ & $\left(m^{2}\right)$ & & 2001 & 20032 & $2004 / 2$ & 2004 all & 2001 & 2003 & 2004 & 2004 all $\mathrm{F}$ & Fruit & Veget. & Stimul. & Spice 1 & Medic. $\subseteq$ & Staple & Wood MP & $T$ Other & 2001 & 2004 & 2004 & Named $\mathrm{C}$ & Used \\
\hline Wuasa & 1 & 519 & 803 & & 55 & 60 & 65 & 65 & 997 & 1,874 & 1,307 & 1,307 & 12 & 11 & 4 & 13 & 12 & 6 & 2 & 2 & 22 & 27 & 808 & 27 & 15 \\
\hline Wuasa & 2 & 1,134 & 1,130 & & 45 & 53 & 68 & 68 & 492 & 1,164 & 690 & 690 & 16 & 8 & 4 & 13 & 11 & 5 & 8 & 2 & 17 & 44 & 355 & 12 & 6 \\
\hline Wuasa & 3 & 283 & 310 & 4 & 15 & 16 & 23 & 23 & 33 & 47 & 91 & 91 & 4 & 6 & 1 & 7 & 2 & 0 & 1 & 2 & 6 & 15 & 51 & 15 & 7 \\
\hline Wuasa & 4 & 778 & 466 & 3 & 38 & 46 & 47 & 47 & 685 & 557 & 570 & 570 & 9 & 6 & 4 & 12 & 5 & 5 & 5 & 1 & 41 & 60 & 931 & 15 & 10 \\
\hline Wuasa & 5 & 670 & 670 & 3 & 33 & 30 & 35 & 35 & 353 & 361 & 467 & 467 & 12 & 9 & 3 & 5 & 0 & 4 & 0 & 2 & 3 & 13 & 138 & 16 & 9 \\
\hline Wuasa & 6 & 236 & 280 & 4 & 20 & 33 & 40 & 40 & 190 & 206 & 191 & 191 & 6 & 8 & 4 & 10 & 6 & 2 & 2 & 2 & 9 & 52 & 461 & 10 & 4 \\
\hline Wuasa & 7 & 858 & 860 & 3 & 41 & 53 & 52 & 52 & 343 & 288 & 478 & 478 & 9 & 5 & 6 & 10 & 13 & 4 & 2 & 2 & 15 & 24 & 283 & 6 & 2 \\
\hline Wuasa & 8 & 547 & 580 & 3 & 26 & 44 & 50 & 50 & 230 & 359 & 545 & 545 & 5 & 9 & 4 & 15 & 9 & 5 & 1 & 2 & 18 & 23 & 346 & 12 & 2 \\
\hline Wuasa & 9 & 865 & 860 & & 36 & 50 & 51 & 51 & 1,136 & 1,858 & 3,392 & 3,392 & 18 & 8 & 5 & 9 & 4 & 5 & 0 & 1 & 23 & 40 & 476 & 23 & 10 \\
\hline Wuasa & 10 & 1,043 & 1,050 & 3 & 43 & 44 & 54 & 54 & 390 & 371 & 465 & 465 & 10 & 8 & 6 & 11 & 6 & 5 & 4 & 2 & 4 & 11 & 192 & 15 & 10 \\
\hline Rompo & 11 & \begin{tabular}{|l|l|}
1,450 \\
\end{tabular} & 1,440 & 2 & 56 & 68 & \begin{tabular}{l|}
65 \\
\end{tabular} & 65 & 498 & 483 & \begin{tabular}{|l|}
672 \\
\end{tabular} & \begin{tabular}{|c|}
672 \\
\end{tabular} & 13 & 10 & 5 & 9 & 5 & 4 & 15 & 3 & 14 & 18 & \begin{tabular}{|l|}
104 \\
\end{tabular} & 12 & 7 \\
\hline Rompo & 12 & 583 & 585 & & 32 & 30 & & & 421 & 451 & & & & & & & & & & & 12 & & & & \\
\hline Rompo & 13 & 445 & 440 & & 36 & 30 & & & 272 & 139 & & & & & & & & & & & 10 & & & 3 & 3 \\
\hline Rompo & 14 & 1,323 & 1,330 & & 44 & 50 & 60 & 60 & 647 & 599 & 1,272 & 1,272 & 12 & 15 & 8 & 11 & 4 & 5 & 2 & 2 & 8 & 9 & 33 & 20 & 18 \\
\hline Rompo & 15 & 534 & 510 & 3 & 32 & 36 & 34 & 34 & 361 & 358 & 341 & 341 & 4 & 6 & 3 & 12 & 3 & 3 & 2 & 1 & 8 & 19 & 188 & 12 & 4 \\
\hline Rompo & 16 & 358 & 370 & 3 & 34 & 38 & 42 & 42 & 200 & 204 & 302 & 302 & 11 & 10 & 5 & 7 & 3 & 3 & 1 & 1 & 7 & 11 & 154 & 11 & 4 \\
\hline Rompo & 17 & 287 & 270 & 4 & 21 & 22 & 28 & 28 & 145 & 124 & 260 & 260 & 4 & 9 & 1 & 9 & 0 & 2 & 0 & 2 & 0 & 5 & 59 & 7 & 5 \\
\hline Rompo & 18 & 381 & 640 & 3 & 33 & 33 & 34 & 34 & 614 & 374 & 522 & 522 & 10 & 8 & 4 & 3 & 4 & 3 & 1 & 1 & 13 & 12 & 149 & 15 & 6 \\
\hline Rompo & 19 & 1,376 & 956 & 1 & 38 & 48 & 47 & 47 & 293 & 405 & 374 & 374 & 8 & 5 & 4 & 3 & 4 & 5 & 14 & 3 & 1 & 1 & 2 & 29 & 20 \\
\hline Rompo & 20 & 668 & 670 & 3 & 48 & 48 & 49 & 49 & 584 & 590 & 428 & 428 & 10 & 9 & 4 & 9 & 9 & 5 & 2 & 1 & 12 & 16 & 235 & 29 & 27 \\
\hline Siliwanga & 21 & 717 & 710 & 3 & 24 & 30 & 39 & 39 & 2,154 & 600 & 654 & \begin{tabular}{|l|}
654 \\
\end{tabular} & 9 & 8 & 5 & 10 & 2 & 3 & 0 & 2 & 4 & 7 & 54 & 2 & 2 \\
\hline Siliwanga & 22 & 471 & 470 & 2 & 30 & 37 & 40 & 40 & 331 & 450 & 516 & 516 & 8 & 8 & 5 & 6 & 5 & 4 & 0 & 4 & 12 & 4 & 11 & 2 & 2 \\
\hline Siliwanga & 23 & 464 & 2,210 & 2 & 19 & & & 22 & 749 & & & 296 & 4 & 3 & 2 & 2 & 1 & 4 & 0 & 4 & 2 & 14 & 66 & & \\
\hline Siliwanga & 24 & 927 & 930 & 2 & 24 & 30 & 33 & 33 & 454 & 298 & 292 & 292 & 8 & 5 & 3 & 6 & 1 & 4 & 1 & 4 & 12 & 10 & 94 & 3 & 3 \\
\hline Siliwanga & 25 & 585 & 528 & 3 & 25 & 30 & 39 & 39 & 242 & 265 & 519 & 519 & 7 & 8 & 2 & 11 & 3 & 5 & 0 & 2 & 9 & 22 & 101 & 4 & 4 \\
\hline Siliwanga & 26 & 633 & 630 & 2 & 43 & 34 & 35 & 35 & 467 & 174 & 217 & 217 & 10 & 5 & 4 & 5 & 1 & 4 & 1 & 4 & 7 & 6 & 18 & 3 & 2 \\
\hline Siliwanga & 27 & 2,383 & 2,380 & 2 & 29 & 42 & 44 & 44 & 603 & 617 & 859 & 859 & 9 & 7 & 4 & 7 & 4 & 4 & 2 & 5 & 14 & 16 & 115 & 3 & 2 \\
\hline Siliwanga & 28 & 999 & 990 & 2 & 30 & 36 & 36 & 36 & 957 & 483 & 488 & 488 & 9 & 7 & 4 & 4 & 3 & 5 & 0 & 2 & 13 & 15 & 93 & 4 & 3 \\
\hline Siliwanga & 29 & 2,225 & 2,420 & 2 & 37 & 40 & 41 & 41 & \begin{tabular}{|l|}
1,120 \\
\end{tabular} & 1,011 & 1,183 & 1,183 & 11 & 6 & 4 & 5 & 5 & 4 & 2 & 3 & 13 & 13 & 118 & 2 & 2 \\
\hline Siliwanga & 30 & 957 & 870 & & 31 & 35 & & 30 & 429 & 481 & & 306 & 10 & 5 & 2 & 2 & 2 & 3 & 1 & 4 & 17 & 11 & 50 & & \\
\hline Tamadue & 31 & & 1,960 & 4 & & & & 28 & & & & 145 & 9 & 5 & 5 & 3 & 2 & 1 & 2 & 1 & & 27 & 119 & 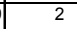 & 2 \\
\hline Tamadue & 32 & & 2,280 & 1 & & & & 30 & & & & 429 & 8 & 6 & 2 & 6 & 0 & 2 & 2 & 3 & & 15 & 152 & 3 & 1 \\
\hline Tamadue & 33 & & 1,869 & 1 & & & & 25 & & & & 348 & 8 & 3 & 3 & 5 & 1 & 3 & 0 & 2 & 0 & 20 & 158 & 0 & 0 \\
\hline Tamadue & 34 & & 2,300 & 1 & & & & 33 & & & & 606 & 9 & 4 & 3 & 6 & 3 & 3 & 2 & 2 & 1 & 17 & 118 & 3 & 0 \\
\hline Tamadue & 35 & & 2,310 & 1 & & & & 28 & & & & 484 & 5 & 5 & 4 & 5 & 0 & 4 & 2 & 2 & & 9 & 114 & 2 & 2 \\
\hline Tamadue & 36 & & 815 & 1 & & & & 34 & & & & 179 & 4 & 6 & 5 & 6 & 4 & 4 & 2 & 2 & & 27 & 135 & 3 & 3 \\
\hline Tamadue & 37 & & 720 & 4 & & & & 22 & & & & 170 & 7 & 3 & 3 & 4 & 0 & 1 & 0 & 3 & & 20 & 73 & 0 & 0 \\
\hline Tamadue & 38 & & 2,220 & 1 & & & & 50 & & & & 1,029 & 12 & 6 & 5 & 9 & 3 & 4 & 6 & 3 & & 17 & 111 & 0 & 0 \\
\hline Tamadue & 39 & & 2,350 & 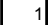 & & & & 38 & & & & 532 & 10 & 6 & 5 & 5 & 2 & 3 & 4 & 3 & p & 14 & 71 & 0 & 0 \\
\hline Tamadue & 40 & & 2,420 & 1 & & & & 42 & & & & 690 & 12 & 3 & 3 & 9 & 3 & 5 & 3 & 4 & & 21 & 114 & 3 & 0 \\
\hline Wanga & \begin{tabular}{|l|}
41 \\
\end{tabular} & & 1,280 & 3 & & & & 48 & & & & 498 & 13 & 8 & 3 & 10 & 4 & 4 & 3 & 2 & & 17 & 237 & 18 & 12 \\
\hline Wan & 42 & & 550 & 3 & & & & 48 & & & & 269 & 10 & 10 & 4 & 9 & 6 & , & 4 & 1 & & 32 & 299 & 10 & , \\
\hline Wanga & 43 & & 250 & 4 & & & & 13 & & & & 72 & 4 & 5 & 2 & 1 & 0 & 0 & 0 & 1 & 0 & 11 & 169 & 9 & 13 \\
\hline Wanga & 44 & & 648 & 3 & & & & 50 & & & & 435 & 7 & 8 & 3 & 13 & 8 & 5 & 4 & 1 & & 20 & 201 & 10 & 7 \\
\hline Wanga & 45 & & 310 & 4 & & & & 25 & & & & 364 & 3 & 3 & 2 & 8 & 2 & 3 & 1 & 2 & i) & 12 & 83 & 7 & 4 \\
\hline Wanga & 46 & & 440 & 4 & & & & 21 & & & & 136 & 4 & 1 & 2 & 4 & 2 & 2 & 4 & 1 & 1 & 11 & 140 & 4 & 3 \\
\hline Wanga & 47 & & 430 & 4 & & & & 38 & & & & 150 & 7 & 4 & 5 & 10 & 5 & 4 & 1 & 1 & i] & 25 & 125 & 4 & 3 \\
\hline Wanga & $48 \mid$ & & 670 & 3 & & & & 54 & & & & 433 & 16 & 10 & 4 & 10 & 3 & 4 & 5 & 2 & & 5 & 14 & 9 & 2 \\
\hline a & 49 & & 1,440 & 3 & & & & 56 & & & & 457 & 12 & 10 & 4 & 13 & 6 & 2 & 7 & 1 & 1 & 33 & 165 & 19 & 14 \\
\hline Wanga & 50 & & 1,377 & 4 & & & & 28 & & & & 272 & 8 & 2 & 3 & 5 & 1 & 2 & 5 & 2 & 0 & 2 & 2 & 6 & 1 \\
\hline
\end{tabular}


Appendix 16. Homegarden (HG) sizes, cluster numbers, as well as crop diversity and evenness indices of 50 homegardens in five villages of the Napu valley, Central Sulawesi, in 2001, 2003, and 2004.

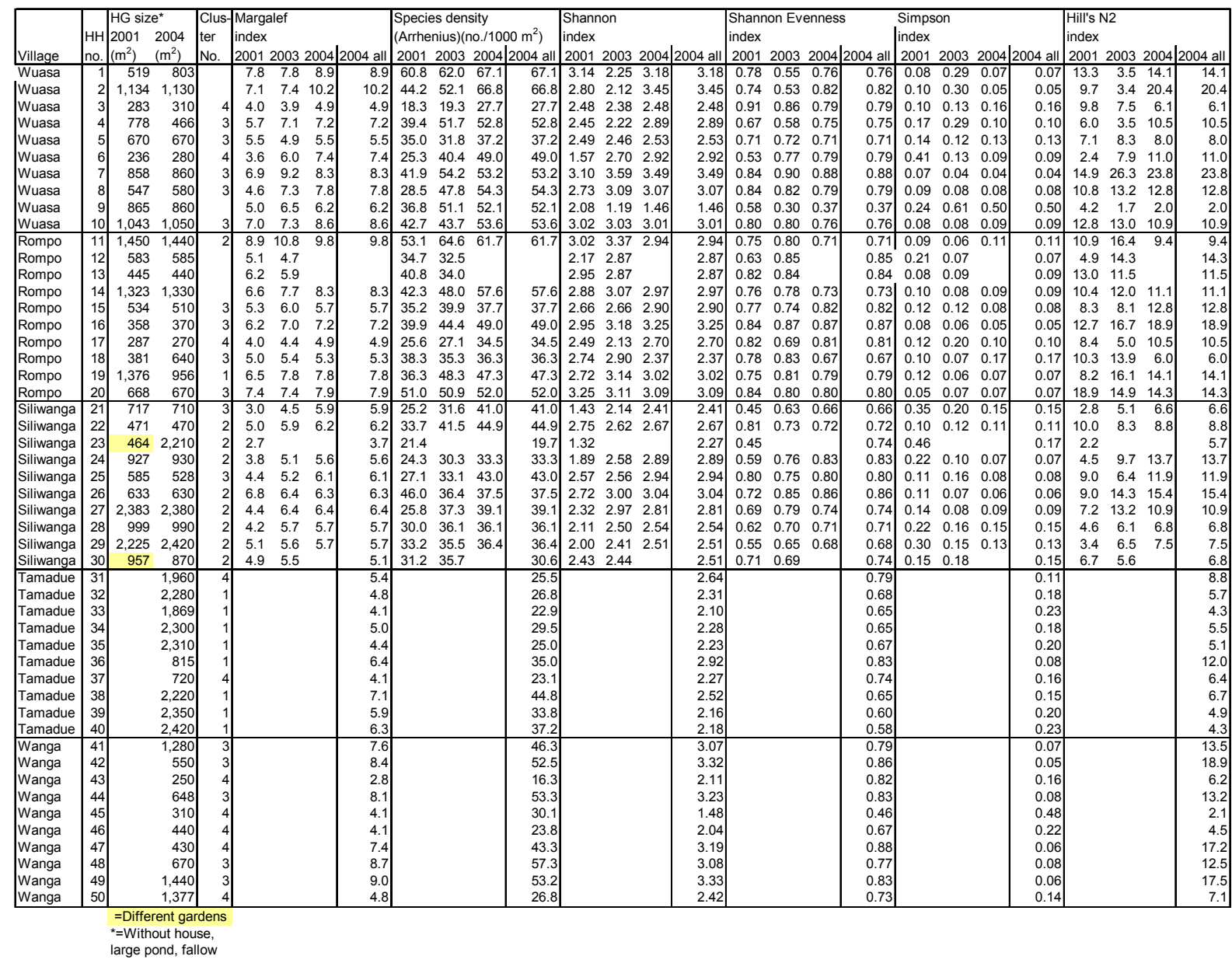


Appendix 17. Dendrogram as result of hierarchical cluster analysis for outlier detection, carried out on the basis of ln-transformed crop species abundance data of 48 homegardens in five villages of the Napu valley, Central Sulawesi, 2004, using 'Nearest neighbour' method and squared Euclidian distances. Homegardens no. 1, 2 (bottom) as well as no. 9 and 14 (top) were identified visually as outliers.

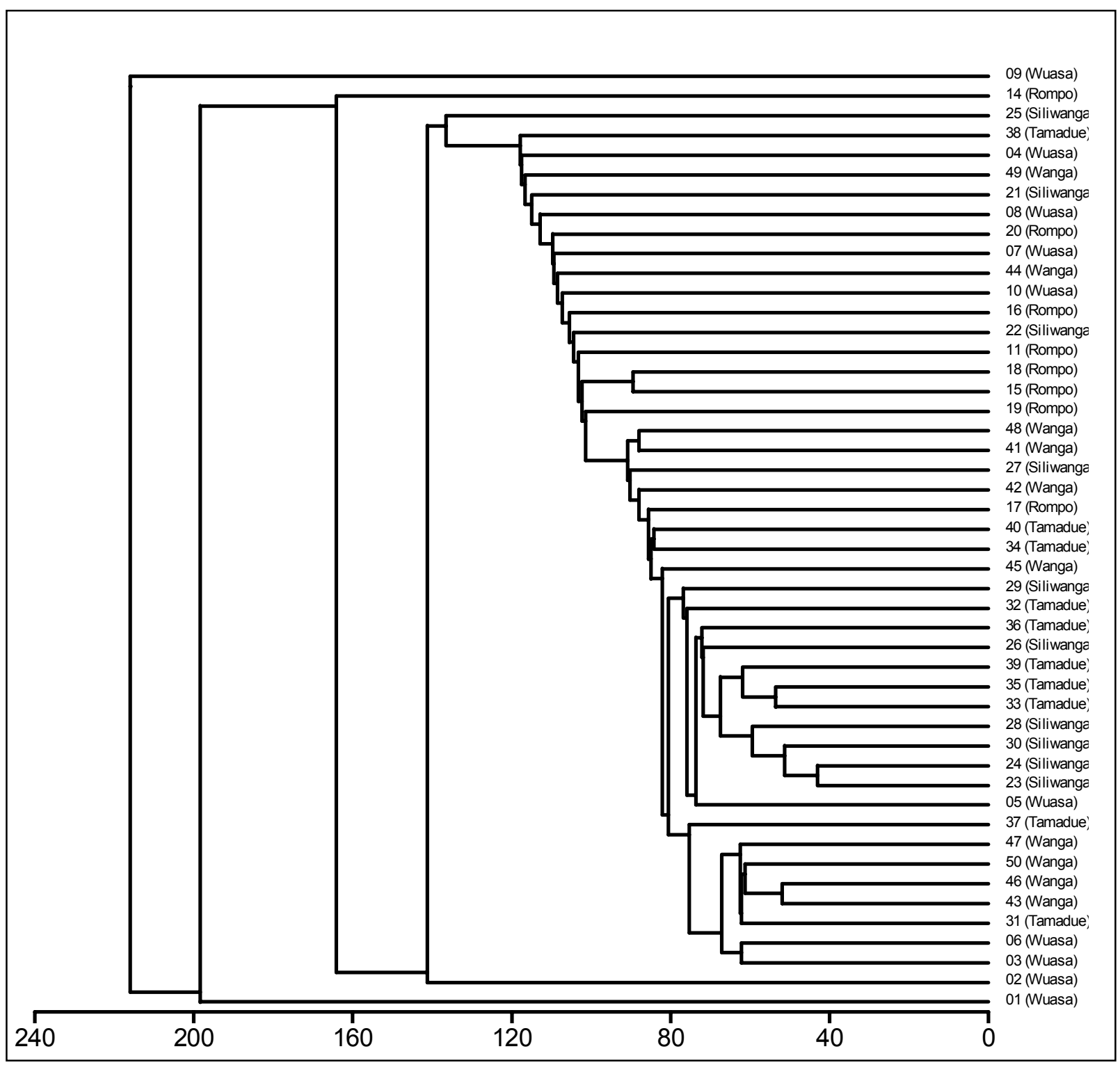

Squared Euclidean distances - data In-transformed 
Appendix 18. Graphical detection of the correct number of clusters for the final solution using the 'elbow' criterion. Sum of squares was plotted against the respective number of clusters. A final solution of 4 clusters was suggested because at the right of the 'elbow' the small decrease of the plotted line indicates no further significant increase in dissimilarity among additional clusters.

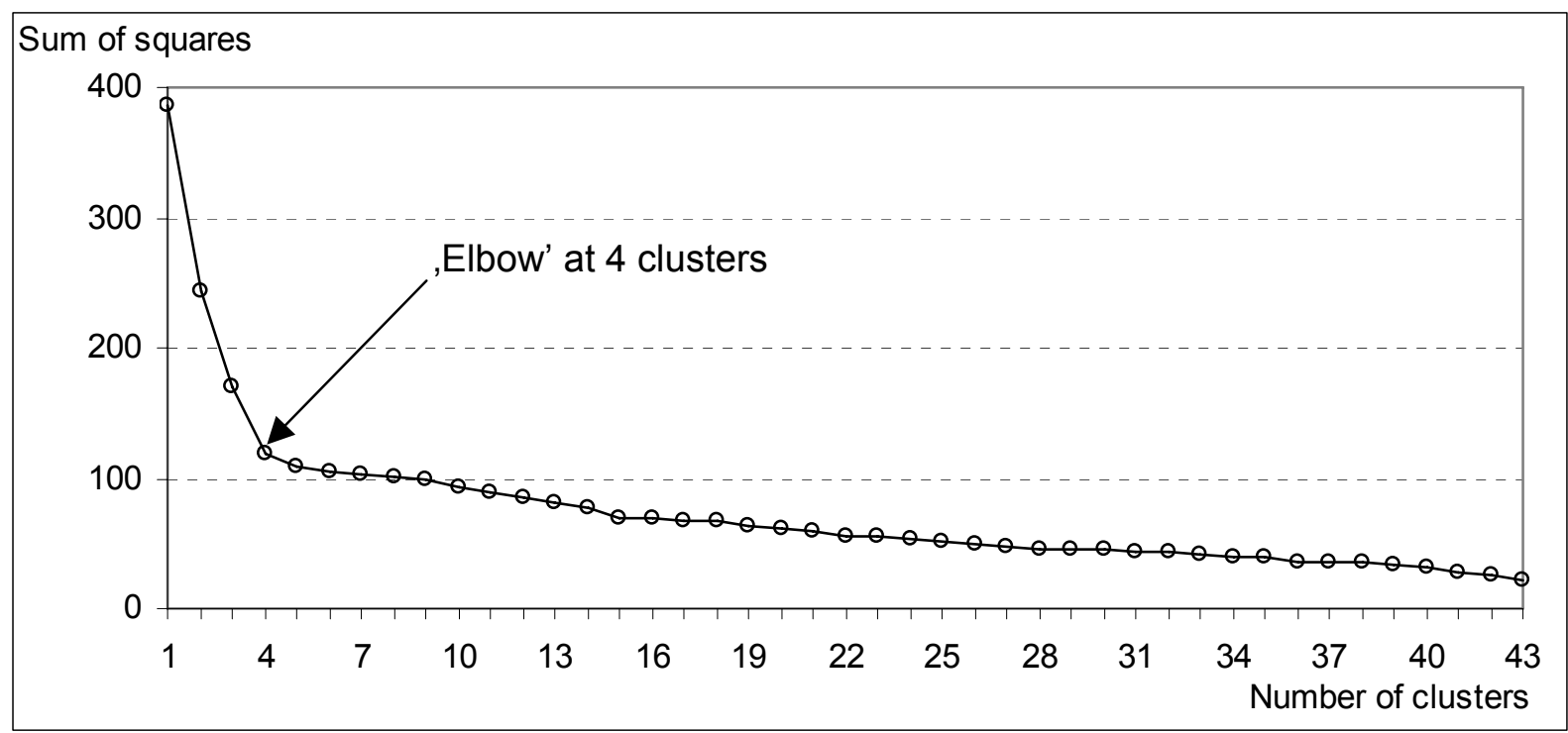

Appendix 19. Number and percentage of cases correctly classified as result of stepwise discriminant analysis, carried out on the basis of ln-transformed crop species abundance data of 44 homegardens in five villages of the Napu valley, Central Sulawesi, 2004.

Klassifizierungsergebniss $e^{b, c}$

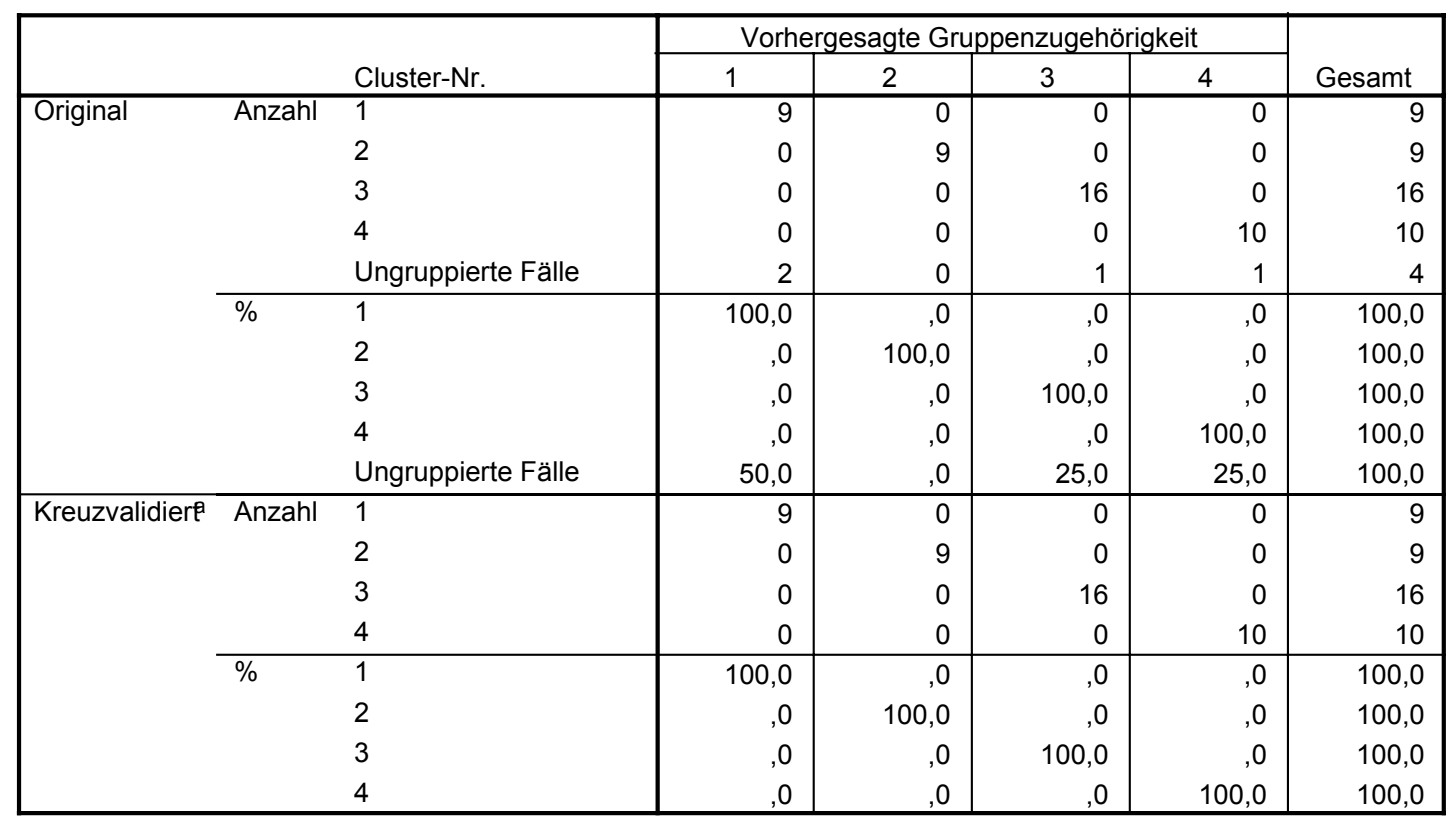

a. Die Kreuzvalidierung wird nur für Fälle in dieser Analyse vorgenommen. In der Kreuzvalidierung ist jeder Fall durch die Funktionen klassifiziert, die von allen anderen Fällen außer diesem Fall abgeleitet werden.

b. $100,0 \%$ der ursprünglich gruppierten Fälle wurden korrekt klassifiziert.

c. $100,0 \%$ der kreuzvalidierten gruppierten Fälle wurden korrekt klassifiziert. 
Appendix 20. Plotted functions of stepwise canonical discriminant analysis, carried out on the basis of lntransformed crop species abundance data of 44 homegardens in five villages of the Napu valley, Central Sulawesi, 2004.

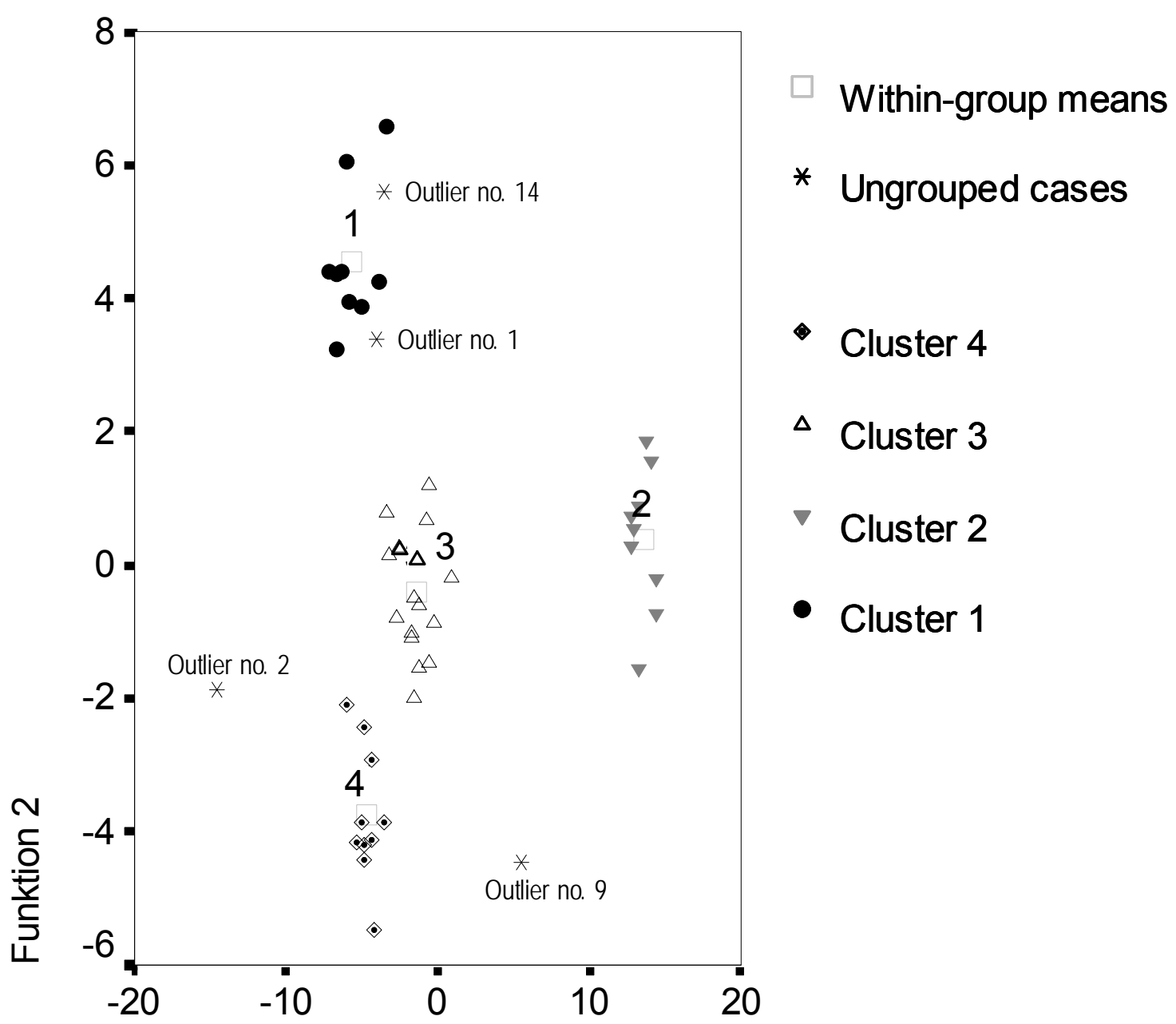

Funktion 1 
Appendix 21. Mean quality parameters of top soil $(0-15 \mathrm{~cm})$ in 50 homegardens of five villages in the Napu valley, Central Sulawesi, in 2004.

\begin{tabular}{|c|c|c|c|c|c|c|c|c|c|c|c|c|c|c|c|c|c|c|c|c|c|}
\hline Village & $\mid \begin{array}{l}\mathrm{HH} \\
\text { no. }\end{array}$ & \multicolumn{3}{|c|}{ Contents (\%) of } & \begin{tabular}{|l|} 
Bulk \\
density \\
(g/cm3)
\end{tabular} & \multicolumn{2}{|c|}{$\begin{array}{ll}\mathrm{pH} & \mathrm{pH} \\
\left(\mathrm{CaCl}_{2}\right) & \left(\mathrm{H}_{2} \mathrm{O}\right)\end{array}$} & \multicolumn{2}{|c|}{\begin{tabular}{|l|} 
P contents \\
(ppm) \\
(Olsen) (Bray I)
\end{tabular}} & \multicolumn{2}{|c|}{$\begin{array}{l}\text { Contents (\%) } \\
\text { of }\end{array}$} & $\begin{array}{l}\mathrm{C} / \mathrm{N} \\
\text { ratio }\end{array}$ & \multicolumn{7}{|c|}{ Cation contents $(\mathrm{cmol} / \mathrm{kg})$} & $\begin{array}{r}\begin{array}{r}\mathrm{CEC}_{\text {eff. }} \\
(\mathrm{cmol} / \\
\mathrm{kg})\end{array} \\
\end{array}$ & $\begin{array}{l}\text { BS } \\
(\%)\end{array}$ \\
\hline Wuasa & 1 & 48 & 28 & 24 & 0.80 & 4.8 & 5.5 & 26 & 78 & 0.16 & 1.9 & 12.1 & 0.14 & 7.8 & 0.01 & 0.58 & 1.8 & 0.34 & 0.20 & 10.9 & 94.0 \\
\hline Wua & 2 & 55 & 29 & 16 & 95 & 5.6 & 5.3 & 90 & 305 & 0 & 2.3 & 12.2 & 0.00 & 9.8 & 0.00 & 0.65 & 2.8 & .14 & 0.12 & 13.6 & 8.8 \\
\hline Wuasa & 3 & 51 & 35 & 14 & 01 & 6.2 & 6.8 & 118 & 333 & 0.14 & 1.7 & 15.0 & 0.01 & 12.6 & 0.00 & 0.80 & 2.2 & .03 & 0.21 & 15.8 & 9.7 \\
\hline Wuasa & 4 & 74 & 11 & 15 & 0 & .5 & 6.0 & 80 & 300 & & 1.7 & 14.1 & & 6.9 & & & 2.1 & 10 & 10 & 9.6 & 9.0 \\
\hline Wuasa & 5 & 6 & 8 & 5 & 15 & 5 & 5.8 & 24 & 91 & & 1.4 & 10.7 & & 6 & 00 & & 0.8 & 11 & .07 & 5.7 & 0.0 \\
\hline Wuasa & 6 & 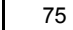 & 1 & 14 & 11 & 0 & 6.5 & 99 & 440 & 0.13 & 1.6 & 12.3 & & 7.6 & .00 & & .7 & .02 & & 9.9 & 99.8 \\
\hline Wuasa & 7 & 75 & 10 & 15 & 09 & 5.4 & 6.0 & 81 & 223 & 01 & 1.8 & 11.6 & 02 & 7.1 & .00 & 0 & .9 & .10 & 6 & 9.9 & 88.3 \\
\hline Wuasa & 8 & 53 & 27 & 19 & 05 & 4.9 & 5.5 & 27 & 73 & 0.11 & 1.3 & 12.1 & 0.13 & 6.2 & 0.00 & 7 & 1.5 & .10 & 11 & 8.7 & 94.7 \\
\hline Wu & 9 & 66 & 1 & 22 & 98 & 4.9 & 5.4 & 32 & 138 & 0.1 & 2.6 & 13.8 & & 6.9 & & & .4 & & & 9.3 & 2.4 \\
\hline Wuasa & 10 & 6 & 14 & 18 & 08 & 4.9 & 5.4 & 24 & 338 & 0.1 & 1.5 & 13.1 & & 5.4 & & & 1.6 & & & 8.0 & 94.7 \\
\hline \begin{tabular}{|l|} 
Rompo \\
\end{tabular} & 11 & & 20 & 26 & 94 & .5 & 5.0 & 11 & 30 & c & 1.6 & 12.7 & & 4 & & & 2.8 & & & 9.5 & 5.9 \\
\hline Rom & 12 & & 2 & 10 & & & 6.0 & 3 & 120 & & 0.9 & 3.6 & & & & & .9 & & & 5.8 & 8.8 \\
\hline 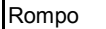 & 1 & & 2 & 25 & & & 5.8 & 26 & 73 & & 1.8 & 2.5 & & & & & & & & 1.6 & 7.9 \\
\hline गाро & 14 & 4 & 2 & 30 & 81 & $4 . \mathrm{S}$ & 5.4 & 44 & 114 & 0.2 & 2.9 & 1.7 & & ${ }^{\circ}$ & & & 7 & & & 12.4 & 34.0 \\
\hline mpo & 15 & 7 & 1 & 15 & 20 & 4.8 & 5.7 & 13 & 46 & 0 & 1.1 & . & & 3.6 & .00 & & .3 & 5 & & 5.5 & 2.9 \\
\hline po & 16 & 7 & 1 & 15 & 13 & 5.2 & 5.6 & 106 & 247 & 00 & 1.3 & 3.6 & & 6.8 & & & 1.6 & & & 9.1 & 8.0 \\
\hline Rompo & 17 & 3 & 40 & 29 & 92 & 6.1 & 6.3 & 74 & 141 & 0.2 & 2.5 & 11.1 & & 13.8 & & & 4.7 & & & 19.5 & 9.8 \\
\hline Rompo & 18 & 6 & 1 & 18 & 94 & 5.0 & 5.4 & 77 & 235 & & 2.5 & 3.1 & & .2 & & & 2.0 & & & 10.8 & 7.7 \\
\hline Romno & 19 & 3 & 3 & 2 & & & 5.5 & 32 & 75 & & 3.2 & 2.7 & & 1 & & & 0 & & & 8.0 & 5.7 \\
\hline Ron & 0 & & & 21 & & & .0 & 51 & 132 & & 2.9 & ... & & 12 & & & & & & 17.3 & 8.9 \\
\hline Siliwang & 21 & 5 & & 19 & $\overline{02}$ & & 4. & $\overline{2}$ & 75 & 0 & 3.0 & 1 & & & & & & & & 4.8 & $\overline{8.4}$ \\
\hline Sili & 2 & 4 & & 20 & & 4 & 5. & 1 & 5 & & 4.7 & & & & & & & & & 6.9 & 1.8 \\
\hline & 23 & 6 & & & & & 4. & 1 & & & 2.8 & & & & & & & & & 4.0 & 9.8 \\
\hline Siliv & 24 & 4 & 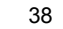 & 15 & & & 5.4 & 9 & 80 & & 3.1 & 2.7 & & & & & & & & 8.2 & 0.8 \\
\hline Siliwanga & 25 & 5 & 3 & 12 & & & 5.6 & 9 & 97 & & 3.0 & 15.0 & & & & & & & & 4.7 & 5.2 \\
\hline Siliwanga & 26 & & 2 & 18 & & & 5.8 & 5 & 52 & & 2.5 & & & & & & & & & 4.4 & 8.8 \\
\hline & 27 & & & & & & & 14 & 4 & & 2.7 & & & & & & & & & 4.9 & 1.2 \\
\hline & 28 & & 2 & 2 & & & & 10 & 111 & 0. & 3 & & & & & & & & & 7.0 & 6.4 \\
\hline & 29 & 4 & 4 & 1 & & & & 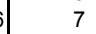 & 29 & & & & & & & & & & & 5.0 & 34.7 \\
\hline Sili & 30 & 22 & & 47 & & & & 34 & 188 & & & & & & & & & & & 4.7 & 85.3 \\
\hline Tam & 31 & 9 & 5 & 38 & & 5. & 5.4 & T & 52 & $\overline{.4}$ & 4.5 & 11.0 & 0.01 & 17.6 & 0 & & & $\overline{9}$ & & 25.4 & 97.5 \\
\hline Tamadue & 32 & 12 & 5 & 30 & & 4 & 5.2 & 2 & 32 & & 3.4 &. .1 & & 14.7 & & & & & & 3.1 & 5.6 \\
\hline & 33 & 15 & 5 & 28 & & & 5.8 & 2 & 34 & & 4.1 & & & & & & & & & 6.7 & 8.9 \\
\hline & 34 & 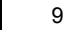 & & 45 & & & 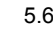 & & 26 & & 3.8 & & & & & & & & & 9.9 & 98.3 \\
\hline & 3 & 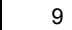 & & & & & & 2 & 0 & & 4 & & & & & & & & & 2.4 & 3.1 \\
\hline & 3 & & & & & & & & & & & & & & & & 1 & & & & \\
\hline & 37 & & & & & & & & & & & & & 13 & & & & & & .8 & 7.9 \\
\hline & 38 & & & & & & & 2 & & & 3.2 & & & 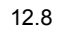 & & & .0 & & & 8.2 & 8.7 \\
\hline Tamadue & 39 & 10 & 4 & 44 & & 0 & 6.1 & 3 & 55 & 0. & 5.1 & 11.2 & 0 & 29.5 & 0 & & 6 & 8 & & 37.9 & 99.0 \\
\hline Tamadue & 40 & 4 & 2 & 27 & & & & 3 & 50 & & 3.9 & 3 & & & & & & & & 0.0 & 99.3 \\
\hline Wanga & 41 & 4 & 2 & 26 & & & 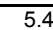 & 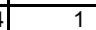 & 15 & & 4.8 & 12.4 & & 10.5 & & & .2 & & & 7.7 & 96.1 \\
\hline & 42 & & 2 & 19 & & & & & & & 1.8 & & & 9.7 & & & .9 & & & 13.1 & 98.4 \\
\hline & 43 & & & 2 & & & & 1 & & & 2 & & & 11.9 & & & & & & 5.0 & 100.0 \\
\hline & 4 & & & & & & & & & & & & & & & & & & & 2.6 & 88.3 \\
\hline & 45 & & & & & & & 1 & & & 2 & & & 11 & & & & & & 15.5 & 99.9 \\
\hline & 46 & 4 & 3 & 23 & & 5.7 & .2 & 19 & 300 & 0 & 2.8 & & & 13.2 & & & 2.9 & 1 & & 16.7 & 99.9 \\
\hline & 47 & 37 & 33 & 30 & 0.80 & 5.3 & 5.7 & 17 & 393 & 0.25 & 3.0 & 12.2 & & 11.7 & 0.00 & 0. & 3.8 & 1 & & 16.3 & 99.9 \\
\hline Wanga & 48 & 33 & 41 & 26 & 0.79 & 5.0 & 5.6 & 11 & 217 & 0.22 & 2.7 & 11.7 & 0.03 & 12.7 & 0.00 & 0.45 & 4.1 & 0.03 & 0.05 & 17.4 & 98.9 \\
\hline & 49 & 44 & 32 & 24 & 0.78 & 5.2 & 5.7 & 17 & 309 & 0.2 & 3. & 11 & 0.0 & 12.0 & 0.00 & 0. & 3.6 & 0.05 & 0. & 16.3 & 99.5 \\
\hline Wanga & 50 & 40 & 37 & 23 & 0.70 & 5.0 & 0.4 & 9 & 203 & 0.27 & 0.4 & 12.0 & 0.06 & 9.8 & 0.00 & 0.51 & 3.7 & 0.13 & 0.02 & 14.3 & 97.8 \\
\hline
\end{tabular}


Appendix 22. Quality parameters of top soil (0-15 cm) of vegetable (=Veg.) and cacao/coffee zones $(=C C)$ in 50 homegardens of five villages in the Napu valley, Central Sulawesi, in 2004.

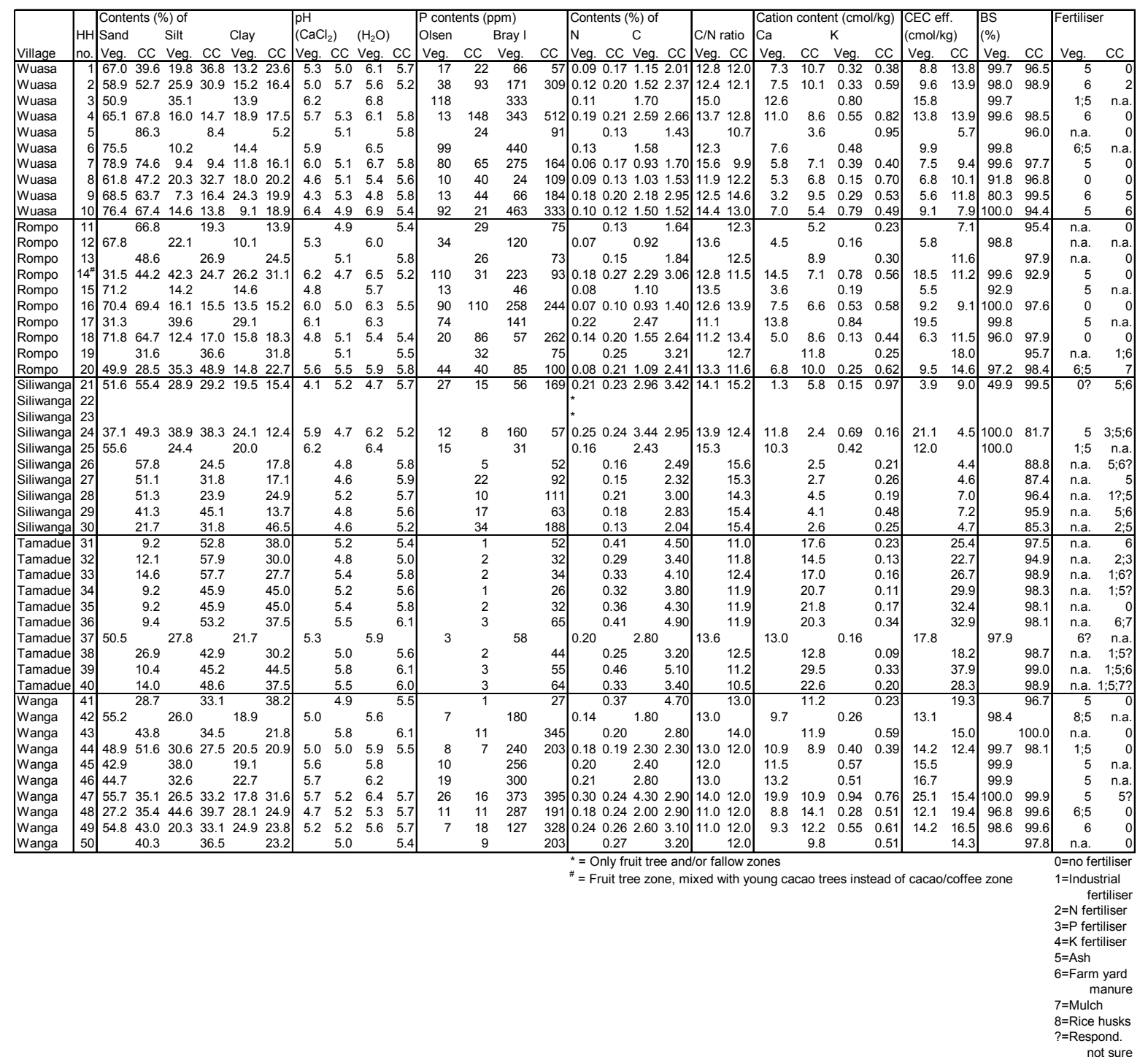


Appendix 23. Medians (ranges in brackets) of different quality parameters of top soil in cacao/coffee production zones of 38 homegardens in five villages of the Napu valley, Central Sulawesi, 2004. $N=8$ in Wuasa; $N=7$ each in Rompo, Wanga, and Siliwanga; $N=9$ in Tamadue.

\begin{tabular}{|c|c|c|c|c|c|}
\hline & $\mathrm{Ncc}$ & ntent (\%) & $\mathrm{C}$ content $(\%)$ & & $\mathrm{N}$ ratio \\
\hline Wuasa & $0.17 \mathrm{~b}$ & $(0.12-0.21)$ & $(1.43-2.95)$ & $12.2 \mathrm{ab}$ & $(9.9-14.6)$ \\
\hline Rompo & $0.20 \mathrm{~b}$ & $(0.10-0.27)$ & $(1.40-3.21)$ & $12.5 \mathrm{ab}$ & $(11.5-13.9)$ \\
\hline Wanga & $0.24 \mathrm{ab}$ & $(0.19-0.37)$ & $2.90 \mathrm{ab} \quad(2.30-4.70)$ & $12.0 \mathrm{ab}$ & $(12.0-14.0)$ \\
\hline Siliwanga & $0.18 b$ & $(0.13-0.24)$ & $2.83 \mathrm{ab} \quad(2.04-3.42)$ & $15.3 \mathrm{a}$ & $(12.4-15.6)$ \\
\hline Tamadue & $0.33 \mathrm{a}$ & $(0.25-0.46)$ & $(3.20-5.10)$ & $11.9 \mathrm{~b}$ & $(10.5-12.5)$ \\
\hline
\end{tabular}

Medians in a column followed by different letters are significantly different at $\mathrm{P} \leq 0.05$.

\begin{tabular}{llllllll}
\hline & \multicolumn{1}{c}{$\mathrm{pH}\left(\mathrm{H}_{2} \mathrm{O}\right)$} & \multicolumn{2}{c}{$\mathrm{pH}\left(\mathrm{CaCl}_{2}\right)$} & \multicolumn{2}{c}{ P-Olsen $(\mathrm{ppm})$} & \multicolumn{2}{c}{ P-Bray $(\mathrm{ppm})$} \\
\hline Wuasa & $5.8 \mathrm{a}(5.2-5.8)$ & $5.1 \mathrm{ab}(4.9-5.7)$ & $42 \mathrm{a}$ & $(21-148)$ & $174 \mathrm{a}$ & $(57-512)$ \\
Rompo & $5.5 \mathrm{a}(5.2-5.8)$ & $5.1 \mathrm{ab}$ & $(4.7-5.5)$ & $32 \mathrm{a}$ & $(26-110)$ & $93 \mathrm{ab}$ & $(73-262)$ \\
Wanga & $5.7 \mathrm{a}(5.4-6.1)$ & $5.2 \mathrm{ab}$ & $(4.9-5.8)$ & $11 \mathrm{ab}$ & $(1-18)$ & $203 \mathrm{a}$ & $(27-395)$ \\
Siliwanga & $5.7 \mathrm{a}(5.2-5.9)$ & $4.8 \mathrm{~b}$ & $(4.6-5.2)$ & $15 \mathrm{ab}$ & $(5-34)$ & $92 \mathrm{ab}$ & $(52-188)$ \\
Tamadue & $5.8 \mathrm{a}(5.0-6.1)$ & $5.4 \mathrm{a}$ & $(4.8-5.8)$ & $2 \mathrm{~b}$ & $(1-3)$ & $44 \mathrm{~b}$ & $(26-65)$ \\
\hline
\end{tabular}

Medians in a column followed by different letters are significantly different at $\mathrm{P} \leq 0.05$.

\begin{tabular}{lclllllll}
\hline & \multicolumn{2}{c}{$\begin{array}{c}\text { CEC } \text { eff. } \\
(\mathrm{cmol} / \mathrm{kg})\end{array}$} & \multicolumn{2}{c}{$\begin{array}{c}\text { Exchangeable K } \\
(\mathrm{cmol} / \mathrm{kg})\end{array}$} & \multicolumn{2}{c}{$\begin{array}{c}\text { Exchangeable Ca } \\
(\mathrm{cmol} / \mathrm{kg})\end{array}$} & \multicolumn{2}{c}{$\begin{array}{c}\text { Base saturation } \\
(\%)\end{array}$} \\
\hline Wuasa & $11.0 \mathrm{~b}$ & $(5.7-13.9)$ & $0.56 \mathrm{a}$ & $(0.38-0.95)$ & $7.8 \mathrm{~b}$ & $(3.6-10.7)$ & $97.3 \mathrm{ab}$ & $(94.4-99.5)$ \\
Rompo & $11.5 \mathrm{~b}$ & $(7.1-18.0)$ & $0.44 \mathrm{ab}$ & $(0.23-0.62)$ & $8.7 \mathrm{~b}$ & $(5.2-11.8)$ & $97.6 \mathrm{ab}$ & $(92.9-98.4)$ \\
Wanga & $15.4 \mathrm{ab}$ & $(12.4-19.4)$ & $0.51 \mathrm{a}$ & $(0.23-0.76)$ & $11.3 \mathrm{ab}$ & $(8.9-14.1)$ & $99.6 \mathrm{a}$ & $(96.7-100)$ \\
Siliwanga & $4.7 \mathrm{~b}$ & $(4.4-9.0)$ & $0.25 \mathrm{ab}$ & $(0.16-0.97)$ & $2.7 \mathrm{~b}$ & $(2.4-5.8)$ & $88.8 \mathrm{~b}$ & $(81.7-99.5)$ \\
Tamadue & $28.3 \mathrm{a}$ & $(18.2-37.9)$ & $0.17 \mathrm{~b}$ & $(0.09-0.34)$ & $20.3 \mathrm{a}$ & $(12.8-29.5)$ & $98.3 \mathrm{ab}$ & $(94.9-99.0)$ \\
\hline
\end{tabular}

Medians in a column followed by different letters are significantly different at $\mathrm{P} \leq 0.05$.

Appendix 24. Rating of changes in soil fertility by gardeners and analysed quality parameters of top soil (0-15 $\mathrm{cm})$ in 26 homegardens of three villages in the Napu valley, Central Sulawesi, in 2001 and 2004.

\begin{tabular}{|c|c|c|c|c|c|c|c|c|c|c|c|c|c|c|c|c|}
\hline \multirow[b]{2}{*}{ Village } & \multirow{2}{*}{$\begin{array}{ll}\mathrm{HH} \\
\text { no. }\end{array}$} & \multirow{2}{*}{\begin{tabular}{|l|} 
Rating of soil fertility \\
changes by gardeners
\end{tabular}} & \multicolumn{2}{|c|}{$\mathrm{N}$ content $(\%)$} & \multicolumn{2}{|c|}{ C content $(\%)$} & \multicolumn{2}{|c|}{$\mathrm{pH}\left(\mathrm{H}_{2} \mathrm{O}\right)$} & \multicolumn{2}{|c|}{ P-Olsen contents $(\mathrm{ppm})$} & \multicolumn{2}{|c|}{ Sand content (\%) } & \multicolumn{2}{|c|}{ Silt content (\%) } & \multicolumn{2}{|c|}{ Clay content $(\%)$} \\
\hline & & & 2001 & 2004 & 2001 & 2004 & 2001 & 2004 & 2001 & 2004 & 2001 & 2004 & 2001 & 2004 & 2001 & 2004 \\
\hline Wuasa & 1 & 1 & 0.18 & 0.16 & 1.96 & 1.88 & 5.4 & 5.5 & 40 & 26 & 47 & 48 & 37 & 28 & 16 & 24 \\
\hline Wuasa & 2 & 1 & 0.19 & 0.19 & 2.23 & 2.33 & 5.5 & 5.3 & 68 & 90 & 57 & 55 & 31 & 29 & 12 & 16 \\
\hline Wuasa & 3 & 1 & 0.13 & 0.11 & 1.93 & 1.70 & 6.5 & 6.8 & 96 & 118 & 52 & 51 & 36 & 35 & 13 & 14 \\
\hline Wuasa & 4 & 1 & 0.18 & 0.13 & 2.19 & 1.73 & 6.3 & 6.0 & 83 & 80 & 69 & 74 & 20 & 11 & 11 & 15 \\
\hline Wuasa & 5 & 1 & 0.11 & 0.13 & 1.27 & 1.43 & 6.3 & 5.8 & 36 & 24 & 87 & 86 & 8 & 8 & 5 & 5 \\
\hline Wuasa & 6 & 1 & 0.13 & 0.13 & 1.69 & 1.58 & 6.4 & 6.5 & 81 & 99 & 70 & 75 & 25 & 10 & 6 & 14 \\
\hline Wuasa & 7 & 3 & 0.16 & 0.16 & 2.15 & 1.79 & 6.4 & 6.0 & 84 & 81 & 68 & 75 & 20 & 10 & 12 & 15 \\
\hline Wuasa & 8 & 3 & 0.17 & 0.11 & 2.03 & 1.32 & 5.8 & 5.5 & 54 & 27 & 53 & 53 & 30 & 27 & 18 & 19 \\
\hline Wuasa & 9 & 1 & 0.15 & 0.19 & 2.05 & 2.65 & 5.3 & 5.4 & 34 & 32 & 69 & 66 & 17 & 13 & 14 & 22 \\
\hline Wuasa & 10 & 1 & 0.14 & 0.12 & 1.64 & 1.52 & 5.5 & 5.4 & 73 & 24 & 72 & 68 & 17 & 14 & 12 & 18 \\
\hline Rompo & 11 & 1 & 0.19 & \begin{tabular}{l|}
0.12 \\
\end{tabular} & 2.19 & 1.50 & 4.7 & 4.9 & 8 & 5 & 38 & 37 & 34 & 33 & 28 & 31 \\
\hline Rompo & 13 & 2 & 0.16 & 0.15 & 1.84 & 1.84 & 5.4 & 5.8 & 29 & 26 & 48 & 49 & 34 & 27 & 19 & 25 \\
\hline Rompo & 14 & 1 & 0.25 & 0.27 & 3.02 & 3.06 & 5.5 & 5.2 & 51 & 31 & 52 & 44 & 31 & 25 & 18 & 31 \\
\hline Rompo & 15 & 2 & 0.15 & 0.08 & 1.70 & 1.10 & 5.2 & 5.7 & 21 & 13 & 64 & 71 & 22 & 14 & 15 & 15 \\
\hline Rompo & 16 & 1 & 0.13 & 0.09 & 1.63 & 1.31 & 5.6 & 5.6 & 77 & 106 & 66 & 70 & 20 & 16 & 14 & 15 \\
\hline Rompo & 18 & 2 & 0.22 & 0.20 & 2.80 & 2.64 & 5.8 & 5.4 & 65 & 86 & 67 & 65 & 21 & 17 & 12 & 18 \\
\hline Rompo & 19 & 2 & 0.29 & 0.25 & 3.35 & 3.21 & 5.3 & 5.5 & 25 & 32 & 33 & 32 & 38 & 37 & 30 & 32 \\
\hline Rompo & 20 & 1 & 0.21 & 0.22 & 2.47 & 2.87 & 5.3 & 5.8 & 40 & 51 & 43 & 32 & 41 & 47 & 16 & 21 \\
\hline Siliwanga & 21 & 3 & 0.29 & 0.21 & 3.70 & 3.04 & 4.5 & 4.8 & 13 & 25 & 49 & 52 & 35 & 29 & 16 & 19 \\
\hline Siliwanga & 22 & 3 & 0.35 & 0.34 & 4.48 & 4.67 & 4.9 & 5.6 & 16 & 18 & 48 & 47 & 32 & 33 & 20 & 20 \\
\hline Siliwanga & 24 & 2 & 0.25 & 0.24 & 3.05 & 3.06 & 5.0 & 5.4 & 20 & 9 & 45 & 47 & 38 & 38 & 18 & 15 \\
\hline Siliwanga & 25 & 3 & 0.20 & 0.20 & 2.62 & 3.00 & 5.0 & 5.6 & 13 & 9 & 53 & 57 & 30 & 31 & 17 & 12 \\
\hline Siliwanga & 26 & 3 & 0.18 & 0.16 & 2.62 & 2.49 & 6.5 & 5.8 & 19 & 5 & 56 & 58 & 30 & 24 & 13 & 18 \\
\hline Siliwanga & 27 & 3 & 0.23 & 0.23 & 3.04 & 2.66 & 4.9 & 5.6 & 13 & 14 & 50 & 50 & 36 & 36 & 14 & 15 \\
\hline Siliwanga & 28 & 3 & 0.27 & 0.21 & 3.58 & 3.00 & 6.3 & 5.7 & 21 & 10 & 55 & 51 & 29 & 24 & 17 & 25 \\
\hline Siliwanga & 29 & 3 & 0.28 & 0.22 & 3.09 & 2.90 & 5.3 & 5.6 & 11 & 6 & 42 & 43 & 40 & 41 & 19 & 17 \\
\hline
\end{tabular}


Appendix 25. Dry weights as well as dry matter and nutrient contents of cacao leaves sampled in 40 homegardens of five villages in the Napu valley, Central Sulawesi, 2004.

\begin{tabular}{|c|c|c|c|c|c|c|c|c|c|c|c|}
\hline & $\mathrm{HH}$ & Dry weight & Dry matter & Contents & $\%$ of & & Contents & $\overline{(p p m) ~ o f ~}$ & & & \\
\hline Village & no. & (g) & content $(\%)$ & $\mathrm{N}$ & C & $\mathrm{C} / \mathrm{N}$ ratio & $\mathrm{P}$ & $\mathrm{K}$ & $\mathrm{Mg}$ & $\mathrm{Fe}$ & $\mathrm{Ca}$ \\
\hline Wuasa & 1 & 16.7 & 39.8 & 1.87 & 50.06 & 26.73 & 2505 & 14,200 & 4690 & 54 & 10,650 \\
\hline Wuasa & 2 & 19.3 & 36.1 & 1.94 & 48.26 & 24.88 & 2390 & 13,150 & 4635 & 40 & 11,050 \\
\hline Wuasa & 4 & 11.9 & 39.7 & 1.62 & 43.64 & 27.01 & 2340 & 11,600 & 5350 & 40 & 19,100 \\
\hline Wuasa & 5 & 13.3 & 41.2 & 1.71 & 45.03 & 26.32 & 1970 & 10,350 & 5800 & 98 & 15,850 \\
\hline Wuasa & 6 & 15.4 & 43.0 & 1.41 & 44.71 & 31.74 & 1640 & 6,850 & 7550 & 133 & 20,100 \\
\hline Wuasa & 7 & 17.4 & 43.0 & 1.43 & 45.52 & 31.81 & 1625 & 9,550 & 6200 & 76 & 16,550 \\
\hline Wuasa & 8 & 12.8 & 42.2 & 1.45 & 45.75 & 31.49 & 1460 & 10,200 & 5500 & 74 & 15,900 \\
\hline Wuasa & 9 & 16.4 & 39.9 & 1.79 & 47.82 & 26.77 & 2515 & 11,850 & 6100 & 31 & 18,150 \\
\hline Wuasa & 10 & 15.6 & 42.4 & 1.56 & 41.92 & 26.87 & 1945 & 9,600 & 6000 & 125 & 20,550 \\
\hline Rompo & 11 & 13.5 & 37.8 & 1.55 & 45.24 & 29.13 & 1700 & 9,600 & 5650 & 36 & 18,850 \\
\hline Rompo & 13 & 13.9 & 39.2 & 1.47 & 42.45 & 28.80 & 1905 & 6,700 & 7400 & 108 & 15,700 \\
\hline Rompo & 14 & 17.7 & 34.4 & 1.73 & 48.62 & 28.10 & 2430 & 11,700 & 5000 & 30 & 9,150 \\
\hline Rompo & 15 & 14.7 & 38.9 & 1.66 & 43.47 & 26.26 & 1660 & 8,850 & 5750 & 237 & 12,900 \\
\hline Rompo & 16 & 12.9 & 35.3 & 1.87 & 47.70 & 25.54 & 2250 & 13,250 & 4490 & 47 & 14,900 \\
\hline Rompo & 18 & 13.8 & 36.8 & 1.65 & 45.65 & 27.64 & 1655 & 10,950 & 5950 & 49 & 18,450 \\
\hline Rompo & 19 & 18.1 & 34.2 & 1.60 & 48.93 & 30.63 & 1995 & 10,700 & 5150 & 139 & 10,750 \\
\hline Rompo & 20 & 14.6 & 35.4 & 1.92 & 44.59 & 23.25 & 2295 & 13,350 & 5150 & 72 & 14,750 \\
\hline Siliwanga & 21 & 10.3 & 41.0 & 1.54 & 51.02 & 33.06 & 2795 & 18,250 & 4815 & 60 & 8,800 \\
\hline Siliwanga & 22 & 14.1 & 42.0 & 1.43 & 48.68 & 33.98 & 2640 & 12,900 & 5900 & 98 & 13,800 \\
\hline Siliwanga & 23 & 13.4 & 42.7 & 1.45 & 43.74 & 30.14 & 1510 & 7,700 & 6050 & 67 & 9,450 \\
\hline Siliwanga & 26 & 9.2 & 39.8 & 1.49 & 46.98 & 31.50 & 2135 & 15,550 & 5950 & 63 & 9,000 \\
\hline Siliwanga & 27 & 11.2 & 35.6 & 1.92 & 49.17 & 25.55 & 2710 & 17,700 & 4440 & 140 & 7,800 \\
\hline Siliwanga & 28 & 13.1 & 41.5 & 1.55 & 46.11 & 29.79 & 1705 & 10,800 & 7450 & 41 & 14,500 \\
\hline Siliwanga & 29 & 13.4 & 47.7 & 1.37 & 42.16 & 30.68 & 1330 & 8,700 & 8550 & 78 & 17,050 \\
\hline Siliwanga & 30 & 9.8 & 37.5 & 1.97 & 47.25 & 23.96 & 2255 & 12,950 & 5550 & 65 & 12,050 \\
\hline Tamadue & 31 & 11.8 & 41.1 & 1.82 & 43.00 & 23.69 & 1710 & 9,200 & 5750 & 156 & 17,950 \\
\hline Tamadue & 32 & 12.3 & 44.4 & 2.43 & 45.57 & 18.74 & 2360 & 4,235 & 7900 & 42 & 12,500 \\
\hline Tamadue & 33 & 15.0 & 42.7 & 1.32 & 42.60 & 32.26 & 1745 & 7,500 & 6700 & 52 & 15,800 \\
\hline Tamadue & 34 & 12.2 & 39.9 & 1.56 & 45.46 & 29.18 & 2680 & 6,450 & 8050 & 100 & 14,550 \\
\hline Tamadue & 35 & 15.0 & 39.1 & 1.42 & 47.20 & 33.32 & 2210 & 6,450 & 6250 & 393 & 13,100 \\
\hline Tamadue & 36 & 10.8 & 40.4 & 1.32 & 42.44 & 32.23 & 2635 & 10,000 & 6100 & 60 & 14,150 \\
\hline Tamadue & 38 & 13.4 & 41.1 & 1.64 & 46.02 & 28.06 & 2200 & 5,150 & 7700 & 79 & 15,650 \\
\hline Tamadue & 39 & 13.1 & 39.0 & 1.64 & 48.87 & 29.80 & 1825 & 11,000 & 4105 & 26 & 10,350 \\
\hline Tamadue & 40 & 16.7 & 40.0 & 1.72 & 47.69 & 27.71 & 2320 & 11,800 & 5400 & 38 & 11,100 \\
\hline Wanga & 41 & 12.0 & 42.3 & 1.57 & 44.00 & 28.09 & 1475 & 6,050 & 7900 & 44 & 18,000 \\
\hline Wanga & 44 & 13.3 & 41.2 & 1.54 & 43.64 & 28.29 & 1960 & 9,850 & 5650 & 43 & 16,350 \\
\hline Wanga & 47 & 11.9 & 37.4 & 1.75 & 48.32 & 27.56 & 2080 & 11,650 & 6150 & 63 & 14,900 \\
\hline Wanga & 48 & 15.7 & 37.4 & 1.32 & 46.60 & 35.44 & 3360 & 16,750 & 4265 & 66 & 12,000 \\
\hline Wanga & 49 & 12.5 & 38.7 & 1.45 & 49.93 & 34.55 & 1600 & 14,550 & 4390 & 31 & 23,350 \\
\hline Wanga & 50 & 15.4 & 39.3 & 1.56 & 47.46 & 30.45 & 1600 & 13,850 & 6400 & 41 & 19,400 \\
\hline
\end{tabular}


Appendix 26. Sketch of the homegarden no. 8 in Wuasa, Napu valley, Central Sulawesi, 2004.

\section{Case study homegarden no. 8 in Wuasa, inventoried in May 2004}

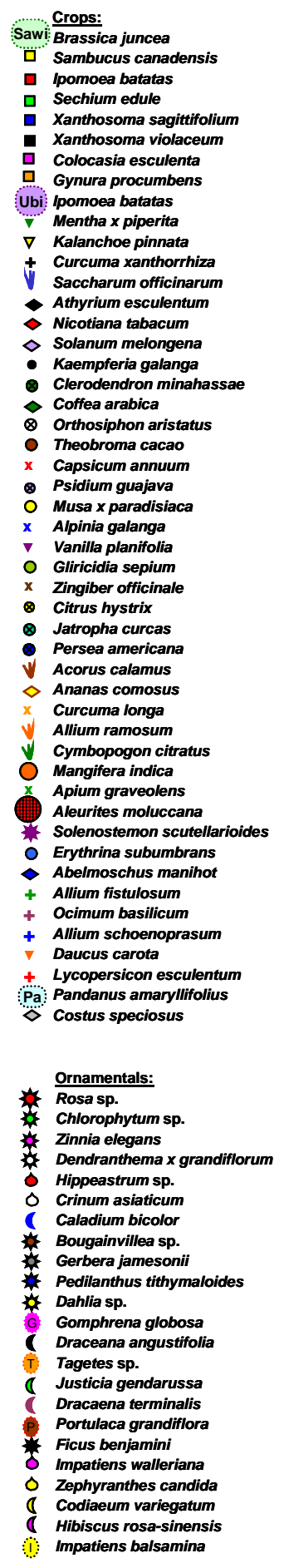

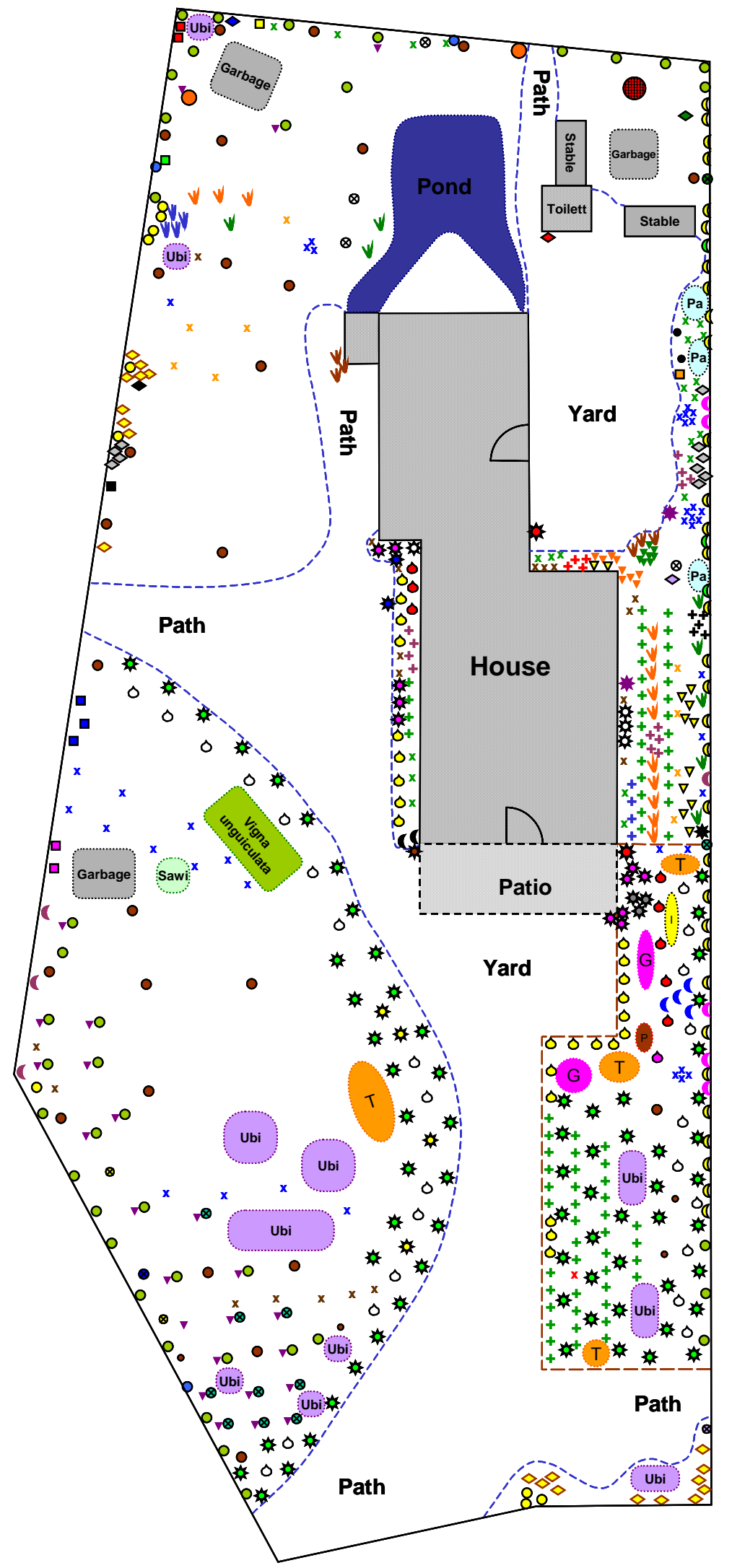




\section{Curriculum Vitae}

\section{Personal data}

Name:

Katja Kehlenbeck

Nationality:

German

Date of birth:

04 June 1969

Place of birth:

Hamburg, Germany

Address:

Department of Crop Sciences

Section Agronomy in the Tropics

Grisebachstr. 6

37077 Göttingen, Germany

Email:

katja_kehlenbeck@yahoo.de

Education and Studies

1975-1979

Primary school, Hamburg, Germany

1979-1988

Secondary school (Elise-Averdieck-Gymnasium), Hamburg, Germany, final exam (Abitur) June 1988

$1990-1997$

Studies in Biology,

Universities of Bielefeld and Hamburg, Germany, Degree: Diploma (equivalent to M.Sc.) in Biology

1999-2002

Master course 'Tropical Agriculture',

Georg-August-University Göttingen, Germany,

Degree: M.Sc. in Agriculture

Since 2003

Ph.D. study, Department of Crop Sciences,

Section Agronomy in the Tropics,

Georg-August-University Göttingen, Germany

\section{Professional Experiences}

1997

Technical assistant, Institute of Applied Botany, University of Hamburg (January-June)

Since 2005

Research assistant, Department of Crop Sciences, Section Agronomy in the Tropics, Georg-August-University Göttingen, Germany 



\section{Acknowledgements}

During the development of this thesis, a large number of people supported me directly or indirectly, making it impossible to name them all.

This study would not have been carried out and completed without my supervisor Dr. Brigitte L. Maass. I am deeply grateful to her for her extensive, unlimited support throughout the entire period of my study. Her professional experience, her always positive and encouraging attitude, and her constant willingness for inspiring, fruitful discussions essentially contributed to the whole work. I would also like to thank Prof. Dr. Holm Tiessen for his willingness to be my first referee. My sincere gratitude extends to my co-referee Prof. Dr. Michael Kessler for his valuable comments and suggestions during the review of my thesis. The readiness of Prof. Dr. Norbert Claassen and PD Dr. Ludwig Kammesheidt to be my first and second examiner, respectively, is highly appreciated.

I am especially grateful to all gardeners and village heads in the five research villages Wuasa, Rompo, Wanga, Siliwanga, and Tamadue, whose readiness to share their knowledge and experiences with me enabled this study. Their hospitality and kindness contributed much to make my stay in the Napu valley such a pleasant experience. Special thanks also to all STORMA members in Palu and Göttingen, particularly to the coordination teams and the head of the STORMA laboratory in Palu, Stefan Köhler, and his family. The identification of plant species in the herbaria Palu and Bogor is also acknowledged.

I would like to address my special gratitude to all members of the Institute/Section of Tropical Agronomy for their support, particularly to Marlies Friedrich, Ute Ronsöhr, Thomas Oesterreich, and Dr. Ronald Kühne, who kindly reviewed the soil quality part of this thesis. Dr. Jürgen Grotheer deserves my thanks for allowing me to use the laboratory of the Department of Landscape Ecology. I am indebted to the staff of the LARI (Laboratory for Radio-Isotopes), Institute of Forest Botany, for analysing Cs-137.

My work was also supported by members of the University of Hamburg. I would like to thank Dr. Hans-Helmut Poppendieck for allowing me to use the Herbarium and the library of the Botanical Garden. Dr. Heidrun Wurm and Ulrike Hermes kindly provided me with valuable literature; I enjoyed very much our chatting in the library of the Biocenter Klein Flottbek. Prof. Dr. Kai Jensen from the Section Ecology and Biology of Useful Plants is acknowledged for suggesting PCA for analysing temporal changes of plant composition.

The financial support of the DAAD during the field research in Sulawesi is gratefully acknowledged.

Finally, I want to express my sincere thankfulness to my family and friends for their understanding and patience. My deepest gratitude, however, deserves my partner Rainer Hanke for his extraordinary, continuous, and absolute support of my work, even as my field assistant in the Napu valley, who not only took and crushed countless soil samples, but who also cinematically documented my work, did the weekly baking, fought against the chicken that destroyed my vegetable garden, and experienced the risks and the fun of riding a motorbike in a very challenging environment. 

